\title{
Reproduktion einer entomophilen Baumart in geringer Populationsdichte
}

- Das Beispiel der Winterlinde (Tilia cordata Mill.) -

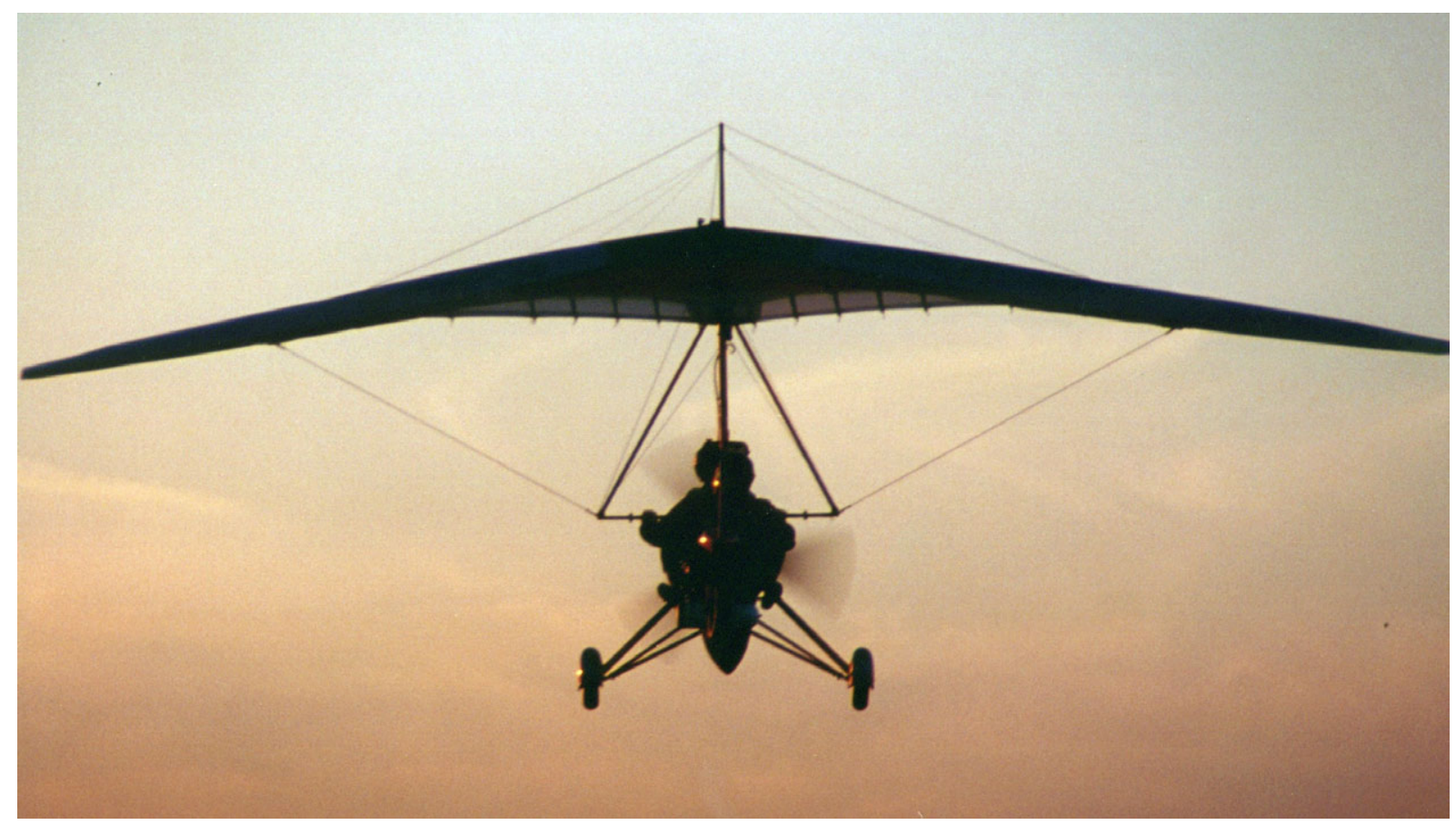

Institut für Forstgenetik und Forstpflanzenzüchtung der Universität Göttingen 


\title{
Reproduktion einer entomophilen Baumart in geringer Populationsdichte
}

- Das Beispiel der Winterlinde (Tilia cordata Mill.) -

\author{
DISSERTATION \\ zur Erlangung des Doktorgrades \\ der Fakultät für Forstwissenschaft und Waldökologie \\ der Georg-August-Universität Göttingen
}

vorgelegt von

Martin Fromm

geboren in Hamburg

Göttingen 2001

Institut für Forstgenetik und Forstpflanzenzüchtung der Universität Göttingen 
1. Berichterstatter: Prof. Dr. H.H. Hattemer

2. Berichterstatter: Prof. Dr. F. Gruber

3. Berichterstatter: Prof. Dr. Dr. S. Herzog

Tag der mündlichen Prüfung: 20. Juli 2001 
meiner Familie und meinen Freunden 


\section{Danksagung}

Erst durch die einzigartigen Rahmenbedingungen des Instituts für Forstgenetik und Forstpflanzenzüchtung der Georg-August-Universität Göttingen war die Entstehung vorliegender Arbeit möglich. Die heterogene Zusammensetzung der Mitarbeiterschaft dieses Instituts zeigte ein derart hohes Anpassungspotential, daß für die vielfältigen Fragen und Probleme, die im Zuge dieses Forschungsvorhabens aufgetreten sind, immer eine adäquate Antwort bzw. Lösung gefunden werden konnte.

Ganz besonderer Dank gilt dabei dem Initiator und Leiter dieser Arbeit, Herrn Prof. Dr. H.H. Hattemer; auch für die Gewährung großer Freiräume und seiner Geduld und Gelassenheit bei der Inanspruchnahme dieser Freiräume.

Unterstützung bei den Außen- und Laborarbeiten gewährten mir die Herren A. Capelle, G. Dinkel, Dr. L. Leinemann, Dr. W. Maurer, S. Krakuhn und Dr. F. Bergmann. Aus vielen Notlagen bei der Anwendung von Hard- und Software befreiten mich Frau Dr. E. Gillet, Herr Priv. Doz. Dr. M. Ziehe und nicht zuletzt mein langjähriger Bürokollege Dr. „Excel“ H. von Werder. Ein andauerndes Interesse, verbunden mit vielen konstruktiven Vorschlägen, zeigte Herr Prof. Dr. Gregorius. Auf die Hilfe von Frau K. Bendixen, Dr. A. Dounavi und Dr. B. Vornam konnte ich mich immer verlassen - mein Dankeschön an sie und alle Angestellten, die zur familiären Atmosphäre im Institut beigetragen haben.

Vielen Dank auch an Herrn Prof. Dr. E. Röhrig und an die Institute für Bioklimatologie bzw. Forsteinrichtung (im besonderen an Dr. T. Beisch) der Universität Göttingen für die Bereitstellung von Literatur, Daten und Gerätschaften.

Für die Durchsicht der Manuskripte möchte ich mich bei Marion Staron und Karin Gruber sowie bei Dr. Monika Konnert, Landesanstalt für forstl. Saat- u. Pflanzenzucht, Teisendorf für die uneingeschränkte Förderung meiner Dissertation bedanken.

Finanziell unterstützt wurde diese Arbeit von der Deutschen Forschungsgemeinschaft, wofür auch an dieser Stelle Dank ausgesprochen sei. 



\section{Inhaltsverzeichnis}

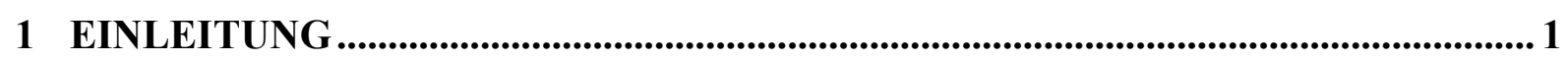

2 STAND DER FORSCHUNG .....................................................................................

$2.1 \quad$ Systematik ..................................................................................................................................... 3

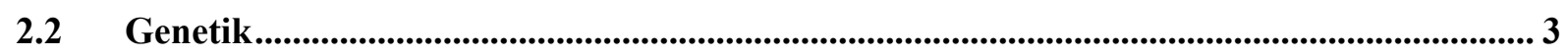

2.3 Geographische Verbreitung......................................................................................................... 4

$2.4 \quad$ Standortsansprüche und Wachstum ......................................................................................... 5

2.5 Waldbauliche Bedeutung der Winterlinde................................................................ 6

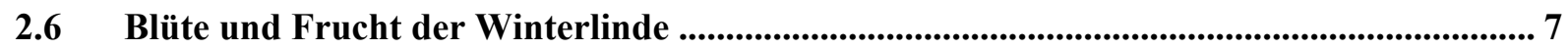

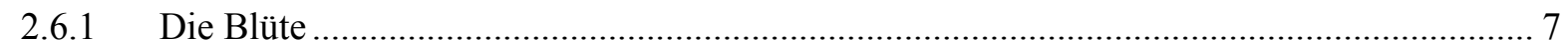

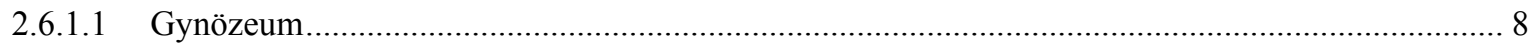

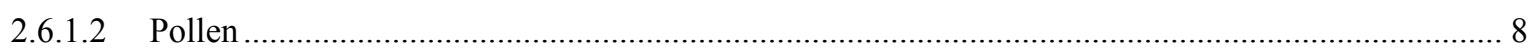

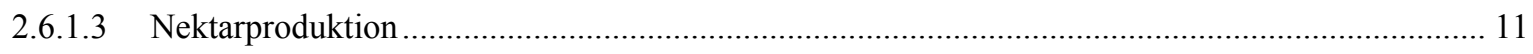

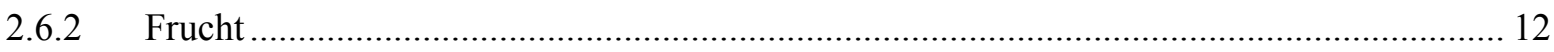

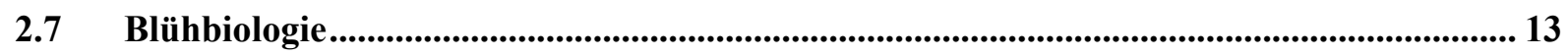

2.8 Die Bestäubungsökologie der Winterlinde ................................................................................ 14

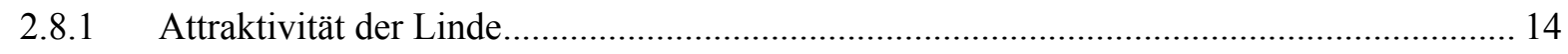

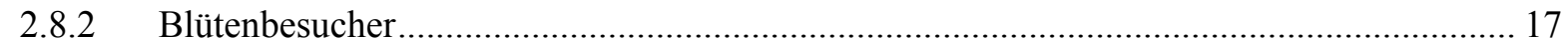

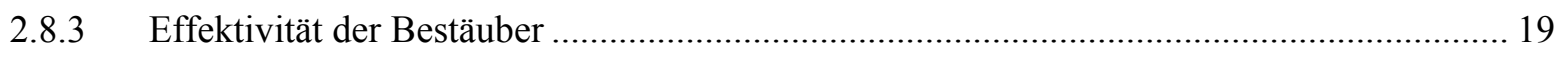

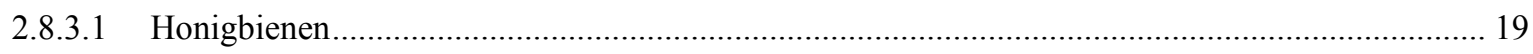

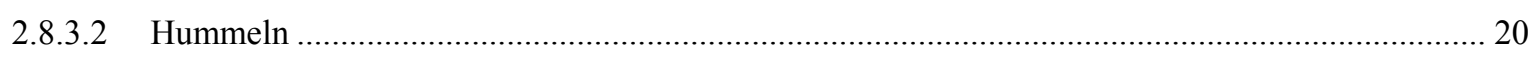

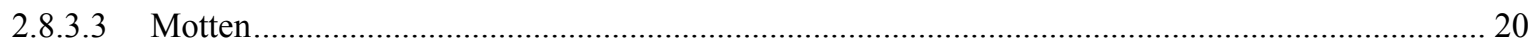

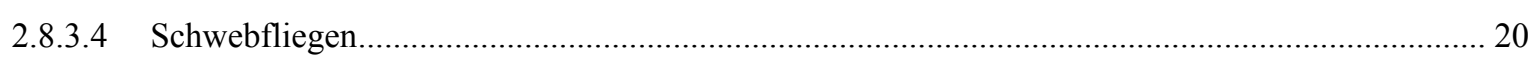

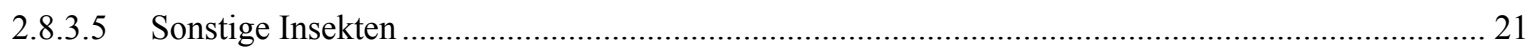

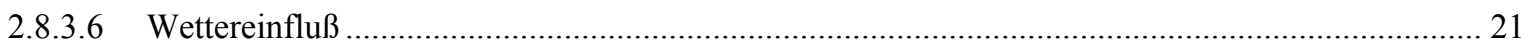

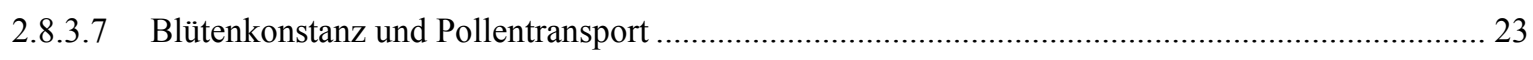

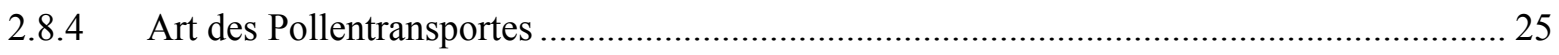

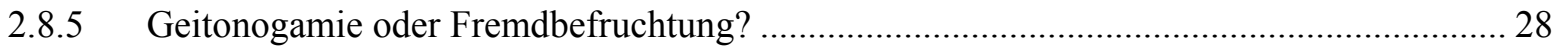

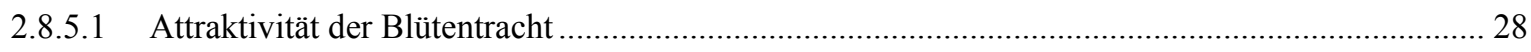

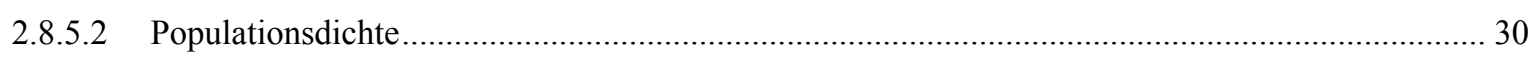

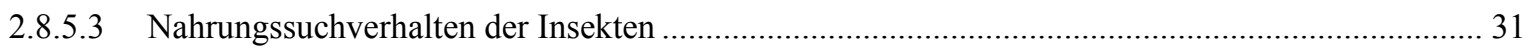




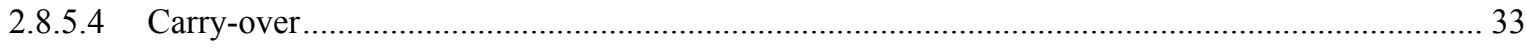

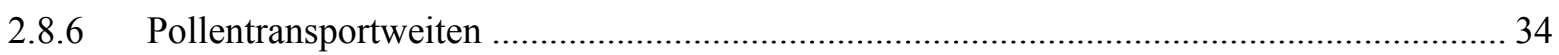

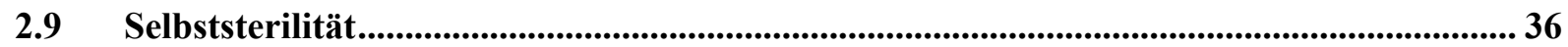

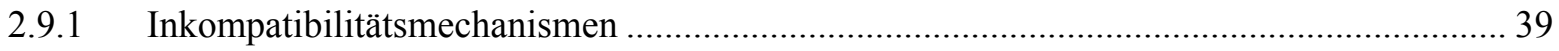

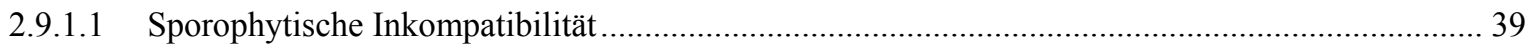

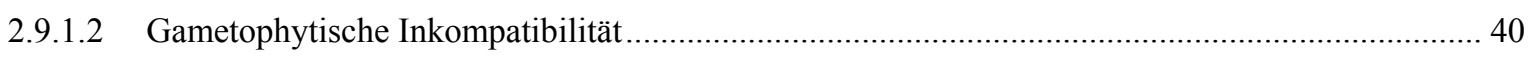

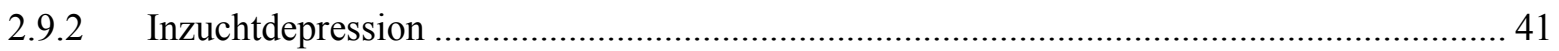

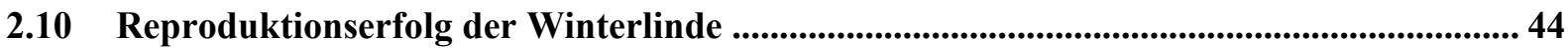

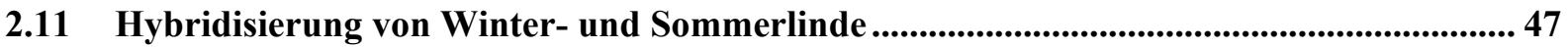

3 MATERIAL UND METHODEN ..............................................................................50

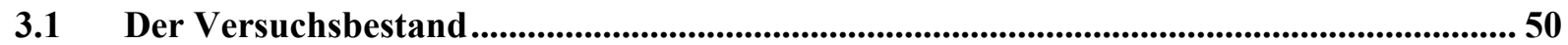

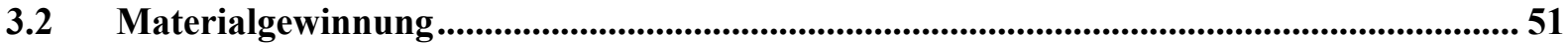

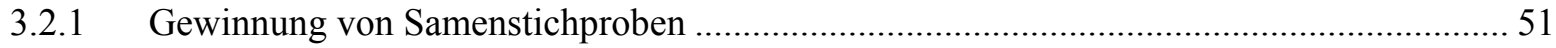

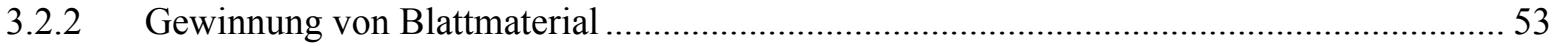

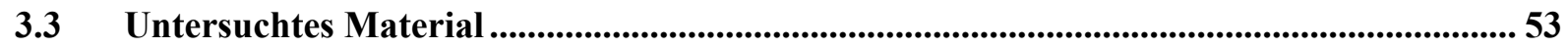

K.4 Kartierung des Versuchsbestandes ..................................................................... 54

Isoenzyme als genetische Marker .................................................................................5 58

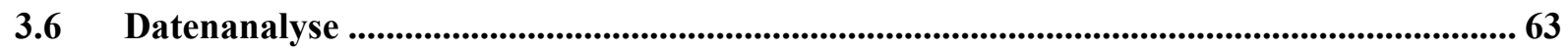

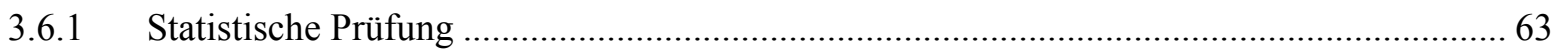

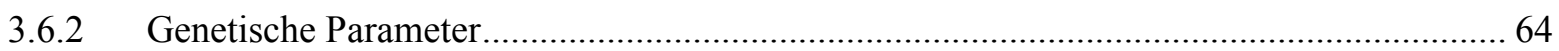

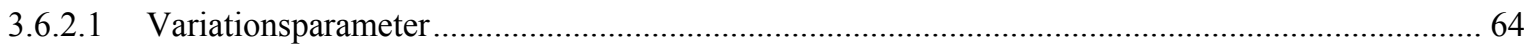

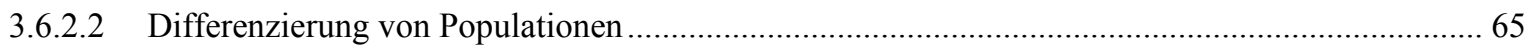

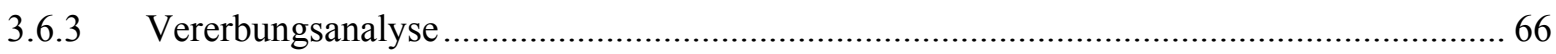

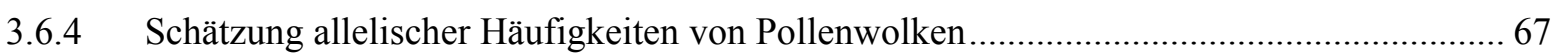

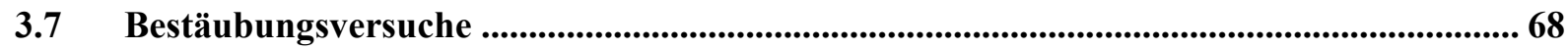

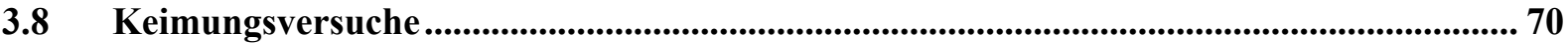

3.9 Bestimmung von Polleneltern ....................................................................................... 71

3.9.1 Das eindeutige Ausschlußverfahren............................................................... 71

3.9.2 Schätzung wahrscheinlichster Polleneltern......................................................... 74 


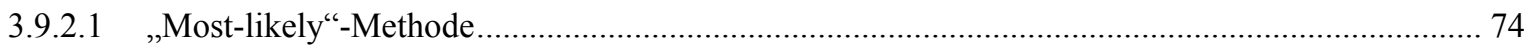

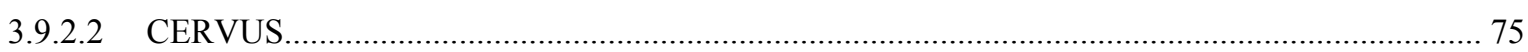

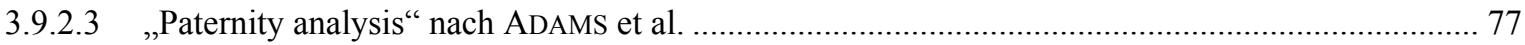

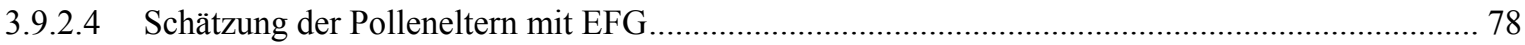

3.10 Bestimmung von Selbstbefruchtungsraten ................................................................... 83

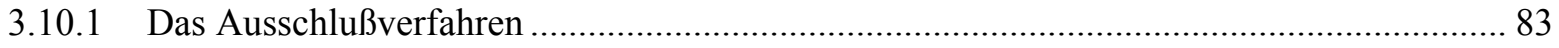

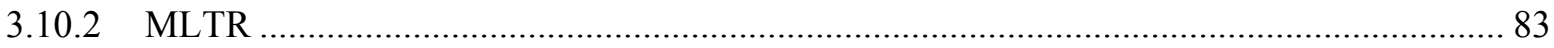

3.10.3 Schätzung der Selbstbefruchtungsrate über die Bestimmung von Polleneltern................ 84

3.11 Bestimmung von Pollentransportweiten........................................................................85

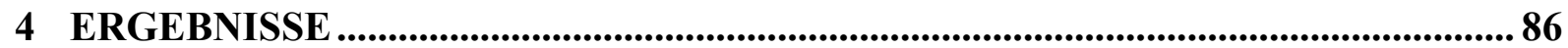

4.1 Genetische Marker ..................................................................................................8 86

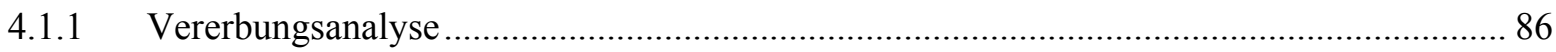

4.1.2 Interpretation der Zymogramme .................................................................... 88

4.2 Genetische Struktur des Versuchsbestandes................................................................... 96

Effektive Pollenwolken ......................................................................................................... 98

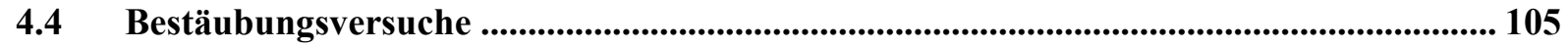

4.4.1 Art des Pollentransportes ............................................................................. 106

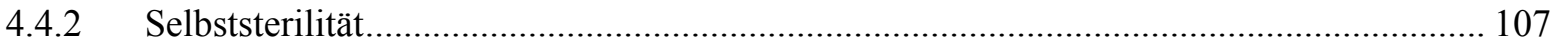

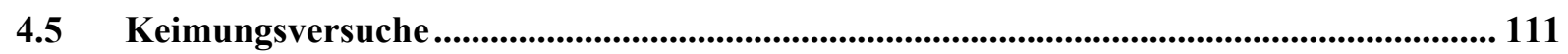

4.6 Bestimmung von Polleneltern ................................................................................ 114

4.6.1 Eindeutiges Ausschlußverfahren.............................................................. 115

4.6.2 EFG

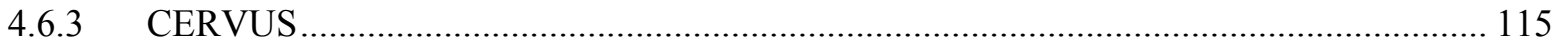

4.6.4 Vergleich der Pollenelterbestimmungsverfahren .............................................. 116

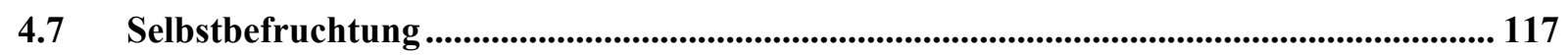

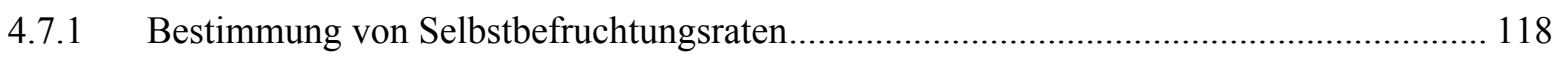

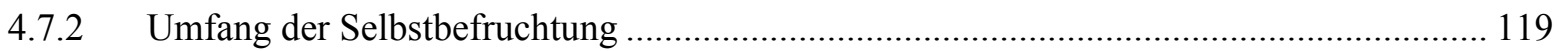

4.7.3 Ursachen der Selbstbefruchtung ................................................................ 125

4.7.4 Auswirkung der Selbstbefruchtung................................................................. 136

4.7.4.1 Auswirkung von Selbstbefruchtung auf das Samengewicht ................................................ 136

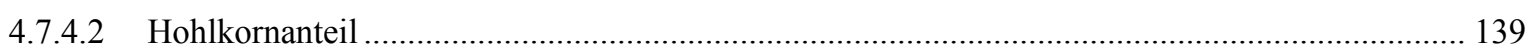


4.8 Genfluß durch Pollen .............................................................................................................. 139

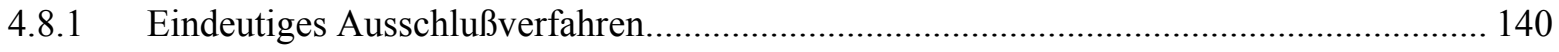

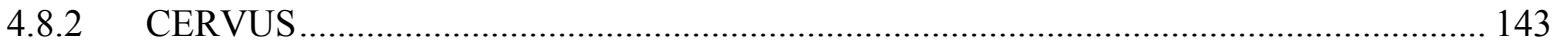

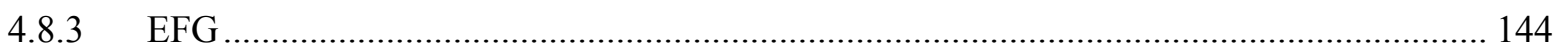

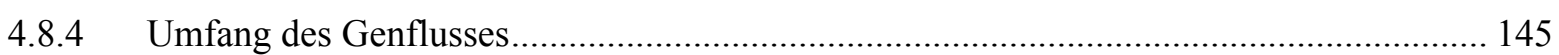

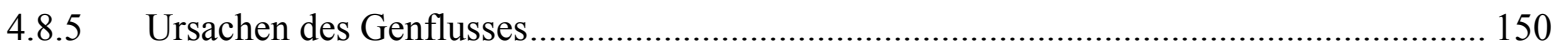

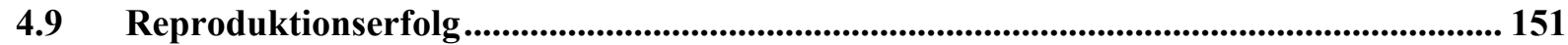

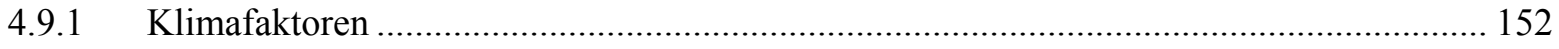

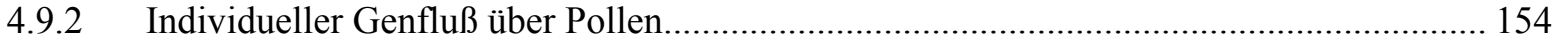

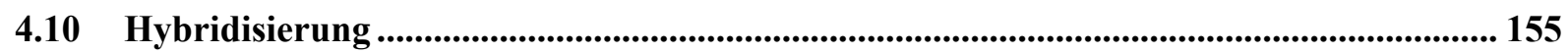

4.10.1 Artunterscheidung mit Hilfe von Isoenzymgenmarkern ................................................ 155

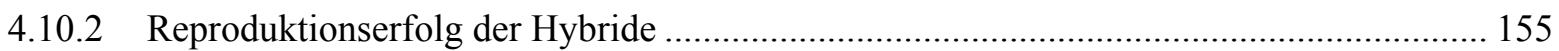

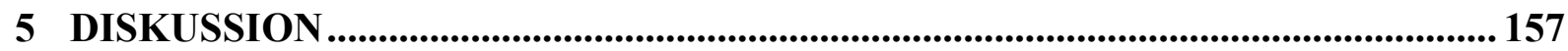

$5.1 \quad$ Vererbungsanalyse ................................................................................................................. 157

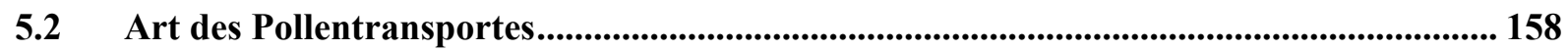

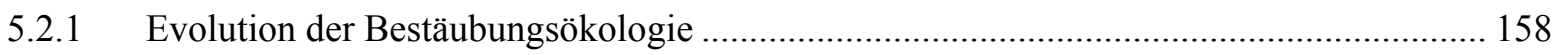

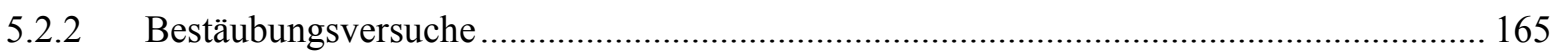

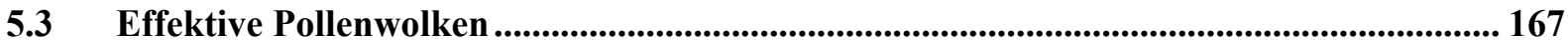

5.4 Bestimmung von Polleneltern ................................................................................................. 169

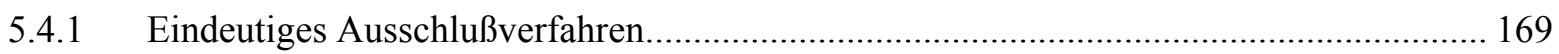

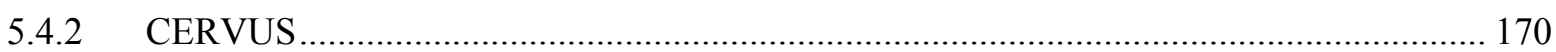

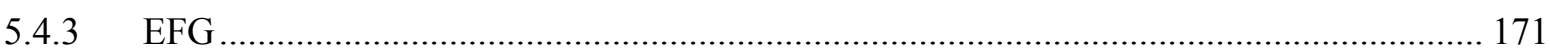

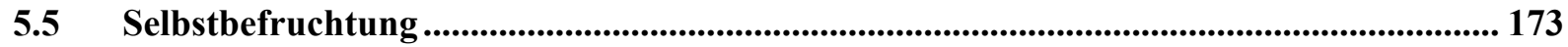

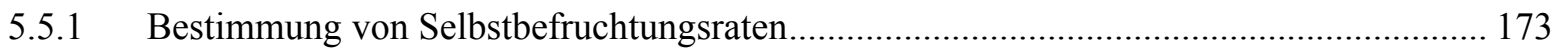

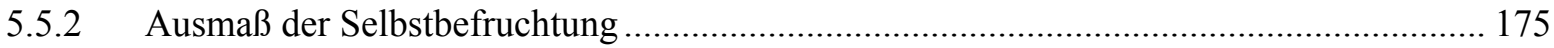

5.5.3 Ursachen selbstbefruchteter Nachkommen..................................................................... 177

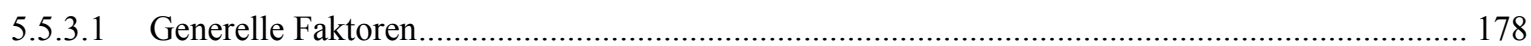

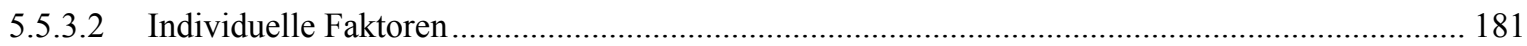

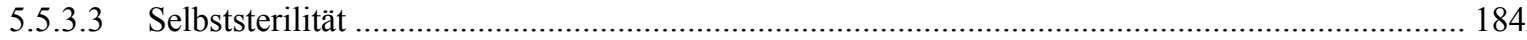

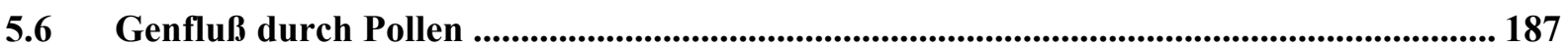

5.6.1 Bestimmung von Pollentransportweiten über Polleneltern............................................... 188

5.6.2 Ausmaß und Faktoren des Genflusses ......................................................................... 192 


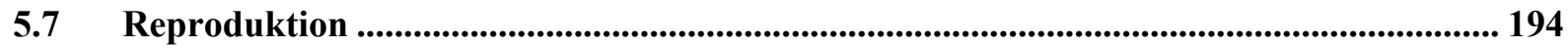

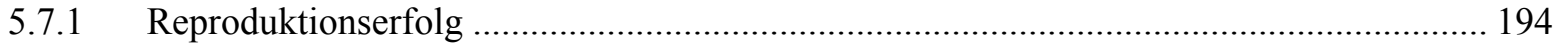

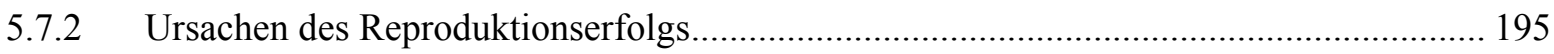

5.7.3 Individueller Genfluß über Pollen............................................................................. 200

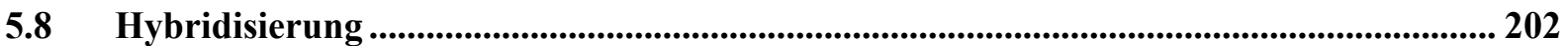

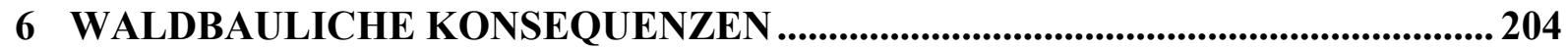

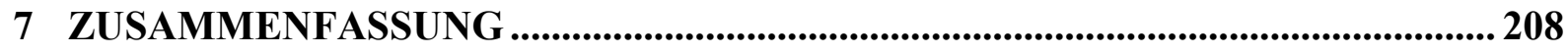

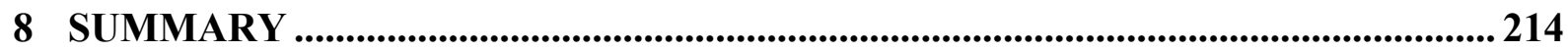

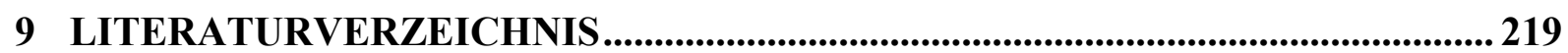

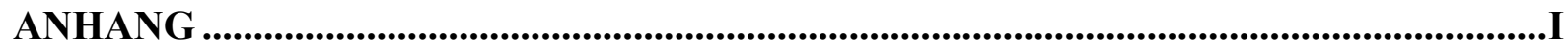




\section{Abbildungsverzeichnis}

Abb. 2.1 Verbreitung der Winterlinde (MEUSEL et al. 1978). sa = synanthrop ................................ 5

Abb. 2.2 Knospen und Früchte von Winterlinde (W), Hybride (H) und Sommerlinde (S) (FROMM 1999).

Abb. 2.3 Verbreitung der Sommerlinde (MEUSEL et al. 1978). sa = synantrop. ............................. 48

Abb. 3.1 Werbung von Nachkommenschaften aus den Kronen von ca. 150-jährigen Winterlinden durch Herrn Dr. Leinemann.

Abb. 3.2 Ultraleichtflugzeug, welches für die Aufnahme der Luftbilder (im Rahmen einer genehmigten Dienstreise) benutzt wurde.

Abb. 3.3 Zur weiteren Auswertung ausgewählte Luftbildaufnahme des Versuchsbestandes Schwiegershausen; weiß abgesetzt die blühenden Kronen der Linden.

Abb. 3.4 Mit dem Programm Erdas.imagine 8.2 digitalisierte und entzerrte Luftbildaufnahme mit 50 x 50 m Gitternetz.

Abb. 3.5 Kronenkartierung der 137 Linden im Versuchsbestand Schwiegershausen. Die vier solitär in der Feldmark stehenden Linden befinden sich außerhalb dieser Karte. .....

Abb. 3.6 Durchführung der Bestäubungsversuche am Beispiel der Winterlinde Nr. 54.

Abb. 3.7 Expected exclusion probabilities when increasing numbers of independent Ioci (each with two codominant alleles in equal frequency) are employed in paternity analysis (dashed curves), and expected proportions of offspring with unambiguous paternity (solid curves) for varying numbers ot possible parents $(N=25-200)$. Figure 1a applies when diploid genotypes of offspring are analyzed, and Fig. 1b when haploid pollen gametes of offspring can be identified (aus ADAMS 1992).

Abb. 3.8 A flow chart illustrating the operation of the CERVUS program's simulation of paternity inference. Boxes indicate repeated loops. Simulation of paternity inference where mothers are unsampled is carried out in a parallel simulation (Abb. und Beschreibung aus MARSHALL et al. 1998).

Abb. 4.1 Aufspaltung der Allele in den 40 Nachkommen des heterozygoten Samenelters Nr. 72 am Genort PGM-C.

Abb. 4.2 Aufspaltung der Allele in den 27 Nachkommen des heterozygoten Samenelters Nr. 59 am Genort SKDH-B. In der Mitte der Zymogramme ist der Samenelter zu sehen.

Abb. 4.3 Vereinfachte schematische Darstellung der Zymogramme von homozygoten bzw. heterozygoten Individuen, bei welchen ein monomeres, dimeres bzw. tetrameres Enzym von einem Genlocus kodiert wird (aus HATTEMER et al. 1993).

Abb. 4.4 Zymogramme und schematische Darstellung für das Enzymsystem AP mit Bezeichnung der Enzymvarianten für den Genort AP-B. Die Trennung erfolgte mit dem Puffersystem Ashton

Abb. 4.5 Zymogramme und schematische Darstellung für das Enzymsystem AP mit Bezeichnung der Enzymvarianten für den Genort AP-D. Die Trennung erfolgte mit dem Puffersystem Histidin-Citrat.

Abb. 4.6 Zymogramme und schematische Darstellung für das Enzymsystem FDH mit Bezeichnung der Enzymvarianten.

Abb. 4.7 Zymogramme und schematische Darstellung für das Enzymsystem MDH mit Bezeichnung der Enzymvarianten für die Genorte MDH-B, -C und -D...................................... 91

Abb. 4.8 Zymogramme und schematische Darstellung für das Enzymsystem MNR mit Bezeichnung der Enzymvarianten. 
Abb. 4.9 Zymogramme und schematische Darstellung für das Enzymsystem PGI mit Bezeichnung der Enzymvarianten für die Genorte PGI-B und -C.............................................. 93

Abb. 4.10 Zymogramme und schematische Darstellung für das Enzymsystem PGM mit Bezeichnung der Enzymvarianten für die Genorte PGM-A, -B, -C und -D.

Abb. 4.11 Zymogramme und schematische Darstellung für das Enzymsystem SKDH mit Bezeichnung der Enzymvarianten für den Genort SKDH-B

Abb. 4.12 Variation innerhalb $\left(\delta_{\mathrm{T}}\right)$ und zwischen $\left(\mathrm{D}_{\mathrm{j}}\right)$ effektiv gewordener Pollenwolken für 49 Winterlinden des Versuchsbestandes Schwiegershausen (gepoolt über 12 Genorte). Als Referenz dient die genetische Struktur des Altbestandes (ganz rechts).

Abb. 4.13 Abhängigkeit von $D_{\mathrm{j}}$ und $\delta_{\mathrm{T}}$ der Pollenwolken von der Selbstbefruchtungsrate für 49 Winterlinden der Gesamtpopulation Schwiegershausen. Die Selbstbefruchtungsraten wurden mit dem Programm MLTR berechnet.

Abb. 4.14 Abhängigkeit von $\mathrm{D}_{\mathrm{j}}$ und $\delta_{\mathrm{T}}$ der Pollenwolken von der $\varnothing$ Entfernung des Samenelters zu den nächsten 10 Paarungspartnern für 49 Winterlinden der Gesamtpopulation Schwiegershausen.

Abb. 4.15 Abhängigkeit von $\mathrm{D}_{\mathrm{j}}$ und $\delta_{\mathrm{T}}$ der Pollenwolken von der Kronengröße des Samenelters für 49 Winterlinden der Gesamtpopulation Schwiegershausen.

Abb. 4.16 Vergleich der Reduktion fremdbefruchteter und unbefruchteter Samenanlagen in verschiedenen ontogenetischen Stadien.

Abb. 4.17 Vergleich der Reduktion fremdbefruchteter und selbstbefruchteter Samenanlagen in verschiedenen ontogenetischen Stadien.

Abb. 4.18 Vergleich der Reduktion selbstbefruchteter und unbefruchteter Samenanlagen in verschiedenen ontogenetischen Stadien.

Abb. 4.19 Dreidimensionale Darstellung des Zusammenhangs zwischen der Selbstbefruchtungsanteilen, den Kronengrößen und dem mittleren Abstand zu den 10 nächsten Paarungspartnern für die im Bestand stehenden Winterlinden (ohne Feldlinden). Der Selbstbefruchtungsanteil wurde mit dem Programm MLTR berechnet.

Abb. 4.20 Dreidimensionale Darstellung des Zusammenhangs zwischen der Selbstbefruchtungsanteilen, den Kronengrößen und dem mittleren Abstand zu den 10 nächsten Paarungspartnern für die im Bestand stehenden Winterlinden (ohne Feldlinden) mit Kronengrößen $>32 \mathrm{~m}^{2}$. Der Selbstbefruchtungsanteil wurde mit dem Programm MLTR berechnet.

Abb. 4.21 Dreidimensionale Darstellung des Zusammenhangs zwischen der Selbstbefruchtungsanteilen, den Kronengrößen und dem mittleren Abstand zu den 10 nächsten Paarungspartnern für die im Bestand stehenden Winterlinden (ohne Feldlinden) mit Kronengrößen $<32 \mathrm{~m}^{2}$. Der Selbstbefruchtungsanteil wurde mit dem Programm MLTR berechnet.

Abb. 4.22 Abb. 4.21 aus veränderter Perspektive. Dreidimensionale Darstellung des Zusammenhangs zwischen der Selbstbefruchtungsanteilen, den Kronengrößen und dem mittleren Abstand zu den 10 nächsten Paarungspartnern für die im Bestand stehenden Winterlinden (ohne Feldlinden) mit Kronengrößen $<32 \mathrm{~m}^{2}$. Der Selbstbefruchtungsanteil wurde mit dem Programm MLTR berechnet.

Abb. 4.23 Nach dem Ausschlußverfahren eindeutig nachgewiesene Transportweiten von 331 Pollen der Lindenpopulation Schwiegershausen, Einteilung in $10 \mathrm{~m}$ Distanzklassen und Anpassung einer Kurvenfunktion $\left(\mathrm{a}^{*} \exp \left(-\mathrm{b}^{*} \ln (\mathrm{x})\right)\right)$ an die Punktwolke unter Annahme unterschiedlicher Pollentransportweiten für Selbstbefruchtung $(0,1 \mathrm{~m} / 1,9 \mathrm{~m} / 3,8 \mathrm{~m})$. 
Abb. 4.24 Ausschnittsvergrößerung von Abb. 4.23 zur Verdeutlichung der Auswirkung unterschiedlicher Annahmen für die $\varnothing$ Pollentransportweite bei Selbstbefruchtung $(0,1 \mathrm{~m} /$ $1,9 \mathrm{~m} / 3,8 \mathrm{~m})$

Abb. 4.25 Kumulative Häufigkeitsverteilung für die nach dem Ausschlußverfahren eindeutig nachgewiesenen Transportweiten von 331 Pollen der Lindenpopulation Schwiegershausen ...... 143

Abb. 4.26 Kumulative Häufigkeitsverteilung der Pollentransportweiten nach verschiedenen Pollenelterbestimmungsverfahren für die Winterlindenpopulation Schwiegershausen.

Abb. 4.27 Kumulative Häufigkeitsverteilung der Pollentransportweiten nach verschiedenen Pollenelterbestimmungsverfahren für die Winterlindenpopulation Schwiegershausen. Gezeigt wird nur der Bereich ab einer Transportweite von mehr als 400 m............................................. 148

Abb. 5.1 Mögliche Ursachen für eingeschränkten Reproduktionserfolg der Winterlinde. 196 


\section{Tabellenverzeichnis}

Tab. 2.1 Pollenkornzahlen je Eizelle, modifiziert nach POHL (1936). I = insektenbestäubt, $\mathrm{W}=$ windbestäubt

Tab. 2.2 Durchschnittliche Pollenerzeugung von Blütenständen (POHL 1936).

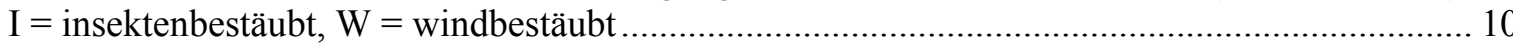

Tab. 2.3 Durchschnittliche Pollenerzeugung eines zehnjährigen Zweigsystems (POHL 1936) ....... 11

Tab. 2.4 Von den Tiergruppen bevorzugte Zuckerkonzentration im Nektar (PYKE und WASER 1981) 16

Tab. 2.5 Pollenanflug in den Kronen blühender Bäume (nach REMPE 1937). 26

Tab. 3.1 Untersuchte Enzymsysteme bei Linde. Die fett gedruckten Enzymsysteme wurden für die genetische Inventur der Altbäume und Nachkommen verwendet. Trennsysteme: Ashton, Histidin-Citrat (H.-C.) und Tris-Histidin (T.-H.).

Tab. 3.2 Zusammensetzung der Stärkegele und Laufbedingungen der im Routineverfahren verwendeten Trennsysteme.

Tab. 3.3 Zusammensetzung der Färbelösungen bei Extraktion aus Samengewebe. Bei Extraktion aus Blattgewebe sind die Substratmengen nach Bedarf zu erhöhen.

Tab. 3.4 Größe blühender Kronen einer Auswahl von Linden des Versuchsbestandes Schwiegershausen. Die logarithmierte Kronenfläche (ln) geht als Faktor Fertilität in das EFGVerfahren ein (vgl. beigefügte Karte 1).

Tab. 3.5 Wahrscheinlichkeit der Gametenproduktion eines potentiellen Pollenelters bei gegebenem Genotyp von Samenelter und Nachkomme. $\mathrm{X}=$ jedes andere Allel außer B, $\mathrm{Y}=$ jedes andere Allel außer B und C.

Tab. 3.6 Herleitung der Wahrscheinlichkeit einer Pollenelternschaft mit dem Verfahren EFG. In die Gesamtwahrscheinlichkeit geht die Entfernung in $\mathrm{m}$ nicht mit ein. (Im Interesse der Übersichtlichkeit wurden die sehr kleinen Werte für die Wahrscheinlichkeit einer Gametenproduktion $(G)$ einheitlich mit dem Faktor 100 multipliziert). Die potentiellen Polleneltern sind nach abnehmender EFG-Wahrscheinlichkeit geordnet (s. beigefügte Karten 1 und 3).

Tab. 4.1 Test auf gleichmäßige Segregation und Zufallsfusion der Gameten in 40 Nachkommen des heterozygoten Samenelters Nr. 72 am Genort PGM-C. k = Fremdtypallel.

Tab. 4.2 Test auf gleichmäßige Segregation und Zufallsfusion der Gameten in 40 Nachkommen des heterozygoten Samenelters Nr. 72 am Genort PGM-C. $\mathrm{N}_{3}=$ Fremdtypallel.

Tab. 4.3 Gentische Analyse des Altbestandes der Winterlindenpopulation Schwiegershausen und der Teilkollektive autochthoner und gepflanzter Winterlinden.

Tab. 4.4 Allelhäufigkeiten und allelischer Abstand an Genorten mit signifikanten Unterschieden zwischen autochthonen und gepflanzten Winterlinden.

Tab. 4.5 Genotyphäufigkeiten, Heterozygotiegrad und genotypischer Abstand an Genorten mit signifikanten Unterschieden zwischen autochthonen und gepflanzten Winterlinden.

Tab. 4.6 Berechnete Korrelation von Diversität (v), hypothetisch gametischer MultilocusDiversität $\left(\mathbf{v}_{\mathbf{g a m}}\right)$, Variation innerhalb einer Pollenwolke $\left(\delta_{\mathbf{T}}\right)$ und Differenzierung zwischen den Pollenwolken $\left(\mathbf{D}_{\mathbf{j}}\right)$ mit dem Heterozygotiegrad des Samenelters. In die Berechnung der Bestimmtheitsmaße ging die Gesamtpopulation jeweils inklusive und exklusive der in der Feldmark stehenden Winterlinden ein. In Klammern die Vorzeichen der entsprechenden Korrelationskoeffizienten. 
Tab. 4.7 Berechnete Korrelation der über verschiedene Verfahren ermittelten Selbstbefruchtungsraten mit $\delta_{\mathbf{T}}$ und $\mathbf{D}_{\mathbf{j}}$ der Pollenwolken für 49 Winterlinden. In die Berechnung der Bestimmtheitsmaße ging die Gesamtpopulation jeweils inklusive und exklusive der in der Feldmark stehenden Winterlinden ein. In Klammern die Vorzeichen der entsprechenden Korrelationskoeffizienten.

Tab. 4.8 Berechnete Korrelation von $\mathbf{D}_{\mathbf{j}}$ und $\boldsymbol{\delta}_{\mathbf{T}}$ der Pollenwolken mit der Entfernung des Samenelters zu den nächsten potentiellen Paarungspartnern, der $\varnothing$ Kronengröße der nächsten potentiellen Paarungspartner und der Kronengröße des Samenelters. In die Berechnung der Bestimmtheitsmaße ging die Gesamtpopulation jeweils inklusive und exklusive der in der Feldmark stehenden Winterlinden ein. In Klammern die Vorzeichen der entsprechenden Korrelationskoeffizienten.

Tab. 4.9 Ausmaß der Entwicklung von Blüten zu vitalen Samen unter verschiedenen Versuchsbedingungen.

Tab. 4.10 Reduktion fremdbefruchteter und unbefruchteter Samenanlagen in verschiedenen ontogenetischen Stadien.

Tab. 4.11 Reduktion fremdbefruchteter und selbstbefruchteter Samenanlagen in verschiedenen ontogenetischen Stadien.

Tab. 4.12 Vergleich der Reduktion selbstbefruchteter und unbefruchteter Samenanlagen in verschiedenen ontogenetischen Stadien.

Tab. 4.13 Entwicklung von Keimlingen bzw. mehrjährigen Pflanzen aus je 200 Samen isoliert (Baum F1 und F3) und dicht stehender Winterlinden (Baum 42 und 82).

Tab. 4.14 Selbstbefruchtungsanteil und Heterozygotiegrad für Samen und Jungpflanzen aus Nachkommenschaften isoliert (Baum F1 und F3) und dicht stehender Winterlinden (Baum 42 und 82). Der Selbstbefruchtungsanteil wurde über das Ausschlußverfahren, der Heterozygotiegrad zum einen für alle Genorte und zum anderen für diejenigen Genorte ermittelt, für die der Samenelter homozygot war. $\Delta=$ Differenz zwischen Samen und Jungpflanzen.

Tab. 4.15 Effizienz bei der Identifizierung von Polleneltern mit verschiedenen Pollenelterbestimmungsverfahren bzw. Eingangsparametern; jeweils ermittelt für die Gesamtpopulation, den im Bestand und den vier in der Feldmark stehenden Linden. Bei CERVUS: $0 \%$ und 1\% = fiktive Fehlerquote, + und * Signifikanzniveau bei 80\% bzw. 95\% ... 114

Tab. 4.16 Selbstbefruchtungsrate in den Nachkommen der Winterlindenpopulation Schwiegershausen, ermittelt über das Verfahren EFG unter Verwendung verschiedener Diskriminanzschwellen $(\Delta)$ vor und nach Bereinigung nicht eindeutig zuzuordnender Nachkommen.

Tab. 4.17 Über mehrere Verfahren ermittelte Selbstbefruchtungsraten für die Gesamtpopulation Schwiegershausen, die Linden im Bestand und in der Feldmark.

Tab. 4.18 Mit verschiedenen Verfahren berechnete Selbstbefruchtungsraten in den Nachkommen von 54 Winterlinden der Population Schwiegershausen. Mit F sind die Winterlinden in der Feldmark bezeichnet.

Tab. 4.19 Vergleich der mit MLTR und EFG 2 $\Delta$ ermittelten Selbstbefruchtungsraten in den Nachkommen von 54 Linden der Population Schwiegershausen. Mit F sind die Linden in der Feldmark bezeichnet.

Tab. 4.20 Über verschiedene Verfahren ermittelte Selbstbefruchtungsraten unter den Nachkommen von 54 Winterlinden der Population Schwiegershausen zusammen mit Kronengröße, Abstand zum nächsten Nachbarn und $\varnothing$ Abstand zu den nächsten 10 Nachbarn des Samenelters. 
Tab. 4.21 Korrelation von Entfernung und Kronengröße mit der Selbstbefruchtungsrate mit Überprüfung des Bestimmtheitsmaßes $\left({ }^{2}\right)$ auf Signifikanz für die Gesamtpopulation und den Bestand (ohne Feldlinden). In Klammern die Vorzeichen der entsprechenden

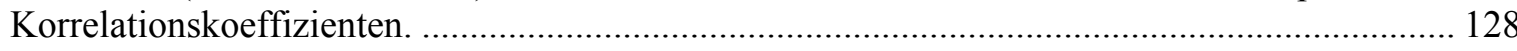

Tab. 4.22 Korrelation von Entfernung und Kronengröße mit der Selbstbefruchtungsrate mit Überprüfung des Bestimmtheitsmaßes $\left(\mathrm{r}^{2}\right)$ auf Signifikanz für die acht Winterlinden der Gesamtpopulation mit einer Kronengrößen $>140 \mathrm{~m}^{2}$. In Klammern die Vorzeichen der entsprechenden Korrelationskoeffizienten.

Tab. 4.23 Korrelation von Entfernung und Kronengröße mit der Selbstbefruchtungsrate mit Überprüfung des Bestimmtheitsmaßes $\left(\mathrm{r}^{2}\right)$ auf Signifikanz für verschiedene Gruppierungen von Kronengrößen der Sameneltern des Bestandes. In Klammern die Vorzeichen der entsprechenden Korrelationskoeffizienten.

Tab. 4.24 Korrelation von Entfernung und Kronengröße mit der Selbstbefruchtungsrate mit Überprüfung des Bestimmtheitsmaßes $\left(\mathrm{r}^{2}\right)$ auf Signifikanz für Sameneltern mit Kronengrößen $<32 \mathrm{~m}^{2}$. In Klammern die Vorzeichen der entsprechenden Korrelationskoeffizienten.

Tab. 4.25 Durchschnittliches Samengewicht nach Fremd- bzw. Selbstbefruchtung für die Gesamtpopulation, den Linden im Bestand und in der Feldmark...

Tab. 4.26 Durchschnittliches Samengewicht, Verhältnis des Hohlkornanteils zu vitalen Samen und über verschiedenen Verfahren ermittelte Selbstbefruchtungsraten in den Nachkommenschaften von 54 Winterlinden.....

Tab. 4.27 Güte der Anpassung der Kurvenfunktion $\mathrm{a}^{*} \exp (-\mathrm{b} * \ln (\mathrm{x}))$ an die Punktwolken bei Annahme unterschiedlicher Pollentransportweiten für Selbstbefruchtung $(0,1 \mathrm{~m} / 1,9 \mathrm{~m} / 3,8 \mathrm{~m}) .140$

Tab. 4.28 Über CERVUS mit verschiedenen Eingabeparameter identifizierte Polleneltern und die daraus hergeleiteten $\varnothing$ Pollentransportweiten für die Nachkommen der Winterlinden 14, 38, 77 und 114. Variierte Eingabeparameter bei CERVUS: Fehlerquote $0 \%$ und $1 \%$, Signifikanzniveau des $\Delta$-Wertes $95 \%\left(^{*}\right)$ und $80 \%(+)$.

Tab.4.29 Über die verschiedenen Pollenelterbestimmungsverfahren ermittelten $\varnothing$ Pollentransportweiten für die Gesamtpopulation Schwiegershausen, die im Bestand und in der Feldmark stehenden Linden einschließlich Selbstbefruchtung. Bei Selbstbefruchtung wird eine Transportweite von 1,9 m angenommen. Dazu ist kleingedruckt die absolute Anzahl der identifizierten Polleneltern angegeben.

Tab.4.30 Über die verschiedenen Pollenelterbestimmungsverfahren ermittelten $\varnothing$ Pollentransportweiten für die Gesamtpopulation Schwiegershausen, die im Bestand und in der Feldmark stehenden Linden für fremdbefruchtete Nachkommen. Dazu die absolute Anzahl der identifizierten Polleneltern (klein gedruckt) und die ermittelte maximale Transportweite. ......... 146

Tab.4.31 Über verschiedene Pollenelterbestimmungsverfahren hergeleitete $\varnothing$ Pollentransportweiten für die Nachkommenschaften von 54 Winterlinden im Versuchsbestand Schwiegershausen und die Zahl der für die Nachkommenschaften identifizierten Polleneltern. 149

Tab.4.32 Korrelation der $\varnothing$ Pollentransportweiten der fremdbefruchteteten Nachkommenschaften von 54 Winterlinden mit den aufgeführten Faktoren. In Klammern die Vorzeichen der entsprechenden Korrelationskoeffizienten.

Tab. 4.33 Gemessene Durchschnittstemperatur für den Zeitraum der Blüte bzw. Samenreife der Winterlinde (im Vorharz) und für die Sommer der Jahre 1995-1998 im Mittel der Wetterstationen Bad Grund, Herzberg und Seesen.

Tab. 4.34 Gemessene Durchschnittstemperatur für den Zeitraum der Blüte bzw. Samenreife der Winterlinde (im Vorharz) und für die Sommer der Jahre 1995-1998 der Wetterstation Herzberg. 
Tab. 4.35 Gemessene mittlere Tageshöchsttemperatur für den Zeitraum der Blüte bzw. Samenreife der Winterlinde (im Vorharz) und für die Sommer der Jahre 1995-1998 der Wetterstation Herzberg.

Tab. 4.36 Reproduktionserfolg zweier Winter-/Sommerlindenhybriden (Tilia $x$ vulgaris) des Versuchsbestandes Schwiegershausen. 


\section{Einleitung}

Die durch die Masse der Blüten weiß erscheinende Krone, ist eines der auffälligsten Merkmale der europäischen Linden. Begriffe wie Lindenblütentee oder Lindenhonig sind sprichwörtlich in aller Munde und deuten gleichzeitig auf eine große Attraktivität der Linde für Insekten hin. Wer einmal während der Blüte unter einer Linde gestanden hat, wird sicherlich sowohl den intensiven Duft des Nektars als auch das Summen der zahlreichen Insekten wahrgenommen haben. Eine üppige Nektarproduktion sowie die farbliche Absetzung der weißen Tracht vom grünen Blätterdach geben vielen Insektenarten Anreiz für einen Besuch der Blüten.

Tatsächlich gilt die Familie der Tiliaceaen als insektenbestäubt, hat sie doch ihren Ursprung in den Tropen und nur wenige Vertreter in den temperierten Zonen. Dazu zählt die Gattung Tilia, die in Deutschland durch die Winterlinde (Tilia cordata MiLl.), die Sommerlinde (Tilia platyphyllos SCOP.) und deren Hybride (Tilia $x$ vulgaris) natürlich vertreten ist.

Im Zuge der klimatischen Abkühlung nach der mittleren Wärmezeit ist die Linde von der konkurrenzstärkeren Buche und in jüngerer Zeit durch anthropogene Einflüsse aus den Wäldern zurückgedrängt worden. In natürlichen Vorkommen ist sie in mitteleuropäischen Wäldern meist als Mischbaumart anzutreffen (ebenfalls ein Merkmal tropischer Baumarten). Ein Vorkommen in geringer Dichte läßt einen eingeschränkten Paarungskontakt innerhalb der Lindenpopulation erwarten. Während der Blüte sind die einzeln oder truppweise im Bestand verteilten Linden nicht nur räumlich, sondern zusätzlich durch andere im vollen Laub stehende Baumarten getrennt. Ungeklärt ist, über welche Entfernungen ein ausreichender Paarungskontakt durch Pollentransport über tierische Vektoren oder den Wind aufrecht erhalten werden kann. Unter der Voraussetzung, daß die Linde nicht über voll wirksame Inkompatibilitätsmechanismen verfügt, ist anzunehmen, daß es bei den hermaphroditischen Linden zu einer Selbstbefruchtung kommt, deren Anteil mit abnehmender Populationsdichte steigt. Dieses könnte eine verringerte Viabilität der Nachkommen zur Folge haben.

In Anbetracht der jährlich schwankenden Samenproduktion der Linden und des hohen Anteils an Hohlkörnern in den Samen beernteter Lindenbestände stellt sich die Frage, ob dieses auf eine unzureichende Effektivität der Insekten als Pollinatoren in unseren gemäßigten Breiten zurückzuführen ist oder ob auch andere Ursachen für die teilweise spärliche Produktion vitaler Samen verantwortlich sind. 


\section{Arbeitsprogramm und Ziele}

Eine eingehende Literaturrecherche sollte einen Überblick auf bisherige, bezüglich des Reproduktionssystems der Linde, relevante Untersuchungen geben. Die Auswahl und Kartierung eines geeigneten Versuchsbestandes war Voraussetzung für alle weiteren Arbeiten. Ziel einer Kartierung war u. a. die Erstellung einer Entfernungsmatrix für alle Mitglieder der Lindenpopulation.

Entscheidend für den Erfolg des gesamten Vorhabens war die Identifikation geeigneter genetischer Marker. Die Effizienz bei der Bestimmung z. B. von Selbstbefruchtungsanteilen und der Identifizierung von Polleneltern steigt mit der Zahl verwendeter variabler Genloci. Aus diesem Grunde war die Entwicklung elektrophoretischer Verfahren zur Identifikation möglichst vieler variabler Markergenloci ein wichtiger Schritt bei der Realisierung dieses Forschungsvorhabens. Die Gattung Tilia war bislang noch nicht Gegenstand eingehender genetischer Untersuchungen.

Über Bestäubungs- und Keimungsversuche sollte eine Quantifizierung der Anteile von Wind- bzw. Insektenbestäubung erfolgen und eine mögliche Selbststerilität in Form von Inkompatibilität und/oder früher Inzuchtdepression untersucht werden. Zudem kann in Zusammenhang mit diesen Versuchen untersucht werden, ob die Linde apomiktisch reproduziert und ob der Hohlkornanteil bei der Linde physiologische und/oder genetische Ursachen hat.

Ziel einer genetischen Inventur zahlreicher Einzelbaumabsaaten war u. a. die Klärung einer möglichen Abhängigkeit des Reproduktionserfolges von der Populationsdichte und eine Quantifizierung des Genflusses über Pollen. Für Letzteres ist zusätzlich eine Bestimmung von Polleneltern nötig. Ohne die Zuordnung von Polleneltern zu ihren Nachkommen ist eine Herleitung von Pollentransportweiten über genetische Marker nicht möglich. Aus diesem Grund war beabsichtigt, neben dem Einsatz bekannter Pollenelterbestimmungsverfahren ein an die Reproduktionsbiologie der Linde angepaßtes Verfahren zu entwickeln. 


\section{Stand der Forschung}

Dieses Kapitel enthält eine Zusammenfassung aller wichtigen Informationen bezüglich des Reproduktionssystems der Winterlinde aus der mir zu Verfügung stehenden Literatur. Dabei gibt es nur wenige Arbeiten, die sich explizit mit dem Reproduktionssystem der Linde beschäftigt haben. Da die Familie der Tiliaceae tropischen Ursprungs ist und die Gattung Tilia typische Merkmale tropischer Baumarten aufweist, finden auch Arbeiten über Pflanzenarten der Tropen und Subtropen Beachtung.

\subsection{Systematik}

Die Familie der Tiliaceae umfaßt etwa 45 Gattungen mit mehr als 400 Arten und ist bis auf die Gattung Tilia in den Tropen und Subtropen beheimatet (BARTELS 1983).

Für die Gattung Tilia werden je nach Autor etwa 10 bis 50 Arten in den gemäßigten Zonen der nördlichen Erdhalbkugel genannt (KRÜSSMANN 1978, SDW 1991). Diese weite Spanne der Artenzahl ist nach EISENHUT (1957) auf eine schwierige Abgrenzung durch den Formenreichtum, die Bildung geographischer Rassen und auf eine Hybridisierung der Arten zurückzuführen. Nach Scheller (1972) enthält die Gattung Tilia 24 Arten, wobei er davon sechs Arten in Europa, Kleinasien und im Kaukasus, vier in Nordamerika und 14 in Asien verbreitet sieht. In den Wäldern Mitteleuropas ist die Gattung Tilia mit der Winterlinde (Tilia cordata MiLl.) und der Sommerlinde (Tilia platyphyllos SCOP.) vertreten. Bei Sympatrie der Winterund Sommerlinde kommt es zur einer spontanen Hybridisierung im Bestand. Die Hybride dieser beiden heimischen Linden, die Holländische Linde (Tilia $x$ vulgaris HAYNE) wird seit dem 17. Jahrhundert intensiv kultiviert und ist die am stärksten verbreitete Linde unter den Park- und Alleebäumen in Europa (PigOTT 1991).

\subsection{Genetik}

Die Gattung Tilia besitzt einen einfachen Chromosomensatz von $\mathrm{n}=41$ und hat damit einen der größten genomischen Anzahlen unter den heimischen Waldbäumen. Es wird vermutet, daß alle Pflanzen mit einer Chromosomenzahl $>12$ auf evolutionär alte oder PaläoPolyploidie zurückgehen. Unter dieser Annahme liegt der Anteil polyploider Holzpflanzen global bei 70 \%. Da sämtliche Verwandte unter den Tiliaceaen nur über einen Chromosomensatz von $\mathrm{n}=7$ verfügen, wird vermutet, daß die Gattung Tilia unter Verlust eines Chromosoms aus einer hexaploiden Art dieser Familie entstanden ist (HATTEMER et al. 1993). 


\subsection{Geographische Verbreitung}

Den Höhepunkt ihrer Verbreitung erreichten die Winter- und Sommerlinde nach der letzten Vereisung in der Eichen-Mischwaldzeit (ca. 6000-2500 v. Chr.). In Pollendiagrammen sind Lindenpollen (vorwiegend der Winterlinde) mit mehr als $20 \%$ vertreten (PIGOTT und HUNTLEY 1978). Die Linde war damit neben Eiche, Ulme und Esche eine der Hauptbaumarten dieser Zeit. Ein Wechsel zu einem feuchteren und kälteren Klima förderte die Konkurrenzkraft der Buche und machte sie zur vorherrschenden Laubbaumart. Eine kontinuierliche Verdrängung der Linde durch die Buche setzte in England etwa 3500 v. Chr. und in Mitteleuropa um 2500 v. Chr. ein. Um 1700 v. Chr. war der Anteil des Lindenpollens in England auf 1 \% gesunken (PigOTT und HunTLEy 1978). Im Raum Göttingen setzte eine starke Reduktion um 2000 v. Chr. ein, bis sie ca. 800 v. Chr. den heutigen Stand erreichte (STRASBURGER et al. 1991).

Eine schlechte Eignung der Linde als Bau- und Brennholz sowie das schwindende Interesse an anderen Lindenprodukten wie Schnitzholz, Honig, Bast, Arzneimittel etc. hat die Linde in den letzten Jahrhunderten waldbaulich ein Schattendasein fristen lassen; sie wurde sogar als „forstliches Unkraut“ aus den Wäldern eliminiert. So hat zwar der anthropogene Einfluß das natürliche Verbreitungsgebiet der Linden kaum beeinflußt, aber deren Anteil am gesamten forstlichen Baumbestand gesenkt.

Das natürliche Verbreitungsgebiet der Winterlinde reicht von Nordspanien bis an den Ural und von Skandinavien bis an den Bosporus, kleinflächig bis in die Osttürkei (Abb. 2.1). Nach Pigott und Huntley (1980) und Pigott (1981) ist die Winterlinde in den Randbereichen ihrer nördlichen Verbreitung nur noch durch Reliktvorkommen vertreten. In Norden Englands und in Skandinavien haben die Populationen ihre Fähigkeit zur sexuellen Reproduktion aufgrund des veränderten Klimas verloren. Die Langlebigkeit der Linde (bis 1000 Jahre) und ihre hervorragende vegetative Vermehrung über Stockausschlag, Wurzelbrut und Absenker haben die dortigen Bestände bis heute erhalten. 


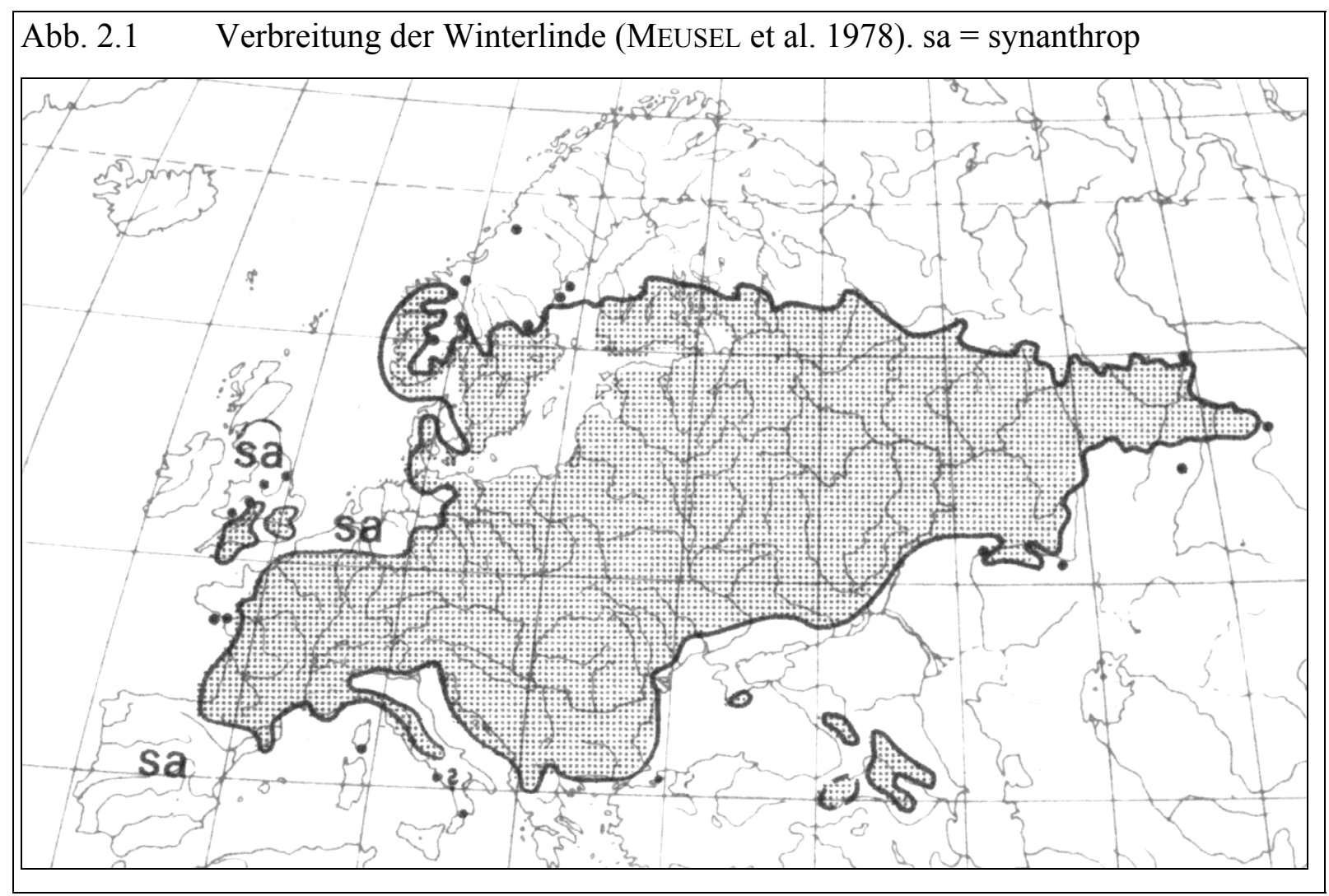

Der Verbreitungsschwerpunkt der Winterlinde liegt eindeutig im östlichen Europa. In den ehemaligen Sowjetrepubliken, Polen und Ungarn kommt Winterlinde teilweise noch in Reinbeständen vor. Der Anteil am Baumbestand liegt mit $6 \%$ deutlich über dem im westlichen Teil Europas (PockBerger 1963). Der Anteil des Lindenholzes am Gesamteinschlag betrug in den sechziger Jahren in den alten Bundesländern durchschnittlich $3 \%$ (KOLTZENBURG 1973). EISENHUT (1957) stuft die Winterlinde in den gemäßigt-kontinental-mediterranen Arealtyp ein. Die Verbreitung der Winterlinde wird nicht durch niedrige Wintertemperaturen, sondern durch mangelnde Sommerwärme eingeschränkt.

In ihrer vertikalen Verbreitung erreicht die Winterlinde im Erzgebirge Höhenlagen bis 590 m, im Bayerischen Wald 615 m, in den Bayerischen Alpen 950 m und in den Schweizer Zentralalpen $1500 \mathrm{~m}$. Grundsätzlich deckt sich das Verbreitungsgebiet der Winterlinde mit dem des Spitzahorns (Acer platanoides L.) (EISENHUT 1957).

\subsection{Standortsansprüche und Wachstum}

Eine gute Wuchsleistung erreicht die Winterlinde nur auf mittel- bis tiefgründigen, lockeren, neutralen bis basischen Böden mit einem ausgeglichenen Wasserhaushalt. Hier zeigt sie sich hinsichtlich ihrer Lichtansprüche als eine Halbschatten oder sogar Schatten ertragende Baumart. Diese Eigenschaft büßt sie auf suboptimalen Standorten aber ein und nähert sich dort den 
gehobeneren Lichtansprüchen der Lichtbaumarten. Als gemäßigt-kontinental-mediterrane Baumart bevorzugt sie ausreichend warme Sommer, wobei sie gegen Winterfrost unempfindlich ist.

Die Winterlinde deckt sich in ihren ökologischen Ansprüchen mit denen der konkurrenzstärkeren Buche und wird von dieser in deren ökologischen Optimum in Mitteleuropa verdrängt. Die Winterlinde ist weitgehend nur noch dort natürlich vertreten, wo die Buche aufgrund des Wasserhaushaltes in ihrer Konkurrenzkraft geschwächt ist, z. B. in der feuchten Hartholzaue oder auf den trockenen Standorten des Eichen-Hainbuchen-Waldes. Dort ist sie der Buche aufgrund ihrer Unempfindlichkeit gegen Staunässe bzw. ihrer Trockenresistenz überlegen. Auch in Regionen mit strenger Winterkälte kann sie sich gegenüber der Buche durchsetzen.

Auf guten Standorten erreicht die Winterlinde im Bestand eine Höhe von durchschnittlich 15$25 \mathrm{~m}$, wobei auch Höhen von über $35 \mathrm{~m}$ erreicht werden können. Nach anfänglich trägem Jugendwachstum ist sie etwa in den ersten 50 Jahren der Buche vor- bis gleichwüchsig, um danach aber von der Buche überwachsen zu werden. Das Höhenwachstum wird ab einem Alter von 150 Jahren eingestellt. Das durchschnittliche Höchstalter der Linden wird mit 800 Jahren angegeben, wobei einzelne Exemplare ein weitaus höheres Alter erreichen können. Damit gehören sie zu den Baumarten der mitteleuropäischen Flora, die am ältesten werden können.

Zitierte Literatur für dieses Kapitel: DeNGLER 1992, EISENHUT 1957, NAMVAR und SPETHMANN 1986, Koss 1982, RÖHRIG 1967, RÜHL 1968, SDW 1991, STRASBURGER et al. 1991.

\subsection{Waldbauliche Bedeutung der Winterlinde}

Die Linde hat in den letzten beiden Jahrhunderten waldbaulich kaum Beachtung gefunden und ist sogar gezielt aus den Forsten verdrängt worden. Selbst bei ansprechender Wuchsleistung auf besseren Standorten wurde dem Anbau anderer Edellaubhölzer bzw. der Buche der Vorzug gegeben. So sind selbst im Großraum Göttingen, wo für die Linde günstige Bedingungen vorherrschen, Lindenaltbestände nur selten vorzufinden.

Die Linde wird im Waldbau meistens als Nebenbaumart eingesetzt, z. B. zur Schaftpflege der Eiche, und weniger als größere Stammholzdimensionen erreichende Hauptbaumart. Erst in den letzten 30-40 Jahren wird ihr wirtschaftlich und vor allem ökologisch eine bedeutendere Rolle zugewiesen. Sie ist aufgrund der sich sehr schnell zersetzenden und mineralstoffreichen Streu die bodenpfleglichste Baumart in unseren Breiten und auch die nektarreiche Blüte im Hochsommer paßt gut in die Zielsetzungen des modernen Waldbaus. So sind denn heute so- 
wohl im Göttinger Umland als auch bundesweit wieder nennenswerte Rein- und Mischbestände in den unteren Altersklassen zu finden.

Die jährlich eingeschlagene Menge von ca. 3500-5000 $\mathrm{m}^{3}$ an Lindenstammholz kann den hiesigen Bedarf im Starkholz nicht decken (ANONYMUS 1979). Die besonders feine und gleichmäßige Struktur der Holzes und die geringen Dichtekontraste (SACHSSE und SCHWAER 1991) machen das Lindenholz für viele Verwendungszwecke gerade bei der drastisch abnehmenden Verfügbarkeit an Tropenholz kaum ersetzbar, so daß zusätzliches Lindenholz importiert werden muß. So sind für Stammholz in den stärkeren Dimensionen gute Erlöse zu erzielen, die um ein Vielfaches über denen der Buche liegen können (SIEPENKÖTTER 1987).

\subsection{Blüte und Frucht der Winterlinde}

\subsubsection{Die Blüte}

Die Linde ist hermaphroditisch, d. h. die männlichen und weiblichen Geschlechtsorgane befinden sich in einer Blüte. Diese ist 5-zählig in einen grünlich gefärbten Kelch und in eine weiße bis cremefarbene Blumenkrone unterteilt (Blütenformel: *K5 C5 Aœ G (5)). Bei der Winterlinde sind 2-16 Einzelblüten ( $\varnothing 5$ Einzelblüten) zu Infloreszenzen vereinigt, die an der Basis ein hellgrün/gelbliches Hochblatt besitzen. Die Blüte entspricht in ihrer Gestalt der typischen Scheiben- und Schalenblume insektenbestäubter Angiospermen. Dieser Gestalttypus wird in Nektar- und Pollenblumen unterteilt, wobei die Linde zu den Nektarblumen gezählt wird (HЕß 1983). Die Blüten folgender Baumarten der gemäßigten Breiten werden ebenfalls diesem Typ zugeordnet:

Spitzahorn (Acer platanoides)

Kornelkirsche (Cornus mas)

Magnolie (Magnolia spec.)

Apfel (Malus sylvestris)

Süßkirsche (Prunus avium)

Birne (Pyrus communis)

Eberesche (Sorbus aucuparia)

Evolutionär werden die Scheiben- und Schalenblumen an den Anfang der Entwicklungsreihe der Angiospermen-Blumentypen gesetzt (HEß 1983, STRASBURGER et al. 1991) und sind von 
allen Blumentypen am wenigsten auf eine Bestäubergruppe spezialisiert; es handelt sich, bezüglich der Attraktivität für Insekten, um Generalisten.

Die Lindenblüten sind ausgesprochen zwittrig und nur in seltenen Fällen funktionell eingeschlechtlich. Für ROHMEDER (1972) gilt die Winterlinde als Beispiel für Ausbildung einer perfekten zwittrigen Blüte. In einigen Fällen konnte EISENHUT (1957) bei der Winterlinde gegen Ende der Blühperiode die Bildung funktionell eingeschlechtlicher Blüten feststellen; während die weiblichen Blütenorgane fertil waren, blieben die Antheren unentwickelt. Ebenso beobachtete er bei einer 250-jährigen Linde eine 95 \%ige Sterilität der weiblichen Blütenorgane, während sich der produzierte Pollen als fertil erwies.

Die Blüte der Winterlinde ist dichogam und blüht protandrisch, d. h. innerhalb der zwittrigen Blüte gelangen erst die männlichen, nachfolgend die weiblichen Blütenorgane zur Reife. Beobachtungen von ANDERSON (1976), EISENHUT (1957) und KLEIN (1992) zeigten, daß diese zeitliche Trennung der geschlechtsreifen männlichen und weiblichen Blütenorgane nicht ausreicht, um eine Selbstbestäubung der Blüte (Autogamie) auszuschließen. Die Antheren entließen noch reichlich Pollen, während die Narbe schon rezeptiv war. Die Blüte ist herkogam; eine räumliche Trennung von Griffel und Staubbeuteln verhindert eine direkte Bestäubung der Narbe mit dem Pollen der eigenen Blüte. Für eine detaillierte Beschreibung der Anthese wird auf EISENHUT (1957) und ANDERSON (1976) verwiesen.

\subsubsection{Gynözeum}

Die Oberfläche der Narbe ist trocken (HESLOP-HARRISON und SHIVANNA 1977). Die Narbe ist 2-5 Tage, bei kühler Witterung bis zu 7 Tage rezeptiv (EISENHUT 1957, PIGOTT und HuNTLEY 1981). Der Fruchtknoten besteht aus fünf Fächern mit je zwei Eizellen. Insgesamt besitzt jede Blüte zehn Eizellen, von denen aber in den meisten Fällen nur eine Eizelle zu einer Frucht heranreift. EISENHUT (1957) konnte unter den untersuchten Früchten bei der Winterlinde nur $8,1 \%$ zweisamige und $0,1 \%$ dreisamige finden.

\subsubsection{Pollen}

Eine Blüte der Winterlinde produziert durchschnittlich etwa $43.500( \pm 3.430)$ Pollen. Bei zehn Samenanlagen pro Fruchtknoten liegt das Pollen/Eizellen-Verhältnis bei 4.350. Damit ist es verglichen mit anderen Baumarten niedrig: 
Tab. $2.1 \quad$ Pollenkornzahlen je Eizelle, modifiziert nach POHL (1936).

$\mathrm{I}=$ insektenbestäubt, $\mathrm{W}=$ windbestäubt

\begin{tabular}{|l|l|c|r|}
\hline \multicolumn{1}{|c|}{ Art } & Bestäubungart & $\begin{array}{c}\text { Pollen/Eizellen- } \\
\text { Verhältnis }\end{array}$ \\
\hline 1. & Corylus avellana & & \\
& nach GREGUSS I & $\mathrm{W}$ & 3591266 \\
& nach POHL & $\mathrm{W}$ & 2548799 \\
& nach GREGUSS II & $\mathrm{W}$ & 219086 \\
\hline 2. & Fagus sylvatica & $\mathrm{W}$ & 636594 \\
\hline 3. & Aesculus hippocastanum & $\mathrm{I}$ & 451543 \\
\hline 4. & Acer pseudoplatanus & $\mathrm{I}$ & 94078 \\
\hline 5. & Pyrus communis & $\mathrm{I}$ & 60778 \\
\hline 6. & Secale cereale & $\mathrm{W}$ & 57310 \\
\hline 7. & Arrhenatherum elatius & $\mathrm{W}$ & 37124 \\
\hline 8. & Plantago lanceolata & $\mathrm{W}$ & 15486 \\
\hline 9. & Zea mais & $\mathrm{I}$ & 14636 \\
\hline 10. & Sanguisorba officinalis & $\mathrm{I} / \mathrm{W}$ & 11040 \\
\hline 11. & Plantago media & $\mathrm{W}$ & 8036 \\
\hline 12. & Betula verrucosa & $\mathrm{I}$ & 6734 \\
\hline 13. & Polygonum bistorta & $\mathrm{I}$ & 5678 \\
\hline 14. & Tilia cordata & & 4350 \\
\hline
\end{tabular}

PoHL (1936) berücksichtigte nicht, daß die Linde zehn Eizellen pro Fruchtknoten besitzt; der ursprüngliche Wert wurde von 43.500 auf 4.350 korrigiert. Dieser Autor berechnete für eine Infloreszenz der Winterlinde die durchschnittliche Produktion von ca. 200.100 Pollen, die im Vergleich zu anderen Baumarten gering ist (Tab. 2.2). Für die Ermittlung der absoluten Pollenerzeugung traf er für die Winterlinde die Annahme, daß ein zehnjähriges Zweigsystem 445 Infloreszenzen trägt, und kam auf einen relativ hohen Wert von rund 89 Millionen Pollen (Tab. 2.3). Diese Werte wurden für frei stehende Bäume berechnet. 
Tab. 2.2 Durchschnittliche Pollenerzeugung von Blütenständen (POHL 1936). $\mathrm{I}=$ insektenbestäubt, $\mathrm{W}=$ windbestäubt

\begin{tabular}{|c|c|c|c|}
\hline & Art & Bestäubungsart & $\begin{array}{l}\text { Ø Pollenerzeugung } \\
\text { pro Blütenstand }\end{array}$ \\
\hline 1. & Rumex acetosa & $\mathrm{W}$ & 392950500 \\
\hline 2. & Typha angustifolia & W & 174000000 \\
\hline 3. & Aesculus hippocastanum & I & 41764800 \\
\hline 4. & Acer pseudoplatanus & I & 24891048 \\
\hline 5. & Ricinus communis & $\mathrm{W}$ & 24063150 \\
\hline 6. & Pinus nigra & $\mathrm{W}$ & 22448225 \\
\hline 7. & Zea mais & $\mathrm{W}$ & 18423320 \\
\hline 8. & Erythrina crista galli & I & 7684000 \\
\hline 9. & Pinus montana & $\mathrm{W}$ & 7541650 \\
\hline 10. & Populus canadensis & $\mathrm{W}$ & 5813333 \\
\hline 11. & Pinus sylvestris & W & 5773445 \\
\hline 12. & Betula verrucosa & $\mathrm{W}$ & 5452500 \\
\hline 13. & Alnus glutinosa & $\mathrm{W}$ & 4445000 \\
\hline 14. & Secale cereale & $\mathrm{W}$ & 4240940 \\
\hline 15. & Corylus avellana & $\mathrm{W}$ & 3933333 \\
\hline 16. & Arrhenatherum elatius & $\mathrm{W}$ & 3730962 \\
\hline 17. & Plantago media & I & 3343780 \\
\hline 18. & Polygonum bistorta & $\mathrm{I}$ & 2861712 \\
\hline 19. & Sanguisorba minor & $\mathrm{W}$ & 2532750 \\
\hline 20. & Plantago lanceolata & $\mathrm{W}$ & 2010063 \\
\hline 21. & Fraxinus excelsior & $\mathrm{W}$ & 1605705 \\
\hline 22. & Acer californicum & $\mathrm{W}$ & 1095110 \\
\hline 23. & Carpinus betulus & $\mathrm{W}$ & 890272 \\
\hline 24. & Sanguisorba officinalis & $\mathrm{I}$ & 589019 \\
\hline 25. & Quercus petrea & $\mathrm{W}$ & 554368 \\
\hline 26. & Pyrus communis & $\mathrm{I}$ & 437602 \\
\hline 27. & Acer platanoides & $\mathrm{I}$ & 238230 \\
\hline 28. & Tilia cordata & I & 200100 \\
\hline 29. & Fagus sylvatica & $\mathrm{W}$ & 173976 \\
\hline 30. & Artemisia pontica & $\mathrm{W}$ & 25100 \\
\hline
\end{tabular}


Tab. 2.3 Durchschnittliche Pollenerzeugung eines zehnjährigen Zweigsystems (POHL 1936)

\begin{tabular}{|l|l|c|}
\hline \multicolumn{1}{|c|}{ Art } & $\begin{array}{c}\text { Pollenerzeugung eines } \\
\text { zehnjähr. Zweigsystems }\end{array}$ \\
\hline 1. & Pyrus communis & 12865499 \\
\hline 2. & Aesculus hippocastanum & 18543571 \\
\hline 3. & Fagus sylvatica & 28010130 \\
\hline 4. & Pinus montana & 51532094 \\
\hline 5. & Tilia cordata & 89044500 \\
\hline 6. & Carpinus betulus & 95259104 \\
\hline 7. & Populus canadensis & 100373008 \\
\hline 8. & Picea excelsa & 106699500 \\
\hline 9. & Quercus petrea. & 110984474 \\
\hline 10. & Betula verrucosa & 118502500 \\
\hline 11. & Pinus nigra & 119716384 \\
\hline 12. & Corylus avellana & 243866646 \\
\hline 13. & Alnus sibirica & 302266000 \\
\hline 14. & Acer pseudoplatanus & 336029148 \\
\hline 15. & Pinus sylvestris & 346412700 \\
\hline
\end{tabular}

Der Winterlindenpollen ist im Mittel $30 \mu \mathrm{m}$ groß und besitzt eine netzig-grubige Außenhaut. Die Sinkgeschwindigkeit eines Einzelpollens wird mit 3,2 cm/sec angegeben (KNOLL 1932). Die Pollengröße und Sinkgeschwindigkeit befinden sich damit im Rahmen windbestäubter Baumarten (ROHMEDER 1972).

Nach HESSE (1979) wird bei der Sommerlinde (Tilia platyphyllos) eine große Menge Pollenkittsubstanz vom Antherentapetum gebildet, welche aber weitgehend an der Loculuswand verbleibt und nicht zu den Pollen transportiert wird. Daraus resultiert nur eine mittelmäßige Pollenklebrigkeit, die auch bei der Silberlinde (Tilia tomentosa) nur geringfügig besser war. Er beschreibt ein Drittel des Sommerlindenpollens als lose, ein Drittel als mäßig verklebt und ein Drittel als gut haftend. REMPE (1937) stellte bei in der Krone deponierten Winterlindenpollen eine Aggregation von 38,5 \% fest, wobei die Aggregate im Schnitt aus vier Pollenkörnern bestanden. PigOTT und HunTLEy (1980) beobachteten eine weitaus größere Klebrigkeit und Aggregation des Pollens der Winterlinde. Bei ihnen waren $85 \%$ des Pollens in Aggregaten zu durchschnittlich neun Pollenkörnern verklebt. K. VON DER OHE (pers. Mitteilung) bescheinigt den Pollen der Winterlinde im norddeutschen Raum eine mittlere Klebrigkeit, welche aus einer dünnen Schicht Pollenkitt resultiert.

\subsubsection{Nektarproduktion}

Die Nektarien der Lindenblüten besitzen die Form von Grübchen und befinden sich paarweise angeordnet an der Basis der Kelchblätter. Es sind aktive Drüsen, die in der Lage sind, den Phloemsaft zu konzentrieren und mit Enzymen anzureichern (ZIEGLER 1953). 
Die Nektarproduktion der Blüte einer Winterlinde beläuft sich auf ca. 1,9 mg pro Tag (BEUTLER 1930) und ist damit im Vergleich zu anderen Blütenpflanzen als groß einzustufen (KUGLER 1970).

Bei der Linde unterliegen die Menge und die Zuckerkonzentration des produzierten Nektars einem tageszeitlichen Rhythmus und sind auch von dem Entwicklungstadium der Blüte abhängig. Die zu allererst entwickelten Blüten der Linde produzieren keinen Nektar; mit zunehmendem Alter der Blüte nimmt die Zuckerkonzentration ab (von $38 \%$ auf $26 \%$ ) und mit der beginnenden Degeneration der Narbe wird die Nektarproduktion eingestellt (BEUTLER 1930, KLEBER 1935). Der höchste Zuckergehalt und die maximale Nektarmenge werden am zweiten Tag nach Öffnung der Blüte erreicht (ANDERSON 1976).

Der tageszeitliche Rhythmus wird von der Luftfeuchtigkeit, der Lufttemperatur, der Sonneneinstrahlung und dem Wasserhaushalt des Bodens bestimmt. Während die Quantität in den Nachtstunden und am frühen Morgen ihr Maximum erreicht, ist die Zuckerkonzentration nach abends und nachts mit weniger als $24 \%$ am niedrigsten und mit $71 \%$ um die Mittagszeit am höchsten (ANDERSON 1976, KleBer 1935). Die gleiche Periodizität stellten auch CORBET et al. (1979) in ihren Untersuchungen fest. Die Untersuchungen von CORBET et al. (1979) zeigten zudem eine räumliche Variation der Zuckerkonzentration innerhalb einer Lindenkrone. Dies wird mit einem unterschiedlich starken Safttransport im Phloem der einzelnen Kronenbereiche begründet.

Eine Degeneration (Braunfärbung) der Narbe hat die sofortige Einstellung der Nektarproduktion zur Folge (EISENHUT 1957).

\subsubsection{Frucht}

Nach der Befruchtung entwickelt sich in den meisten Fällen nur eine der zehn Samenanlagen zu einer kugeligen Nuß, welche Endosperm enthält. Häufig sind auch zwei, selten drei, Samen in einer Winterlindenfrucht vorhanden. In diesen Fällen bilden die Samen in ihrer Gesamtheit eine kugelige Form, die einzelnen Nüsse weichen dementsprechend von der Kugelform ab. Das Gewicht der Nüsse aus mehrsamigen Früchten ist geringer als aus einsamigen Früchten (EISENHUT 1957, PigOTT 1991).

Die Samenreife ist im September, spätestens Mitte Oktober erreicht. Die Samen können aber noch einige Wochen oder Monate am Baum hängen bleiben, ehe sie vom Wind verweht werden (ROHMEDER 1972; eigene Beobachtungen). Die Windverfrachtung der Samen wird durch das Hochblatt an der Basis der Infloreszenz unterstützt. Bei einer Windgeschwindigkeit von 
5,9 m/sec ermittelte KOHLERMANN (1950) aus 14 m Höhe die Verbreitung der Winterlindensamen bis zu einer Entfernung von $64 \mathrm{~m}$.

Die Früchte der Linde gehören zu dem stark keimgehemmten forstlichen Saatgut. PUCHNER (1922) berichtet bei der Winterlinde von Saatgut, welches noch sieben Jahre nach Aussaat mit der Keimung begann. Die Dormanz wird durch eine geringe Wasserdurchlässigkeit der Testa verursacht. Der Anteil des überliegenden Saatgutes kann durch eine Aussaat noch nicht vollständig ausgereifter grüner Früchte verringert werden (EISENHUT 1957).

\subsection{Blühbiologie}

Die Blühreife der Winterlinde hängt stark von der sozialen Stellung des Baumes im Bestand ab. Im Freistand beginnt sie im Alter von 20-25 Jahren zu blühen, Stockausschläge sogar schon im Alter von 10 Jahren. Im geschlossenen Bestand erreicht sie ihre Geschlechtsreife erst nach 30-50 Jahren (EISENHUT 1957). Die Blüte der Linde ist im Mischbestand regelmäßiger und stärker als im Reinbestand. Die Winterlinde blüht erst nach Laubausbruch gegen Ende Juni/Anfang Juli und damit am spätesten von allen einheimischen Baumarten (BARTELS 1983).

Der Blühtermin der Winterlinde variiert je nach geographischer Breite und Höhenlage. Der Blühbeginn verzögert sich bei Zunahme um einen Breitengrad um sieben Tage und je $100 \mathrm{~m}$ Höhenzunahme um vier Tage (EISENHUT 1957). 1995 begann die Blüte im Vorharzgebiet in 250 m Höhenlage am 12. Juli, im Stadtgebiet von Göttingen (150 m ü. NN) ca. eine Woche früher.

Generell ist die Blütenbildung von einer ausreichenden Lichtversorgung abhängig. Blüten werden nur in den gut mit Licht versorgten Kronenbereichen gebildet. EISENHUT (1957) stellte eine Abhängigkeit der Anzahl von Infloreszenzen von der jeweiligen Exposition des Kronenmantels fest. Bei der Krimlinde (Tilia euchlora K.KoCH) befanden sich dreimal mehr Infloreszenzen in der mittleren und oberen Kronenpartie als im unteren Kronenbereich. Die Entwicklung der einzelnen Blüte begann zuerst im mittleren und oberen Bereich der nach Süden exponierten Krone, während die Blüten sich bei östlicher Exposition im unteren Bereich als letztes entwickelten. Dagegen berichten PigOTT und HUNTLEY (1981) von einer über den ganzen Baum nahezu simultanen Blütenentwicklung der Winterlinde. Nur die Blühabfolge innerhalb einer Infloreszenz sei zeitlich versetzt, wobei sich die Terminalblüte als erste öffnet. Diese Blühabfolge innerhalb einer Infloreszenz wurde auch von EISENHUT (1957) beschrieben und dieser Autor weist darauf hin, daß sich zum gleichen Zeitpunkt stäubende und embryonale Blüten in einer großen Infloreszenz befinden können. ANDERSON (1976) betont 
ebenfalls, daß während der Blühphase alle Entwicklungsstadien der Blüte innerhalb eines Baumes vorzufinden sind. Insgesamt erstreckt sich die Blüte einer Linde in Abhängigkeit von den klimatischen Gegebenheiten über einen Zeitraum ca. zwei Wochen.

Die Öffnung der einzelnen Blüte ist an keine Tageszeit gebunden. Während sich bei den Untersuchungen von ANDERSON (1976) der überwiegende Teil der Blüten in den Nachmittagsund Abendstunden öffnete ( $82 \%$ ) und nur $18 \%$ in den Morgenstunden, begann bei der Untersuchung von PigOtT und HunTLEy (1981) die Mehrheit der Blüten am späten Morgen und frühen Nachmittag mit der Öffnung.

Die individuellen Unterschiede zwischen früh- und spätblühenden Winterlinden gibt EISENHUT (1957) mit maximal sechs Tagen an. Eine weitgehende Synchronie der Blüte der Mitglieder einer Winterlindenpopulation konnte auch mit Hilfe eigener Luftbildaufnahmen festgestellt werden (s. Kap. 3.4).

\subsection{Die Bestäubungsökologie der Winterlinde}

\subsubsection{Attraktivität der Linde}

Wie bereits erwähnt, ist die Linde auf keine Bestäubergruppe spezialisiert - sie ist ein Generalist. Die Blüte ist einfach gebaut und Tag und Nacht geöffnet (ANDERSON 1976, CzUBACKI 1996, KNUTH 1898). Es ist also ein Leichtes für Insekten, zu jeder Zeit an Pollen und Nektar zu gelangen.

Die weiße Farbe der in Infloreszenzen gebündelten Einzelblüten hebt sich für tag- und nachtaktive Insekten deutlich sichtbar vom grünen Blätterdach ab. Diese farbliche Abhebung dient vielen Insektengruppen zur Nah- und Fernorientierung.

Eine Orientierung wird den Insekten zudem durch den unverwechselbaren, intensiven Duft der Lindentracht ermöglicht, der von dem Blütenduftstoff Farnesol herrührt. Er stellt eine weitere starke Stimulation für einen Anflug der Linde dar. Dieser zu den Sesquiterpenen gehörende Blütenduftstoff wird im Pflanzenreich sonst nur noch von den Maiglöckchen produziert (HEß 1983). Der eigentliche Nektar ist hingegen geruchlos. Der Blütenduftstoff Farnesol enthält zudem Geraniol und Zitral. Das Bemerkenswerte daran ist, daß diese auch als Pheromone von den Bienen produziert werden und ihr Duft eine enorme Anziehungskraft auf diese ausübt. Die Attraktivität des Blütenduftstoffes der Linde ist so stark, daß Bienen von Linden angelockt werden, selbst wenn die Blüten wenig oder gar keinen Nektar produzieren (pers. Mitteilung VON DER OHE, W.). 
Das Hochblatt der Infloreszenz trägt ebenfalls zur Attraktivität der Linde bei (ENGLER 1909). Dieses ist vom Blattgrün farblich differenziert und dient laut ANDERSON (1976) weniger als Flugorgan für die Windverbreitung der Samen als vielmehr der optischen Anlockung von Insekten. Das Hochblatt ist nach ANDERSON (1976) insbesondere für nachtaktive Insekten attraktiv.

Pollen und Nektar werden von der Linde reichlich angeboten (s. Kap. 2.6.1). Damit stellen vereinzelt im Mischbestand stehende Linden eine lohnende Nahrungsquelle dar. Die Lindenpopulation als Einheit bietet genügend Anreize, um Insekten und Insektenvölker aus größerer Entfernung anzulocken und um in der interspezifischen Konkurrenz mit anderen Blütenpflanzen zu bestehen (HEINRICH 1975). Die starke Konkurrenzkraft der Linde bezüglich ihrer Attraktivität für Insekten konnte ANDERSON (1976) eindrucksvoll nachweisen: Der Anteil der Lindenpollen auf den 114 von ihm untersuchten Insekten betrug durchschnittlich $70 \%$. Bei den seiner Meinung nach wichtigsten Bestäubergruppen, den Bienen (ink1. Hummeln), Motten und Fliegen, lag der Anteil sogar bei $85 \%, 82 \%$ bzw. $77 \%$. Diese Angaben sprechen für eine hohe Blütenkonstanz der Insekten während der Lindenblüte. Nach CORBET et al. (1979) wird das üppige Nahrungsangebot der Linde in dieser Phase von keiner anderen Pflanze erreicht. Gerade in der in Mitteleuropa weit verbreiteten Agrarlandschaft stellt die Tracht der Linde für Insekten im Sommer die einzig nennenswerte Nahrungsquelle dar. VON DER OHE (pers. Mitteilung) konnte Honigbienenvölker beobachten, die als Hauptnahrungsquelle Lindenpopulationen in $4 \mathrm{~km}$ bis $6 \mathrm{~km}$ Entfernung anflogen. Nicht umsonst gilt die Linde bei den Imkern seit jeher als sehr wichtiger Trachtbaum.

Eine weitere Strategie zur Anlockung eines breiten Insektenspektrums ist eine Abdeckung unterschiedlicher Nahrungsbedürfnisse der verschiedenen Insektengruppen. Dieses geschieht bei der Linde durch eine im Tagesrhythmus variierende Nektarmenge und -konzentration. Da die verschiedenen Insektengruppen unterschiedliche Nektarkonzentrationen bevorzugen (s. Kap. 2.8.2), beeinflußt die Linde durch eine im Tagesverlauf wechselnde Zuckerkonzentration des Nektars (s. Kap. 2.6.1.3) die Artenzusammensetzung der sie besuchenden Insekten: Choi (1987), Corbet et al. (1979) und Kleber (1935) stellten bei der Linde eine im Laufe des Tages wechselnde und versetzte Abundanz von Fliegen, Hummeln und Honigbienen fest. Diese ist nach CORBET et al. (1979) vorrangig auf die Variation der Nektarkonzentration zurückzuführen. Die Nektarmenge variiert auch im Tagesverlauf, ist aber immer im Überfluß vorhanden und stellt daher im Sinne der Periodizität des Blütenbesuchs von Insekten kein alternierendes Attraktivitätskriterium dar. Nach KLEBER (1935) ist Nektar mit einem Zucker- 
gehalt unter $25 \%$ für Honigbienen uninteressant; ein lebhafter Bienenbesuch ist erst ab einem Zuckergehalt von $35 \%$ zu verzeichnen, während ein Zuckergehalt von $45 \%$ auf die Hummel die größte Anziehungskraft ausübt (CORBET et al. 1979). KLEBER (1935) berichtet, daß trotz einer sehr hohen Nektarkonzentration über die Mittagsstunden nur spärlicher Bienenbesuch auf der Linde zu beobachten war. Sie führt dieses auf einen zu hohen Zuckergehalt und eine geringe Nektarmenge zurück: Der Nektar sei dann so dickflüssig, daß er nur noch schwer von den Bienen aufgesaugt werden könne und die geringe Nektarmenge sei für einen Blütenbesuch nicht ausreichend attraktiv.

PYKE und WASER (1981) haben den Zuckergehalt der Nektare von insgesamt 447 zoophilen Arten von Blütenpflanzen zusammengetragen. Sie ermittelten die durchschnittliche Zuckerkonzentration der Nektare von Pflanzen, die nur von einer bestimmten Tiergruppe bestäubt werden und konnten zeigen, daß für die einzelnen Tiergruppen der bevorzugte Zuckergehalt des Nektars unterschiedlich ist. Abweichend von Pyke und WASER (1981) gibt Heß (1983) die Zuckerkonzentration der meisten Bienenblumen mit $30 \%$ bis $35 \%$ an.

Tab. 2.4 Von den Tiergruppen bevorzugte Zuckerkonzentration im Nektar (PYKE und WASER 1981)

\begin{tabular}{|l|c|c|}
\hline Bestäubergruppe & $\begin{array}{c}\varnothing \text { Nektar- } \\
\text { konzentration } \\
\text { in \% }\end{array}$ & $\begin{array}{c}\text { Anzahl } \\
\text { untersuchter } \\
\text { Pflanzenarten }\end{array}$ \\
\hline Fledermäuse & 18,9 & 7 \\
\hline Motten & 22,1 & 36 \\
\hline Kolibris & 25,4 & 202 \\
\hline Schmetterlinge & 28,8 & 40 \\
\hline Bienen & 41,6 & 134 \\
\hline Hummeln & 46,5 & 22 \\
\hline
\end{tabular}

Die von vielen Autoren berichteten zahlreichen Besuche von Motten auf der Linde sind somit leicht zu erklären (vgl. Kap. 2.8.2). Die Nektarproduktion der Linde ist in der Nacht am größten und die Nektarkonzentration mit weniger als $24 \%$ am niedrigsten (s. Kap. 2.6.1.3); sie entspricht der bevorzugten Nektarkonzentration der Motten.

\section{Fazit}

Von der Linde werden sehr viele Insektengruppen angelockt. Sowohl optisch als auch aufgrund ihres reichhaltigen Nahrungsangebots an Nektar und Pollen am Tage und in der Nacht, bis hin zu (den Pheromonen der Bienen ähnlichen) Blütenduftstoffen verfügt sie über zahlreiche relevante Attraktionen. Sie ist spezialisiert auf das „Nichtspezialisiert-sein". 


\subsubsection{Blütenbesucher}

Im vorigen Kapitel wurden die morphologischen Merkmale der Linde beschrieben, die einen Besuch für eine Vielzahl von Insektenspezies interessant macht. Diese Rolle der Linde als Generalist wird durch viele Untersuchungen bestätigt, die den Anflug von Insekten auf die Arten der Gattung Tilia beobachteten.

Die Liste der auf den Linden nach Nahrung suchenden Insekten ist lang und soll hier nur in Umrissen beschrieben werden. Eine sehr ausführliche Untersuchung über die Artenvielfalt der die Linde aufsuchenden Insekten wurde von ANDERSON (1976) durchgeführt. In einem dreiseitigen Anhang führt dieser Autor 66 Insektenarten aus 29 Gattungen auf, die an Tilia americana, Tilia platyphyllos und Tilia cordata beobachtet wurden. Dabei konnten allein an der auf dem Campus der Universität von Connecticut stehenden Tilia cordata 38 Arten aus 24 Gattungen gezählt werden. Zusätzlich wurde bei 114 Insekten der an ihnen haftende Pollen untersucht. Es stellte sich eine schon in Kap. 2.8.1 erwähnte Blütenkonstanz der Insekten heraus. Auf fast allen untersuchten Insekten befanden sich überwiegend Lindenpollen; Pollen anderer Pflanzenarten waren wenig vertreten und selten fand sich Pollen von mehr als zwei Arten auf einem Insekt. ANDERSON (1976) stellte die höchsten absoluten Mengen transportierter Pollen an Bienen, Hummeln und Fliegen fest. Seine Versuche zeigten eine hohe Wirksamkeit nachtaktiver Insekten bei der Bestäubung der Linde und er zählt die Motten (Lepidoptera) neben den Bienen (Apidae) und Schwebfliegen (Syrphidae) zu den wichtigsten Bestäubergruppen. Den beobachteten Käfern und Wanzen mißt er eine eher unbedeutende Rolle als Pollinatoren bei.

PigOTT (1991) berichtet ebenfalls, daß es von Insekten während der Blüte der Winterlinde nur so schwärmt. Bei warmem Wetter konnte er in der englischen Waldlandschaft einen enormen Anflug verschiedenster Insekten beobachten. Mit einer großen Häufigkeit waren wiederum die Schwebfliegen (Syrphidae) vertreten, aber auch viele nicht identifizierte Fliegen und Kleinfliegen aus der Ordnung Diptera, die hier nicht aufgezählt werden. Hinzu kommen noch mehrere Bombus-Arten, die auch bei kaltem und windigem Wetter ihre Nahrungssuche fortsetzten. Auch Faltenwespen (Vespidae) und mehrere Mottenarten (Lepidoptera) werden als Besucher der Winterlinde angegeben. Die Honigbiene (Apis mellifera) konnte PigOTT (1991) in der Waldlandschaft an der Winterlinde nur in geringer Zahl antreffen, in einer anderen Region Englands hingegen in großer Abundanz (PigOTT und HunTLEY 1981). Die Untersuchungen von CORBET et al. (1979) und EISENHUT (1957) bestätigen die Beobachtungen von ANDERSON (1976) und PIGOTT (1991) im weitesten Sinne; auch hier waren die häufigsten Besucher der Linde Fliegen, Hummeln und Bienen. 
Bei sieben koreanischen Tilia-Arten wurden 43 Insektenarten aus 30 Familien als Blütenbesucher gezählt (CHUNG und KIM 1984). Bienen, Hummeln und Motten waren bei den koreanischen Linden die wichtigsten Pollinatoren, in Japan waren bei Tilia japonica überwiegend Bienen, Hummeln, Schwebfliegen und sonstige Fliegen zu finden (ISHIDA und NAGASAKA 1997). Bei der koreanischen Tilia kiusiana waren 67 \% aller beobachteten Insekten Honigbienen (CHOI 1987). FERRAZZI (1996) berichtet neben Honigbienen, Hummeln und Schwebfliegen auch über ein häufiges Auftreten von Schmetterlingen bei der Winterlinde in Italien.

Nach HEDKTE (1996) sind einige Hummelarten regelrecht spezialisiert auf die Linde. Bombus hypnorum und Bombus pratorum fliegen auf ihren Futterflügen fast ausschließlich nur die Linde an. Ebenso betont FREE (1970) die Bedeutung der Linden als wichtige Pollenquelle für Hummeln.

Bei den Autoren, die ihre Untersuchungen nur am Tage durchgeführt haben, werden Motten nicht als Bestäuber aufgezählt. Motten gehören aber mit Sicherheit zu den regelmäßigen Besuchern der Linde.

EISENHUT (1957) erwähnt den geringen Anteil von Lindenpollen im Honig (ZANDER 1935) und deutet dies als Hinweis für einen seltenen Anflug der Lindenblüten durch Honigbienen. Er folgert daraus, daß die Honigbiene als Bestäuber nicht sonderlich effektiv sein kann. Diesen geringen Anteil von Lindenpollen mit Werten von 7,2-16,3 \% am Gesamtpollen im Honig haben unter anderem auch FERRAZZI (1996) und VON DER OHE et al. (1993) feststellen können. VON DER OHE et al. (1993) konnten jedoch nachweisen, daß dieser geringe Anteil an Lindenpollen nicht auf die geringe Sammelaktivität der Honigbiene auf der Linde zurückzuführen ist. Im Gegenteil, der untersuchte Honig bestand zu über $80 \%$ aus Lindennektar. Dieser Umstand ist vielmehr mit der geringen Einstäubung des Lindennektars mit Pollen zu erklären. Durch die senkrechte Position der Blüte und durch die Haftung des Pollens in den Antheren fällt sehr wenig Pollen in den von den Blüten produzierten Nektar (pers. Mitteilung VON DER OHE). Diese Einstäubung ist bei den meisten anderen Nektarpflanzen dagegen sehr viel größer; deren Pollen ist im Bienenhonig überrepräsentiert, während ihr Nektaranteil gering ist. Der von den Bienen als Eiweiß- und Proteinquelle von der Linde reichlich gesammelte Pollen gelangt nicht in den Honig.

\section{Fazit}

Zu den häufigsten Besuchern der Linde zählen die Honigbienen (Apis mellifera), Hummeln (Bombus), Schwebfliegen (Syrphidae) und Motten (Lepidoptera). Auch sonstige Fliegen (Diptera) wurden in größerer Anzahl in den Kronen der Linden beobachtet. 


\section{Wildbienen (Apidae) sind bezüglich ihrer Abundanz hinter den voran genannten Insek- ten einzuordnen.}

\subsubsection{Effektivität der Bestäuber}

Die Individuenzahl, mit der Insektengruppen in der Tracht der Linde anzutreffen sind (s. Kap. 2.8.2), ist nur ein Faktor, der die Effektivität der Insekten als Bestäuber bestimmen kann. Ebenso beeinflußt das Verhalten bei der Nahrungssuche und die Gestalt der Insekten in hohem Maße, wieviel Pollen auf den Narben der Blüten deponiert wird.

\subsubsection{Honigbienen}

Auch wenn bei einigen Pflanzen eine geringe Bestäubungseffizienz der Honigbiene nachgewiesen wurde (HURYN 1997, WESTERKAMP 1991), gilt sie seit jeher als der Universalbestäuber schlechthin. Die große Individuenzahl der sozial lebenden Völker (bis zu 40.000), das große Nahrungsaufkommen eines Volkes (120 kg Nektar und $20 \mathrm{~kg}$ Pollen im Jahr), ihr schnelles Aufspüren lukrativer Nahrungsquellen über weite Entfernungen (nachgewiesen bis $14 \mathrm{~km}$ ) und nicht zuletzt aufgrund ihrer wirkungsvollen Pollenübertragung bei vielen ökologischen Blumentypen gilt die Honigbiene für zahlreiche Pflanzenarten als wichtiger Bestäuber (SEELEY 1997, ECKERT et al. 1994). Die Bedeutung der Honigbiene als effektiver Universalbestäuber für die verschiedensten Pflanzenarten ist zahlreicher Literatur zu entnehmen; auf eine Ausführung wird in diesem Zusammenhang aber verzichtet. Es sollen hier nur die Ergebnisse der Bestäubungseffektivität von Honigbienen bei den Rosaceae erwähnt werden. Diese sind am ehesten auf die Linde übertragbar, da die Rosaceae ebenfalls Scheiben- und Schalenblumen besitzen, baum- und strauchartige Formen annehmen und in einigen Fällen mit der Linde sympatrisch vorkommen. Die wichtige Funktion der Honigbienen als Pollinator sind für Pflaume, Birne, Pfirsich, Aprikose, Kirsche etc. nachgewiesen (CALzONI und SPERANZA 1998, JAY 1986, LANGRIDGE und GOODMAN 1985, WESTRICH 1989).

Die Honigbiene wird für die Linde dann einen wichtigen Bestäuber darstellen, wenn sich Lindenpopulationen in dem oft über $100 \mathrm{~km}^{2}$ großen Einzugsgebiet von Bienenvölkern befinden. Innerhalb dieses Bereiches werden von der Biene lukrative Futterquellen mit einer 95 \%igen Wahrscheinlichkeit entdeckt (SEELEY 1997). Diese wird durch die Produktion des Blütenduftstoffs Farnesol, welches die bieneneigenen Pheromone Geraniol und Zitral enthält, erhöht (s. Kap. 2.8.1). VON DER OHE (pers. Mitteilung) hat das Verhalten der Honigbiene auf den Blüten der Winterlinde eingehend studiert und beurteilt die Honigbiene in ihrer Häufigkeit und ihrem Verhalten auf der Lindenblüte als einen sehr effektiven Bestäuber dieser Baumart. 


\subsubsection{Hummeln}

Die Aktivitätsschwelle der Hummeln ist bei tieferen Lufttemperaturen angesiedelt als bei den anderen für die Linde bestäubungsökologisch relevanten Insekten (s. 2.8.3.6, S. 21). Sie gehen schon bei Temperaturen um $16^{\circ} \mathrm{C}$ in großer Zahl auf Nahrungssuche, während Honigbienen und andere Insektengruppen unter diesen Bedingungen nur vereinzelt als Blütenbesucher anzutreffen sind. Da während der Blühperiode der Winterlinde im europäischen Raum nicht immer über die gesamte Tageszeit hinweg Temperaturen von $16^{\circ} \mathrm{C}$ erreicht werden, beginnt die Hummel an kalten Tagen früher und mit höherer Abundanz mit ihren Futterflügen und hört später am Tage auf. Läßt man das unbekannte Verhalten der Motten unberücksichtigt, ist die Hummel deshalb bei kühlen Sommern effizienter als andere Bestäuber. In extrem kühlen Sommern ist sie unter Umständen vielleicht sogar der einzige bedeutsame Pollinator der Linde.

Aufgrund ihrer guten Thermoregulierung hat die Hummel einen hohen Energiebedarf und muß dementsprechend viele Blüten besuchen, um die nötige Energie in Form von Nektar aufzunehmen. Die Besuchsrate von Blüten ist deshalb bei Hummeln doppelt so hoch wie bei der Honigbiene und viermal so hoch wie bei Wildbienen (in HEINRICH 1975). Betrachtet man zusätzlich die hohe Spezialisierung einiger Hummelarten auf den Pollen der Linde (s. Kap. 2.8.2), ist die Bedeutung der Hummeln als Bestäuber der Linde nicht zu unterschätzen.

\subsubsection{Motten}

Untersuchungen über die Effektivität der für die Linde relevanten Pollinatoren hat bisher nur ANDERSON (1976) durchgeführt. Bei seinen Versuchen hat er die Effektivität der tag- und nachtaktiven Insekten verglichen. Dabei waren in Connecticut Motten für ca. $20 \%$ der Samenproduktion bei der Winterlinde verantwortlich. Bei der in Nebraska untersuchten Tilia americana waren die Anteile der durch tag- und nachtaktive Insekten bestäubten Samen genau umgekehrt. Der von den Motten erzeugte Samenansatz lag bei 75 \%, der durch die tagaktiven Insekten initiierte nur bei $25 \%$. ANDERSON (1976) führt dieses auf eine beträchtlich höhere Abundanz der Motten in Nebraska zurück.

\subsubsection{Schwebfliegen}

Schwebfliegen werden von der Linde in großer Anzahl angelockt; teilweise übertraf ihre Häufigkeit die der anderen Insektengruppen. Da auch auf ihnen große Mengen an Pollen gefunden wurde und ihre Blütenkonstanz der von Honigbienen, Hummeln und Motten nicht nachsteht, können sie zumindest für einen Teil der effektiven Pollenübertragung verantwortlich gemacht werden (s. Kap. 2.8.2). 
HEARD et al. (1990) haben Cashewbäume mit Käfigen versehen, in denen sich entweder Honigbienen, Schwebfliegen oder Wollschweber befanden. Die Honigbienen bestäubten $96 \%$, die Schwebfliegen $43 \%$ und die Wollschweber $36 \%$ der Blüten. Wie weit die Blüte des Cashewbaums mit der einer Linde vergleichbar ist, sei dahingestellt.

\subsubsection{Sonstige Insekten}

Von den 380 blütenbesuchenden Wildbienenarten in Deutschland sind ca. $30 \%$ auf eine Pflanzenfamilie spezialisiert (oligolektisch) und $70 \%$ wie die Honigbiene polylektisch (WESTRICH 1989). Wie viele dieser polylektischen Arten nicht durch die Honigbiene oder durch die Kulturlandschaft verdrängt worden sind, ist schwer einzuschätzen; Gleiches gilt auch für ihre Bedeutung als Pollinatoren der Linde. Sollten Wildbienen Lindenblüten zur Nahrungsaufnahme aufsuchen, werden durch sie mit großer Bestimmtheit Pollen bestäubungseffektiv transportiert.

Bei den Kleininsekten ist die umgekehrte Situation gegeben. Sie können in großer Zahl in den Kronen blühender Linden beobachtet werden (s. Kap. 2.8.2). Ob sie aber Pollen auf die Narben befördern, ist bei der Linde bislang nicht untersucht worden.

Interessant ist in diesem Zusammenhang die Arbeit von KEYS et al. (1995). Sie untersuchten die Bestäubungseffektivität der Insekten auf Prosopis velutina, einer für die Honigindustrie in den U.S.A. wichtigen Baumart (Leguminosae). Als wichtigste Bestäuber für Prosopis velutina galten Honigbienen, Wildbienen und Schwebfliegen. In den Versuchen, bei denen die Blüten mit einem Netz mit $3 \mathrm{~mm}$ Maschenweite vor größeren Insekten geschützt wurden, stellte sich ein gleich großer Fruchtansatz ein wie bei den ungeschützten Blüten. KEYs et al. (1995) machen Kleininsekten für den Fruchtansatz verantwortlich, die zahlreich auf den Blüten dieser Baumart beobachtet werden konnten.

\subsubsection{Wettereinfluß}

Einen großen Einfluß auf die Aktivität der Insekten und damit auf eine mögliche Bestäubung haben die Witterungsverhältnisse während der Blühperiode der Linde.

Bei Regen, starkem Wind und zu niedrigen oder zu hohen Temperaturen werden Futterflüge eingestellt. Leichter Regen scheint zumindest die Honigbienen nur bedingt zu stören, bei stärkerem Regen wird der Stock jedoch nicht verlassen (KLEBER 1935). Der leichte Regen ist nach BRITTAIN (1935) nicht die Ursache für die etwas reduzierte Aktivität der Honigbienen, sondern die mit dem bewölkten Himmel verbundene niedrige Lichtintensität. Ist eine gewisse Temperaturschwelle erst einmal überschritten, wird die Flugaktivität hauptsächlich von der Stärke des Lichtes bestimmt. 
Unterschreitet die Lufttemperatur die Grenze von $15^{\circ} \mathrm{C}$, nimmt die Sammelaktivität der Honigbienen rapide ab. Herrscht akuter Nahrungsmangel im Bienenstock, können Futterflüge auch schon bei einer Temperatur von $9{ }^{\circ} \mathrm{C}$ beobachtet werden, die aber bei zahlreichen Sammlerinnen zum Kältetod führen. Die Flugaktivität erreicht ihr Maximum bei Temperaturen von etwa $23-25{ }^{\circ} \mathrm{C}$, bei Temperaturen von $36{ }^{\circ} \mathrm{C}$ war keine Insektenaktivität mehr zu verzeichnen. (Kleber 1935, Pigott und Huntley 1981, Seeley 1997, Weber el Ghobary 1984). Ebenso scheint stärkerer Wind (5-8 m/sec), ungeachtet der sonstigen Wetterverhältnisse, die Honigbienen zu einem Verbleiben im Stock zu veranlassen (FrEE 1970, KLEBER 1935, PigotT und HuntLey 1981). Wenig empfindlich reagieren Hummeln auf Kälte. Aufgrund der besseren Thermoregulierung ihres Körpers fliegen sie auch bei niedrigeren Temperaturen die Linde an (EISENHUT 1957, PigOtT und HunTLEY 1981). Die Nahrungssuche wird auch nicht so sehr vom Wind beeinflußt, wie es bei der Honigbiene beobachtet wurde, wird aber bei Regen ebenso eingestellt.

Über den Einfluß des Wetters auf die Flugaktivität der Fliegen ist bisher wenig bekannt. SEDGLEY und GRIFFIN (1983) schließen aus der bis dahin erschienenen Literatur, daß diese in ähnlicher Weise auf Wettereinflüsse reagieren wie die Honigbienen. VoGT (1986) beobachtete bei der Fliegenart Musca vetustissima (Muscidae) einen Beginn der Flugaktivität ab einer Lufttemperatur von $12^{\circ} \mathrm{C}$. Diese steigerte sich kontinuierlich bis zu einer Lufttemperatur von $27^{\circ} \mathrm{C}$, um bei höheren Temperaturen wieder abzufallen. Regen, Sonneneinstrahlung und Windgeschwindigkeit nennt er als weitere wichtige Faktoren, die eine Aktivität einschränken können.

Die Beeinflussung des Verhaltens nachtaktiver Insekten, speziell der Motten, durch Wetterfaktoren wurde bislang nicht untersucht. Generell reagieren größere Insekten unempfindlicher auf ungünstige Witterungsverhältnisse.

PigotT und HunTley (1981) haben für die Winterlinde den Einfluß des schlechten Wetters auf den effektiven Pollentransport bei der Winterlinde nachgewiesen. Während der Blühperiode 1973 verglichen sie die Anteile der bestäubten Stigmata mehrerer Winterlindenbestände im Nordwesten und im Süden Englands. Im regnerischem Nordwesten wiesen die Bestände nur $23 \%$ bis $71 \%$ bestäubte Stigmata auf, während der Anteil im sonnigeren Süden Englands bei $95 \%$ lag. In dem außergewöhnlich warmen und sonnigen Sommer 1976 konnten PIGOTT und HuNTLEY (1981) auf allen untersuchten Narben Pollen feststellen. Dabei ist nicht nur die geschilderte verminderte Flugaktivität der bestäubungsrelevanten Insekten ausschlaggebend. Wie in Kap. 2.6.1.3 erwähnt, hängt die Nektarproduktion und Nektarmenge von dem Wasserhaushalt, der Sonneneinstrahlung und der Luftfeuchtigkeit ab. Vereinfachend kann man sa- 
gen, daß mit zunehmender Feuchtigkeit und abnehmender Sonneneinstrahlung die Nektarmenge zunimmt und die Nektarkonzentration abnimmt. SEDGLEY und GRIFFIN (1989) nehmen an, daß bei ungünstigen Wetterbedingungen eine ausreichende Nektarkonzentration für die Anlockung bestimmter Insektengruppen nicht mehr erreicht wird. Zudem machen sie auf eine mögliche Verdünnung und Auswaschung des Nektars durch Regenfälle aufmerksam. Umgekehrt kann es bei extremer Trockenheit zum Erliegen der Nektarproduktion und damit zum Erliegen des Insektenbesuchs kommen; eine Ausnahme bildet dabei die Honigbiene (s. Kap. 2.8.1). Ein weiterer wichtiger Faktor ist das Wetter für die Artenvielfalt und Abundanz von Insekten. Kalte Winter und Frühjahre bzw. lang anhaltende Feuchtigkeit führen zu einer erhöhten Mortalität und Reduktion von Insektenpopulationen und haben zwangsläufig einen verminderten Blütenbesuch der Winterlinde zur Folge. Auf diesen Aspekt soll im Rahmen dieser Arbeit aber nicht weiter eingegangen werden.

\section{Fazit}

Ungünstige Witterungsverhältnisse führen bei der Linde, u. a. durch verminderte Flugaktivität bestäubungsrelevanter Insekten, über eingeschränkten Pollentransport zu einer unzureichenden Bestäubung.

\subsubsection{Blütenkonstanz und Pollentransport}

Wichtig für eine effektive Bestäubung einer Art ist die Blütenkonstanz oder Konditionierung der Insekten auf eine Art. Je weniger die Insekten Futterflüge zwischen verschiedenen Pflanzenarten unternehmen, desto geringer ist die Pollenfracht auf den Insekten durchmischt und die Wahrscheinlichkeit steigt, daß die Narbe mit arteigenem Pollen bestäubt wird.

PETANIDOU et al. (1995) haben nachgewiesen, daß die Narben bei Gentania cruiciata durch eine Hummel (Bombus pascuorum) mit artfremden Pollen benachbarter Kratzbeeren (Rubus caesius) regelrecht verstopft werden und sehen dies als Grund für den geringen Fruchtansatz. Wie in Kap. 2.8.1 erwähnt, ist die Blütenkonstanz (Konditionierung) bei den wichtigsten Bestäubergruppen der Linde (Honigbienen, Hummeln, Fliegen und Motten) hoch. Die Unterschiede zwischen den Insektengruppen sind gering; einige Hummelarten zeichnen sich durch eine besonders ausgeprägte Blütenkonstanz aus.

Nicht nur die Blütenkonstanz und damit die Artreinheit der Pollenfracht auf den Insekten ist von Bedeutung, sondern auch die Menge des den Antheren entnommenen und transportierten Pollens. ANDERSON (1976) wies große Mengen an Lindenpollen auf den Honigbienen, Hummeln, Fliegen und Wildbienen nach. Motten transportierten dagegen geringere Mengen an 
Pollen auf ihrem Körper, erwiesen sich aber aufgrund ihrer Abundanz oder der gezielten Pollenübertragung als gute Bestäuber der Linde.

Ein großer Teil des produzierten Pollens geht beim Transport durch Insekten verloren. Dieser ist um so größer, je weniger Pflanzen und Insekten aufeinander spezialisiert sind. Untersuchungen über den tatsächlichen Verlust von Pollen durch Nahrung und Transport sind bisher nur wenige gemacht worden. Ihre Ergebnisse sind auf die Bestäubungseffektivität der für die Linde relevanten Insekten nicht direkt übertragbar, geben aber eine Vorstellung über den möglichen Pollenverlust bei der Linde:

Young und STANTON (1990) haben den Pollenverlust durch den Besuch der Honigbiene $(A$ pis mellifera) bei der Weiderichart Raphanus sativa gemessen. 93,7 \% des von einer Honigbiene aus Blüten exportierten Pollens ging während des Transportes verloren. Nach dem Besuch von zehn Blüten befanden sich noch $4 \%$ auf dem Körper der Bienen, 2 \% wurden auf den nichtstigmatischen Oberflächen der Blüten entdeckt. Insgesamt gelangten 0,3 \% des produzierten Pollens auf Narbengewebe, überwiegend innerhalb der eigenen Pflanze. Nur 0,06 \% des Pollens wurde auf die Narben anderer Populationsmitglieder transportiert. Ähnliche Beobachtungen machten HOLSINGER und THOMSON (1994) bei Erythronium grandiflorum, einer durch Hummeln bestäubten Zahnlilie. Hier wurde 0,5 \% des Pollens auf die Stigmata anderer Blüten deponiert, 0,4\% verblieb auf Narben derselben Pflanze. Über $99 \%$ des Pollens war nicht erfolgreich. Ebenfalls nur $1 \%$ des von Calystegia spec. (Convolvulaceae) produzierten Pollens wurde von Insekten erfolgreich auf deren Narben deponiert. Interessanterweise wird diese in Japan von UsHimARU und KIHACHIRO (1999) untersuchte Zaunwinde, wie die Linde, ebenfalls von Honigbienen, Hummeln, Fliegen und Wildbienen bestäubt. WEBB und BAWA (1983) konnten bei einer tropischen Malvenart (Malvaviscus arboreus) eine 3 \%ige Pollendeposition durch Kolibris auf die Stigmata eigener und fremder Blüten feststellen. Man kann demnach auch bei der Linde nicht davon ausgehen, daß mehr als ein Prozent des Pollen auf die Stigmata befördert wird. Der Anteil dürfte sogar noch weitaus geringer sein, da die Linde als Generalist und als massenblühende Baumart höhere Pollenverluste erwarten läßt.

\section{Fazit}

Nicht nur bezüglich ihrer Abundanz (s. Kap. 2.8.2) sondern auch aufgrund ihres effektiven Pollentransportes gehören Honigbienen, Hummeln, Schwebfliegen und Motten in den Kreis der wichtigsten Bestäuber der Linde. Eine generelle Gewichtung der Effektivität der einzelnen Bestäubergruppen soll und kann hier nicht vorgenommen werden, da diese in Abhängigkeit von Abundanz der Insekten, Landschaft, Klima etc. örtlich verschieden und einem ständigen Wechsel unterworfen ist. Eine unbekannte Größe 
bleiben die zahlreichen Kleininsekten verschiedener Ordnungen. Sollten sie zu einer Pollendeposition auf die Narben der Lindenblüte fähig sein, wurde ihre Bedeutung bislang unterschätzt.

\subsubsection{Art des Pollentransportes}

Die Frage über die Art des bestäubungseffektiven Pollentransportes bei der Winterlinde kann anhand bisher erschienener Literatur nicht eindeutig beantwortet werden.

Als grundlegende und viel zitierte Arbeit über die Bestäubungsökologie der Linde kann die Dissertation von EISENHUT aus dem Jahre 1957 gelten. Seit dieser Arbeit wird die Linde bis heute als überwiegend windbestäubt angesehen. Nach seinen Ergebnissen sind Insekten als Pollenvektoren nicht notwendig. Ein voller Fruchtansatz werde durch eine alleinige Pollenverbreitung über den Wind erreicht.

Die Untersuchungen von ANDERSON (1976) haben die Aussagen EISENHUTs relativiert. Nach seinen Ergebnissen wird die Linde überwiegend von Insekten bestäubt. Bei seinen Bestäubungsversuchen erreichte eine ausschließliche Windbestäubung weniger als ein Drittel des Samenansatzes des durch Insekten bestäubter Blüten. Oft sind in der jüngeren Literatur beide Arbeiten mit ihren konträren Untersuchungsergebnissen zitiert.

Die Argumentation EISENHUTs (1957) für eine effektive Windbestäubung bei der Linde basiert im wesentlichen auf der seiner Auffassung nach tendenziell anemophilen Pollenproduktion und -morphologie der Linde im Vergleich zu anderen anemophil und entomophilen Baumarten und auf die Ergebnisse seiner durchgeführten Bestäubungsversuche. Nach seiner Ansicht zeichnen sich windbestäubte gegenüber insektenbestäubten Baumarten durch ein wesentlich höheres Pollen/Eizellen-Verhältnis aus. Diese hohe Pollenproduktion sieht er auch bei der Linde gegeben und verweist dabei auf die von PoHL (1936) ermittelten Werte. Eine einzelne Blüte der Winterlinde produziere demnach mehr Pollen als die Blüten der windbestäubten Quercus petrea, Carpinus betulus, Fraxinus excelsior und Betula verrucosa. Ein weiteres Indiz für Anemophilie sieht EISENHUT (1957) in dem von ihm gezählten durchschnittlichen Pollenanflug von ca. 5700 Pollenkörnern je $\mathrm{cm}^{2}$ in der Krone einer frei stehenden Winterlinde, wobei er REMPE (1937) u. a. mit den Worten zitiert: „Ihr Pollenanflug im Kronenraum kann durchaus (von der größeren Häufigkeit von Gruppen abgesehen) demjenigen von Eiche, Ulme und Buche zur Seite gestellt werden. “ Wobei anzumerken ist, daß genannte Baumarten allesamt Windbestäuber sind. REMPE (1937) selber beobachtete mit 12006800 Pollenkörnern pro $\mathrm{cm}^{2}$ einen ähnlich starken Pollenanflug innerhalb der Krone älterer, 
gut entwickelter, kräftig blühender und frei stehender Linden für die Dauer der gesamten Blühperiode (s. Tab. 2.5). Er setzte den gemessenen Pollenanflug anschließend aber noch in Relation zur der absoluten Pollenproduktion von Winterlinden und kommt zu folgender Schlußfolgerung, die indes von EISENHUT (1957) nicht zitiert wird: „Eine auffällige Unstimmigkeit liegt in der Stellung der Linde und des Bergahorns vor, da beide Bäume nach POHL besonders große Pollenmengen erzeugen, ihr Anflug dagegen gering blieb. Doch ist dies, wie auch POHL unter Hinweis auf die Stellung der Linde bei HESMER betont, leicht erklärlich, da bei diesen insektenblütigen Bäumen eben offenbar nur ein geringer Teil des Pollens verweht wird."

Tab. 2.5 Pollenanflug in den Kronen blühender Bäume (nach REMPE 1937).

\begin{tabular}{|l|l|c|}
\hline \multicolumn{1}{|c|}{ Art } & $\begin{array}{c}\text { Anflug pro } \mathrm{cm}^{2} \\
\text { innerhalb des Kronenraumes } \\
\text { in 1000 Pollenkörnern }\end{array}$ \\
\hline 1. & Corylus avellana & $61-105$ \\
\hline 2. & Taxus baccata & $80-100$ \\
\hline 3. & Alnus glutinosa & $46-85$ \\
\hline 4. & Betula verrucosa & $60-63$ \\
\hline 5. & Populus tremula & 57,5 \\
\hline 6. & Carpinus betulus & $43-50$ \\
\hline 7. & Pinus sylvestris & $7,2-15,2$ \\
\hline 8. & Fagus sylvatica & $15-20$ \\
\hline 9. & Quercus petraea & $7,6-11,6$ \\
\hline 10. & Quercus robur & 10,2 \\
\hline 11. & Castanea sativa & $2,0-17,6$ \\
\hline 12. & Ulmus montana & $4,6-7,9$ \\
\hline 13. & Ulmus campestris & 3,5 \\
\hline 14. & Larix europaea & $3,0-5,3$ \\
\hline 15. & Salix caprea & $27,6-36,8$ \\
\hline 16. & Salix fragilis & $10,4-18,2$ \\
\hline 17. & Salix alba & 8,0 \\
\hline 18. & Salix aurita & 3,5 \\
\hline 19. & Salix cinerea & 1,0 \\
\hline 20. & Acer monspessulanum & 12,2 \\
\hline 21. & Acer italum & 4,4 \\
\hline 22. & Acer pseudoplatanus & $0,73-1,7$ \\
\hline 23. & Acer platanoides & $0,44-0,94$ \\
\hline 24. & Tilia cordata/platyphyllos & $1,2-6,8$ \\
\hline 25. & Malus toringo & 2,0 \\
\hline 26. & Pyrus communis & 1,7 \\
\hline & & \\
\hline
\end{tabular}

EISENHUT verweist weiterhin auf die geringe Aggregation und Sinkgeschwindigkeit des Pollens (s. Kap. 2.6.1), die für Einzelpollen der Linde im Rahmen windbestäubter Baumarten liegen. Zudem sollen die Narben einiger Lindenarten eine klebrige Oberfläche besitzen, welches ebenfalls auf eine anemogame Eignung hinweise. Ferner macht er darauf aufmerksam, 
daß Lindenpollen im Honig unterrepräsentiert sei. Er schließt daraus auf eine geringe Effektivität der Honigbiene als Bestäuber der Linde. Bei den Bestäubungsversuchen hat er Zweige mit einem sechseckigen Maschengeflecht mit einer Maschenweite von 1,9 mm gegen Insekten isoliert. Der komplette Ergebnisteil seiner Bestäubungsversuche stellt sich folgendermaßen dar: „An allen eingebeutelten Zweigen bildeten sich normale Früchte; die Früchte unterschieden sich weder mengen- noch gütemäßig, vor allem auch nicht in der Keimfähigkeit, von jenen, die aus ungeschützten Blüten entstanden.“

Für ANDERSON (1976) dagegen spielt die Windbestäubung bei der Linde nur eine untergeordnete Rolle. Bei seinen Bestäubungsversuchen an Tilia americana bildeten nur 0,9\% der gegen Insekten geschützten Blüten fertile Früchte, während der Samenansatz bei den ungeschützten Blüten $3 \%$ erreichte. Als Isoliermaterial gegen einen Insektenbesuch verwendete er Nylongewebe mit einer Maschenweite von 1,2 $\mathrm{mm}$.

PigotT und HUNTLEY (1980) untersuchten die Pollendeposition auf dem Waldboden in der Umgebung einer isolierten, sehr stark blühenden Winterlinde in einem Mischbestand aus Quercus petraea, Larix decidua und Acer pseudoplatanus. Der meiste Pollen wurde von Quercus- und Betula- Arten deponiert, der Pollen der Winterlinde war ab einer Entfernung von $60 \mathrm{~m}$ vom Baum nicht mehr signifikant vertreten. Selbst direkt unterhalb der Baumkrone konnte nur $9 \%$ Winterlindenpollen gefunden werden, $91 \%$ des Pollens wurde von anderen Baumarten eingetragen. Sie führen diese geringe Pollenverbreitung über den Wind auf die im Vergleich zu anderen Baumarten relativ geringe Pollenproduktion der Winterlinde, auf die Aggregation des Pollens und der damit verbundenen geringen Vermischung mit der Luft sowie auf die Filterwirkung des belaubten Kronendaches zurück.

\section{Fazit}

Lindenpollen wird in mäßigen Mengen in die Atmosphäre entlassen und nur kleinräumig verbreitet. Sollte der Pollen in der Phase der Windverbreitung noch befruchtungsfähig sein, so kann er nur in der Krone des Baumes selbst oder in direkt benachbarten Lindenkronen effektiv sein. Eine Windbestäubung hätte größtenteils Selbstbefruchtung zur Folge. Für einen weitaus effektiveren Transport des Lindenpollens durch Insekten sprechen die entomophile Morphologie der Lindenblüten (vgl. Kap. 2.6), die große Anzahl und der Artenreichtum der sie besuchenden Insekten (vgl. Kap. 2.8.2) und, bis auf die Arbeit von EISENHUT (1957), die Ergebnisse aller bisherigen Untersuchungen. 


\subsubsection{Geitonogamie oder Fremdbefruchtung?}

Es gibt viele Arbeiten, die sich mit dieser Problematik beschäftigt haben (u. a. FRANKIE und HABER 1983, HeinRich 1975, HeinRICH 1983, KlinKHAMmer et al. 1994, VogEL und WeSTERKAMP 1991, WASER und PRICE 1983). Im folgenden Abschnitt soll anhand bisheriger Untersuchungen kurz umrissen werden, wie groß die Anteile von Selbst- und Fremdbestäubung bei entomogamen Blütenpflanzen sind und welche Faktoren diese Anteile beeinflussen können. Es wird in diesem Zusammenhang bewußt Bestäubung und Befruchtung unterschieden, da mit einer Bestäubung der Narbe noch keine Befruchtung der Eizelle verbunden ist. Es wird zudem angenommen, daß der Anteil der Autogamie durch eine Herkogamie und Dichogamie der Lindenblüten zu vernachlässigen ist.

\subsubsection{Attraktivität der Blütentracht}

Mit zunehmender Anzahl von Blüten auf einer Pflanze wird deren Attraktivität für Insekten gesteigert, aber auch Selbstbestäubung durch Geitonogamie gefördert (ANDERSSON 1988, Guitan 1993, KATO und HiURA 1999, KLINKHAMMER et al. 1989, ROBERTSON und MACNAIR 1995, STEPHENSON 1982). Der Anteil der Geitonogamie an der Bestäubung kann bei blütenreichen Individuen bis zu 90 \% betragen (KLINKHAMMER und DE JONG 1993).

IWASA et al. (1995) und BROYLES und WYATT (1995) stellten bei eigenen Untersuchungen und einer Interpretation der Literatur eine relative Abnahme der Besuche auf Pflanzen mit vielen Blüten fest. Absolut wurden Pflanzen mit einer großen Blütenanzahl häufiger besucht und es wurden auch mehr Blüten innerhalb dieser Pflanze von den Insekten angeflogen. Proportional nimmt die Zahl der besuchten Blüten jedoch mit der Anzahl der Blüten einer Pflanze ab. Es werden relativ gesehen weniger Blüten auf großen Pflanzen als auf kleinen Pflanzen besucht. In einem Experiment von BeLL (1985) wurde die Anzahl der Blüten bei einigen Individuen reduziert. Diese wurden von den Insekten nicht so häufig angeflogen wie Individuen mit großer Blütenzahl, welches sich in einer geringeren Besuchsrate pro Blüte niederschlug. Eine große Blütentracht kann andererseits auch zu einer Vergrößerung der Pollentransportweite führen. Werden Nahrungsflüge zwischen Pflanzen einer Art unternommen, dann werden (z. B. von Honigbienen) weit entfernt gelegene große Nahrungsquellen direkt angeflogen und kleinere dabei überflogen (HEINRICH 1975). Eine große Nektarproduktion pro Blüte kann die Insekten ebenfalls zu längeren Aufenthalten auf einer Pflanze veranlassen (CRAWLEY 1997, Hodges 1995, Pyke 1982, WAddington 1981). 
Aus der Sicht der Pflanze wäre die Kombination großer Attraktivität für Insekten und dem Besuch nur weniger Blüten pro Pflanze optimal für einen gesicherten Genfluß. Eine große Attraktivität kann die Pflanze durch eine große Blütenanzahl erreichen. Ein kurzer Aufenthalt der Insekten auf einer Pflanze wird durch eine Begrenzung des Nahrungsangebotes ermöglicht. Bieten nicht alle geöffneten Blüten die gleiche Menge und Qualität an Nektar und Pollen zu einem Zeitpunkt an, werden nur die Blüten besucht, die für die jeweilige Insektengruppe ein optimales Nahrungsangebot offerieren.

In Kap. 2.6.1.3 werden die Periodizität und die räumliche Variation der Nektarproduktion und -konzentration der Linde ausführlich beschrieben. Während der Blühperiode der Linde finden sich zudem alle Entwicklungstadien der Anthese innerhalb einer Krone (s. Kap. 2.7). Diese Faktoren bedingen Folgendes: Eine hohe Attraktivität für eine Fernorientierung der Insekten ist durch optische Präsenz der zahlreichen Blüten gegeben, aber nicht alle Blüten bieten die für die jeweilige Insektengruppe optimale Pollen- und Nektarmenge bzw. -konzentration an (vgl. Kap. 2.8.1). Die Insekten sammeln nur von einem relativ kleinen Anteil der Blüten Nahrung, werden aber von der Gesamtheit der Blüten angelockt.

Genau die für die Linde beschriebene Blühphänologie beobachteten FRANKIE und HABER (1983) bei vier massenblühenden Baumarten in Costa Rica. Die Insekten bildeten einen schmalen Ring um den Baum, welcher im Tagesverlauf der optimalen Nektarproduktion folgend vom Fuß bis zur Spitze der Krone hinauf wanderte. Als Gründe für diese Variation nennen sie das unterschiedliche Alter der Blüten in einer Krone und die Abhängigkeit der Nektarproduktion von Saftstrom, Luftfeuchtigkeit, Wasserhaushalt des Bodens und Sonneneinstrahlung. Dies sind die gleichen Ursachen, die für Linde genannt werden. Als Konsequenz des durch die Blühphänologie reduzierten Nahrungsangebots unternehmen die Insekten weniger Futterflüge innerhalb einer Krone und wechseln schneller auf andere Bäume.

Eine weitere Möglichkeit, die Effizienz der Bestäubung zu erhöhen und Flüge zwischen Populationsmitgliedern zu fördern, ist eine vorzeitige Seneszenz schon bestäubter Blüten. Eine Bestäubung der Narbe ist mit einem sofortigen Anstieg der Ethylenproduktion verbunden, die eine Seneszenz der Blüte induziert (BOTHA und WHITEHEAD 1992, WOLTERING et al. 1993). Eine vorzeitige Seneszenz ist mit Signalen verbunden, welche die Blüte für Insekten unattraktiv werden läßt. Diese Signale können eine Verfärbung oder Welke der Blüte, eine Umfunktionierung der Kelchblätter zu Blättern und eine veränderte Produktion von Duftstoffen oder Nektar sein (HEINRICH 1975, LALONDE und RoITBERG 1994, ROBERTSON und MACNAIR 1995, STEPHENSON 1982). Schon bestäubte Blüten werden nicht mehr besucht, das Nahrungs- 
angebot des Individuums sinkt mit jeder erfolgreichen Bestäubung und die Insekten konzentrieren sich auf die noch nicht bestäubten Blüten bzw. setzen ihre Nahrungssuche auf anderen Pflanzen fort. Bei der Linde berichtet EISENHUT (1957) von einer sofortigen Einstellung der Nektarproduktion nach Degeneration des Griffels.

Eingehend hat STEPHENSON (1982) die Auswirkungen einer Blütenreduktion bei Catalpa speciosa untersucht. Die Blühphänologie und die Blütenbesucher dieser nordamerikanischen Baumart sind mit der Linde vergleichbar (s. o.). Der Autor verglich die Zahl der bestäubten Blüten und der aus Fremdbefruchtung entstandenen Früchte in der Anfangs-, Haupt- und Endphase einer Blühperiode. In den Blühperioden zweier Jahre wurden die wenigsten Blüten in der Anfangsphase bestäubt (26\% aller untersuchten Blüten). Ebenfalls war hier der Anteil der Fremdbefruchtung am niedrigsten (5,7 \%). Im Zeitraum der größten Zahl geöffneter Blüten und damit des größten Nahrungsangebotes (Hauptphase) stieg der Anteil der bestäubten Narben auf $38 \%$ und der Anteil der fremdbefruchteten Blüten auf $12 \%$. Der mit Abstand größte Anteil an bestäubten Blüten und an Fremdbefruchtung wurde in der Endphase der Blühperiode mit 60 \% bzw. 34 \% erreicht. STEPHENSON (1982) nimmt an, daß die Anfangsund Hauptphase vornehmlich dazu dienen, Insekten anzulocken und deren Nahrungssuche auf diese Baumart zu konditionieren. Eine Konditionierung (Blütenkonstanz) der Insekten hat ANDERSON (1976) auch bei der Linde festgestellt (s. Kap. 2.8.1). In der Hauptphase ist das Nahrungsangebot so groß, daß nicht alle Blüten angeflogen werden und der Anreiz für Futterflüge zwischen Bäumen gering ist. In der Endphase kommt es dann zu einem schnellen Rückgang der Blütenneubildung und zusätzlich fallen die schon bestäubten Blüten durch vorzeitige Seneszenz aus. Die Folge ist ein rapide sinkendes Nahrungsangebot eines Baumes für die mittlerweile konditionierten Insekten. Die relativ kleine Zahl der verbliebenen rezeptiven Blüten wird von der noch großen Insektenzahl deutlich intensiver besucht und effektiver bestäubt. Das reduzierte Nahrungsangebot zwingt die Insekten vermehrt zu Futterflügen zwischen den Bäumen, was in einem größeren Anteil an fremdbestäubten Narben resultiert.

\subsubsection{Populationsdichte}

In welchem Ausmaß und über welche Entfernungen Pollen zwischen Individuen einer Population transportiert werden, hängt in großem Maße von der Dichte und Struktur einer Population ab. Davon ausgenommen sind hochspezialisierte Bestäuber/Pflanze-Beziehungen, bei denen ein Pollentransport bei geringer Populationsdichte und über sehr weite Entfernungen die Regel darstellt. Auf Würgefeigen (Ficus) spezialisierte Wespen legen z. B. routinemäßig Entfernungen von 6-14 km zurück und führen erfolgreich Fremdbefruchtungen durch (NASON und 
HAMrICK 1997). Bei Solitärbienen (Xylocopa) konnten Flugweiten von über 20 km nachgewiesen werden (JANZEN 1971).

Bei Generalisten steigt in der Regel der Anteil der Fremdbefruchtung mit der Populationsdichte (Ellstrand 1992). Der Anreiz für Insekten für einen Flug von Pflanze zu Pflanze ist in einer eng stehenden Population größer als in einer verstreut stehenden Population. Eine Asynchronie der Blühperioden verringert die Anzahl der potentiellen Paarungspartner und damit die reproduktionseffektive Dichte einer Population. Während die Häufigkeit der Fremdbefruchtungen in einer dichten Population ansteigt, verringert sich die durchschnittliche Pollentransportweite, da der Pollen nur über kurze Entfernungen zwischen den Pflanzen transportiert wird. Kommt es in einer zerstreut stehenden Population zu einer Fremdbefruchtung, müssen längere Entfernungen überbrückt worden sein und die durchschnittliche Pollentransportweite ist relativ groß. Der Anreiz für Pollinatoren, Flüge zwischen Pflanzen zu unternehmen, sinkt mit zunehmendem Abstand zwischen diesen. Bei isoliert stehenden Pflanzen besteht die Gefahr, daß eine Fremdbefruchtung nur in sehr geringem Maße oder unter Umständen überhaupt nicht stattfindet (BOSHIER et al. 1995, HouSE 1993, LALONDE und ROITBerg 1994, Murawski und HAMrick 1991, StaCy et al. 1996, SCHMitT 1983, TALAVERA et al. 1993, WEBB und BAWA 1983).

Nach KLINKHAMMER und DE JONG (1990) unternehmen Insekten vermehrt Futterflüge innerhalb isoliert stehender Pflanzen. Sie begründen dieses nicht nur mit dem geringeren Anreiz für die Insekten, die weit entfernten Nachbarn anzufliegen. Isoliert stehende Pflanzen werden seltener besucht, die Insekten finden ein kaum verbrauchtes Nahrungsangebot vor und halten sich auch deshalb länger auf dieser Pflanze auf.

\subsubsection{Nahrungssuchverhalten der Insekten}

Generell versuchen die Insekten Nahrung ökonomisch zu sammeln, d. h. sie versuchen auf schnellstem Wege an die maximale Nahrungsmenge zu gelangen. Daher werden auf vielblütigen Pflanzen mehrere Blüten besucht und beim Verlassen dieser Pflanze die nächststehende angeflogen.

Futterflüge der Insekten zwischen Blüten auf einer Pflanze werden in der Literatur in zahlreichen Fällen beschrieben; einige Arbeiten haben den Anteil der Geitonogamie zugleich quantitativ bestimmt: Nach DE JONG et al. (1992) werden im Durchschnitt 47 \% der Blüten von Ipomopsis aggregata durch Geitonogamie bestäubt, bei Asclepias syriaca 37 \% (PLEASANTS 1991) und bei Erythronium grandiflorum 40 \% (HOLSINGER und THOMSON 1994). Motten bestäubten $30 \%$ der Narben der tropischen Orchidee Aerangis ellisii mit eigenem Pollen 
(NILSSON et al. 1992), im gleichen Ausmaß deponierten Schmetterlinge Eigenpollen auf die Blüten von Cnidoscolus urens (BAWA und WEBB 1983). Bei ROBERTSON und MACNAIR (1995) flog die Raupenfliege Protohystricia huttonii bis zu 40 Blüten von Myosotis colensoi an, bevor sie zur nächsten Pflanze wechselte. Dieselben Autoren zählten bei Mimulus guttatus bis zu 20 Blütenbesuche durch Bombus terrestris und Apis mellifera auf einer Pflanze. Hummel und Honigbiene zeigten auf Mimulus guttatus ein ähnliches Verhalten. Bei Ipomopsis aggregata fanden 78 \% aller Futterflüge der Hummeln innerhalb eines Individuums statt, bei Kolibris betrug der Anteil 85 \% (WASER und PRICE 1983).

Eine große Lindenkrone dürfte im Vergleich zu den vorher genannten krautigen Pflanzen noch höhere Selbstbestäubungsanteile haben. Die der Linde ähnliche australische Baumart Syzigium tierneyanum ist ebenfalls hermaphroditisch und massenblühend. Der weitaus größte Teil aller von Honigbienen und Motten beobachteten Flüge zwischen den Blüten von Syzigium tierneyanum spielten sich innerhalb einer Krone ab (HOPPER 1980). Für Nektar suchende Vögel beziffert HoPPER diesen Anteil sogar mit 99,95 \%. Die massenblühende Baumart Andira inermis wird in Costa Rica von 70 Bienenarten besucht. Futterflüge zwischen Individuen dieser Baumart unternahmen nur 0,3-1,3 \% der Bienen; die meisten Bienen sammelten Nahrung nur innerhalb einer Krone (FRANKIE et al. 1976). STEPHENSON (1982) bestimmte den Anteil der Selbstbestäubung durch Geitonogamie bei Catalpa speciosa mit 60,5\%. Dieser in den USA beheimatete Baum hat einer der Linde vergleichbare Blühphänologie und wird wie diese tagsüber von Bienen, Hummeln und nachts von Motten bestäubt. Hummeln besuchen für gewöhnlich Hunderte von Blüten auf einem Strauch, bevor sie den nächsten Strauch anfliegen (HESSING 1988, JoHNSTON 1992). Bei der vielblütigen Orchidee Aerangis ellisii sind durch Motten dagegen 70 \% der Pollen auf die Stigmata anderer Populationsmitglieder transportiert worden (NILSSON et al. 1992).

Den Anteil der Geitonogamie betreffend zeigen die Untersuchungen geringe Unterschiede beim spezifischen Verhalten zwischen den Bestäubergruppen (s. a. WASER und PRICE 1983). Schmetterlinge stellen eine Ausnahme dar, da ihr Flugverhalten nicht nur der Nahrungsaufnahme, sondern auch der Partnersuche dient (SCHMITT 1980). Schmetterlinge fördern Fremdbefruchtung durch häufige und lange Flüge zwischen Pflanzen. Bei einem Vergleich des Nahrungssucheverhaltens von Honigbienen und Schmetterlingen auf einer Mangrovenart (Kandelia candel) waren die Schmetterlinge viel bessere Fremdbestäuber als die Honigbiene, welche viel mehr Blüten ein und desselben Baums besuchten, bevor sie weiterflogen (SUN et al. 1998). Auf das Territorialverhalten von Kolibris (LINHART 1973) oder andere, die Tropen betreffende, Besonderheiten soll hier nicht eingegangen werden. Die in großer Zahl bei der 
Linde beobachteten Kleininsekten (s. Kap. 2.8.2) aus den Ordnungen der Fliegen, Käfer und Wanzen werden, wenn bestäubungsrelevant, sich überwiegend nur innerhalb einer Lindenkrone aufhalten und weitgehend zur Selbstbestäubung beitragen (KEYS et al. 1995).

Im Bezug auf einen effizienten Pollentransport sind spezifische Eigenschaften der Insekten von Bedeutung. Viele Insekten sind in der Lage, Nahrungsquellen höchst effizient auszunutzen. Ob eine Blüte über ein lohnendes Nahrungsangebot verfügt, stellen viele Insekten fest, bevor sie eine Blüte anfliegen. Hummeln können optisch die Pollenmenge bestimmen und meiden Blüten mit wenig Pollen (CRESSwell und RoBERTSON 1994). Honigbienen sind in der Lage, Nektarmenge und -konzentration einer Blüte zu riechen (HEß 1983, SEELEY 1997). Die von Honigbienen besuchten Blüten werden zudem von ihnen mit einem Duft markiert (GIURFA und NúNEZ 1992). So wird vermieden, daß die entleerten Blüten ein weiteres Mal angeflogen werden. Dieser Duft verfliegt recht schnell und die Blüte wird bei erneuter Nektarproduktion wieder besucht.

Wichtig für einen Pollentransport über weitere Entfernungen ist auch eine Direktionalität der Futterflüge vieler Insekten. Hummeln und Motten fliegen gegen die Windrichtung (HEß 1983), Honigbienen orientieren sich an der Sonne oder an Geländemarken (GINSBERG 1986). So werden Pollen nicht erst $50 \mathrm{~m}$ in die eine Richtung verfrachtet, um dann wieder $50 \mathrm{~m}$ zurück transportiert zu werden.

Eine große Abundanz der Insekten kann ebenfalls zu mehr Futterflügen zwischen Pflanzen und zu größeren Pollentransportweiten führen. Dieses läßt sich zum einem durch eine größere intra- und interspezifische Konkurrenz der Insekten erklären, die zu kürzeren Besuchszeiten auf einer Pflanze führt (ARroyo 1976, FrANKIE et al. 1976, FrEE 1970, HurYN 1997). Zudem wird das Nahrungsangebot auf einer Pflanze schneller aufgebraucht und die Insekten werden veranlaßt, zur nächsten Nahrungsquelle zu fliegen.

\subsubsection{Carry-over}

Der für eine Bestäubung effektive Pollen wird durch die Insekten bei dem Besuch einer Blüte unfreiwillig aufgenommen (einmal als Nahrung aufgenommener Pollen gelangt nicht mehr zur Bestäubung). Wird dieser Pollen nicht vollständig auf der nächsten angeflogenen Blüte deponiert, sondern erst auf später besuchten Blüten, spricht man von einem Carry-over des Pollens. Die Wahrscheinlichkeit, daß sich noch Pollen einer Blüte auf dem Körper eines Insektes befindet, nimmt nach jedem weiteren Besuch weiterer Blüten ab. Dieses Übertragen 
des Pollens über mehrere angeflogene Blüten hinweg kann zu erheblich größeren Pollentransportweiten führen, als es die direkten Flugweiten der Insekten allein ermöglichen.

Bei KARRON et al. (1995) waren die Pollentransportweiten durch Carry-over um den Faktor 1,5 länger als die gemessenen Flugweiten der Insekten. Hummeln transportierten bei WASER und PRICE (1983) den Pollen noch bis zur 18. Blüte, über mehr als 20 Blüten bei THOMSON et al. (1986) und bei THOMSON und Plowright (1980) sogar bis zur 54. Blüte. STANTON et al. (1992) beobachteten nach dem Besuch der 10. Blüte immer noch große Pollenmengen der erstbesuchten Blüte auf der Honigbiene. Von einer Übertragung des Pollens von Insekt zu Insekt innerhalb des Stockes sozial lebender Bienen und Hummeln berichten FrEE (1966 und 1972) und VON DER OHE (pers. Mitteilung). Bei einem Carry-over von Pollen über den Bienenstock sind enorme Transportweiten vorstellbar. Durch den Effekt des Carry-over kann der Anteil der Geitonogamie erheblich gesenkt werden (WASER und PRICE 1983).

\subsubsection{Pollentransportweiten}

Die Pollentransportweiten zwischen Populationsmitgliedern sind weitgehend von der Dichte der Population abhängig (s. Kap. 2.8.5.2). In eng stehenden Populationen krautiger Pflanzen findet der durchschnittliche Pollentransport nur kleinräumig statt. Die meisten Insekten suchen den nächsten konspezifischen Nachbarn auf und die Flugweiten zwischen den Pflanzen sind bei Bienen, Hummeln, Fliegen und Motten nur selten länger als ein Meter. Häufig betragen sie nur wenige Dezimeter (Plowright und Galen 1985, Pyke 1978, SChMitT 1980, Waddington 1981, Waser und Price 1983). Treten die Pflanzen oder Gruppen von Pflanzen zerstreut auf und wird der Effekt des Carry-overs mit berücksichtigt, ist die mittlere Pollentransportweite schon beträchtlich größer (z. B. 14 m, GODT und HAMRICK 1993).

Interessanter für Rückschlüsse auf das Reproduktionssystem der Linde sind die beobachteten Flugdistanzen bzw. Pollentransporte der Insekten bei vergleichbaren Baum- und Straucharten, also entomophile Arten, die in unterschiedlicher Dichte (von geklumpt bis weit zerstreut) in Mischbeständen vorkommen. Es werden zudem nur die Untersuchungen an den Insektenordnungen aufgeführt, die auch bei der Linde als Bestäuber von Bedeutung sind (Diptera, Hymenoptera, Lepidoptera).

Bei der Baumart Gliricida sepium (Leguminosae) wurden mindestens 6,1 \% der Pollen weiter als $75 \mathrm{~m}$ transportiert. Die größte Transportweite dieser durch verschiedene Insekten bestäubten Baumart wird mit $275 \mathrm{~m}$ angegeben (DAWSON et al. 1997). Die Pollentransportweiten zweier weiterer Leguminosen sind von HAMRICK und MURAWSKI (1990) und LOVELESS et al. (1998) geschätzt worden. Bei Platypodium elegans wurden $25 \%$ des effektiv gewordenen 
Pollens mehr als 750 m transportiert. 21 \% der Früchte von Tachigali versicolor sind von Pollen befruchtet worden, der mindestens $500 \mathrm{~m}$ transportiert worden sein muß. Diese beiden tropischen Baumarten werden überwiegend von Bienen bestäubt. Die mittlere Transportweite des effektiven Pollens von Pithecellobium elegans durch Motten lag bei $142 \mathrm{~m}$, die maximale bei 350 m (CHASE et al. 1996). HouSE (1993) konnte einen Pollentransport durch kleine unspezialisierte Insekten in $330 \mathrm{~m}$ Entfernung bei der diözischen Baumart Neolitsea dealbata nachweisen. Die Bestäubungsrate der Blüten sank rapide mit der Entfernung zum nächsten Paarungspartner. Stand der nächste Paarungspartner 6,5 m entfernt, wurden nur noch $50 \%$ der Blüten bestäubt, in $330 \mathrm{~m}$ Entfernung lag der Anteil der bestäubten bei $10 \%$. Bei Cordia alliodora findet der größte Teil der Pollenverbreitung über Bienen und Schmetterlinge innerhalb von $75 \mathrm{~m}$ statt (max. $280 \mathrm{~m}$, BoshiER et al. 1995). STACY et al. (1996) schätzten, daß mindestens $62 \%$ der Nachkommen bei Calophyllum longifolium von Nachbarbäumen befruchtet worden sind, die $210 \mathrm{~m}$ und weiter entfernt standen. Bei Spondias mombin geben die selben Autoren eine 5,2 \%ige Samenproduktion durch Pollen von über $300 \mathrm{~m}$ entfernt stehenden Nachbarbäumen an. Bei dem australischen Strauch Persoonia mollis sind 70 \% der Samen vom nächsten Nachbar und $82 \%$ von den ersten drei Nachbarn bestäubt worden. Wildund Honigbienen transportierten den effektiv gewordenen Pollen im Mittel $33 \mathrm{~m}$ und maximal $72 \mathrm{~m}$ weit (KRAUSS 1994). Die von Schwebfliegen bestäubte Baumart Nesohedyotis arborea wurde von PERCY und CRONK (1997) untersucht. Sie bezeichnen den Pollentransport durch die Schwebfliegen bis zu einer Distanz von $50 \mathrm{~m}$ als höchst effizient.

ADAMS et al. (1992) ermittelten bei Eucalyptus regnans eine durchschnittliche Pollentransportweite nach Fremdbefruchtung von $57 \mathrm{~m}$. Allerdings wurden die fiktiven Nachkommenschaften per Computer simuliert. Basis für die simulierten Datensätze war eine, im Rahmen einer anderen Arbeit genetisch inventierte, 2 ha große, 10 Jahre alte Samenplantage in Australien. Diese Eukalyptusart ist der Linde bezüglich ihrer Reproduktionsbiologie sehr ähnlich.

Konkrete Angaben über die Pollentransportweiten von Insekten für Bäume und Sträucher der gemäßigten Breiten wurden von CASILDA et al. (1994) und ENGLUND (1993) gemacht. ENGLUND (1993) beobachtete die Futterflüge von Käfern auf Viburnum opulus in Schweden. Die Flüge des Käfers (Cetonia) zwischen den Sträuchern von Viburnum opulus waren durchschnittlich 18 m weit, der längste Flug wurde mit 98 m gemessen. CASILDA et al. (1994) untersuchten die Bestäubung von Prunus salicina durch Honigbienen in Spanien. Sie untersuchten den Fruchtansatz der Pflaumenbäume in Abhängigkeit von ihrer Entfernung zum Bienen- 


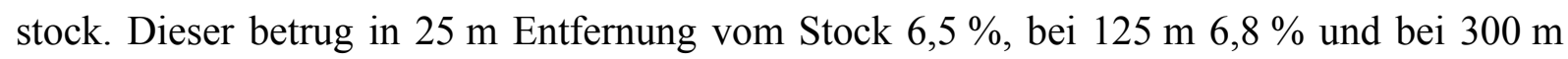
sank er auf $2 \%$.

Fast allen Untersuchungen gemeinsam ist eine leptokurtisch abfallende Kurve der Pollentransportweite. Nur bei CHASE et al. (1996) befruchtete der von Motten transportierte Pollen in $350 \mathrm{~m}$ Entfernung genau so viele Eizellen wie in $50 \mathrm{~m}$ Entfernung und die Flugweiten der von ENGLUND (1993) untersuchten Käfer ergaben ebenfalls keine leptokurtisch abfallende Kurve. ENGLUND führt dies aber weniger auf das besondere Nahrungssuchverhalten der Käfer, sondern auf die ungleichmäßige Verteilung der Sträucher zurück.

\section{Fazit}

Je nach Struktur und Nahrungsangebot eines Bestandes werden auch von nicht spezialisierten Insekten Futterflüge über größere Entfernungen unternommen. Dabei wird Pollen über mehrere hundert Meter effektiv transportiert. Prinzipiell wird die nächststehende lukrative Nahrungsquelle aufgesucht. Motten und Schmetterlinge zeigen indes ein davon abweichendes Nahrungssucheverhalten. Die tatsächlichen Pollentransportweiten können durch ein Carry-over von Pollen die Flugweiten der Bestäuber ein Vielfaches übertreffen.

\subsection{Selbststerilität}

Das vorige Kapitel zeigt, daß Selbstbestäubung durch Auto- oder Geitonogamie eine häufige Erscheinung bei vielblütigen Pflanzen ist. Unter Selbststerilität versteht man die Selektion gegen Eigenpollen durch präzygotale Inkompatibilitätsmechanismen und/oder postzygotale Inzuchtdepression. Sind diese wirksam, gewährleisten sie eine hohe, selbst wenn ein großer Teil der bestäubenden Pollen Eigenpollen waren. Die weibliche Blüte hat keinen Einfluß darauf, welcher und wieviel Pollen auf ihrer Narbe deponiert wird. Durch die Mechanismen der Inkompatibilität und Inzuchtdepression wird aber zwischen den deponierten Pollen eine Auswahl getroffen (CHARNOv 1979, SNOW 1994, STEPHENSON und WiNSOR 1986). BAWA (1974) führt die Existenz von Inkompatibilitätsmechanismen bei zoophilen Pflanzen auf den großen Anteil an Selbstbestäubung durch Geitonogamie zurück. Vollständige Selbststerilität ist mit Entstehung aller Nachkommen aus Fremdbefruchtung verbunden. Entweder wird eine Befruchtung durch Eigenpollen verhindert (Inkompatibilität) oder aus Selbstbefruchtung entstandene Nachkommen verfügen über eine verminderte Viabilität (Inzuchtdepression) und werden verstärkt selektiert. Eine Fremdbefruchtungsrate von $100 \%$ ist unter genetischen Aspekten ein anzustrebendes Ziel. Trotzdem verfügen die wenigsten blühenden Pflanzen über 
vollständig wirksame Mechanismen der Inkompatibilität oder Inzuchtdepression und dadurch wird eine Reproduktion über Selbstbefruchtung ermöglicht (CRAWLEY 1997). Es stellt sich daher die Frage, warum sich vollständige Selbststerilität im Laufe der Evolution nicht bei allen Arten durchgesetzt hat. Vollständige Selbststerilität setzt für die Erzeugung von Nachkommen eine ausreichende Fremdbestäubung durch geeignete Pollenvektoren voraus. Faktoren wie ungünstige Wetterverhältnisse (s. Kap. 2.8.3.6), eine geringe Populationsdichte (s. Kap. 2.8.5.2), fehlende Pollinatoren bzw. starke interspezifische Konkurrenz um Pollinatoren (GiLl 1989, JAY 1986, RATHKE und REAL 1993) etc. können dazu führen, daß geeignete Pollenvektoren für eine ausreichende Fremdbestäubung nicht zur Verfügung stehen. Bei einer Limitation von Fremdpollen stellt sich in Verbindung mit vollständiger Selbststerilität kein oder nur geringer Reproduktionserfolg ein und kann über einen längeren Zeitraum den Fortbestand einer Population oder der ganzen Art gefährden. Viele Arten in marginalen Umwelten sind daher in unterschiedlichen Graden selbstfertil und ermöglichen eine Reproduktion der Art über Selbstbefruchtung. Selbstfertilität wird deshalb von einigen Autoren als eine Art „Versicherung“ für den Fall einer Pollenlimitation gesehen (DARWIN 1862, HAGERUP 1951, LLOYd 1992, RATHKE und REAL 1993, Rick 1966, WHISLER und SNOW 1992, WyATT 1988). Ein weiterer Vorteil der Selbstfertilität ist ein erhöhter Fruchtansatz, da auch die selbstbefruchteten Blüten Samen ausbilden. Für die gleiche Menge an Früchten müssen weniger Blüten produziert werden und die Kosten der Reproduktion werden gesenkt (BAWA 1974).

Der Zustand unzureichender Fremdbefruchtung stellt sich in der Pflanzenwelt recht häufig ein: Nach BURD (1994) leiden von 258 Pflanzenarten 62 \% zumindest zeitweise unter einer Pollenlimitation. PIGOTT und HunTLEY (1981) beschreiben unzureichende Bestäubung bei der Winterlinde (s. Kap. 2.8.3.6), GUITAN (1993) bei der Heckenkirsche (Prunus mahaleb), MEDAN (1994) für Frangula alnus. Künstliche Bestäubung erhöhte den Fruchtansatz beim Tulpenbaum (Liriodendron tulipifera) um durchschnittlich das Sechsfache (HOUSTON und JOEHLIN 1989). Die zahlreichen Beispiele einer Pollenlimitation bei krautigen und in den Tropen und Subtropen beheimateter Pflanzen sollen hier nicht aufgeführt werden.

Viele Autoren betrachten eine über einen langen Zeitraum anhaltende Limitation an Fremdpollen als die evolutionäre Kraft, die bei vielen Arten zu einer Entwicklung von Selbststerilität zu Selbstfertilität geführt hat (ASHTON 1984, BARRETT 1988, BAWA 1974, BAWA et al. 1985, MurAWSKI und HAMrICK 1991, LinHART et al. 1987, USHIMARU und KIKUZAWA 1999, WHISLER und SNOW 1992). 
Selbstfertilität ist bei hermaphroditen entomophilen Baumarten der temperierten nördlichen Hemisphäre z. B. bei dem Tulpenbaum (Liriodendron tulipifera), der Robinie (Robinia pseudoacacia), der Heckenkirsche (Prunus mahaleb) und den Gattungen Aesculus und Sorbus bekannt. Der Anteil der Selbstbefruchtung in den Nachkommen von Liriodendron tulipifera variiert nach BROTSCHOL et al. (1986) von $14 \%$ bis $45 \%$. Bei der Robinie wurde die Selbstbefruchtungsrate in den Absaaten verschiedener Populationen auf bis $\mathrm{zu} 55 \%$ geschätzt (SURLES et al. 1990). Bei Prunus mahaleb (Rosaceae) konnten GUITAN et al. (1993) eine Fruchtbildung nach Geitonogamie feststellen, die allerdings signifikant geringer als nach Fremdbefruchtung ausfiel. Tabellarisch sind in SEDGLEY und GRIFFIN (1989) die Paarungssysteme zahlreicher Gattungen aufgelistet und nach dieser sind die Gattungen Aesculus und Sorbus ebenfalls selbstfertil. SEgDLEY und GRIFFIN (1989) betonen, daß der Grad der Selbstfertiliät innerhalb einer Gattung und innerhalb einer Art stark variieren kann.

Nach EISENHUT (1956) sind die Linden generell selbstfertil. ANDERSON (1976) bezeichnet die Winterlinde als begrenzt selbstfertil, die amerikanische Linde (Tilia americana) als weitgehend und die Sommerlinde als vollkommen selbststeril. Unter Ausschluß von Fremdpollen produzierten bei der Winterlinde $8 \%$ der Blüten fertile Früchte (17\% nach freier Abblüte), bei der amerikanischen Linde 0,4\% (3\% nach freier Abblüte). Die Sommerlinde zeigte bei diesen Versuchen keinen Fruchtansatz und die ungeschützten Blüten entwickelten $3 \%$ fertile Früchte. Eingehende Untersuchungen bezüglich der Selbstfertilität der Winterlinde haben PigotT und HuntLey (1981) unternommen. Sie kommen zu dem Schluß, daß die Winterlinde prinzipiell selbstfertil, der Grad der Selbstfertilität aber individuell sehr unterschiedlich ist.

Das Paarungssystem anderer Vertreter der Familie der Tiliaceaen reicht von vollständiger Selbstkompatibilität nach obligatorischer Selbstbestäubung bei den Jutearten Corchorus capsularis und C. olitorius (in FREE 1970) bis hin zu vollständiger Inkompatibilität bei der Baumart Grewia occidentalis (ZIETSMAN 1991). Ebenfalls vollständig selbstkompatibel ist die krautige Tiliaceae Triumfetta semitriloba. Fremdpollen erhöht den Fruchtansatz jedoch erheblich und läßt auf eine Pollenlimitation und/oder Inzuchtdepression schließen (COLLEVATTI et al. 1997). Ähnliches war auch bei den beiden Jutearten zu beobachten. Drei tropische Tiliaceaen der Gattung Luehea untersuchten HABER und FRANKIE (1982). Während sich Luehea candida als sebststeril erwies, zeigten Luehea speciosa und Luehea seemannii einen von Baum zu Baum unterschiedlichen Grad der Selbststerilität. Einige Bäume produzierten nach Selbstbestäubung so viel Fruchtansatz wie nach Fremdbestäubung, andere Individuen zeigten nach Selbstbestäubung kaum Fruchtansatz. 


\subsubsection{Inkompatibilitätsmechanismen}

Wie eingangs in Kapitel 2.9 erwähnt, ist der Begriff Inkompatibilität für genetisch gesteuerte Mechanismen definiert, die eine Befruchtung der Eizelle durch Eigenpollen hemmen oder verhindern, also in präzygotalen Stadien wirksam werden. Mechanismen, die eine Reduktion der Viabilität aus Selbstbefruchtung entstandener Nachkommen bewirken, werden als (postzygotale) Inzuchtdepression bezeichnet.

BARRETT (1988) bezeichnet die Inkompatibilität als den effektivsten Mechanismus, um eine Selbstbefruchtung bei hermaphroditen Pflanzen zu verhindern. Inkompatibilitätsmechanismen werden im allgemeinen durch einen oder wenige Inkompatibilitäts-Genort(e) mit vielen Allelen gesteuert (BARRETT 1988, HATTEMER et al. 1993, STEINER 1992), aber auch eine Kontrolle durch mehrere Genorte ist bekannt (GODLEY und SMITH 1981). Es ist dabei zu beachten, daß Inkompatibilitätsmechanismen nicht nur nach Selbstbestäubung wirksam werden, sondern gleiche Inkompatibilitätsallelen auch nach Fremdbestäubung zusammentreffen können. Die Wahrscheinlichkeit einer Kombination subletaler Allele ist jedoch nach Selbstbefruchtung größer als nach Fremdbefruchtung (STEINER 1992).

BAWA (1974) bezeichnet Pflanzen, deren Anteil befruchteter Eizellen (Embryonen) nach Selbstbefruchtung $20 \%$ kleiner ist als nach Fremdbefruchtung, als selbststeril. Pflanzen mit einem relativ höheren Anteil befruchteter Embryonen nach Selbstbefruchtung sind dementsprechend selbstfertil. BAWA (1974) betont, daß diese Grenze von $20 \%$ willkürlich gezogen wurde und bereits in dem zur Definition benutzten Fall die Selbststerilität nur partiell ist.

\subsubsection{Sporophytische Inkompatibilität}

Eine sporophytische Inkompatibilität wird durch Inkompatibilitätsallele der diploiden Exine des Pollens und der diploiden Narbenoberfläche kontrolliert. Bei einer sporophytischen Inkompatibilität wird eine Pollenkeimung auf der Oberfläche der Narbe verhindert, es kommt zu keinem oder nur minimalem Pollenschlauchwachstum (НЕß 1983). Die sporophytische Inkompatibilität wird unterteilt in homomorphe und heteromorphe Inkompatibilität. Eine heteromorphe Inkompatibilität ist mit der Ausprägung verschiedener Blütenformen gekoppelt (Distylie oder Tristylie), wie dies bei den Primeln, Sauerklee oder beim Blutweiderich zu finden ist. Die Morphologie der Blüte ist bei der Linde einheitlich und daher käme nur eine homomorphe Inkompatibilität für die Linde in Betracht

Experimente zum Nachweis von Inkompatibilitätsmechanismen bei der Winterlinde haben PigotT und HuntLey (1981) durchgeführt. Dabei wurden die Stigmata von 13 Winterlinden mit Eigenpollen versehen. PigotT und Huntley (1981) stellten dabei auf den Narben von 
drei der 13 Bäume ein Ausbleiben der Keimung von Eigenpollen nach Selbstbestäubung fest. Bei fünf der übrigen Winterlinden war das Keimprozent des Eigenpollens niedriger, bei einem Baum gleich und in vier Fällen höher im Vergleich mit dem Keimprozent aus freier Bestäubung stammender Pollen. Im Mittel aller 13 Winterlinden lag der Anteil der Griffel mit nachgewiesenen Pollenschläuchen nach Selbstbestäubung mit $52 \%$ signifikant niedriger als nach freier Bestäubung (66\%). Dabei wird der aus freier Bestäubung stammende Pollen sich sehr wahrscheinlich nicht nur aus Fremdpollen zusammengesetzt haben; es kann (oder muß) ein Anteil an Eigenpollen angenommen werden. Demnach wird das Ausmaß der sporophytischen Inkompatibilität in diesem Versuch eher unterschätzt.

Auch wenn die relativ kleine Zahl der untersuchten Narben pro Baum keine statistische Absicherung sporophytischer Inkompatibilität für den einzelnen Baum erlaubt und eine endgültige Sicherheit nur über Vererbungsanalysen zu erhalten wäre, zeichnet sich eine große individuelle Variation von Baum zu Baum ab. Insgesamt wurden von PigOTT und HuntLey (1981) an den 13 Winterlinden 251 Narben bzw. Griffel untersucht.

\subsubsection{Gametophytische Inkompatibilität}

Im Gegensatz zur sporophytischen Inkompatibilität wird die gametophytische Inkompatibilität nicht durch die Inkompatibilitätsallele der diploiden Pollenexine, sondern des haploiden Mikrogametophyten und des diploiden Griffelgewebes kontrolliert (HEß 1983). Die Inkompatibilitätsreaktion setzt zu einem späteren Zeitpunkt ein. Es kommt nicht zu einer Beeinträchtigung der Pollenkeimung, sondern der Pollen beginnt mit der Ausbildung eines Pollenschlauches und dieser durchdringt die Narbenoberfläche. Erst beim Erreichen des Griffelgewebes kommt es bei einer entsprechenden Allelkombination zu einer Hemmung des Pollenschlauchwachstums. Dabei werden von kompatiblen Pollen am Ende des Pollenschlauches „Callose-Pfropfen“ gebildet, während bei einer Inkompatibilität das Ende des Pollenschlauches eine Art Verzweigung aufweist (Sтотт 1972).

PigOtT und HunTLEY (1981) stellten bei den 13 untersuchten Winterlinden kein signifikant unterschiedliches Pollenschlauchwachstum in den Griffeln frei bestäubter und selbstbestäubter Blüten fest. An anderem Untersuchungsmaterial haben PIGOTT und HuNTLEY (1981) große Unterschiede in den Längen der Pollenschläuche in den Griffeln gefunden. Bei diesen Beobachtungen erwähnen sie nicht explizit, ob es sich dabei tatsächlich um Inkompatibilitätsmechanismen handelt oder ob die Pollen lediglich zu verschiedenen Zeitpunkten auf die Narbe gelangten und ein Wachstumsvorsprung Grund für die verschiedenen Pollenschlauchlängen gewesen ist. Aufschlußreicher ist ein ebenfalls von PIGOTT und HuNTLEY (1981) durchge- 
führter Laborversuch. Unter identischen Bedingungen wurde das Pollenschlauchwachstum am Blütenmaterial dreier verschiedener Winterlindenpopulationen gemessen. Die Blüten einer Population wurden mit Eigenpollen bestäubt, die der beiden anderen Populationen mit Fremdpollen. Die Geschwindigkeit des Pollenschlauchwachstums betrug bei den fremdbefruchteten Blüten im Mittel $101 \mu \mathrm{m} / \mathrm{h}$ bzw. $103 \mu \mathrm{m} / \mathrm{h}$, bei den selbstbefruchteten Blüten $40 \mu \mathrm{m} / \mathrm{h}$. Unter der Annahme, daß die Wachstumsunterschiede nicht auf Unterschiede zwischen den drei Populationen, sondern auf Effekte der Selbst- bzw. Fremdbestäubung beruhen, ist hier von einer gametophytischen Inkompatibilität auszugehen.

\section{Fazit}

Die Untersuchungen von PigotT und HuntLey (1981) zeigen die Existenz sporophytischer Inkompatibilität bei der Winterlinde. Diese variiert jedoch individuell sehr stark, bis hin zu völliger Selbstkompatibilität. Die Existenz gametophytischer Inkompatibilität kann bei der Winterlinde vermutet werden, ist aber nach den bisherigen Untersuchungen nicht gesichert. Eine sichere Unterscheidung ist erst durch Vererbungsanalysen möglich.

\subsubsection{Inzuchtdepression}

Wenn Inkompatibilitätsmechanismen Selbstbefruchtung nicht verhindern konnten, können Mechanismen der Inzuchtdepression greifen und eine Entwicklung aus Selbstbefruchtung hervorgegangener Nachkommen erschweren. Letale oder subletale rezessive Allele, meist an mehreren Fitness-Genorten, reduzieren die Viabilität der Nachkommen, wenn sie in homozygoter Form auftreten (CHARLESWORTH und CHARLESWORTH 1987, WRIGHT 1977). Ist eine Homozygotie dieser Allele über mehrere solcher Fitness-Genorte gegeben, ist der Rückgang der Viabilität nicht nur die Summe der subletalen Wirkung der einzelnen Fitness-Genorte, sondern sie wirken synergetisch (CHARLESWORTH et al. 1991). Eine Homozygotie dieser Fitness-Allele ist nicht nur bei den aus Selbstbefruchtung entstandenen Nachkommen möglich, sonder auch fremdbefruchtete Individuen können gleichermaßen unter Inzuchtdepression leiden. Die Wahrscheinlichkeit für Homozygotie an vielen Genorten steigt mit zunehmenden Inzuchtkoeffizienten. Dieser ist nach Selbstbefruchtung am höchsten, nach Paarung unter nicht verwandten Individuen am geringsten.

Viele Arbeiten befassen sich nur mit Inzuchtdepression in den ersten ontogenetischen Phasen nach Selbstbefruchtung. Bei vielen Pflanzen kommt es durch inzuchtdepressive Mechanismen im Stadium der Embryonalentwicklung zu verringertem Fruchtansatz (z. B. GUITAN 1993, 
Morse 1994, Rathke und Real 1993, Robertson und MCNAir 1994, StaCy et al. 1996, STEPHENSON und WinSOR 1986, TYBIRK 1993). ECKERT und BARRETT (1994) sowie SURLES et al. (1989) haben Inzuchtdepression in Form geringerer Keimprozente selbstbefruchteter Samen festgestellt.

Mehrere (in ihrer Blühbiologie der Linde sehr ähnliche) Eukalyptusarten zeigen Inzuchtdepression über einen langen Lebensabschnitt. In der Phase vom Fruchtansatz bis hin zum mehrjährigen Baum liegt die Viabilität selbstbefruchteter Nachkommen unter denen fremdbefruchteter (ELDRIDGE und GRIFFIN 1983, GRIFFIN und COTTERILl 1988, HARDNER und POTTS 1995, KENNINGTON und JAMES 1997). Inzuchtdepression kann auch noch während der Reproduktionphase von bis dahin nicht selektierten Nachkommen auftreten. Inzuchtdepressive Pflanzen produzieren weniger Blüten und bilden weniger und kleinere Früchte aus (CARR und Dudash 1995, HAUSER und LoeschKe 1995, van Teuren et al. 1993). Der Grad der Inzuchtdepressivität von Nachkommenschaften ist auch davon abhängig, ob die Eltern ihrerseits schon aus Verwandtschaftspaarung oder Selbstbefruchtung hervorgegangen sind. Je größer der Inzuchtkoeffizient der Eltern, umso größer auch der Grad der Homozygotie und infolgedessen die Inzuchtdepression ihrer Nachkommen. Dieser Effekt ist besonders ausgeprägt, wenn diese Nachkommen wiederum aus Selbstbefruchtung (fortgesetzte Selbstbefruchtung) entstanden sind (HAUSER und LoeschKe 1995, KREBS und HANCOCK 1990, WOLFE 1993, VAN TEUREN et al. 1993).

Inzuchtdepression kann in den verschiedensten ontogenetischen Stadien und in unterschiedlichen Ausmaßen wirksam werden. Bei HolsINGER und THOMSON (1994) ist Inzuchtdepression in Stadien der Embryonalentwicklung und der Keimung der Samen wirksam. In nachfolgenden Stadien weisen ingezüchtete Individuen keine verminderte Viabilität gegenüber fremdbefruchteten Individuen auf. Bei HAUSER und LOESCHKE (1995) war der Fruchtansatz selbstbefruchteter Blüten und das Gewicht der Samen mit denen fremdbefruchteter vergleichbar und Inzuchtdepression setzte erst später ein. Ebenfalls wird von Inzuchtdepressionen unterschiedlicher ontogenetischer Stadien berichtet, die in zeitlicher Abfolge voneinander getrennt sind (SCHEMSKE 1983, VAN TEUREN et al. 1993).

Die Stärke der Inzuchtdepression kann auch indirekt von der Dichte der Population beeinflußt werden. Nach StAnTON et al. (1991) und KENNINGTON und JAMES (1997) ist die Selektion in dichten Populationen ausgeprägter, da hier ein größeres Artenspektrum an Insekten in höherer Abundanz angelockt wird, die zu einer erhöhten Fremdbefruchtungsrate der Blüten beitragen. Eine erhöhte mittlere Fremdbefruchtungsrate führt zu einem verstärkten Konkurrenzdruck gegen den geringen Anteil selbstbefruchteter Nachkommen. Ebenfalls steigern inter- und 
intraspezifische Konkurrenz sowie physiologische Streßfaktoren die Wirkung von Inzuchtdepression (CARR und Dudash 1995, Dudash 1990, Marshall und Ellstrand 1988, SCHEMSKE 1983, VAN TEUREN et al. 1993).

Das Ausmaß von Inzuchtdepression ist des weiteren abhängig vom vorherrschenden Paarungssystem der Pflanzenart. Obligatorisch fremdbefruchtete Arten weisen stärkere Inzuchtdepressionsmechanismen auf als obligatorisch selbstbefruchtete Arten. Als grober Richtwert wird bei obligatorisch fremdbefruchteten Arten ein 50 \%iger Viabilitätsnachteil selbstbefruchteter Nachkommen angegeben. Bei obligatorisch selbstbefruchteten Arten liegt der Viabilitätsnachteil dieser Nachkommen bei $25 \%$ im Vergleich mit den aus Fremdbefruchtung entstandenen (CHARLESWORTH und CHARLESWORTH 1987, LANDE und SCHEMSKE 1985).

Hohlkörner können durch ausbleibende Befruchtung der Eizellen (Pollenlimitation, Inkompatibilitäten) oder durch gehemmte Entwicklung der Embryonen (z. B. durch Inzuchtdepression) gebildet werden. Häufig ist eine genaue Unterscheidung, auf welche der Ursachen die Bildung von Hohlkörnern genau zurückzuführen ist, schwierig (HATTEMER et al. 1993).

Mit Hilfe lichtmikroskopischer Untersuchungen haben PigotT und HuntLey (1981) den Fruchtansatz einer Winterlinde detailliert untersucht. In dem für England außergewöhnlich warmen Sommer 1976 produzierte diese Winterlinde 16\% fertile Früchte und in weiteren $20 \%$ waren die Embryonen waren unvollständig entwickelt. Die restlichen $64 \%$ wiesen verschrumpelte Eizellen auf, die auf eine nicht erfolgte Befruchtung hinweisen. Auf die Möglichkeit, daß diese $20 \%$ unterentwickelten Samen auf die Existenz inzuchtdepressiver Mechanismen zurückzuführen sind, wird in der Arbeit von PIGOTT und HunTLEY (1981) nicht explizit eingegangen, ihre Beobachtungen machen diese aber sehr wahrscheinlich.

Nach RoHMEDER (1972) sind im Durchschnitt langjähriger Samenprüfungen nur knapp 48 \% der Samen der Winterlinde keimfähig. Als Normwert für Handelssaatgut wird für die Winterlinde jedoch 80 \% Keimfähigkeit der Samen vorausgesetzt (ROHMEDER 1972). In einer jüngeren Arbeit von KLEIN (1992) wird von weitaus geringeren Anteilen keimfähiger Samen berichtet. Nach Angaben der hessischen Samendarre Wolfgang erwiesen sich im langjährigen Mittel nur $9 \%$ bzw. $22 \%$ der geernteten Samen zweier Winterlindenbestände als keimfähig. Bei eigenen Untersuchungen beerntete KLEIN (1992) 18 Winterlinden und überprüfte die Lebensfähigkeit optisch vital erscheinender Samen mittels des Tetrazoliumtests. Dabei zeigte sich, daß von diesen optisch vitalen Samen laut Tetrazoliumtest 15-89\%, im Mittel 56\%, nicht lebensfähig waren. 
KLEIN (1992) erwägt die Möglichkeit, daß inzuchtdepressive Mechanismen bei der Winterlinde die Ursache für den von ihm beobachteten vorzeitigen Fruchtabort und den hohen Anteil nicht lebensfähiger Samen sein könnten. Über vorzeitige Fruchtabortion im großen Umfang wird ebenfalls von anderen Autoren berichtet (siehe dazu folgendes Kap. 2.10). Über $90 \%$ der Früchte der Winterlinde enthalten einen, weniger als $10 \%$ zwei Samen und nur vereinzelt werden drei Samen pro Frucht gebildet (EISENHUT 1957, PigOTT und HuNTLEY 1981). Vielen fertilen Eizellen bleibt demnach eine Entwicklung zum Samen vorenthalten. Nach EISENHUT (1957) tritt nach der Befruchtung mehrerer Eizellen eines Ovariums ein starker Konkurrenzkampf um Platz und Nährstoffe ein, durch die eine Auslese eingeleitet wird. EISENHUT (1957) zieht nicht direkt eine Selektion durch Inzuchtdepression in Erwägung; da er aber die Linde als selbstfertil bezeichnet und Geitonogamie als die vorherrschende Bestäubungsart bei der Linde erachtet, ist die Existenz inzuchtdepressiver Mechanismen bei der Linde eine sehr plausible Schlußfolgerung aus seinen Beobachtungen.

\section{Fazit}

Mechanismen der Inzuchtdepression sind von sehr vielen Blütenpflanzen bekannt. Ein Inzuchtdepression kann verstärkte Selektion gegen aus Selbstbefruchtung entstandene Nachkommen in allen ontogenetischen Stadien von der Embryonalentwicklung bis hin zur erneuten Reproduktionsphase und in unterschiedlichster Intensität bewirken. Bei der Winterlinde kann aufgrund bisheriger Untersuchungen die Existenz von Inzuchtdepression zumindest für die Phasen der Embryonalentwicklung und der Keimung der Samen angenommen werden.

\subsection{Reproduktionserfolg der Winterlinde}

Nach DENGLER (1992) ist eine biologische Eigenschaft der Linde die reichliche Fruktifikation, der aber nur ein geringer Verjüngungserfolg gegenübersteht. Danach reproduziere sich die Linde überwiegend asexuell über Ausschläge am Stammfuß oder aus dem Stock. Über ein nicht unerhebliches Aufkommen an Naturverjüngung wird jedoch in anderen Arbeiten berichtet (Hocker 1979, Klein 1992, PigOtT und Huntley 1981, von BerlePsCH 1979). KleiN (1992) sieht eine natürliche Verjüngung der Winterlinde trotz der hohen Hohlkornanteile als gesichert an. Bei einer Produktion von 25000 Samen (ca. 1 kg) einer Winterlinde würden die bei einem 80 \%igen Verlust durch Hohlkörnern verbleibenden 5000 Samen für Naturverjüngung ausreichen.

Auffallend ist bei der Winterlinde, daß weit mehr Blüten mit entwicklungsfähigen Samenanlagen produziert werden, als fertile Samen aus ihnen entstehen. Ein umfangreicher vorzeitiger 
Abwurf unterentwickelter Früchte ist bei der Winterlinde die Regel (ANDERSON 1976, EISENHUT 1957, PigOtT und HunTLEy 1981). KLEIN (1992) berichtet von Winterlinden, bei denen zwei Monate nach der Blüte der komplette Fruchtanhang abgefallen war. In Untersuchungen von ANDERSON (1976) entwickelten sich bei der Winterlinde 17\%, bei der amerikanischen und der Sommerlinde $3 \%$ der Blüten zu fertilen Früchten. Von den am Baum verbleibenden Früchten sind viele hohl oder weisen unterentwickelte Embryonen auf. Der Anteil der Früchte mit toten Samen kann unter Umständen bis zu 90 \% erreichen (KLEIN 1992, PIGOTT und HuNTLEY 1981). Für die im Verhältnis zur Blütenproduktion geringe Ausbildung vitaler Samen werden von den Autoren verschiedene Gründe genannt:

Nach EISENHUT (1957) sind bei den Linden in der Regel alle zehn Samenanlagen eines Ovariums entwicklungsfähig. Bei PigOTT und HunTLEY (1981) variierte der durchschnittliche Anteil fertiler Eizellen unterschiedlicher Populationen von 23 bis 77 \%. Eine sehr alte Winterlinde wies in ihren Untersuchungen vollständige Sterilität der Eizellen auf und die genannten Autoren sehen ebenso wie EISENHUT (1957) zunehmende Sterilität der Eizellen in Abhängigkeit von dem Alter eines Baumes gegeben. Letztgenannter Autor ermittelte den Hohlkornanteil einer 30-jährigen Winterlinde mit 37,4\%, einer 180-jährigen von 63,8 \% und eine 250jährige Winterlinde hatte 97,5\% hohle Früchte. Auch KLEIN (1992) führt die von ihm beobachtete vorzeitige Fruchtabortion sowie Hohlkornanteile u. a. auf die Seneszenz des betreffenden Baumes zurück.

EISENHUT (1957) und KLEIN (1992) machen neben der im Alter zunehmenden Sterilität der Eizellen auch die Unterversorgung an Nährstoffen für den geringen Reproduktionserfolg verantwortlich. Diese ist nach EISENHUT (1957) von der Exposition des Baumes und seiner Krone abhängig. In der Kronenspitze und in den südlich exponierten Kronenteilen von Tilia corinthiaca Bosc. konnte er den höchsten Anteil mehrsamiger Früchte und den geringsten Anteil hohler und toter Samen finden. PigotT und HunTLEy (1981) stellten bei der Winterlinde in den südlich exponierten Kronenteilen den höchsten Fruchtansatz fest. KLEIN (1992) vermutet, daß physiologischer Streß durch Trockenheit und Bodenversauerung die Bildung von Hohlkörnern fördert, ohne dieses jedoch statistisch zu belegen.

PigOTT und HunTLEY (1981) führen den verhältnismäßig geringen Reproduktionserfolg der Winterlinde in den Randzonen an der nördlichen Grenze des natürlichen Verbreitungsgebietes der Winterlinde auf zu kühle Sommer zurück. Sie stellten eine Abhängigkeit der Pollenkeimung und des Pollenschlauchwachstums von der Lufttemperatur fest. Eine Keimung des Pollens erfordert Temperaturen von über $15^{\circ} \mathrm{C}$. Ein nennenswertes Wachstum des Pollenschlauches ist erst ab Temperaturen über $19{ }^{\circ} \mathrm{C}$ zu verzeichnen und steigert sich bei Temperaturen 
um $24{ }^{\circ} \mathrm{C}$ deutlich. Nach PigotT und HuntLey (1981) ist mit einem Ausfall der Reproduktion zu rechnen, wenn während der Blühperiode im Juli die Lufttemperatur nur selten über $20^{\circ} \mathrm{C}$ ansteigt. Die hohe Rate nicht befruchteter Eizellen im Nordwesten Englands führen sie auf die niedrigen Julitemperaturen in dieser Region zurück. Lufttemperaturen von über $20^{\circ} \mathrm{C}$ über mehrere Stunden täglich werden auch für die Samenreife im August und September benötigt. PIGOTT (1981) konnte im kontinentaler geprägten Klima in Schweden und Finnland eine hohe Rate erfolgreich befruchteter Eizellen finden, da hier die Temperaturen während der Blüte der Winterlinde ausreichend hoch sind. Der Reifungsprozeß der Samen wurde aber durch den in dieser Region klimatisch bedingten starken Temperaturabfall ab Ende August gestoppt und es wurden keine fertilen Samen gebildet. Über einen Zeitraum von 25 Jahren produzierten Populationen im kälteren Norden Englands nur in drei überdurchschnittlich warmen Jahren geringe Mengen (max. $15 \%$ ) an fertilen Nachkommen; in den restlichen Jahren war kein fertiler Fruchtansatz zu verzeichnen (PigOTT 1991). Im Süden Englands sind hingegen regelmäßig nennenswerte Fruchtansätze mit (für die Winterlinde) relativ geringen Hohlkornanteilen von 40 bis 95 \% zu verzeichnen. Die durchschnittliche Tageshöchsttemperatur ist mit $18{ }^{\circ} \mathrm{C}$ in den Monaten Juli und August im Nordwesten Englands um $2{ }^{\circ} \mathrm{C}$ niedriger als im Süden Englands und ist nach PigOTT und HuntLey (1981) die Ursache für den äußerst geringen sexuellen Reproduktionserfolg in dieser Region. Aber auch eine Pollenlimitation durch geringen Insektenflug bei widrigen Witterungsverhältnissen und Inkompatibilitätsmechanismen (s. Kap. 2.9.1) werden von PIGOTT und HUNTLEY (1981) als Gründe für eine unzureichende Befruchtung der Eizellen angegeben. Bei nasser und kühler Witterung variierte der Anteil bestäubter Stigmata von 23 bis $71 \%$; bei besserem Wetter blieben maximal $5 \%$ der untersuchten Narben ohne Pollen. Ein zusätzlicher ungünstiger Einfluß regnerischen und kühlen Wetters kann die von PACINI und FRANCHI (1982) bei den Linden festgestellte vorzeitige Pollenkeimung innerhalb der Antheren sein. Bestäubung der Stigmata mit schon gekeimten Pollen bleibt erfolglos, es kommt zu keinem Pollenschlauchwachstum und infolgedessen zu keiner Befruchtung der Eizelle.

\section{Fazit}

Selbst unter günstigen klimatischen Bedingungen ist die Bildung viabler Nachkommen in Relation zu der Produktion von Blüten bei der Winterlinde gering. In kühlen Sommern ist oft ein kompletter Ausfall der sexuellen Reproduktion zu verzeichnen. Bei den bisherigen Untersuchungen werden die Schwerpunkte für die Begründung der relativ geringen Fruchtansätze und Keimprozente bei physiologischen und weniger bei genetischen Ursachen gesetzt. 


\subsection{Hybridisierung von Winter- und Sommerlinde}

Bereits im 19. Jh. berichten Botaniker (z. B. SPACH 1834, BAYER 1862, SiMONKAI 1888) über Hybridisierung der Sommerlinde (Tilia platyphyllos) und Winterlinde (Tilia cordata) zur Holländischen Linde (Tilia $x$ vulgaris). Die Holländische Linde wird seit dem 17. Jahrhundert intensiv kultiviert und ist die am stärksten verbreitete Linde unter den Park- und Alleebäumen in Europa (PIGOTT 1991). Ein natürliches Vorkommen dieser Zwischenform in mitteleuropäischen Wäldern wird in vielen Abhandlungen beschrieben (u. a. BOINSKA und CHMIELEWSKA 1977, Fromm 1999, KeIPER 1916, PigotT 1969). Ferner weisen Pollenanalysen die Existenz dieser Arthybride schon in der Holstein-Warmzeit ca. 150.000 v. Chr. und 5500 v. Chr. nach (PIGOTT 1991). Es muß demnach von einer mehr oder weniger starken Vermischung von Sommer- und Winterlinde in den heutigen Beständen und somit von einem nicht nur artreinen Vorkommen dieser beiden Linden ausgegangen werden. Im praktischen Waldbau wird nicht immer zwischen den verschiedenen Lindenarten unterschieden, häufig ist nur von der „Linde“ die Rede. Eine Ursache dafür könnte die über lange Zeit untergeordnete Rolle der Linde im Waldbau sein, da sie dort meist nur als dienende Baumart Verwendung fand. Ein weiterer Grund ist sicherlich die selbst für geübte Beobachter anhand morphologischer Merkmale nur schwere Ansprache und Unterscheidung der Sommer-, Winter- und Holländischen Linde. Im unbelaubten Zustand und ohne Samenanhang ist dieses sogar weitestgehend unmöglich (SCHELLER 1972).

Sommer- und Winterlinde unterscheiden sich erheblich u. a. aufgrund ihrer Standortansprüche, ihrer Frost- und Trockenresistenz, ihres Wachstumsverhaltens, ihrer Holzeigenschaften sowie der Austriebs- und Blühtermine voneinander und decken deshalb im Waldbau verschiedene Einsatzbereiche ab. Bezüglich ihrer ökologischen Anforderungen gilt die Winterlinde gegenüber der Sommerlinde generell als anspruchsloser. Sie hat geringere Bedürfnisse an Licht und Boden und gilt als kältetoleranter sowie trockenresistenter. Durch den späteren Austrieb ist sie weniger durch Spätfrost gefährdet, auch soll der Jungwuchs der Winterlinde weniger unter Mäuseverbiß leiden. Die Winterlinde zeigt ein langsameres Wachstum als die Sommerlinde und erreicht geringere Endhöhen. Allgemein besitzt die Winterlinde bessere waldbauliche Eignung für den Einsatz als Mischbaumart und, da sie im Vergleich zur Sommerlinde ein schwereres, dichteres und härteres Holz besitzt, ist sie auch auf dem Holzmarkt stärker gefragt (EISENHUT 1957, NAMVAR und SPETHMANN 1986, RÜHL 1968, SDW 1991).

Die Holländische Linde liegt bezüglich der meisten morphologischen Merkmale zwischen denen der Sommer- und der Winterlinde (Fromm 1999, PigotT 1969 und 1991). Selbst der Pollen der Hybride zeigt eine intermediäre Morphologie (ANDREW 1971). 


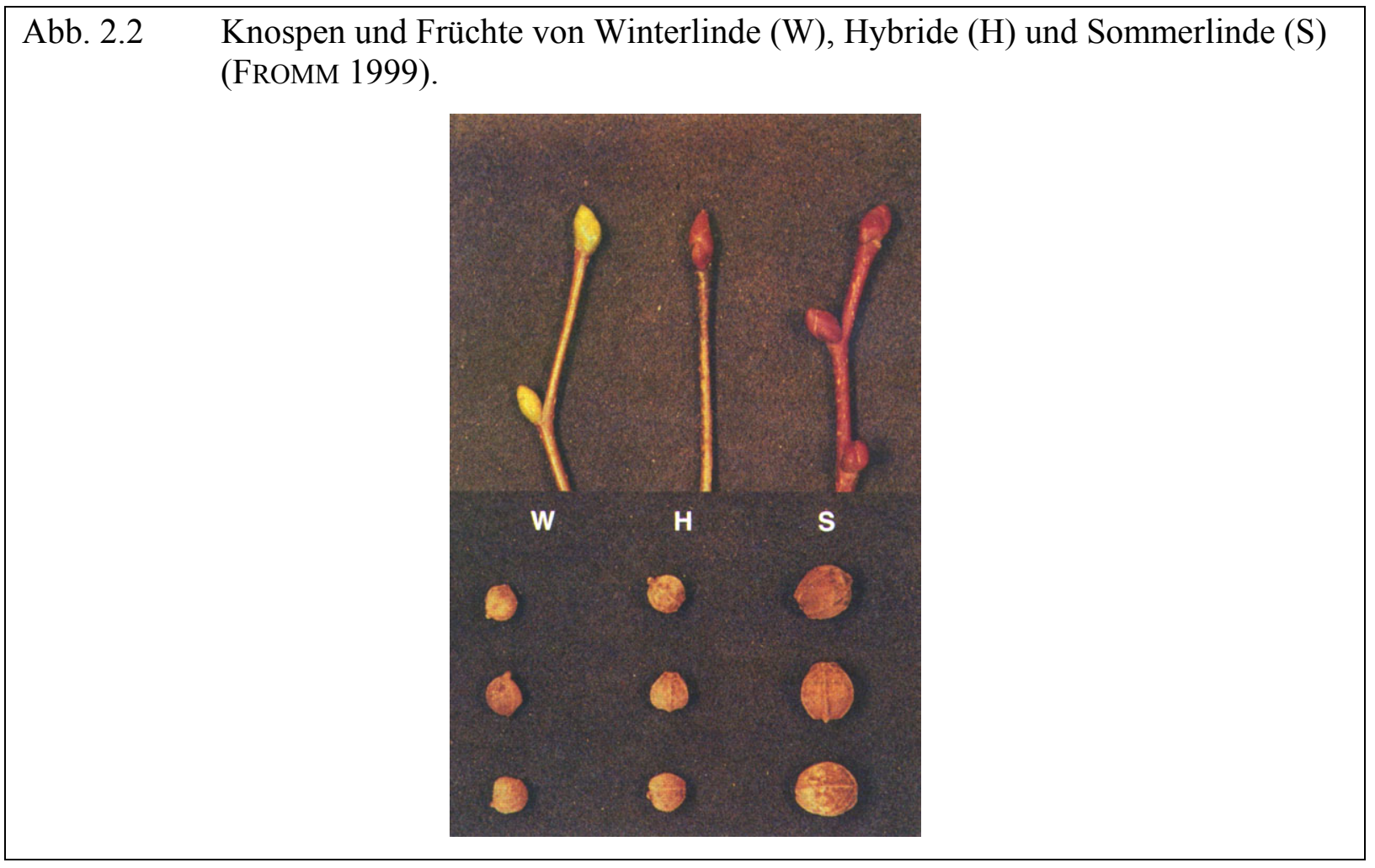

Winter- und Sommerlinde haben ein über weite Teile Europas überschneidendes Verbreitungsgebiet. Die Sommerlinde dringt im Vergleich zur Winterlinde nicht so weit in den Norden, Westen und Osten vor (vgl. Abb. 2.3 mit Abb. 2.1 auf S. 5).

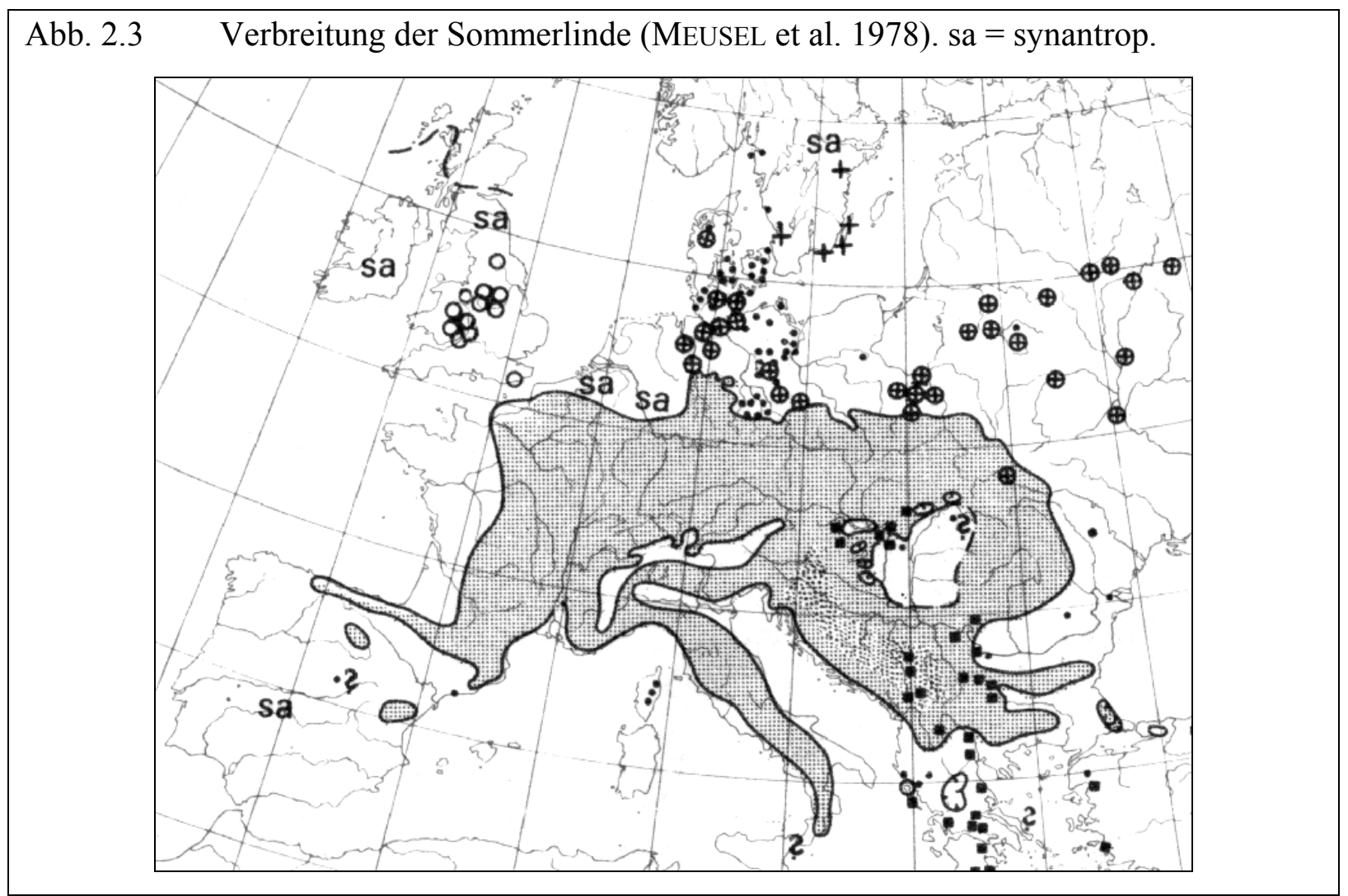


Auf Standorten, die den Ansprüchen beider Arten genügen, können Winter- und Sommerlinde im Bestand gemischt vorkommen. Bezüglich ihrer Blütenmorphologie sind die Lindenarten nicht klar von einander abgrenzbar und werden von den gleichen Insektengruppen besucht; ein interspezifischer Pollentransport durch Insekten ist möglich. Bei Untersuchungen in den USA konnte ANDERSON (1976) bei sich teilweise überschneidenden Blühperioden von Tilia americana, Tilia platyphyllos und Tilia cordata keine Bevorzugung der Insekten für eine bestimmte Lindenart feststellen. In Mitteleuropa sind die Blühperioden von Winter- und Sommerlinde zeitlich getrennt. Die Sommerlinde beginnt mit ihrer Blüte zwei bis drei Wochen früher als die Winterlinde (EISENHUT 1957, Fromm 1999, PigotT 1969). Die Hybride (Holländische Linde) liegt mit ihrer Blühperiode zwischen denen der Winter- und Sommerlinde oder deckt sich mit der Blüte der Sommerlinde (PIGOTT 1991). Eine spontane Hybridisierung zeigt, daß diese zeitliche Trennung nicht immer ausreicht, um zwischenartlichen Genfluß zu verhindern.

Über die Fertilität der Hybride gibt es unterschiedliche Angaben. SCHELLER (1972) beobachtete bei allen von ihm untersuchten Arthybriden einen trotz ausgiebiger Blüte sehr schwachen Samenansatz mit gleichzeitig stark erhöhtem Hohlkornanteil. NAMVAR und SPETHMANN (1986) berichten von vollständiger Unfruchtbarkeit der Holländischen Linde. Nach PIGOTT (1969, 1991) sind viele Hybriden fertil und der Jungwuchs zeigt eine Rekombination und Segregation der elterlichen Merkmale. Über mögliche Paarungen der Holländischen Linde mit Winter- oder Sommerlinde ist bislang nichts bekannt. 


\section{Material und Methoden}

\subsection{Der Versuchsbestand}

Als typische Nebenbaumart kommt die Linde weitgehend nur in Mischungsanteilen unter $5 \%$ vor. In den Bestandesbüchern werden aber erst Bäume ab einem Mischungsanteil von $5 \%$ ausgewiesen. Die Existenz einer Winterlindenpopulation ist deshalb oft nicht dokumentiert und erschwert ein Auffinden derselben.

Um die Zielsetzungen dieses Forschungsvorhabens nicht von vornherein auszuschließen, sollte die Lindenpopulation folgenden Kriterien genügen:

- Der Bestand muß die Fruktifikationsreife erreicht haben.

- Die Linden müssen vorherrschend oder wenigstens mitherrschend sein, da sie sonst nicht fruktifizieren und für vorliegenden genetische Untersuchungen ausscheiden.

- In dem Bestand sollten neben den Winterlinden möglichst keine Sommer- bzw. Hybridlinden vorkommen.

- Um eine Vollaufnahme zu ermöglichen, wäre eine Größe der Winterlindenpopulation von nicht mehr als 100 Individuen wünschenswert.

- Der Bestand sollte von anderen Lindenvorkommen isoliert sein, um einen Eintrag von Fremdpollen ausschließen zu können.

- Voraussetzung für populationsgenetische Vergleiche zwischen Winterlinden mit starkem bzw. geringem Paarungskontakt ist eine Winterlindenpopulation mit hoher bzw. teilweise geringer Dichte in verschiedenen Teilen des Bestandes.

- Ein Auftreten der Winterlinden in wechselnder physischer Bestandesstruktur würde eine Quantifizierung der Transportweiten effektiven Pollens durch tierische Vektoren ermöglichen, wenn die genetische Struktur der Altbäume (etwa durch Fehlen genetischer Variation) dieses nicht von vornherein ausschließt.

Nach dreimonatiger Suche wurde im Genossenschaftsforst Schwiegershausen (bei Osterode/Harz) ein Bestand entdeckt, der alle oben genannten Kriterien weitgehend erfüllt.

In diesem 40,2 ha großen Bestand befinden sich neben der Hauptbaumart Buche (Anteil ca. $90 \%$ ) und diversen anderen Baumarten 138 Winterlinden und drei Winter-/SommerlindenHybriden (Tilia x vulgaris). Ein Bereich, der nach den Bestandesbüchern überwiegend aus 
Pflanzung hervorgegangen ist, weist 45 Winterlinden auf, die nur vereinzelt von Buchen durchsetzt sind. Diese Teilpopulation kann als Lindenreinbestand angesehen werden. In einer weniger starken Konzentration befinden sich in einem anderem Teil des Bestandes ca. 25 Winterlinden. Des weiteren bietet der Versuchsbestand Schwiegershausen die Möglichkeit, gruppenweise, locker verteilte und isoliert stehende Linden in die Untersuchungen mit einzubeziehen (s. Abb. 3.5 auf S. 58).

In den Bestandesbüchern wird nur der oben genannte Bereich als Pflanzung erwähnt, die übrigen Winterlinden der Population Schwiegershausen sind vermutlich aus Naturverjüngung entstanden. Die uneinheitliche Verteilung im Bestand und heterogene Altersstruktur deuten darauf hin. Durch die genetische Inventur der Altbäume konnte bei sechs ca. 150-200 Jahre alten Linden der Ursprung aus Stockausschlag oder Wurzelbrut nachgewiesen werden (s. Kap. 4.2); zumindest für diese sechs Winterlinden ist eine Entstehung aus Naturverjüngung wahrscheinlich.

Der Versuchsbestand ist, auf einer Kuppe liegend (150-250 m ü. NN), weiträumig von Feldmark umgeben und ein Eintrag von Fremdpollen anderer Lindenpopulationen kann weitgehend ausgeschlossen werden. In Entfernungen von 300-1000 m vom Versuchsbestand befinden sich in der Feldmark lediglich vier Winterlinden, die als potentielle Paarungspartner mit einbezogen werden müssen. Diese Solitärbäume stellen eine interessante Erweiterung dar, weil das Reproduktionssystem der in der Feldmark isoliert stehenden Linden mit denen im Bestand verglichen werden kann.

\subsection{Materialgewinnung}

\subsubsection{Gewinnung von Samenstichproben}

Eine Analyse verschiedener Aspekte des Reproduktionssystems verlangt eine Ernte der Nachkommen direkt vom Baum, da dadurch die Nachkommen dem Samenelter eindeutig zugeordnet werden können. Eine Zuordnung der Nachkommen zum Samenelter ist z. B. bei der Bestimmung von Pollenvektoren, von Selbstbefruchtungsanteilen und die Analyse des Vererbungsmodus von Isoenzymen notwendig.

Mit der Stangenschere konnten Äste bis zu einer Höhe von ca. neun Metern erreicht werden. Da die Mehrzahl der Linden ein Alter von weit über 100 Jahren mit den entsprechenden Baumhöhen aufwiesen, konnten nur tief beastete Rand- und Einzelbäume mit Hilfe der Stangenschere beerntet werden. Im Oktober 1995 wurden folgenden, vor der Beerntung mit Nummern markierten, Linden Samen geworben: 
Nr. $0,1,2,4,6,8,10,11,12,13,14,15,16,20,28,29,33,36,38,57,59,60,61,64,65,66$, 67, 68, 69, 69a, 71, 72, 73, 92, 114, 116, 117, 118, 119, 120, 121, 122, F1,F2, F3 und F4 (F steht für Feldmark).

Die restlichen Bäume wurden mit einer Schrotflinte (4 mm-Schrot) Ende Oktober bis Mitte November 1995 beerntet. Dieses Verfahren erwies sich selbst bei über 30 m hohen Linden als praktikabel. Der um den 10.11.95 beginnende Laubfall erleichterte die Arbeit erheblich und der von Baum zu Baum sehr stark variierende Samenansatz wurde deutlich sichtbar. Blütenbildung und ein entsprechender Samenansatz erfolgt lediglich in den ausreichend mit Licht versorgten Teilen der Krone. Mitherrschende Linden zeigen oftmals nur einen spärlichen, vorherrschende hingegen üppigen Samenansatz. Folgende Linden konnten nicht beerntet werden, da diese entweder keine oder nur sehr geringe Samenbildung aufwiesen:

Nr. 31, 41, 53, 63, 70, 96, 102, 103, 110, 127, 131.

Für die Keimungsversuche wurden größere Mengen Samen benötigt. Da für die Keimungsversuche auch Nachkommenschaften aus einer dicht stehenden Gruppe Linden verwendet und auf die Beerntung von Randbäume verzichtet werden sollte, kam für die Probenahme nur eine Besteigung der ca. $25 \mathrm{~m}$ hohen Linden mit einer Zapfenpflückerausrüstung in Frage. Um die tausend Samen wurden auf diese Weise von den Linden 42 und 82 geworben. 
Abb. 3.1 Werbung von Nachkommenschaften aus den Kronen von ca. 150-jährigen Winterlinden durch Herrn Dr. Leinemann.
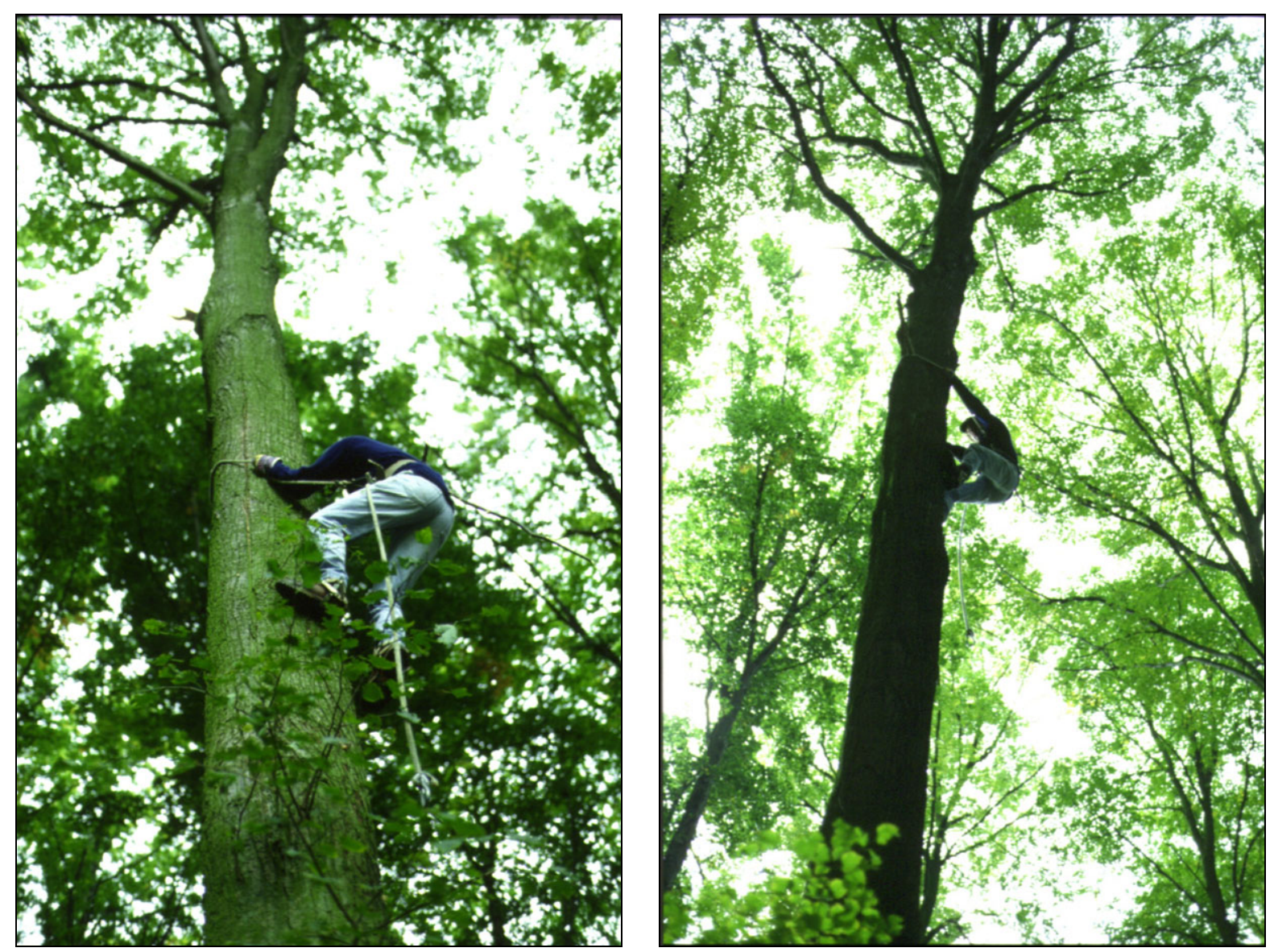

\subsubsection{Gewinnung von Blattmaterial}

Für die genetische Inventur des Altbestandes wurden im Frühjahr vor dem Austrieb von allen Linden Zweige geworben. Bis auf wenige Ausnahmen konnte auf den Einsatz der Schrotflinte verzichtet werden, da die Linde zur Bildung von Wasserreisern und zu Wurzelausschlag neigt. Die Zweige wurden in Klimakammern zum Austreiben gebracht und das für Laboruntersuchungen benötigte junge Blattmaterial umgehend analysiert oder mit flüssigem Stickstoff schockgefroren und bei $-80{ }^{\circ} \mathrm{C}$ gelagert.

\subsection{Untersuchtes Material}

Für die genetische Inventur des Altbestandes wurde zunächst Blattmaterial aller 141 Altbäume elektrophoretisch untersucht. Um die Auswahl der Linden einzugrenzen, von denen größere Nachkommenschaften untersucht werden sollten, wurden zu Beginn je zehn Samen von den 130 Bäumen untersucht, von denen Nachkommen geworben werden konnten. Auswahlkriterien waren neben der genetischen Struktur des Altbaumes auch dessen Lage im Bestand. In die engere Auswahl kamen 49 Winterlinden, von denen mindestens 20 bis maximal 180 
Nachkommen untersucht wurden. Insgesamt beläuft sich der Umfang der in dieser Arbeit genetisch inventierten Samen auf über 4800. Im Zuge der Bestäubungsversuche wurden 76 Samen und bei den Keimungsversuchen 87 Jungpflanzen untersucht.

\section{Hybridisierung}

Für die Etablierung einer Artunterscheidung über Isoenzymgenmarker sind neben den Altbäumen des Versuchsbestandes Schwiegershausen 91 Winterlinden, 67 Sommerlinden und 10 Hybriden genetisch inventiert worden. Das Knospenmaterial wurde mir von der Bayerischen Landesanstalt für Forstliche Saat- und Pflanzenzucht Teisendorf, der FVA Freiburg und der FVA Rheinland-Pfalz zur Verfügung gestellt.

\subsection{Kartierung des Versuchsbestandes}

Eine konservative Methode in Form terrestrischer Vermessungsarbeiten mit Maßband, Bussole, Theodolit etc. kam für die Winterlindenpopulation in Schwiegershausen nicht in Betracht, da:

- der 40,2 ha große Versuchsbestand Ausmaße von ca. 600 x 1000 m besitzt und die maximalen Abstände zwischen den Linden sehr groß sein können.

- die 141 Linden über insgesamt 40,2 ha, teilweise stark verstreut, in Mischung mit anderen Baumarten stehen.

- der Bestand topographisch uneinheitlich ist und terrestrische Vermessungsarbeiten erschwert.

- die Anzahl der Linden mit 141 Individuen zu groß ist, um alle Abstände der Linden voneinander zu bestimmen.

Diese Bedingungen schließen eine Vermessung mit oben genannten Methoden entweder von vornherein aus oder wären nicht nur zu arbeitsintensiv gewesen, sondern auch mit einer nicht einzukalkulierenden Ungenauigkeit der so gewonnenen Daten verbunden gewesen.

Während ca. zwei Wochen im Jahr hebt sich die Linde durch ihre intensive und alle Populationsmitglieder umfassende Blüte deutlich in Form weißlich erscheinender Kronen von den übrigen Baumarten ab. Aufgrund dieses Sachverhaltes wurde die Idee entwickelt, diese Besonderheit mittels Luftbildaufnahmen festzuhalten, die Luftbildaufnahmen zu digitalisieren und mit Hilfe spezieller Computerprogramme auszuwerten. 
Mit Hilfe zweier technischer Angestellten des Instituts für Forstgenetik und der Leihgabe eines Theodoliten des Instituts für Forsteinrichtung der Universität Göttingen wurden rund um den Versuchsbestand alle 50 Meter Vermessungspunkte gesetzt. Die Verbindungslinien zwischen den Punkten weisen einen Winkel von $180^{\circ}$ oder $90^{\circ}$ zueinander auf und ergeben somit ein Gitternetz über den Versuchsbestand. Diese Vermessungspunkte wurden mit weißen Eimern und roten Röhren auf einer Fläche von ca. einem $\mathrm{m}^{2}$ markiert, um sie auf den Luftbildaufnahmen sichtbar zu machen.

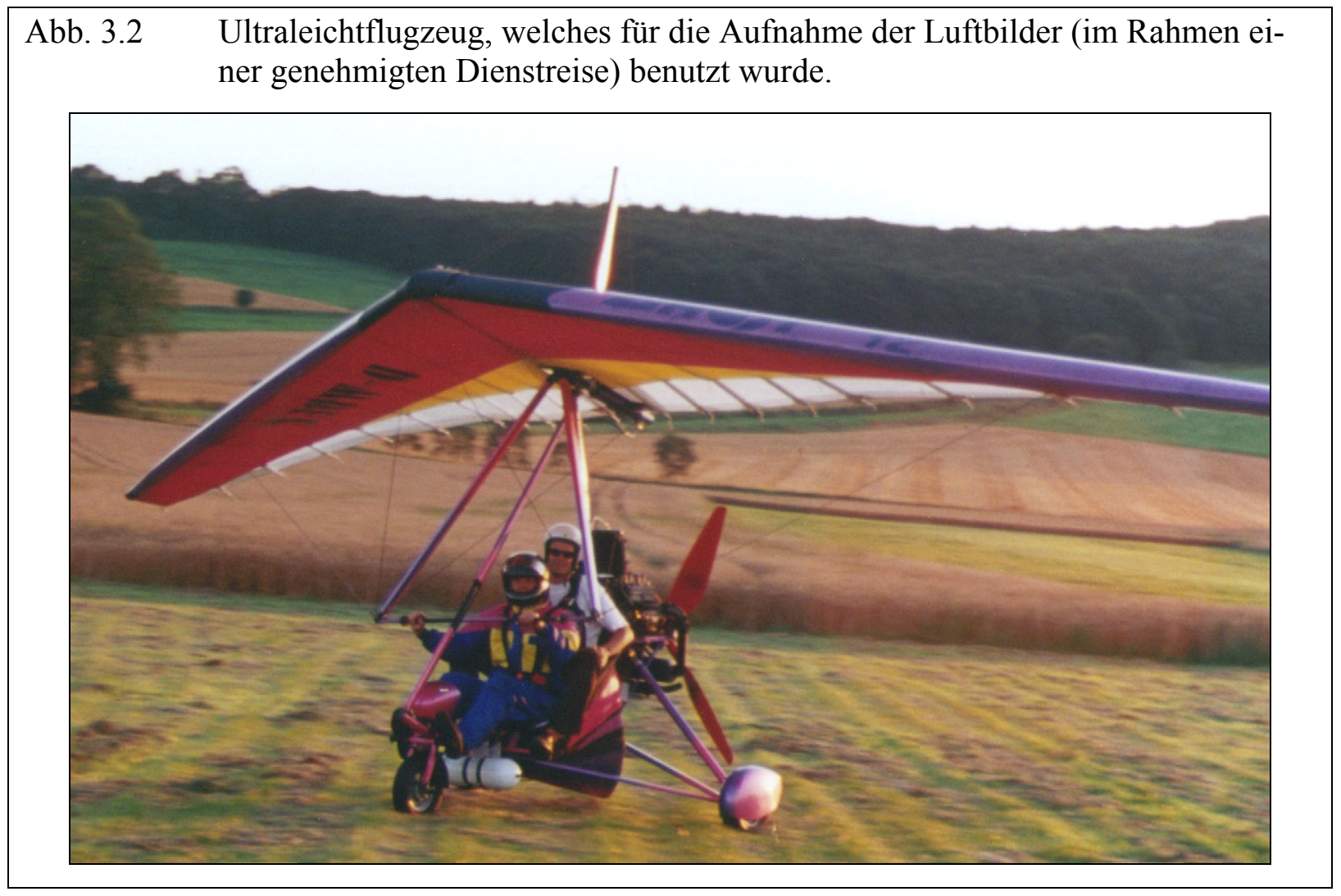

Der Bestand wurde während der Blühperiode der Linde mit einem zweisitzigen Ultraleichtflugzeug (s. o.) überflogen und aus einer Höhe von ca. $1800 \mathrm{~m}$ mit einer handelsüblichen Spiegelreflexkamera fotografiert. Das folgende Foto wurde für die weitere Verarbeitung und Auswertung ausgewählt. 


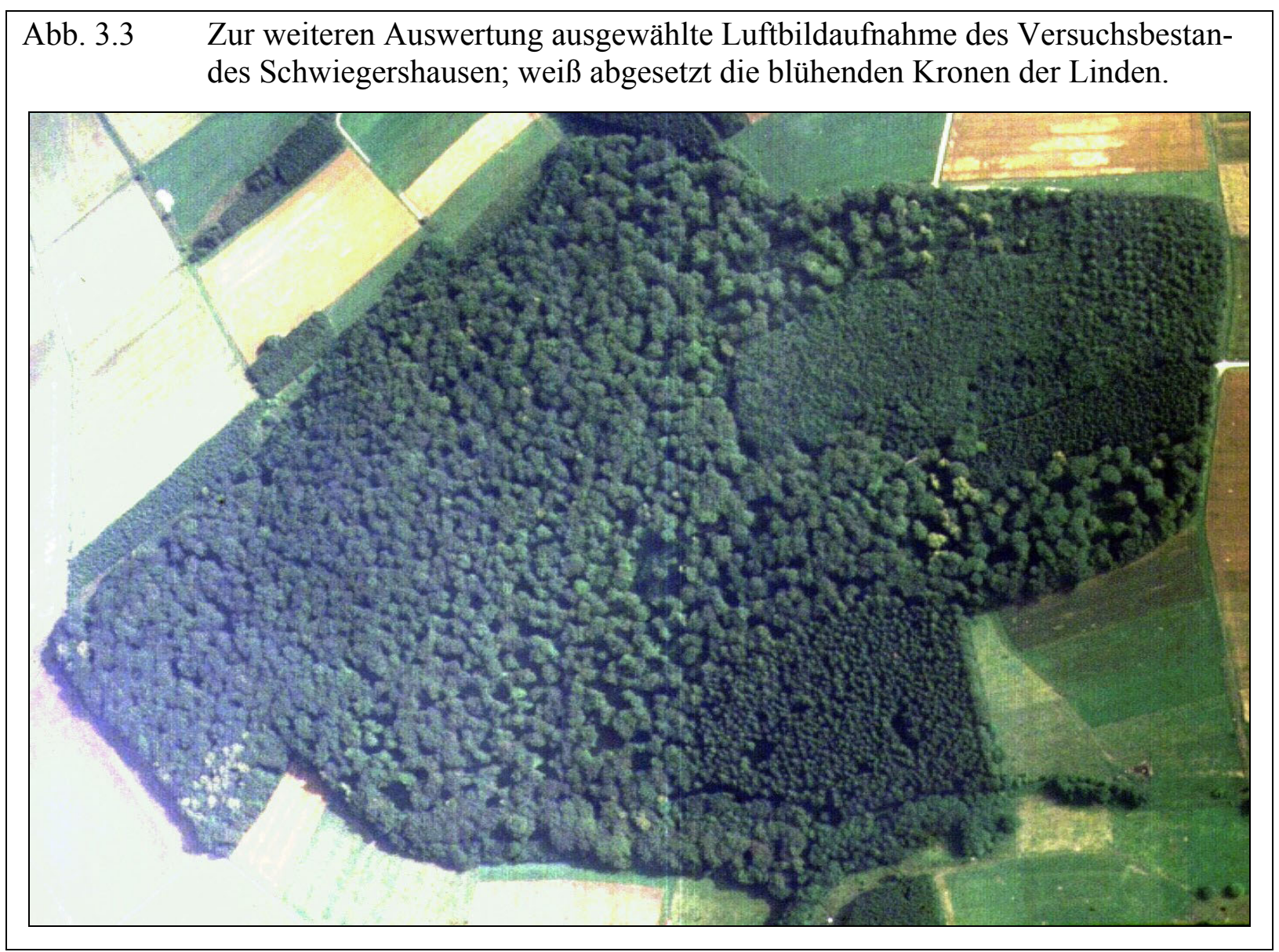

Die Auswertung der Luftbildaufnahmen mit Hilfe eines Großrechners und des Programms Erdas.imagine 8.2 erfolgte im Institut für Forsteinrichtung der Universität Göttingen. Über Erdas.imagine 8.2 wurde das Bild entzerrt und über die Vermessungspunkte ein 50x50 m Gitternetz gelegt (Abb. 3.4). 


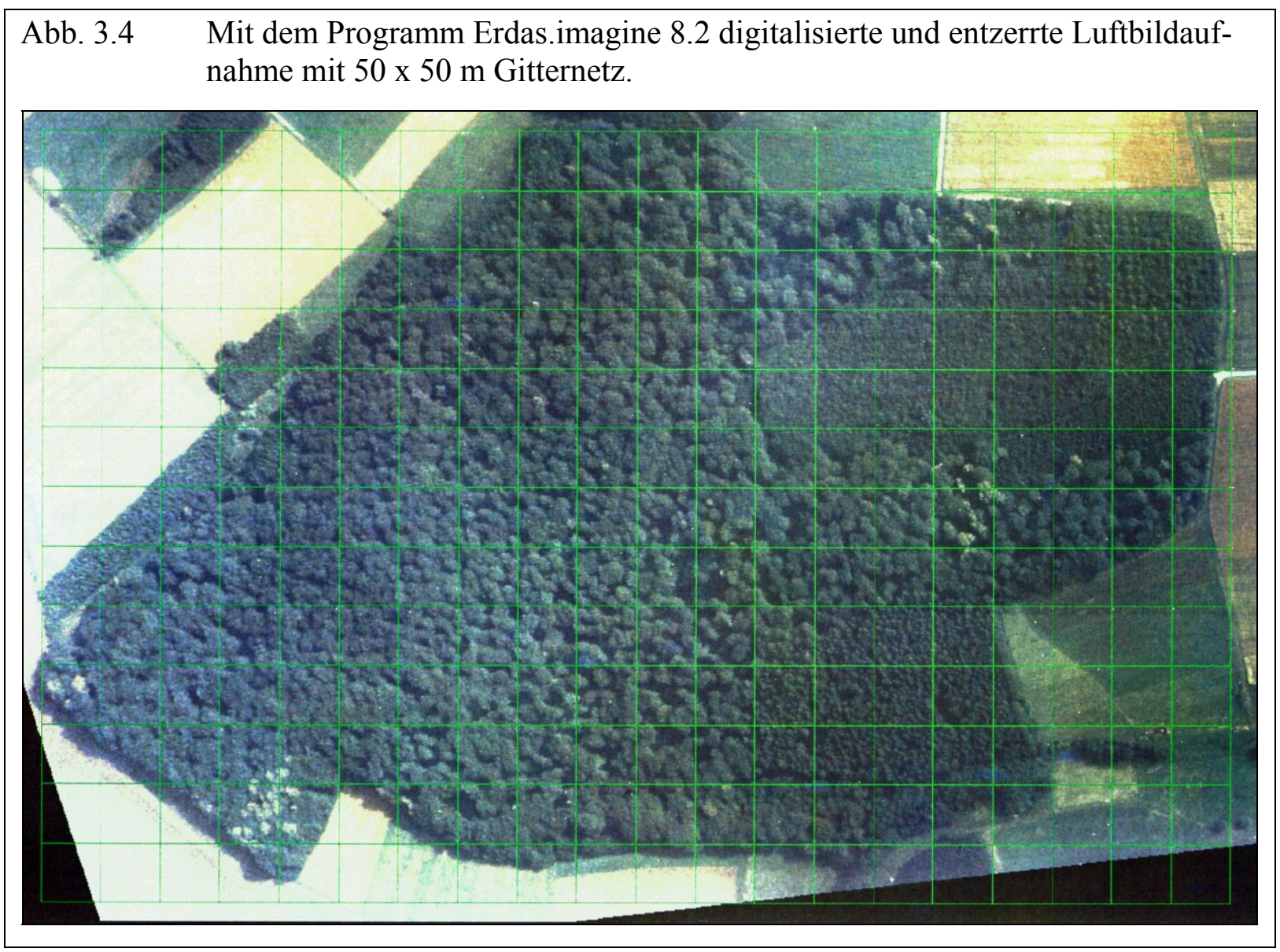

Der mit Erdas.imagine 8.2 berechnete Meßfehler bei den Vermessungsarbeiten beträgt weniger als einen Meter auf $50 \mathrm{~m}$ und ist damit für die Bestimmung von Pollentransportweiten mehr als akzeptabel. Auf der digitalen Karte kann nun per Mausklick die Entfernung zweier oder mehrerer Punkte (und damit auch zweier Linden) bestimmt werden bzw. aus der Datenbank eine Entfernungsmatrix generiert werden.

Zudem ermöglicht das Programm eine Berechnung des in der Blüte stehenden Kronenraums in $\mathrm{m}^{2}$ und die Schätzung der Blühintensität bzw. des damit korrelierten Pollenbeitrags der einzelnen Linden (s. Kap. 3.9.2.4). Die letzte Stufe der Auswertung wird in Abb. 3.5 dokumentiert. Zu sehen sind die Umrisse des Versuchsbestandes und der blühenden Kronenflächen der Linden. 


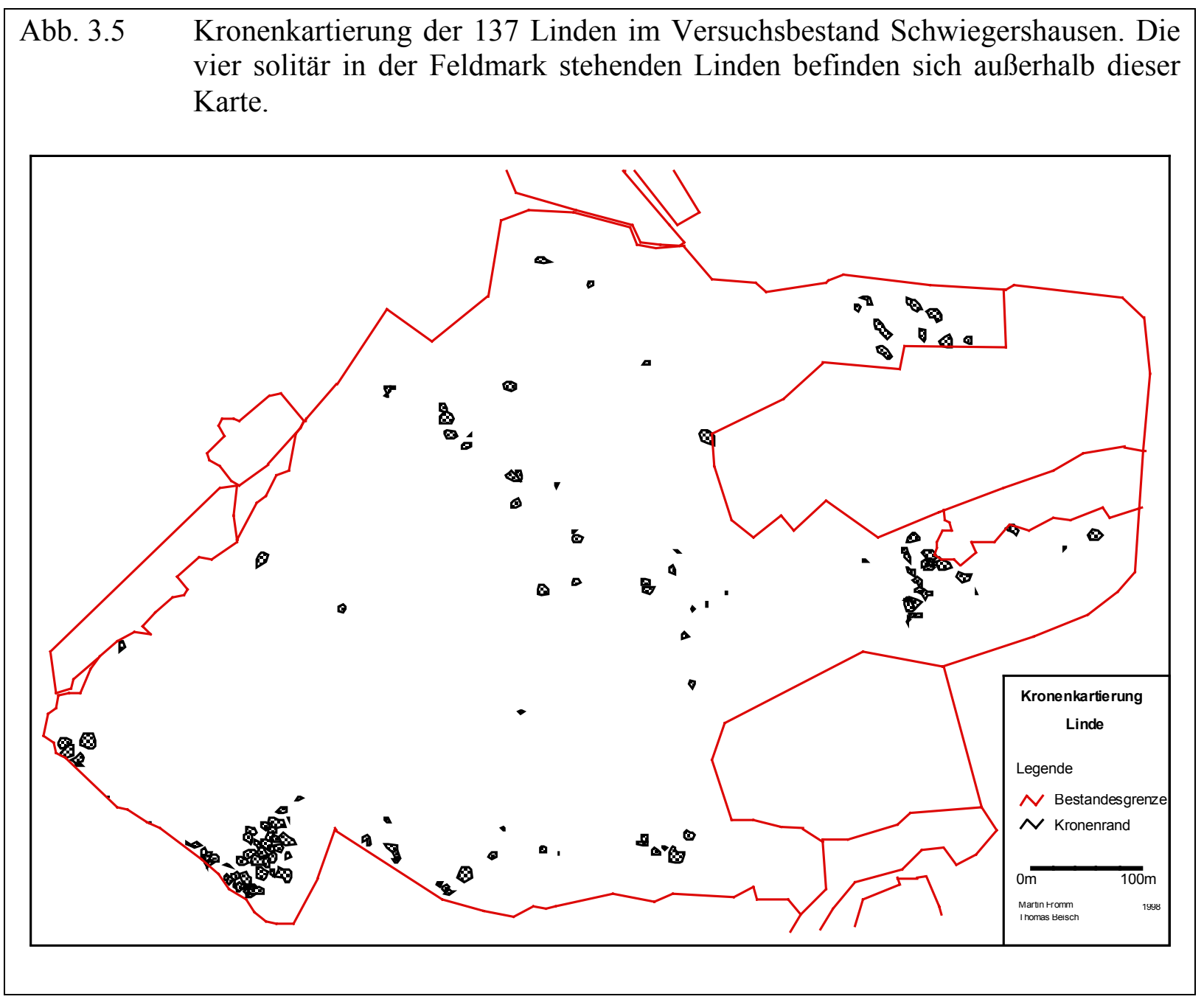

Einen detaillierten Überblick mit Angabe der Baumnummern geben die am Ende der Arbeit beigefügten Karten 1 bis 3.

\subsection{Isoenzyme als genetische Marker}

Bei Anwendung der Elektrophoresetechnik der bislang am Institut für Forstgenetik zahlreich untersuchten Baumarten konnte für die Linde keine befriedigenden Ergebnisse erzielt werden. Erst eine ausgedehnte experimentelle Laborphase führte letztendlich zu den gewünschten Resultaten, die eine Routineuntersuchung des gesammelten Probenmaterials erlaubten.

Hilfreich war ein dreitägiges Praktikum bei Herrn Dr. Maurer an der Forstlichen Versuchsanstalt Rheinland-Pfalz in Trippstadt. Freundlicherweise stellte Dr. Maurer mir die bis dahin erarbeiteten Rezepturen zur Verfügung (s. a. MAURER und TABEL 1995c). Für einige Enzymsysteme war die Elektrophoresemethodik nur geringfügig zu verändern; für den überwiegenden Teil der Enzymsysteme mußte die Methodik jedoch stark modifiziert werden.

Die Linde stellt auch deshalb besondere Anforderungen an die Methodik, weil sie einen hexaploiden Chromosomensatz besitzt $(n=41)$. Dies hat zur Folge, daß bei den meisten Enzym- 
systemen eine erhöhte Anzahl von Genloci aktiv sind. So hat das Enzymsystem PGM (Phosphoglucomutase) bei diploiden Pflanzen in der Regel zwei kontrollierende Genloci, bei der Linde hingegen vier, das Enzymsystem PGI (Phosphoglucose-Isomerase) drei statt zwei und so fort (s. Tab. 3.1). Die von diesen Genloci kontrollierten Zonen der Zymogramme müssen gut voneinander getrennt sein, um eine sichere Interpretation der Enzymmuster zu gewährleisten.

In Tab. 3.1 sind alle getesteten Enzymsysteme aufgeführt. Fett gedruckt sind die Systeme, die letztendlich für die genetische Inventur der Altbäume und Nachkommen verwendet wurden. Bei einigen Systemen ließen sich trotz umfangreicher Versuchsreihen keine befriedigenden Ergebnisse erzielen. Es wurden neben den aufgeführten Trennsystemen auch weitreichende Versuche mit den Trennsystemen Tris-Citrat und Poulik durchgeführt. In der Tab. 3.1 sind nur die Trennsysteme aufgeführt, die nach meinem Befinden die besten Ergebnisse für die jeweiligen Enzymsysteme geliefert haben. Bei den Systemen mit verbesserungswürdiger Methodik sind teilweise gute, aber nicht konstante Ergebnisse erzielt worden. Bei den Enzymsystemen 6-PGDH und GOT ließen sich überlappende Zonen nicht trennen; bei ACO und ADH wurden gute Ergebnisse bei der Verwendung von Blattmaterial erzielt, in den Samen war die Enzymaktivität hingegen sehr schwach. 
Tab. 3.1 Untersuchte Enzymsysteme bei Linde. Die fett gedruckten Enzymsysteme wurden für die genetische Inventur der Altbäume und Nachkommen verwendet. Trennsysteme: Ashton, Histidin-Citrat (H.-C.) und Tris-Histidin (T.-H.).

\begin{tabular}{|c|c|c|c|c|c|}
\hline $\begin{array}{l}\text { Enzymsystem } \\
\text { (E.C.-Nr.) }\end{array}$ & Abkürzung & $\begin{array}{l}\text { Trenn- } \\
\text { system }\end{array}$ & $\begin{array}{l}\text { Stand der } \\
\text { Methodik }\end{array}$ & $\begin{array}{l}\text { Anzahl } \\
\text { Genloci }\end{array}$ & $\begin{array}{l}\text { Isoenzym- } \\
\text { variation }\end{array}$ \\
\hline $\begin{array}{l}\text { Aconitase } \\
\text { (E.C. } 4.2 .1 .3)\end{array}$ & $\mathrm{ACO}$ & Ashton & gut & mind. 2 & hoch \\
\hline $\begin{array}{l}\text { Aminopeptidasen } \\
\text { (E.C. 3.4.11.1) }\end{array}$ & AP & Ashton/H.-C. & gut & 4 & hoch \\
\hline $\begin{array}{l}\text { Alkohol- Dehydrogenase } \\
\text { (E.C. 1.1.1.1) }\end{array}$ & ADH & & gut & 2 & gering \\
\hline $\begin{array}{l}\text { Esterase } \\
\text { (E.C. 3.1.1.1) }\end{array}$ & EST & Ashton & schlecht & & \\
\hline $\begin{array}{l}\text { Formiat-Dehydrogenase } \\
\text { (E.C. } 1.2 .1 .2)\end{array}$ & FDH & Ashton & gut & 1 & gering \\
\hline $\begin{array}{l}\text { Glucose-6-Phosphat-Dehydrogenase } \\
\text { (E.C. 1.1.1.49) }\end{array}$ & G-6-PGDH & T.-H. & verbess. w. & mind.1 & mittel \\
\hline $\begin{array}{l}\text { Glutamat-Dehydrogenase } \\
\text { (E.C. 1.4.1.3.) }\end{array}$ & GDH & T.-H. & verbess. w. & mind.1 & gering \\
\hline $\begin{array}{l}\text { Glutathion-Reduktase } \\
\text { (E.C. 1.6.4.2) }\end{array}$ & GRD & T.-H. & verbess. w. & mind.1 & gering \\
\hline $\begin{array}{l}\text { Glutamat-Oxalacetat-Transaminase } \\
\text { (E.C. 2.6.1.1) }\end{array}$ & GOT & Ashton & gut & 2 & mittel \\
\hline $\begin{array}{l}\text { Isocitrat-Dehydrogenase } \\
\text { (E.C. } 1.1 .1 .42 \text { ) }\end{array}$ & IDH & H.-C. & gut & 1 & gering \\
\hline $\begin{array}{l}\text { Malic-Enzym } \\
\text { (E.C. } 1 \cdot 1 \cdot 1 \cdot 40 \text { ) }\end{array}$ & ME & H.-C. & verbess. w. & 2 & gering \\
\hline $\begin{array}{l}\text { Malat-Dehydrogenase } \\
\text { (E.C. } 1.1 .1 .37 \text { ) }\end{array}$ & MDH & H.-C. & gut & 4 & gering \\
\hline $\begin{array}{l}\text { Menadion-Reduktase } \\
\text { (E.C. } 1.6 .99 .2 \text { ) }\end{array}$ & MNR & H.-C. & gut & 1 & gering \\
\hline $\begin{array}{l}\text { NADH-Dehydrogenase } \\
\text { (E.C. } 1.6 .99 .3 \text { ) }\end{array}$ & $\mathrm{NDH}$ & & verbess. w. & 2 & gering \\
\hline $\begin{array}{l}\text { Phosphoglucose-Isomerase } \\
\text { (E.C. 5.3.1.9) }\end{array}$ & PGI & Ashton & gut & 3 & hoch \\
\hline $\begin{array}{l}\text { Phosphoglucomutase } \\
\text { (E.C. 2.7.5.1) }\end{array}$ & PGM & Ashton & gut & 4 & hoch \\
\hline $\begin{array}{l}\text { Saure Phosphatase } \\
\text { (E.C. } 3.1 .3 .2 \text { ) }\end{array}$ & SAP & & schlecht & & \\
\hline $\begin{array}{l}\text { Shikimat-Dehydrogenase } \\
\text { (E.C. } 1.1 .1 .25)\end{array}$ & SKDH & H.-C. & gut & 2 & hoch \\
\hline $\begin{array}{l}\text { 6-Phosphogluconat-Dehydrogenase } \\
\text { (E.C. 1.1.1.44) }\end{array}$ & 6-PGDH & H.-C. & gut & mind. 2 & mittel \\
\hline
\end{tabular}

Samen zeigten mit Ausnahme von ACO, ADH und SKDH eine höhere Enzymaktivität als Blattmaterial. Eine Enzymextraktion aus Samen erwies sich als unproblematisch. Die Blätter der Winter- und Sommerlinde hingegen enthalten viele Lipide, Saccharide und Phenole, die eine Extraktion der Enzyme aus diesem Gewebe erschwerten oder gar verhinderten. Auch der Einsatz von Mercaptoethanol im Extraktionspuffer brachte nicht den gewünschten Erfolg. Generell konnte bei den Blättern/Knospen der Sommerlinde bei gleicher Extraktionsmethode 
eine höhere Enzymkonzentration als bei der Winterlinde festgestellt werden. Frisches Blattmaterial zeigte eine höhere Enzymaktivität als tiefgefrorenes Material. Waren frisch ausgetriebene Blätter verfügbar, wurden diese bevorzugt für die Elektrophorese verwendet. Allgemein zeigten die Blattproben der einzelnen Bäume im selben ontogenetischen Stadium große individuelle Unterschiede von Lipid-, Saccharid- und Phenolgehalten. Die Blätter bzw. Knospen von Jungpflanzen (aus den Keimungsversuchen) zeigten durchweg eine schlechtere Enzymaktivität und noch höhere Gehalte an Inhaltsstoffen. Die Zonen PGM-A und -B konnten nicht ausgewertetet werden und bei den meisten Enzymsystemen war eine Interpretation der Zymogramme schwierig.

Bei der Bearbeitung der Proben wurde eine möglichst hohe Enzymkonzentration des Extraktes angestrebt. Deshalb wurde genau die Menge an Extraktionspuffer hinzugegeben, die ausreichte, um die Chromotographiepapierblättchen zu sättigen.

Für Blätter, Samen und sich kurz vor dem Austreiben befindliche Knospen wurde ein einheitlicher Extraktionspuffer verwendet:

\section{Extraktionspuffer}

$\begin{array}{lr}\mathrm{H}_{2} 0 \text { bidest } & 10 \mathrm{ml} \\ \text { Tris } & 97 \mathrm{mg} \\ \text { Saccharose } & 1 \mathrm{~g} \\ \text { PVP } 15 & 300 \mathrm{mg} \\ \text { EDTA } & 15 \mathrm{mg} \\ \text { BSA } & 10 \mathrm{mg} \\ \text { DTT } & 30 \mathrm{mg}\end{array}$

Mit $\mathrm{HCl}$ auf $\mathrm{pH}$ 7,5 titrieren 
Tab. 3.2 Zusammensetzung der Stärkegele und Laufbedingungen der im Routineverfahren verwendeten Trennsysteme.

\begin{tabular}{|l|l|l|l|}
\hline Elektrodenpuffer & Stärkegel & Laufbedingungen & Enzymsysteme \\
\hline Ashton pH 8,1 & Ashton pH 8,1 & $40 \mathrm{~mA}, 17 \mathrm{~h}$ & FDH \\
& mit 10\% E.-Puffer & oder & LAP \\
& $10 \%$ Stärke & $80 \mathrm{~mA}, 6 \mathrm{~h}$ & PGM \\
& $2,5 \%$ Urea & & PGI \\
& $0,03 \%$ EDTA & & \\
\hline Histidin-Citrat pH 6,2 & Histidin-Maleat pH 6,2 & $40 \mathrm{~mA}, 17 \mathrm{~h}$ & MDH \\
& G.-Puffer : bidest 1:3 & max. 250 V & MNR \\
& $10,7 \%$ Stärke & oder & IDH \\
& $2,7 \%$ Urea & $80 \mathrm{~mA}, 6 \mathrm{~h}$ & SKDH \\
& $0,07 \%$ EDTA & & \\
& $4 \%$ Saccharose & & \\
\hline Histidin-Citrat pH 6,7 & Histidin-Maleat pH 6,2 & $30 \mathrm{~mA}, 17 \mathrm{~h}$ & LAP \\
& G.-Puffer : bidest $1: 7$ & max. 250 V & ACO \\
& $10,7 \%$ Stärke & oder & \\
& $2,7 \%$ Urea & $70 \mathrm{~mA}, 6 \mathrm{~h}$ & \\
& $0,07 \%$ EDTA & & \\
& $4 \%$ Saccharose & & \\
\hline
\end{tabular}

Alle Stärkegele wurden in der Mikrowelle gekocht.

Ist keine Artbestimmung, sondern allein die Untersuchung von Winterlindenmaterial vorgesehen, kann auf die Enzymsysteme IDH und ACO verzichtet werden, da diese bei der Winterlinde keine auswertbare Variation zeigen. Somit kann beim Histidin-Citrat-Gel pH 6,2 das Enzymsystem IDH ohne Weiteres durch LAP ersetzt werden und für die Untersuchung der übrigen Enzymsysteme werden nur zwei Stärkegele benötigt.

Zum Anfärben der Enzyme wurden folgende Färbelösungen verwendet: 
Tab. 3.3 Zusammensetzung der Färbelösungen bei Extraktion aus Samengewebe. Bei Extraktion aus Blattgewebe sind die Substratmengen nach Bedarf zu erhöhen.

\begin{tabular}{|c|c|c|c|c|c|c|}
\hline $\begin{array}{l}\text { Enzym } \\
\text { system }\end{array}$ & $\begin{array}{l}\text { Vorpuffer } \\
(70 \mathrm{ml})\end{array}$ & Substrat/Enzym & Koenzym & Farbstoff & $\begin{array}{l}\text { Elektronen } \\
\text { transport }\end{array}$ & $\begin{array}{l}\text { Metall- } \\
\text { ionen }\end{array}$ \\
\hline$\overline{\mathbf{A A P}}$ & $\begin{array}{l}\text { Tris-Maleat } \\
\text { pH } 6.0\end{array}$ & $\begin{array}{l}\text { L-Alanin- } \beta \text {-Naphtylamide } \\
80 \mathrm{mg}\end{array}$ & & $\begin{array}{l}\text { Fast Black K } \\
30 \mathrm{mg}\end{array}$ & & \\
\hline FDH & $\begin{array}{l}\text { Tris-HCl } \\
\mathrm{pH} 7.0\end{array}$ & $\begin{array}{l}\text { Na-Formiat } \\
1 \mathrm{~g}\end{array}$ & $\begin{array}{l}\text { NAD } \\
20 \mathrm{mg}\end{array}$ & $\begin{array}{l}\text { MTT } \\
20 \mathrm{mg}\end{array}$ & $\begin{array}{l}\text { PMS } \\
3 \mathrm{mg}\end{array}$ & \\
\hline LAP & $\begin{array}{l}\text { Tris-Maleat } \\
\text { pH } 5.4\end{array}$ & $\begin{array}{l}\text { L-Leucin- } \beta \text {-Naphtylamide } \\
40 \mathrm{mg}\end{array}$ & & $\begin{array}{l}\text { Fast Black K } \\
20 \mathrm{mg}\end{array}$ & & \\
\hline MDH & $\begin{array}{l}\text { Tris-HCl } \\
\text { pH } 8.0\end{array}$ & L-Malic.acid. Na-salt & $\begin{array}{l}\text { NAD } \\
16 \mathrm{mg}\end{array}$ & $\begin{array}{l}\text { MTT } \\
15 \mathrm{mg}\end{array}$ & $\begin{array}{l}\text { PMS } \\
2 \mathrm{mg}\end{array}$ & $\begin{array}{l}\mathrm{MgCl} 2 \\
100 \mathrm{mg}\end{array}$ \\
\hline MNR & $\begin{array}{l}\text { Tris-HCl } \\
\text { pH } 8.0\end{array}$ & $\begin{array}{l}\text { Menadion } \\
75 \mathrm{mg}\end{array}$ & $\begin{array}{l}\text { NADH } \\
30 \mathrm{mg}\end{array}$ & $\begin{array}{l}\text { MTT } \\
15 \mathrm{mg}\end{array}$ & & \\
\hline PGI & $\begin{array}{l}\text { Tris-HCl } \\
\text { pH } 8.0\end{array}$ & $\begin{array}{l}\text { Fructose-6-Phosphat } \\
25 \text { mg + Glucose-6-Phosphat- } \\
\text { dehydrogenase } 20 \text { Units }\end{array}$ & $\begin{array}{l}\text { NADP } \\
30 \mathrm{mg}\end{array}$ & $\begin{array}{l}\text { MTT } \\
15 \mathrm{mg}\end{array}$ & $\begin{array}{l}\text { PMS } \\
2 \mathrm{mg}\end{array}$ & $\begin{array}{l}\mathrm{MgCl} 2 \\
100 \mathrm{mg}\end{array}$ \\
\hline PGM & $\begin{array}{l}\text { Tris-HCl } \\
\text { pH } 8.0\end{array}$ & $\begin{array}{l}\text { a-D-Glucose-1-Phosphat } \\
100 \mathrm{mg}+\text { Glucose-6-Phosphat- } \\
\text { dehydrogenase } 20 \text { Units }\end{array}$ & $\begin{array}{l}\text { NADP } \\
30 \mathrm{mg}\end{array}$ & $\begin{array}{l}\text { MTT } \\
15 \mathrm{mg}\end{array}$ & $\begin{array}{l}\text { PMS } \\
2 \mathrm{mg}\end{array}$ & $\begin{array}{l}\mathrm{MgCl}_{2} \\
100 \mathrm{mg}\end{array}$ \\
\hline SKDH & $\begin{array}{l}\text { Tris-HCl } \\
\mathrm{pH} 8.5\end{array}$ & $\begin{array}{l}\text { Shikimisäure } \\
80 \mathrm{mg}\end{array}$ & $\begin{array}{l}\text { NADP } \\
30 \mathrm{mg}\end{array}$ & $\begin{array}{l}\text { MTT } \\
15 \mathrm{mg}\end{array}$ & $\begin{array}{l}\text { PMS } \\
2 \mathrm{mg}\end{array}$ & \\
\hline
\end{tabular}

\subsection{Datenanalyse}

Die Berechnung der genetischen Variationsparameter erfolgte mit dem Programm GSED von GILLET (1994). Darüber hinausreichende Auswertungen und Berechnungen (z. B. lineare Regressionsanalysen) wurden mit dem Tabellenkalkulationsprogramm MS EXCEL 7.0 durchgeführt.

\subsubsection{Statistische Prüfung}

Falls nicht anders angegeben, wird in dieser Arbeit für alle Tests zweier Stichproben die konventionelle Methode des Pearson'schen goodness-of-fit-Test angewendet (Chi²-Test). Er prüft auf der Basis der $\mathrm{Chi}^{2}$-Verteilung die Wahrscheinlichkeit dafür, daß die betrachteten Stichproben einer gemeinsamen Grundgesamtheit entstammen.

Die Prüfgröße bezeichnet bei den statistischen Testverfahren die Diskrepanz zwischen dem Modell (Verteilungsfunktion der $\mathrm{Chi}^{2}$-Verteilung) und der Beobachtung (Stichprobe).

$$
X^{2}=\sum_{i} \frac{\left(x_{i}-E\left(x_{i}\right)\right)^{2}}{E\left(x_{i}\right)}
$$


Unter der Bedingung, daß weniger als $20 \%$ der Erwartungswerte kleiner als 5 und keiner der Erwartungswerte kleiner als 1 ist, ist die Approximation der Beobachtung mittels der Prüfgröße an die $\mathrm{Chi}^{2}$-Verteilung hinreichend genau (HARTUNG 1989).

Insbesondere für Verteilungen mit geringeren Häufigkeiten wird alternativ zum $\mathrm{Chi}^{2}$-Test der Likelihood-ratio-Test (auch G-Test genannt) verwendet. Als Prüfgröße G wird die doppelte, über alle Merkmalsausprägungen gebildete Summe aus der Beobachtung multipliziert mit der Differenz zwischen dem Logarithmus der Beobachtung und dem Logarithmus des Erwartungswertes verwendet.

$$
\mathrm{G}=2 * \sum_{\mathrm{i}} \mathrm{x}_{\mathrm{i}} *\left(\ln \mathrm{x}_{\mathrm{i}}-\ln \mathrm{E}\left(\mathrm{x}_{\mathrm{i}}\right)\right)
$$

Im Folgenden ist ein Signifikanzniveau mit einer Irrtumswahrscheinlichkeit von $5 \%$ mit *, von $1 \%$ mit ** und von $0,1 \%$ mit *** gekennzeichnet. Unterscheiden sich zwei Verteilungen nicht signifikant, wird dies nicht explizit erwähnt.

\subsubsection{Genetische Parameter}

\subsubsection{Variationsparameter}

\section{Diversität $v$}

Die Diversität v (GREgORIUS 1978, 1987; RoUTLEDGE 1979) nimmt eine Bewertung der auftretenden Merkmalsausprägungen nach ihrer Häufigkeit vor. Diese Bewertung ist über den Index a gesteuert. Für a $\mathrm{v}_{\mathrm{a}}=\left[\sum_{\mathrm{i}=1}^{\mathrm{n}} \mathrm{p}_{\mathrm{i}}^{\mathrm{a}}\right]^{1-\mathrm{a}}, 0<\mathrm{a} \neq 1$ $=0$ beschreibt die Diversität die Vielfalt, d. h. alle auftretenden Typen eines Merkmals, während für $\mathrm{a} \rightarrow \infty$ die Diversität gegen $\mathrm{v}_{\infty}=\mathrm{p}_{\max }^{-1}$, den Kehrwert der größten Typhäufigkeit, strebt. Die Steigung der für a $\rightarrow \infty$ monoton fallenden Funktion der Diversität wird mit zunehmender Abweichung von der Gleichverteilung größer.

\section{Heterozygotie $\mathbf{H}$}

Die Heterozyogtie ist ein Parameter, der aus der genotypischen Struktur abgeleitet wird. Er beschreibt als Heterozygotenanteil $\mathbf{H}_{\mathbf{a}}$ die Anzahl $\mathrm{H}_{\mathrm{a}}=\sum_{\mathrm{i}} \sum_{\mathrm{j}} \mathbf{P}_{\mathrm{ij}}^{(\mathrm{k})}, \mathrm{i} \neq \mathrm{j}$ von Individuen, welche an einem Genort k verschiedene Allele tragen (HATTEMER et al. 1993). 
Der Heterozygotiegrad beschreibt den Anteil heterozygoter Genorte eines Individuums. Liegen für n Individuen genetische Informationen an $\mathrm{k}$ Genorten voll$\mathrm{H}=\frac{1}{\mathrm{~m}} * \sum_{\mathrm{k}=1}^{\mathrm{m}} \mathrm{f}_{\mathrm{ij}}^{(\mathrm{k})} ; \quad \mathrm{f}_{\mathrm{ij}}=\left\{\begin{array}{ll}0 & \text { wenn } \mathrm{i}=\mathrm{j} \\ 1 & \text { wenn } \mathrm{i} \neq \mathrm{j}\end{array}\right\}$ ständig vor, dann stellt deren mittlerer Heterozygotiegrad den Mittelwert der Heterozygotenanteile dar.

\section{Hypothetisch gametische Multilocus-Diversität $v_{\text {gam }}$}

Unter Berücksichtigung der Häufigkeiten der auftretenden Merkmalsausprägungen an den untersuchten Genorten beschreibt die hypothetisch-gametische Multilocus-Diversität die Anzahl der Multilocus-Genotypen, die maximal in der nächsten Generation aus dem vorhandenen Genvorrat gebildet werden können.

\subsubsection{Differenzierung von Populationen}

Die bislang erwähnten Parameter dienten der Beschreibung einzelner Merkmalsverteilungen. Sie wurden aus den relativen Häufigkeiten einer Verteilung (Vielfalt, Diversität) oder der Abfolge relativer Häufigkeiten in einer Verteilung abgeleitet. Mit dem Parameter der Differenzierung werden verschiedene Verteilungen hinsichtlich der sie differenzierenden Informationen verglichen. Als Abstandsmaß wird der Abstand $\mathrm{d}_{0}$ verwendet, dessen Eigenschaften kurz dargestellt werden sollen.

\section{Genetischer Abstand d 0}

Der $\mathrm{d}_{0}$-Abstand mißt die absolute Differenz zwischen den relativen Typhäufigkeiten zweier Verteilungen (GREGORIUS 1974). Durch die Verwendung relativer Häufigkeiten ist der $\mathrm{d}_{0^{-}}$ Abstand auf den reellen Wertebereich zwischen Null und eins begrenzt. Damit erreicht der $\mathrm{d}_{0^{-}}$ Abstand dann sein Maximum $\left(\mathrm{d}_{0}=1\right)$, wenn die betrachteten Deme (z. B. Population, effektive Pollenwolken) keine der Merkmalsausprägungen gemeinsam haben. Er wird null, wenn beide Deme in der Anzahl der Typen und in ihren relativen Häufigkeiten übereinstimmen. Der $\mathrm{d}_{0}$-Abstand nimmt damit reelle, nichtnegative Werte an.

\section{Die genetische Differenzierung $D_{j}$}

Die Differenzierung ist ein Maß für den Unterschied zwischen mindestens zwei Verteilungen und baut auf dem $\mathrm{d}_{0}$-Abstand auf. Werden mehr als zwei Verteilungen verglichen, so werden n-1 Verteilungen

$\mathrm{D}_{\mathrm{j}}=\frac{1}{2} * \sum_{\mathrm{i}=1}^{\mathrm{n}_{\mathrm{k}}}\left|\mathrm{p}_{\mathrm{i}}^{(\mathrm{j})}-\overline{\mathrm{p}_{\mathrm{i}}^{(\mathrm{j})}}\right|$ des Kollektivs als Komplement der jeweils interessierenden Verteilung zusammengefaßt. Für die dargestellte allelische Differenzierung gibt $\mathrm{p}_{\mathrm{i}}^{(\mathrm{j})}$ die relative Häufigkeit des Allels i am k-ten Genort an, während $\overline{\mathrm{p}_{\mathrm{i}}^{(\mathrm{j})}}$ die relativen Allelhäufigkeiten im Komplement beschreibt. Innerhalb 
des Komplements werden die Wahrscheinlichkeiten der Typen aus den über die Populationsgröße gewichteten Häufigkeiten bestimmt (GREGORIUS 1985).

\section{Die Gesamtdifferenzierung $\delta_{\mathrm{T}}$}

Das Konzept der Differenzierung kann auch für die Messung der Variation innerhalb von Demen verwendet werden. Man betrachtet $\delta_{\mathrm{T}}=\frac{\mathrm{N}}{\mathrm{N}-1}\left(1-\sum_{\mathrm{i}} \mathrm{p}_{\mathrm{i}}^{2}\right)$ die genetischen Abstände einer Einheit (Individuum, Pollen etc.) zu seinem Komplement (GREGORIUS 1987). Diese Komplement besteht aus allen anderen Einheiten des Dems (Population, Pollenwolke etc.), wobei $\mathrm{N}$ den Umfang des Dems bezeichnet. Ist $\mathrm{N}$ unendlich groß und geht $\frac{\mathrm{N}}{\mathrm{N}-1}$ gegen unendlich, stimmt $\delta_{\mathrm{T}}$ mit der Diversität $v$ überein. Die beiden Parameter unterscheiden sich nur, wenn der Umfang eines Dems endlich ist.

\subsubsection{Vererbungsanalyse}

Um die klassische und aufwendige Methode der Vererbungsanalyse über kontrollierte Kreuzungen zu umgehen, entwickelten GILLET (1997) und GILLET und HATTEMER (1989) Verfahren, bei dem mittels Samen einzelner Bäume aus freier Abblüte eine Überprüfung der genetischen Kontrolle des Merkmals möglich ist. Bei regulärer Segregation der Eizellen und zufälliger Fusion der Gameten gibt ein heterozygoter Samenelter die Allele i und j im Verhältnis 1:1 an seine Samen weiter. Werden die Isoenzymallele zudem kodominant exprimiert, gelten nach GiLlet und HatTemER (1989) folgende Beziehungen für die Genotyphäufigkeiten in der Nachkommenschaft:

$\mathrm{N}_{\mathrm{ii}}+\mathrm{N}_{\mathrm{jj}}=\mathrm{N}_{\mathrm{ij}}$ und $\mathrm{N}_{\mathrm{ij}}=\mathrm{N}_{\mathrm{ik}}$

Die statistische Prüfung dieser Beziehungen wurde von GILLET (1997) in Verbindung mit der Schätzung der Allelhäufigkeiten in der Pollenwolke präzisiert, wie im nächsten Abschnitt beschrieben. 


\subsubsection{Schätzung allelischer Häufigkeiten von Pollenwolken}

Die allelische Struktur der Pollenwolke ${ }^{1}$ eines Samenelters über dessen Nachkommenschaft kann mit der Maximum-Likelihood-Methode von GILLET (1997) geschätzt werden. Betrachtet sei ein Genlocus mit Kodominanz als Genwirkungsmodus. Unter der Annahme von zufallsmäßiger Segregation der Allele unter den Eizellen eines heterozygoten Samenelters, Zufallsfusion der Eizellen mit dem Pollen in der Pollenwolke sowie Abwesenheit von Selektion unter den Zygoten beträgt die Maximum-Likelihood-Schätzung der Allelhäufigkeiten in der Pollenwolke:

$\hat{\mathrm{p}}^{\hat{\sigma}_{\mathrm{i}}}=\frac{\mathrm{N}_{\mathrm{ii}}}{\mathrm{N}} * \frac{\mathrm{N}_{\mathrm{ii}}+\mathrm{N}_{\mathrm{jj}}+\mathrm{N}_{\mathrm{ij}}}{\mathrm{N}_{\mathrm{ii}}+\mathrm{N}_{\mathrm{jj}}}, \quad \hat{\mathrm{p}}^{\hat{\sigma}_{\mathrm{j}}}=\frac{\mathrm{N}_{\mathrm{jj}}}{\mathrm{N}} * \frac{\mathrm{N}_{\mathrm{ii}}+\mathrm{N}_{\mathrm{jj}}+\mathrm{N}_{\mathrm{ij}}}{\mathrm{N}_{\mathrm{ii}}+\mathrm{N}_{\mathrm{jj}}} \quad$ und $\quad \hat{\mathrm{p}}^{\hat{\sigma}_{\mathrm{k}}}=\frac{\mathrm{N}_{\mathrm{ik}}+\mathrm{N}_{\mathrm{jk}}}{\mathrm{N}}$

$\mathrm{N}=$ Anzahl untersuchter Nachkommen

$\hat{\mathrm{p}}^{\hat{\sigma}}{ }_{i}, \hat{\mathrm{p}}^{\hat{\sigma}}{ }_{\mathrm{j}}, \hat{\mathrm{p}}^{\hat{\sigma}}{ }_{\mathrm{k}}=$ Häufigkeit des Allels $\mathrm{i}, \mathrm{j}$ und $\mathrm{k}$ in der Pollenwolke $(\mathrm{k} \neq \mathrm{i}, \mathrm{k} \neq \mathrm{j})$

$\mathrm{N}_{\mathrm{ii}}, \mathrm{N}_{\mathrm{jj}}, \mathrm{N}_{\mathrm{ij}}, \mathrm{N}_{\mathrm{ik}}$ und $\mathrm{N}_{\mathrm{jk}}=$ Anzahl der Homo - und Heterozygoten in der Nachkommenschaft, worin $\mathrm{k}$ ein nicht in den Sameneltern enthaltenes Allel bezeichnet

Diese Schätzung beschreibt diejenige Pollenwolke, welche die in den Samen des betrachteten Individuums auftretenden Genotyphäufigkeiten am besten erklärt. Hieraus lassen sich die erwarteten Häufigkeiten unter den Genotypen in den Samen berechnen als

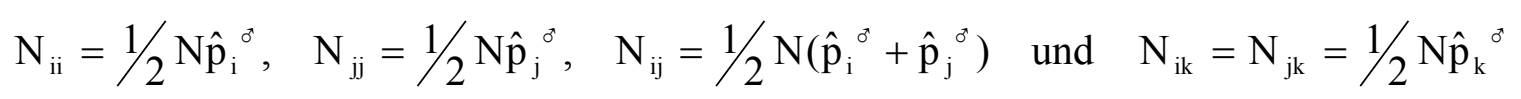

Eventuell vorhandene Abweichungen zwischen beobachteten und erwarteten Genotyphäufigkeiten werden mittels eines Anpassungtests ( $\mathrm{Chi}^{2}$ - bzw. G-Test) auf statistische Signifikanz überprüft. Ist die Abweichung signifikant, dann deutet dies auf das Nichtzutreffen mindestens einer der verwendeten Annahmen, einschließlich des Vererbungsmodus.

Wird hingegen auf die Annahme der regulären Segregation unter den Eizellen verzichtet, läßt sich nach GILLET (1997) eine gemeinsame Maximum-Likelihood-Schätzung für die Allelhäu-

\footnotetext{
1 Mit der Terminologie „Pollenwolke“ soll nicht der Eindruck erweckt werden, daß es sich im bildlichen Sinne um eine windverfrachtete Wolke von Pollen handelt. Der Begriff steht allgemein für effektiv gewordene Pollen; gleich welcher Art des Pollentransportes ihnen vorausgegangen ist.
} 
figkeiten unter den Eizellen und in der Pollenwolke als Lösung des folgenden Gleichungssystems analytisch ableiten:

$$
\begin{aligned}
& \mathrm{N}\left(\hat{\mathrm{p}}_{\mathrm{i}}{ }^{\odot}+\hat{\mathrm{p}}_{\mathrm{i}}{ }^{\circ}\right)=2 \mathrm{~N}_{\mathrm{ii}}+\mathrm{N}_{\mathrm{ij}}+\mathrm{N}_{\mathrm{ik}}
\end{aligned}
$$

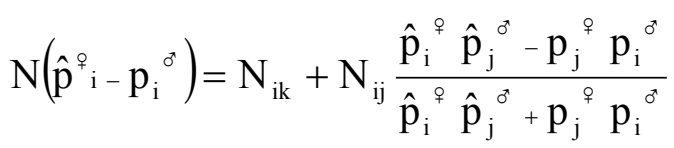

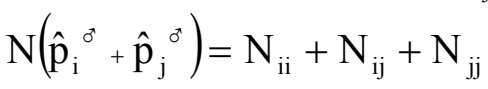

$$
\begin{aligned}
& \mathrm{Np}_{\mathrm{k}}{ }^{{ }^{3}}=\mathrm{N}_{\mathrm{ik}}+\mathrm{N}_{\mathrm{jk}}
\end{aligned}
$$

$\hat{\mathrm{p}}_{\mathrm{i}}{ }^{\circ}, \hat{\mathrm{p}}_{\mathrm{j}}^{\circ}=$ Häufigkeit des Allels $\mathrm{i}, \mathrm{j}$ unter den Eizellen $(\mathrm{i} \neq \mathrm{j})$

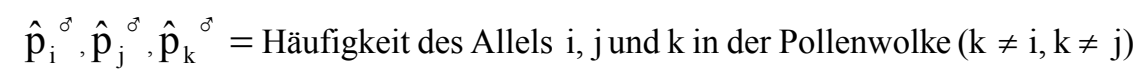

Aufgrund der Komplexität in der Darstellung der analytischen Lösung soll hier nur auf die entsprechende Formel in GILLET (1997) verwiesen werden. Wiederum ergeben sich aus den gemeinsam geschätzten Allelhäufigkeiten in den Eizellen und der Pollenwolke die erwarteten Genotyphäufigkeiten in den Nachkommen als:

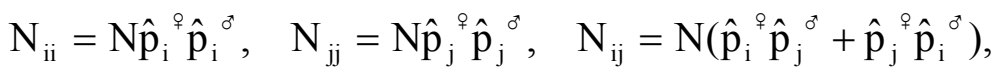

$$
\begin{aligned}
& \mathrm{N}_{\mathrm{ik}}=\mathrm{N} \hat{\mathrm{p}}_{\mathrm{i}}^{\circ} \hat{\mathrm{p}}_{\mathrm{k}}^{\delta^{\circ}} \text { und } \mathrm{N}_{\mathrm{ik}}=\mathrm{N} \hat{\mathrm{p}}_{\mathrm{j}}^{\circ} \hat{\mathrm{p}}_{\mathrm{k}}^{\sigma^{\circ}}
\end{aligned}
$$

Mit Hilfe eines Anpassungtests der beobachteten an die erwarteten Genotyphäufigkeiten wird das Zutreffen aller verwendeten Annahmen, einschließlich des Vererbungsmodus, zugleich getestet. Eine signifikante Abweichung deutet auf das Nichtzutreffen mindestens einer der Annahmen hin.

\subsection{Bestäubungsversuche}

Für die Durchführung der Bestäubungsversuche wurden die Randbäume Nr. 56, 64 und 65 ausgewählt. Die tief herabhängenden Äste ermöglichten eine Behandlung der Blüten in sechs Meter Höhe von einer Leiter aus. 


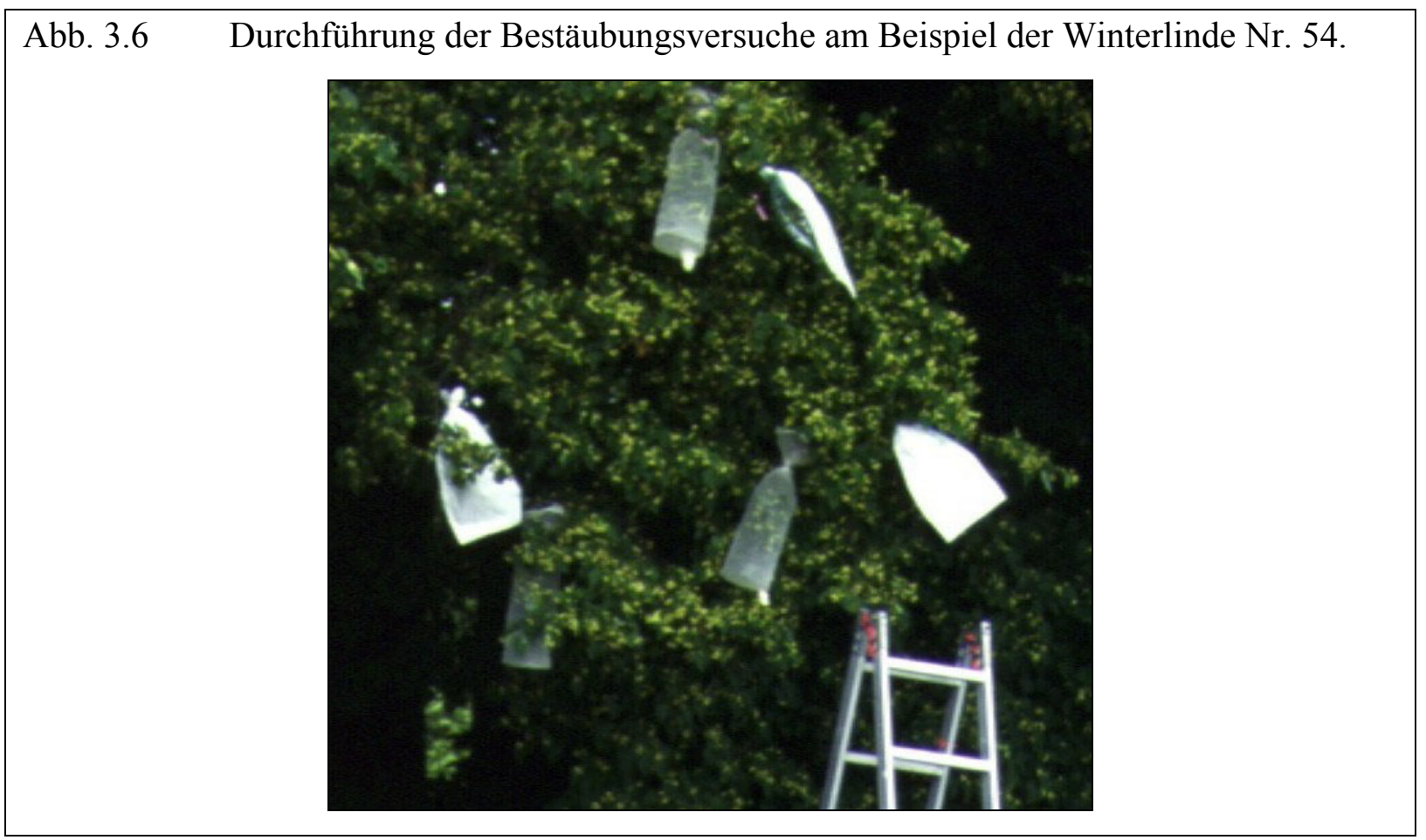

Eine Versuchsreihe setzt sich aus neun verschiedenen Behandlungen der Blüten zusammen und wurde auf jeden dieser drei Bäume angewendet.

Blütentragende Äste der drei Winterlinden wurden im Sommer 1995 wie folgt behandelt:

1. Tüte + unbehandelt

2. Tüte + emaskuliert

3. Tüte + emaskuliert + künstliche Bestäubung

4. Nylon + unbehandelt

5. Nylon + emaskuliert

6. Nylon + emaskuliert + künstliche Bestäubung

7. Frei + unbehandelt

8. Frei + emaskuliert

9. Frei + emaskuliert + künstliche Bestäubung

Das Überstreifen spezieller Tüten über den Ast isoliert die Blüten und unterbindet eine Bestäubung, sowohl durch Wind als auch durch Insekten. Die Verwendung von Nylongewebe, welches auf einer Drahthose aufgespannt war, schließt auf der einen Seite Insekten als Pollenvektoren aus, ermöglicht auf der anderen Seite aber eine Windbestäubung. Bei einer weiteren Versuchsreihe „frei“ werden keine Bestäubungsbarrieren eingesetzt und sowohl Wind- als auch Insektenbestäubung sind möglich. Die Emaskulation erfolgte durch die Entfernung sämt- 
licher Antheren einer Blüte. Auf diese Weise wird eine Bestäubung innerhalb ein und derselben Blüte und/oder zwischen benachbarten Blüten ausgeschlossen. Eine künstliche Bestäubung soll vergleichend die Effektivität oben genannter Pollenvektoren bestimmen.

Problematisch war das Ab- und Überstreifen der Tüten bzw. der Nylonkäfige, da in dieser Phase eine ungewollte Bestäubung nicht auszuschließen war, Insekten in diese gelangen und Beschädigungen am Versuchszweig und/oder am Material auftreten konnten. Zur Reduzierung dieser Risiken wurden die frisch entfalteten Blüten nur jeden zweiten Tag emaskuliert bzw. künstlich bestäubt. Ein möglicher Transport von Pollen durch Erschütterung wird angenommen.

Für die künstliche Bestäubung wurden Blüten unterschiedlicher Entwicklungsstadien anderer Winterlinden entnommen und gebündelt. Mit diesen Bündeln wurden die rezeptiven Narben des Versuchsbaumes betupft. Als Spenderbäume fungierten die Winterlinden Nr. 36, 62, 58, 69 und 72.

\subsection{Keimungsversuche}

Über die Keimungsversuche sollten die Auswirkungen von Selbst- und Fremdbefruchtung auf die Nachkommen untersucht werden.

Ein weiteres Ziel dieser Versuche ist die Beobachtung von Viabilitätsauslese im Entwicklungstadium vom Samen bis zur Jungpflanze. Dazu werden eingelagerte Samen der gleichen Stichprobe und die mehrjährigen Jungpflanzen untersucht und deren genetische Strukturen verglichen. Falls über diesen Vergleich der Nachkommenschaften eine Abnahme homozygoter Genotypen festgestellt werden kann, könnte zusammen mit Hilfe der Ergebnisse der Bestäubungsversuche eruiert werden, in welchem ontogenetischen Stadium die zu vermutende Inzucht wirksam wird.

Die Keimbeete wurden im Herbst 1995 angelegt. Zwei in der Feldmark isoliert stehende Winterlinden (Nr. F1 u. F3) wurden unter der Annahme beerntet, daß sie nur eingeschränkten Paarungskontakt zu anderen Winterlinden haben und ihre Nachkommen einen entsprechend hohen Selbstbefruchtungsanteil aufweisen. Vergleichend dazu wurden die Winterlinden Nr. 42 u. 82 aus dem Teil des Versuchsbestandes beerntet, der als Lindenreinbestand bezeichnet werden kann. Hier stehen über 45 Linden auf engstem Raum, was eine hohe Fremdbefruchtungsrate erwarten läßt. Nach ROHMEDER (1972) kann die bei der Winterlinde mögliche Keimhemmung durch eine Grünernte der Samen teilweise ausgeschaltet werden. Unter diesem Aspekt wurde mit der Beerntung der Bäume bereits im September 1995 begonnen. Die 
Bäume F1 und F2 wurden mit der Stangenschere und die Bäume 42 und 82 durch Besteigung mittels Steigeisen beerntet. Von jedem Baum wurden ca. 1000 Samen geworben.

Ein Keimbeet wurde im Versuchsbestand, also vor Ort, das andere im Gewächshaus angelegt. Die jeweils 200 Samen keimten im Gewächshaus in Styroporschachteln, welche mit speziell zubereiteter Pflanzenerde (sog. Einheitserde) gefüllt und regelmäßig gewässert wurden. Während der frostfreien Monate standen diese auf geschützten Freiflächen zwischen den Gewächshäusern. Im Versuchsbestand wurde in dem lindenreichen Bereich eine Fläche von vier $\mathrm{m}^{2}$ von Laub befreit und mit einem Zaun vor Wildverbiß geschützt. Zur Bekämpfung von Mäusen wurde Giftweizen auf die Fläche ausgebracht. Sameneinflug wird durch eine oberseitige Bespannung mit einem engmaschigen Kunststoffnetz verhindert. Abgesehen von der regelmäßigen Reinigung des Kunststoffnetzes von Laub blieb dieses Keimbeet sich selbst überlassen.

\subsection{Bestimmung von Polleneltern}

Ohne die Zuordnung von Polleneltern zu ihren Nachkommen ist eine direkte Herleitung von Transportweiten effektiver Pollen über genetische Marker nicht möglich (s. a. Kap. 3.11). Ist ein ausreichend großer Anteil Polleneltern identifizierbar, können auch Selbstbefruchtungsraten mit hoher Genauigkeit bestimmt werden.

Die dafür erforderliche Abstammungsrekonstruktion von Nachkommen ist erst durch die Etablierung genetischer Marker möglich geworden. Prinzipiell könnte der aus der Humanmedizin bekannte Begriff der Vaterschaftsanalyse übernommen werden. Da kosexuelle Pflanzen sowohl als „Vater“ als auch als „Mutter“ fungieren können, wird statt „Vater“ die Bezeichnung „Pollenelter“ und für „Mutter“ die Bezeichnung „Samenelter“ verwendet.

Für die Bestimmung von Polleneltern standen mehrere Verfahren zur Verfügung, die sich durch Art und Anzahl zu treffender Annahmen bzw. Simulationen unterscheiden. Zweck dieser Annahmen und Simulationen ist es, aus den gegebenen Daten einen höheren Informationsgehalt zu ziehen, d. h. den Anteil identifizierter (bzw. geschätzter) Polleneltern zu vergröBern. Allerdings birgt jede Annahme bzw. Simulation die Gefahr zusätzlicher Fehlerquellen.

\subsubsection{Das eindeutige Ausschlußverfahren}

Beim Ausschlußverfahren werden nur die Genotypstrukturen von Eltern und Nachkommen betrachtet. Vorausgesetzt wird eine Erfassung der Genotypstrukturen aller potentiellen Pol- 
leneltern, Segregation der Gameten (auch ungleichmäßige) und die Isolation der Population vor Pollenmigration von außen. Weitere Annahmen werden nicht gemacht.

Die Nachkommen der Lindenpopulation Schwiegershausen wurden einzelbaumweise beerntet, die Identität des Samenelters ist somit bekannt und nur die Bestimmung des Pollenelters ist von Interesse.

Durch den Vergleich genetischer Strukturen werden von allen potentiellen Polleneltern diejenigen ausgeschlossen, die aufgrund ihrer Genotypstruktur keinen Gameten erzeugen können, der bei Fusion mit den Eizellen des bekannten Samenelters zur Bildung des betreffenden Nachkommens geführt haben könnte. Werden dabei alle bis auf einen Pollenelter ausgeschlossen, ist dieser als Pollenelter eindeutig bestimmt. Verbleiben mehr als ein Pollenelter, ist eine eindeutige Bestimmung nicht möglich.

Über Isoenzymanalysen sind in der Regel Polleneltern nur zu einem geringen Prozentsatz eindeutig bestimmbar bzw. der Anteil nicht auszuschließender Polleneltern ist groß. Die Höhe des Prozentsatzes der eindeutigen Zuordnung von Polleneltern zu den Nachkommen hängt von mehreren Faktoren ab (s. a. ADAMS 1992, CHAKRABORTY et al. 1988); und zwar steigt die Wahrscheinlichkeit einer eindeutigen Bestimmung von Polleneltern mit:

- der Anzahl untersuchter polymorpher Genorte

- der Anzahl (kodominanter) Allele

- und deren Gleichverteilung an den betrachteten Genorten (Diversität v, s. Kap. 3.6.2.2)

Die Wahrscheinlichkeit einer eindeutigen Bestimmung von Polleneltern sinkt mit:

- steigender Anzahl potentieller Polleneltern

- höherem Heterozygotiegrad von Sameneltern und Nachkommen

- Uniformität der Population (geringes $\delta_{\mathrm{T}}$, s. Kap 3.6.2.2)

Ist ein Pollenelter einziger Träger eines seltenen Allels (sog. Markerbaum) und ist dieses Allel in den Nachkommen nachweisbar, ist eine eindeutige Bestimmung anhand nur eines Genortes möglich. Falls dies nicht der Fall ist, könnten nach Berechnungen von ADAMS (1992) für $90 \%$ der Nachkommen ein eindeutiger Pollenelter unter 25 potentiellen Polleneltern bestimmt werden, wenn 26 Genorte mit je zwei gleich häufigen Allelen $(v=2)$ zur Verfügung stünden. Der hohe Bedarf an polymorphen Genorten für eine befriedigende Bestimmung von Polleneltern über das eindeutige Ausschlußverfahren wird von ADAMS (1992) anhand einer Abbildung veranschaulicht, welche samt Beschriftung als Abb. 3.7 übernommen wurde (s. aber auch CHAKRABORTY et al. 1988). 


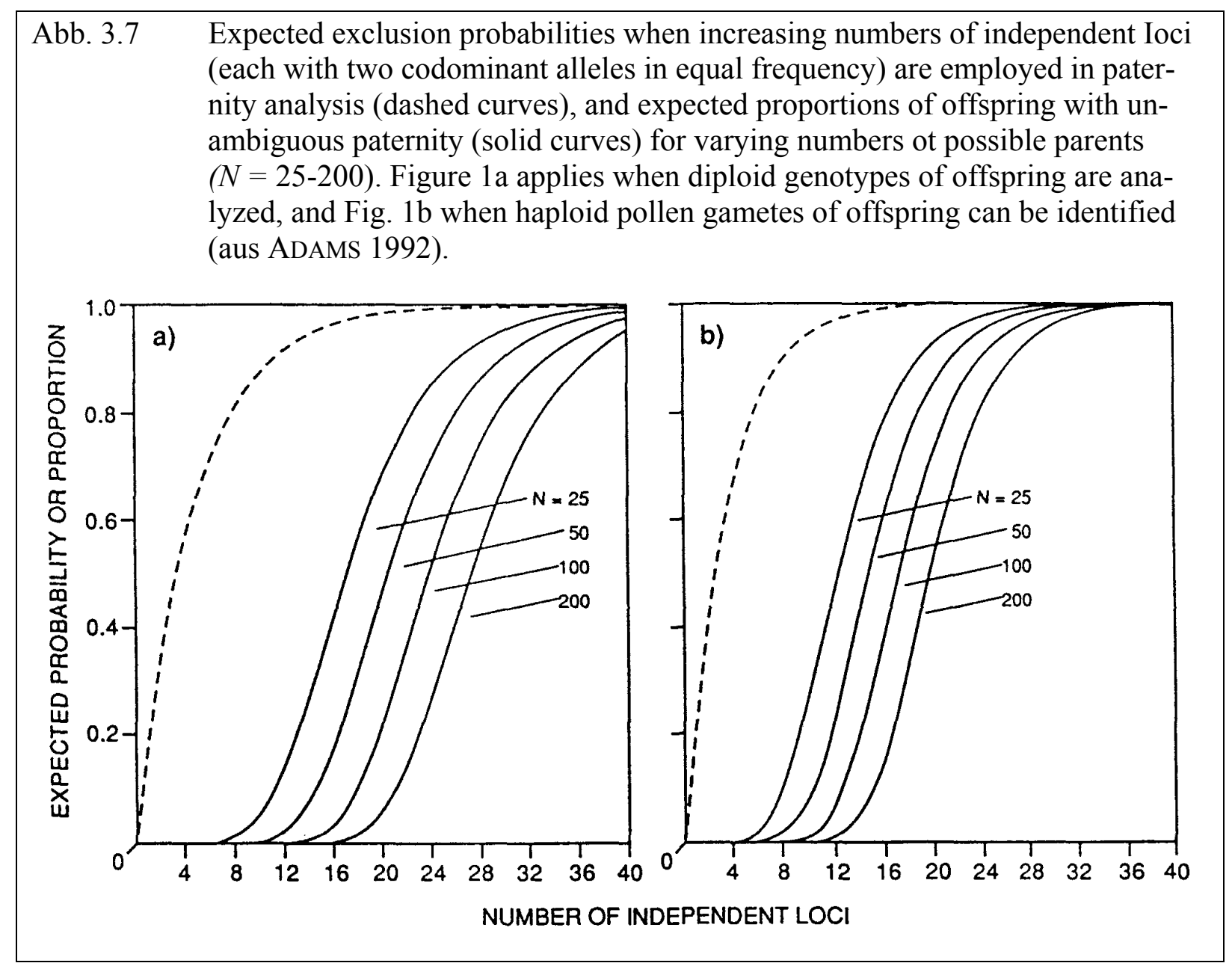

In der Praxis ist die Anzahl potentieller Polleneltern für eine Population meistens bedeutend höher und die Anzahl polymorpher, hochdiverser Genloci geringer. Ist die Anzahl der potentiellen Polleneltern unendlich groß oder nicht von allen ihr Genotyp bekannt, ist eine Bestimmung mit diesem Verfahren nicht möglich.

Bei einer genetischen Inventur von 2255 Nachkommen, 273 o und 70 ㅇ Individuen der diözischen Chamaelirium luteum (Liliaceae) an acht Genorten konnten CHAKRABORTY et al. (1988) nur in 57 Fällen (2,5 \%) einen Pollenelter eindeutig bestimmen. Für jeden Nachkommen konnten im Durchschnitt lediglich $73 \%$ der potentiellen Polleneltern ausgeschlossen werden. Bei 273 potentiellen Polleneltern bedeutet dies, daß im Mittel für jeden Nachkommen 74 Polleneltern in Betracht kommen. Dieses Ergebnis ist zur Bestimmung von Pollentransportweiten oder Selbstbefruchtungsraten nur in Einzelfällen nutzbar. Der Informationsgehalt und die Anzahl der von CHAKRABORTY et al. (1988) untersuchten Genorte entspricht in etwa dem anderer bisher isoenzymatisch untersuchter Pflanzenarten. Somit führt das Ausschlußverfahren bei den meisten Pflanzenarten nur in bescheidenem Umfang zu einer Identifizierung von Polleneltern. Der Vorteil des Ausschlußverfahrens ist, unter der Annahme einer fehler- 
freien Datenerhebung, eine sichere Bestimmung der Polleneltern. Werden zwecks Eingrenzung des Kreises potentieller Polleneltern Annahmen und/oder Simulationen hinzugezogen, kann nur von einer Schätzung wahrscheinlicher Polleneltern gesprochen werden.

\subsubsection{Schätzung wahrscheinlichster Polleneltern}

Über das Ausschlußverfahren kann in der Regel also nur für einen Bruchteil der untersuchten Nachkommen ein eindeutiger Pollenelter bestimmt werden. Für die meisten Nachkommen kann zwar ein mehr oder weniger großer Anteil von Polleneltern ausgeschlossen werden, sobald aber mehr als ein Pollenelter in Betracht kommt, ist eine eindeutige Bestimmung nicht mehr möglich. Die folgenden Verfahren zur Schätzung wahrscheinlichster Polleneltern basieren letztendlich auf dem Ausschlußverfahren und daher steigt auch bei diesen Verfahren der Erfolg bei der Bestimmung von Polleneltern mit der Anzahl variabler Genorte. Deren Anzahl ist aber nicht beliebig zu steigern, daher die nachfolgend beschriebenen Methoden.

\subsubsection{1 „Most-likely“-Methode}

Eine Methode, auf der Basis der Ausschlußverfahrens den Kreis der verbliebenen Polleneltern weiter einzugrenzen, entwickelte MEAGHER (1986). Bei der „,most-likely“-Methode wird für jeden Genort die Wahrscheinlichkeit eines bestimmten Pollenelters berechnet, Gameten zu produzieren, die zur Bildung des Multilocus-Genotyps eines Nachkommens eines bekannten Samenelters geführt haben könnte. Sind die Genorte nicht gekoppelt, werden die Wahrscheinlichkeiten multipliziert und das Ergebnis logarithmiert $\left(\log _{\mathrm{e}}\right)$. Dieser sogenannte LOD-score (log of likelihood ratios) des betrachteten Pollenelters wird ins Verhältnis zu den LOD-scores der restlichen potentiellen Polleneltern der Population gesetzt. Besitzt ein Pollenelter einen negativen LOD-score, ist er als Pollenelter weniger wahrscheinlich als ein zufällig gewählter potentieller Pollenelter. Ein LOD-score von Null bedeutet, daß die Wahrscheinlichkeit einer Pollenelterschaft des eines zufällig gewählten Pollenelters entspricht. Dementsprechend impliziert ein positiver LOD-score eine über dem Zufall liegende Wahrscheinlichkeit einer Pollenelterschaft. Erreicht ein Pollenelter den höchsten LOD-score aller potentiellen Polleneltern, wird er als wahrscheinlichster Pollenelter bestimmt. Teilen sich mehrere Polleneltern einen Höchstwert, ist keine Aussage möglich, der Nachkomme fällt für weitere Betrachtungen aus. Dabei wird angenommen, daß alle potentiellen Polleneltern den gleichen Paarungserfolg haben. Auch wird von gleichmäßiger Segregation der Gameten, gleicher Fertilität der Polleneltern und einer für alle Sameneltern einheitlichen Pollenwolke ausgegangen. 
MEAGHER verwendete den später auch von CHAKRABORTY et al. (1988) genutzten Datensatz von Chamaelirium luteum (Liliaceae) (s. o.). Mit der most-likely Methode konnte für 575 der 2255 untersuchten Samen $(25,5 \%)$ ein Pollenelter bestimmt werden, da einzig für sie ein höchster LOD-score berechnet wurde.

Ein ähnliches Verfahren stellt die „fractional paternity assignment“ von DEVLIN et al. (1988) dar. Die Wahrscheinlichkeit einer Pollenelternschaft wird in dieser Arbeit „,transition probability“ genannt. Näheres ist bei Bedarf der angegebener Literatur zu entnehmen.

\subsubsection{CERVUS}

Mit dem Ansatz von MEAGHER's „,most-likely“-Methode entwickelten MARSHALL et al. (1998) ein Programm Namens CERVUS. Wie der Name andeutet, wurde dieses Programm mit den Daten einer mittels Mikrosatelliten genetisch inventierten Rotwildpopulation generiert, soll aber für alle Datensätze mit kodominanten Markern zu verwenden sein.

MEAGHER's Methode zur Berechnung von LOD-scores (3.9.2.1) wurde von MARSHALL et al. (1998) aufgenommen u. a. um folgende Merkmale erweitert: Das Programm kalkuliert die Möglichkeit fehlerhafter Datensätze (Tippfehler, Nullallele etc.) über die Eingabe einer fiktiven Fehlerquote mit ein. Es müssen nicht alle potentiellen Väter bekannt sein und über Monte-Carlo-Simulationen wird ein sogenannter $\Delta$-Wert berechnet; nur wenn der wahrscheinlichste Vater einen um diesen $\Delta$-Wert höheren LOD-score als der zweitwahrscheinlichste Vater besitzt, wird er als solcher angenommen. Sinn der Eingabe einer Irrtumshäufigkeit ist die Vermeidung nicht gerechtfertigter Ausschlüsse von Vätern aufgrund fehlerhafter Dateneingabe oder -erhebung. Die Anzahl und der Anteil der untersuchten Väter kann ebenso variiert werden wie das Signifikanzniveau bei der Berechnung des $\Delta$-Wertes. Die Arbeitsweise von CERVUS wird von MARSHALL et al. (1998) wie folgt veranschaulicht: 


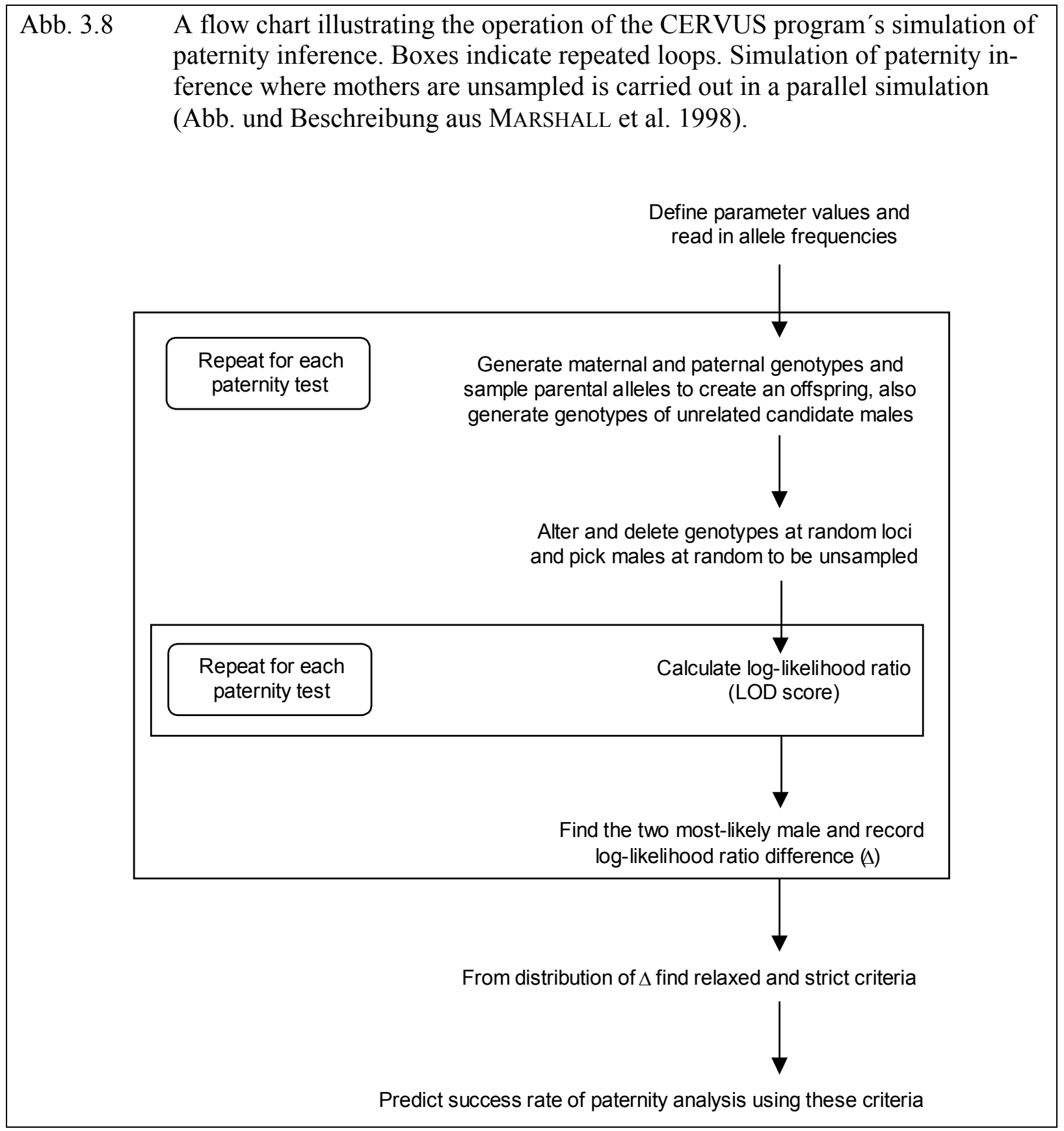

Für viele Schritte in Abb. 3.8 werden Simulationen verwendet. Die Eingabe einer fiktiven Fehlerquote weicht die Stringenz des Ausschlußverfahrens auf. Es werden weniger Väter ausgeschlossen und damit sinkt die Wahrscheinlichkeit, daß der wahrscheinlichste Vater sich um den $\Delta$-Wert vom zweitwahrscheinlichsten ausreichend absetzt, um als solcher bestimmt zu werden. Die Wahl eines niedrigen Signifikanzniveaus bei der Berechnung der LOD-scores (z. B. $80 \%$ ), welches gleichbedeutend mit einem kleineren $\Delta$-Wert ist, erhöht den Anteil der so ermittelten Vaterschaften ebenso wie eine geringe Zahl potentieller und ein hoher Anteil bekannter potentieller Väter. 
Unter Verwendung von drei Enzym- und neun Mikrosatellitengenorten konnten MARSHALL et al. (1998) für eine Rotwildpopulation (Cervus elaphus) mit ihrem Programm bei bekannter Mutter für 59,3\% bzw. für 28,9\% der Nachkommen einen Vater bestimmen (bei Signifikanzniveau des $\Delta$-Wertes von $80 \%$ bzw. $95 \%$ ). Dabei wurden 75 (65\%) potentielle Väter untersucht, $35 \%$ blieben unbekannt. Die Fehlerquote wurde mit $1 \%$ eingegeben.

Bei den Schätzungen der wahrscheinlichsten Polleneltern für die Lindenpopulation Schwiegershausen wurden in das Programm CERVUS die Genotypstrukturen aller potentiellen Polleneltern (141 Linden), der 54 Einzelbaumnachkommenschaften mit $\mathrm{n} \geq 20$ (insgesamt 3863 Samen) und die der zugehörigen Sameneltern eingegeben. Es wurde angenommen, daß alle potentiellen Polleneltern bekannt sind. Als Eingangsparameter für die Fehlerquote wurden $0 \%$ und $1 \%$, für das Signifikanzniveaus des $\Delta$-Wertes $80 \%$ und $95 \%$ gewählt. Der Datensatz des Versuchsbestandes wurde somit in vier verschiedenen Kombinationen innerhalb des CERVUS-Programmes durchgerechnet; für die Simulationen sind jeweils 10.000 Zyklen verwendet worden.

\subsubsection{3 „Paternity analysis“" nach ADAMs et al.}

Einen neuen Weg schlugen ADAMS et al. (1992) ein, indem sie der Pollenelternbestimmung über die wahrscheinliche Gametenproduktion, in diesem Fall die Übergangswahrscheinlichkeit (transition probability) von DEVLINS et al. (1988), den Term $\Phi$ hinzufügten. Dieser Term $\Phi$ steht für eine a priori-Wahrscheinlichkeit der Pollenelternschaft, die nicht über genetische Parameter berechnet wird. In erster Linie sind Informationen über Blühtermin, Fertilität und Abstand der potentiellen Polleneltern zum Samenelter als geeignete Parameter für die Berechnung von $\Phi$ zu nennen.

Als Grundlage diente die, bereits im Rahmen einer anderen Arbeit erhobene, genetische Struktur von 285 Eukalypten (Eucalyptus regnans) einer zehnjährigen Samenplantage und 1679 ihrer Nachkommen. Dabei zeigten sieben der zehn untersuchten Genorte einen Majorpolymorphismus, drei einen Minorpolymorphismus. Mit diesen zehn Genorten generierten ADAMS et al. (1992) für acht Sameneltern dieser Samenplantage mit Monte-Carlo-Simulationen eine Nachkommenschaft von je 50 Samen. Mit Hilfe der Übergangswahrscheinlichkeit wurde für diese 400 simulierten Nachkommen eine Bestimmung der Polleneltern vorgenommen. Für 23 Nachkommen konnte ein wahrscheinlichster Pollenelter bestimmt werden und daraus wurde eine vorläufige mittlere Pollentransportweite berechnet, welche zusammen mit einer optisch ermittelten Fekundität der Eukalypten in die Formel für die Herleitung von $\Phi$ einging. Unter Einbeziehung von $\Phi$ und der Übergangswahrscheinlichkeit konnte, je nach Stringenz 
der verschiedenen Annahmen, der Anteil wahrscheinlichster Polleneltern mindestens verdoppelt werden.

Der Argumentation von ADAMS et al. (1992) konnte nicht immer gefolgt werden bzw. kamen Zweifel an deren Plausibilität auf (z. B. Herleitung von Ф). Auch stand ein Anwendungsprogramm für die Herleitung wahrscheinlichster Polleneltern nach der Methode von ADAMS et al. nicht zur Verfügung. Eine eigene Programmierung hätte Umfang und Anspruch des Arbeitsrahmens gesprengt.

Der Ansatz, a priori die Wahrscheinlichkeit einer Pollenelterschaft z. B. über den Abstand vom Paarungspartner und Fertilität zu schätzen, ist mit Sicherheit einleuchtend; zumal die, u. a. von MEAGHER (1986) für seine „most-likely“-Methode gemachte Annahmen einheitlicher Fertilität der Polleneltern und der Existenz einer einheitlichen Pollenwolke nur in den seltensten Fällen gegeben ist. Viele Arbeiten haben gezeigt, daß eine einheitliche Pollenwolke eher die Ausnahme als die Regel darstellt. Bei dem leptokurtischen Verlauf der Kurven der Pollentransportweiten für entomophile Arten (s. Kap. 2.8.6) wäre besonders im vorliegenden Fall eine gleichmäßige Verteilung des Pollens über die gesamte Population auch nicht zu erwarten. Die Annahme gleicher Fertilität aller Polleneltern muß ebenfalls als zu stark vereinfacht angesehen werden, ist aber in der Praxis oft nur schwer zu überprüfen.

Wegen der oben geschilderten Problematik wurde das Verfahren von ADAMS et al. (1992) nicht für den Datensatz der Winterlindenpopulation Schwiegerhausen eingesetzt.

\subsubsection{Schätzung der Polleneltern mit EFG}

Das Pollenelterbestimmungsverfahren EFG wurde im Rahmen dieser Arbeit entwickelt. Da über die Luftbildaufnahmen der Lindenpopulation Schwiegershausen die Fertilität der Polleneltern gut und über die digitalisierte Karte die Entfernungen zwischen allen Populationsmitgliedern genau ermitteln werden können (s. Kap. 3.4), liegt es nahe, solche bezüglich des Reproduktionssystems wichtigen Informationen für die Bestimmung von Polleneltern zu nutzen. Gegenüber der Methode von ADAMS et al. (1992) sollte das Hauptaugenmerk auf einer gesicherten Datenerhebung liegen und auf Annahmen und Simulationen möglichst verzichtet werden. Neben der Entfernung (E) und der über den blühenden Kronenraum ermittelten Fertilität (F) wird bei dem hier vorgestellten Verfahren EFG zur Bestimmung von Polleneltern eine relativ simple Berechnung der Wahrscheinlichkeit für die Produktion bestimmter Gameten durch potentielle Pollenelter gewählt (s. u.). 
Vorgehensweise für die Bestimmung der Polleneltern mittels EFG:

\section{Faktor Entfernung (E)}

Nach genetischer Inventur von Eltern und Nachkommen werden die Polleneltern der Nachkommen über das eindeutige Ausschlußverfahren bestimmt. Wird nur ein Pollenelter ausgewiesen, ist dieser als eindeutig anzusehen (s. Kap. 3.9.1). Da nur wenige Annahmen gemacht werden (s. Kap. 3.9.1), kann diese Art der Bestimmung als sehr sicher bezeichnet werden. Samen- und Pollenelter sind somit bekannt und die Entfernung zwischen diesen wird aus der vorhandenen Entfernungsmatrix (s. Kap. 3.4) abgelesen, welche mit der Pollentransportweite identisch ist. Kann auf diesem Wege eine ausreichende Anzahl Pollentransportweiten bestimmt werden, um an die resultierende Punktwolke eine Kurvenfunktion anzupassen, wird diese Kurvenfunktion als Faktor für die Entfernung eingesetzt. Ein willkürliches Beispiel: Ein Pollenelter mit einem Abstand von $10 \mathrm{~m}$ zum Samenelter könnte über die Kurvenfunktion etwa den Faktor 0,9, bei einem Abstand von $50 \mathrm{~m}$ den Faktor 0,6 und bei $500 \mathrm{~m}$ den Faktor 0,2 erhalten.

In das Pollenelterbestimmungsverfahren EFG ging als Faktor (E) für die Entfernung die Kurvenfunktion der in Abb. 4.25 dargestellten kumulativen Häufigkeitsverteilung ein.

\section{Faktor Fertilität (F)}

Die Linde bildet nur im äußeren, von direkter Sonneneinstrahlung beeinflußten Kronenmantel Blüten aus. Die Pollenproduktion einer Blüte ist im Gegensatz zur Eizellenbildung altersunabhängig (EISENHUT 1957). Nach ROHMEDER (1972) entspricht die Lindenblüte dem Prototyp einer perfekten zwittrigen Blüte. POHL (1936) stellte bei den von ihm untersuchten Blüten

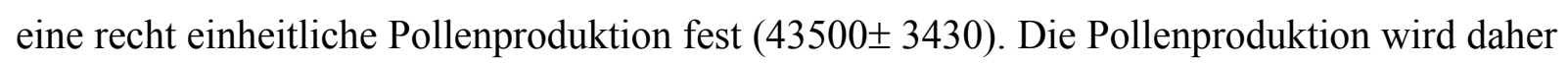
pro Blüte eines Individuums und für alle Populationsmitglieder als weitestgehend einheitlich angenommen. Somit kann über die Größe der weiß blühenden Kronenoberfläche die Pollenproduktion einer Linde geschätzt werden. Auf den Luftbildaufnahmen hebt sich die weiße Tracht der Linde deutlich vom grünen Blätterdach ab. In der digitalisierten Karte werden diese weiß abgehobenen Flächen markiert und in $\mathrm{m}^{2}$ umgerechnet (s. Kap. 3.4). Die Luftbildaufnahme kann nur zweidimensionale Informationen liefern, ein dreidimensionaler blühender Kronenmantel bleibt unberücksichtigt. Deshalb wurde die berechnete Fläche für am Bestandesrand stehende Bäume mit dem Faktor 1,5 und für Solitärbäume mit dem Faktor 2 multipliziert. Die so ermittelte Fläche der blühenden Krone wird als Faktor für die Pollenproduktion für die einzelnen Linde genommen. Um einer Überbewertung des Faktors Fertilität vorzubeu- 
gen, geht der logarithmierte Wert als Faktor Fertilität in die Berechnungen ein. Die Größen der blühenden Kronen variierten im Versuchsbestand Schwiegershausen von 1,3 $\mathrm{m}^{2}$ (Nr. 96 und 127) für eine unterständige, im Absterben befindliche, Linde bis $300 \mathrm{~m}^{2}$ für imposante, frei in der Feldmark stehende und bis zum Boden beastete Exemplare (F1 bis F4). Im Durchschnitt der gesamten Population belief sich die blühende Kronenoberfläche auf 59,2 m². Um eine Vorstellung über die Größenordnungen zu geben, sind in folgender Tab. 3.4 beispielhaft die Kronengrößen einiger Linden aus dem Bestand Schwiegershausen aufgeführt.

Tab. 3.4 Größe blühender Kronen einer Auswahl von Linden des Versuchsbestandes Schwiegershausen. Die logarithmierte Kronenfläche (ln) geht als Faktor Fertilität in das EFG-Verfahren ein (vgl. beigefügte Karte 1).

\begin{tabular}{|c|r|c|}
\hline $\begin{array}{c}\text { Baum } \\
\text { Nr. }\end{array}$ & \multicolumn{2}{|c|}{ Kronenfläche } \\
\hline & \multicolumn{1}{|c|}{$\mathbf{m}^{\mathbf{2}}$} & ln \\
\hline $\mathbf{1 1 8}$ & 146,42 & 4,99 \\
\hline $\mathbf{1 1 9}$ & 180,39 & 5,20 \\
\hline $\mathbf{1 2 0}$ & 109,59 & 4,70 \\
\hline $\mathbf{1 2 1}$ & 203,19 & 5,31 \\
\hline $\mathbf{1 2 2}$ & 65,10 & 4,18 \\
\hline $\mathbf{1 2 3}$ & 10,41 & 2,34 \\
\hline $\mathbf{1 2 4}$ & 23,02 & 3,14 \\
\hline $\mathbf{1 2 5}$ & 8,88 & 2,18 \\
\hline $\mathbf{1 2 6}$ & 27,29 & 3,31 \\
\hline $\mathbf{1 2 7}$ & 1,32 & 0,27 \\
\hline $\mathbf{1 2 8}$ & 45,37 & 3,81 \\
\hline $\mathbf{1 2 9}$ & 140,61 & 4,95 \\
\hline
\end{tabular}

\section{Faktor Gametenproduktion (G)}

Die Wahrscheinlichkeit eines potentiellen Pollenelters, bei gegebenem Samenelter den bestimmten Gameten produziert zu haben, welcher in den untersuchten eingegenagen sein könnte, ist schon bei MEAGHER's „most-likely“-Methode in Kap. 3.9.2 beschrieben worden. Bei der „most-likely“-Methode gehen u. a. auch die Genotypstrukturen der Population und der Polleneltern in Form von Allelhäufigkeiten zur Berechnung der LOD-scores ein. Im vorliegenden Fall werden diese Wahrscheinlichkeiten nur aus der Genotyp-Kombination von Samenelter, Nachkomme und potentiellem Pollenelter berechnet. Allelhäufigkeiten in der Population bzw. unter den potentiellen Polleneltern bleiben im Gegensatz zu der „most-likely“Methode und dem Programm CERVUS dabei unberücksichtigt. Als Vorlage diente dabei eine bei MARSHALL et al. (1998) im Methodenteil publizierte Tabelle: 
Tab. 3.5 Wahrscheinlichkeit der Gametenproduktion eines potentiellen Pollenelters bei gegebenem Genotyp von Samenelter und Nachkomme. $\mathrm{X}=$ jedes andere Allel außer B, Y = jedes andere Allel außer B und C.

\begin{tabular}{|c|c|c|c|}
\hline $\begin{array}{c}\text { Genotyp } \\
\text { Nachkomme }\end{array}$ & $\begin{array}{c}\text { Genotyp } \\
\text { Samenelter }\end{array}$ & $\begin{array}{c}\text { Genotyp des potentiellen } \\
\text { Pollenelters }\end{array}$ & $\begin{array}{c}\text { Wahrscheinlichkeit einer } \\
\text { Gametenproduktion }\end{array}$ \\
\hline BB & BB & BB & 1 \\
\hline BB & BX & BB & $1 / 2$ \\
\hline BB & BB & BX & $1 / 2$ \\
\hline BB & BX & BX & $1 / 4$ \\
\hline BC & BB & CC & $1 / 2$ \\
\hline BC & BX & CC & $1 / 2$ \\
\hline BC & BB & CY & $1 / 4$ \\
\hline BC & BX & CY & $1 / 2$ \\
\hline BC & BB & BC & $1 / 4$ \\
\hline BC & BY & BC & $1 / 2$ \\
\hline BC & BC & BC & \\
\hline
\end{tabular}

Ist keine dieser Kombinationen realisiert, bedeutet dies den Ausschluß des Pollenelters von einer Pollenelterschaft. Die Wahrscheinlichkeitswerte werden über alle Genorte multipliziert und gehen als Faktor G in das EFG-Verfahren ein. Dabei liegt die Annahme ungekoppelter Genorte zu Grunde.

Schließlich werden die Faktoren Entfernung (E), Fertilität (F) und Gametenproduktion (G) multipliziert und der daraus resultierende Wert ergibt die Wahrscheinlichkeit der Pollenelternschaft. Bei einem Vergleich aller potentiellen Polleneltern kann jetzt der wahrscheinlichste Pollenelter bestimmt werden. Die Kriterien für diese Bestimmung können frei gewählt werden (z. B. höchster Wahrscheinlichkeitswert, eine gewisse Differenz zum zweitwahrscheinlichsten Pollenelter etc.). Das Kriterium einer absolut höchsten Wahrscheinlichkeit wurde als nicht ausreichend diskriminierend abgelehnt; der Wert des wahrscheinlichsten Pollenelters sollte ein Vielfaches des zweitwahrscheinlichsten betragen. Als Schwellen wurde für die Bestimmung eines Pollenelters zunächst der zwei-, vier- und achtfache Abstand zum EFG-Wert des zweitwahrscheinlichsten Pollenelters verwendet (2 $\Delta, 4 \Delta$ und $8 \Delta)$. Im Interesse der Verständlichkeit soll hier auf ein willkürliches Beispiel aus dem Ergebnisteil vorgegriffen werden. 
Tab. 3.6 Herleitung der Wahrscheinlichkeit ${ }^{2}$ einer Pollenelternschaft mit dem Verfahren EFG. In die Gesamtwahrscheinlichkeit geht die Entfernung in m nicht mit ein. (Im Interesse der Übersichtlichkeit wurden die sehr kleinen Werte für die Wahrscheinlichkeit einer Gametenproduktion (G) einheitlich mit dem Faktor 100 multipliziert). Die potentiellen Polleneltern sind nach abnehmender EFGWahrscheinlichkeit geordnet (s. beigefügte Karten 1 und 3).

\begin{tabular}{|c|c|c|c|c|c|c|}
\hline \multicolumn{3}{|l|}{$\begin{array}{l}\text { Samenelter } \\
\text { Baum Nr. } 82\end{array}$} & \multicolumn{4}{|c|}{$\begin{array}{c}\text { potentielle Polleneltern } \\
\text { Baum Nr. }\end{array}$} \\
\hline Same Nr. 8 & 43 & 79 & 88 & 86 & 94 & 44 \\
\hline Entfernung in $\mathrm{m}$ & 18,80 & 16,66 & 26,35 & 8,63 & 421,61 & 10,19 \\
\hline Entfernung $(\mathbf{E})$ & 0,90 & 0,91 & 0,87 & 0,95 & 0,17 & 0,95 \\
\hline Fertilität $(\mathbf{F})$ & 4,65 & 4,49 & 4,20 & 3,29 & 4,89 & 3,38 \\
\hline Gametenprod. (G) & 0,39 & 0,20 & 0,20 & 0,10 & 0,20 & 0,02 \\
\hline Wahrscheinlichkeit (EFG) & 1,64 & $\mathbf{0 , 8 0}$ & 0,71 & $\mathbf{0 , 3 1}$ & 0,16 & 0,08 \\
\hline Same Nr. 9 & 82 & 43 & 79 & 94 & 113 & 44 \\
\hline Entfernung in $\mathrm{m}$ & 3,80 & 18,80 & 16,66 & 421,61 & 542,57 & 10,19 \\
\hline Entfernung $(\mathbf{E})$ & 0,98 & 0,90 & 0,91 & 0,17 & 0,12 & 0,95 \\
\hline Fertilität $(\mathbf{F})$ & 4,17 & 4,65 & 4,49 & 4,89 & 4,89 & 3,38 \\
\hline Gametenprod. (G) & 1,56 & 0,39 & 0,20 & 0,20 & 0,20 & 0,02 \\
\hline Wahrscheinlichkeit (EFG) & 6,41 & 1,64 & $\mathbf{0 , 8 0}$ & 0,16 & $\mathbf{0 , 1 1}$ & $\mathbf{0 , 0 8}$ \\
\hline Same Nr. 10 & 134 & 74 & 45 & 109 & 122 & 121 \\
\hline Entfernung in $\mathrm{m}$ & 204,40 & 187,53 & 21,08 & 442,63 & 781,49 & 763,37 \\
\hline Entfernung (E) & 0,38 & 0,41 & 0,89 & 0,16 & 0,06 & 0,06 \\
\hline Fertilität (F) & 3,30 & 5,08 & 3,04 & 3,62 & 4,18 & 5,31 \\
\hline Gametenprod. (G) & 25,00 & 6,25 & 0,78 & 3,13 & 1,56 & 0,78 \\
\hline Wahrscheinlichkeit (EFG) & 31,40 & 12,97 & 2,12 & $\mathbf{1 , 8 0}$ & $\mathbf{0 , 4 0}$ & 0,26 \\
\hline
\end{tabular}

Bei den drei in Tab. 3.6 untersuchten Nachkommen der Winterlinde Nr. 82 (Samenelter) können bei einer Diskriminanzschwelle von $2 \Delta$ allen drei Samen ein Pollenelter zugeordnet werden, da die EFG-Werte des wahrscheinlichsten Polleneltern mehr als das zweifache der zweitwahrscheinlichsten betragen. Setzt man die Diskriminanzschwelle auf $4 \Delta$ herauf, ist in diesem Beispiel kein Pollenelter für die drei Nachkommen zu bestimmen. Zudem ist ersichtlich, das der Same Nr. 9 auch das Produkt einer Selbstbefruchtung sein könnte, da die Winterlinde Nr. 82 selbst auch als Pollenelter in Betracht kommt. Der hohe Wert des Faktors Gametenproduktion (G) unterstützt in diesem Falle die Annahme einer Selbstbefruchtung (der Entfernungswert für Selbstbefruchtung ist mit 1,9 m angegeben, dazu Näheres im Kap. 4.8.1). Ersichtlich wird, daß der Faktor Entfernung (E) erst bei relativ großen Distanzen an Einfluß gewinnt; der 18,8 m vom Samenelter Nr. 82 entfernt stehende potentielle Pollenelter Nr. 43

2 Es handelt sich beim Produkt der Faktoren E, F und G nicht im mathematischen Sinne um eine Wahrscheinlichkeit. 
verfügt über einen nur geringfügig niedrigeren Faktor Entfernung $(\mathrm{E}=0,90)$ als der Baum Nr. 82 selbst $(\mathrm{E}=0,98)$.

Im Zuge dieser Arbeit wurde eine Schätzung wahrscheinlichster Polleneltern nach dem Ausschlußverfahren, dem CERVUS-Programm und der EFG-Methode durchgeführt.

\subsection{Bestimmung von Selbstbefruchtungsraten}

Die in der Literatur gebräuchlichsten Verfahren zur Schätzung der Selbstbefruchtungsrate in der Nachkommenschaft eines bekannten Samenelters sind das Verfahren MLTR von RITLAND (1994) und das in Kap. 3.9.1 vorgestellte Ausschlußverfahren. Unterschieden wird ausschließlich zwischen Selbst- und Fremdbefruchtung. Dabei spielt die genaue Bestimmung der Polleneltern keine Rolle. Sind indessen mit einem anderen Verfahren Sameneltern als Polleneltern bestimmt worden, ist diese Information selbstverständlich auch für die Schätzung von Selbstbefruchtungsraten verwertbar.

\subsubsection{Das Ausschlußverfahren}

Beim eindeutigen Ausschlußverfahren ist die Zielsetzung die Bestimmung eines Pollenelters (s. Kap. 3.9.1). Im Unterschied dazu wird beim Ausschlußverfahren durch den Vergleich der Genotypen von Samenelter und betrachtetem Nachkommen untersucht, ob der Nachkomme ein Allel aufweist, welches nicht vom Samenelter stammen kann (Fremdtypallel). Wird ein solches Fremdtypallel nachgewiesen, ist eine Selbstbefruchtung ausgeschlossen. Der Anteil Samen, der von einer Selbstbefruchtung nicht ausgeschlossen werden konnte, bildet die obere Grenze der Selbstbefruchtung bzw. entspricht der maximal möglichen Selbstbefruchtungsrate. Wie schon in Kap. 3.9.1 erwähnt steigt der Umfang des Ausschlusses mit der Anzahl untersuchter Genorte und der Seltenheit der Samenelterallele in der Population an.

\subsubsection{MLTR}

Ein in vielen Arbeiten verwendetes Verfahren bzw. Computerprogramm zur Schätzung von Selbstbefruchtungsraten ist das von RITLAND und JAIN 1981 vorgestellte MLT bzw. die modifizierte Version MLTR (RITLAND 1994). Eine der Voraussetzungen zur Anwendung des Programms ist, daß die Genotypen aller potentiellen Eltern und ihren Nachkommen bekannt sind. Ist der Genotyp des Samenelters bekannt (z. B. bei vom Baum geernteten Samen), erhöht sich die Genauigkeit der Schätzung. Bei diesem Programm wird über die Abweichung des Genotyps der Samen von dem der Sameneltern eine Maximum-Likelihood-Schätzung der Eigenund Fremdpollenbeiträge vorgenommen. Angenommen wird u. a. die Homogenität der indi- 
viduell effektiven Pollenwolken und damit Zufallsmäßigkeit der Fremdbefruchtungen. Ausgiebig wird von Monte-Carlo-Simulationen und Bootstrapping Gebrauch gemacht. Auf die genaue Herleitung der Selbstbefruchtungsraten über MLTR soll nicht eingegangen werden.

\subsubsection{Schätzung der Selbstbefruchtungsrate über die Bestimmung von Polleneltern}

Die verschiedenen Verfahren zur Schätzung wahrscheinlichster Polleneltern (s. Kap. 3.9.2) sind für die Ermittlung von Selbstbefruchtungsraten dann geeignet, wenn mit ihnen ein hoher Anteil Polleneltern bestimmt werden kann. Von den im Kap. 3.9.2 vorgestellten Verfahren zur Schätzung von Polleneltern wurden für die Bestimmung der Selbstbefruchtung das Programm CERVUS und die Methode EFG getestet. Sind im idealen Fall zu allen Nachkommen eindeutige Polleneltern zuzuordnen, kann der Anteil der Selbstbefruchtung recht genau ermittelt werden.

Sind die über CERVUS oder EFG bestimmten wahrscheinlichsten Polleneltern mit dem Samenelter identisch, sind die Nachkommen aus Selbstbefruchtung hervorgegangen. Die Anzahl der ermittelten selbstbefruchteten Nachkommen wird durch die Anzahl der restlichen Nachkommen dividiert, unabhängig davon, ob ihnen ein wahrscheinlichster Pollenelter zugeordnet werden konnte oder nicht. Aus dieser Division resultiert die Selbstbefruchtungsrate. Es wird davon ausgegangen, daß alle anderen Samen nicht aus Selbstbefruchtung hervorgegangen sind. Bei der Methode EFG wird zusätzlich dieser Rest der nicht selbstbefruchteten Nachkommen bereinigt: Werden mit dem EFG-Verfahren einem Samen mehrere potentielle Polleneltern, darunter aber keinem wahrscheinlichsten zugewiesen, ist es für die Berechnung der Selbstbefruchtungsrate entscheidend, ob sich auch der Samenelter selbst unter den potentiellen Polleneltern befindet. Ist dies nicht der Fall, liegt Fremdbefruchtung vor; die genaue Bestimmung eines eindeutigen Pollenelters ist nicht weiter von Belang. Befindet sich hingegen auch der Samenelter selbst unter den potentiellen Polleneltern, kann diesbezüglich keine Aussage getroffen werden. Ist es nicht möglich, zwischen Selbst- und Fremdbefruchtung zu unterscheiden, ist eine Einteilung des betrachteten Nachkommen zu einer Gruppe schwierig. Eine Einordnung sowohl in die Gruppe Selbstbefruchtung als auch in die Gruppe Fremdbefruchtung, ist argumentativ plausibel erklärbar. Auf eine Einteilung in eine der beiden Gruppen wird deshalb verzichtet und damit auf die Informationen der entsprechenden Nachkommen, da sie nicht in die Schätzung der Selbstbefruchtungsrate eingehen. Dieser Verzicht geht mit einer erhöhten Genauigkeit bei der Bestimmung der Selbstbefruchtungsrate einher. 


\subsection{Bestimmung von Pollentransportweiten}

Frühere Versuche mit Pollenfallen, radioaktiv markierten Pollen oder durch direkte Beobachtungen der Flugweiten von Insekten konnten aufgrund methodischer Unzulänglichkeiten nur Eindrücke über die Verbreitung der Pollen geben. Enormer Arbeitsaufwand und mangelnde Praktikabilität dieser Verfahren ließen eine genaue Datenerhebung nur im begrenzten Umfang zu (s. a. ADAMS 1992). Mit diesen Methoden können evtl. Pollentransportweiten ermittelt werden; darüber, ob dieser Pollen im Sinne einer sexuellen Reproduktion tatsächlich effektiv geworden ist, kann jedoch keine Aussage getroffen werden.

Zeigt sich in der Elternpopulation ein einziger Baum als Träger eines seltenen Allels, kann dieser als Markerbaum verwendet werden (s. MüLLER [-STARCK] 1977). Wird das seltene Allel in den Nachkommen anderer Populationsmitglieder nachgewiesen, kann nur dieser Markerbaum als Pollendonator fungiert haben. Für die Ermittlung der Pollentransportweite für die entsprechenden Nachkommen bleibt noch die Entfernung zwischen den Eltern zu messen. Diese Methode ist dann erfolgreich, wenn genau ein Baum Träger dieses seltenen Allels ist und ein Polleneintrag von außen ausgeschlossen werden kann. Die erste Bedingung ist jedoch gerade in größeren Populationen selten gegeben. Zudem sind die ermittelten Pollentransportweiten nur für den Markerbaum zu ermitteln und da Standort, soziale Stellung, Fertilität, Blühperiode, Alter usw. von anderen Populationsmitgliedern abweichen können, nicht für die Population repräsentativ. In der Lindenpopulation in Schwiegershausen war kein Baum Träger eines seltenen Allels. Daher konnte diese Methode in dieser Arbeit nicht eingesetzt werden. Ein anderes Verfahren auf der Basis seltener Allele stellt FINKELDEY (1999) vor, aber auch auf dessen Verwendung wird aus dem eben genannten Grund verzichtet. Deshalb wird für die Ermittlung von Pollentransportweiten in dieser Arbeit auf die Bestimmung von Polleneltern zurückgegriffen.

Der Samenelter ist durch die Ernte des Samens vom Baum bekannt. Kann zu diesem Samen ebenfalls ein Pollenelter bestimmt werden, entspricht die Entfernung zwischen den Eltern der Transportweite des Pollens. Im Falle des Versuchsbestandes Schwiegershausen sind mittels der in Kap. 3.4 beschriebenen digitalisierten Karte alle Distanzen zwischen allen Mitgliedern der Lindenpopulation abrufbar. Nach der genetischen Inventur von Eltern und Nachkommen werden in dieser Arbeit die Polleneltern mit Hilfe des Ausschlußverfahrens, des CERVUSProgrammes (MARSHALL et al. 1998) und der Methode EFG ermittelt (s. Kap. 3.9). 


\section{Ergebnisse}

\subsection{Genetische Marker}

\subsubsection{Vererbungsanalyse}

Die Gattung Tilia ist hexaploid $(\mathrm{n}=41)$, spaltet dennoch an allen untersuchten Genloci disom. Mittels 49 Einzelbaumnachkommenschaften mit $n \geq 20$ Samen wurden die gleichmäßige Segregation und Zufallsfusion der Gameten überprüft. Nach der Methode von GiLLET (1997, s. Kap 3.6.3) lassen sich bei den 3739 dafür untersuchten Samen an zwölf polymorphen Genorten keine signifikanten Abweichungen ( $\mathrm{Chi}^{2}$ - und G-Test) von einer gleichmäßigen Segregation bzw. einer zufallsmäßigen Gametenfusion erkennen. Für die Genorte MDH-B und MDH$\mathrm{C}$ bedarf es einer Bestimmung der Genotypen über Intensitätsunterschiede der Enzymvarianten: die Bestimmung der Genotypen über Intensitätsunterschiede erschien mir indessen zu unsicher, weshalb die beiden Genorte nur für Mustervergleiche herangezogen wurden.

Für die populationsgenetische Analyse stehen somit zwölf, für die Bestimmung von Selbstbefruchtungsraten und Polleneltern vierzehn polymorphe Genorte zur Verfügung.

Exemplarisch für alle untersuchten Nachkommenschaften soll die Vererbungsanalyse anhand von zwei Beispielen verdeutlicht werden. Bei der Untersuchung von Knospen des Samenelters Nr. 72 zeigte dieser am Genort PGM-C den heterozygoten Genotyp C12. In 40 untersuchten Samen des Samenelters Nr. 72 fanden sich für den Genort PGM-C folgende Genotyphäufigkeiten (vgl. Abb. 4.1):

$\begin{array}{cccc}\text { Genotyp } & \text { C11 } & \text { C12 } & \text { C22 } \\ \mathbf{N} & 15 & 18 & 7\end{array}$

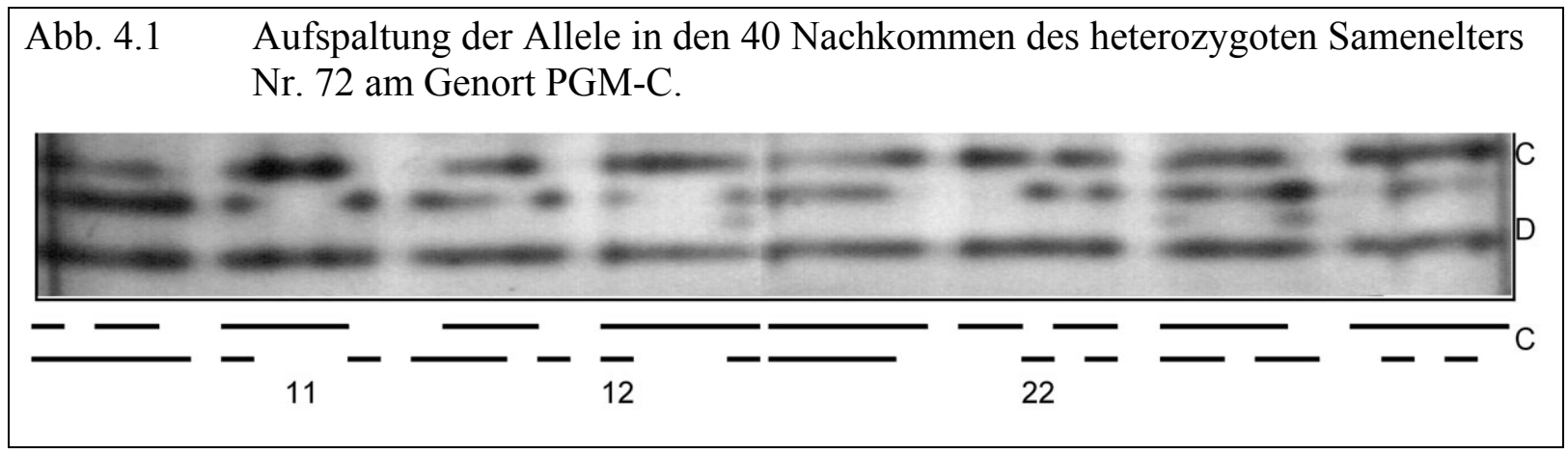


Aus Platzgründen mußte in der Abb. 4.1 auf eine Bezeichnung der einzelnen Genotypen verzichtet werden. Ein Test auf Homogenität zeigte keine signifikanten Abweichungen von der Hypothese einer gleichmäßigen Segregation bzw. einer Zufallsfusion der Gameten (s. Tab. 4.1).

Tab. 4.1 Test auf gleichmäßige Segregation und Zufallsfusion der Gameten in 40 Nachkommen des heterozygoten Samenelters Nr. 72 am Genort PGM-C. k = Fremdtypallel.

\begin{tabular}{|l|c|c|c|}
\hline Samenelter Nr. 72 & PGM-C & Chi' $^{\mathbf{2}}$ & \\
\hline $\mathbf{N}_{\mathbf{1 1}}+\mathbf{N}_{\mathbf{2 2}}: \mathbf{N}_{\mathbf{1 2}}$ & $22: 18$ & 0,527 & 0,40 n.s. \\
\hline $\mathbf{N}_{\mathbf{1 k}}: \mathbf{N}_{\mathbf{2 k}}$ & kein Fremdtypallel & - & - \\
\hline
\end{tabular}

Der Samenelter Nr. 59 war mit dem Genotyp B24 heterozygot für den Genort SKDH-B. Seine 27 auf dem Zymogramm in Abb. 4.2 zu sehenden Nachkommen zeigten folgenden Genotyphäufigkeiten (vgl. Abb. 4.2):

$\begin{array}{cccccc}\text { Genotyp } & \text { B22 } & \text { B23 } & \text { B24 } & \text { B34 } & \text { B44 } \\ \text { N } & 6 & 4 & 8 & 3 & 6\end{array}$

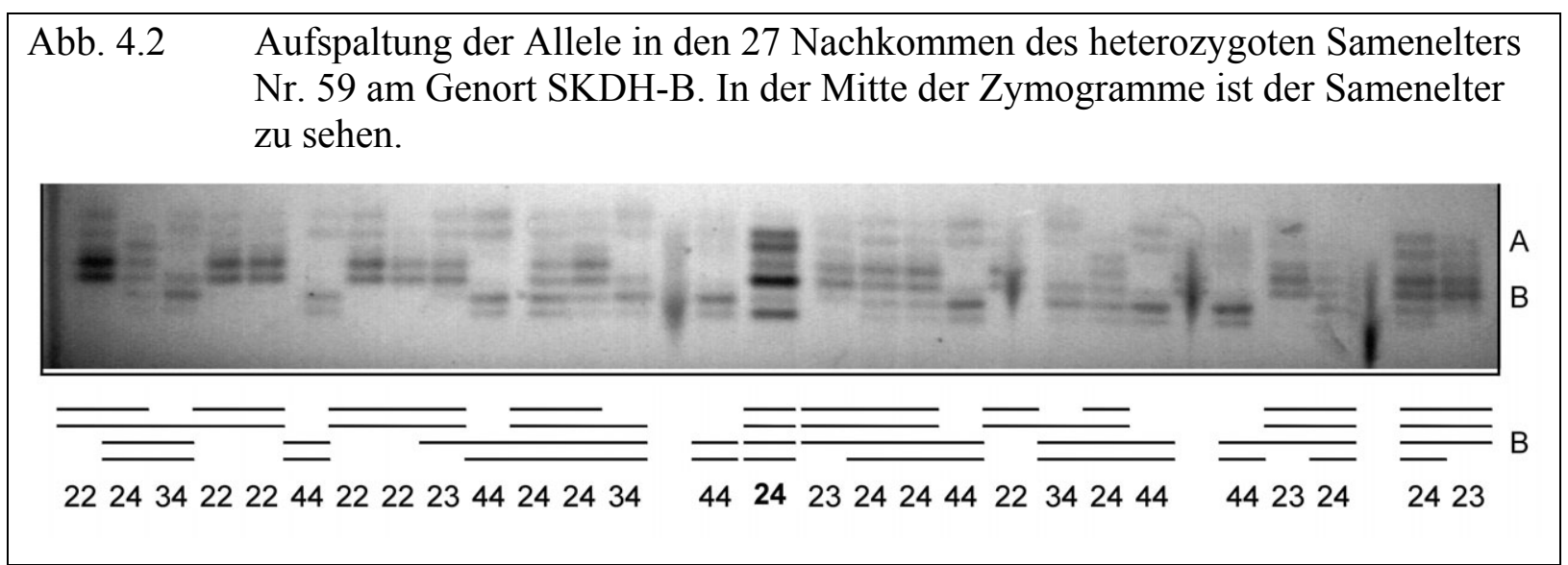

Der Test auf eine Gleichverteilung der beobachteten und erwarteten Häufigkeiten in den Nachkommen des Samenelters Nr. 59 zeigte keine signifikante Abweichung von den Annahmen gleichmäßiger Segregation und Zufallsfusion der Gameten (Tab. 4.2).

Tab. 4.2 Test auf gleichmäßige Segregation und Zufallsfusion der Gameten in 40 Nachkommen des heterozygoten Samenelters Nr. 72 am Genort PGM-C. $\mathrm{N}_{3}=$ Fremdtypallel.

\begin{tabular}{|l|c|c|c|}
\hline Samenelter Nr. 59 & SKDH-B & Chi' $^{\mathbf{2}}$ & \\
\hline $\mathbf{N}_{\mathbf{1 1}}+\mathbf{N}_{\mathbf{2 2}}: \mathbf{N}_{\mathbf{1 2}}$ & $12: 8$ & 0,371 & 0,80 n.s. \\
\hline $\mathbf{N}_{\mathbf{1 3}}: \mathbf{N}_{\mathbf{2 3}}$ & $4: 3$ & 0,705 & 0,14 n.s. \\
\hline
\end{tabular}




\subsubsection{Interpretation der Zymogramme}

Die alphabetische Bezeichnung der Genorte und die numerische Bezeichnung der Enzymvarianten eines Genortes sind durch deren Wandergeschwindigkeiten vorgegeben. Der Genort eines Enzymsystems, dessen Enzyme aufgrund des Stromfeldes am schnellsten durch das Gel migrieren, wird mit A bezeichnet, der Genort mit den zweitschnellsten Enzymvarianten mit B usw. Desgleichen wird die schnellste Enzymvariante eines Genortes mit 1 bezeichnet, die zweitschnellste mit 2 etc.

Bei den folgenden Abbildungen ist der anodische Teil oben, so daß eine Wanderung der Enzyme von unten nach oben vorzustellen ist. Des weiteren sind für eine Interpretation der Zymogramme Kenntnisse über die Quartärstrukturen der Enzyme erforderlich.

Abb. 4.3 Vereinfachte schematische Darstellung der Zymogramme von homozygoten bzw. heterozygoten Individuen, bei welchen ein monomeres, dimeres bzw. tetrameres Enzym von einem Genlocus kodiert wird (aus HATTEMER et al. 1993)

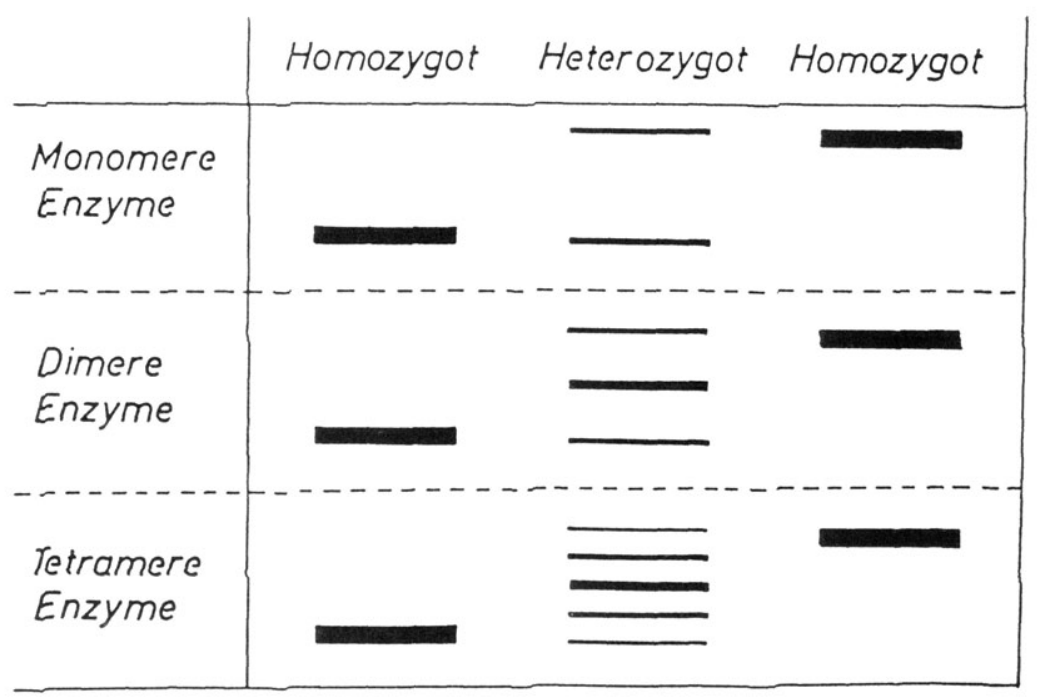

Bei einer monomeren Struktur besteht ein von einem Genlocus kodiertes Enzym aus einem Polypeptid. Homozygote Individuen kodieren im Falle einer monomeren Quartärstruktur ein Alloenzym, heterozygote zwei Alloenzyme. Auf den Zymogrammen sind ein Band bzw. zwei Bänder zu sehen (s. Abb. 4.3). Dimere Enzyme werden aus zwei Polypeptiden gebildet. Homozygote Individuen kodieren ein Alloenzym, bei Heterozygotie und zufallsmäßiger Aggregation der Polypeptide werden drei Alloenzyme von einem Genlocus kodiert. Auf dem Zymogramm sind drei Banden sichtbar, wobei die mittlere Bande ein sogenanntes Hybridenzym 
darstellt. Bei tetrameren Strukturen bestehen die Enzyme aus vier Polypeptiden. Auf dem Zymogramm zeigen Heterozygote ein Muster aus fünf Banden, von denen die mittleren drei Hybridbanden sind (HATTEMER et al. 1993).

Bei den folgenden Abbildungen von Zymogrammen ist der anodische Teil oben, so daß man sich eine Wanderung der Enzyme von unten nach oben vorzustellen hat.

\section{AP - Aminopeptidasen}

Trennsystem Ashton.

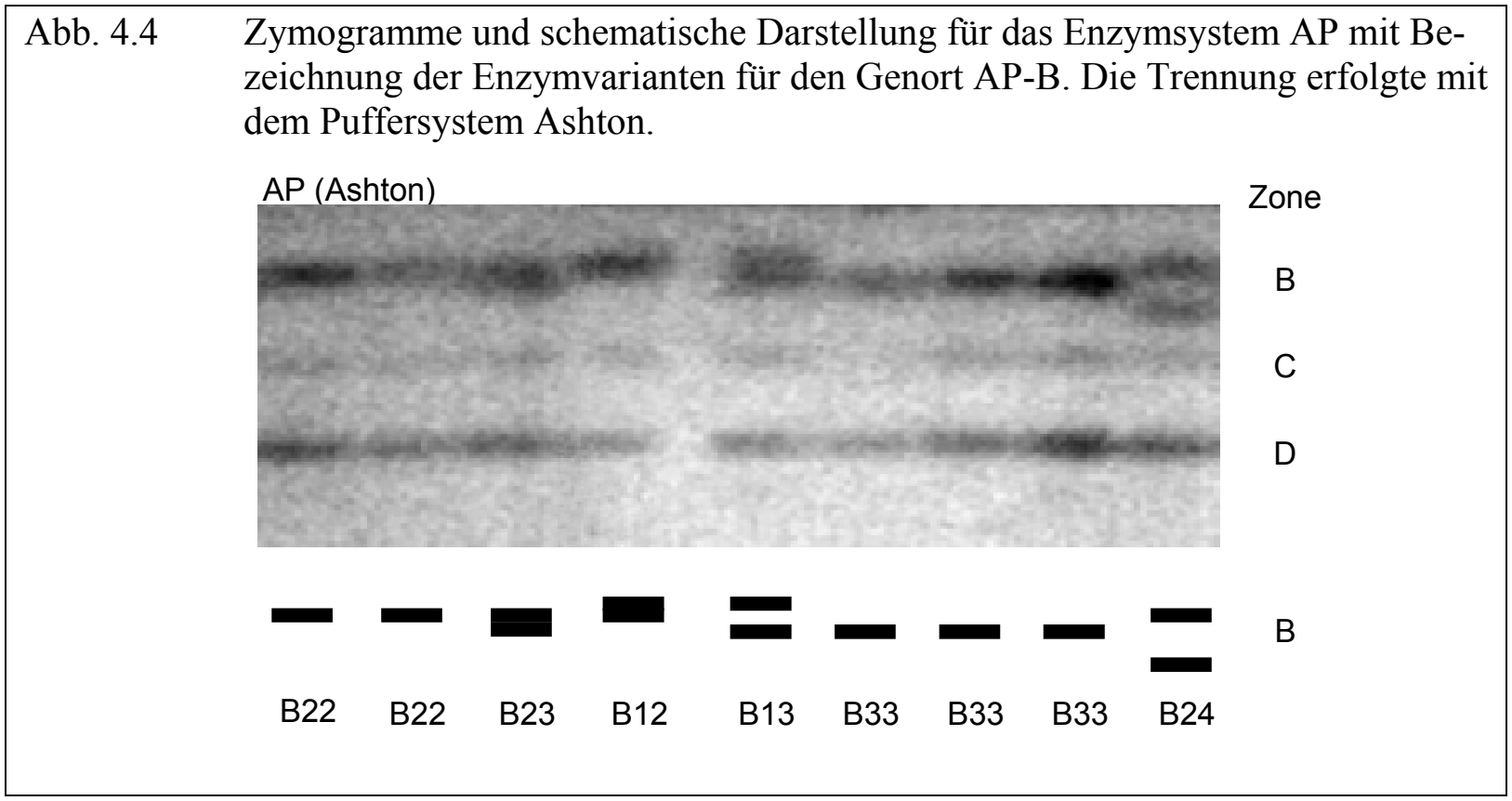

Trennsystem Histidin-Citrat

Abb. 4.5 Zymogramme und schematische Darstellung für das Enzymsystem AP mit Bezeichnung der Enzymvarianten für den Genort AP-D. Die Trennung erfolgte mit dem Puffersystem Histidin-Citrat.

AP (Histidin-Citrat)

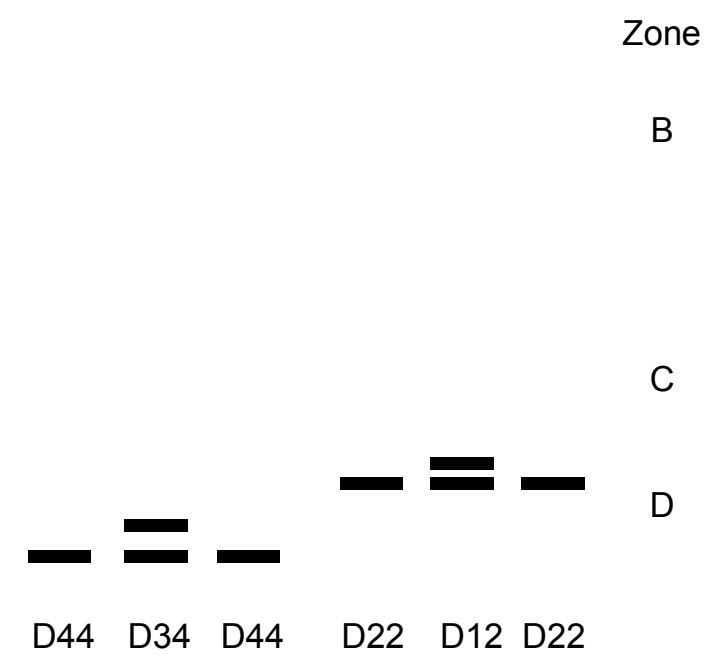


Das monomere Enzymsystem AP zeigt vier Zonen, von denen die Zonen AP-A und -C in der Regel nur eine schwache Intensität aufwiesen, so daß auf deren Auswertung verzichtet werden mußte. Für die Auswertung des Genortes AP-B wurde das Trennsystem Ashton bevorzugt. Das Trennsystem Histidin-Citrat zeigte eine bessere Trennung der Enzymvarianten, aber auch störende Nebenbänder, die eine sichere Identifizierung erschwerten (s. B-Zone in Abb. 4.5). Für den Genort AP-D gelang eine Auftrennung der Enzyme nur mit dem Trennsystem Histidin-Citrat; mit dem Trennsystem Ashton war an diesem Genort die Trennung so gering, daß dieser monomorph erschien.

Für Genort AP-B wurden vier Enzymvarianten gefunden, von denen keine für eine der beiden Lindenarten spezifisch ist. Ebenfalls vier Varianten besitzt der Genort AP-D. Während die Enzymvarianten AP-D1 und -D2 bei Winterlinden beobachtet werden konnten, traten die Varianten AP-D3 und -D4 nur bei Sommerlinden auf. Bei Hybriden aus Winter- und Sommerlinde sind auf den Zymogrammen beide dieser artspezifischen Enzymvarianten zu sehen.

\section{FDH - Formiatdehydrogenase}

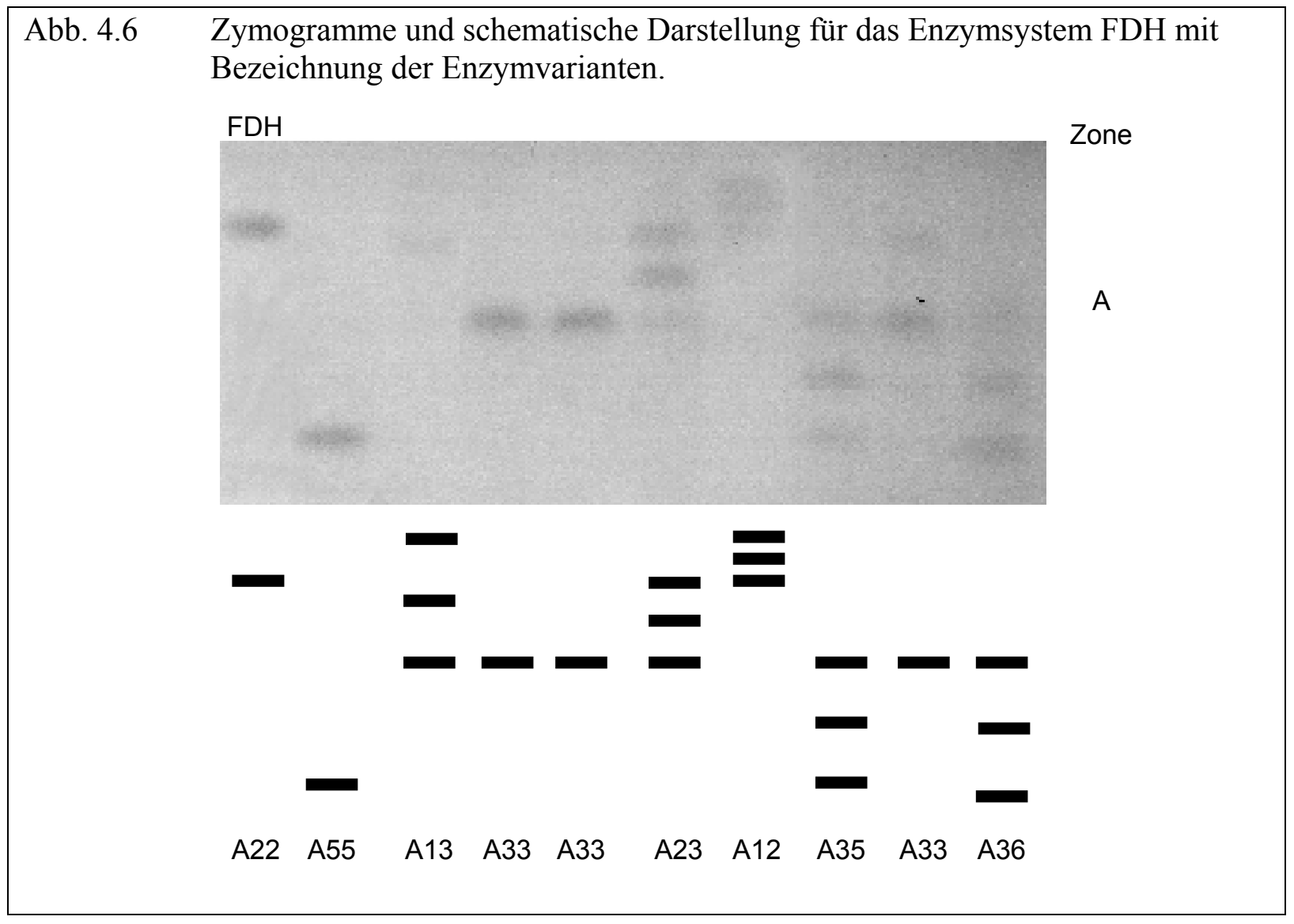


Eine Anfärbung der Gele auf FDH zeigte generell eine schwache Intensität. Sicht- und auswertbar war lediglich eine Zone, für die sechs Enzymvarianten gefunden wurden. Für die genetische Analyse und Pollenelterbestimmung wurden die Varianten FDH 5 und 6 zusammengefaßt, da eine Unterscheidung nicht immer eindeutig herbeizuführen war.

Die Enzymvarianten FDH 5 und 6 sind artspezifisch für die Winterlinde, die Varianten FDH 1, 2 und 4 für Sommerlinde.

\section{MDH - Malatdehydrogenase}

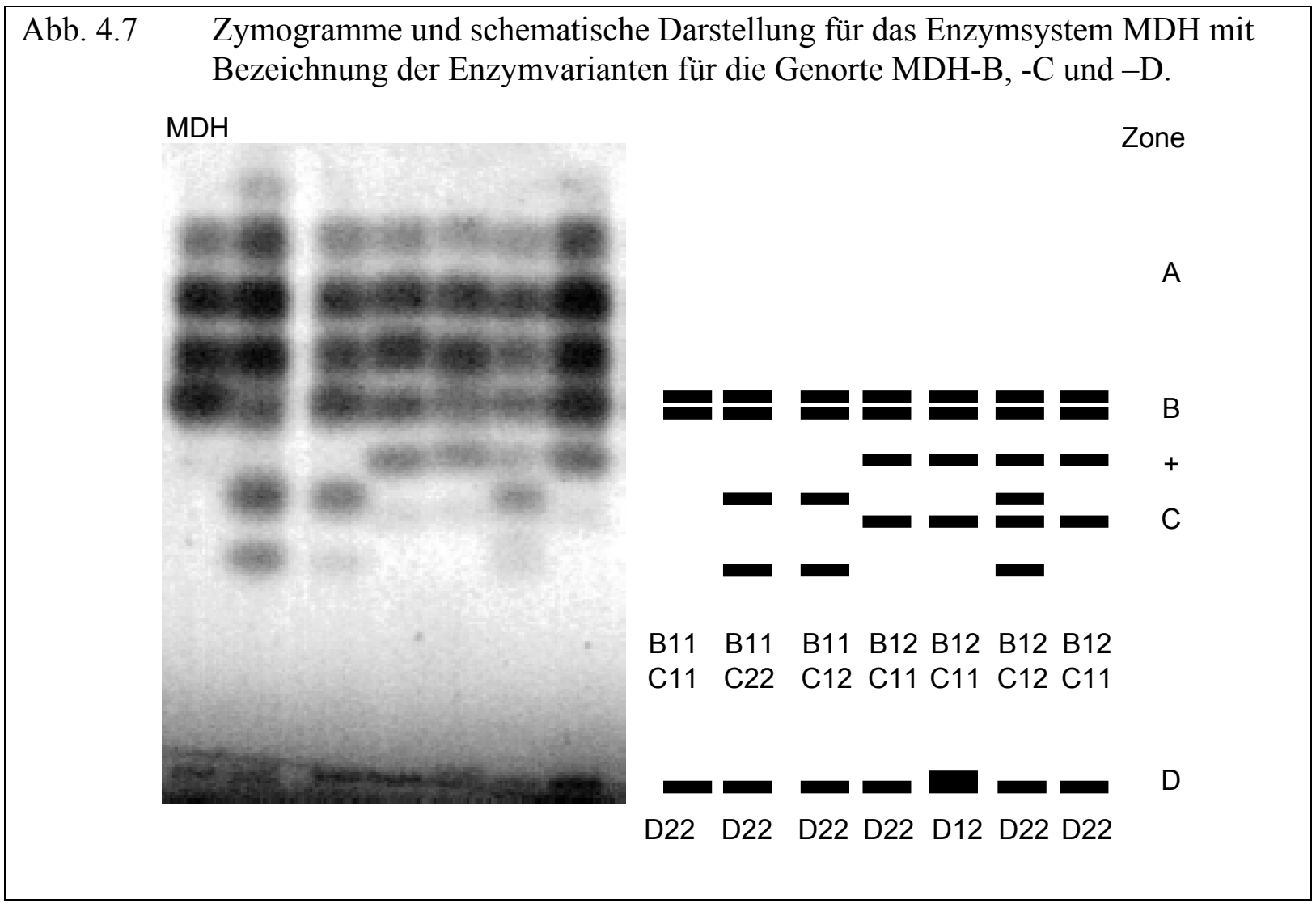

Das dimere Enzymsystem MDH besitzt bei der Linde mindestens vier Genorte. Die Zone(n) oberhalb der gestrichelten Linie in Abb. 4.7 zeigten keine auswertbare Variation. Obwohl es sich vermutlich um mindestens zwei Genorte handelt, die Interlocushybridbänder bilden, wird dieser Bereich als A-Zone definiert. Für die genetische Analyse wurde bei dem Enzymsystem MDH nur der Genort MDH-D verwendet, da auch die variablen Genorte MDH-B und -C Interlocushybridbänder bilden und eine Identifizierung der Genotypen B12 und B22, bzw. C12 und C22 nur anhand von Intensitätsunterschieden möglich ist. Wenn aus Blatt- oder Knospengewebe Enzyme extrahiert wurden, ist eine Unterscheidung unproblematisch (s. Abb. 4.7) und die Enzymmuster in den Nachkommen der betreffenden Linden bestätigten die korrekte Interpretation der Zymogramme. Für die Altbäume der Winterlindenpopulation Schwie- 
gershausen war eine Bestimmung der Enzymvarianten in den Zonen MDH-B und $-\mathrm{C}$ möglich. Bei Samen waren diese Intensitätsunterschiede dagegen weniger stark ausgeprägt. Da auf eine mit Unsicherheiten belastete Identifizierung der Varianten zu verzichten wurde, gehen die Genorte deshalb nur über einen Mustervergleich in die Bestimmung von Selbstbefruchtungsraten und Polleneltern ein. Alle drei Genorte weisen jeweils zwei Enzymvarianten und keine artspezifischen Allele auf.

MNR - Menadionreduktase

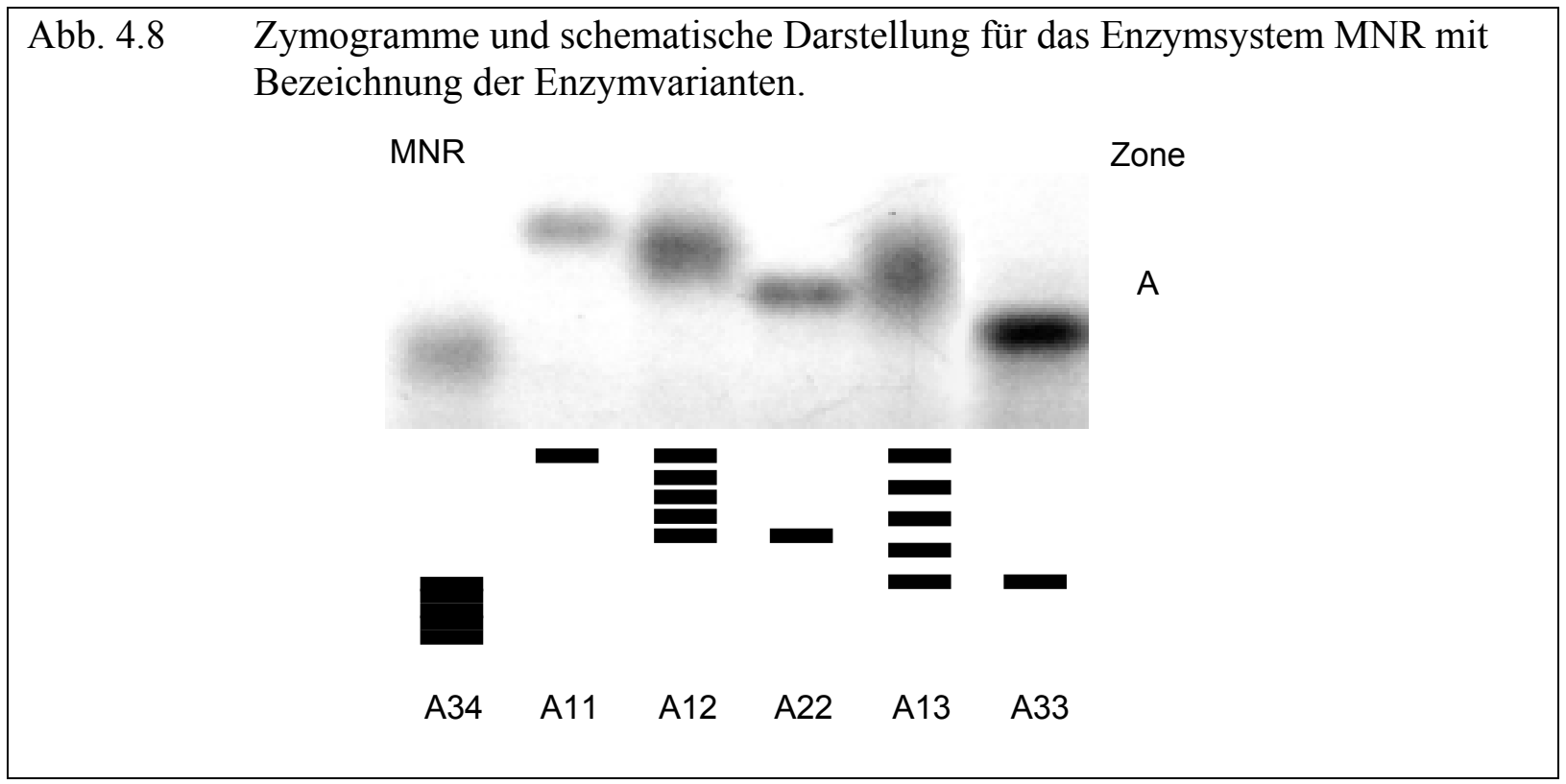

Nach Anfärbung auf das tetramere Enzymsystem MNR wurde eine Zone mit vier Enzymvarianten sichtbar. Dabei erwiesen sich die Enzymvarianten MNR 3 und 4 artspezifisch für Winterlinde und die Varianten MNR1 und 2 für Sommerlinde. 


\section{PGI - Phosphogluco-Isomerase}

Abb. 4.9 Zymogramme und schematische Darstellung für das Enzymsystem PGI mit Bezeichnung der Enzymvarianten für die Genorte PGI-B und $-\mathrm{C}$.

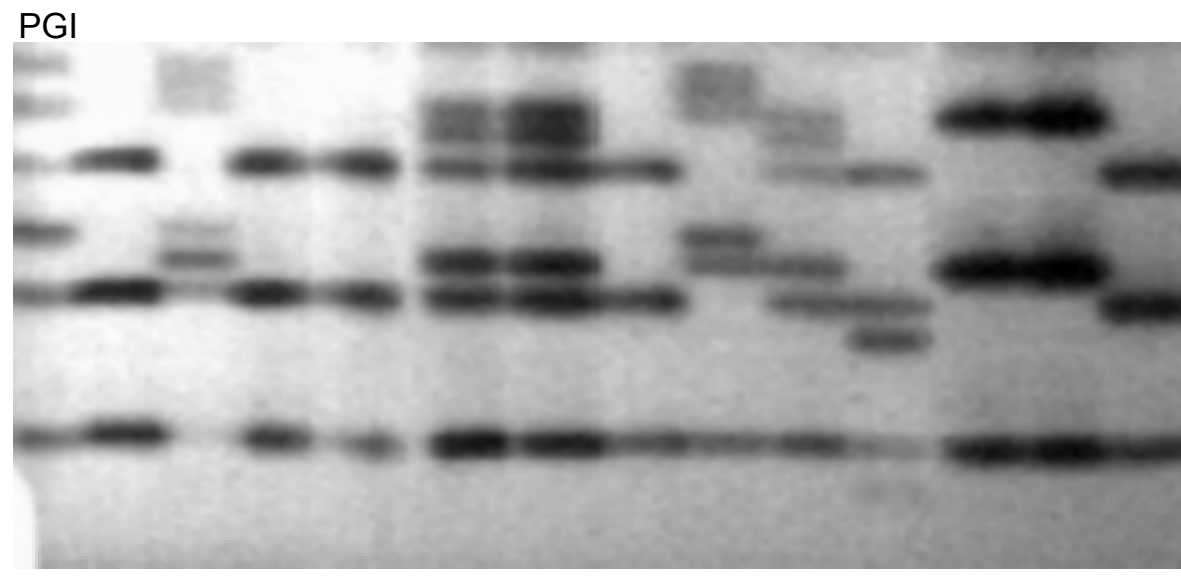

Zone

\section{B}

Interlocus-

Hybridzone

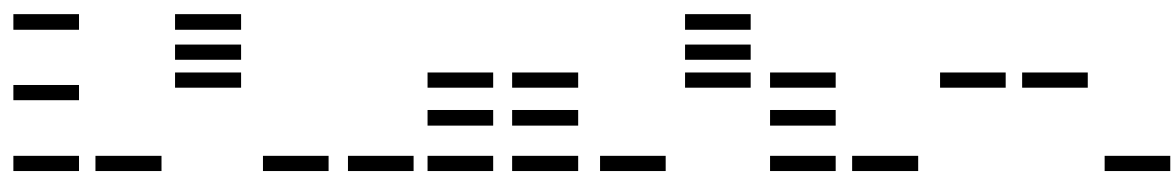

B

C
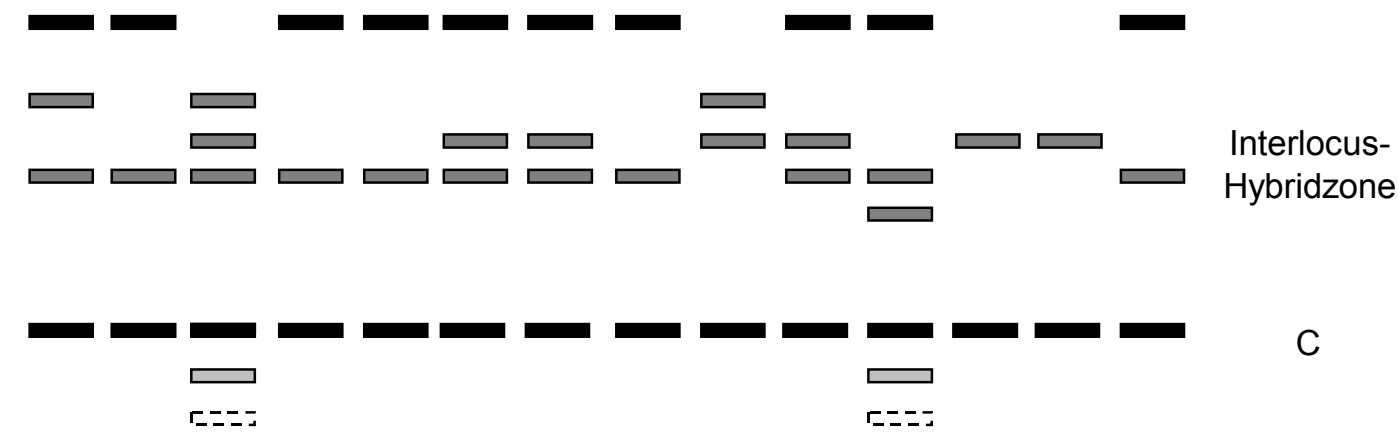

C

B13 B33 B12 B33 B33 B23 B23 B33 B12 B23 B33 B22 B22 B33

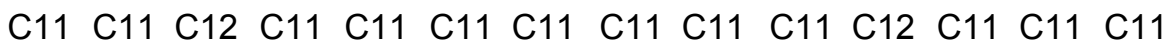

Die A-Zone des Enzymsystems PGI (in Abb. 4.9 nicht abgebildet) deutete eine Variation der Enzyme an, die jedoch aufgrund der Unschärfe der Muster nicht ausgewertet werden konnte. Dagegen sind die Muster der Genorte PGI-B und -C klar und, nach anfänglichen Schwierigkeiten, sehr gut auszuwerten. Die anfänglichen Schwierigkeiten waren begründet durch die Bildung von Interlocushybridbänder zwischen den Genorten PGI-B und -C sowie der Existenz eines Nullallels am Genort PGI-C, dessen als C2 bezeichnetes Enzym sich phänotypisch nur über Intra- und Interlocushybridbänder auf dem Zymogramm nachweisen läßt. Für die Winterlinde konnten bislang für den Genort PGI-B drei und für PGI-C zwei Enzymvarianten entdeckt werden.

Unter den Enzymvarianten der Sommerlinde wurden gänzlich andere Muster gefunden (ohne Abb.). 


\section{PGM - Phosphglucomutase}

Abb. 4.10 Zymogramme und schematische Darstellung für das Enzymsystem PGM mit Bezeichnung der Enzymvarianten für die Genorte PGM-A, $-\mathrm{B},-\mathrm{C}$ und -D.

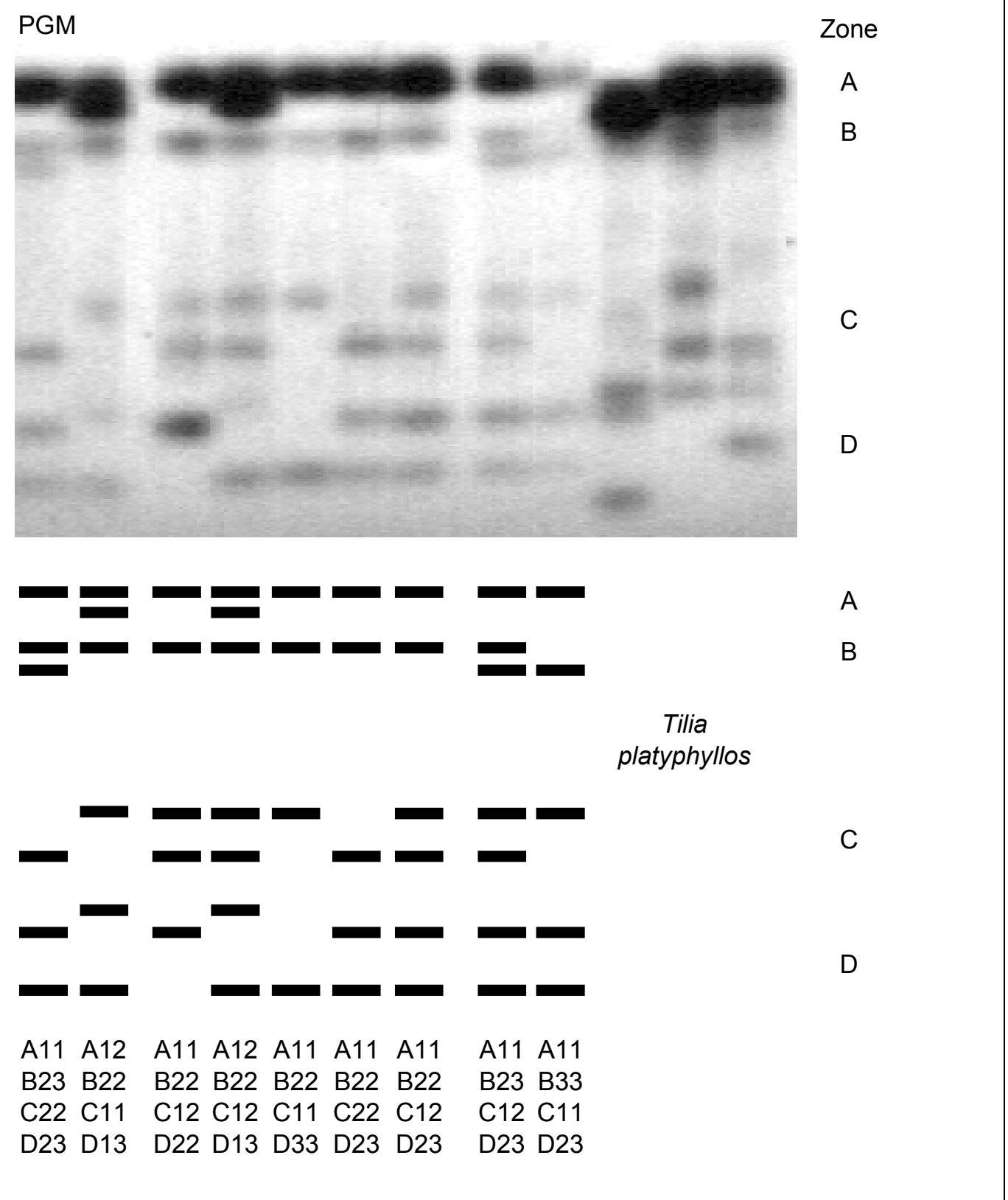

Für die Winterlinde konnten beim monomeren Enzymsystem PGM vier Genorte ausgewertet werden. Dabei zeigten sich für die Zonen PGM-A und -C je zwei Enzymvarianten, für PGM$B$ und $-C$ je drei. Die Enzymvariante PGM-D1 ist ein für die Sommerlinden artspezifisches Enzym. Die drei in der Abb. 4.10 ganz rechts zu sehenden Muster sind Enzymvarianten der Sommerlinde, welche teilweise mit denen der Winterlinde identisch, zum Teil artspezifisch sind. Das vierte Zymogramm von links ist eine Hybride; neben typischen Enzymvarianten der Winterlinde besitzt es auch die Variante D1, welche artspezifisch für die Sommerlinde ist. Für 
die meisten artspezifischen Enzyme der Sommerlinde erfolgte noch keine Benennung; dazu bedarf es einer speziell auf die Vererbungsanalyse der Sommerlinde abgestimmten Untersuchung.

\section{SKDH - Shikimatdehydrogenase}

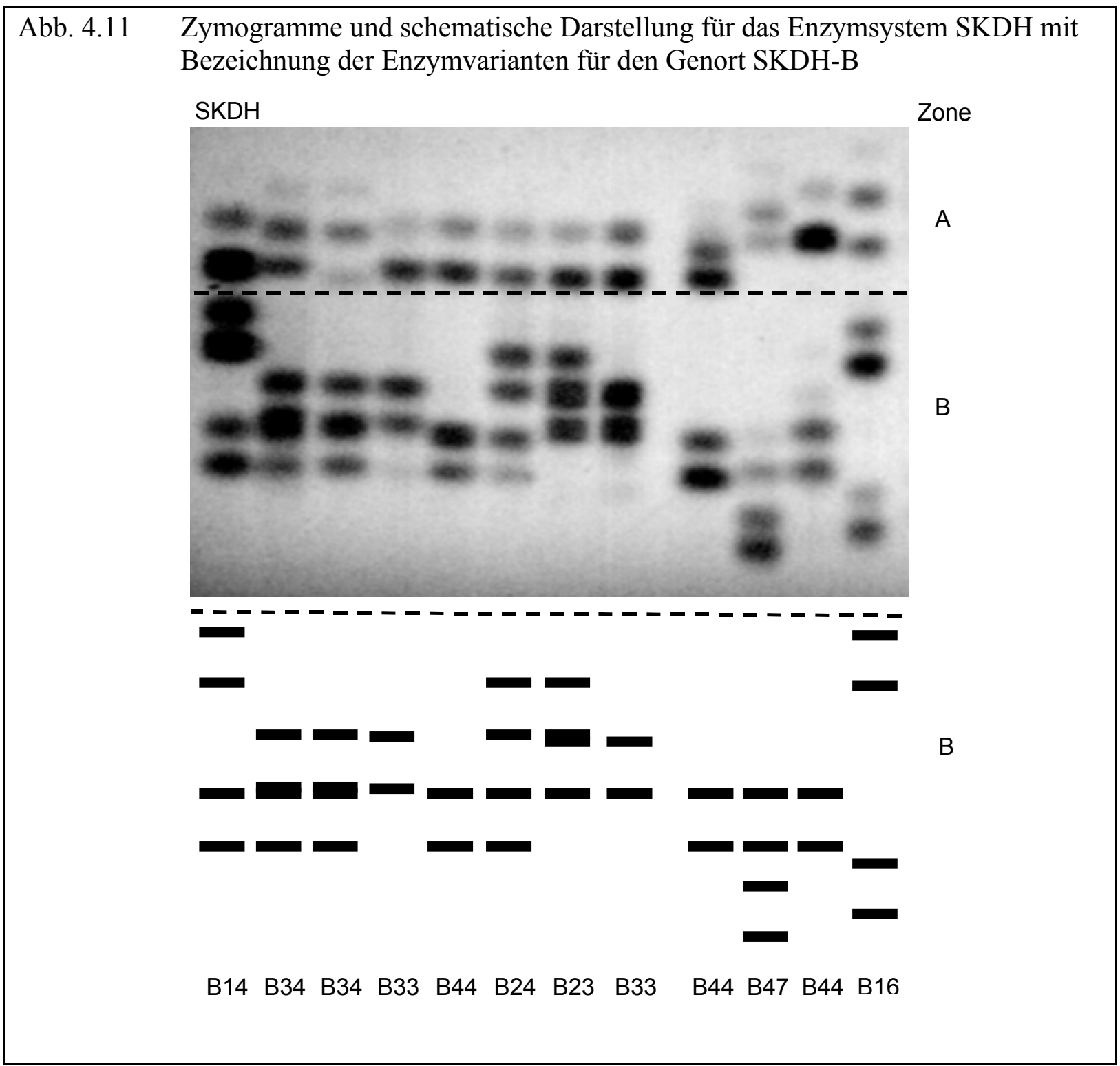

Anfänglich wurde bei dem monomeren Enzymsystem SKDH auch die A-Zone für die populationsgenetische Analyse und die Bestimmung von Selbstbefruchtungsrate und Polleneltern eingesetzt. In den Nachkommenschaften einzelner Winterlinden traten jedoch Unstimmigkeiten auf, die bis zum Abschluß der Laborphase ungeklärt blieben. Der Genort SKDH-B entschädigt dafür mit einer großen Variation von sieben Enzymen, von denen die Varianten 1 bis 4 artspezifische Enzyme der Winterlinde und die Varianten 5 bis 7 artspezifisch für Sommerlinde sind. Der Genort SKDH-B zeigte sich lange Zeit resistent gegenüber einer Interpretation 
der Zymogramme. Erst nach Untersuchung zahlreicher Nachkommenschaften wurde herausgefunden, daß ein homozygot vorliegendes Enzym als Doppelbande erscheint und daß bei Heterozygoten, je nach Wandergeschwindigkeit der Enzyme, Dreifach- oder Vierfach-Bänder zu sehen waren. Zusätzlich erschwert wurde die Interpretation der Zymogramme durch die entgegengesetzte Intensität der Doppelbänder: Bei Verwendung von Blatt- oder Knospengewebe stellt sich bei den Enzymen das untere Band als Hauptband und das obere als Nebenband dar; bei den Samen verhält es sich genau umgekehrt (s. Abb. 4.2!).

\subsection{Genetische Struktur des Versuchsbestandes}

Der Versuchsbestand Schwiegershausen umfaßt 138 Winterlinden und drei Winter/Sommerlinde-Hybriden. Bei der Aufnahme des Bestandes wurden zunächst 144 Winterlinden gezählt. Bei deren genetischer Inventur konnten 138 verschiedene Multilocus-Genotypen gefunden werden. Es zeigte sich, daß sechs Paare von Winterlinden identische Genotypstrukturen besaßen. Ein Blick auf die digitalisierte Karte zeigte, daß alle genetisch übereinstimmenden Paare in direkter Nachbarschaft zueinander standen. Bei einer Überprüfung im Bestand war zu sehen, daß diese Winterlinden am Stammfuß zusammengewachsen waren, was auf deren Abstammung von ein und demselben Elter aus Stockausschlag oder Wurzelbrut hindeutet. Diese genetisch identischen Einzelstämme wurden als ein Individuum betrachtet. Populationsgenetisch analysiert wurden die 138 Winterlinden. Die drei Hybriden blieben unberücksichtigt, da für die Sommerlinde eine erforderliche Vererbungsanalyse und damit eine Bezeichnung der Enzymvarianten nur zum Teil existiert (s. Kap. 4.1). Zusätzlich wird die Gesamtpopulation in zwei Teilkollektive aus vermutlich 93 autochthonen und 45 vermutlich gepflanzten Winterlinden unterteilt (s. Kap. 3.1). Die Teilkollektive der autochthonen und gepflanzten Winterlinden unterscheiden sich bezüglich der gebräuchlichsten populationsgenetischen Parameter nur geringfügig (Tab. 4.3).

Tab. 4.3 Gentische Analyse des Altbestandes der Winterlindenpopulation Schwiegershausen und der Teilkollektive autochthoner und gepflanzter Winterlinden.

\begin{tabular}{|lccccc|}
\hline Kollektiv & \multicolumn{2}{c}{ Diversität } & Differenzierung & Heterozygotiegrad & $\begin{array}{c}\text { allelischer } \\
\text { Abstand } \\
\mathbf{d}_{\mathbf{o}}\end{array}$ \\
Gesamt & $\mathbf{v}$ & $\mathbf{v}_{\mathbf{g a m}}$ & $\delta_{\mathbf{T}}$ & & \\
Autochthon & 1,457 & 346971 & 0,316 & $32,0 \%$ & \\
Pflanzung & 1,452 & 322394 & 0,313 & $31,7 \%$ & $7,9 \%$ \\
\hline
\end{tabular}


An allen Genorten wurden weder für den Altbestand noch für dessen Teilkollektive signifikante Homo- bzw. Heterozygotenüberschüsse festgestellt. Bezüglich der Allelhäufigkeiten an den Genorten FDH, MDH-C, PGI-B und PGM-B unterscheiden sich dagegen autochthone und gepflanzte Winterlinden signifikant (Tab. 4.4).

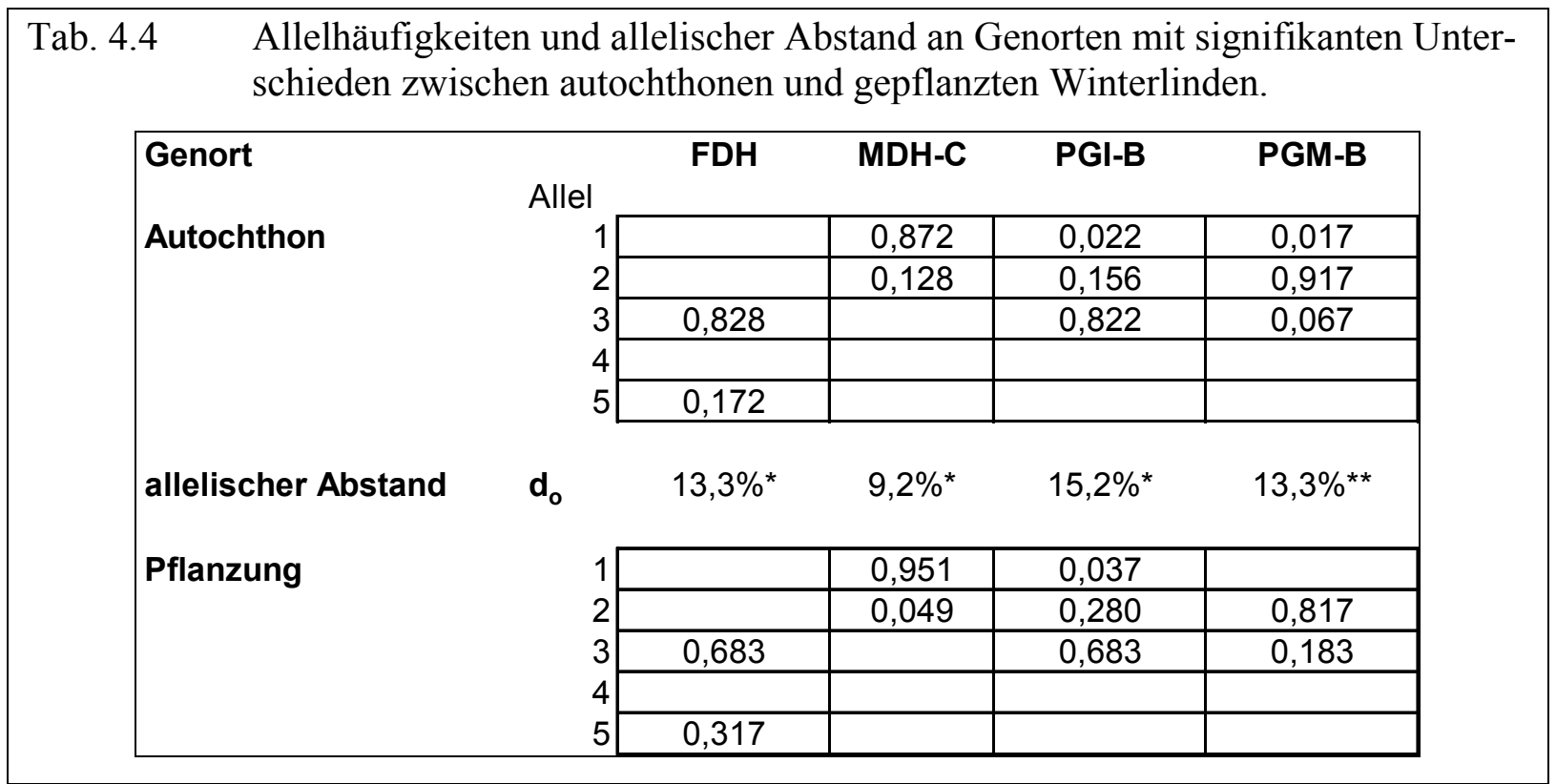

Man kann davon ausgehen, daß keine Wildlinge aus dem Bestand für die Pflanzung verwendet wurden, sondern Material unbestimmter Herkunft. Auch die hohen genotypischen Abstände und der unterschiedliche Heterozygotiegrad autochthoner und gepflanzter Winterlinden an den Genorten FDH und PGM-B deuten darauf hin (Tab. 4.5). 
Tab. 4.5 Genotyphäufigkeiten, Heterozygotiegrad und genotypischer Abstand an Genorten mit signifikanten Unterschieden zwischen autochthonen und gepflanzten Winterlinden.

\begin{tabular}{|c|c|c|c|}
\hline \multicolumn{2}{|l|}{ Genort } & FDH & PGM-B \\
\hline \multirow[t]{6}{*}{ Autochthon } & 12 & & 0,033 \\
\hline & 22 & & 0,833 \\
\hline & 23 & & 0,133 \\
\hline & 33 & 0,667 & \\
\hline & 35 & 0,322 & \\
\hline & 55 & 0,011 & \\
\hline \multicolumn{2}{|c|}{ Heterozygotiegrad } & $34,0 \%$ & $16,5 \%$ \\
\hline \multicolumn{2}{|c|}{ genotypischer Abstand $d_{0}$} & $24,2 \%$ * & $22,7 \%$ ** \\
\hline \multirow[t]{6}{*}{ Pflanzung } & 12 & & \\
\hline & 22 & & 0,634 \\
\hline & 23 & & 0,366 \\
\hline & 33 & 0,415 & \\
\hline & 35 & 0,537 & \\
\hline & 55[ & 0,049 & \\
\hline \multicolumn{2}{|c|}{ Heterozygotiegrad } & $53,7 \%$ & $36,6 \%$ \\
\hline
\end{tabular}

\subsection{Effektive Pollenwolken}

Die genetische Struktur effektiv gewordener Pollenwolken wurde für die Nachkommenschaften von 49 Winterlinden ermittelt. Eine Bestimmung der Pollenwolken erfolgte über die Maximum-Likelihood-Methode von GILLET (1997, s. Kap.3.6.4).

Für die Messung der Variation wurde der Parameter $\delta_{\mathrm{T}}$, für die Messung der Differenzierung wurden der allelische Abstand $\mathrm{d}_{0}$ und das Differenzierungsmaß $\mathrm{D}_{\mathrm{j}}$ verwendet.

In Abb. 4.12 zeigen die einzelnen Pollenwolken ein höchst unterschiedliches Maß der Differenzierung $D_{j}$. Die Differenzierung der einzelnen Pollenwolken reicht von fast $28 \%$ (Winterlinde Nr. 129) bis zu einer geringen Differenzierung von etwas über $6 \%$ zum Komplement der Pollenwolken (Winterlinde Nr. 92). Sehr unterschiedlich ist auch die Variation innerhalb der einzelnen Pollenwolken. Mit einem $\delta_{\mathrm{T}}$ von $10 \%$ die geringste Variation besitzt die Pollenwolke der Winterlinde Nr. F4, welche von den vier in der Feldmark stehenden Winterlinden mit $1000 \mathrm{~m}$ am weitesten vom Bestandesrand entfernt steht. Über die höchste Variation verfügt die Pollenwolke der Winterlinde Nr. 98 mit knapp 34 \%. Bei der Abb. 4.12 ist zu beachten, daß die $\mathrm{D}_{\mathrm{j}}$-Werte für die Pollenwolken ohne die aus der Genotypstruktur des Altbestandes simulierte Pollenwolke berechnet wurden; der $\mathrm{D}_{\mathrm{j}}$-Wert für die simulierte Pollenwolke 
des Altbestands wurde in einer zweiten Berechnung gesondert ermittelt und der Abb. 4.12 nur als Vergleichswert hinzugefügt.

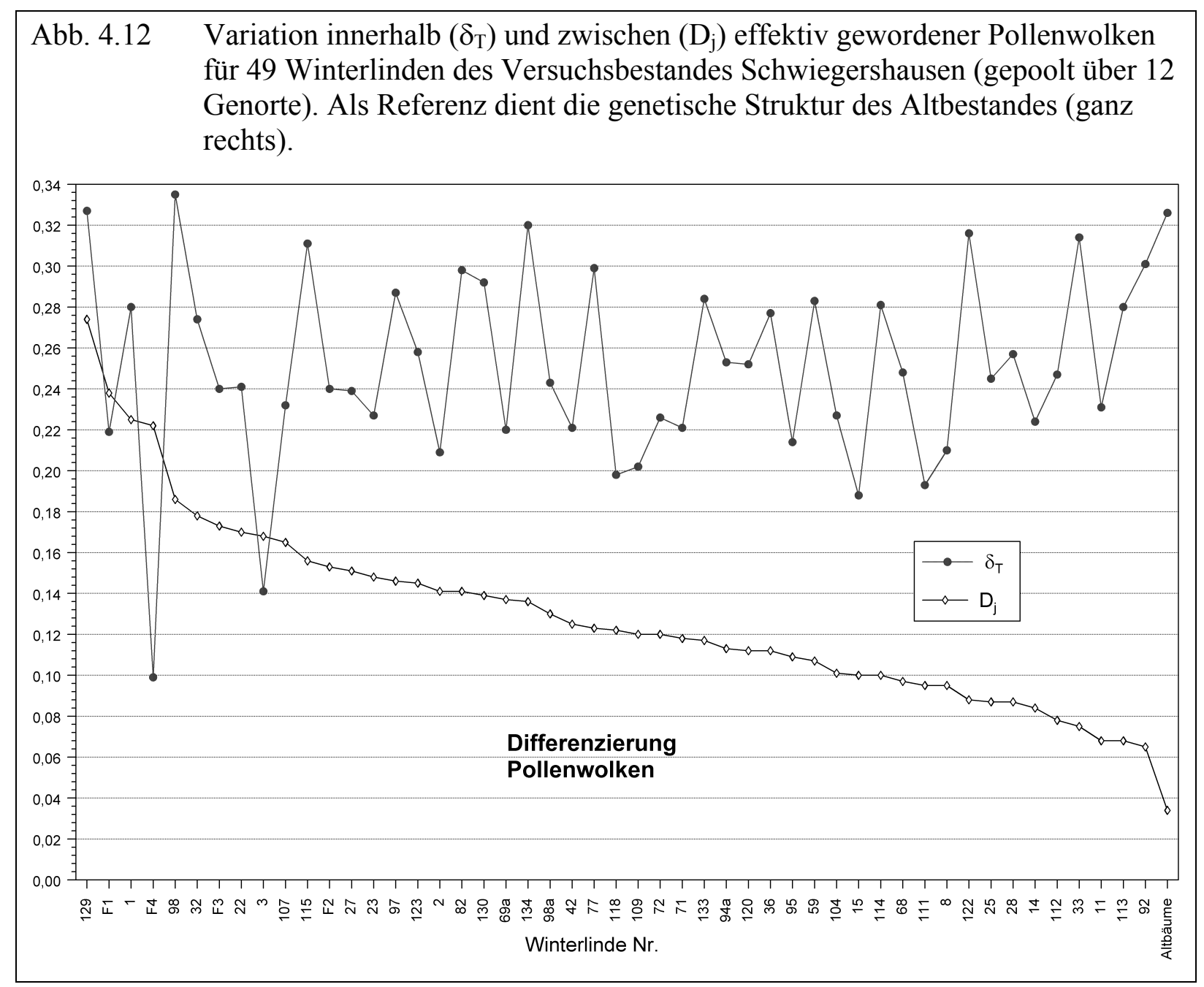

Eine nennenswerte Abhängigkeit der Parameter $\mathrm{D}_{\mathrm{j}}$ und $\delta_{\mathrm{T}}$ voneinander war nicht festzustellen.

Noch deutlicher werden die Unterschiede zwischen den Pollenwolken bei Betrachtung des allelischen Abstands $\mathrm{d}_{0}$. Die Auswertung aller 1176 Paarvergleiche zwischen den Pollenwolken der 49 Winterlinden ergab

- einen minimalen allelischen Abstand $\mathrm{d}_{0}$ von $1,7 \%$

- einen maximalen allelischen Abstand d $d_{0}$ von 94,7 \%

- einen mittleren allelischen Abstand $\mathrm{d}_{0}$ von $44,9 \%$.

Folglich haben je zwei Pollenwolken im Einzelfall bis zu 94,7\% und im Mittel 44,9\% der Allele nicht gemeinsam! 
Aus dem Teil der Population, in dem 45 Winterlinden in der Dichte eines Reinbestandes stehen, wurden die effektiven Pollenwolken von vier Winterlinden ermittelt. Der geringste allelische Abstand zwischen den acht Paarvergleichen betrug 6,5\%, der höchste 33,5\% und das Mittel 25,9\%.

Die Pollenwolke eines Baumes kann für $\delta_{\mathrm{T}}$ dann hohe Werte annehmen, wenn überwiegend Fremdpollen von vielen, genetisch variablen Polleneltern effektiv geworden sind. Bei einem hohen Anteil der Selbstbefruchtung wird dann ein großes $\delta_{\mathrm{T}}$ berechnet, wenn der Samenelter an vielen Genorten heterozygot ist, also einen hohen Heterozygotiegrad aufweist. Verfügt der Samenelter über einen geringen Heterozygotiegrad und besteht die effektiv gewordene Pollenwolke zu großen Teilen aus Eigenpollen, ist die genetische Variation innerhalb dieser Pollenwolke klein. Diese Abhängigkeit der Variation innerhalb einer Pollenwolke vom Heterozygotiegrad des Samenelters zeigt sich auch für die 49 Winterlinden. Während $D_{j}$ unbeeinflußt vom Heterozygotiegrad des Samenelters bleibt, korreliert $\delta_{\mathrm{T}}$ signifikant mit diesem (s. Tab. 4.6).

\begin{tabular}{|c|c|c|c|c|c|}
\hline Tab. 4.6 & $\begin{array}{l}\text { Berechnete Ko } \\
\text { cus-Diversität } \\
\text { zierung zwisch } \\
\text { menelters. In d } \\
\text { tion jeweils ink } \\
\text { den ein. In Kla1 } \\
\text { zienten. }\end{array}$ & $\begin{array}{l}\text { lation von } \\
\text { m), Variati } \\
\text { den Pollen } \\
\text { Berechnun } \\
\text { ive und ex } \\
\text { ern die Vc }\end{array}$ & $\begin{array}{l}\text { iversität ( } \\
\text { innerhalb } \\
\text { lken }\left(\mathbf{D}_{\mathbf{j}}\right) \\
\text { ler Bestim } \\
\text { ssive der ir } \\
\text { eichen der }\end{array}$ & $\begin{array}{l}\text { lypothetis } \\
\text { er Pollent } \\
\text { dem Het } \\
\text { eeitsmaße } \\
\text { er Feldma } \\
\text { tsprechenc }\end{array}$ & $\begin{array}{l}\text { ametisch } \\
\left(\delta_{T}\right) \text { un } \\
\text { ygotiegr } \\
\text { die Ges } \\
\text { ehenden } \\
\text { Korrelati }\end{array}$ \\
\hline & & & Bestimm & tsmaß $r^{2}$ & \\
\hline & & $\mathbf{v}$ & $\mathbf{v}_{\text {gam }}$ & $\delta_{\mathrm{T}}$ & $D_{i}$ \\
\hline & Gesamtpopulation & (+) $0,14^{* *}$ & (+) $0,15^{\star *}$ & (+) $0,13^{*}$ & (+) 0,02 \\
\hline & ohne Feldlinden & $(+) 0,16^{* *}$ & $(+) 0,18^{* *}$ & $(+) 0,15^{* *}$ & (+) 0,01 \\
\hline
\end{tabular}

Die genetische Differenzierung der Pollenwolke eines Samenelters zum Komplement aller restlichen Pollenwolken wird von der genetischen Struktur des Samenelters weniger beeinflußt (s. o.); vielmehr ist für eine geringe Differenzierung zum Komplement entscheidend, ob ein nennenswerter Beitrag genetischer Information anderer Populationsmitglieder in dieser Pollenwolke enthalten ist. Sind die Nachkommen des betrachteten Samenelters von vielen verschiedenen Polleneltern befruchtet worden, wird $D_{j}$ tendenziell kleine Werte annehmen; sind die Nachkommen überwiegend aus Selbstbefruchtung entstanden, wird die effektiv gewordene Pollenwolke ein hohes $\mathrm{D}_{\mathrm{j}}$ zum Komplement der restlichen Pollenwolken 
aufweisen. Bei einer linearen Regressionsanalyse wird diese Aussage eindrucksvoll durch die positive und hoch signifikante Korrelation der (über verschiedene Verfahren ermittelten) Selbstbefruchtungsraten mit dem $\mathrm{D}_{\mathrm{j}}$ der Pollenwolken für die 49 Winterlinden untermauert (s. Tab. 4.7).

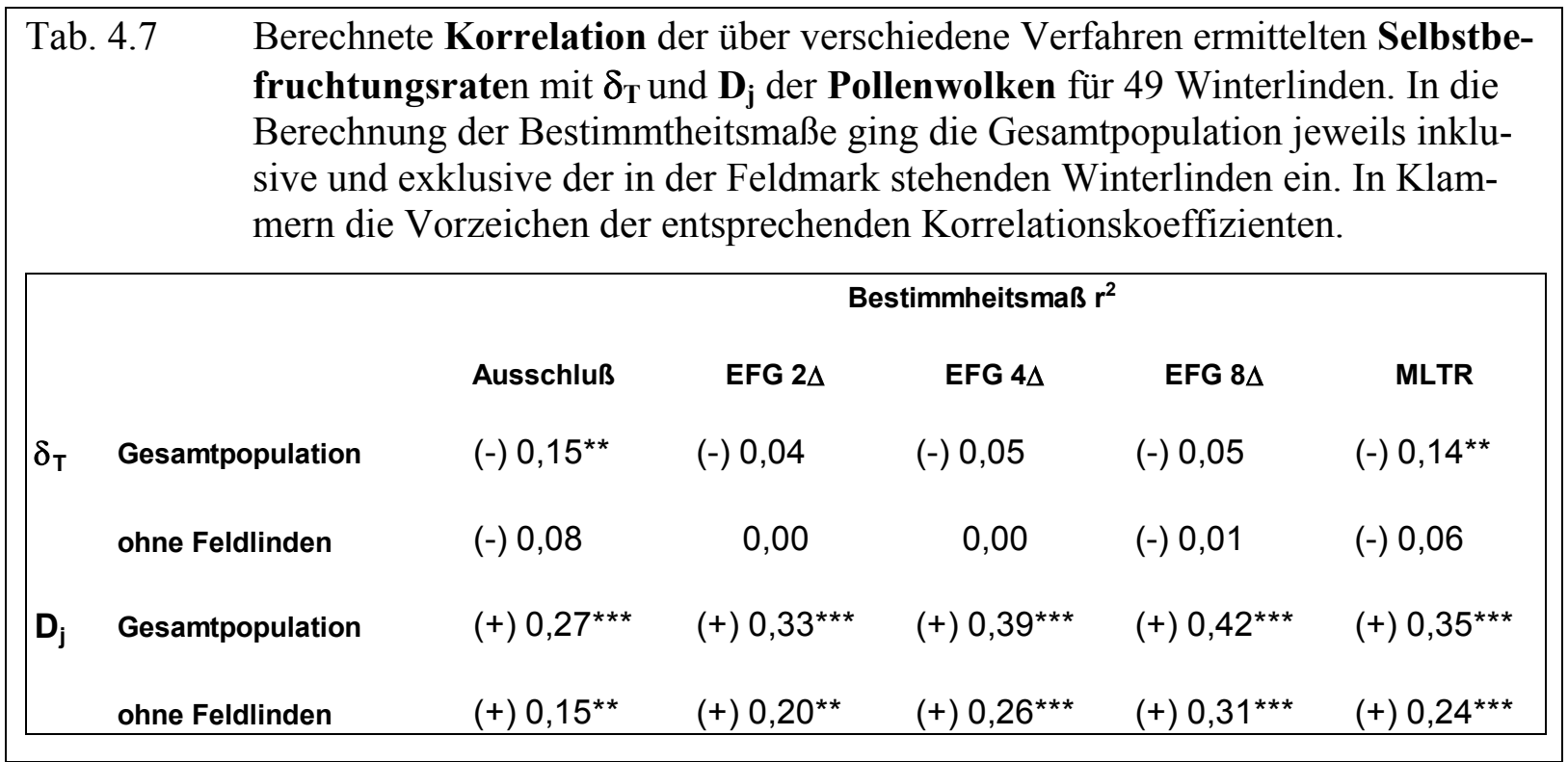

Diese starke Korrelation mit der Selbstbefruchtungsrate ist für $\delta_{\mathrm{T}}$ nicht in dem Maße gegeben. Wie oben geschildert, kann auch bei einer hohen Selbstbefruchtungsrate eine große Variation in der Pollenwolke zu finden sein, wenn der Samenelter einen hohen Heterozygotiegrad aufweist. Trotzdem sollte, je nach Verfahren, von einem mäßigen negativen Einfluß eines hohen Anteils an Selbstbefruchtung auf $\delta_{\mathrm{T}}$ ausgegangen werden. Der Zusammenhang zwischen $\mathrm{D}_{\mathrm{j}}$, $\delta_{\mathrm{T}}$ und der Selbstbefruchtungsrate (ermittelt mit dem Programm MLTR) ist in der folgenden Abb. 4.13 veranschaulicht: 


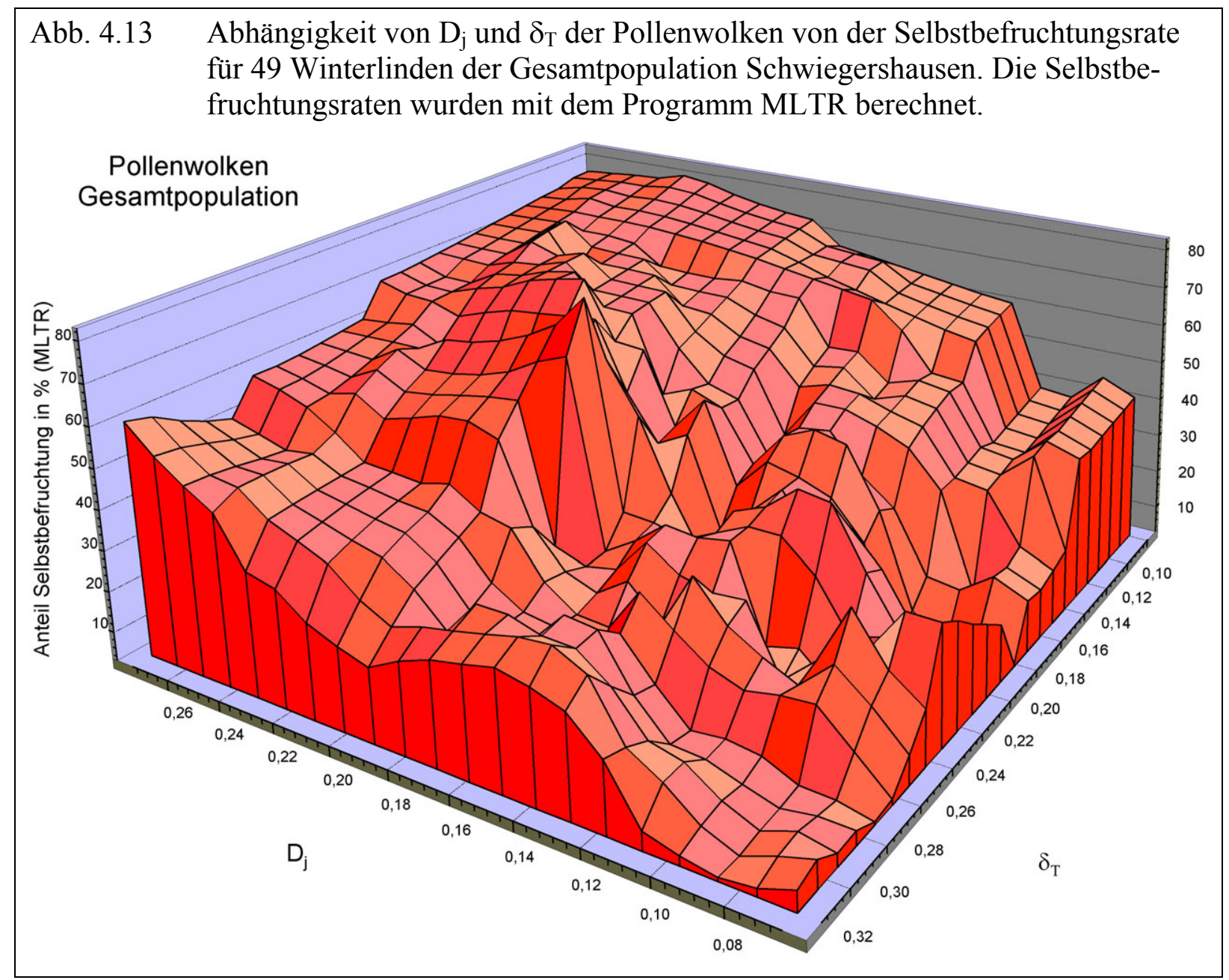

Neben dem Heterozygotiegrad und der Selbstbefruchtungsrate des Samenelters werden noch weitere Faktoren bezüglich eines möglichen Einflusses auf die Variation der Pollenwolken überprüft. In Frage kommen dafür Faktoren, die eine hohe Selbstbefruchtungsrate und gleichzeitig den Beitrag nur weniger Polleneltern fördern könnten: Der Abstand des Samenelters zum nächsten und der $\varnothing$ Abstand zu den nächsten 5 bzw. 10 Nachbarn, die Kronengröße des Samenelters und die $\varnothing$ Kronengröße der nächsten 5 bzw. 10 Nachbarn. Dabei zeigen sich lediglich bei der Betrachtung der Gesamtpopulation, also inklusive der isoliert in der Feldmark stehenden Winterlinden, eine signifikante positive Korrelation von $\mathrm{D}_{\mathrm{j}}$ bzw. eine negative Korrelation von $\delta_{\mathrm{T}}$ mit der Entfernung zu den nächsten Paarungspartnern. Für $\mathrm{D}_{\mathrm{j}}$ wird betreffend der Gesamtpopulation auch eine signifikante positive Abhängigkeit mit der Kronengröße des Samenelters berechnet (s. Tab. 4.8). 


\begin{tabular}{|c|c|c|c|c|c|c|c|c|}
\hline \multirow{4}{*}{\multicolumn{2}{|c|}{ Tab. 4.8}} & \multicolumn{7}{|c|}{$\begin{array}{l}\text { Berechnete Korrelation von } \mathbf{D}_{\mathbf{j}} \text { und } \delta_{\mathbf{T}} \text { der Pollenwolken mit der Entfernung } \\
\text { des Samenelters zu den nächsten potentiellen Paarungspartnern, der } \varnothing \text { Kro- } \\
\text { nengröße der nächsten potentiellen Paarungspartner und der Kronengröße des } \\
\text { Samenelters. In die Berechnung der Bestimmtheitsmaße ging die Gesamtpopu- } \\
\text { lation jeweils inklusive und exklusive der in der Feldmark stehenden Winterlin- } \\
\text { den ein. In Klammern die Vorzeichen der entsprechenden Korrelationskoeffi- } \\
\text { zienten. }\end{array}$} \\
\hline & & & \multirow{3}{*}{$\begin{array}{c}\text { Entfernung } \\
\text { nächster } \\
\text { Nachbar }\end{array}$} & \multirow{2}{*}{\multicolumn{3}{|c|}{ Bestimmheitsmaß $\mathrm{r}^{2}$}} & \multirow{2}{*}{\multicolumn{2}{|c|}{ nächste 5 Nachbarn }} \\
\hline & & & & & & Nachbarn & & \\
\hline & & & & Samenelter & Entfernung & Kronengrößen & Entfernung & Kronengrößen \\
\hline \multirow[t]{2}{*}{$\delta_{\mathrm{T}}$} & \multicolumn{2}{|c|}{ Gesamtpopulation } & $(-) 0,11^{\star *}$ & $(-) 0,06$ & (-) $0,12^{* *}$ & (-) 0,02 & (-) $0,13^{\star *}$ & (-) 0,02 \\
\hline & \multicolumn{2}{|c|}{ ohne Feldlinden } & (+) 0,02 & 0,00 & $(+) 0,03$ & (+) 0,01 & (+) 0,01 & (+) 0,03 \\
\hline \multirow[t]{2}{*}{$D_{j}$} & \multicolumn{2}{|c|}{ Gesamtpopulation } & (+) $0,20^{* *}$ & $(+) 0,13^{*}$ & $(+) 0,14^{* *}$ & (+) 0,02 & (+) $0,14^{* *}$ & (+) 0,02 \\
\hline & \multicolumn{2}{|c|}{ ohne Feldlinden } & 0,00 & 0,00 & 0,00 & (-) 0,01 & (-) 0,01 & $(-) 0,02$ \\
\hline
\end{tabular}

Die folgenden 3D-Graphiken zeigen die Abhängigkeit von $\mathrm{D}_{\mathrm{j}}$ und $\delta_{\mathrm{T}}$ von dem $\varnothing$ Abstand des Samenelters zu den nächsten 10 Nachbarn (Abb. 4.14) und von der Kronengröße des Samenelters (Abb. 4.15) bei Betrachtung der Gesamtpopulation Schwiegershausen.

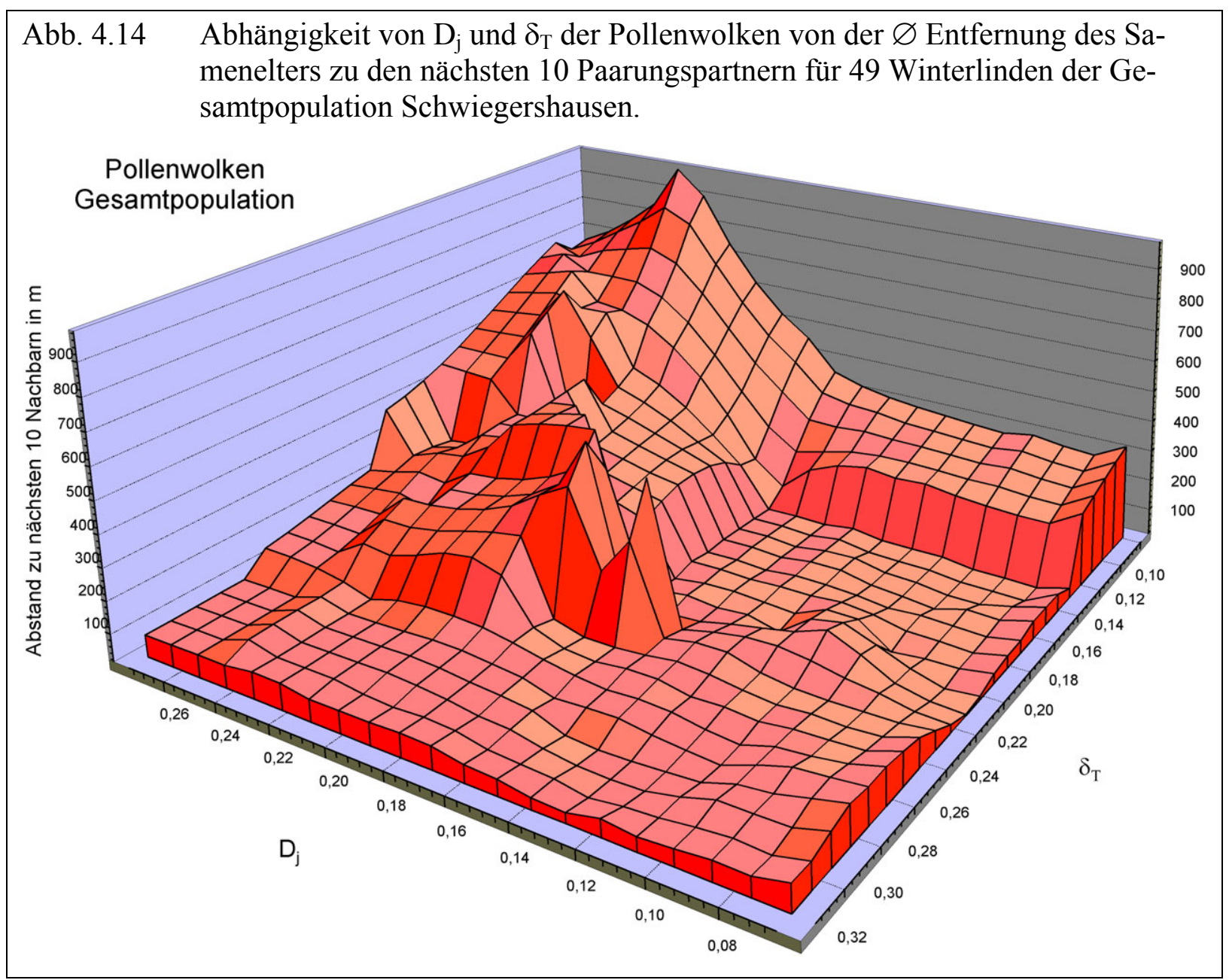


Während die Abhängigkeit von $\mathrm{D}_{\mathrm{j}}$ und $\delta_{\mathrm{T}}$ von der Entfernung des Samenelters zu den nächsten zehn Nachbarn offensichtlich ist (Abb. 4.14), ist dieses für die Kronengröße des Samenelters nur für $\mathrm{D}_{\mathrm{j}}$ gegeben (Abb. 4.15). $\delta_{\mathrm{T}}$ zeigt lediglich eine nicht signifikante Tendenz, bei größeren Kronen einen kleineren Wert anzunehmen.

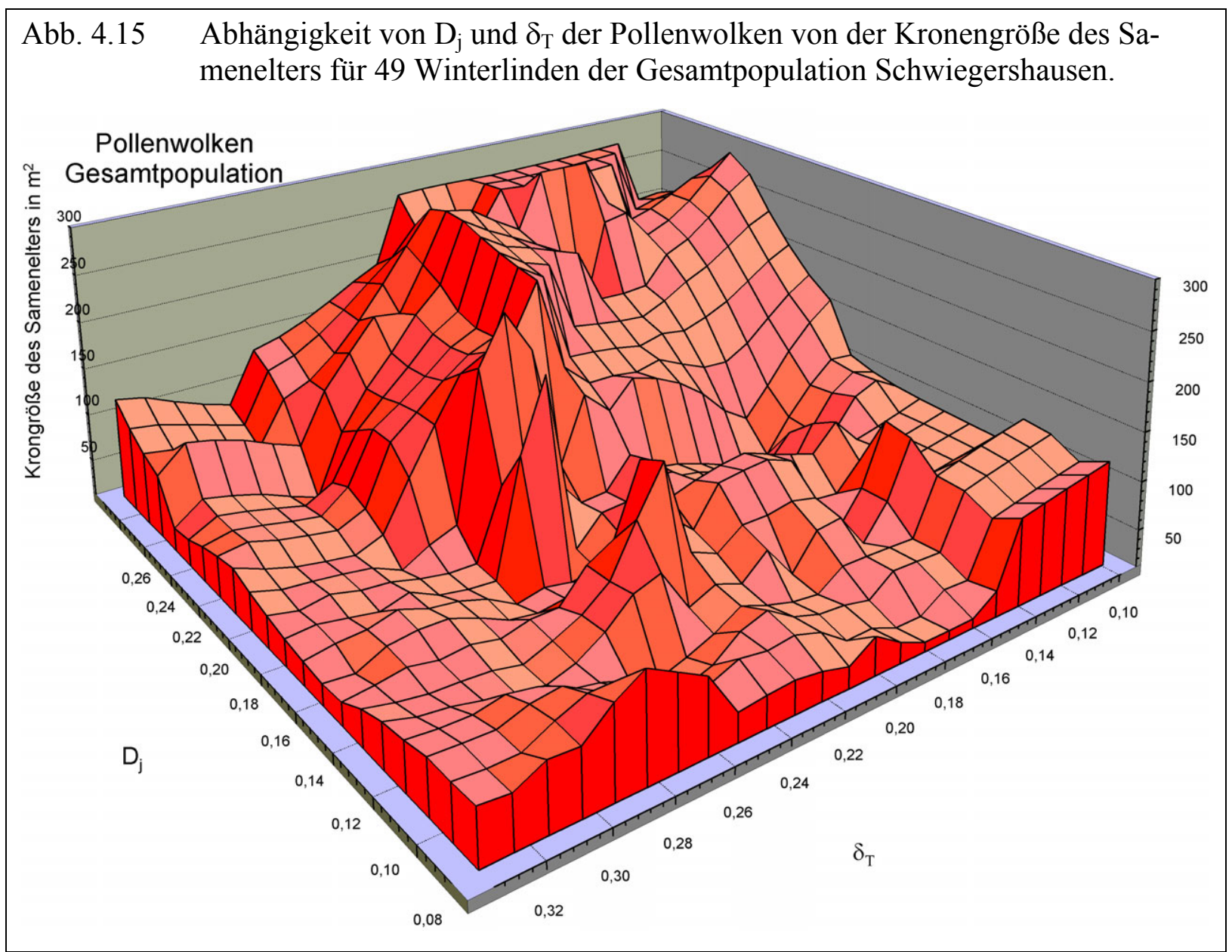

$\mathrm{Zu}$ beachten ist, daß eine signifikante Korrelation von den Faktoren Abstand zu den nächsten Paarungspartnern und Kronengröße des Samenelters nur für die Gesamtpopulation berechnet werden. Gehen die abseits in der Feldmark stehenden Winterlinden nicht in die Berechnungen ein, wird für die Winterlinden im Bestand keine Abhängigkeit von diesen Faktoren ausgewiesen.

\section{Fazit}

Die Unterschiede zwischen den effektiv gewordenen Pollenwolken der einzelnen Winterlinden sind groß. Sehr unterschiedliche und teilweise große Werte ihrer Differenzierung bestätigen dies. Im Mittel haben die Pollenwolken 44,9 \% der Allele nicht gemeinsam, im Einzelfall sogar bis zu 94,7 \%. 
Die Variation innerhalb einer Pollenwolke $\left(\delta_{\mathrm{T}}\right)$ ist dann hoch, wenn die Nachkommen überwiegend aus Fremdbefruchtung hervorgegangen sind. Bei einem hohen Selbstbefruchtungsanteil kann die Variation innerhalb einer Pollenwolke ebenfalls groß sein, wenn der Samenelter einen hohen Heterozygotiegrad aufweist.

Eine strikte Korrelation besteht zwischen dem $D_{j}$ der Pollenwolke und der Selbstbefruchtungsrate des betreffenden Samenelters. Die Differenzierung zwischen einer Pollenwolke und dem Komplement der restlichen Pollenwolke $\left(D_{j}\right)$ steigt mit der Selbstbefruchtungsrate des Samenelters. $D_{j}$ bleibt hingegen vom Heterozygotiegrad des Samenelters unbeeinflußt.

Nur für die Gesamtpopulation (inklusive der in der Feldmark stehenden Winterlinden) kann eine Abhängigkeit der Parameter $D_{j}$ und $\delta_{T}$ von der Entfernung des Samenelters zu den nächsten Paarungspartnern und für $D_{j}$ von der Kronengröße des Samenelters festgestellt werden.

\subsection{Bestäubungsversuche}

Grundlage für dieses Kapitel bilden die im Sommer in der Blühperiode 1995 durchgeführten Bestäubungsversuche an drei Winterlinden des Versuchsbestandes Schwiegershausen (ausführliche Beschreibung s. Kap. 3.6.3). Die Ergebnisse der verschiedenen Versuche für die untersuchten Bäume Nr. 56, 64 und 65 werden in der Tab. 4.9 zusammengefaßt.

\begin{tabular}{|c|c|c|c|c|c|c|c|c|c|c|c|}
\hline \multicolumn{2}{|c|}{ Tab. 4.9} & \multicolumn{10}{|c|}{$\begin{array}{l}\text { Ausmaß der Entwicklung von Blüten zu vitalen Samen unter verschiedenen } \\
\text { Versuchsbedingungen. }\end{array}$} \\
\hline \multirow[b]{2}{*}{ Nr. } & \multirow{2}{*}{\multicolumn{2}{|c|}{$\begin{array}{l}\text { Versuch } \\
\text { Bedingungen }\end{array}$}} & \multirow{2}{*}{$\begin{array}{c}\text { Blüten } \\
12.07 .95\end{array}$} & \multicolumn{6}{|c|}{ Samenansatz } & \multicolumn{2}{|c|}{ Samen } \\
\hline & & & & \multicolumn{2}{|c|}{04.08 .95} & \multicolumn{2}{|c|}{31.08 .95} & \multicolumn{2}{|c|}{10.10 .95} & \multicolumn{2}{|c|}{ vital } \\
\hline 1 & Tüte+ & nbehandelt & 345 & 205 & $59,4 \%$ & 33 & $9,6 \%$ & 7 & $2,0 \%$ & 4 & $1,2 \%$ \\
\hline 2 & Tüte+ & maskuliert & 282 & 228 & $80,9 \%$ & 72 & $25,5 \%$ & 2 & $0,7 \%$ & 0 & $0,0 \%$ \\
\hline \multirow[t]{2}{*}{3} & Tüte+ & mask.+künstl.Best. & 319 & 223 & $69,9 \%$ & 100 & $31,3 \%$ & 52 & $16,3 \%$ & 21 & $6,6 \%$ \\
\hline & & $1-3$ & 946 & 656 & $69,3 \%$ & 205 & $21,7 \%$ & 61 & $6,4 \%$ & 25 & $2,6 \%$ \\
\hline 4 & Nylon & unbehandelt & 397 & 153 & $38,5 \%$ & 25 & $6,3 \%$ & 4 & $1,0 \%$ & 1 & $0,3 \%$ \\
\hline 5 & Nylon & emaskuliert & 306 & 175 & $57,2 \%$ & 61 & $19,9 \%$ & 1 & $0,3 \%$ & 1 & $0,3 \%$ \\
\hline \multirow[t]{2}{*}{6} & Nylon & emask.+künstl.Best. & 348 & 185 & $53,2 \%$ & 53 & $15,2 \%$ & 22 & $6,3 \%$ & 17 & $4,9 \%$ \\
\hline & & $4-6$ & 1051 & 513 & $48,8 \%$ & 139 & $13,2 \%$ & 27 & $2,6 \%$ & 19 & $1,8 \%$ \\
\hline 7 & Frei+c & behandelt & 388 & 188 & $48,5 \%$ & 62 & $16,0 \%$ & 19 & $4,9 \%$ & 13 & $3,4 \%$ \\
\hline 8 & Frei+c & naskuliert & 342 & 195 & $57,0 \%$ & 79 & $23,1 \%$ & 34 & $9,9 \%$ & 12 & $3,5 \%$ \\
\hline \multirow[t]{3}{*}{9} & Frei+c & nask.+künstl.Best. & 156 & 98 & $62,8 \%$ & 52 & $33,3 \%$ & 21 & $13,5 \%$ & 6 & $3,8 \%$ \\
\hline & & $7-9$ & 886 & 481 & $54,3 \%$ & 193 & $21,8 \%$ & 74 & $8,4 \%$ & 31 & $3,5 \%$ \\
\hline & & $1-9$ & 2883 & 1650 & $57,2 \%$ & 537 & $18,6 \%$ & 162 & $5,6 \%$ & 75 & $2,6 \%$ \\
\hline
\end{tabular}


Bei vollständiger Isolation und Emaskulierung der Blüten (Versuchsbedingung 2) und fehlerfreier Durchführung ist mit dem Ausbleiben von Fruchtansatz zu rechnen. Dies ist allerdings nur dann gegeben, wenn die Winterlinde nicht asexuell über Apomixis reproduzieren kann. Die Versuchsbedingung 2 (Tüte + emaskuliert) stellt somit eine Nullkontrolle dar. Wie der Tab. 4.9 zu entnehmen ist, hat nur unter der Versuchsbedingung 2 überhaupt keine Samenbildung stattgefunden. Eine Samenbildung wird durch eine Isolation per se nicht beeinträchtigt (unter den Versuchsbedingungen 3 und 6 werden prozentual die meisten Samen gebildet).

Aus den isolierten unbehandelten Blüten (Versuchsbedingung 1) entwickelten sich vier vitale Samen (1,2\% der so behandelten Blüten), die nach dem Pollenelterbestimmungsverfahren EFG $2 \Delta$ aus Selbstbefruchtung entstanden sind.

Einen Fruchtansatz von jeweils 0,3\% erreichten die gegen Insekten isolierten und nicht künstlich bestäubten Blüten (Versuchsbedingungen 4 und 5).

Der höchste Samenansatz wird unter Versuchsbedingung 3 mit 6,6 \% der untersuchten Blüten erreicht, gefolgt von 4,9\% unter Versuchsbedingung 6. Dieses zeigt die hohe Effizienz künstlicher Bestäubung bei der Winterlinde. Bei den frei liegenden Blüten (Versuchsbedingungen 7-9) ist nach künstlicher Bestäubung kein signifikant höherer Samenansatz zu beobachten. Bei freier Abblüte (Versuchsbedingung 7) entwickelten 13 der 388 unbehandelten Blüten vitale Samen $(3,4 \%)$.

\subsubsection{Art des Pollentransportes}

Bei den Versuchen 4 und 5 ist eine Bestäubung der Narben durch Insekten mittels Nylonnetze unterbunden worden. Das Nylonnetz für sich hat keinen negativen Einfluß auf die Samenbildung, da aus Versuch 6 nach künstlicher Bestäubung ein hoher Samenansatz resultierte.

Nach einer Pollenelterbestimmung über das Ausschlußverfahren bzw. über die Methode EFG $2 \Delta$ (vgl. Kap. 3.9) wurde der Samen in Versuch 4 von Fremdpollen, der in Versuch 5 von Eigenpollen befruchtet. Im Versuch 5 wurden die Blüten emaskuliert, der Eigenpollen muß von anderen Blüten des Samenelters durch die Nylonmaschen von außen auf die Narbe gelangt sein. In beiden Fällen kann der Pollen nur über Wind bzw. Schwerkraft auf die Narben transportiert worden sein. 


\subsubsection{Selbststerilität}

Die Zahl der Samenanlagen für die jeweiligen Versuchsbedingungen wurde in vier verschiedenen Entwicklungsstadien, vom Beginn der Blüte am 12.7. bis zur Beerntung am 10.10., ermittelt (Tab. 4.9, S. 105). Durch einen Vergleich der Reduktion fremd-, selbst- und unbefruchteter Samenanlagen in verschiedenen ontogenetischen Stadien ist festzustellen, ob Selektion in Form von Selbstinkompatibilität und/oder Inzuchtdepression wirksam ist. Zwischen Selbstinkompatibilität und früher Inzuchtdepression (bis zur Entwicklung des vitalen Samens) läßt sich über die durchgeführten Versuchsreihen nicht unterscheiden. Dazu wäre zusätzlich eine Untersuchung des Pollenschlauchwachstums im Griffel der Blüten nötig gewesen.

Repräsentativ für selbstbestäubte Blüten sind die Versuche 1 und 4. Eine Selbstbestäubung durch Schwerkraft, Erschütterung, Thermik oder Kleininsekten innerhalb der Isolation ist möglich, da die Blüten nicht emaskuliert wurden. Bei der vollständigen Isolierung (Versuch 1) ist jeglicher Eintrag von Fremdpollen unterbunden. Bei der Nylonisolation in Versuch 4 wird allein der durch Insekten transportierte Fremdpollen ausgeschlossen, durch Wind von außen eingetragener Fremdpollen nicht. Der Eintrag ist jedoch aufgrund der Ergebnisse des vorigen Kapitels als unbedeutend einzuschätzen. Aus diesem Grund kann auch, zusammen mit dem Versuch 2, der Versuch 5 als repräsentativ für unbestäubte Blüten gelten. Die emaskulierten Blüten können nur durch Polleneintrag bestäubt werden, die durch die Isolation gelangt sind. Bei Versuch 2 ist Bestäubung aufgrund vollständiger Isolation gänzlich ausgeschlossen, bei Versuch 5 kann der Polleneintrag über Wind durch die Nylonmaschen ebenfalls vernachlässigt werden.

Für Fremdbestäubung stehen die Versuche 3 und 6. Die Blüten wurden emaskuliert und mit Pollen anderer Winterlinden künstlich bestäubt. Eine Selbstbestäubung ist ausgeschlossen und Samen können nur aus Fremdbefruchtung entstanden sein. $\mathrm{Zu}$ beachten ist, daß sich unter den als fremd- und selbstbestäubt eingestuften Blüten ein nicht zu quantifizierender Anteil unbestäubter Blüten befinden können.

Die mit dem $\mathrm{Chi}^{2}$-Test berechneten Signifikanzen für die Reduktion des Samenansatzes werden vom Ausgangsstadium (am 12.7.95) und den verschiedenen Beobachtungszeitpunkten berechnet. Damit können generelle Unterschiede zwischen der Samenreduktion verschiedener Bestäubungsvarianten auf Signifikanz getestet werden. Für eine Bestimmung des Zeitraumes einer evtl. einsetzenden Selektion werden zudem Signifikanzen schrittweise von Stadium zu Stadium berechnet, d. h. der Samenansatz des jeweils vorhergehenden Stadiums bildet das 
Ausgangsstadium für die Reduktion des Samenansatzes (und nicht durchgehend der Blütenansatz am 12.7).

\section{Vergleich fremdbefruchtete/unbefruchtete Samenanlagen}

Abb. 4.16 Vergleich der Reduktion fremdbefruchteter und unbefruchteter Samenanlagen in verschiedenen ontogenetischen Stadien.

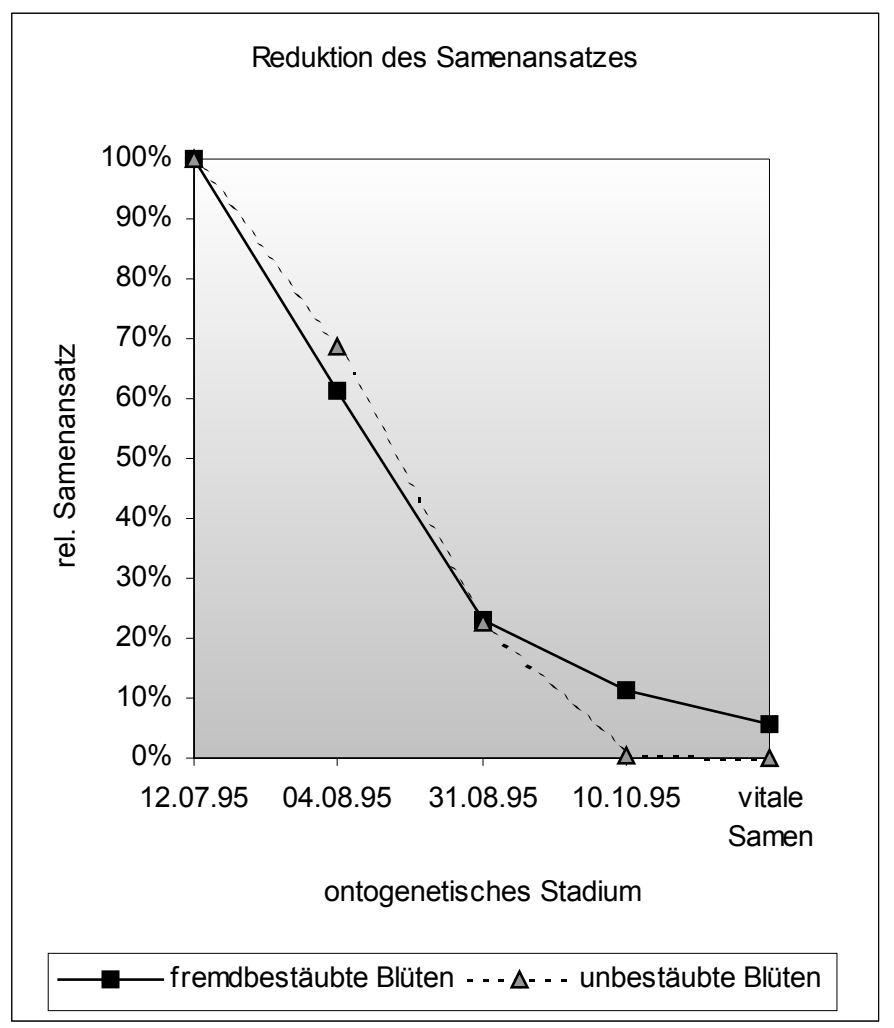

Zum Beobachtungszeitpunkt am 31.8. (sechs Wochen nach Blühbeginn) sind die fremdbefruchteten und die unbefruchteten Samenanlagen in gleichem Umfang reduziert worden. Zum 4.8. ist sogar eine geringere Reduktion unbefruchteter Samenanlagen zu verzeichnen, welche aber nicht signifikant ist. Erst zwischen dem 31.8. und 10.10. kommt es zu einem Abwurf aller unbefruchteten Samenanlagen. Bei den Fremdbefruchteten ist die Reduktion in diesem Zeitraum hingegen signifikant geringer (Tab. 4.10). 


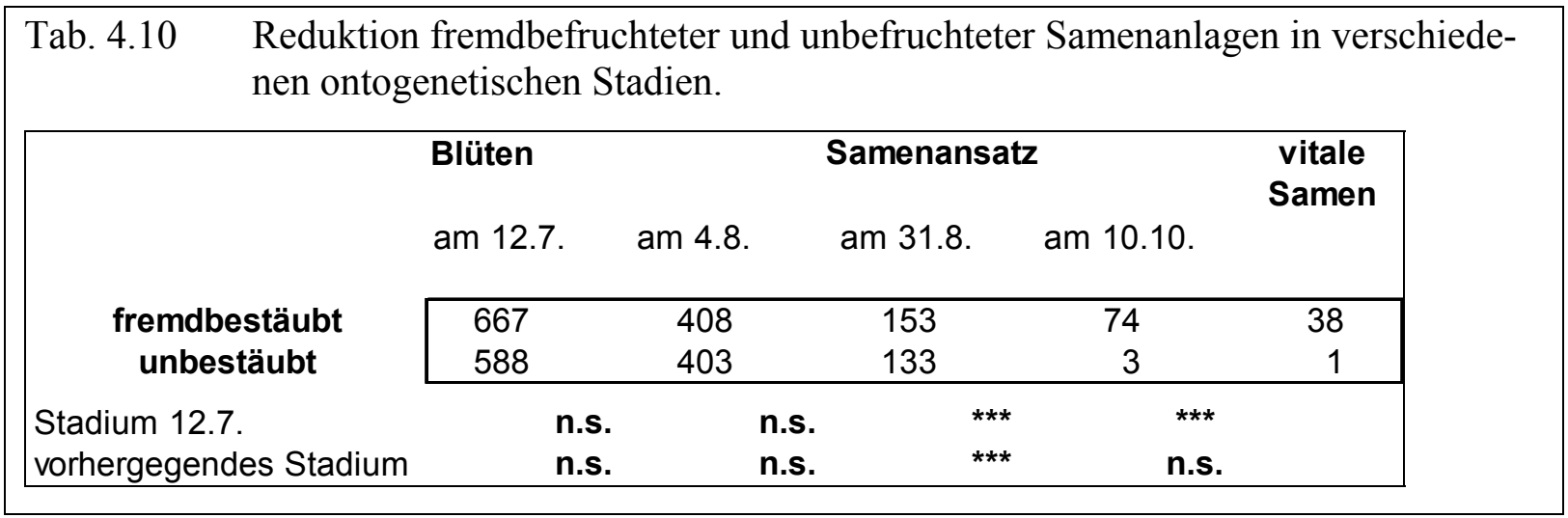

\section{Vergleich fremdbefruchtete/selbstbefruchtete Samenanlagen}

Abb. 4.17 Vergleich der Reduktion fremdbefruchteter und selbstbefruchteter Samenanlagen in verschiedenen ontogenetischen Stadien.

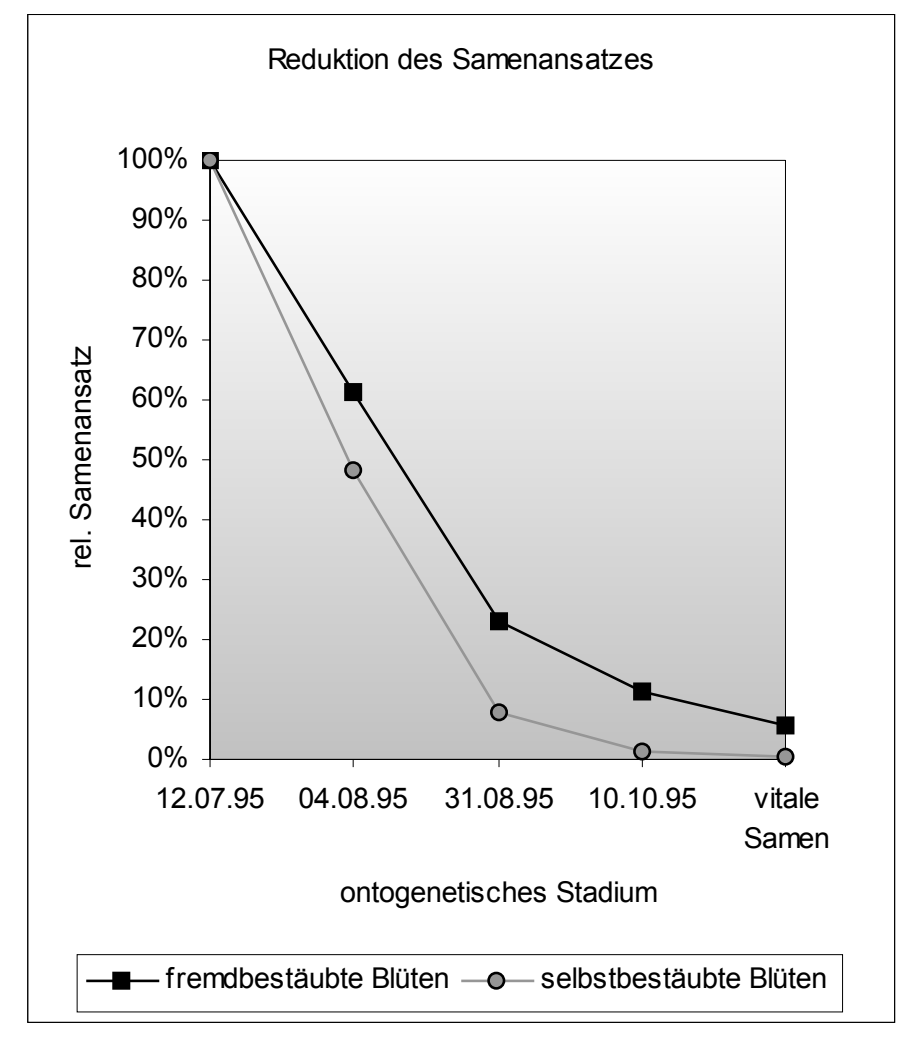

Aus der Abb. 4.17 und Tab. 4.11 wird ersichtlich, daß von Anbeginn der Beobachtungen am 12.7. starke Selektion gegen selbstbefruchtete Samenanlagen wirksam war. Vom 12.7. bis einschließlich 10.10. werden in jedem der drei beobachteten ontogenetischen Stadien gegenüber den fremdbefruchteten die selbstbefruchteten Samenanlagen signifikant stärker reduziert. Nach dem 10.10. treten keine selektiven Kräfte auf. Bei Betrachtung von Stadium zu Stadium 
kann ab diesem Zeitpunkt kein signifikanter Unterschied zwischen Selbst- und Fremdbefruchtung festgestellt werden.

Tab. 4.11 Reduktion fremdbefruchteter und selbstbefruchteter Samenanlagen in verschiedenen ontogenetischen Stadien.

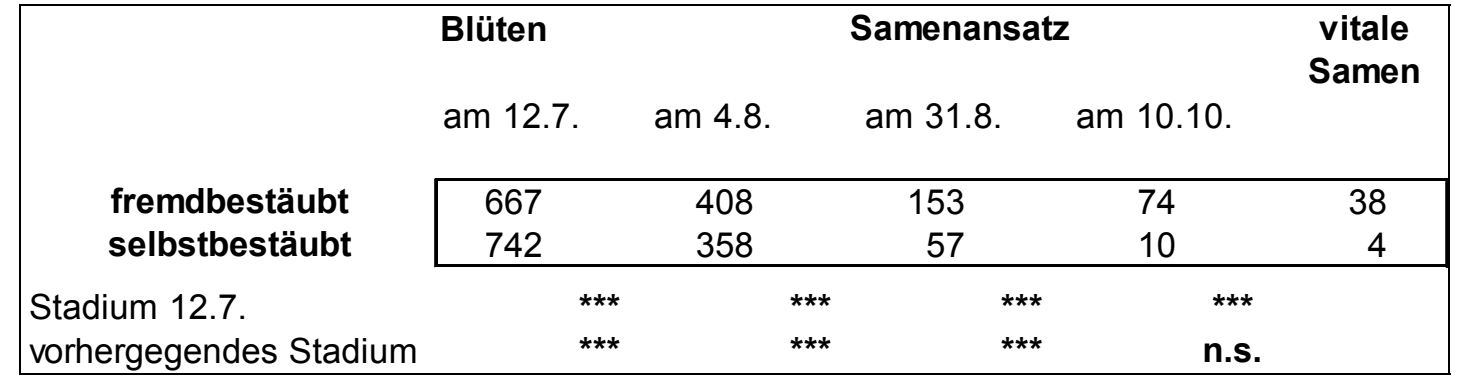

\section{Vergleich selbstbefruchtete/unbefruchtete Samenanlagen}

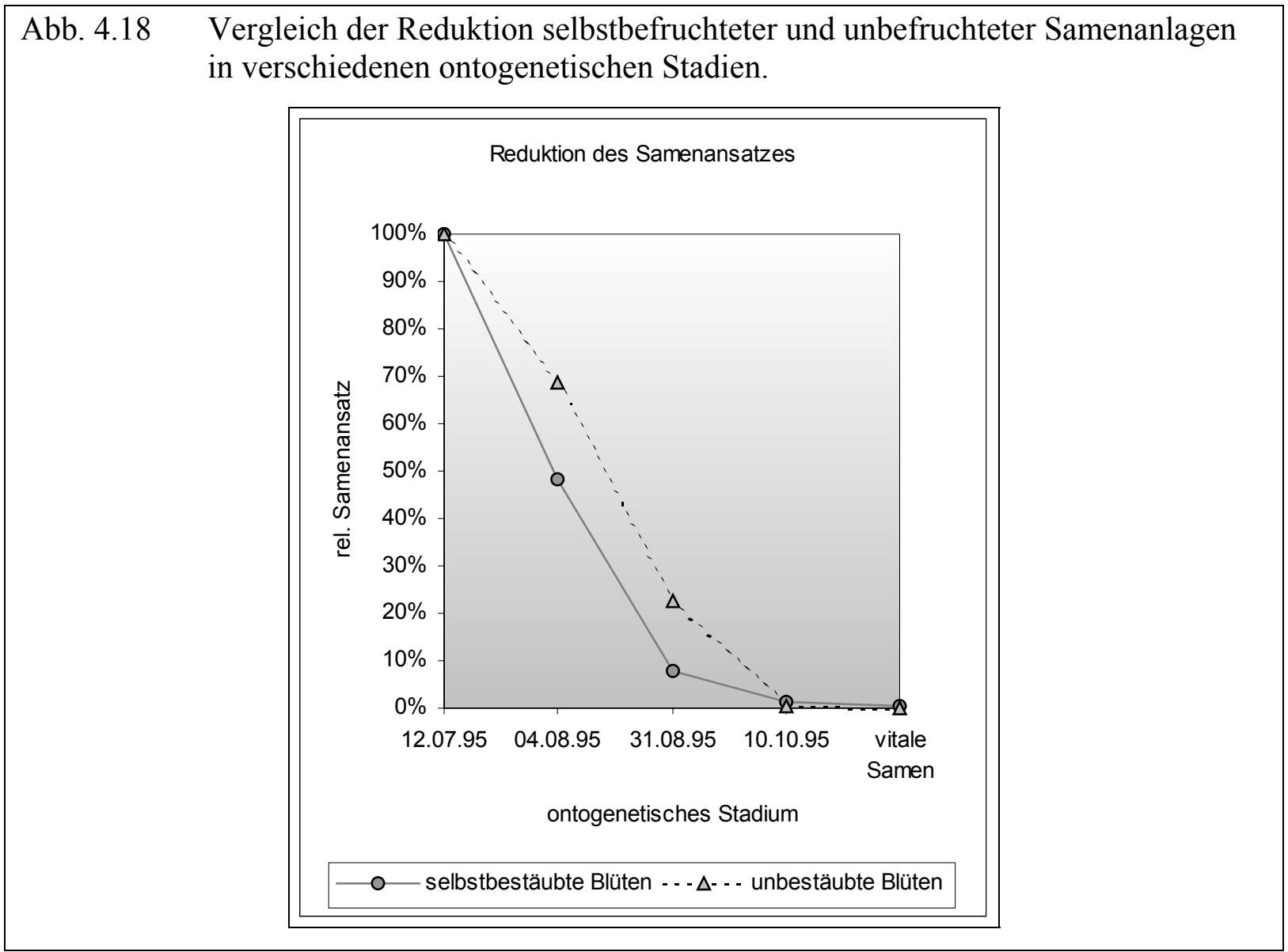

Die nach Selbstbefruchtung sofort einsetzende Selektion ist auch im Vergleich mit unbefruchteten Samenanlagen signifikant. Die unbefruchteten Samenanlagen wurden erst zum Beobachtungszeitpunkt am 10.10.95 abgeworfen, vorher nur in dem Umfang fremdbefruchteter 
Samenanlagen (s. o.). Nach Selbstbefruchtung kommt es hingegen bereits vor dem 10.10.95 zu einer deutlich stärkeren Reduktion der Samenanlagen (s. Abb. 4.18 bzw. Tab. 4.12).

Tab. 4.12 Vergleich der Reduktion selbstbefruchteter und unbefruchteter Samenanlagen in verschiedenen ontogenetischen Stadien.

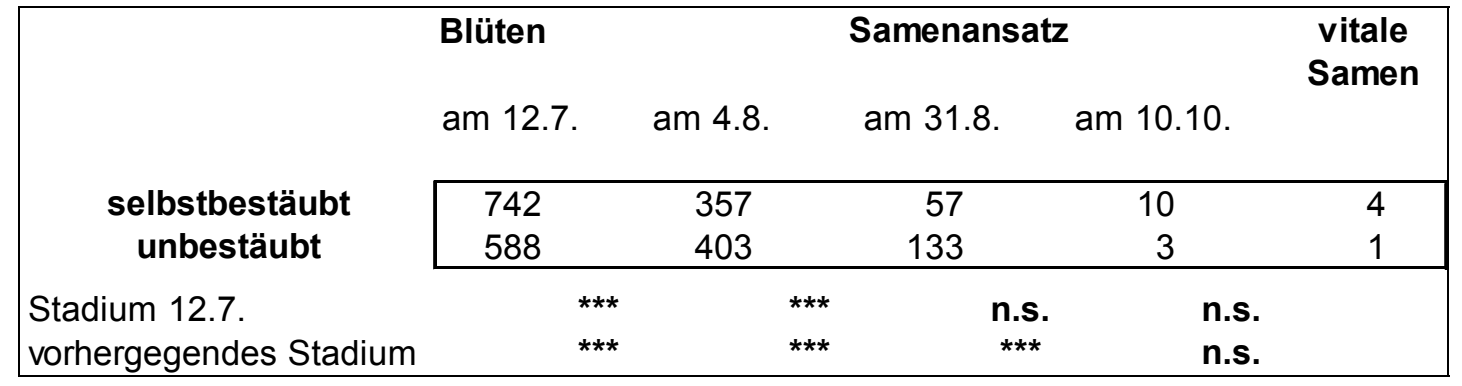

\section{Fazit}

Nachweislich sind 0,3 \% der Blüten vitale Samen aus Befruchtung entstanden, nachdem der Pollen über Wind oder Schwerkraft transportiert wurde.

Nach Selbstbefruchtung setzt von Beginn an eine starke Reduktion der Samenanlagen ein. Diese Reduktion ist in den ersten sechs (bis zwölf) Wochen nach Blühbeginn hochsignifikant stärker als nach Fremdbefruchtung oder bei unbefruchteten Samenanlagen.

\subsection{Keimungsversuche}

Motivation für die Durchführung von Keimversuchen war u. a. die Überprüfung des Einflusses einer erhöhten Selbstbefruchtungsrate auf die Viabilität der Nachkommen. Die Selbstbefruchtungsraten der in der Feldmark stehender Winterlinden F1 und F3 liegen mit 88 \% bzw. $90 \%$ deutlich über denen der Winterlinden 42 und 82 mit $57 \%$ bzw. $53 \%$ (s. Tab. 4.14). Der beabsichtigte Viabilitätsvergleich der aus Selbst- bzw. Fremdbefruchtung entstandenen Nachkommen ist über die Keimversuche möglich. Aus den im Versuchsbestand ausgebrachten Samen keimten nur sehr wenige und keiner dieser Keimlinge erreichte das Stadium einer vierjährigen Jungpflanze. Obwohl eine Bestandeslücke für das Keimbeet ausgesucht wurde, deutete starkes Vermoosen der Fläche auf ungünstige Lichtverhältnisse unter dem Schirm des Altbestandes hin. Die weiteren Ausführungen beziehen sich daher nur auf die Ergebnisse der im Gewächshaus angelegten Keimbeete. Der Tab. 4.13 ist zu entnehmen, daß die Keimprozente der Nachkommen isoliert in der Feldmark stehender Linden (F1 und F3) weitaus geringer sind, als die von im Bestand mit anderen Winterlinden in Paarungskontakt stehenden Bäumen Nr. 42 und 82. Aus jeweils 200 ausgesäten Samen der Winterlinden Nr. 42 und 82 entwickelten sich 13,5 \% bzw. 25,0 \%, aus den der Winterlinden F1 und F3 5,0 \% bzw. keine 
vierjährigen Jungpflanzen. Ein maximales Keimprozent von $25 \%$ im Gewächshaus ist, verglichen mit anderen Baumarten, als gering einzustufen.

Tab. 4.13 Entwicklung von Keimlingen bzw. mehrjährigen Pflanzen aus je 200 Samen isoliert (Baum F1 und F3) und dicht stehender Winterlinden (Baum 42 und 82).

\begin{tabular}{|c|c|c|c|c|c|c|c|c|c|c|c|c|c|}
\hline & & & & & eimung & & uch 1 & /95 & & & & & \\
\hline & & & & & stand & & & & & ewä & ichshau & & \\
\hline & & $\mathrm{Ke}$ & imlinge & & Jungp & & & Kei & imlinge & & Jungpf & $\operatorname{lanz}$ & zen \\
\hline Baum & Samen & & 10/96 & & $3 / 97$ & & 99 & & $10 / 96$ & & $8 / 97$ & & $6 / 99$ \\
\hline 42 & 200 & 12 & $6,0 \%$ & 3 & $1,5 \%$ & & $0,0 \%$ & & $12,0 \%$ & 27 & $13,5 \%$ & 27 & $13,5 \%$ \\
\hline 82 & 200 & 28 & $14,0 \%$ & 8 & $4,0 \%$ & U & $0,0 \%$ & 46 & $23,0 \%$ & 50 & $25,0 \%$ & 50 & $25,0 \%$ \\
\hline F1 & 200 & 9 & $4,5 \%$ & 2 & $1,0 \%$ & 0 & $0,0 \%$ & 2 & $1,0 \%$ & 10 & $5,0 \%$ & 10 & $5,0 \%$ \\
\hline F3 & 200 & 0 & $0,0 \%$ & 0 & $0,0 \%$ & 0 & $0,0 \%$ & 0 & $0,0 \%$ & 0 & $0,0 \%$ & 0 & $0,0 \%$ \\
\hline
\end{tabular}

Die Zunahme der Auflaufprozente von 1996 auf 1997 im Gewächshaus für die Bäume 42, 82 und F1 erklärt sich durch zusätzliche Keimlinge aus überliegenden Samen, die erst im zweiten Jahr nach der Aussaat keimten.

Eine genetische Inventur der vierjährigen Pflanzen für populationsgenetische Parameter konnte an neun Genorten und an elf für die Bestimmung von Selbstbefruchtungsraten durchgeführt werden. Die Blätter der Jungpflanzen zeigten für die Genorte MDH-D, PGM-C und -D für eine sichere Auswertung der Zymogramme zu geringe Enzymaktivität. Um eine Vergleichbarkeit zu gewährleisten, wurde auf diese Genorte auch bei der genetischen Analyse der Samen verzichtet und die in Tab. 4.14 berechneten Ergebnisse können von denen anderer Kapitel abweichen. 


\begin{tabular}{|c|c|c|c|c|c|c|c|c|}
\hline \multicolumn{2}{|c|}{ Tab. 4.14} & \multicolumn{7}{|c|}{$\begin{array}{l}\text { Selbstbefruchtungsanteil und Heterozygotiegrad für Samen und Jungpflanzen } \\
\text { aus Nachkommenschaften isoliert (Baum F1 und F3) und dicht stehender Win- } \\
\text { terlinden (Baum } 42 \text { und 82). Der Selbstbefruchtungsanteil wurde über das } \\
\text { Ausschlußverfahren, der Heterozygotiegrad zum einen für alle Genorte und } \\
\text { zum anderen für diejenigen Genorte ermittelt, für die der Samenelter homozy- } \\
\text { got war. } \Delta=\text { Differenz zwischen Samen und Jungpflanzen. }\end{array}$} \\
\hline \multirow[t]{4}{*}{$\begin{array}{c}\text { Baum } \\
\text { Nr. }\end{array}$} & \multirow{4}{*}{\multicolumn{2}{|c|}{ Stadium }} & \multirow{3}{*}{\multicolumn{2}{|c|}{$\begin{array}{c}\text { Selbstbefruchtung } \\
\text { Anteil }\end{array}$}} & \multicolumn{4}{|c|}{ Heterozygotiegrad } \\
\hline & & & & & \multirow{2}{*}{\multicolumn{2}{|c|}{ alle }} & & \\
\hline & & & \multirow[b]{2}{*}{$\%$} & & & & \multicolumn{2}{|c|}{ Samenelter homozygot } \\
\hline & & & & $\Delta$ & $\%$ & $\Delta$ & $\%$ & $\Delta$ \\
\hline \multirow[t]{2}{*}{42} & \multirow{2}{*}{\multicolumn{2}{|c|}{$\begin{array}{l}\text { Samen } \\
\text { Jungpflanzen }\end{array}$}} & 57 & & 12,8 & & 6,7 & \\
\hline & & & 33 & $-24^{* * *}$ & 17,4 & $+4,6$ n.s. & 12,5 & $+5,8$ n.s \\
\hline \multirow[t]{2}{*}{82} & \multirow{2}{*}{\multicolumn{2}{|c|}{$\begin{array}{l}\text { Samen } \\
\text { Jungpflanzen }\end{array}$}} & 53 & & 25,9 & & 10,5 & \\
\hline & & & 36 & $-15 *$ & 24,7 & $-1,2$ n.s & 12,3 & $+1,8$ n.s \\
\hline \multirow[t]{2}{*}{ F1 } & \multirow{2}{*}{\multicolumn{2}{|c|}{$\begin{array}{l}\text { Samen } \\
\text { Jungpflanzen }\end{array}$}} & 88 & & 20,0 & & 2,4 & \\
\hline & & & 70 & $-18 * *$ & 25,6 & $+5,6$ n.s & 10,0 & $+7,6$ * \\
\hline \multirow[t]{2}{*}{ F3 } & \multirow{2}{*}{\multicolumn{2}{|c|}{$\begin{array}{l}\text { Samen } \\
\text { Jungpflanzen }\end{array}$}} & 90 & & 17,4 & & 1,5 & \\
\hline & & & - & - & & - & - & - \\
\hline
\end{tabular}

Bei Betrachtung der Genorte konnte weder in den Samen ein signifikanter (durch Selbstbefruchtung induzierter) Homozygotenüberschuß noch in den Jungpflanzen ein signifikanter Heterozygotenüberschuß festgestellt werden. Durch die in den Jungpflanzen höher geschätzte Fremdbefruchtungsrate müßte der Heterozygotiegrad ansteigen, wie im Fall der Nachkommenschaft der Winterlinde Nr. 42 auch zu beobachten ist. Dieser erwartete Anstieg kann aber durch Genotyp des Samenelters verdeckt werden, wenn dieser an vielen Genorten heterozygot ist und auch nach Selbstbefruchtung für diese Genorte heterozygote Nachkommen entstehen. Dies trifft z. B. für die Nachkommen der Winterlinde Nr. 82 zu. Daher wurde der Heterozygotiegrad in den Samen und in den Jungpflanzen zusätzlich nur auf der Basis der Genorte berechnet, für die der Samenelter homozygot ist (s. Tab. 4.14). Werden diese Genorte betrachtet, wird zwischen dem Samenstadium und den vierjährigen Pflanzen in den Nachkommen der Winterlinden F1 signifikant gegen homozygote bzw. aus Selbstbefruchtung entstandene Nachkommen selektiert.

Eine gegen bestimmte Allele gerichtete Selektion ist für die verwendeten Genorte nicht nachzuweisen. Die genetischen Abstände $\left(\mathrm{d}_{0}\right)$ an den einzelnen Genorten waren zwischen Samen und Jungpflanzen generell gering und nur selten signifikant. Bei näherer Betrachtung dieser Unterschiede war die Signifikanz auf den höheren Anteil effektiver Fremdpollen in den Jungpflanzen und nicht auf eine gerichtete Selektion gegen bestimmte Allele zurückzuführen. Im 
Mittel aller Genorte lag die Spanne der allelischen Abstände von Samen und Jungpflanzen bei 3,3 \% (Baum Nr. 82) und 6,5\% (Baum F1).

\subsection{Bestimmung von Polleneltern}

In der Tab. 4.15 sind die Ergebnisse der Pollenelterbestimmung mit dem Ausschlußverfahren, der Methode EFG und dem Programm CERVUS dargestellt (s. Kap. 3.9).

Tab. 4.15 Effizienz bei der Identifizierung von Polleneltern mit verschiedenen Pollenelterbestimmungsverfahren bzw. Eingangsparametern; jeweils ermittelt für die Gesamtpopulation, den im Bestand und den vier in der Feldmark stehenden Linden. Bei CERVUS: $0 \%$ und 1\% = fiktive Fehlerquote, + und * Signifikanzniveau bei $80 \%$ bzw. $95 \%$.

\begin{tabular}{|c|c|c|}
\hline \multirow[t]{2}{*}{ Unters. Samen } & \multicolumn{2}{|c|}{$\begin{array}{l}3864 \\
\text { identifiziert }\end{array}$} \\
\hline & absolut & relativ \\
\hline \multirow{2}{*}{ 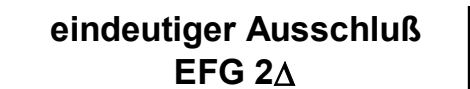 } & \begin{tabular}{|l|}
331 \\
\end{tabular} & $8,6 \%$ \\
\hline & 2163 & $56,0 \%$ \\
\hline EFG $4 \Delta$ & 1331 & $34,4 \%$ \\
\hline \multirow{2}{*}{$\begin{array}{c}\text { EFG 8 } \Delta \\
\text { Cervus } 0 \%+\end{array}$} & 895 & $23,2 \%$ \\
\hline & 734 & $19,0 \%$ \\
\hline $\begin{array}{l}\text { Cervus } 0 \%+ \\
\text { Cervus } 1 \%+\end{array}$ & 628 & $16,3 \%$ \\
\hline \multirow{2}{*}{$\begin{array}{l}\text { Cervus } 0 \%{ }^{*} \\
\text { Cervus } 1 \%^{*}\end{array}$} & 709 & $18,4 \%$ \\
\hline & 367 & $9,5 \%$ \\
\hline \multicolumn{3}{|l|}{ BESTAND } \\
\hline \multirow[t]{2}{*}{ Unters. Samen } & \multicolumn{2}{|c|}{$\begin{array}{l}3481 \\
\text { identifiziert }\end{array}$} \\
\hline & absolut & relativ \\
\hline \multirow{2}{*}{$\begin{array}{c}\text { eindeutiger Ausschluß } \\
\text { EFG } 2 \Delta\end{array}$} & \begin{tabular}{|l|}
301 \\
\end{tabular} & $8,6 \%$ \\
\hline & 1841 & $52,8 \%$ \\
\hline $\begin{array}{l}\text { EFG 2 } 2 \\
\text { EFG } 4 \Delta\end{array}$ & 1038 & $29,8 \%$ \\
\hline \multirow{5}{*}{$\begin{array}{c}\text { EFG } 8 \Delta \\
\text { Cervus } 0 \%+ \\
\text { Cervus } 1 \%+ \\
\text { Cervus } 0 \%{ }^{*} \\
\text { Cervus } 1 \%{ }^{*}\end{array}$} & 628 & $18,0 \%$ \\
\hline & 619 & $17,8 \%$ \\
\hline & 523 & $15,0 \%$ \\
\hline & 594 & $17,1 \%$ \\
\hline & 277 & $8,0 \%$ \\
\hline \multicolumn{3}{|l|}{ FELDLINDEN } \\
\hline \multirow[t]{2}{*}{ Unters. Samen } & \multicolumn{2}{|c|}{$\begin{array}{l}383 \\
\text { identifiziert }\end{array}$} \\
\hline & absolut & relativ \\
\hline eindeutiger Ausschluß & \begin{tabular}{|l|}
30 \\
\end{tabular} & $7,8 \%$ \\
\hline & 323 & $84,2 \%$ \\
\hline \multirow{6}{*}{$\begin{array}{c}\text { EFG } 4 \Delta \\
\text { EFG } 8 \Delta \\
\text { Cervus } 0 \%+ \\
\text { Cervus } 1 \%+ \\
\text { Cervus } 0 \%^{*} \\
\text { Cervus } 1 \%{ }^{*}\end{array}$} & 293 & $76,3 \%$ \\
\hline & 267 & $69,6 \%$ \\
\hline & 115 & $30,0 \%$ \\
\hline & 105 & $27,4 \%$ \\
\hline & 115 & $30,0 \%$ \\
\hline & 90 & $23,5 \%$ \\
\hline
\end{tabular}




\subsubsection{Eindeutiges Ausschlußverfahren}

Bei dem Ausschlußverfahren werden nur diejenigen Polleneltern berücksichtigt, die aufgrund ihres Genotyps von allen Populationsmitgliedern als einzige nicht von einer Pollenelternschaft ausgeschlossen wurden. Daher die Formulierung eindeutiger Ausschluß. Nach dem Ausschlußprinzip konnten auf der Basis vierzehn polymorpher Genloci bei den 3864 untersuchten Samen 331 (8,6 \%) Polleneltern zweifelsfrei identifiziert werden (Tab. 4.15).

\subsubsection{EFG}

Mit der Wahl der Diskriminanzschwelle $\Delta$ variiert erwartungsgemäß der Anteil ermittelter wahrscheinlichster Polleneltern. Wird die Schwelle so hoch angesetzt, daß der EFG-Wert des wahrscheinlichsten Pollenelters mindestens den achtfachen Wert des zweitwahrscheinlichsten beträgt (84), kann für 895 (23,2 \%) der 3864 Samen der Gesamtpopulation ein Pollenelter ermittelt werden (s. Tab. 4.15). Bei einer Diskriminanzschwelle von $4 \Delta$ erhöht sich der Anteil ermittelter wahrscheinlichster Polleneltern auf 1331 (34,4 \%) bzw. bei $2 \Delta$ auf 2163 (56,0 \%). Somit konnte, je nach Wahl der Diskriminanzschwelle, weit mehr als der Hälfte der Samen ein Pollenelter zugeordnet werden. Durch Veränderung der Diskriminanzschwelle $\Delta$ ändert sich die Rangfolge der Polleneltern nicht, da der davon unabhängige (weil zuvor berechnete) EFG-Wert für die möglichen Polleneltern des betrachteten Nachkommen gleich bleibt. Nur der Anteil der ermittelten Polleneltern wird durch die Diskriminanzschwelle beeinflußt. Wird

für einen bestimmten Samen ein wahrscheinlichster Pollenelter mit allen drei Diskriminanzschwellen bestimmt, ist dieser immer derselbe; es entstehen somit quantitative, aber keine qualitativen, Unterschiede.

\subsubsection{CERVUS}

Das Programm CERVUS bietet die Option der Wahl mehrerer Eingabemodi (s. Kap. 3.9.2.2). Um den Einfluß unterschiedlich gewählter Eingangsparameter auf die Bestimmung von Polleneltern zu überprüfen, wurden bei gleichbleibendem Datensatz vier verschiedene Kombinationen getestet, die sich innerhalb des von den Autoren des Programmes empfohlenen Wertebereichs befinden. Der Anteil identifizierter Polleneltern variiert, je nach Kombination von Fehlerquote $(0 \%$ und $1 \%)$ und Signifikanzniveau des $\Delta$-Wertes $\left(80 \%(+)\right.$ und $95 \%\left(^{*}\right)$ in Tab. 4.15), zum Teil erheblich. Bei einer Fehlerquote von $1 \%$ und einem Signifikanzniveau von $80 \%(+)$ konnte ein Pollenelter nur für 9,5\% der Nachkommen ermittelt werden. Die mit 
19 \% höchste Effizienz wurde erwartungsgemäß mit der Kombination Fehlerquote 0 \% und Signifikanzniveau $80 \%$ erreicht (Tab. 4.15).

Ein direkter Vergleich der für die einzelnen Samen bestimmten Polleneltern zeigte qualitative Unterschiede in der Reaktion auf variierte Eingabeparameter. Ein identischer Datensatz von 711 Nachkommen (acht Nachkommenschaften) wurde mit CERVUS bei einem Signifikanzniveau $95 \%$ und Fehlerquote $0 \%$ bzw. mit einem Signifikanzniveau $80 \%$ und Fehlerquote $1 \%$ berechnet. Bei beiden Kombinationen stellte sich eine nahezu identischer Anteil ermittelter wahrscheinlichster Polleneltern von 18,2 \% heraus (129 bzw. 130). Die Vermutung lag daher nahe, daß für die betrachteten Nachkommen jeweils derselbe wahrscheinlichste Pollenelter bestimmt worden ist. Tatsächlich aber wurden bei einem Signifikanzniveau $95 \%$ und Fehlerquote $0 \%$ bei 25 Samen Polleneltern ermittelt, für die bei einem Signifikanzniveau $80 \%$ und Fehlerquote $1 \%$ kein wahrscheinlichster Pollenelter bestimmt werden konnte. Umgekehrt wurden bei einem Signifikanzniveau $80 \%$ und Fehlerquote $1 \%$ für 24 Nachkommen ein wahrscheinlichster Pollenelter ermittelt, bei einem Signifikanzniveau $95 \%$ und Fehlerquote $0 \%$ jedoch nicht. In zwei Fällen wurden den Samen unterschiedliche Polleneltern zugeordnet. Insgesamt stimmen demnach 51 ( $\approx 39,2 \%)$ der 129 bzw. 130 ermittelten Polleneltern nicht überein.

\subsubsection{Vergleich der Pollenelterbestimmungsverfahren}

Trotz der relativ hohen Zahl von vierzehn überwiegend hochvariablen Genorten und der relativ geringen Zahl von 141 potentiellen Polleneltern kann mit dem Ausschlußverfahren ein eindeutiger Pollenelter nur 8,6\% der Samen zugeordnet werden. Ein Blick in die Tab. 4.15 verdeutlicht im Vergleich dazu die sehr hohe Effizienz des EFG-Verfahrens. Bei einer Diskriminanzschwelle $2 \Delta$ beträgt der Anteil der ermittelten Polleneltern $56 \%$, also eine Steigerung um das Sechsfache. Auch mit der sehr hoch angesetzten Diskriminanzschwelle $8 \Delta$ werden immer noch deutlich mehr wahrscheinlichste Polleneltern ermittelt als mit dem Ausschlußverfahren und mit den CERVUS-Kombinationen.

Interessant ist aber nicht nur der Anteil der identifizierten Polleneltern, sondern auch die Frage, ob die mit den verschiedenen Verfahren ermittelten Polleneltern für den jeweils betrachteten Nachkommen übereinstimmen. Ein qualitativer Vergleich zwischen den 709 mit CER-

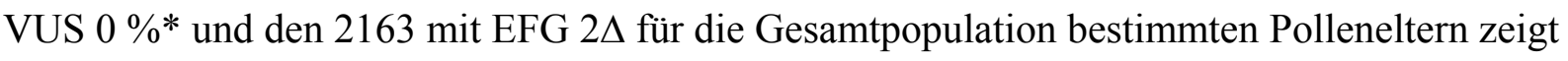
erhebliche Abweichungen. Bei 84 Samen sind von CERVUS Polleneltern bestimmt worden, nicht aber von EFG 2 $\Delta$. In 26 Fällen wurden mit diesen beiden Verfahren den Nachkommen 
unterschiedliche Polleneltern zugeordnet. Insgesamt sind 110 (15,5\%) der 709 Polleneltern nicht mit den von EFG $2 \Delta$ ermittelten identisch. Es wurde zudem überprüft, ob die nach dem Ausschlußprinzip eindeutig bestimmten Polleneltern auch mit CERVUS als solche identifiziert wurden. Da im betrachteten Fall bei CERVUS die Fehlerquote mit $0 \%$ eingegeben wurde und CERVUS als Basis der Berechnungen das Ausschlußverfahren verwendet, kann davon ausgegangen werden, daß die mit dem Ausschlußverfahren eindeutig bestimmten Polleneltern sich bei CERVUS vollständig wiederfinden. Indes tauchen aber zwölf eindeutig bestimmte Polleneltern bei CERVUS nicht als Polleneltern auf. Auch bei EFG ist das Ausschlußverfahren eine Basis für die Schätzung der Polleneltern. Damit kongruent wurden alle mit dem Ausschlußverfahren eindeutig ermittelten Polleneltern auch mit dem EFG-Verfahren als wahrscheinlichste Polleneltern bestimmt. Abweichungen davon konnten nicht festgestellt werden.

Bei allen mir bekannten genetischen Auswertungsverfahren besteht keine Option, eventuelle Fehler in den Datensätzen bei der Analyse zu berücksichtigen. Um eine Vergleichbarkeit zu gewährleisten, werden für spätere Erörterungen für CERVUS nur die Ergebnisse bei Eingabe einer $0 \%$ igen Fehlerquote verwendet. Da sich der Anteil der identifizierter Polleneltern bei einer Fehlerquote von 0 \% zwischen den beiden verwendeten Signifikanzniveaus zur Berechnung des $\Delta$-Wertes nur geringfügig unterscheidet (18,35\% bzw. 19,0\%), sollen bevorzugt die Ergebnisse für das sicherere 95 \%ige Signifikanzniveau betrachtet werden. Für weitere Betrachtungen (z. B. Herleitung von Pollentransportweiten) werden nur die von CERVUS $0 \%$ * bestimmten Polleneltern eingehen. Eine vorab in Kauf genommene Fehlerquote ist nichts anderes als ein Abstrich am Ausschlußprinzip.

\subsection{Selbstbefruchtung}

Voraussetzung für sexuelle Reproduktion bei Pflanzen ist der Transport des Pollens auf die Narbe. Dieses gilt auch für Selbstbefruchtung. Die Weite des Pollentransportes kann im Falle von Autogamie wenige Millimeter, in einer ausladenden Lindenkrone bei Geitonogamie mehrere Meter betragen. Die Distanzklasse „Selbstbefruchtung“ wird in der Literatur mit einem Pollentransport von null Metern gleichgesetzt, welches aber eine zu starke und nicht korrekte Vereinfachung des Sachverhaltes darstellt (dazu siehe auch Kap. 4.7.4). 


\subsubsection{Bestimmung von Selbstbefruchtungsraten}

Mit dem Ausschlußverfahren wird die obere Grenze möglicher Selbstbefruchtung definiert, da hier alle Nachkommen in die Selbstbefruchtungsrate eingehen, bei denen der Samenelter gleichzeitig Pollenelter gewesen sein könnte. Es spielt keine Rolle, ob Fremdbefruchtung auch über andere Polleneltern möglich gewesen wäre. Neben dem Ausschlußverfahren wurden die Selbstbefruchtungsraten mit dem Programm MLTR (RITLAND 1994) berechnet. Ferner wurde versucht, die Selbstbefruchtungsrate über verschiedene Pollenelterbestimmungsverfahren zu ermitteln. Für die Methode EFG wurden die Polleneltern mit den Diskriminanzschwellen $2 \Delta, 4 \Delta$ und $8 \Delta$ ermittelt, anschließend bereinigt und daraus die Selbstbefruchtungsrate berechnet. Mit dem Programm CERVUS wurden die Polleneltern mit einer 0 \%igen Fehlerquote der Daten und einem Signifikanzniveau von $95 \%$ (*) bei der Berechnung des $\Delta$ Wertes bestimmt, ohne eine vorangegangene Bereinigung der Nachkommen, denen kein wahrscheinlichster Pollenelter zugeordnet werden konnte. Die mit CERVUS berechneten Selbstbefruchtungsraten sind daher nur bedingt vergleichbar. Die Methodik zur Berechnung der Selbstbefruchtungsraten ist in Kap. 3.10 beschrieben.

Wird mit den Pollenelterbestimmungsverfahren CERVUS und EFG der Samenelter selbst als wahrscheinlichster Pollenelter ermittelt, geht der entsprechende Nachkomme als selbstbefruchtet in die Berechnung der Selbstbefruchtungsrate ein. Ähnlich wird verfahren, wenn eine Fremdbefruchtung ermittelt wird. Mit EFG konnten für maximal $56 \%$ der Nachkommen ein Pollenelter bestimmt werden. Aus diesen $56 \%$ ließe sich schon eine Selbstbefruchtungsrate ableiten (Tab. 4.15); über das Ausmaß der Fremd- und Selbstbefruchtung in den restlichen $44 \%$ der Nachkommen, für die kein wahrscheinlichster, sondern mehrere wahrscheinliche Polleneltern ausgewiesen wurden, kann aber keine Aussage getroffen werden. Um die Information dieser unbestimmten Nachkommen besser zu nutzen, wird für das Verfahren EFG eine Bereinigung vorgenommen (s. Kap. 3.10.3), mit der ein Großteil dieser Nachkommen in selbst- oder fremdbefruchtet unterteilt werden kann. Über das Ausmaß und die Wirkung dieser Bereinigung gibt die Tab. 4.16 Aufschluß: 


\begin{tabular}{|c|c|c|c|c|c|c|c|}
\hline Tab. 4.16 & $\begin{array}{l}\text { Selbstbef } \\
\text { Schwiege } \\
\text { schiedene } \\
\text { tig zuzuor }\end{array}$ & $\begin{array}{l}\text { htungsrat } \\
\text { hausen, erı } \\
\text { Diskrimina } \\
\text { hender Nac }\end{array}$ & $\begin{array}{l}\text { a den } \mathrm{Na} \\
\text { telt über } \\
\text { schwell } \\
\text { xommen }\end{array}$ & $\begin{array}{l}\text { hkommen } \\
\text { das Verfah } \\
(\Delta) \text { vor u }\end{array}$ & $\begin{array}{l}r \text { Winte } \\
\text { EFG u } \\
\text { nach B }\end{array}$ & $\begin{array}{l}\text { ndenpopul } \\
\text { er Verwen } \\
\text { einigung } n\end{array}$ & $\begin{array}{l}\text { on } \\
\text { ng ver- } \\
\text { t eindeu- }\end{array}$ \\
\hline Gesamtpopt & tion & EF & & & & EF & \\
\hline & & unbereinigt & bereinigt & unbereinigt & bereinigt & unbereinigt & bereinigt \\
\hline Untersuchte & amen & 3864 & 3387 & 3864 & 3117 & 3864 & 2866 \\
\hline Anteil verbli & ener Samen & $100 \%$ & $87,7 \%$ & $100 \%$ & $80,7 \%$ & $100 \%$ & $74,2 \%$ \\
\hline nicht selbstl & ruchtet & 2846 & 2369 & 3115 & 2368 & 3366 & 2368 \\
\hline selbstbefruc & & 1018 & 1018 & 748 & 748 & 497 & 497 \\
\hline Anteil Selbs & fruchtung & $26,3 \%$ & $30,1 \%$ & $19,4 \%$ & $24,0 \%$ & $12,9 \%$ & $17,3 \%$ \\
\hline
\end{tabular}

Wie in der Tab. 4.16 zu sehen ist, sind von einer Bereinigung nur wenige Nachkommen betroffen. Bei einer Diskriminanzschwelle von $2 \Delta$ ist eine Zuordnung zu Selbst- bzw. Fremdbefruchtung bei 477 Samen (12,3 \%) nicht möglich. Diese werden daher aus einer weiteren Betrachtung herausgenommen. Bei der Diskriminanzschwelle $8 \Delta$ erhöht sich dieser Anteil auf 998 Samen, was einer Reduktion des auswertbaren Probenumfangs um 25,8 \% entspricht. Die Bereinigung hat keinen Einfluß auf die über EFG bestimmten selbstbefruchteten Nachkommen, wohl aber auf den verbleibenden Umfang der in die Bestimmung der Selbstbefruchtungsrate eingehenden Samen. Daher erhöht eine Bereinigung den Anteil der Selbstbefruchtung ebenso wie die Genauigkeit bei deren Bestimmung.

\subsubsection{Umfang der Selbstbefruchtung}

Wie schon erwähnt, bildet die nach dem Ausschlußverfahren berechnete Selbstbefruchtungsrate die obere Grenze, da allein aufgrund des Genotyps von Samenelter und Nachkommen keine höhere Schätzung möglich ist. Werden über die verschiedenen Verfahren höhere Anteile an Selbstbefruchtung ermittelt, kann dies nur auf eine fehlerhafte Dateneingabe oder auf ein fehlerhaftes Programm zurückzuführen sein. Um es vorwegzunehmen: bei keinem Verfahren ist ein solcher Fall aufgetreten. 
Tab. 4.17 Über mehrere Verfahren ermittelte Selbstbefruchtungsraten für die Gesamtpopulation Schwiegershausen, die Linden im Bestand und in der Feldmark.

\begin{tabular}{|c|c|c|c|c|c|c|}
\hline \multirow[b]{2}{*}{ Gesamtpopulation } & \multicolumn{6}{|c|}{ Selbstbefruchtungsraten } \\
\hline & Ausschluß & EFG $2 \Delta$ & EFG 4A & EFG $8 \Delta$ & MLTR & Cervus $0 \%{ }^{*}$ \\
\hline \multirow{4}{*}{$\begin{array}{l}\text { einbezogene Samen } \\
\text { fremdbefruchtet } \\
\text { selbstbefruchtet } \\
\text { Anteil Selbstbefruchtung }\end{array}$} & 3864 & 3387 & 3117 & 2866 & 3864 & 3864 \\
\hline & 2370 & 2369 & 2368 & 2368 & & 3560 \\
\hline & 1494 & 1018 & 748 & 497 & & 303 \\
\hline & $38,7 \%$ & $30,1 \%$ & $24,0 \%$ & $17,3 \%$ & $32,6 \%$ & $7,8 \%$ \\
\hline \multicolumn{7}{|l|}{ Bestand } \\
\hline & Ausschluß & EFG 2 $\Delta$ & EFG 4 $\Delta$ & EFG 8 $\Delta$ & MLTR & Cervus $0 \%{ }^{*}$ \\
\hline \multirow{4}{*}{$\begin{array}{l}\text { einbezogene Samen } \\
\text { fremdbefruchtet } \\
\text { selbstbefruchtet } \\
\text { Anteil Selbstbefruchtung }\end{array}$} & 3481 & 3004 & 2739 & 2508 & 3481 & 3480 \\
\hline & 2235 & 2234 & 2234 & 2234 & & 3259 \\
\hline & 1246 & 769 & 504 & 273 & & 221 \\
\hline & $35,8 \%$ & $25,6 \%$ & $18,4 \%$ & $10,9 \%$ & $28,8 \%$ & $6,4 \%$ \\
\hline \multicolumn{7}{|l|}{ Feldlinden } \\
\hline & Ausschluß & EFG 2 $\Delta$ & 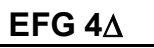 & EFG 8 $\Delta$ & MLTR & Cervus $0 \%{ }^{*}$ \\
\hline \multirow{4}{*}{$\begin{array}{l}\text { einbezogene Samen } \\
\text { fremdbefruchtet } \\
\text { selbstbefruchtet } \\
\text { Anteil Selbstbefruchtung }\end{array}$} & 383 & 383 & 378 & 359 & 383 & \begin{tabular}{|c|}
383 \\
\end{tabular} \\
\hline & 135 & 135 & 134 & 135 & & 301 \\
\hline & 248 & 248 & 244 & 224 & & 82 \\
\hline & $64,8 \%$ & $64,8 \%$ & $64,5 \%$ & $62,5 \%$ & $59,0 \%$ & $21,4 \%$ \\
\hline
\end{tabular}

Bei einem Blick in die Tab. 4.17 fällt auf, daß die mit CERVUS berechneten Selbstbefruchtungsraten durchgehend deutlich unter denen anderer Verfahren liegen. Dieses ist begründet in der in Kapitel 4.6 beschriebenen geringen Effizienz dieses Programmes bei der Bestimmung wahrscheinlichster Polleneltern. Dementsprechend gering ist der Anteil der Nachkommen, bei denen Selbstbefruchtung nachgewiesen wurde. Aus diesen wenigen selbstbefruchteten Samen wird durch Division mit der Anzahl insgesamt untersuchter Samen die Selbstbefruchtungsrate berechnet. Diese geringe Effizienz bei der Identifizierung von Polleneltern bedingt daher nur eine eingeschränkte Eignung des CERVUS-Programmes für die Bestimmung von Selbstbefruchtungsraten. Ähnliches gilt für das Verfahren EFG. Auch hier nimmt der Anteil der Anteil der Nachkommen, bei denen Selbstbefruchtung nachgewiesen wurde mit Höhe der verwendeten Diskriminanzschwelle ab (s. Tab. 4.15). Dadurch ist der von EFG $2 \Delta$ zu EFG $8 \Delta$ abnehmende Anteil der Selbstbefruchtungen zu erklären. Wie bei CERVUS erscheint der Anteil identifizierter Polleneltern der Diskriminanzschwelle $8 \Delta$ zu gering für eine repräsentative Bestimmung von Selbstbefruchtungsanteilen.

Ins Auge fallen die hohen Selbstbefruchtungsraten bei den solitär in der Feldmark stehen Linden (Feldlinden), die beträchtlich über denen der Linden im Bestand liegen. Im Mittel der Gesamtpopulation und des Bestandes liegen die mit MLTR berechneten Selbstbefruchtungsraten zwischen der oberen Grenze des Ausschlußverfahrens und den mit EFG ermittelten 
Werten. Allein für die vier Winterlinden in der Feldmark wird mit MLTR ein niedrigerer Selbstbefruchtungsanteil als mit EFG berechnet. Insgesamt stimmen die Selbstbefruchtungsraten bei MLTR und EFG $2 \Delta$ gut überein.

Eine detaillierte Betrachtung der Selbstbefruchtungsraten in den Nachkommen der einzelnen Winterlinden liefert die Tab. 4.18. 
Tab. 4.18 Mit verschiedenen Verfahren berechnete Selbstbefruchtungsraten in den Nachkommen von 54 Winterlinden der Population Schwiegershausen. Mit F sind die Winterlinden in der Feldmark bezeichnet.

\begin{tabular}{|c|c|c|c|c|c|c|}
\hline \multicolumn{7}{|c|}{ Selbstbefruchtungsraten der Einzelbäume in \% } \\
\hline Baum Nr. & Ausschluß & EFG 2 $\Delta$ & EFG 4 $\Delta$ & EFG 8 $\Delta$ & MLTR & $\begin{array}{c}\text { CER } \\
\text { 0\% }\end{array}$ \\
\hline 1 & 45 & 31 & 31 & 31 & 44 & 25 \\
\hline 2 & 49 & 45 & 37 & 25 & 34 & 11 \\
\hline 3 & 70 & 0 & 0 & 0 & 70 & 0 \\
\hline 8 & 5 & 0 & 0 & 0 & 4 & 0 \\
\hline 10 & 31 & 8 & 8 & 6 & 19 & 6 \\
\hline 11 & 48 & 0 & 0 & 0 & 29 & 0 \\
\hline 14 & 15 & 13 & 0 & 0 & 5 & 0 \\
\hline 15 & 43 & 15 & 8 & 0 & 36 & 0 \\
\hline 22 & 18 & 0 & 0 & 0 & 10 & 0 \\
\hline 23 & 14 & 9 & 6 & 3 & 12 & 3 \\
\hline 25 & 11 & 3 & 0 & 0 & 6 & 0 \\
\hline 26 & 68 & 0 & 0 & 0 & 62 & 0 \\
\hline 27 & 41 & 17 & 5 & 0 & 38 & 0 \\
\hline 28 & 47 & 22 & 0 & 0 & 40 & 0 \\
\hline 32 & 46 & 46 & 37 & 5 & 45 & 26 \\
\hline 33 & 14 & 13 & 11 & 6 & 7 & 3 \\
\hline 36 & 32 & 31 & 23 & 15 & 31 & 16 \\
\hline 38 & 19 & 14 & 0 & 0 & 16 & 10 \\
\hline 42 & 52 & 47 & 32 & 0 & 47 & 18 \\
\hline 59 & 13 & 0 & 0 & 0 & 9 & 0 \\
\hline 68 & 22 & 7 & 1 & 1 & 3 & 1 \\
\hline $69 a$ & 34 & 27 & 15 & 13 & 27 & 9 \\
\hline 71 & 20 & 10 & 8 & 6 & 10 & 5 \\
\hline 72 & 55 & 54 & 46 & 21 & 52 & 0 \\
\hline 77 & 14 & 14 & 9 & 3 & 15 & 3 \\
\hline 82 & 46 & 34 & 20 & 16 & 44 & 15 \\
\hline 92 & 26 & 20 & 10 & 6 & 7 & 4 \\
\hline 93 & 5 & 5 & 5 & 0 & 3 & 0 \\
\hline $94 a$ & 36 & 20 & 0 & 0 & 31 & 0 \\
\hline 95 & 43 & 43 & 43 & 43 & 43 & 0 \\
\hline 97 & 5 & 5 & 0 & 0 & -4 & 0 \\
\hline 98 & 18 & 18 & 18 & 15 & 17 & 18 \\
\hline $98 \mathrm{a}$ & 40 & 35 & 27 & 25 & 35 & 10 \\
\hline 104 & 63 & 38 & 33 & 9 & 61 & 0 \\
\hline 107 & 67 & 23 & 17 & 17 & 63 & 0 \\
\hline 109 & 54 & 54 & 51 & 28 & 50 & 0 \\
\hline 111 & 3 & 0 & 0 & 0 & 1 & 0 \\
\hline 112 & 43 & 12 & 0 & 0 & 35 & 0 \\
\hline 113 & 9 & 7 & 2 & 0 & $\begin{array}{l}-7 \\
\end{array}$ & 0 \\
\hline 114 & 29 & 2 & 1 & 1 & 14 & 0 \\
\hline 115 & 31 & 32 & 29 & 13 & 31 & 17 \\
\hline 118 & 57 & 57 & 53 & 44 & 50 & 0 \\
\hline 120 & 17 & 11 & 6 & 2 & 8 & 9 \\
\hline 121 & 90 & 83 & 78 & 67 & 90 & 18 \\
\hline 122 & 5 & 0 & 0 & 0 & 0 & 0 \\
\hline
\end{tabular}




\begin{tabular}{|c|c|c|c|c|c|c|}
\hline 123 & 39 & 39 & 28 & 16 & 37 & 12 \\
\hline 129 & 68 & 68 & 68 & 68 & 68 & 59 \\
\hline 130 & 54 & 29 & 19 & 0 & 47 & 0 \\
\hline 133 & 10 & 11 & 11 & 11 & 9 & 10 \\
\hline 134 & 39 & 33 & 23 & 18 & 36 & 11 \\
\hline F1 & 68 & 68 & 67 & 62 & 66 & 28 \\
\hline F2 & 47 & 48 & 48 & 47 & 32 & 22 \\
\hline F3 & 90 & 89 & 88 & 84 & 90 & 5 \\
\hline F4 & 82 & 82 & 82 & 82 & 81 & 20 \\
\hline Gesamt & 38,7 & 30,1 & 24,0 & 17,3 & 32,6 & 7,8 \\
\hline
\end{tabular}

Die von MLTR berechneten Werte sind bis auf zwei Fälle durchweg plausibel. Einzig für die Bäume 97 und 113 werden, trotz wiederholter Kalkulationen, negative Selbstbefruchtungsraten ausgewiesen. Eine negative Selbstbefruchtungsrate kann nur mit den bekannten Unzulänglichkeiten des Programms erklärt werden (IVEY und WyATT 1999). Ob dieser Programmfehler sich auf die Berechnung der Selbstbefruchtungsraten dieser beiden Bäume beschränkt oder auch Werte für die anderen Bäume fehlerhaft sind, kann an dieser Stelle nicht geklärt werden. Wie aus Tab. 4.18 zu ersehen ist, weisen auch die mit ein und demselben Verfahren geschätzten Selbstbefruchtungsraten der einzelnen Bäume erhebliche Unterschiede auf. Ein Vergleich zwischen den Verfahren zur Bestimmung der Selbstbefruchtungsraten ergibt für die einzelnen Linden kein einheitliches Bild. Im Mittelpunkt weiterer Betrachtungen stehen die mit MLTR und EFG $2 \Delta$ ermittelten Selbstbefruchtungsraten, da diese im Mittel der Gesamtpopulation die höchste Kongruenz aufweisen. Deutlich wird, daß für die einzelnen Linden in einem Fall mit der Methode EFG 2 $\Delta$, im anderen mit MLTR eine höhere Selbstbefruchtungsrate berechnet wird. Diese Unterschiede zwischen den Verfahren werden eingehender in der Tab. 4.19 analysiert. Die auffälligsten Differenzen sind in der Tabelle unterlegt. Die mit MLTR berechneten negativen Selbstbefruchtungsraten bei den Bäumen 97 und 113 wurden durch den Wert $0 \%$ ersetzt. 
Tab. 4.19 Vergleich der mit MLTR und EFG 2 $\Delta$ ermittelten Selbstbefruchtungsraten in den Nachkommen von 54 Linden der Population Schwiegershausen. Mit F sind die Linden in der Feldmark bezeichnet.

\begin{tabular}{|c|c|c|c|c|}
\hline \multicolumn{5}{|c|}{ Selbstbefruchtungsraten der Einzelbäume in \% } \\
\hline Baum Nr. & EFG 2 $\Delta$ & MLTR & Differenz & Betrag \\
\hline 1 & 31,3 & 44 & $-12,8$ & 12,8 \\
\hline 2 & 44,5 & 34 & 10,5 & 10,5 \\
\hline 3 & 0,0 & 70 & $-70,0$ & 70,0 \\
\hline 8 & 0,0 & 4 & $-4,0$ & 4,0 \\
\hline $\mathbf{1 0}$ & 8,0 & 19 & $-11,0$ & 11,0 \\
\hline 11 & 0,0 & 29 & $-29,0$ & 29,0 \\
\hline 14 & 12,8 & 5 & 7,8 & 7,8 \\
\hline 15 & 14,9 & 36 & $-21,1$ & 21,1 \\
\hline 22 & 0,0 & 10 & $-10,0$ & 10,0 \\
\hline 23 & 9,1 & 12 & $-2,9$ & 2,9 \\
\hline 25 & 3,0 & 6 & $-3,0$ & 3,0 \\
\hline 26 & 0,0 & 62 & $-62,0$ & 62,0 \\
\hline 27 & 16,7 & 38 & $-21,3$ & 21,3 \\
\hline 28 & 22,1 & 40 & $-17,9$ & 17,9 \\
\hline 32 & 46,3 & 45 & 1,3 & 1,3 \\
\hline 33 & 12,9 & 7 & 5,9 & 5,9 \\
\hline 36 & 30,8 & 31 & $-0,2$ & 0,2 \\
\hline 38 & 13,6 & 16 & $-2,4$ & 2,4 \\
\hline 42 & 47,2 & 47 & 0,2 & 0,2 \\
\hline 59 & 0,0 & 9 & $-9,0$ & 9,0 \\
\hline 68 & 7,1 & 3 & 4,1 & 4,1 \\
\hline $69 a$ & 26,9 & 27 & $-0,1$ & 0,1 \\
\hline 71 & 10,2 & 10 & 0,2 & 0,2 \\
\hline 72 & 54,0 & 52 & 2,0 & 2,0 \\
\hline 77 & 14,2 & 15 & $-0,8$ & 0,8 \\
\hline 82 & 34,1 & 44 & $-9,9$ & 9,9 \\
\hline 92 & 19,6 & 7 & 12,6 & 12,6 \\
\hline 93 & 5,0 & 3 & 2,0 & 2,0 \\
\hline 94a & 20,0 & 31 & $-11,0$ & 11,0 \\
\hline 95 & 43,3 & 43 & 0,3 & 0,3 \\
\hline 97 & 5,2 & 0 & 5,2 & 5,2 \\
\hline 98 & 17,7 & 17 & 0,7 & 0,7 \\
\hline 98a & 35,1 & 35 & 0,1 & 0,1 \\
\hline 104 & 37,5 & 61 & $-23,5$ & 23,5 \\
\hline 107 & 23,1 & 63 & $-39,9$ & 39,9 \\
\hline 109 & 54,1 & 50 & 4,1 & 4,1 \\
\hline 111 & 0,0 & 1 & $-1,0$ & 1,0 \\
\hline 112 & 12,0 & 35 & $-23,0$ & 23,0 \\
\hline 113 & 6,5 & 0 & 6,5 & 6,5 \\
\hline 114 & 1,9 & 14 & $-12,1$ & 12,1 \\
\hline 115 & 31,8 & 31 & 0,8 & 0,8 \\
\hline 118 & 56,7 & 50 & 6,7 & 6,7 \\
\hline 120 & 10,7 & 8 & 2,7 & 2,7 \\
\hline 121 & 82,6 & 90 & $-7,4$ & 7,4 \\
\hline 122 & 0,0 & 0 & 0,0 & 0,0 \\
\hline 123 & 39,0 & 37 & 2,0 & 2,0 \\
\hline
\end{tabular}




\begin{tabular}{|c|c|c|c|c|}
\hline 129 & 68,4 & 68 & 0,4 & 0,4 \\
\hline 130 & 29,2 & 47 & $-17,8$ & 17,8 \\
\hline 133 & 10,7 & 9 & 1,7 & 1,7 \\
\hline 134 & 32,5 & 36 & $-3,5$ & 3,5 \\
\hline F1 & 68,2 & 66 & 2,2 & 2,2 \\
\hline F2 & 47,7 & 32 & 15,7 & 15,7 \\
\hline F3 & 89,3 & 90 & $-0,7$ & 0,7 \\
\hline F4 & 81,9 & 81 & 0,9 & 0,9 \\
\hline & \multirow{2}{*}{\multicolumn{2}{|c|}{$\begin{array}{r}\text { Summe } \\
\text { Mittelwert }\end{array}$}} & $-330,7$ & 524,1 \\
\hline & & & $-6,1$ & 9,7 \\
\hline
\end{tabular}

Im ungewichteten Mittel aller 54 Selbstbefruchtungsraten beträgt der Unterschied zwischen MLTR und EFG $2 \Delta$ nur 6,1 \%, gewichtet reduziert sich die Differenz sogar auf 2,5 \% (s. Tab. 4.18). Im Durchschnitt werden mit MLTR höhere Selbstbefruchtungsraten berechnet. Die Summe der Differenzen bei den Einzelbäumen von über 330,7 \%, bzw. der Beträge von $524,1 \%$ zeigen deutlich, daß auf der Ebene der einzelnen Nachkommenschaften lediglich eine bedingte Vergleichbarkeit zwischen den beiden Verfahren hergestellt werden kann. Eine unreflektierte Betrachtung geschätzter Selbstbefruchtungsraten über den Mittelwert der gesamten Population hätte eine weitgehende Übereinstimmung der Verfahren MLTR und EFG vorgetäuscht, welche de facto für die einzelnen Winterlinden nur bedingt existiert.

\subsubsection{Ursachen der Selbstbefruchtung}

Mit Hilfe linearer Regressionsanalysen wird versucht, die Einflußgrößen zu finden, welche für Fremd- bzw. Selbstbefruchtung verantwortlich sind. Als mögliche Ursachen für unterschiedliche Selbstbefruchtungsraten kommen der Abstand zu den nächsten Paarungspartnern, die Größe der Kronen benachbarter Paarungspartner und die Kronengröße des Samenelters in Frage. Dabei wurde zwischen dem $\varnothing$ Abstand und der $\varnothing$ Kronengröße der nächsten 5 bzw. 10 Nachbarn (Paarungspartner) des Samenelters unterschieden, um den Einfluß der örtlichen Populationsdichte auf die Selbstbefruchtungsrate zu bestimmen.

Um einen Überblick über die Kronengrößen der Sameneltern und deren Abstände zu den anderen Linden zu bekommen, enthält die Tab. 4.20 die für dieses Kapitel relevanten Daten der 54 eingehender untersuchten Winterlinden. Aus Platzgründen wird dabei auf Werte für die $\varnothing$ Kronengröße der nächsten Nachbarn und den $\varnothing$ Abstand zu den nächsten 5 Nachbarn verzichtet. 
Tab. 4.20 Über verschiedene Verfahren ermittelte Selbstbefruchtungsraten unter den Nachkommen von 54 Winterlinden der Population Schwiegershausen zusammen mit Kronengröße, Abstand zum nächsten Nachbarn und $\varnothing$ Abstand zu den nächsten 10 Nachbarn des Samenelters.

\begin{tabular}{|c|c|c|c|c|c|c|c|c|c|}
\hline \multirow{3}{*}{$\begin{array}{c}\text { Baum } \\
\text { Nr. }\end{array}$} & \multicolumn{6}{|c|}{ Selbstbefruchtungsrate in \% } & \multirow{3}{*}{$\begin{array}{c}\text { Kronen- } \\
\text { größe m } \\
\text { 2 } \\
\text { Samen } \\
\text { elter }\end{array}$} & \multicolumn{2}{|c|}{ Abstand in $\mathrm{m}$} \\
\hline & & & & & & & & nächster & $\begin{array}{c}\text { nächste } \\
10\end{array}$ \\
\hline & $\begin{array}{l}\text { Aus- } \\
\text { schluß }\end{array}$ & eindeutig & MLTR & EFG 2 $\Delta$ & EFG $4 \Delta$ & EFG 8 $\Delta$ & & Nachbar & Nachbarn \\
\hline 1 & 45 & 15 & 44 & 31 & 31 & 31 & 14,8 & 29,9 & 91,7 \\
\hline 2 & 49 & 0 & 34 & 45 & 37 & 25 & 105,3 & 50,6 & 68,4 \\
\hline 3 & 70 & 0 & 70 & 0 & 0 & 0 & 4,1 & 17,5 & 35,4 \\
\hline 8 & 5 & 0 & 4 & 0 & 0 & 0 & 39,0 & 5,2 & 13,4 \\
\hline 10 & 31 & 0 & 19 & 8 & 8 & 6 & 3,0 & 3,9 & 12,8 \\
\hline 11 & 48 & 0 & 29 & 0 & 0 & 0 & 36,5 & 3,9 & 12,5 \\
\hline 14 & 15 & 0 & 5 & 13 & 0 & 0 & 79,2 & 7 & 18,9 \\
\hline 15 & 43 & 0 & 36 & 15 & 8 & 0 & 43,3 & 10,9 & 18,3 \\
\hline 22 & 18 & 0 & 10 & 0 & 0 & 0 & 24,7 & 6,4 & 21,5 \\
\hline 23 & 14 & 3 & 12 & 9 & 6 & 3 & 17,4 & 5,7 & 20,9 \\
\hline 25 & 11 & 0 & 6 & 3 & 0 & 0 & 5,9 & 37 & 49,0 \\
\hline 26 & 68 & 8 & 62 & 0 & 0 & 0 & 3,5 & 20,5 & 71,6 \\
\hline 27 & 41 & 0 & 38 & 17 & 5 & 0 & 7,9 & 12,4 & 60,4 \\
\hline 28 & 47 & 0 & 40 & 22 & 0 & 0 & 11,4 & 12,4 & 56,0 \\
\hline 32 & 46 & 0 & 45 & 46 & 37 & 5 & 17,7 & 106,4 & 131,0 \\
\hline 33 & 14 & 3 & 7 & 13 & 11 & 6 & 61,9 & 23,1 & 66,2 \\
\hline 36 & 32 & 4 & 31 & 31 & 23 & 15 & 26,6 & 6,6 & 55,9 \\
\hline 38 & 19 & 0 & 16 & 14 & 0 & 0 & 32,5 & 5,8 & 57,7 \\
\hline 42 & 52 & 0 & 47 & 47 & 32 & 0 & 96,6 & 8,1 & 15,3 \\
\hline 59 & 13 & 0 & 9 & 0 & 0 & 0 & 22,1 & 4,2 & 13,8 \\
\hline 68 & 22 & 0 & 3 & 7 & 1 & 1 & 5,0 & 40,6 & 59,4 \\
\hline $69 a$ & 34 & 0 & 27 & 27 & 15 & 13 & 10,0 & 10 & 61,7 \\
\hline 71 & 20 & 1 & 10 & 10 & 8 & 6 & 90,3 & 6 & 71,6 \\
\hline 72 & 55 & 1 & 52 & 54 & 46 & 21 & 280,5 & 6 & 79,7 \\
\hline 77 & 14 & 0 & 15 & 14 & 9 & 3 & 35,2 & 5,5 & 13,4 \\
\hline 82 & 46 & 10 & 44 & 34 & 20 & 16 & 64,9 & 5,4 & 11,2 \\
\hline 92 & 26 & 4 & 7 & 20 & 10 & 6 & 68,1 & 91,9 & 138,6 \\
\hline 93 & 5 & 0 & 3 & 5 & 5 & 0 & 77,0 & 84,9 & 184,1 \\
\hline 94a & 36 & 0 & 31 & 20 & 0 & 0 & 72,6 & 17,9 & 53,6 \\
\hline 95 & 43 & 0 & 43 & 43 & 43 & 43 & 61,0 & 48,5 & 153,9 \\
\hline 97 & 5 & 0 & -4 & 5 & 0 & 0 & 35,6 & 10,4 & 55,6 \\
\hline 98 & 18 & 4 & 17 & 18 & 18 & 15 & 65,6 & 56,9 & 83,9 \\
\hline 98a & 40 & 10 & 35 & 35 & 27 & 25 & 21,0 & 48,5 & 151,5 \\
\hline 104 & 63 & 0 & 61 & 38 & 33 & 9 & 32,0 & 84,9 & 176,4 \\
\hline 107 & 67 & 0 & 63 & 23 & 17 & 17 & 42,9 & 8,4 & 53,6 \\
\hline 109 & 54 & 0 & 50 & 54 & 51 & 28 & 37,3 & 18,5 & 54,6 \\
\hline 111 & 3 & 0 & 1 & 0 & 0 & 0 & 12,5 & 6,4 & 62,0 \\
\hline 112 & 43 & 0 & 35 & 12 & 0 & 0 & 47,5 & 6,4 & 61,8 \\
\hline 113 & 9 & 0 & -7 & 7 & 2 & 0 & 132,7 & 86,7 & 129,5 \\
\hline 114 & 29 & 0 & 14 & 2 & 1 & 1 & 34,5 & 10,8 & 71,8 \\
\hline 115 & 31 & 13 & 31 & 32 & 29 & 13 & 34,9 & 10,8 & 70,2 \\
\hline 118 & 57 & 0 & 50 & 57 & 53 & 44 & 146,4 & 21 & 62,4 \\
\hline 120 & 17 & 0 & 8 & 11 & 6 & 2 & 109,6 & 20,6 & 58,0 \\
\hline
\end{tabular}




\begin{tabular}{|r|r|r|r|r|r|r|r|r|r|}
\hline $\mathbf{1 2 1}$ & 90 & 64 & 90 & 83 & 78 & 67 & 203,2 & 21,2 & 65,9 \\
\hline $\mathbf{1 2 2}$ & 5 & 0 & 0 & 0 & 0 & 0 & 65,1 & 21,2 & 78,3 \\
\hline $\mathbf{1 2 3}$ & 39 & 9 & 37 & 39 & 28 & 16 & 10,4 & 5,4 & 76,4 \\
\hline $\mathbf{1 2 9}$ & 68 & 64 & 68 & 68 & 68 & 68 & 140,6 & 12,1 & 81,5 \\
\hline $\mathbf{1 3 0}$ & 54 & 0 & 47 & 29 & 19 & 0 & 60,5 & 21,3 & 89,1 \\
\hline $\mathbf{1 3 3}$ & 10 & 0 & 9 & 11 & 11 & 11 & 34,2 & 5,8 & 67,2 \\
\hline $\mathbf{1 3 4}$ & 39 & 16 & 36 & 33 & 23 & 18 & 27,2 & 25,8 & 53,9 \\
\hline F1 & 68 & 37 & 66 & 68 & 67 & 62 & 300,0 & 350 & 322,1 \\
\hline F2 & 47 & 0 & 32 & 48 & 48 & 47 & 300,0 & 140 & 745,8 \\
\hline F3 & 90 & 0 & 90 & 89 & 88 & 84 & 300,0 & 140 & 701,9 \\
\hline F4 & 82 & 0 & 81 & 82 & 82 & 82 & 300,0 & 360 & 1046,3 \\
\hline
\end{tabular}

Bei dem Verfahren EFG gehen die Entfernung zu den Paarungspartnern und die Kronengröße des Samenelters a priori als Faktoren in die Bestimmung der wahrscheinlichsten Polleneltern ein. Daher ist eine hohe Korrelation über die mit EFG ermittelten Selbstbefruchtungsraten zu erwarten und ist, zumindest für die Gesamtpopulation (inkl. Feldlinden), auch gegeben (s. Tab. 4.21). Durch die Involvierung der Faktoren Entfernung und Kronengröße der über EFG berechneten Selbstbefruchtungsraten sind bei linearen Regressionsanalysen eingesetzten Variablen nicht voneinander unabhängig. Von der Plausibilität einer Einbeziehung dieser Faktoren für die Schätzung von Selbstbefruchtungsraten einmal abgesehen, sind daher nur die Korrelationen der diesbezüglich „,neutralen“ Verfahren (zur Bestimmung von Selbstbefruchtungsanteilen) aussagekräftig: Ausschlußverfahren, eindeutiger Ausschluß und MLTR. Bei diesen Verfahren werden allein die Genotypen von Eltern und Nachkommen berücksichtigt, andere Faktoren haben keinen Einfluß auf die Selbstbefruchtungsrate. 


\begin{tabular}{|c|c|c|c|c|c|c|c|}
\hline \multirow[t]{4}{*}{ Tab. 4.21} & \multicolumn{7}{|c|}{$\begin{array}{l}\text { Korrelation von Entfernung und Kronengröße mit der Selbstbefruchtungsrate } \\
\text { mit Überprüfung des Bestimmtheitsmaßes }\left(\mathrm{r}^{2}\right) \text { auf Signifikanz für die Gesamt- } \\
\text { population und den Bestand (ohne Feldlinden). In Klammern die Vorzeichen } \\
\text { der entsprechenden Korrelationskoeffizienten. }\end{array}$} \\
\hline & & & & Bestimn & theitsmaß $\mathrm{r}^{2}$ & & \\
\hline & & $\begin{array}{l}\text { Abstand } \\
\text { nächster }\end{array}$ & Kronengröße & nächste & 0 Nachbarn & nächste & 5 Nachbam \\
\hline & & Nachbar & Samenelter & Abstand & Kronengrößen & Abstand & Kronengrößen \\
\hline \multirow[t]{2}{*}{ Ausschluß } & Gesamtpopulation & (+) $0,14^{* \star}$ & $(+) 0,23^{* * *}$ & (+) $0,17^{\star *}$ & (+) 0,05 & $(+) 0,17^{* *}$ & (+) 0,05 \\
\hline & ohne Feldlinden & ( \pm ) 0,00 & (+) 0,07 & (+) 0,01 & ( \pm ) 0,00 & ( \pm ) 0,00 & (-) 0,01 \\
\hline \multirow{2}{*}{$\begin{array}{l}\text { eindeutiger } \\
\text { Ausschluß }\end{array}$} & Gesamtpopulation & (+) 0,02 & (+) $0,09^{*}$ & ( \pm ) 0,00 & ( \pm ) 0,00 & ( \pm ) 0,00 & ( \pm ) 0,00 \\
\hline & ohne Feldlinden & ( \pm ) 0,00 & (+) $0,15^{\star *}$ & ( \pm ) 0,00 & (+) 0,02 & ( \pm ) 0,00 & (+) 0,02 \\
\hline \multirow[t]{2}{*}{ MLTR } & Gesamtpopulation & (+) $0,14^{\star *}$ & (+) $0,21^{\star \star \star \star}$ & (+) $0,17^{\star * *}$ & (+) 0,03 & $(+) 0,16^{* *}$ & (+) 0,04 \\
\hline & ohne Feldlinden & (+) 0,00 & $(+) 0,06$ & (+) 0,01 & (-) 0,01 & ( \pm ) 0,00 & (-) 0,01 \\
\hline \multirow[t]{2}{*}{$\operatorname{EFG} 2 \Delta$} & Gesamtpopulation & $(+) 0,27^{\star * *}$ & (+) $0,50^{* * *}$ & (+) $0,31^{* * *}$ & (+) $0,14^{\star *}$ & $(+) 0,30^{* * *}$ & $(+) 0,15^{\star *}$ \\
\hline & ohne Feldlinden & (+) 0,02 & (+) $0,29^{* \star *}$ & (+) 0,06 & (+) 0,01 & (+) 0,02 & (+) 0,01 \\
\hline \multirow[t]{2}{*}{ EFG $4 \Delta$} & Gesamtpopulation & (+) $0,32^{* * \star}$ & (+) $0,54^{* \star *}$ & (+) $0,37^{* * *}$ & (+) $0,19^{* * *}$ & (+) $0,36^{* * \star}$ & $(+) 0,20^{\star \star \star}$ \\
\hline & ohne Feldlinden & (+) 0,02 & $(+) 0,30^{* * *}$ & $(+) 0,08^{*}$ & (+) 0,03 & (+) 0,03 & (+) 0,02 \\
\hline \multirow[t]{2}{*}{ EFG $8 \Delta$} & Gesamtpopulation & (+) $0,36^{* * *}$ & (+) $0,56^{* \star *}$ & (+) $0,47^{* \star *}$ & $(+) 0,24^{\star \star \star}$ & (+) $0,45^{* \star \star}$ & $(+) 0,27^{\star * *}$ \\
\hline & ohne Feldlinden & (+) 0,00 & $(+) 0,23^{\star \star \star}$ & (+) 0,05 & (+) 0,04 & (+) 0,01 & (+) 0,03 \\
\hline
\end{tabular}

Auffällig ist die signifikante, positive Korrelation der Selbstbefruchtungsrate mit der Kronengröße des Samenelters und mit den Abständen zu den nächsten Paarungspartner für die Gesamtpopulation. Eine Korrelation ist dann nicht mehr gegeben, wenn die vier isoliert in der Feldmark stehenden Linden (Feldlinden) ausgeschlossen werden. Die vier Feldlinden haben die größten Kronen aller untersuchten Linden $\left(300 \mathrm{~m}^{2}\right)$, sie haben den größten Abstand zu den nächsten Paarungspartnern und zudem wurden für sie überdurchschnittlich hohe Selbstbefruchtungsraten ermittelt (s. Tab. 4.20). Die vier Feldlinden haben bei der Berechnung des Bestimmtheitsmaße über lineare Regression durch ihre einheitlich extremen Werte ein überproportional hohes Gewicht gegenüber den restlichen 50 im Mischbestand untersuchten Linden. Mit Blick auf die gesamte Population wird ersichtlich, daß der Anteil der Selbstbefruchtung mit der Größe der Krone des Samenelters und mit zunehmenden Abstand zu den nächsten Paarungspartner steigt; die Kronengröße der nächsten Nachbarn spielt keine Rolle. Für die im Bestand stehenden Linden gilt diese Aussage nicht, die Korrelationen sind nicht signifikant (die signifikante Korrelation der Selbstbefruchtungsrate mit der Kronengröße des Samenelters bei eindeutigem Ausschluß bildet die Ausnahme). Über dieses Verfahren kann nur 
8,6 \% (s. Tab. 4.15, S. 114) der untersuchten Samen ein Pollenelter zugeordnet werden; es ist daher bedingt repräsentativ bezüglich der Herleitung von Selbstbefruchtungsraten. Für die Population ohne Feldlinden trifft diese Aussage somit nicht ohne Weiteres zu.

Aber auch für die Gesamtpopulation kann bei einem Vergleich der acht größten Linden der Population (vier Feldlinden und vier Winterlinden aus dem Bestand) nicht der Schluß gezogen werden, die Feldlinden hätten überdurchschnittlich hohe Selbstbefruchtungsraten aufgrund ihrer räumlichen Isolation. Die vier im Bestand und im engen Verbund mit anderen Paarungspartnern stehenden Winterlinden Nr. 72, 118, 121, und 129 weisen ähnlich hohe Selbstbefruchtungsraten auf wie die in der Feldmark stehenden Bäume (s. Tab. 4.20). Bei Betrachtung dieser acht Winterlinden mit einer Kronengröße $>140 \mathrm{~m}^{2}$ ist die Korrelation der Selbstbefruchtungsrate mit der Entfernung zu den nächsten Paarungspartnern bei allen Selbstbefruchtungsermittlungsverfahren gering und nicht signifikant (s. Tab. 4.22, Ausnahme wiederum der eindeutige Ausschluß, s. o.).

\begin{tabular}{|c|c|c|c|c|c|c|}
\hline \multirow[t]{5}{*}{ Tab. 4.22} & \multicolumn{6}{|c|}{$\begin{array}{l}\text { Korrelation von Entfernung und Kronengröße mit der Selbstbefruchtungsrate } \\
\text { mit Überprüfung des Bestimmtheitsmaßes }\left(\mathrm{r}^{2}\right) \text { auf Signifikanz für die acht Win- } \\
\text { terlinden der Gesamtpopulation mit einer Kronengrößen }>140 \mathrm{~m}^{2} \text {. In Klam- } \\
\text { mern die Vorzeichen der entsprechenden Korrelationskoeffizienten. }\end{array}$} \\
\hline & \multicolumn{6}{|c|}{ Bestimmtheitsmaß $\mathrm{r}^{2}$} \\
\hline & \multicolumn{4}{|c|}{ Kronengröße des Samenelters $>140 \mathrm{~m}^{2} \quad(\mathrm{~N}=8)$} & & \\
\hline & $\begin{array}{l}\text { Abstand } \\
\text { nächster }\end{array}$ & Kronengröße & nächste & Nachbarn & \multicolumn{2}{|c|}{ nächste 5 Nachbarn } \\
\hline & Nachbar & Samenelter & Abstand & Kronengrößen & Abstand & Kronengrößen \\
\hline Ausschluß & (+) 0,04 & $(+) 0,00$ & $(+) 0,04$ & (+) 0,06 & $(+) 0,04$ & (+) 0,05 \\
\hline eind. Auss. & (-) 0,05 & (-) 0,26 & (-) 0,29 & (-) 0,31 & (-) 0,27 & (-) 0,35 \\
\hline MLTR & (+) 0,03 & ( \pm ) 0,00 & $(+) 0,01$ & (+) 0,01 & (+) 0,02 & $(+) 0,01$ \\
\hline EFG $2 \Delta$ & (+) 0,09 & (+) 0,01 & (+) 0,08 & (+) 0,07 & (+) 0,09 & $(+) 0,06$ \\
\hline EFG $4 \Delta$ & $(+) 0,14$ & (+) 0,02 & $(+) 0,14$ & (+) 0,09 & (+) 0,15 & (+) 0,09 \\
\hline EFG $8 \Delta$ & (+) 0,23 & (+) 0,01 & (+) 0,27 & $(+) 0,14$ & (+) 0,28 & (+) 0,15 \\
\hline
\end{tabular}

Weder für die Gesamtpopulation noch für den Bestand kann eine signifikante Abhängigkeit zwischen den Faktoren Kronengröße(n) und Abständen zu den nächsten Paarungspartnern festgestellt werden (die relativ hohen aber nicht signifikanten Korrelationen bei den mit dem eindeutigen Ausschlußverfahren sind dadurch begründet, daß für vier der acht Bäume der Anteil an Selbstbefruchtung mit $0 \%$ geschätzt wurde). Die Betrachtung der Selbstbefruch- 
tungsraten erweckte jedoch den Eindruck, daß bei den im Bestand stehenden Linden eine Abhängigkeit von Selbstbefruchtungsrate und Kronengröße bestünde. Die Population (ohne Feldlinden) wurde deshalb zusätzlich nach Kronengrößen gruppiert und ein weiteres Mal auf signifikante Korrelation überprüft. Betrachtet man alle Sameneltern, die eine Kronengröße von $>10 \mathrm{~m}^{2}$ aufweisen, wird jetzt für alle ,neutralen“ Bestimmungsverfahren eine signifikante Korrelation mit der Kronengröße berechnet (s. Tab. 4.23). Noch höhere Signifikanzen auf dem Niveau von $1 \%$ und $0,1 \%$ werden mit den über EFG ermittelten Selbstbefruchtungsraten berechnet.

Tab. 4.23 Korrelation von Entfernung und Kronengröße mit der Selbstbefruchtungsrate mit Überprüfung des Bestimmtheitsmaßes $\left(r^{2}\right)$ auf Signifikanz für verschiedene Gruppierungen von Kronengrößen der Sameneltern des Bestandes. In Klammern die Vorzeichen der entsprechenden Korrelationskoeffizienten.

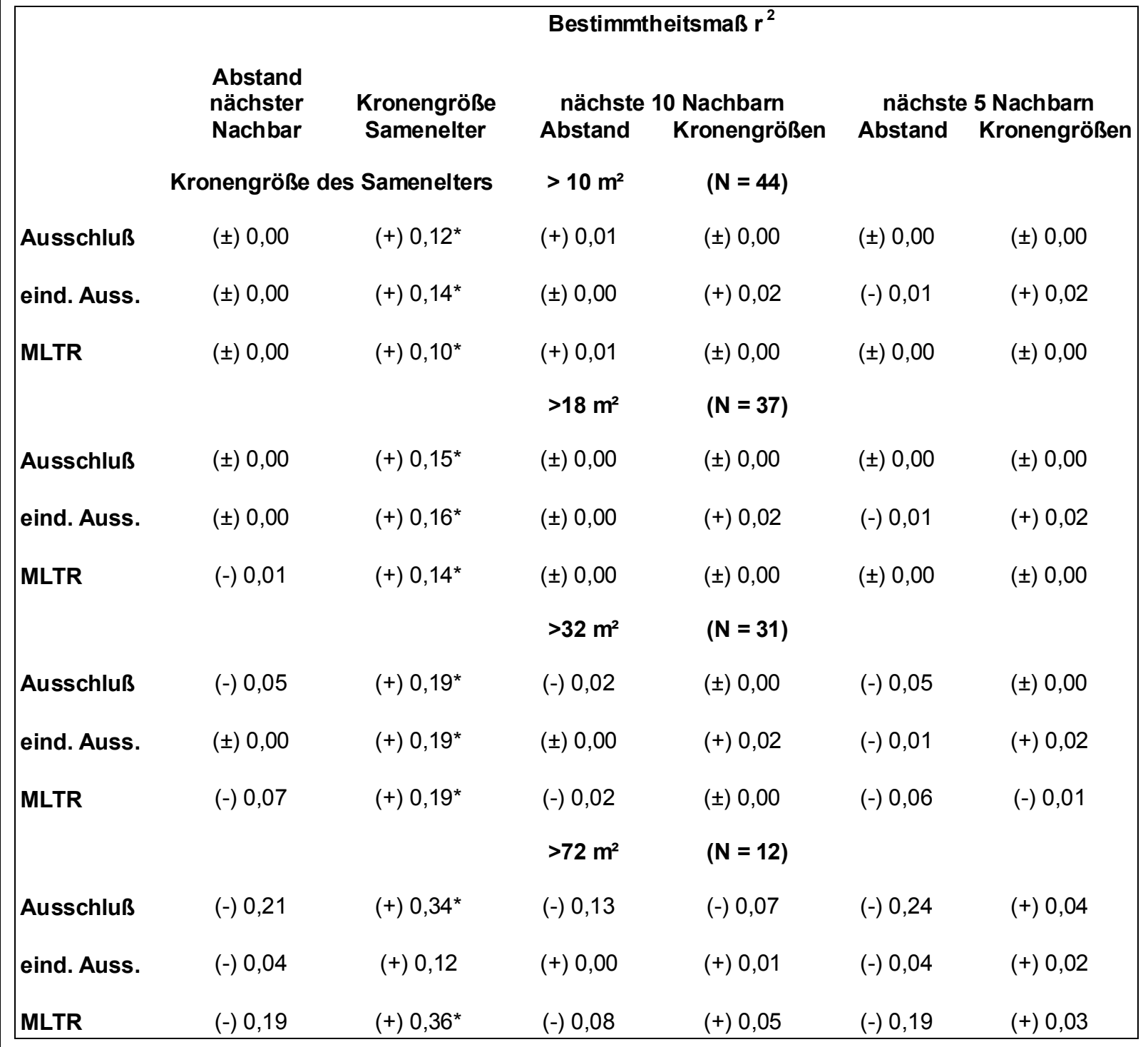


Einerseits demonstrieren die signifikanten Bestimmheitsmaße, daß auch noch bei Betrachtung der Winterlinden mit einer Kronengröße $>72 \mathrm{~m}^{2}$ mit größer werdender Krone der Anteil der Selbstbefruchtung steigt. Ein Blick in die Tab. 4.20 und Abb. 4.19 zeigt überdurchschnittlich hohe Selbstbefruchtungsraten sowohl für große und als auch für sehr kleine Winterlinden. Der Trend ist somit gegenläufig und erklärt, warum für den Bestand (ohne Feldlinden) eine signifikante Korrelation zwischen Selbstbefruchtungsrate und Kronengröße des Samenelters nicht ausgewiesen wird. Als Verfahren für die Bestimmung von Selbstbefruchtungsraten wurden hier MLTR gewählt, welches aber nur marginale Unterschiede zum Ausschlußverfahren aufweist.

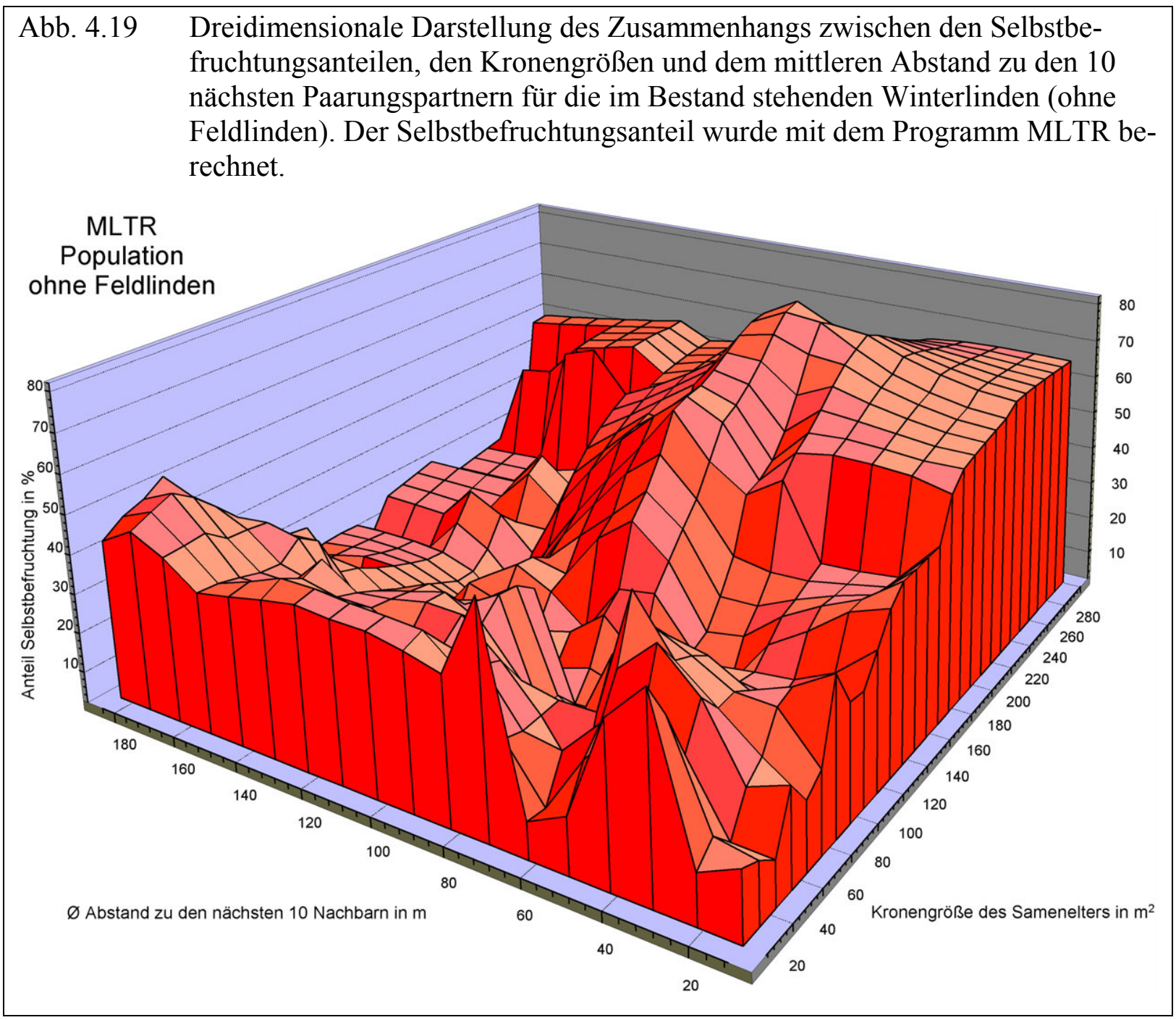

Gut erkennbar ist, daß einerseits der Anteil der Selbstbefruchtung mit der Kronengröße des Samenelters zunimmt, andererseits aber bei den sehr kleinen Linden ebenfalls sehr hoch ist. Teilt man den Bestand in zwei Gruppen, jeweils mit Kronengrößen $>32 \mathrm{~m}^{2}$ und $<32 \mathrm{~m}^{2}$, ergibt sich durch den Vergleich der Abb. 4.20 mit Abb. 4.21 folgendes Bild: 


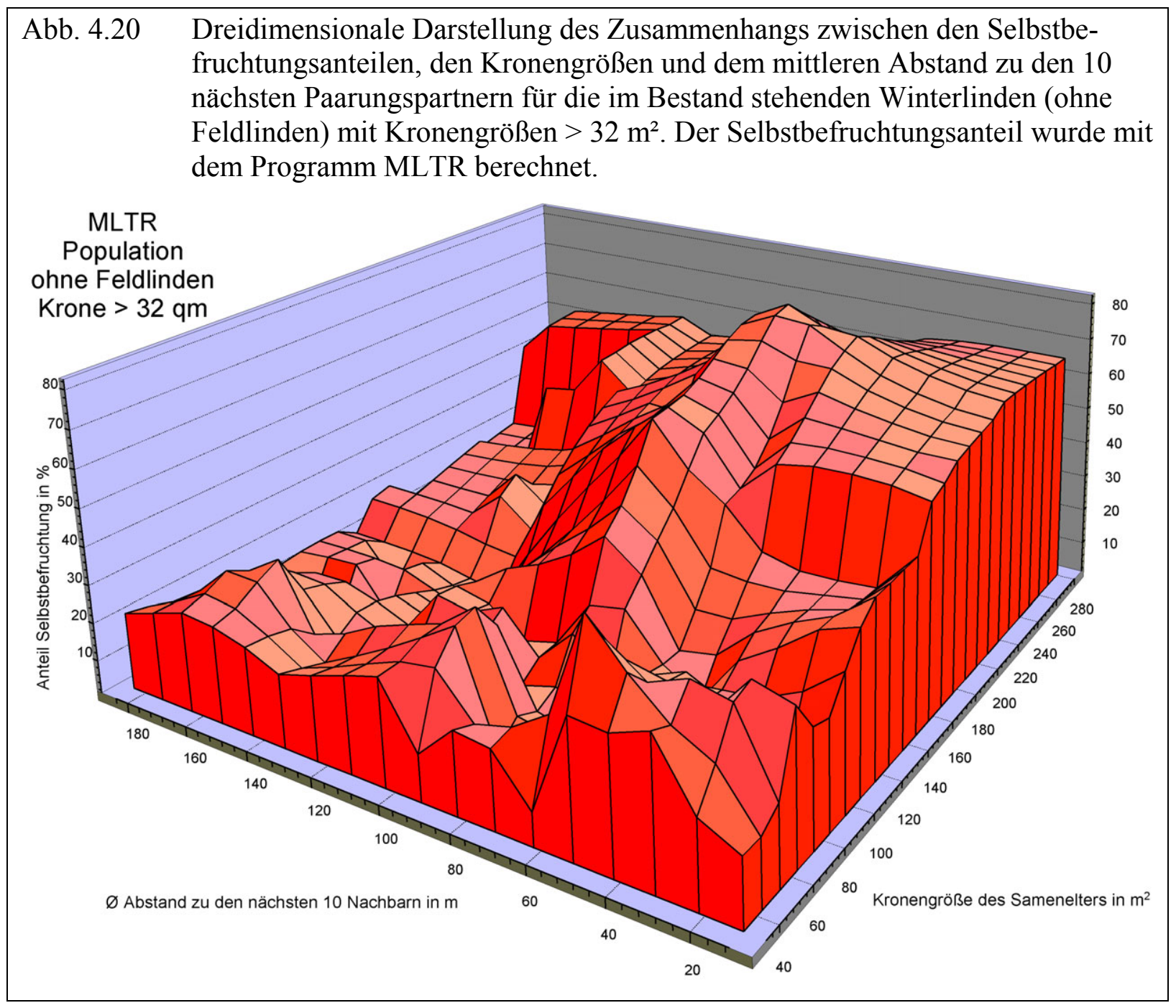

Ohne die Winterlinden mit einer Krone $>32 \mathrm{~m}^{2}$ sieht man in Abb. 4.20 jetzt eine einheitliche Tendenz. Die Selbstbefruchtungsrate erhöht sich mit zunehmender Kronengröße der Sameneltern. Dieser optische Eindruck wird über eine lineare Regressionsanlayse als statistisch signifikant bestätigt (s. Tab. 4.23). Der Tab. 4.23 kann ebenfalls entnommen werden, daß im Gegensatz zur Kronengröße des Samenelters die Entfernung zu den nächsten Paarungspartnern ebensowenig wie deren Kronengrößen keine Rolle spielt. Auch dies ist gut in der Abb. 4.20 $\mathrm{zu}$ sehen. Ein anderes Bild ergibt sich bei Betrachtung der Linden mit Kronen $>32 \mathrm{~m}^{2}$ in Abb. 4.21: 


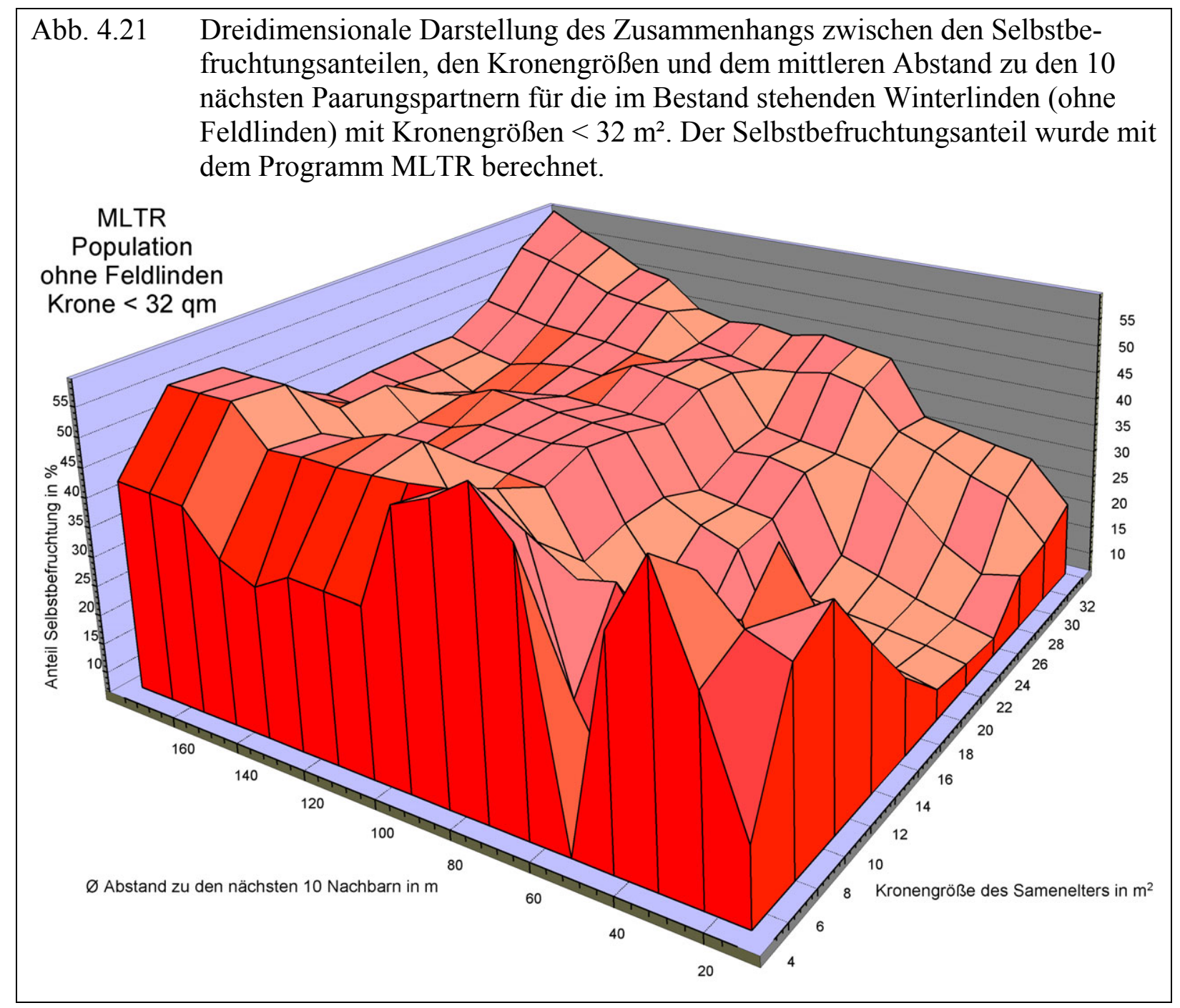

Bei den sehr kleinen Linden ist nicht mehr so sehr die Kronengröße für die Höhe der Selbstbefruchtungsrate entscheidend, sondern diese wird mehr vom Abstand dieser Bäume zu den nächsten Paarungspartnern beeinflußt. Je größer die Entfernung zu den nächsten Paarungspartnern, desto größer wird der Anteil Selbstbefruchtung in den Nachkommen. Die Korrelation der Selbstbefruchtungsrate mit dem Abstand zu den nächsten Paarungspartnern kann der Tab. 4.24 entnommen werden: 


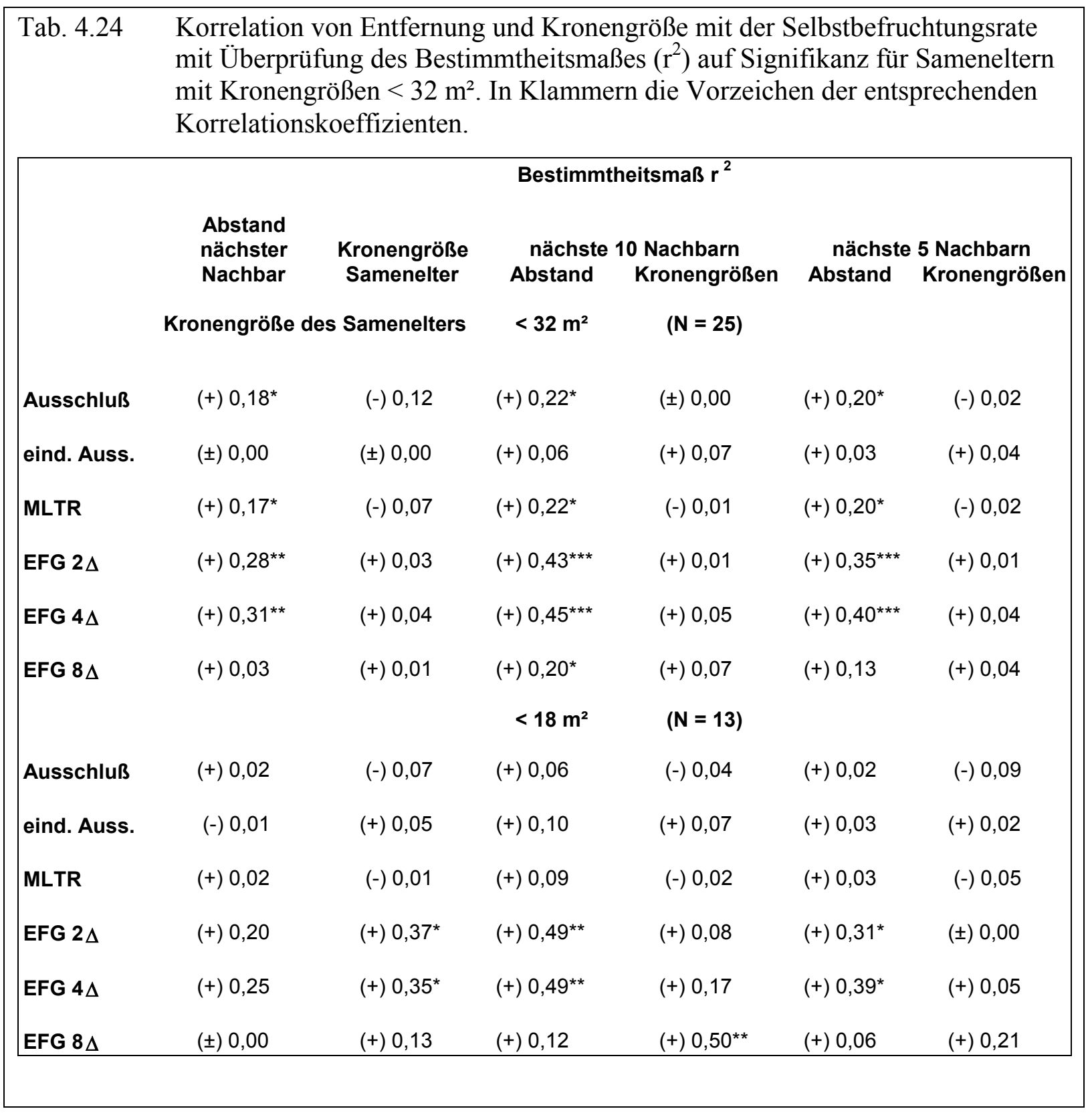

Geht man einen Schritt weiter und konzentriert sich auf die Sameneltern mit einer Kronengröße $<18 \mathrm{~m}^{2}$, ist für die ,neutralen“ Bestimmungsverfahren keine signifikante Korrelation der Selbstbefruchtungsrate zum Abstand der nächsten Paarungspartnern festzustellen. Bei Kronengrößen der Sameneltern $<18 \mathrm{~m}^{2}$ ist, unabhängig von allen Faktoren, eine hohe Selbstbefruchtungsrate zu verzeichnen (s. Tab. 4.24). Um dies wiederum graphisch zu veranschaulichen wurde in Abb. 4.22 die Perspektive der Abb. 4.21 verändert. Ab einer Kronengröße von $<18 \mathrm{~m}^{2}$ ist ein relativ gleichmäßig hoher Anteil an Selbstbefruchtung zu erkennen, der unabhängig von der Kronengröße des Samenelters und der Entfernung zu den nächsten Paarungspartnern ist. 


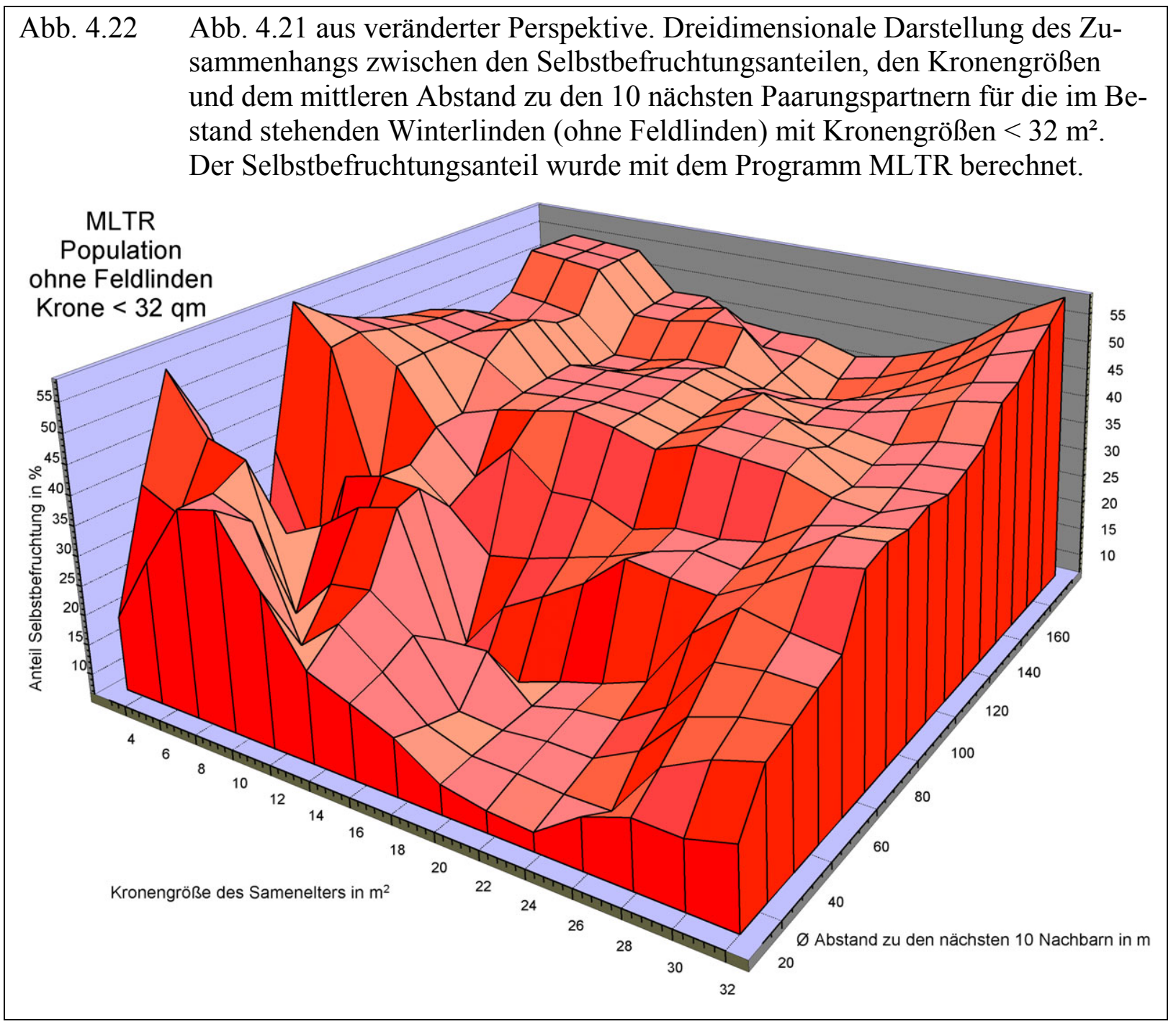

Fazit

Hohe Selbstbefruchtungsraten in den Nachkommenschaften einzelner Winterlinden sind weniger auf eine räumliche Trennung des Samenelters zu anderen Paarungspartnern zurückzuführen, sondern sind signifikant mit der Kronengröße des Samenelters selbst korreliert. Bei Betrachtung aller Linden mit einer Kronengröße $\geq 10 \mathrm{~m}^{2}$ steigt der Anteil Selbstbefruchtung kontinuierlich mit der Kronengröße. Allerdings sind auch unter den Nachkommenschaften sehr kleiner Winterlinden $\left(<10 \mathrm{~m}^{2}\right)$ hohe Selbstbefruchtungsraten zu finden. Bei Winterlinden mit Kronengrößen bis zu $32 \mathrm{~m}^{2}$ gewinnt neben der Kronengröße auch die Entfernung zum nächsten Paarungspartner signifikant an Einfluß: Je weiter kleine Winterlinden von anderen Paarungspartnern entfernt stehen, desto höher ist Selbstbefruchtungsrate in deren Nachkommen. Für Winterlinden mit Kronengrößen $\geq 32 \mathbf{m}^{2}$ wurde bezüglich des Abstandes zu den nächsten Paarungspartnern hingegen keine signifikante Korrelation mehr festgestellt. 


\subsubsection{Auswirkung der Selbstbefruchtung}

\subsubsection{Auswirkung von Selbstbefruchtung auf das Samengewicht}

Von insgesamt 3487 Samen, die mittels des Ausschlußprinzips bzw. mit dem EFG-Verfahren in fremd- und selbstbefruchtet eingeteilt werden konnten, wurde das Gewicht gemessen. Bei der Ermittlung des Gewichtes wurde zuvor das Perikarp entfernt nur der Embryo mit Testa gewogen. Das durchschnittliche Gewicht des Perikarps kann mit ca. 10 mg angegeben werden; bei einem Vergleich mit nicht präparierten Samen müssen dementsprechend ca. $10 \mathrm{mg}$ hinzugerechnet werden.

Das durchschnittliche Samengewicht aller 3487 Samen betrug 30,16 mg, wobei $10 \mathrm{mg}$ das Minimum und $65 \mathrm{mg}$ das Maximum darstellten. Wie schon von EISENHUT (1957) und PIGOTT (1991) beobachtet, lag das Gewicht der Samen aus mehrsamigen Früchten deutlich unter denen aus einsamigen Früchten. Die 244 aus mehrsamigen Früchten entnommenen Samen wiesen auch bei meinen Messungen mit durchschnittlich 25,95 mg ein geringeres Gewicht als die Samen aus einsamigen Früchten auf.

Da bei diesen 244 Samen das geringe Gewicht mit hoher Wahrscheinlichkeit auch physiologische Ursachen hat (Konkurrenz um Raum und Nährstoffe), können mögliche genetische Ursachen, wie Inzuchtdepression, davon nicht getrennt werden. Deshalb blieben die 244 Samen bei der Berechnung der durchschnittlichen Samengewichte nach Fremd- bzw. Selbstbefruchtung unberücksichtigt. In die Tab. 4.25 gehen nur die Gewichte der 3243 einsamigen Nachkommen ein. Ein Vergleich der einzelnen Samengewichte mit MLTR ist nicht möglich, da MLTR nur die Selbstbefruchtungsraten von Familien oder Populationen berechnet; ob ein einzelner Nachkomme aus Fremd- oder Selbstbefruchtung entstanden ist, kann mit diesem Programm nicht eruiert werden. 


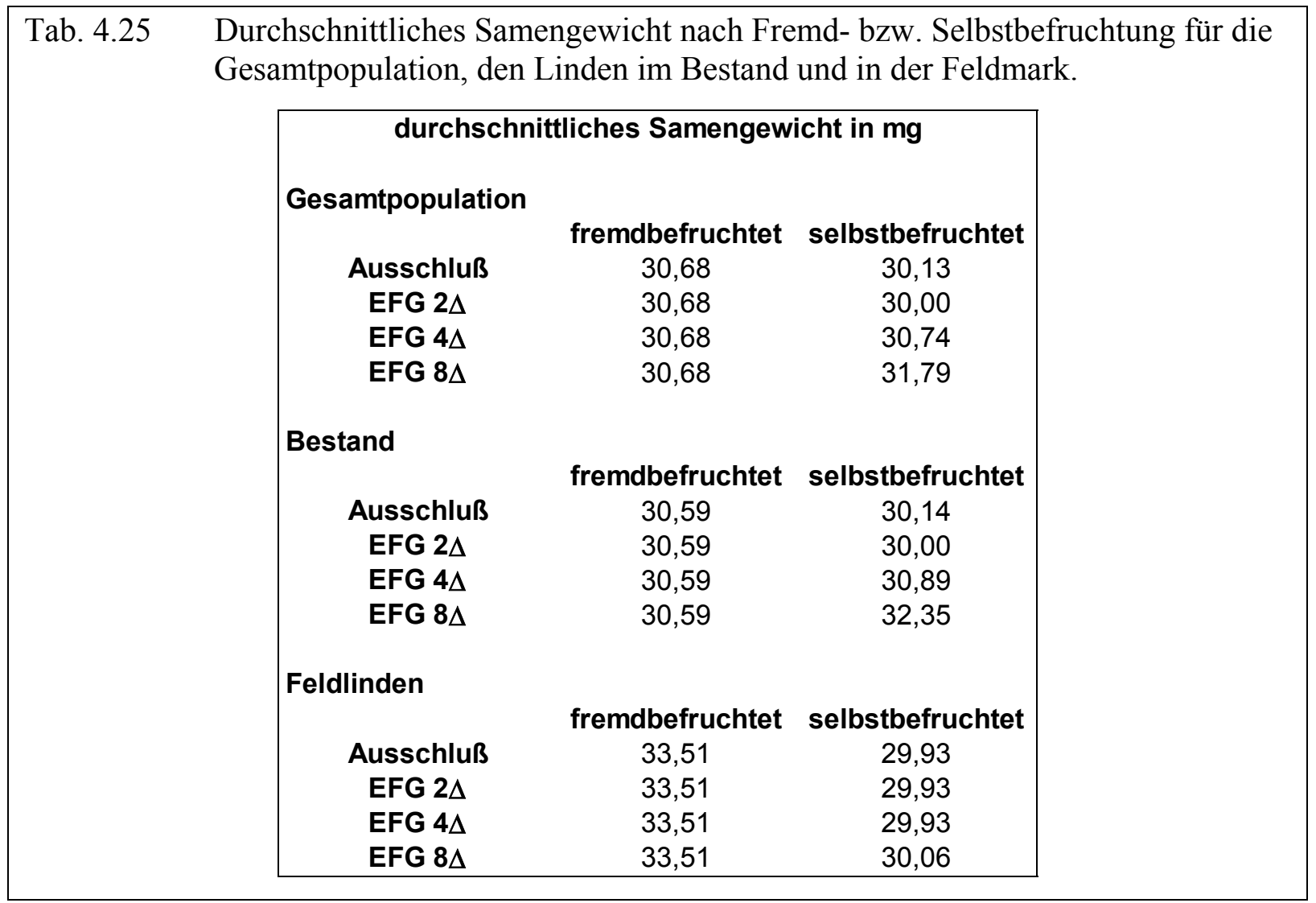

Unterschiede der Samengewichte nach Fremd- bzw. Selbstbefruchtung sind nur bei den vier Feldlinden ersichtlich, diese sind aber statistisch nicht signifikant. Demnach läßt sich ein Zusammenhang zwischen der Selbstbefruchtungsrate und dem Samengewicht nicht herstellen. Eine Überprüfung auf eine Korrelation zwischen Selbstbefruchtung und Samengewicht erfolgte zusätzlich auf der Ebene von 49 Einzelbaumabsaaten, für welche Samengewichte gemessen wurden. Das Durchschnittsgewicht der Samen je Baum variiert von 19,8 mg bis 49,8 mg und damit sehr stark zwischen den 49 Nachkommenschaften. Da auch die Selbstbefruchtungsrate für die Winterlinden individuell sehr unterschiedlich ausgeprägt ist (s. Tab. 4.18), war eine Korrelation dieser beiden Faktoren zumindest zu vermuten. Ein kurzer Blick auf die Daten in der Tab. 4.26 läßt erkennen, was eine lineare Regressionsanalyse statistisch bestätigt: Es besteht kein Zusammenhang zwischen dem Durchschnittsgewicht der Nachkommenschaften und den nach den verschiedenen Verfahren ermittelten Anteilen aus Selbstbefruchtung entstandener Samen. 
Tab. 4.26 Durchschnittliches Samengewicht, Verhältnis des Hohlkornanteils zu vitalen Samen und über verschiedenen Verfahren ermittelte Selbstbefruchtungsraten in den Nachkommenschaften von 54 Winterlinden.

\begin{tabular}{|c|c|c|c|c|c|}
\hline \multirow{2}{*}{$\begin{array}{c}\text { Baum } \\
\text { Nr. }\end{array}$} & \multirow{2}{*}{$\begin{array}{c}\text { mittleres } \\
\text { Samengewicht } \\
\text { in } \mathbf{~ m g}\end{array}$} & \multirow{2}{*}{$\begin{array}{l}\text { Hohlkorn- } \\
\text { anteil } \\
\text { in \% }\end{array}$} & \multicolumn{3}{|c|}{ Selbstbefruchtungsrate in \% } \\
\hline & & & Ausschluß & EFG 2 $\Delta$ & MLTR \\
\hline 1 & & 20 & 45 & 31 & 44 \\
\hline 2 & 33,1 & 33 & 49 & 45 & 34 \\
\hline 3 & & 15 & 70 & 0 & 70 \\
\hline 8 & 20,7 & 510 & 5 & 0 & 4 \\
\hline 10 & 30,1 & 39 & 31 & 8 & 19 \\
\hline 11 & & 186 & 48 & 0 & 29 \\
\hline 14 & 28,3 & 40 & 15 & 13 & 5 \\
\hline 15 & 28,1 & 47 & 43 & 15 & 36 \\
\hline 22 & 25,7 & 8 & 18 & 0 & 10 \\
\hline 23 & 21,3 & 31 & 14 & 9 & 12 \\
\hline 25 & 22,4 & 44 & 11 & 3 & 6 \\
\hline 26 & 26,7 & 42 & 68 & 0 & 62 \\
\hline 27 & 26,1 & 21 & 41 & 17 & 38 \\
\hline 28 & 33,9 & 87 & 47 & 22 & 40 \\
\hline 32 & 29,6 & 34 & 46 & 46 & 45 \\
\hline 33 & 22,3 & 418 & 14 & 13 & 7 \\
\hline 36 & 27,8 & 94 & 32 & 31 & 31 \\
\hline 38 & 26,7 & 900 & 19 & 14 & 16 \\
\hline 42 & 24,9 & 19 & 52 & 47 & 47 \\
\hline 59 & 27,4 & 7 & 13 & 0 & 9 \\
\hline 68 & 49,8 & 13 & 22 & 7 & 3 \\
\hline $69 a$ & 33,0 & 19 & 34 & 27 & 27 \\
\hline 71 & 35,5 & 13 & 20 & 10 & 10 \\
\hline 72 & 30,5 & 15 & 55 & 54 & 52 \\
\hline 77 & 21,5 & 7 & 14 & 14 & 15 \\
\hline 82 & 30,6 & 17 & 46 & 34 & 44 \\
\hline 92 & 30,2 & 128 & 26 & 20 & 7 \\
\hline 93 & 35,7 & 95 & 5 & 5 & 3 \\
\hline 94a & 32,8 & 80 & 36 & 20 & 31 \\
\hline 95 & 33,8 & 93 & 43 & 43 & 43 \\
\hline 97 & 23,6 & 35 & 5 & 5 & -4 \\
\hline 98 & 29,7 & 3 & 18 & 18 & 17 \\
\hline 98a & 19,8 & 58 & 40 & 35 & 35 \\
\hline 104 & 28,2 & 26 & 63 & 38 & 61 \\
\hline 107 & 26,2 & 17 & 67 & 23 & 63 \\
\hline 109 & 27,5 & 12 & 54 & 54 & 50 \\
\hline 111 & 24,8 & 30 & 3 & 0 & 1 \\
\hline 112 & 32,6 & 0 & 43 & 12 & 35 \\
\hline 113 & 32,4 & 60 & 9 & 7 & -7 \\
\hline 114 & 24,4 & 47 & 29 & 2 & 14 \\
\hline 115 & 25,4 & 123 & 31 & 32 & 31 \\
\hline 118 & 42,2 & 37 & 57 & 57 & 50 \\
\hline 120 & 25,5 & 50 & 17 & 11 & 8 \\
\hline 121 & & 175 & 90 & 83 & 90 \\
\hline 122 & 24,0 & 253 & 5 & 0 & 0 \\
\hline 123 & 33,0 & 17 & 39 & 39 & 37 \\
\hline
\end{tabular}




\begin{tabular}{|r|r|r|r|r|r|}
\hline $\mathbf{1 2 9}$ & 27,4 & 74 & 68 & 68 & 68 \\
\hline $\mathbf{1 3 0}$ & 26,3 & 49 & 54 & 29 & 47 \\
\hline $\mathbf{1 3 3}$ & 30,9 & 7 & 10 & 11 & 9 \\
\hline $\mathbf{1 3 4}$ & 27,9 & 23 & 39 & 33 & 36 \\
\hline $\mathbf{F 1}$ & & 16 & 68 & 68 & 66 \\
\hline $\mathbf{F 2}$ & 32,4 & 16 & 47 & 48 & 32 \\
\hline $\mathbf{F 3}$ & 27,0 & 774 & 90 & 89 & 90 \\
\hline $\mathbf{F 4}$ & 34,0 & 141 & 82 & 82 & 81 \\
\hline
\end{tabular}

\subsubsection{Hohlkornanteil}

Betreffend der ermittelten Hohlkornanteile sind prinzipiell die gleichen Aussagen zu machen wie für die Samengewichte. Auch die Hohlkornanteile sind von Winterlinde zu Winterlinde individuell sehr verschieden, ohne daß sie auch nur annähernd in einem Zusammenhang mit der Selbstbefruchtungsrate gebracht werden könnten (Tab. 4.26). Die berechneten Bestimmtheitsmaße $\left(\mathrm{r}^{2}\right)$ liegen, wie bei den Samengewichten, bei allen Vergleichen unter der $5 \%$ Marke und sind weit entfernt von einer statistischen Signifikanz (ohne Abb.).

Die Hohlkornanteile wurden, auf die gleichen Weise wie mit den Selbstbefruchtungsraten, auf Korrelation mit der Kronengröße des Samenelters, dem Abstand zu dem und den nächsten Nachbarn und der $\varnothing$ Kronengröße der nächsten 5 bzw. 10 Nachbarn überprüft. Bei allen Vergleichen zeigten sich keine signifikanten Korrelationen und das Bestimmtheitsmaß $\left(\mathrm{r}^{2}\right)$ liegt unter $1 \%$.

\subsection{Genfluß durch Pollen}

Anliegen dieses Kapitels ist die Quantifizierung von Genfluß bzw. von Pollentransportweiten. Für die Bestimmung von Pollentransportweiten ist bei bekanntem Samenelter für den Nachkommen eine Zuordnung zu einem Pollenelter notwendig. Diese Zuordnung ermöglicht das Ausschlußverfahren, das Programm CERVUS und das Verfahren EFG (s. Kap. 4.5). Wie ebenfalls aus dem Kap. 4.5 ersichtlich, gibt es große quantitative und qualitative Unterschiede bei der Identifizierung von Polleneltern zwischen den und innerhalb der verschiedenen Verfahren. Es stellt sich die Frage, wie gravierend die Auswirkungen bei der Verwendung unterschiedlicher Pollenelterbestimmungsverfahren auf die ermittelten Pollentransportweiten sind. Zunächst werden die Ergebnisse der einzelnen Verfahren dargelegt, um anschließend die Pollentransportweiten in Kap. 4.8.4 zusammenfassend darzustellen. 


\subsubsection{Eindeutiges Ausschlußverfahren}

Mit diesem Verfahren konnte für 331 (8,6\%) der 3864 Nachkommen der Gesamtpopulation ein Pollenelter bestimmt werden (s. Kap. 4.6.1). Die 331 Pollentransportweiten ergeben bei Bildung von 10 m-Distanzklassen die in Abb. 4.23 gezeigte Verteilung der Punktwolke.

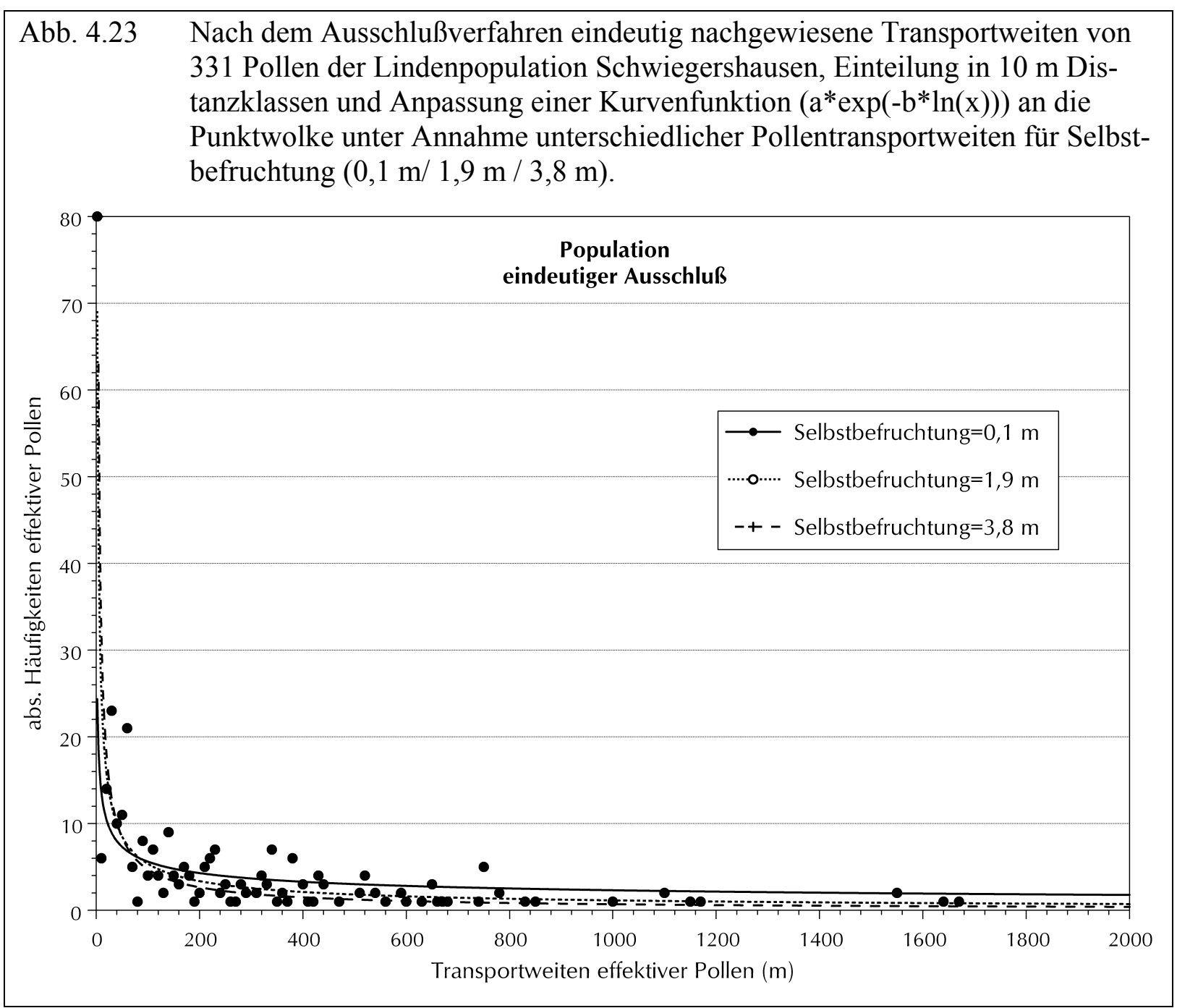

Tab. 4.27 Güte der Anpassung der Kurvenfunktion $a^{*} \exp \left(-b^{*} \ln (\mathrm{x})\right)$ an die Punktwolken bei Annahme unterschiedlicher Pollentransportweiten für Selbstbefruchtung $(0,1 \mathrm{~m} / 1,9 \mathrm{~m} / 3,8 \mathrm{~m})$.

\begin{tabular}{|lrrr|}
\hline & \multicolumn{3}{c|}{ Pollentransportweite für Selbstbefruchtung } \\
& $\mathbf{0 , 1} \mathbf{~ m}$ & $\mathbf{1 , 9} \mathbf{~ m}$ & $\mathbf{3 , 8} \mathbf{~}$ \\
Varianz der Residuen & 10,6635 & 13,3365 & 19,6035 \\
Stdabw. der Residuen & 3,2655 & 3,6519 & 4,4276 \\
Bestimmtheit der Funktion & 0,9341 & 0,9502 & 0,9391 \\
\hline
\end{tabular}

Die Funktion $a^{*} \exp \left(-b^{*} \ln (\mathrm{x})\right)$ zeigte eine sehr gute Anpassung an die Punktwolke (s. Tab. 4.27) und gibt eine optische Vorstellung über die Pollentransportweiten. Die von MüLLER 
[-STARCK] (1977) in einem Kiefernbestand ermittelte Funktion einer Pollenverbreitungskurve $a^{*} \exp \left(-b^{*} x\right)$ zeigte eine unbefriedigende Anpassung (deutlich höhere Varianz der Residuen). Dies war nicht anders zu erwarten, da die Problematik in seiner Untersuchung sich stark von der eines Lindenmischbestandes unterscheidet. MÜLLER [-STARCK] (1977) ermittelte die Pollentransportweiten mit Hilfe eines Markerbaumes innerhalb eines ca. 60x130 m großen Kiefernreinbestandes. Der größtmögliche Abstand eines Samenelters vom Markerbaum betrug ca. $94 \mathrm{~m}$ und daher konnten bei dieser windbestäubten Konifere auch keine größere Pollentransportweiten beobachtet werden.

Bei der Bildung von 80 der 331 Samen ist eine Selbstbefruchtung vorausgegangen (24,2 \%). Die erste Distanzklasse repräsentiert die Anzahl dieser aus Selbstbefruchtung entstandenen Nachkommen. Die Frage, wie weit im Falle geitonogamer Selbstbefruchtung der Pollen durchschnittlich transportiert wird, wurde im Rahmen dieser Arbeit nicht untersucht. Über die Transportweiten bei Selbstbefruchtung kann in diesem Falle nur gemutmaßt bzw. aus den in Kap. 2.8 aufgeführten Ergebnissen anderer Arbeiten geschlossen werden. Für alle weiteren Berechnungen wird für Selbstbefruchtung ein durchschnittlicher Transport des Pollens von 1,9 m (innerhalb einer Lindenkrone) angenommen. Der Wert von 1,9 m entspricht der Hälfte des durchschnittlichen Kronenradius aller 141 Mitglieder der Population Schwiegershausen.

Wie in Abb. $4.23 \mathrm{zu}$ sehen, ist die Wahl des Wertes für die durchschnittliche Pollentransportweite bei Selbstbefruchtung bei einer Exponentialfunktion von nicht geringer Bedeutung. Als durchschnittliche Transportweite für Selbstbefruchtung wurden jeweils $0,1 \mathrm{~m}, 1,9 \mathrm{~m}$ und 3,8 m eingesetzt, was einen deutlichen Einfluß auf den Kurvenverlauf hat. In Abb. 4.24 ist durch eine Ausschnittsvergrößerung der Abb. 4.23 die Empfindlichkeit der Exponentialfunktion gegenüber unterschiedlichen Ausgangswerten in der ersten Distanzklasse (Selbstbefruchtung) veranschaulicht. 


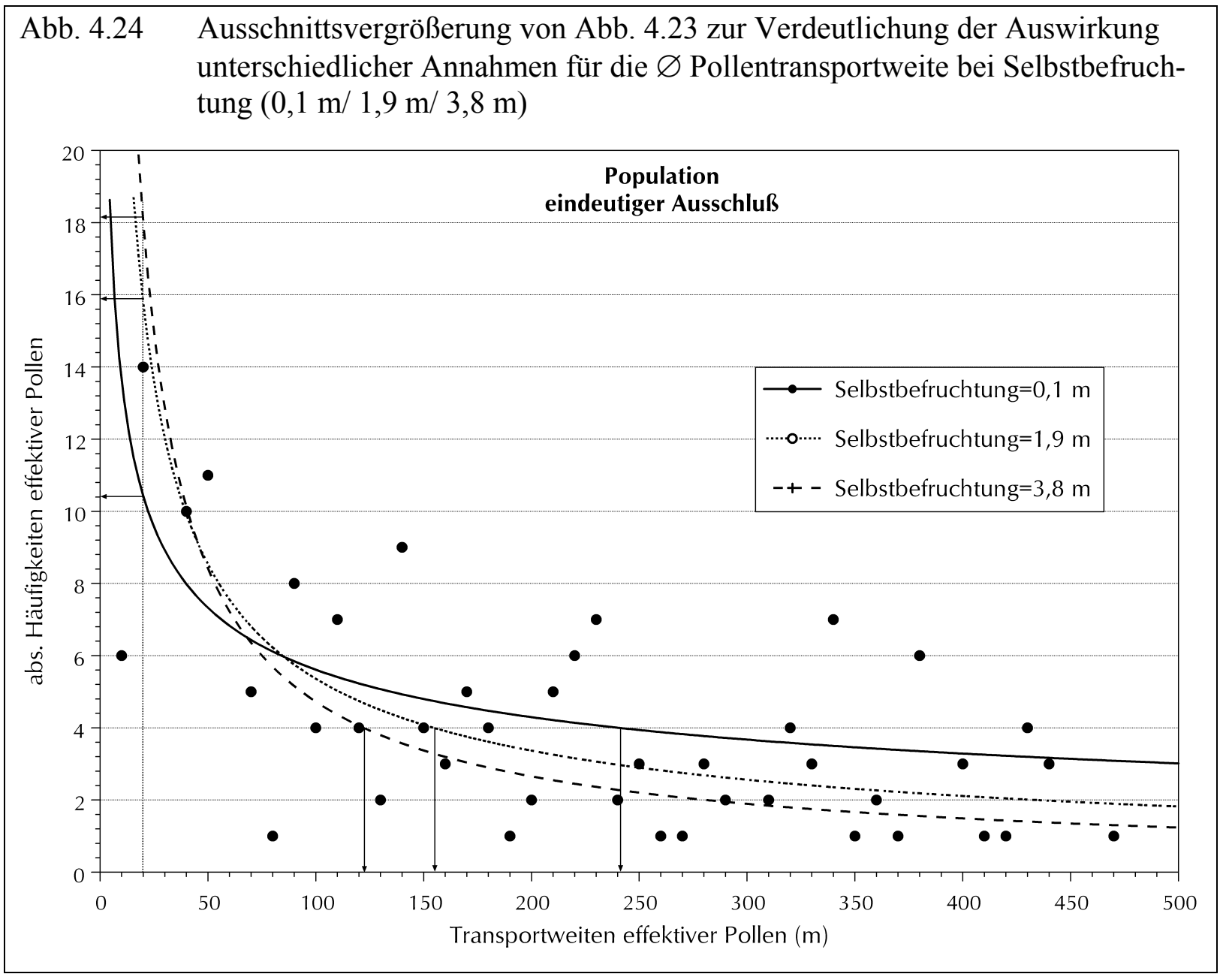

Der Verlauf der Kurven ist, je nach eingesetzter Pollentransportweite für Selbstbefruchtung, sehr unterschiedlich. So variieren bei der absoluten Häufigkeit von vier Pollen die Pollentransportweiten in von ca. $120 \mathrm{~m}$ (Selbstbefruchtung =3,8 m) bis $240 \mathrm{~m}$ (Selbstbefruchtung $=$ 0,1 m, Abb. 4.24).

Eine Alternative zur Exponentialfunktion stellt die Beschreibung der Pollentransportweiten in Form einer kumulativen Häufigkeitsverteilung dar. Gehen die 331 Pollentransportweiten ohne die Bildung von Klassen direkt in die Berechnungen ein, entfällt und die Angleichung einer Kurve an die streuende Punktwolke. Dies wirkt sich auch in sehr guter statistischer Anpassung (Varianz/Standardabweichung der Residuen, Bestimmtheit etc.) aus. Ein weiterer Vorteil der kumulativen Häufigkeitsverteilung (Abb. 4.26) ist die minimale Beeinflussung verschiedener Annahmen von Transportweiten bei Selbstbefruchtung auf den Kurvenverlauf. Die Kurve verschiebt sich lediglich, optisch nicht wahrnehmbar, auf der x-Achse nach rechts oder nach links. Diese Eigenschaften stellen einen deutlichen Vorteil gegenüber der an eine Punktwolke angepaßten Exponentialfunktion dar. Die in der Legende der Abb. 4.25 darge- 
stellte Kurvenfunktion $\left((1-a)+a * \exp \left(1 /(x+b)^{3,6}\right)\right) * 100$ ging daher als Faktor Entfernung (E) in das Pollenelterbestimmungsverfahren EFG ein (Kap. 3.9.2.4).

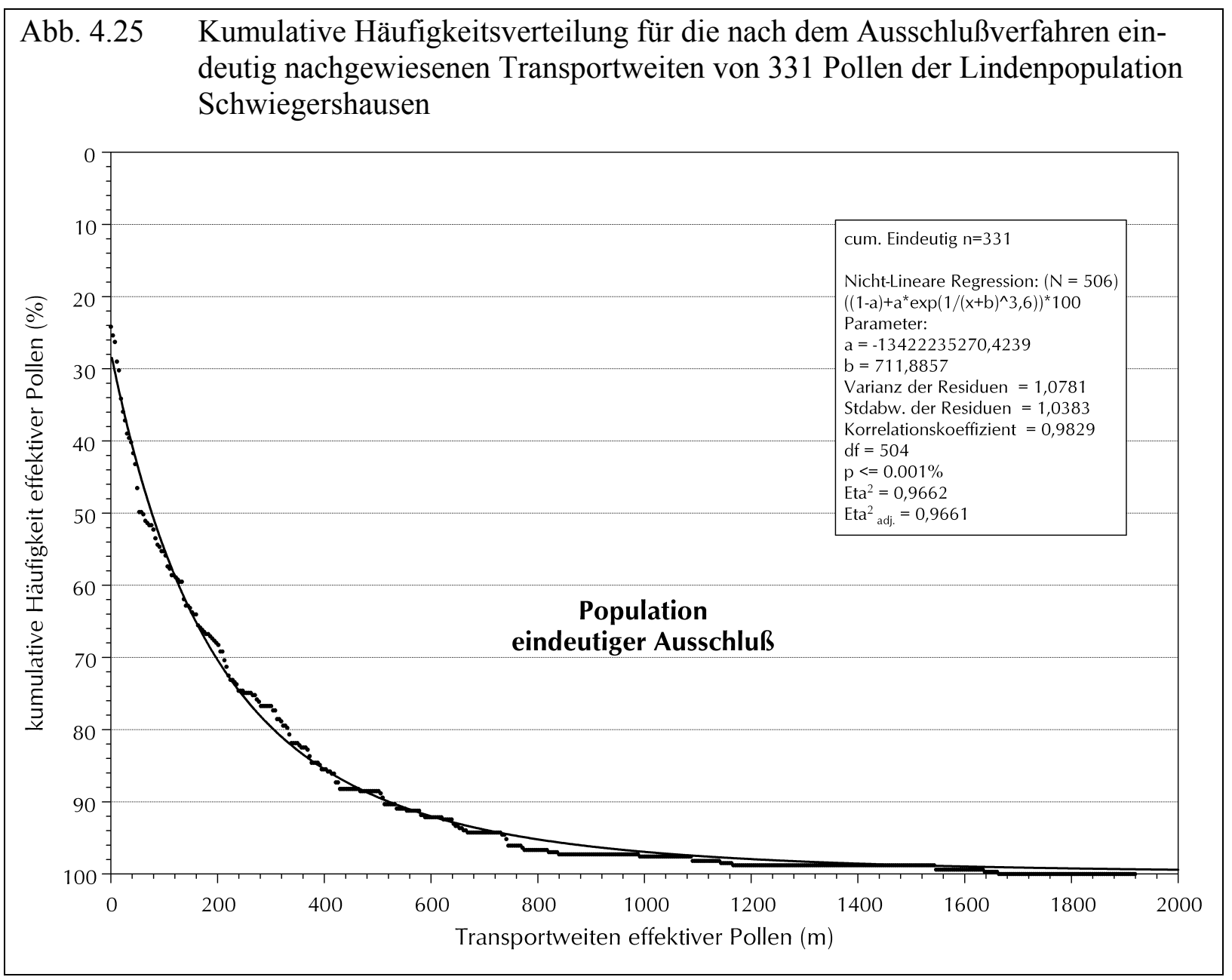

\subsubsection{CERVUS}

In Kap. 4.6.4 wurde entschieden, für weitere Studien in Zusammenhang mit CERVUS bei der Bestimmung des $\Delta$-Wertes die Kombination der Eingangsparameter $0 \%$ Fehlerquote und 95 \% Signifikanzniveau zu verwenden. Je nach den gewählten Eingangsparametern differieren die mit CERVUS ermittelten Polleneltern sowohl qualitativ als auch quantitativ und damit auch die daraus hergeleiteten Pollentransportweiten zum Teil erheblich. Für vier Einzelbaumabsaaten waren die Unterschiede der mit den verschiedenen Eingabeparametern ermittelten Polleneltern so offensichtlich, daß zusätzlich auch für die Kombinationen 1 \% Fehlerquote, $95 \%$ Signifikanzniveau und $1 \%$ Fehlerquote, $80 \%$ Signifikanzniveau die Pollentransportweiten berechnet wurden. Aus der Tab. 4.28 ist gut zu ersehen, daß je nach Wahl der Eingabeparameter CERVUS unterschiedliche und unterschiedlich viele Polleneltern identifiziert und folglich die Pollentransportweiten für ein und denselben Datensatz sehr stark variieren können. 


\begin{tabular}{|c|c|c|c|c|}
\hline \multirow[t]{7}{*}{ Tab. 4.28} & \multicolumn{4}{|c|}{$\begin{array}{l}\text { Über CERVUS mit verschiedenen Eingabeparameter identifizierte Polleneltern } \\
\text { und die daraus hergeleiteten } \varnothing \text { Pollentransportweiten für die Nachkommen der } \\
\text { Winterlinden } 14,38,77 \text { und } 114 \text {. Variierte Eingabeparameter bei CERVUS: } \\
\text { Fehlerquote } 0 \% \text { und } 1 \% \text {, Signifikanzniveau des } \Delta \text {-Wertes } 95 \%\left(^{*}\right) \text { und } 80 \% \\
(+) \text {. }\end{array}$} \\
\hline & \multicolumn{4}{|c|}{$\varnothing$ Pollentransportweite in $\mathrm{m}$} \\
\hline & Baum Nr. & CERVUS $0 \%^{*}$ & CERVUS $1 \%^{*}$ & CERVUS $1 \%+$ \\
\hline & $\begin{array}{c}14 \\
\text { identifiziert }\end{array}$ & $\begin{array}{c}409,7 \\
9\end{array}$ & $\begin{array}{c}70,0 \\
1\end{array}$ & $\begin{array}{c}383,1 \\
7\end{array}$ \\
\hline & $\begin{array}{c}38 \\
\text { identifiziert }\end{array}$ & $\begin{array}{c}157,3 \\
8\end{array}$ & $\begin{array}{c}156,4 \\
3\end{array}$ & $\begin{array}{c}107,5 \\
6\end{array}$ \\
\hline & $\begin{array}{c}77 \\
\text { identifiziert }\end{array}$ & $\begin{array}{c}18,4 \\
4\end{array}$ & $\begin{array}{c}266,1 \\
2\end{array}$ & $\begin{array}{c}105,7 \\
15\end{array}$ \\
\hline & $\begin{array}{c}114 \\
\text { identifiziert }\end{array}$ & $\begin{array}{c}83,5 \\
7\end{array}$ & $\begin{array}{c}73,9 \\
5\end{array}$ & $\begin{array}{c}176,6 \\
12\end{array}$ \\
\hline
\end{tabular}

Für nachfolgende Vergleiche der aus verschiedenen Pollenelterbestimmungsverfahren resultierenden Pollentransportweiten findet nur CERVUS $0 \%$ * $(0 \%$ Fehlerquote, $95 \%$ iges Signifikanzniveau) Verwendung.

\subsubsection{EFG}

Je nach Höhe der verwendeten Diskriminanzschwelle $\Delta$ werden auch mit EFG unterschiedliche Identifizierungsquoten erreicht. Bei einer Diskriminanzschwelle $8 \Delta$ konnte 23,2 \% aller untersuchten Nachkommen ein wahrscheinlichster Pollenelter zugeordnet werden, bei einer Diskriminanzschwelle von $2 \Delta$ waren es $56 \%$ (s. Kap. 4.6.2). Qualitative Unterschiede sind bei EFG zwischen den verschiedenen Diskriminanzschwellen nicht zu verzeichnen, d. h. einem Samen werden nicht unterschiedliche Polleneltern zugewiesen, wie es bei CERVUS der Fall ist. Die unterschiedliche Anzahl der ermittelten Polleneltern variiert aber sehr stark und hat einen Einfluß auf die $\varnothing$ Pollentransportweiten, die zu ähnlich unterschiedlichen Pollentransportweiten führen wie im vorigen Kapitel für CERVUS gezeigt wurde.

Wie schon erwähnt, ist die Diskriminanzschwelle $8 \Delta$ sehr hoch angesetzt und ein $\Delta$-Wert von 2 erscheint für eine Bestimmung von Polleneltern ausreichend. Daher sollen die Ergebnisse der Diskriminanzschwellen $4 \Delta$ und $8 \Delta$ im folgenden Kap. 4.8.4 nur vergleichende Funktion haben. Das Hauptaugenmerk soll auf den Ergebnissen mit einer Diskriminanzschwelle von $2 \Delta$ liegen. 


\subsubsection{Umfang des Genflusses}

Die in Tab. 4.29 gezeigten $\varnothing$ Pollentransportweiten beziehen sich auf alle ermittelten Pollentransportweiten einschließlich den Werten für Selbstbefruchtung. Die Transportweite des Pollens bei Selbstbefruchtung wird mit 1,9 m angesetzt. Wird für Selbstbefruchtung der Wert 0,1 m bzw. 3,8 m eingesetzt, hat dieses kaum Einfluß auf die $\varnothing$ Pollentransportweite, sie verringert bzw. erhöht sich um weniger als einen $\mathrm{m}$.

\begin{tabular}{|c|c|c|c|c|c|c|}
\hline \multirow[t]{6}{*}{ Tab. 4.29} & \multicolumn{6}{|c|}{$\begin{array}{l}\text { Über die verschiedenen Pollenelterbestimmungsverfahren ermittelten } \varnothing \text { Poller } \\
\text { transportweiten für die Gesamtpopulation Schwiegershausen, die im Bestand } \\
\text { und in der Feldmark stehenden Linden einschließlich Selbstbefruchtung. Bei } \\
\text { Selbstbefruchtung wird eine Transportweite von } 1,9 \text { m angenommen. Dazu ist } \\
\text { kleingedruckt die absolute Anzahl der identifizierten Polleneltern angegeben. }\end{array}$} \\
\hline & \multirow[t]{2}{*}{$\begin{array}{l}\text { einschließlich } \\
\text { Selbstbefruchtung }\end{array}$} & \multicolumn{5}{|c|}{$\varnothing$ Pollentransportweite in $\mathbf{m}$} \\
\hline & & eind. Ausschluß & EFG $2 \Delta$ & EFG $4 \Delta$ & EFG $8 \Delta$ & Cervus $0 \%$ * \\
\hline & $\begin{array}{c}\text { Gesamtpopulation } \\
\text { identifiziert }\end{array}$ & $\begin{array}{c}174,0 \\
331\end{array}$ & $\begin{array}{r}79,3 \\
2163\end{array}$ & $\begin{array}{r}72,9 \\
1331\end{array}$ & $\begin{array}{c}80,6 \\
895\end{array}$ & $\begin{array}{c}197,7 \\
709\end{array}$ \\
\hline & $\begin{array}{l}\text { Bestand } \\
\text { identifiziert }\end{array}$ & $\begin{array}{c}152,0 \\
301\end{array}$ & $\begin{array}{c}75,2 \\
1841\end{array}$ & $\begin{array}{c}73,3 \\
1038\end{array}$ & $\begin{array}{c}87,4 \\
628\end{array}$ & $\begin{array}{l}185,9 \\
594\end{array}$ \\
\hline & $\begin{array}{l}\text { Feldlinden } \\
\text { identifiziert }\end{array}$ & $\begin{array}{c}361,2 \\
30\end{array}$ & $\begin{array}{c}102,7 \\
323\end{array}$ & $\begin{array}{c}71,4 \\
293\end{array}$ & $\begin{array}{c}64,7 \\
267\end{array}$ & $\begin{array}{c}258,4 \\
115\end{array}$ \\
\hline
\end{tabular}

Tab. 4.29 zeigt, wie weit der effektiv gewordene Pollen im Durchschnitt transportiert wurde. Läßt man die Weiten für EFG $4 \Delta$ und $8 \Delta$ außer Betracht, werden Werte von 79,2 m für EFG, 174,0 m für den eindeutigen Ausschluß und für CERVUS der höchste Wert mit 197,7 m hergeleitet. Damit beträgt die $\varnothing$ Transportweite des Pollens für die Gesamtpopulation bei CERVUS das $2 \frac{1}{2} 2$-fache dessen von EFG $2 \Delta$, wobei die $\varnothing$ Transportweite für CERVUS und dem eindeutigen Ausschlußverfahren in vergleichbarer Größenordnung liegen. Bei Betrachtung des Bestandes und der Feldlinden klaffen die Ergebnisse von CERVUS und dem eindeutigen Ausschlußverfahren weiter auseinander. Für den Bestand wird über CERVUS eine $\varnothing$ Pollentransportweite von 185,9 m und über das Ausschlußverfahren 152,0 m ermittelt, bzw. für die Feldlinden 258,4 m und 361,2 m. Die Weiten für EFG $2 \Delta$ liegen wiederum mit 75,2 m bzw. 102,7 m bedeutend niedriger. Werden die Pollentransportweiten ohne die aus Selbstbefruchtung entstandenen Nachkommen ermittelt, ergibt sich ein etwas verändertes Bild (Tab. 4.30). 
Tab. 4.30 Über die verschiedenen Pollenelterbestimmungsverfahren ermittelten $\varnothing$ Pollentransportweiten für die Gesamtpopulation Schwiegershausen, die im Bestand und in der Feldmark stehenden Linden für fremdbefruchtete Nachkommen. Dazu die absolute Anzahl der identifizierten Polleneltern (klein gedruckt) und die ermittelte maximale Transportweite.

\begin{tabular}{|lccccc|}
\hline nur & \multicolumn{5}{c|}{$\varnothing$ Pollentransportweite in m } \\
& & & & & \\
Fremdbefruchtung & eind. Ausschluß & EFG 2 $\Delta$ & EFG 4 $\Delta$ & EFG 8 $\Delta$ & Cervus 0\% * \\
Gesamtpopulation & 237,5 & 148,2 & 164,0 & 178,8 & 338,8 \\
$\quad$ identifiziert & 195 & 1145 & 583 & 398 & 412 \\
Bestand & 200,2 & 127,8 & 140,8 & 153,1 & 290,3 \\
identifiziert & 181 & 1071 & 534 & 355 & 379 \\
Feldlinden & 720,4 & 442,0 & 417,2 & 391,7 & 895,8 \\
$\quad$ identifiziert & 14 & 74 & 49 & 43 & 33 \\
\multicolumn{1}{c}{ Maximum } & 1666,4 & 1666,4 & 1666,4 & 1666,4 & 1985,3 \\
\hline
\end{tabular}

Für die Gesamtpopulation und den Bestand sind die Unterschiede zwischen dem Ausschlußverfahren und EFG $2 \Delta$ geringer als zwischen dem Ausschlußverfahren und CERVUS. Über CERVUS werden durchweg die größten, mit EFG 2 $\Delta$ durchweg die kleinsten $\varnothing$ Pollentransportweiten ermittelt. Geht man von der vorsichtigsten Schätzung, also von EFG, aus, wird der Pollen innerhalb des Bestandes im Mittel 127,8 m, in der Feldmark 442,0 m und für die Gesamtpopulation 148,2 m weit verfrachtet. Über CERVUS werden erheblich größere $\varnothing$ Transportweiten hergeleitet: 290,3 m innerhalb des Bestandes, 895,8 $\mathrm{m}$ in der Feldmark und für die Gesamtpopulation $338,8 \mathrm{~m}$. Die maximalen Transportweiten belaufen sich für EFG $2 \Delta$ und das Ausschlußverfahren auf 1666,4 m und für CERVUS auf 1985,3 m.

Mit der Angabe der Transportweiten bis auf Dezimeter soll nicht der Eindruck erweckt werden, daß die Messungen und die Methodik dazu geeignet wären, diese so exakt zu bestimmen; die aus den Berechnungen resultierenden Werte wurden der Einfachheit halber unverändert übernommen.

Eine graphische Darstellung der über die verschiedenen Verfahren hergeleiteten Pollentransportweiten in Form einer kumulativen Häufigkeitsverteilung zeigt fast identische Kurvenverläufe für EFG $2 \Delta$ und EFG $4 \Delta$, die sich ihrerseits deutlich von denen des eindeutigen Ausschlusses und CERVUS unterscheiden (Abb. 4.26). 


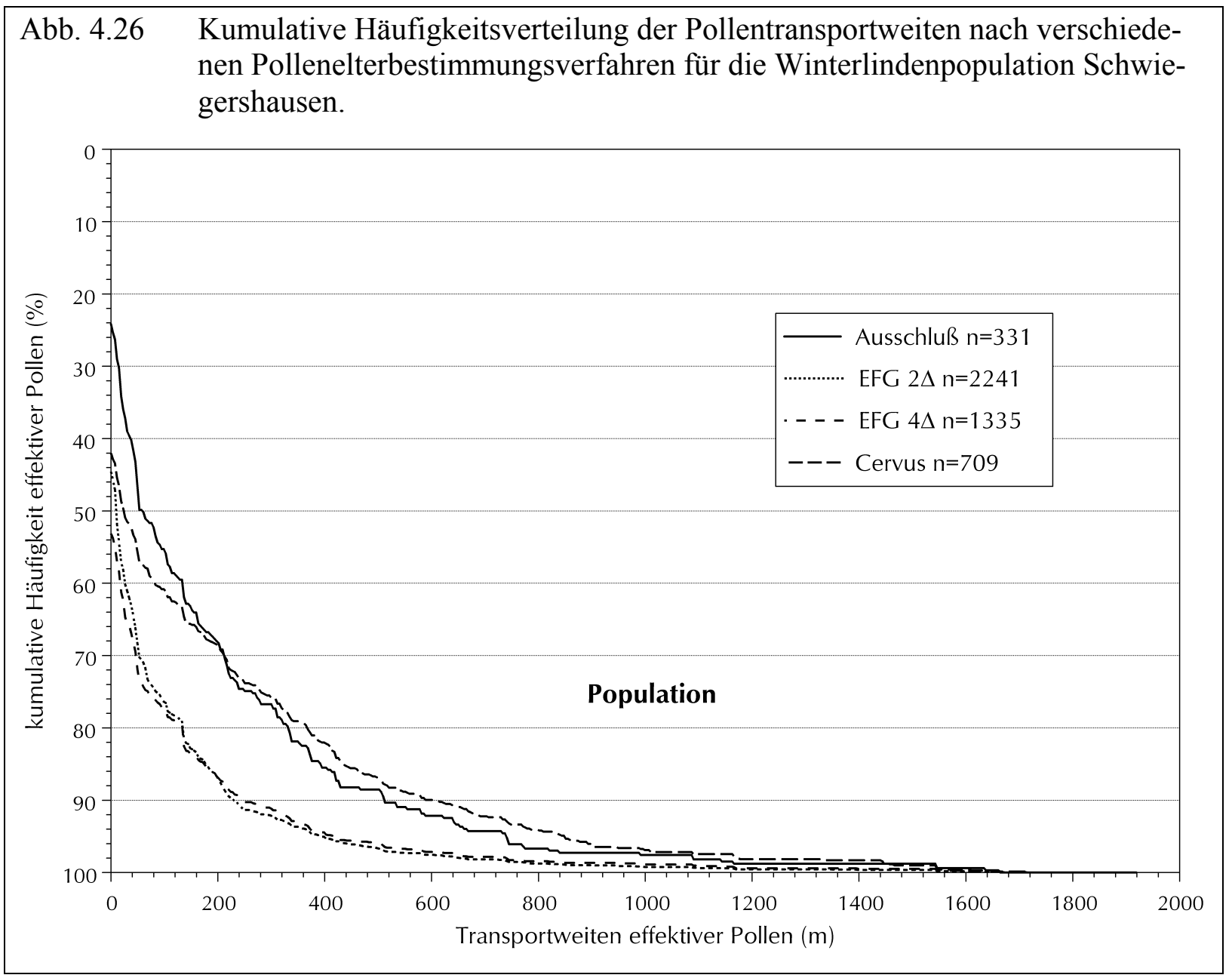

Über das eindeutige Ausschlußverfahren und CERVUS werden durchweg größere Pollentransportweiten ermittelt als mit EFG. Die Kurve von CERVUS verläuft flacher als die des eindeutigen Ausschlusses. Bei ca. 240 m schneiden sich die Kurven von CERVUS und eindeutigem Ausschluß) und prozentual werden ab diesem Punkt die größten Pollentransportweiten über CERVUS hergeleitet (s. Abb. 4.26 und Abb. 4.27). 


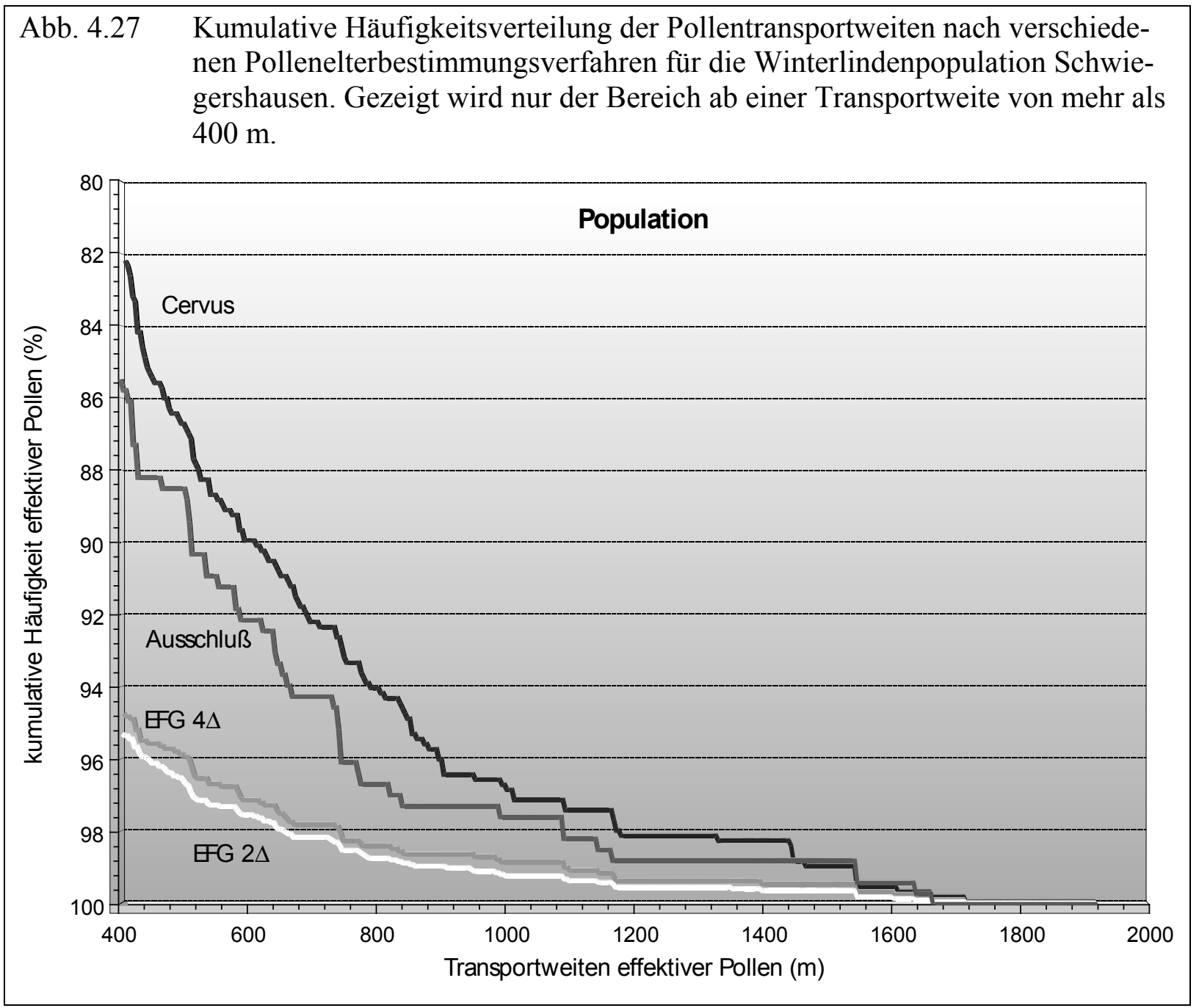

Für die Nachkommenschaften der 54 Winterlinden werden, je nach Pollenelterbestimmungsverfahren, zum Teil sehr unterschiedliche $\varnothing$ Pollentransportweiten ermittelt. Ein Blick auf die Tab. 4.31 zeigt, daß übereinstimmende Pollentransportweiten nur selten zu finden sind. Es fällt schwer, die gravierendsten Differenzen hervorzuheben, da für fast alle Nachkommenschaften starke Abweichungen in den $\varnothing$ Pollentransportweiten berechnet werden. 
Tab. 4.31 Über verschiedene Pollenelterbestimmungsverfahren hergeleitete $\varnothing$ Pollentransportweiten für die Nachkommenschaften von 54 Winterlinden im Versuchsbestand Schwiegershausen und die Zahl der für die Nachkommenschaften identifizierten Polleneltern.

\begin{tabular}{|c|c|c|c|c|c|c|c|c|c|}
\hline \multirow[b]{2}{*}{$\begin{array}{c}\text { Baum } \\
\mathrm{Nr} .\end{array}$} & \multirow[b]{2}{*}{$\begin{array}{c}\text { untersuchte } \\
\text { Samen }\end{array}$} & \multicolumn{5}{|c|}{$\varnothing$ Pollentransportweiten der Nachkommenschaften in $\mathrm{m}$} & \multirow[b]{2}{*}{ ident. } & \multirow[b]{2}{*}{ Cervus $0 \%$ * } & \multirow[b]{2}{*}{ ident } \\
\hline & & $\begin{array}{l}\text { eindeutiger } \\
\text { Ausschluß }\end{array}$ & ident. & EFG $2 \Delta$ & ident. & EFG $4 \Delta$ & & & \\
\hline 1 & 20 & 59,1 & 4 & 34,0 & 8 & 34,6 & 7 & 34,6 & 7 \\
\hline 2 & 150 & 128,8 & 9 & 42,3 & 98 & 36,8 & 69 & 138,8 & 35 \\
\hline 3 & 20 & 159,9 & 3 & 94,1 & 11 & 159,9 & 3 & 159,9 & 3 \\
\hline 8 & 20 & 13,9 & 1 & 98,1 & 8 & 13,9 & 1 & 13,9 & 1 \\
\hline 10 & 67 & 102,9 & 2 & 47,4 & 11 & 35,6 & 6 & 35,6 & 6 \\
\hline 11 & 69 & 66,5 & 5 & 112,6 & 23 & 103,1 & 11 & 226,1 & 11 \\
\hline 14 & 72 & 279,3 & 4 & 64,8 & 38 & 115,5 & 13 & 409,7 & 9 \\
\hline 15 & 150 & 29,3 & 4 & 39,0 & 47 & 62,3 & 18 & 228,3 & 9 \\
\hline 22 & 39 & 68,0 & 4 & 44,0 & 19 & 46,3 & 13 & 419,8 & 11 \\
\hline 23 & 35 & 51,5 & 2 & 27,6 & 13 & 29,2 & 9 & 81,1 & 4 \\
\hline 25 & 36 & 219,6 & 1 & 89,4 & 14 & 203,2 & 4 & 392,6 & 6 \\
\hline 26 & 33 & - & 0 & 193,1 & 9 & 421,9 & 2 & 983,6 & 2 \\
\hline 27 & 34 & 227,7 & 1 & 99,2 & 15 & 88,0 & 3 & 670,5 & 3 \\
\hline 28 & 127 & 219,8 & 5 & 71,8 & 49 & 111,2 & 12 & 220,8 & 7 \\
\hline 32 & 34 & 352,1 & 3 & 85,3 & 23 & 76,9 & 14 & 107,4 & 14 \\
\hline 33 & 39 & 82,0 & 4 & 74,5 & 18 & 70,5 & 11 & 213,9 & 10 \\
\hline 36 & 155 & 166,5 & 23 & 86,2 & 95 & 89,8 & 61 & 100,3 & 53 \\
\hline 38 & 32 & 142,5 & 4 & 97,6 & 17 & 116,3 & 8 & 157,3 & 8 \\
\hline 42 & 149 & 275,9 & 4 & 35,1 & 98 & 50,8 & 48 & 90,0 & 40 \\
\hline 59 & 30 & - & 0 & 44,4 & 10 & 70,5 & 4 & 154,5 & 5 \\
\hline 68 & 134 & 489,7 & 3 & 127,1 & 51 & 211,5 & 16 & 406,7 & 16 \\
\hline $69 a$ & 148 & 562,7 & 3 & 109,7 & 79 & 123,3 & 32 & 194,9 & 22 \\
\hline 71 & 173 & 486,1 & 4 & 51,8 & 92 & 97,0 & 32 & 95,6 & 14 \\
\hline 72 & 148 & 263,4 & 7 & 60,1 & 131 & 43,6 & 94 & 205,5 & 24 \\
\hline 77 & 70 & 35,3 & 2 & 42,7 & 30 & 32,3 & 16 & 17,4 & 4 \\
\hline 82 & 150 & 28,1 & 9 & 25,0 & 73 & 20,3 & 34 & 15,4 & 32 \\
\hline 92 & 139 & 308,9 & 13 & 171,5 & 82 & 207,5 & 41 & 380,3 & 36 \\
\hline 93 & 20 & 306,1 & 3 & 254,4 & 7 & 281,5 & 6 & 382,8 & 5 \\
\hline $94 a$ & 25 & - & 0 & 92,9 & 14 & 256,2 & 4 & 394,0 & 3 \\
\hline 95 & 30 & 111,6 & 4 & 57,7 & 20 & 27,7 & 17 & 203,4 & 5 \\
\hline 97 & 19 & 369,7 & 1 & 170,2 & 7 & 277,4 & 2 & 330,5 & 3 \\
\hline 98 & 62 & 211,5 & 6 & 141,2 & 29 & 124,9 & 21 & 149,7 & 20 \\
\hline $98 a$ & 40 & 147,5 & 4 & 95,0 & 26 & 99,6 & 17 & 202,7 & 6 \\
\hline 104 & 27 & 221,0 & 1 & 109,7 & 12 & 103,0 & 9 & 418,1 & 5 \\
\hline 107 & 30 & - & 0 & 31,8 & 9 & 10,4 & 3 & - & 0 \\
\hline 109 & 85 & 286,0 & 4 & 59,4 & 62 & 32,9 & 46 & 328,2 & 10 \\
\hline 111 & 37 & 304,6 & 2 & 294,7 & 10 & 327,1 & 4 & 313,5 & 4 \\
\hline 112 & 52 & 280,4 & 3 & 117,6 & 16 & 277,8 & 5 & 303,8 & 5 \\
\hline 113 & 47 & 307,8 & 2 & 190,6 & 14 & 202,0 & 4 & 265,6 & 3 \\
\hline 114 & 148 & 100,0 & 10 & 118,1 & 70 & 88,5 & 44 & 83,5 & 7 \\
\hline 115 & 29 & 27,1 & 5 & 54,2 & 23 & 60,9 & 16 & 19,9 & 7 \\
\hline 118 & 150 & 41,9 & 1 & 27,8 & 110 & 13,1 & 82 & 609,2 & 8 \\
\hline 120 & 149 & 64,3 & 10 & 58,9 & 99 & 49,3 & 70 & 131,7 & 36 \\
\hline 121 & 40 & 1,9 & 7 & 4,0 & 21 & 3,2 & 15 & 94,9 & 8 \\
\hline 122 & 38 & 46,9 & 6 & 129,8 & 21 & 145,6 & 12 & 175,8 & 8 \\
\hline 123 & 33 & 259,7 & 2 & 92,4 & 19 & 87,6 & 12 & 177,4 & 8 \\
\hline 129 & 38 & 28,5 & 23 & 53,3 & 34 & 23,6 & 29 & 41,0 & 25 \\
\hline 130 & 37 & 127,4 & 3 & 51,3 & 11 & 55,7 & 7 & 127,4 & 3 \\
\hline 133 & 28 & 41,5 & 6 & 63,6 & 17 & 39,4 & 14 & 140,0 & 9 \\
\hline 134 & 44 & 138,4 & 12 & 87,0 & 27 & 112,8 & 17 & 210,3 & 14 \\
\hline F1 & 74 & 67,9 & 15 & 38,0 & 55 & 21,7 & 50 & 96,1 & 23 \\
\hline F2 & 167 & 545,1 & 11 & 148,2 & 139 & 101,6 & 120 & 316,1 & 63 \\
\hline F3 & 39 & - & 0 & 99,1 & 37 & 83,4 & 33 & 339,5 & 4 \\
\hline F4 & 103 & 1548,9 & 2 & 74,2 & 92 & 54,1 & 90 & 249,4 & 25 \\
\hline
\end{tabular}


Man sieht, daß in einigen Fällen keine Polleneltern identifiziert werden konnten oder nur sehr wenige Werte in die Berechnung der $\varnothing$ Pollentransportweite einer Nachkommenschaft eingehen. Gerade in solchen Fällen besteht die Gefahr der Berechnung extremer und höchst wahrscheinlich nicht repräsentativer Werte. Explizit zu erwähnen sind u. a. die Winterlinden Nr. 118,121 , und F4, bei denen die $\varnothing$ Pollentransportweiten, je nach Verfahren, um mehr als das Zehnfache differieren.

\subsubsection{Ursachen des Genflusses}

Um die Ursachen des Ferntransportes von Pollen zu determinieren, wird geprüft, ob die $\varnothing$ Pollentransportweiten der 54 Nachkommenschaften mit anderen Faktoren (Abstand zum Nachbarn, Kronengröße etc.) in Zusammenhang gebracht werden können. Diese Fragestellung berührt nur den Pollentransport zwischen Populationsmitgliedern und nicht den innerhalb einer Winterlindenkrone (= Selbstbefruchtung). In die Analyse einer Abhängigkeit der Weite des Pollentransportes von den denkbaren Faktoren gehen deshalb nur die Pollentransportweiten nach Fremdbefruchtung ein.

Wie aus den in Kap. 4.7.3 genannten Gründen ergeben sich bei Einbeziehung der in der Feldmark stehenden Linden auch für die $\varnothing$ Pollentransportweiten überwiegend hochsignifikante Korrelationen mit der Kronengröße des Samenelters, den Abständen zu den nächsten 5 bzw. 10 Nachbarn und der $\varnothing$ Kronengröße der nächsten 5 bzw. 10 Nachbarn (Tab. 4.32). Daher soll auch hier das Augenmerk auf die Ergebnisse für die im Bestand stehenden Winterlinden (ohne Feldlinden) gerichtet werden. 


\begin{tabular}{|c|c|c|c|c|c|c|c|}
\hline \multirow[t]{4}{*}{ Tab. 4.32} & \multicolumn{7}{|c|}{$\begin{array}{l}\text { Korrelation der } \varnothing \text { Pollentransportweiten der fremdbefruchteteten Nachkom- } \\
\text { menschaften von } 54 \text { Winterlinden mit den aufgeführten Faktoren. In Klammern } \\
\text { die Vorzeichen der entsprechenden Korrelationskoeffizienten. }\end{array}$} \\
\hline & & \multicolumn{6}{|c|}{ Bestimmheitsmaß $r^{2}$} \\
\hline & & \multirow{2}{*}{$\begin{array}{l}\text { Abstand } \\
\text { nächster } \\
\text { Nachbar }\end{array}$} & \multirow{2}{*}{$\begin{array}{l}\text { Kronengröße } \\
\text { Samenelter }\end{array}$} & \multicolumn{2}{|c|}{ nächste 10 Nachbarn } & \multicolumn{2}{|c|}{ nächste 5 Nachbarn } \\
\hline & & & & Abstand & Kronengrößen & Abstand & Kronengrößen \\
\hline \multirow{2}{*}{$\begin{array}{l}\text { eindeutiger } \\
\text { Ausschluß }\end{array}$} & Gesamtpopulation & $(+) 0,69^{* * *}$ & $(+) 0,33^{* * *}$ & $(+) 0,61^{* \star *}$ & (+) 0,07 & $(+) 0,64^{\star \star \star}$ & (+) $0,09^{\star}$ \\
\hline & ohne Feldlinden & (+) $0,12^{*}$ & (+) 0,00 & (+) $0,17^{* *}$ & (-) 0,06 & (+) $0,14^{\star}$ & (-) 0,05 \\
\hline \multirow[t]{2}{*}{ CERVUS } & Gesamtpopulation & $(+) 0,55^{\star \star \star}$ & $(+) 0,32^{* * *}$ & (+) $0,50^{* * *}$ & $(+) 0,11^{*}$ & $(+) 0,52^{* * *}$ & $(+) 0,14^{* *}$ \\
\hline & ohne Feldlinden & (+) 0,05 & (+) 0,01 & $(+) 0,07$ & (+) 0,00 & $(+) 0,06$ & (+) 0,00 \\
\hline \multirow[t]{2}{*}{ EFG 2 $\Delta$} & Gesamtpopulation & (+) $0,62^{* * *}$ & $(+) 0,39^{* * *}$ & (+) $0,74^{* * *}$ & $(+) 0,17^{* *}$ & $(+) 0,76^{* * *}$ & $(+) 0,24^{* * *}$ \\
\hline & ohne Feldlinden & $(+) 0,31^{* * *}$ & $(+) 0,00$ & $(+) 0,42^{* * *}$ & (-) 0,06 & $(+) 0,36^{* * *}$ & (-) 0,04 \\
\hline \multirow[t]{2}{*}{ EFG $4 \Delta$} & Gesamtpopulation & $(+) 0,69^{* * *}$ & $(+) 0,32^{* * *}$ & $(+) 0,51^{* * *}$ & (+) $0,07^{*}$ & $(+) 0,55^{\star \star *}$ & (+) $0,10^{*}$ \\
\hline & ohne Feldlinden & $(+) 0,23^{* * *}$ & (-) 0,04 & $(+) 0,23^{* * *}$ & (-) 0,07 & $(+) 0,22^{* \star *}$ & (-) 0,05 \\
\hline \multirow[t]{2}{*}{ EFG $8 \Delta$} & Gesamtpopulation & $(+) 0,61^{* * *}$ & $(+) 0,26^{\star \star \star}$ & $(+) 0,40^{\star \star \star}$ & $(+) 0,04$ & (+) $0,50^{* * *}$ & (+) 0,07 \\
\hline & ohne Feldlinden & $(+) 0,17^{\star *}$ & (-) 0,03 & $(+) 0,25^{\star * *}$ & (-) $0,10^{*}$ & $(+) 0,22^{\star * *}$ & (-) 0,08 \\
\hline
\end{tabular}

Bei der Herleitung der $\varnothing$ Pollentransportweiten mit dem Verfahren EFG geht die Entfernung des Pollenelters zu dem betrachteten Samenelter a priori in die Bestimmung des wahrscheinlichsten Pollenelters ein; ein signifikanter Zusammenhang der Pollentransportweite mit den Abständen zu den nächsten Nachbarn war daher zu erwarten. Jedoch liegt auch bei den ,neutralen“ Pollenelterbestimmungsverfahren nach dem eindeutigen Ausschluß eine signifikante Korrelation der $\varnothing$ Pollentransportweiten mit dem Abstand zu den nächsten Nachbarn bei den im Bestand stehenden Linden, nicht aber für CERVUS vor.

\subsection{Reproduktionserfolg}

Ein Ergebnis der Bestäubungsversuche in Kap. 4.4 ist die Bildung von lediglich 3,4 \% vitaler Samen aus frei abgeblühten Blüten. Trotzdem vermittelten die Linden bei der Beerntung im Herbst 1995 den Eindruck eines üppigen Samenansatzes. Dieses ist auf die hohe Zahl Blüten zurückzuführen, welche die Linde unter guten Lichtverhältnissen bildet. Auch bei einer prozentual geringen Entwicklung von 3,4 \% der Blüten zu Samen ist die Samenproduktion, absolut gesehen, beachtlich (s. a. Kap. 2.10).

Im darauffolgenden Jahr wurden einige Winterlinden einer wiederholten Beerntung unterzogen werden; jedoch blieb dies erfolglos. Bei Winterlinden, die 1995 noch einen üppigen Samenansatz zeigten, erschien 1996 kein einziger Same vital. Dieses Bild wiederholte sich in 
den Jahren 1997 und 1998 in ähnlicher Weise: 1997 zeigte sich ein spärlicher und 1998 kein Samenansatz. Die Frage nach den Ursachen drängte sich auf und beim Vergleich der zurückliegenden Sommer, erinnerte ich mich an die exzellenten Witterungsverhältnisse während der Vermessungsarbeiten, der Bestäubungsversuche und beim Überfliegen des Versuchsbestandes im Jahre 1995. Nach meinem Empfinden war der Sommer 1995 außergewöhnlich warm und sonnig und ich kam gedanklich auf eine Arbeit von PIGOTT und HUNTLEY (1981) zurück, in der eine Abhängigkeit des Reproduktionserfolgs der Winterlinde von Klimafaktoren vermutet wurde (s. Kap. 2.10).

\subsubsection{Klimafaktoren}

Die Empfindung, der Sommer im Jahre 1995 wäre außergewöhnlich warm und sonnig gewesen, ist selbstredend unzureichend für eine wissenschaftliche Beantwortung der Frage, ob der Faktor Klima während der Periode der Blüte und Samenreife der Winterlinde entscheidenden Einfluß auf deren Samenproduktion hat, wie PigOTT und HunTLEY (1981) postulierten. Freundlicherweise wurden die Wetterdaten des Deutschen Wetterdienstes für die Meßstationen in Bad Grund, Herzberg und Seesen über Herrn Prof. Gravenhorst (Institut für Bioklimatologie der Universität Göttingen) zur Verfügung gestellt. Diese Wetterstationen liegen, wie der Versuchsbestand Schwiegershausen im Vorharz und in vergleichbarer Exposition und Höhenlage (um $250 \mathrm{~m}$ ü. NN, Versuchsbestand Schwiegershausen 150-250 m ü. NN). Einzig die Wetterstation in Bad Grund liegt ca. 100 m höher, was zur Findung eines möglichen Klimatrends in den Jahren 1995 bis 1998 unbedeutend sein dürfte. Die Auswertung der Wetterdaten ergab, daß der Sommer 1995, zumindest für den Zeitraum der Blüte der Winterlinde, außergewöhnlich und deutlich wärmer als die nachfolgenden Sommer 1996-1998 war (s. Tab. 4.33).

\begin{tabular}{|c|c|c|c|c|c|}
\hline \multirow[t]{6}{*}{ Tab. 4.33} & \multicolumn{5}{|c|}{$\begin{array}{l}\text { Gemessene Durchschnittstemperatur für den Zeitraum der Blüte bzv } \\
\text { reife der Winterlinde (im Vorharz) und für die Sommer der Jahre } 19 \\
\text { Mittel der Wetterstationen Bad Grund, Herzberg und Seesen. }\end{array}$} \\
\hline & & \multicolumn{4}{|c|}{ Durschnittstemperatur in ${ }^{\circ} \mathrm{C}$} \\
\hline & & 1995 & 1996 & 1997 & 1998 \\
\hline & $\begin{array}{l}\text { 12.-31.Juli } \\
\text { (Blüte) }\end{array}$ & 19,9 & 15,9 & 17,0 & 16,7 \\
\hline & $\begin{array}{l}\text { August/Sept. } \\
\text { (Samenreife) }\end{array}$ & 15,2 & 13,8 & 16,6 & 14,4 \\
\hline & $\begin{array}{l}\text { Juli-Sept. } \\
\text { (Sommer) }\end{array}$ & 16,7 & 14,2 & 16,6 & 14,8 \\
\hline
\end{tabular}


Herzberg liegt per Luftlinie lediglich $10 \mathrm{~km}$ vom Versuchsbestand Schwiegershausen entfernt. Deshalb sollen die Klimadaten dieser Wetterstation noch einmal gesondert betrachtet werden:

\begin{tabular}{|c|c|c|c|c|c|}
\hline \multirow[t]{6}{*}{ Tab. 4.34} & \multicolumn{5}{|c|}{$\begin{array}{l}\text { Gemessene Durchschnittstemperatur für den Zeitraum der Blüte bzw. Samen- } \\
\text { reife der Winterlinde (im Vorharz) und für die Sommer der Jahre 1995-1998 } \\
\text { der Wetterstation Herzberg. }\end{array}$} \\
\hline & & \multicolumn{4}{|c|}{ Durschnittstemperatur in ${ }^{\circ} \mathrm{C}$} \\
\hline & & 1995 & 1996 & 1997 & 1998 \\
\hline & $\begin{array}{l}\text { 12.-31.Juli } \\
\text { (Blüte) }\end{array}$ & 20,7 & 16,9 & 17,9 & 17,5 \\
\hline & $\begin{array}{l}\text { August/Sept. } \\
\text { (Samenreife) }\end{array}$ & 15,8 & 14,5 & 17,5 & 15,1 \\
\hline & $\begin{array}{l}\text { Juli-Sept. } \\
\text { (Sommer) }\end{array}$ & 17,4 & 15,0 & 17,6 & 15,5 \\
\hline
\end{tabular}

In der Tendenz sind die Temperaturen für die Wetterstation Herzberg und das Mittel der drei Wetterstationen vergleichbar und eine Beschreibung der Daten der Wetterstation Herzberg (Tab. 4.34) erscheint ausreichend. Die Temperaturen der Sommermonate Juli bis September waren im Durchschnitt 1995 mit 17,4 ${ }^{\circ} \mathrm{C}$ bzw. 1997 mit 17,6 ${ }^{\circ} \mathrm{C}$ etwa gleich hoch und um mehr als $2{ }^{\circ} \mathrm{C}$ höher als 1996 und 1998. Die annähernd gleich warmen Sommer der Jahre 1995 und 1997 zeigen bezüglich der Temperaturverläufe große Unterschiede: während der Blühperiode der Winterlinde herrschte 1995 im Mittel eine um 2,8 ${ }^{\circ} \mathrm{C}$ höhere Durchschnittstemperatur als 1997, für den Zeitraum der Samenreife war diese um $1,7^{\circ} \mathrm{C}$ niedriger als 1997. Die Durchschnittstemperatur repräsentiert die Tag und Nacht gemessenen Werte. Diese Durchschnittstemperatur vermittelt nur eine vage Vorstellung, wie warm ein Sommer war, da dieses meist über die Tageshöchsttemperatur definiert wird. Da die meisten bestäubungsrelevanten Insekten der Linden, abgesehen von den Motten, tagaktiv sind und deren Flugaktivität stark von der Lufttemperatur beeinflußt wird (s. Kap. 2.8.3.6), sind zusätzlich in Tab. 4.35 die mittleren Tageshöchsttemperaturen der Wetterstation Herzberg aufgeführt. 


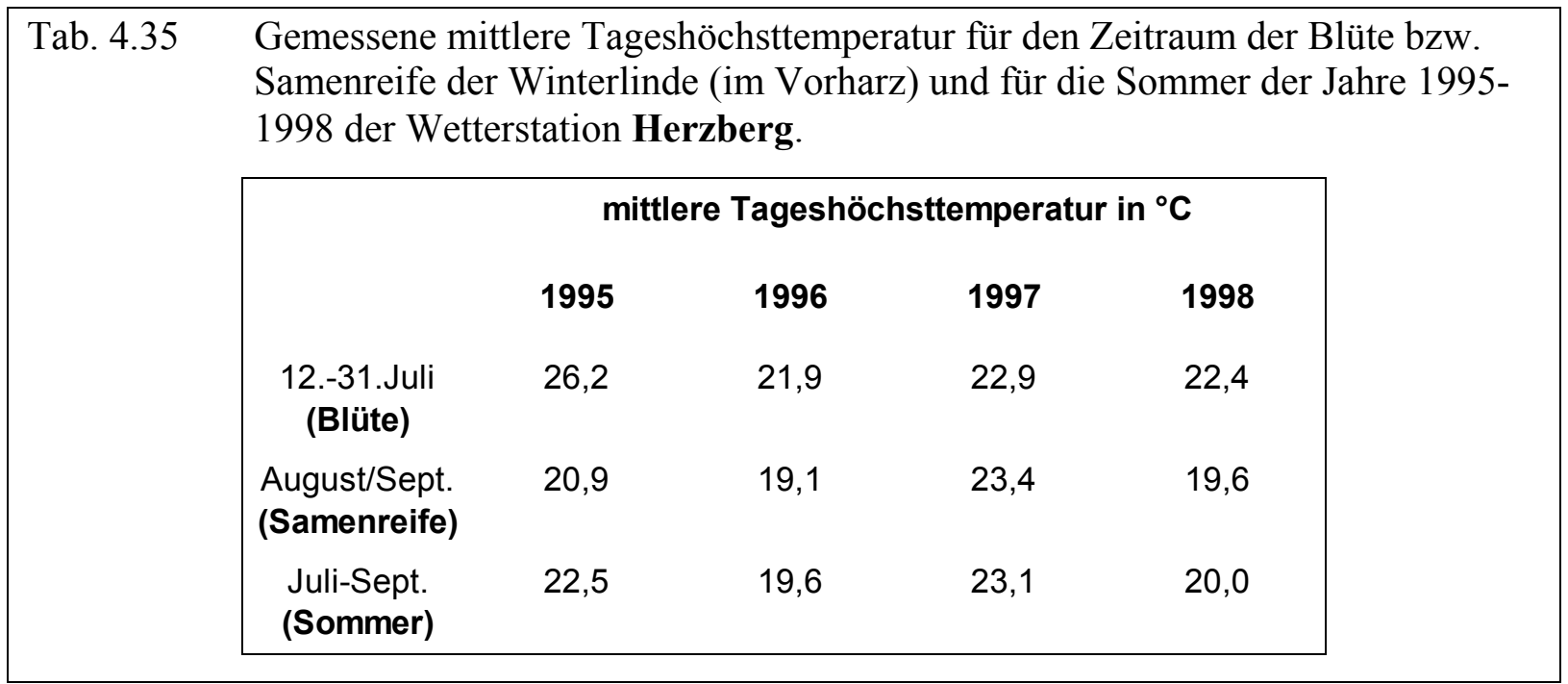

Für den 21. Juli 1995 wurde mit 33,2 ${ }^{\circ} \mathrm{C}$ die höchste Tagestemperatur der Jahre 1995-1998 gemessen. Für die mittere Tageshöchsttemperatur während der Blühphase der Winterlinde fallen die Unterschiede mit mindestens $3,3^{\circ} \mathrm{C}$ zwischen 95 und den nachfolgenden Jahren noch deutlicher aus.

Alle Temperaturen sind, wie beim Deutschen Wetterdienst üblich, im Schatten gemessenen.

Fazit

Bei einem Vergleich der Jahre 1995-1998 heben sich die Sommer der Jahre 1995 und 1997 durch hohe Durchschnittstemperaturen hervor. Die Wetterdaten zeigen, daß 1995 im Bestand Schwiegershausen während der Blühperiode der Winterlinde überdurchschnittlich hohe und während der Samenreife durchschnittliche Temperaturen herrschten. Umgekehrt verhält es sich für das Jahr 1997: ausgesprochen warmes Wetter prägte die Phase der Samenreife, während für die Blühperiode 1997 durchschnittliche Temperaturen gemessen wurden. In den Jahren 1995-1998 war der mit Abstand größte Samenansatz im Jahr 1995 zu verzeichnen Die Ergebnisse lassen auf einen Einfluß des Klimas, insbesondere zum Zeitpunkt der Blüte bzw. des Pollenschlauchwachstums, auf den Reproduktionserfolg der Winterlinde schließen.

\subsubsection{Individueller Genfluß über Pollen}

Über das Pollenelterbestimmungsverfahren wurde für 56\% der 3864 Nachkommen von 54 Sameneltern ein wahrscheinlichster Pollenelter bestimmt. Diese Information impliziert u. a., wieviel Eigenpollen bzw. Fremdpollen in den Nachkommen einer Linde erfolgreich wurden. Auch ist es mit dieser Information möglich zu quantifizieren, wie viele Pollen einzelner Linden bei anderen Sameneltern effektiv geworden sind - in diesem Fall, wie häufig die geneti- 
sche Information der 138 Winterlinden und 3 Hybriden in den 2369 fremdbefruchteten Nachkommen der 54 Winterlinden vertreten ist. Von diesen 2369 aus Fremdbefruchtung entstandenen Samen wurde für 1058 ein wahrscheinlichster Pollenelter bestimmt. Im Mittel der 141 Linden sind 7,5 Pollen auf die Narben anderer Linden transportiert worden. Bei 30 Linden war kein Pollen bei andern Sameneltern erfolgreich; maximal wurden von einer Winterlinde 75 Eizellen anderer Linden befruchtet. Wie in den vorigen Kapiteln wurde mit Hilfe linearer Regressionsanalysen versucht, die Einflußfaktoren zu determinieren, welche für den unterschiedlichen Erfolg der einzelnen Winterlinden bedeutsam sind. Als mögliche Ursachen wurden wiederum der Abstand zum nächsten Paarungspartner bzw. zu den nächsten 5 bzw. 10 Paarungspartnern, die Größe der Kronen der nächsten 5 bzw. 10 Paarungspartner und die Kronengröße des Samenelters in Erwägung gezogen. Obwohl in die Bestimmung der Polleneltern über EFG die Kronengrößen und Entfernung eingingen, waren signifikante Korrelationen mit den genannten Faktoren nicht festzustellen.

\subsection{Hybridisierung}

\subsubsection{Artunterscheidung mit Hilfe von Isoenzymgenmarkern}

Die Winter- und die Sommerlinde verfügen an mehreren Genorten über artspezifische Enzymvarianten, die eine Artbestimmung und die Identifizierung von Arthybriden ermöglichen. Artspezifische Genvarianten wurden an den kontrollierenden Genorten der Enzymsysteme AP (Aminopeptidase), FDH (Formiatdehydrogenase), MNR (Menadionreduktase), PGI (Phosphoglucose-Isomerase), PGM (Phosphoglucomutase) und SKDH (Shikimatdehydrogenase) gefunden, welche ausführlich in Kap. 4.1 dargestellt sind. Neben den in Kap. 4.1 beschriebenen Enzymsystemen verfügen auch ACO (Aconitase) und IDH (Isocitratdehydrogenase) über Enzymvarianten, die eine Artunterscheidung ermöglichen (s. a. FROMM 1999).

Die Ergebnisse der genetischen Analyse stimmten immer mit der Artzuordnung über morphologische Merkmale überein (Kap. 2.11).

\subsubsection{Reproduktionserfolg der Hybride}

Von zwei der drei im Versuchsbestand Schwiegershausen stehenden Hybriden konnten Nachkommen geworben werden. Die $42 \mathrm{~m}^{2}$ große und mitherrschende Krone der Hybride Nr. 102 war so eng in die sie umgebenden Buchen eingebettet, daß eine Beerntung mit der Schrotflinte nicht möglich war. Die Hybriden Nr. 116 und Nr. 137 nahmen eine herrschende soziale Stellung im Bestand ein und aus den überdurchschnittlich großen Kronen $\left(215 \mathrm{~m}^{2}\right.$ bzw. 
$129 \mathrm{~m}^{2}, \varnothing$ aller 141 Linden $=59 \mathrm{~m}^{2}$ ) wurden 52 bzw. 63 Samen geworben. Bei der Hybride Nr. 116 stellten sich von den 52 Samen fünf als vital heraus, von den 63 Samen der Hybriden Nr. 137 lediglich zwei. Nach dem Ausschlußverfahren stammen vier der fünf Samen der Hybride Nr. 116 aus Fremdbefruchtung durch andere Winterlinden, ein Nachkomme ist aus Selbstbefruchtung entstanden. Bei den beiden Nachkommen der Hybride Nr. 137 konnte eine Pollenelternschaft durch Winterlinden nachgewiesen worden. (Tab. 4.36).

Tab. 4.36 Reproduktionserfolg zweier Winter-/Sommerlindenhybriden (Tilia $x$ vulgaris) des Versuchsbestandes Schwiegershausen.

\begin{tabular}{|cccccc|}
\hline Hybride Nr. & vitale Samen & $\begin{array}{c}\text { befruchtet von } \\
\text { Winterlinden }\end{array}$ & $\begin{array}{c}\text { Pollenelter für } \\
\text { Winterlinden }\end{array}$ \\
116 & 5 & $9,6 \%$ & 4 & $80 \%$ & $13 x$ \\
137 & 2 & $3,2 \%$ & 2 & $100 \%$ & $7 x$ \\
\hline
\end{tabular}




\section{Diskussion}

\subsection{Vererbungsanalyse}

Wie sich bei der formalen Vererbungsanalyse der insgesamt 3.739 Nachkommen von 49 Winterlinden zeigte, wurden an allen untersuchten Genorten die Annahmen gleichmäßiger disomer Segregation bzw. Zufallsfusion der Gameten nie verletzt.. Die Zymogramme der hexaploiden Winterlinde zeigten die typischen Zymogrammuster diploider Pflanzenarten. Die Paläo-Polyploidie der Winterlinde drückt sich bei einigen Enzymsystemen nur durch eine größere Anzahl an Genorten und nicht durch die Bildung einer größeren Anzahl von Hybridbanden bei heterozygoten Individuen aus. Die Vermutung liegt nahe, daß die Gattung Tilia ursprünglich aus Hybridisierung verschiedener diploider Arten entstanden ist. Bilden sich bei den daraus resultierenden Hybriden in der meiotischen Anaphase Restitutionskerne, werden die inhomologen Chromosomenpaare nicht getrennt und verbleiben in einem Kern. Das Endprodukt sind nicht reduzierte „quasi-diploide“ Gameten, die bei Fusion allopolyploide Nachkommen ergeben. Diese sogenannten ,amphidiploiden“ Nachkommen zeigen wiederum die reguläre Meiose diploider Organismen; nur verfügen die Gameten über einen potenzierten Chromosomensatz (HATTEMER et al. 1993). Danach muß es zu einem weiteren Vorgang von Hybridisierung zwischen der tetraploiden und einer diploiden Art gekommen sein. Da alle Verwandten unter den Tiliaceae eine Grundzahl von $\mathrm{x}=7$ besitzen, muß bei der gametischen Anzahl der hexaploiden Gattung Tilia von $\mathrm{n}=41$ ein Chromosom verlorengegangen sein (Aneuploidie). Der Anteil Polyploider unter den höheren Pflanzen beträgt weltweit $47 \%$. Unter der Annahme, daß bei allen Pflanzen mit Chromosomenanzahlen $\geq 12$ von einer Polyploidie auszugehen ist, können ca. 70 \% der Baumarten regenfeuchter Tropenwälder als polyploid gelten (HATTEMER et al. 1993).

Viele in dieser Arbeit verwendeten Verfahren liegen den Annahmen einer gleichmäßigen Segregation und nachfolgender Zufallsfusion der Gameten zu Grunde (Bestimmung effektiver Pollenwolken, Polleneltern, Selbstbefruchtungsanteilen etc.). Die Vererbungsanalyse der Winterlinde ergab, daß diese Annahmen an allen untersuchten Genorten erfüllt werden und daher keine Einschränkungen der aus den angewendeten Verfahren resultierenden Ergebnisse und Schlußfolgerungen aufgrund grundsätzlich fehlerhafter genetischer Interpretation der Zymogramme zu erwarten sind. 


\subsection{Art des Pollentransportes}

Die Ergebnisse der Bestäubungsversuche ergaben, daß bei der Winterlinde überwiegend Insekten als Pollenvektoren effektiv sind. Windbestäubung war zwar nachzuweisen, spielte aber quantitativ eine untergeordnete Rolle. Diese Ergebnisse decken sich mit den Aussagen fast aller anderen Autoren. Lediglich EISENHUT (1957) deklariert die Linde für überwiegend anemophil und hält Insektenbestäubung für nicht notwendig. Uneingeschränkte sexuelle Reproduktion der Winterlinde könne allein durch Windbestäubung gesichert werden. Nach EISENHUT befindet sich die Gattung Tilia am Ende einer evolutionären Entwicklung von ursprünglich entomophiler zu anemophiler Bestäubungsökologie. Er beruft sich dabei auf diverse Veröffentlichungen sowie eigene Beobachtungen und sieht diese Entwicklung durch die von ihm durchgeführten Bestäubungsversuche bestätigt (Kap. 2.8.4).

Auf die Argumentation von EISENHUT (1957) wird deshalb explizit eingegangen, da seine Kernaussage, die Lindenarten seien überwiegend anemophil, in vielen Arbeiten anderer Autoren zitiert wird.

\subsubsection{Evolution der Bestäubungsökologie}

EISENHUT (1957) stützt seine Behauptung u. a. auf die Pollenmorphologie und -produktion der Linden, aufgrund welcher er sie zu den anemophilen Baumarten zuordnet. Windbestäubte Baumarten würden sich durch kleine, leichte, nicht aggregierte Pollen und eine große Pollenproduktion bzw. ein hohes Pollen/Eizellen-Verhältnis auszeichnen, welches er auch für die Linden gegeben sieht. Eine Einteilung in anemophil und entomophil über die Pollenproduktion, oder auch über die Pollenbeschaffenheit ist umstritten und wird schon in der Literatur zur Zeit EISENHUTs kontrovers diskutiert. POHL (1936) argumentiert gegen eine Einteilung von entomophil und anemophil mit Hilfe der Pollenproduktion und nennt mehrere Beispiele. Unter anderem produzieren die Blütenstände des auf Insektenbestäubung angewiesenen Bergahorns (Acer pseudoplatanus) 20mal so viele Pollen wie die des windbestäubten Acer californicum. Neuere Untersuchungen ergeben zudem, daß der Umfang der Pollenproduktion von vielen Faktoren abhängig sein kann:

Nach Heß (1983) sowie Vogel und WesterkAmP (1991) ist bei Generalisten (wie der Linde) hohe Pollen- bzw. Nektarproduktion notwendig, da diese durch den einfachen Aufbau ihrer Blüten einen leichten Zugang zu ihrem Nahrungsangebot gewähren. Dieses Angebot wird nicht nur von bestäubungseffektiven Insekten genutzt, sondern auch von Insekten, die weitgehend nur als Pollen- und/oder Nektarräuber fungieren. Dadurch wird die Wahrscheinlichkeit 
einer erfolgreichen Bestäubung des Einzelpollens reduziert. Generalisten gleichen diesen Verlust durch ein hohes Pollen/Eizellen-Verhältnis aus, die an Größenordnungen windbestäubter Pflanzen heranreichen. Bei der Linde dient nachweislich ein großer Teil der Pollen ausschließlich der Nahrung zahlreicher Insekten. Verschiedene Bombus-Arten sind sogar auf Lindenpollen als Proteinquelle spezialisiert (FrEE 1970) und es ist bekannt, daß das Nahrungsaufkommen eines durchschnittlichen Honigbienenvolkes bei $20 \mathrm{~kg}$ Pollen im Jahr liegt (SEELEY 1997). Neben dem Verlust der als Nahrung dienenden Pollen gehen zudem mindestens $99 \%$ der Pollen beim Transport durch Insekten verloren (s. Kap. 2.8.3.7).

CRUdEN (1977) beschreibt, daß generell das höchste Pollen/Eizellen-Verhältnis bei Pflanzen vorzufinden ist, welche sich am Ende der Sukzession befinden. Als bestandesbildende Baumart ist die Linde dort anzusiedeln. Einen weiteren Ansatz einer Hierachie der Pollenproduktion sehen RAMIREZ und SERES (1994) innerhalb verschiedener zoophiler Bestäubungsarten gegeben. Bei den von ihnen untersuchten Pflanzen stellten sie die höchste Pollenproduktion bei insektenbestäubten Arten fest, eine geringere bei Pflanzen, bei denen überwiegend Vögel als Pollenvektoren fungieren. Die niedrigste Produktion von Pollen stellten sie bei Arten fest, die von Fledermäusen bestäubt werden.

Ungeachtet einer nicht sicheren Einteilung von anemophil und entomophil über die Pollenproduktion sei hier die Argumentationskette von EISENHUT (1957) aufgegriffen.

Die in der Arbeit von EISENHUT (1957) verwendeten Werte für die Pollenproduktion der Winterlinde sind der Arbeit von POHL (1936) entnommen. PoHL berechnete neben dem Pollen/Eizellen-Verhältnis die Pollenproduktion der Winterlinde auf der Ebene der Blüte, einer Infloreszenz, ein- und zehnjähriger Zweigsysteme und schließlich eines 1 ha großen Winterlindenreinbestandes und verglich die Werte mit diversen anemophilen und entomophilen Baumarten (vgl Tab. 2.1, S. 9).

Bei der Berechnung des Pollen/Eizellen-Verhältnisses ging POHL damals von einer einzigen Samenanlage im Fruchtknoten einer Lindenblüte aus und berechnete einen Wert von 43500, welches der Winterlinde im Vergleich zu anderen Baumarten ein mittleres Pollen/EizellenVerhältnis bescheinigt. Bis 1957 hatte sich der Wissensstand verändert und EISENHUT berichtet bei der Gattung Tilia von zehn fertilen Samenanlagen pro Fruchtknoten. Das Pollen/Eizellen-Verhältnis verringert sich damit auf 4350 und ist die niedrigste Rate aller von POHL (1936) untersuchten Bäume. Damit wäre die Winterlinde klar als entomophil einzuordnen (s. Tab. 2.1, S. 9). Obwohl EISENHUT die Arbeit von PoHL (1936) zitiert und diese Tatsache für ihn evident gewesen sein müßte, wird sie in seiner Arbeit nicht erwähnt. Dies ist um so verwunderlicher, da er in einem anderen Zusammenhang eine andere Arbeit von POHL 
(1929a) zitiert, in der POHL der Zahl der Samenanlagen pro Fruchtknoten große Bedeutung bei der evolutionären Entwicklung von entomophil zu anemophil beimißt. Bei der evolutionären Entwicklung von entomophilen zu anemophilen Blüten wird nach POHL (1929a) die Zahl der Samenanlagen pro Fruchtknoten auf eine bis maximal zwei reduziert. Mit zehn fertilen Samenanlagen wäre die Linde unter diesem Kriterium ebenfalls klar in die Gruppe der insektenbestäubten Baumarten einzustufen. Dieses wichtige Kriterium ist EISENHUT (1957) anscheinend entgangen oder er hielt es für unbedeutend. Um so bedeutender war für EISENHUT (1957) die Aussage PoHLs (1936), mit der hochgerechneten Pollenproduktion eines 1 ha großen Winterlindenreinbestandes gehöre die Linde zu den reichlich Pollen erzeugenden Bäumen. Dabei zitiert er den zweiten Teil des letzten Satzes (,,...gehört die Linde zu den reichlich Pollen erzeugenden Bäumen“) im Zusammenhang mit der Pollenerzeugung eines einjährigen bzw. zehnjährigen Zweigsystems, obwohl die Pollenproduktion dieser Zweigsysteme bei der Winterlinde vergleichsweise niedrig ist (Tab. 2.2, S. 10 und Tab. 2.3, S. 11). POHL (1936) spricht erst im Zusammenhang mit der Pollenproduktion für einen 1 ha großen Winterlindenreinbestand von einer mit windbestäubten Baumarten vergleichbaren Pollenproduktion. Die Werte für die Pollenproduktion eines 1 ha großen Winterlindenreinbestandes durch POHL (1936) erwähnt EISENHUT nicht, Zumal die von POHL (1936) durchgeführte Hochrechnung nicht immer plausibel erscheint: Zunächst berechnete POHL (1936) die Anzahl der Blütenstände eines zehnjährigen Zweigsystems. Die Anzahl zehnjähriger Zweigsysteme für 1 ha berechnete er über die anfallenden Reisholzmassen 120jähriger Reinbestände. Die Reisholzmassen wurden nach den Ertragstafeln I. Klasse von SCHWAPPACH (1929) bestimmt. Für die Winterlinde verwendete POHL die Ertragstafel für Rotbuche (Fagus sylvatica), da für die Winterlinde damals noch keine Ertragstafel existierte. Die ermittelte Summe der Blütenstände pro ha multiplizierte POHL mit der Pollenerzeugung eines Blütenstandes und gelangte so zu der Pollenproduktion eines 1 ha großen Reinbestandes.

Schon die von POHL (1936) berechnete Pollenerzeugung eines zehnjährigen Zweigsystems erscheint zu hoch angesetzt. Die Ermittlung dieses Wertes ist aber aus seiner Arbeit nicht genau zu erkennen und muß daher als gegeben angenommen werden. Auch die Verwendung von Ertragstafeln der Buche für die anfallende Reisholzmasse der Winterlinde ist sicherlich diskutabel, dürfte aber die Hochrechnungen der Pollenproduktion nicht immens verfälscht haben. Das Problem liegt darin, daß POHL (1936) die Anzahl der Blütenstände eines zehnjährigen Zweigsystemes anhand einer einzeln stehenden, tiefbeasteten Winterlinde im Botanischen Garten in Prag ermittelt und auf einen Reinbestand übertragen hat. EISENHUT (1957) selbst beschreibt ausführlich die nach seinen Beobachtungen starke Abhängigkeit der Blüten- 
bildung von ausreichender Lichtintensität. Ausreichende Lichtintensität für die Blütenbildung ist nur im Kronenmantel, also im äußeren Randbereich der Krone, gegeben. Im Bestandesschluß erzeugen Winterlinden nur in den oberen Kronenpartien Blüten, und dies nur, wenn sie mit- oder vorherrschend sind. Der von PoHL (1936) berechnete Wert für die Pollenerzeugung für einen 1 ha großen Winterlindenreinbestand dürfte bei weitem zu hoch angesetzt sein. Seine diesbezüglich gemachte Aussage, die Linde gehöre zu den reichlich Pollen erzeugenden Bäumen, muß also kritisch beurteilt werden. PIGOTT und HunTLEY (1980) sprechen bei ihren Untersuchungen von ein geringer Pollenproduktion der Winterlinde im Vergleich zu anderen Baumarten (Kap. 2.8.4). Irritierend bleibt, warum EISENHUT (1957), der sich in seiner Arbeit sehr ausführlich mit der Bildung von Blüten und Blütenständen auseinandersetzt, die Pollenproduktionswerte von POHL (1936) unreflektiert übernimmt und zudem die Aussagen POHLs in einem falschen Zusammenhang zitiert (s. o.).

Ein weiteres Indiz für Anemophilie sieht EISENHUT (1957) in dem von ihm gezählten durchschnittlichen Pollenanflug von ca. 5700 Pollenkörnern je $\mathrm{cm}^{2}$ in der Krone einer frei stehenden Winterlinde. REMPE (1937) beobachtete einen Pollenanflug in vergleichbarer Größenordnung (s. Tab. 2.5, S. 26) und kommt u. a. zu dem von EISENHUT (1957) zitierten Schluß: „Ihr Pollenanflug im Kronenraum kann durchaus (von der größeren Häufigkeit von Gruppen abgesehen) demjenigen von Eiche, Ulme und Buche zur Seite gestellt werden.“ Dabei berücksichtigt EISENHUT (1957) nicht den einleitenden Satz des aus REMPE (1937) zitierten Absatzes: „Die Werte zeigen, daß der dichteste Anflug zweifellos bei den typischen Windblütlern erreicht wird.“ Für alle nicht zitierten windbestäubten Baumarten wurde ein deutlich höherer Pollenanflug gemessen und deshalb rangiert die Winterlinde in puncto Pollenanflug im unteren Drittel einer Tabelle in REMPE (1937). REMPE (1937) setzte den gemessenen Pollenanflug anschließend noch in Relation zur absoluten Pollenproduktion eines 1 ha großen Winterlindenreinbestandes und kommt zu folgender Schlußfolgerung, die indes von EISENHUT (1957) ebenfalls nicht zitiert wird: „Eine auffällige Unstimmigkeit liegt in der Stellung der Linde und des Bergahorns vor, da beide Bäume nach POHL besonders große Pollenmengen erzeugen, ihr Anflug dagegen gering blieb. Doch ist dies, wie auch POHL unter Hinweis auf die Stellung der Linde bei HESMER betont, leicht erklärlich, da bei diesen insektenblütigen Bäumen eben offenbar nur ein geringer Teil des Pollens verweht wird.“ Anzumerken ist, daß auch REMPE (1937) sich auf die von PoHL (1936) berechnete Pollenproduktion eines 1 ha großen Lindenreinbestandes bezieht und damit die Aussage zu relativieren ist (s. o.). HESMER (1933) stufte nach den Ergebnissen seiner pollenanalytischen Befunde unter den von ihm untersuchten Baumarten die Pollenproduktion der Linde am niedrigsten ein. Dieser Befund dürfte, da von 
POHL (1936) zitiert und ausgiebig diskutiert, EISENHUT nicht entgangen sein. POHL (1936) erklärt die Diskrepanz zwischen der geringen von HESMER (1933) ermittelten Pollenproduktion und seinen Ergebnissen folgendermaßen: „Die Linde als ausgesprochen tierblütiger Baum mit Pollenkörnern, die, wenn auch nicht reichlich, so doch Klebstoffe besitzen, wird offenbar nur einen Teil des erzeugten Pollens unter gewissen Umständen dem Winde übergeben können. Die Hauptmasse des Pollens wird wohl von Tieren abgeholt werden und der Teil des Pollens, der allenfalls auf den Antheren zurückbleibt, wird erst mit dem Regenwasser oder beim Abfallen der Staubblätter zur Erde gelangen. Aber selbst ein Teil des vom Winde davongetragenen Pollens dürfte bald absinken, jener Teil, wo zahlreiche Pollenkörner durch Kittstoffe miteinander verbunden sind.“ Selbst wenn ein großer Anteil Lindenpollen in der Atmosphäre hätte beobachtet werden können, wäre dies noch kein Indiz für die Anemophilie der Linde gewesen. Bei Salix lasiolepis wurde ebenfalls eine weitgehende Übertragung des Pollens durch den Wind erst dann angenommen, nachdem große Pollenmengen dieser Baumart in der Atmosphäre nachgewiesen worden waren. SACCHI und PRICE (1988) konnten aber nachweisen, daß Salix lasiolepis zu 99,9\% insektenbestäubt und nur zu 0,1 \% windbestäubt ist.

Die Existenz bzw. Wirksamkeit von Pollenkittstoffen zweifelt EISENHUT (1957) bei der Gattung Tilia an und begründet dies u. a. durch eine hohe, von ihm und REMPE (1937) gemessene Deposition von Lindenpollen in den Kronen blühender Linden (s. o.) und er weist darauf hin, daß auch auf den Färöer-Inseln Lindenpollen nachgewiesenen werden konnten. Die FäröerInseln befinden sich im Atlantik, rund $1000 \mathrm{~km}$ von den nächsten Lindenpopulationen entfernt. Dies ist nach EISENHUT (1957) ein weiteres Indiz für die Anemophilie der Linde. Nach EISENHUT (1957) aggregieren bei entomophilen Arten mehrere Pollenkörner durch Pollenkitt zu einem Pollenklumpen. Nennenswerte Pollentransportweiten durch Wind sind damit aufgrund der Schwere dieser Aggregate nicht möglich, große Transportweiten bei Lindenpollen jedoch nachgewiesen worden. Neben der Tatsache, daß über das Kriterium Pollenaggregation ebenfalls keine eindeutige Einteilung in anemophile und entomophile Pflanzen durchzuführen ist (POHL 1929a, 1929b, 1936, HESSE 1979), kann auch bei einer Einteilung über das Kriterium Pollenkitt meiner Meinung nach die Linde zu den entomophilen Arten gezählt werden. Dabei wäre zum einen über die von EISENHUT (1957) zitierten Angaben REMPEs (1937) über die Pollenaggregation des Lindenpollens anzumerken, daß REMPE die Aggregation von Pollen untersucht hat, die durch Wind auf im Kronenbereich ausgelegte Fangröllchen transportiert wurden. REMPE konnte nur eine mäßige Pollenaggregation von 38,5 \% der untersuchten Pollen beobachten, die nach EISENHUT (1957) von überwiegender Windblütigkeit der Linde zeu- 
gen. HESSE (1979) und POHL (1929b) beschreiben, daß anfänglich klebrige Pollen an der Luft trocken und mehlig werden und es erst dann zum Zerfall der Pollenaggregate kommt. Bei HESSE (1979) waren bei der Sommerlinde zwei Drittel der Pollen mäßig bis gut verklebt und bei Pigott und Huntley (1980) waren 85 \% der Pollen der Winterlinde zu Pollenklumpen aggregiert. Im Gegensatz zu REMPE (1937) stellten PigotT und HunTLEY (1980) ihre Pollenfallen auf dem Waldboden auf. Mit dem Hintergrund, daß die Pollenaggregate erst nach Austrocknung zerfallen, ist aufgrund der unterschiedlichen Ergebnisse genannter Autoren zu schließen, daß der Zeitpunkt der Beobachtung auf den Aggregationszustand des Lindenpollens entscheidend Einfluß nimmt. Je älter die Pollen sind, desto mehr ist die Austrocknung und damit der Zerfall der Aggregate in Einzelpollen fortgeschritten. REMPE (1937) hat über seine Versuchsanordnung nur den durch Wind transportierten Pollen erfaßt, welcher weitgehend aus älteren, schon zerfallenen, Pollenaggregaten bestanden haben dürfte. Dieses Vorgehen ist auch nicht zu beanstanden. Keineswegs aber sind diese Pollen repräsentativ für die Messung einer Pollenaggregation bzw. für die Einteilung der Linde zu den anemophilen oder entomophilen Pflanzen. Laut POHL (1929b) ist es kein Zeichen des Übergangs von Entomophilie zu Anemophilie, wenn anfänglich klebrige Pollen nach Austrocknung zur Windübertragung geeignet sind. Nicht nur Austrocknung ist der Grund für den Zerfall der Pollenaggregate. Die Aggregation der Pollenklumpen kann ebenso durch mechanische Erschütterung, z. B. durch nektarsammelnde Insekten, zerstört werden (EISENHUT 1957). Die Zerstörung der Pollenaggregate durch nahrungssuchende Insekten dürfte nicht zu unterschätzen sein. Auch ist vorstellbar, daß aufgrund eines Mangels an Bestäubern nicht alle Blüten besucht werden und die Pollen in den Antheren verbleiben. Nach einer gewissen Zeit trocknen die Antheren aus und die Pollenaggregate zerfallen. Ob Pollen, die einmal in die Atmosphäre gelangt sind, noch in Befruchtungsvorgängen effektiv werden, ist anzuzweifeln, zumal nach HeSLOP-HARRISON und SHIVANNA (1977) die Narben der Gattung Tilia in die Gruppe der trockenen Narbentypen einzuordnen sind. Ein trockener Narbentyp ist ein Merkmal entomophiler Pflanzen, feuchte bzw. klebrige Narben dagegen ein Merkmal windbestäubter Pflanzen (über Wind transportierte Pollen haften besser auf feuchten Narben). Eine klebrige Narbe will EISENHUT (1957) bei vielen Lindenarten beobachtet haben, um auch damit die Anemophilie der Linde nachzuweisen. Leider nennt EISENHUT weder die Arten der Gattung Tilia, welche über den klebrigen Narbentyp verfügen sollen, noch zitiert er andere Autoren. HeSLOP-HARRISON und SHIVANNA (1977) ordnen den Narbentyp der Gattung Tilia nicht einmal in die Gruppe trockener bis feuchter Stigmata ein, geschweige denn in die Gruppe mit feuchter Narbe. Dies entspricht auch eigenen Beobachtungen bei der Winterlinde. 
Zudem könnte die Befruchtung durch älteren, windverbreiteten Pollen aufgrund einer mit dem Alter abnehmenden Pollenviabilität eingeschränkt sein (KLEBER 1935), wobei Lindenpollen bislang nicht Gegenstand solcher Untersuchungen waren.

Einig darüber sind sich indes die Autoren über die geringen Transportweiten windverfrachteter Lindenpollen (Eisenhut 1957, Pigott und Huntley 1979, Pohl 1936, RemPe 1937). Obwohl EISENHUT (1957) den Transport von Lindenpollen bis auf die Färöer erwähnt, spricht selbst er nur von einer kleinräumigen Verbreitung der Lindenpollen durch Wind, was weitgehend Selbstbefruchtung zur Folge hätte. PIGOTT und HunTLEY (1980) konnten bei der Winterlinde in einer Entfernung von $60 \mathrm{~m}$ keine Pollen mehr feststellen (vgl. Kap. 2.8.4); sie kommen zu dem Schluß, daß Lindenpollen rascher fallen, als sie vom Wind verweht werden.

EISENHUT (1957) macht darauf aufmerksam, daß Lindenpollen im Honig unterrepräsentiert sei (s. Kap. 2.8.2). Er führt dies auf eine mangelnde Effektivität der Honigbiene (und generell der Insekten) als Bestäuber der Linde zurück - für ihn ein weiterer Hinweis auf die Anemophilie der Linde. VON DER OHE et al. (1993) und andere Autoren (Kap. 2.8.2) bestätigen den geringen Anteil an Lindenpollen im Honig. Bei einer Analyse des Honigs stellten VON DER OHE et al. (1993) allerdings fest, daß dieser trotzdem zu $80 \%$ aus Lindennektar besteht. Von einer geringen Effektivität der Honigbiene als Bestäuber der Winterlinde kann somit nicht ausgegangen werden. Im Gegenteil sprechen die Ergebnisse für eine hohe Blütenkonstanz der Honigbiene bei der Winterlinde. VON DER OHE (pers. Mitteilung) führt den geringen Anteil an Lindenpollen im Honig u. a. auf die Haftung der Pollenaggregate in den Antheren zurück (vgl. die obige Diskussion zum Thema Pollenkitt).

Für PoHL (1929b) und Hesse (1979) ist eine zwittrige Blüte ein Indiz für Entomophilie. Die evolutionäre Entwicklung von Entomophilie zur Anemophilie ist mit der Ausbildung eingeschlechtlicher und einfacher Blüten verbunden. Dieses Argument von POHL (1929b) wird von EISENHUT (1957) nicht erwähnt. Man muß aber davon ausgehen, daß EISENHUT Kenntnis von POHLs Arbeit (1929b) hatte, da eine andere Arbeit von POHL (1929a) von ihm zitiert wird, welche auf den vorhergehenden Seiten der gleichen Zeitschrift veröffentlicht ist. Für RoHMEDER (1972) verfügt die Winterlinde über perfekte zwittrige Blüten. Daher ist die Winterlinde auch bezüglich der Blütenmorphologie klar als entomophile Baumart einzuordnen.

Die große Nektarproduktion, die Produktion des Duftstoffes Farnesol, die Tatsache, daß 80 \% des Bienenhonigs aus Lindennektar besteht, die zahlreich beobachteten und mit großer Blütenkonstanz die Linde besuchenden Insekten usw. sind weitere deutliche Hinweise für die Bestäubung der Linden durch Insekten (s. Kap. 2.8). 


\subsubsection{Bestäubungsversuche}

KEYs et al. (1995) verwendeten bei ihren Bestäubungsversuchen Netze mit einer Maschenweite von $3 \mathrm{~mm}$, um eine Bestäubung der Blüten von Prosopis velutina (Leguminosae) durch Insekten zu unterbinden. Sie wählten diese Maschenweite, da als wichtigste Bestäubergruppen dieser Leguminosen, ähnlich wie bei den Lindenarten, u. a. Honigbienen und Schwebfliegen galten. Bei den isolierten Blüten stellte sich aber der gleiche Samenansatz wie bei den ungeschützten Blüten ein. Damit erwiesen sich diverse Kleininsekten, für welche die $3 \mathrm{~mm}$ Maschenweite kein Hindernis darstellten, als effektive Pollenvektoren (s. Kap. 2.8.3.5). Auch auf den Blüten der Lindenarten konnten zahlreich diverse Kleininsekten beobachtet werden (Kap. 2.8.2). Aus diesem Grund wurde bei den eigenen Bestäubungsversuchen die Maschenweite von ca. $1 \mathrm{~mm}$ gewählt. Diese Maschenweite birgt jedoch evtl. die Gefahr, Luftströmungen zu reduzieren und durch statische Aufladung ein Pollentransport durch Wind oder Schwerkraft zu beeinträchtigen. Bei den eigenen Bestäubungsversuchen wurden durch Wind nachweislich nur 0,3 \% der Blüten effektiv bestäubt. Dies entspricht weniger als einem Zehntel des Samenansatzes aus freier Abblüte (Kap. 4.4). Eine Beurteilung, inwieweit die genannten Faktoren die geringe Effizienz des Pollentransportes durch Wind und/oder Schwerkraft beeinflußt haben, ist hier nicht möglich.

EISENHUT (1957) wählte für seine Bestäubungsversuche eine Maschenweite von 1,9 mm und die eingebeutelten Zweige erreichten einen den ungeschützten Zweigen vergleichbaren Samenansatz. ANDERSON (1976) verwendete für seine Bestäubungsversuche Netze mit einer Maschenweite 1,2 $\mathrm{mm}$ und der Samenansatz der isolierten Zweige erreichte ein Drittel des Samenansatzes frei abgeblühter Zweige. Man könnte argumentieren, daß je kleiner die Maschenweite gewählt wird, der Luftaustausch desto geringer wird und Windbestäubung desto größer beeinträchtigt wird. Die Ergebnisse von KEYs et al. (1995, s. o.) und die zahlreich auf den Blüten der Linden beobachteten Kleininsekten lassen aber auch eine andere Argumentation zu: Je größer die Maschenweite, desto größer die Gefahr, daß Kleininsekten als effektive Pollenvektoren in Erscheinung treten. Eine Gewichtung beider Argumente wäre ohne weitere Untersuchungen rein spekulativer Natur. Viel wichtiger ist die Tatsache einzustufen, daß sowohl EISENHUT (1957) als auch ANDERSON (1976) für ihre Versuche Parkbäume auswählten; denn die tiefbeasteten Solitärbäume ermöglichen eine leichte Durchführung der Bestäubungsversuche. Wie schon im vorigen Kapitel erwähnt, sind einzelnstehende Winterlinden allerdings nur bedingt mit im Bestand stehenden Winterlinden vergleichbar. Die Blütenbildung erfolgt bei der Linde nur in den frei exponierten Kronenteilen und daher im Bestand nur zweidimensional, horizontal im Kronendach. Frei stehende Bäume entwickeln Blüten bis in 
die untersten Kronenbereiche und die Tracht nimmt eine dreidimensionale kugelige Form an. Pollentransport in vertikaler Richtung von oben nach unten kann hier möglicherweise zu einer Bestäubung tiefer liegender Blüten durch die Schwerkraft führen; bei im Bestand stehenden Linden ist dies nicht möglich. Wie den Fotos der Arbeit von EISENHUT (1957) zu entnehmen ist, hat zumindest EISENHUT bevorzugt leicht erreichbare, tief liegende Äste für seine Bestäubungsversuche gewählt. Da windverfrachtete Lindenpollen rascher fallen als fliegen und daher die Pollenflugweiten nur sehr bescheiden sind (s. a. Kap. 5.2.1), dürfte bei angenommener Windbestäubung überwiegend Eigenpollen effektiv werden (s. a. Kap. 5.2.1).

Zudem sind durch die Wahl von Parkbäumen als Untersuchungsobjekte weitere Faktoren zu beachten, die einen Transport von Pollen aus oberen Kronenpartien auf die Narben tiefer gelegener Blüten fördern: Die untersuchten Parkbäume werden vermutlich keinen oder nur eingeschränkten Kontakt zu anderen Paarungspartnern gehabt haben. Dies bedingt zum einen, daß die aus einer oder nur wenigen Winterlinden bestehende Parkpopulation nicht mit der Attraktivität größerer Winterlindenpopulationen vergleichbar und eine Anlockung bzw. Konditionierung bestäubungsrelevanter Insekten geringer einzuschätzen ist. Dies könnte u. a. einen unzureichenden Besuch der Blüten und zahlreiche nicht entleerte Antheren zur Folge gehabt haben. Die nicht entleerten Antheren entlassen nach Austrocknung die Pollen, welche möglicherweise auf die Narben tiefer gelegener Blüten fallen und zu Selbstbestäubung führen. Da keine oder nur wenige potentielle Paarungspartner zur Verfügung stehen, ist Konkurrenz durch Fremdpollen nur marginal vorhanden und ermöglicht die Etablierung selbstbefruchteter Nachkommen. Es ist anzunehmen, daß bei EISENHUT (1957) für die ungeschützten Zweige keine wesentlich anderen Bestäubungsbedingungen vorgelegen haben als für die eingebeutelten Zweige. Dies bedeutet, daß auch bei den ungeschützten Zweigen wohl ein Großteil der an gebildeten Samen aus Selbstbefruchtung hervorgegangen sein dürfte. Leider sind diese Vermutungen nicht zu überprüfen, da EISENHUT (1957) seine Ergebnisse mit keinerlei Zahlen belegt. Er nennt weder die Anzahl vitaler Samen noch macht er Angaben über Hohlkornanteile. Der schon in Kapitel 2.8.4 zitierte ungekürzte Ergebnisteil der Bestäubungsversuche von EISENHUT (1957) sei hier wiederholt: „An allen eingebeutelten Zweigen bildeten sich normale Früchte; die Früchte unterschieden sich weder mengen- noch gütemäßig, vor allem auch nicht in der Keimfähigkeit, von jenen, die aus ungeschützten Blüten entstanden.“ Etwas überraschend belegt EISENHUT (1957) die Anemophilie der Winterlinde und die uneingeschränkte Keimfähigkeit windbestäubter Winterlindenfrüchte mit einer Tabelle über eine dreitägige Keimprüfung der Samen frei abgeblühter bzw. insektensicher eingebeutelter Salweidenzweige (Salix caprea)! 
Sowohl der von ANDERSON (1976) als auch der in eigenen Versuchen ermittelte Umfang der Windbestäubung liegt im Rahmen anderer, eindeutig als entomophil eingestufter Baumarten. Bei Prunus salicina (Rosaceae) sind durch Windbestäubung bis zu $1 \%$ der Blüten erfolgreich befruchtet worden (CASILDA et al. 1994) und bei Prunus mahaleb (Rosaceae) wurden 0,3\% der Blüten erfolgreich durch Wind bestäubt (GUITAN 1993). GUITAN betont, daß die Felsenkirsche (Prunus mahaleb) nicht zu den anemophilen oder ambophilen Arten gezählt wird .

Ebenfalls für Entomophilie der Winterlinde sprechen die sehr uneinheitlichen effektiven Pollenwolken (Kap. 4.3). Zumindest für die Populationsmitglieder, welche in den Teilen des Bestandes stehen, der als Reinbestand zu bezeichnen ist, wären bei vorwiegender Windbestäubung einheitlichere Pollenwolken zu erwarten gewesen (vgl. Kap. 5.3). Bei der Rotbuche (Fagus sylvatica) und bei der Fichte (Picea abies), beides windbestäubte Baumarten, wurden im Vergleich zur Winterlinde nur relativ geringe Unterschiede zwischen einzelnen effektiven Pollenwolken und deren Komplement festgestellt. Während bei der Winterlinde ein maximales $\mathrm{D}_{\mathrm{j}}$ von 0,34 ermittelt wurde (Kap. 4.3), beläuft sich das maximale $\mathrm{D}_{\mathrm{j}}$ bei der Buche auf 0,12 und bei der Fichte auf 0,078 (HATTEMER et al. 2001).

Bei Windbestäubung wäre auch ein der Fertilität der Winterlinden entsprechender Beitrag an Fremdpollen zu den effektiven Pollenwolken zu erwarten gewesen; nach den Ergebnissen des Kapitels 4.9.2 war dies aber nicht der Fall.

\section{Schlußfolgerung}

Die Winterlinde bzw. die Gattung Tilia ist aufgrund ihrer Blütenmorphologie und ihrer Bestäubungsökologie als entomophil einzustufen. Eine nennenswerte Bestäubung durch Wind ist nur in besonderen Fällen (z. B. bei isolierten Solitärbäumen und/oder nach Ausbleiben von Insekten) zu erwarten und in der Regel weit unter der Effektivität der Insektenbestäubung einzustufen. Sollte Lindenpollen effektiv durch Wind transportiert werden, wird er nur kleinräumig verbreitet und führt daher überwiegend zu Selbstbestäubung.

Die von EISENHUT (1957) deklarierte Anemophilie der Lindenarten ist vermutlich durch nicht repräsentative Bestäubungsversuche sowie die unvollständige Interpretation der Ergebnisse seiner eigenen Arbeiten und denen anderer Autoren zu erklären.

\subsection{Effektive Pollenwolken}

Die individuellen effektiven Pollenwolken der Winterlinden in der Population Schwiegershausen waren in der Blühperiode des Jahres 1995 sehr unterschiedlich zusammengesetzt. Die 
berechneten Werte der Parameter $\mathrm{D}_{\mathrm{j}}, \delta_{\mathrm{T}}$ und $\mathrm{d}_{0}$ belegen die starke Differenzierung dieser Pollenwolken (Kap. 4.3). Auch kleinräumig kann von guter Durchmischung der effektiven Pollen nicht die Rede sein. In der Literatur wird indes oft von einheitlichen Pollenwolken ausgegangen, bzw. wird diese Grundannahme für viele Modelle und Programme vorausgesetzt. Die Ursache für die großen Unterschiede zwischen den individuellen Pollenwolken könnte in einer überwiegenden Bestäubung der Winterlinden durch Insekten begründet sein. Windbestäubung hätte vermutlich ebensowenig einheitliche Pollenwolken für alle Populationsmitglieder zur Folge gehabt, nur wären die Unterschiede zwischen den individuellen Pollenwolken mit hoher Wahrscheinlichkeit moderater ausgefallen (s. Kap. 5.1).

Eine direkte Abhängigkeit der Parameter $\mathrm{D}_{\mathrm{j}}$ (Differenzierung individueller Pollenwolken vom Komplement der restlichen Pollenwolken) und $\delta_{\mathrm{T}}$ (Variation innerhalb einer Pollenwolke) existiert nicht. Dies könnte darin begründet liegen, daß nach Selbstbefruchtung $\delta_{\mathrm{T}}$ signifikant mit dem Heterozygotiegrad des Samenelters korreliert ist, während $D_{j}$ von diesem gänzlich unbeeinflußt bleibt (Tab. 4.6, S. 100). Große Diversität (v) und damit hohe Variation innerhalb individueller Pollenwolken $\left(\delta_{\mathrm{T}}\right)$ ist nicht nur dann zu erwarten, wenn der Samenelter viele Fremdpollen von vielen verschiedenen Polleneltern erhalten hat. $\delta_{\mathrm{T}}$ kann auch sehr hohe Werte annehmen, wenn bei großem Selbstbefruchtungsanteil der Samenelter einen hohen Heterozygotiegrad aufweist. Bei Individuen oder Populationen mit nennenswertem Umfang an Selbstbefruchtung sind diese Parameter bei Betrachtung effektiver Pollenwolken oder Nachkommenschaften ohne Einbeziehung des Heterozygotiegrades des Samenelters nur bedingt aussagekräftig.

Über Regressionsanalysen wurde nachgewiesen, daß effektiv gewordene Pollenwolken dann ein hohes $\mathrm{D}_{\mathrm{j}}$ zum Komplement der restlichen Pollenwolken aufweisen, wenn die Nachkommen überwiegend aus Selbstbefruchtung entstanden sind (Tab. 4.7, S. 101). Die individuellen Pollenwolken der Winterlinden in der Feldmark sind stark vom Komplement der restlichen Pollenwolken differenziert. Neben den Feldlinden zeichnen sich aber auch andere, im Bestand stehende Bäume, durch eine hohes $\mathrm{D}_{\mathrm{j}}$ aus (vgl. Abb. 4.12, S. 99). Die räumliche Isolation durch die Entfernung zu den nächsten Paarungspartnern kann demnach nicht oder nicht die alleinige Ursache hoher $\mathrm{D}_{\mathrm{j}}$-Werte bzw. hoher Selbstbefruchtungsraten sein. Daß in der Population Schwiegershausen zwischen der Selbstbefruchtungsrate und der Entfernung des Samenelters zu den nächsten Nachbarn nur bedingt ein Zusammenhang festgestellt werden kann, wurde in Kap. 4.7.3 gezeigt. Als eine Ursache hoher Selbstbefruchtungsraten (und damit hoher $\mathrm{D}_{\mathrm{j}}$-Werte) hat sich dabei die Kronengröße des Samenelters herausgestellt (s. a. Kap. $5.5 .3 .2)$. 


\section{Schlußfolgerung}

Die effektiven Pollenwolken der einzelnen Mitglieder der Winterlindenpopulation Schwiegershausen sind sehr unterschiedlich. Von einer einheitlichen Pollenwolke für alle Populationsmitglieder kann nicht die Rede sein.

Sind Nachkommen im nennenswerten Umfang aus Selbstbefruchtung entstanden, sind die Parameter $v$ und $\delta_{\mathrm{T}}$ stark vom Heterozygotiegrad des Samenelters abhängig und daher als Parameter für die Analyse von Pollenwolken und Nachkommenschaften nur bedingt geeignet.

Eine hochsignifikante Korrelation besteht zwischen $D_{j}$ und der Selbstbefruchtungsrate. Je mehr Selbstbefruchtung stattgefunden hat, desto mehr unterscheiden sich die individuellen Pollenwolken von ihrem Komplement. Dabei wird der $D_{j}$-Wert weniger von der Entfernung des Samenelters zu den nächsten Paarungspartnern, als von der Kronengröße des Samenelters beeinflußt.

\subsection{Bestimmung von Polleneltern}

In diesem Kapitel wird lediglich auf die Effizienz und Plausibilität der Methodik der verschiedenen Pollenelterbestimmungsverfahren eingegangen. Die Ergebnisse der über die Pollenelterbestimmungsverfahren hergeleiteten Selbstbefruchtungsraten und Pollentransportweiten erlauben Rückschlüsse auf deren Plausibilität bei der Bestimmung von Polleneltern. Aus Gründen der Übersicht erfolgt die Diskussion über die Qualität der Pollenelterbestimmung später im Kontext der Kapitel Selbstbefruchtung (5.5.1) bzw. Bestimmung von Polleneltern (5.6.1).

Es bleibt darauf hinzuweisen, daß die Wahrscheinlichkeit für die Bestimmung als Pollenelter generell für diejenigen Populationsmitglieder höher ist, die ein seltenes Allel bzw. eine seltene Allelkombination besitzen und/oder über viele Genorte homozygot sind. Die Möglichkeit der Überrepräsentation dieser Populationsmitglieder besteht für alle Verfahren, bei denen die Genotypen der Paarungspartner Grundlage ihrer Berechnungen sind, und trifft für alle im Rahmen dieser Arbeit verwendeten Verfahren zu. Daher ist die Vergleichbarkeit der Ergebnisse gewährleistet.

\subsubsection{Eindeutiges Ausschlußverfahren}

Das Ausschlußverfahren ist eine mit wenigen Annahmen und nicht durch Simulationen belastete und daher relativ sichere Methode zur Bestimmung von Polleneltern. Liegt eine fehlerfreie Datenerhebung vor und wurden alle potentiellen Paarungspartner berücksichtigt, kann 
man von einer genauen Identifizierung des Pollenelters ausgehen. Ein weiterer Vorteil ist die leichte rechnerische Umsetzung des Verfahrens. Nachteilig ist die geringe Effizienz. Ein eindeutiger Ausschluß, d. h. die Bestimmung nur eines Pollenelters mit der bei Pflanzen üblichen Anzahl und Variation von Isoenzymgenmarkern, ist nur selten gegeben. Selbst mit den vierzehn überwiegend hochvariablen Genorten im Falle der Winterlinde konnten nur für 8,6 \% der Nachkommen Polleneltern eindeutig bestimmt werden. Auf der Basis weniger und/oder gering variierender Genloci werden die Erfolgsaussichten auf eindeutige Bestimmung von Polleneltern drastisch reduziert (Abb. 3.7).

\subsubsection{CERVUS}

Die Effizienz, mit der das CERVUS-Programm wahrscheinlichste Polleneltern identifiziert ist ungenügend. Bei einer fiktiven Fehlerquote von $1 \%$ und einem Signifikanzniveau von $80 \%$ konnte nur für 9,5\% der Nachkommen ein Pollenelter bestimmt werden, nach der simplen Methode des eindeutigen Ausschlußverfahrens hingegen 8,6 \% (Tab. 4.15, S. 114). Anhand dieser Ergebnisse stellt sich die Frage, wozu ein solch komplexes Auswertungsprogramm nötig ist. Der höchste Anteil ermittelter Polleneltern von $19 \%$ wurde bei CERVUS mit der Kombination Fehlerquote von $0 \%$ und Signifikanzniveau $80 \%$ erreicht; dies bedeutet immerhin mehr als eine Verdoppelung gegenüber dem eindeutigen Ausschlußverfahren. Für viele Fragestellungen und in Anbetracht der zahlreich durchgeführten Simulationen (s. Abb. 3.8, S. 76) ist dies aber immer noch ein dürftiges Resultat. Die Effizienz des Programmes ist stark abhängig von der Wahl der Eingabeparameter, die teilweise den Charakter der Beliebigkeit trägt (s. Tab. 4.15, S. 114). Ein weiteres Problem ist, daß die Wahl der Eingangsparameter nicht nur Folgen für die quantitative, sondern auch für die qualitative Bestimmung von Polleneltern hat. Für ein und denselben Datensatz wurden unter Verwendung zweier verschiedener Kombinationen von Eingabeparametern mit CERVUS jeweils für ca. 18,2 \% der Nachkommen ein Pollenelter bestimmt. Ein Abgleich der für die einzelnen Samen ermittelten Polleneltern zeigt indes große Unterschiede: 39,2 \% dieser Polleneltern stimmten nicht überein! Nur durch die Variation der Eingangsparameter kommt es in 39,2 \% der Fälle also zu einer unterschiedlichen Bestimmung des wahrscheinlichsten Pollenelters (s. Kap. 4.6.2); dies hat natürlich Folgen für die davon abzuleitenden Transportweiten effektiver Pollen.

Nicht plausibel sind auch jene zwölf nach dem Ausschlußverfahren eindeutig ermittelten Polleneltern, welche von CERVUS nicht als wahrscheinlichste Polleneltern bestimmt wurden. Die Fehlerquote war bei CERVUS mit 0 \% eingegeben; daher hätte CERVUS aufgrund ihres Genotyps diese Polleneltern von der Pollenelterschaft nicht nur nicht ausschließen dürfen, 
sondern sie auch als wahrscheinlichste Polleneltern ausweisen müssen, da alle anderen Populationsmitglieder aufgrund ihres Genotyps von einer Pollenelterschaft auszuschließen waren. Da die restlichen 319 mit dem Ausschlußverfahren eindeutig bestimmten Polleneltern mit den mittels CERVUS gefundenen übereinstimmten, ist dies nur durch eine Ungenauigkeit in diesem Programm zu erklären (Kap. 4.6.4). Durch letzteren Aspekt, die Problematik bei der Wahl der Eingangsparameter und die relativ geringe Effizienz ist der Einsatz von CERVUS nicht empfehlen. Wird von CERVUS dennoch Gebrauch gemacht, bleibt dem Benutzer entweder die Hoffnung, auf Anhieb die für seinen Datensatz effizienteste Kombination der Eingangsparameter zu erwischen oder zeitraubend mehrere Kombinationsmöglichkeiten empirisch durchzuspielen. Wird das Programm CERVUS verwendet, sollten bei der Berechnung verschiedener Datensätze die Eingangsparameter nicht variiert werden, da eine Vergleichbarkeit der Ergebnisse dann nicht gewährleistet ist.

\subsubsection{EFG}

Bei dem Pollenelterbestimmungsverfahren EFG kann die Höhe einer Diskriminanzschwelle $\Delta$ beliebig gewählt werden. Bei dem Verfahren EFG erscheint eine Diskriminanzschwelle von $2 \Delta$ ausreichend, um die Sicherheit einer richtigen Bestimmung von Polleneltern zu gewährleisten. Bei der „,most-likely“-Methode von MEAGHER (1986) z. B. reicht die absolute höchste Wahrscheinlichkeit einer Pollenelterschaft zur Bestimmung eines Pollenelters aus. Aus diesem Grund wird auf die Ergebnisse bei dem Verfahren EFG mit einer Diskriminanzschwelle von $4 \Delta$ und $8 \Delta$ nicht weiter eingegangen. Mit EFG $2 \Delta$ konnte für $56 \%$ der untersuchten Nachkommen ein wahrscheinlichster Pollenelter ermittelt werden, ein im Vergleich zu anderen Methoden sehr hoher Wert (s. o.). Die hohe Effizienz bei der Bestimmung von Polleneltern wird durch die Einbeziehung der Faktoren Entfernung (E), Fertilität (F) und Wahrscheinlichkeit der Gametenproduktion (G) ermöglicht. Diese Faktoren grenzen den Kreis potentieller Polleneltern stark ein. Die Verwendung der Faktoren „Entfernung“ und „Fertilität“ erscheint sinnvoll, da die individuell sehr unterschiedlichen Pollenwolken darauf hindeuten, daß jeder Samenelter über spezifische Bestäubungsverhältnisse verfügt, die nicht über die Gesamtpopulation vereinheitlicht werden sollten (Kap. 4.3).

Die Entfernungen zu den nächsten Paarungspartnern konnten im Falle des Versuchsbestandes sehr genau ermittelt werden. Der Einsatz des Faktors Entfernung auf der Basis einer über das eindeutige Ausschlußverfahren generierten kumulativen Verteilungsfunktion (s. Kap. 4.8.4 mit Abb. 4.26, S. 147) erscheint auch aufgrund der Ergebnisse anderer Autoren gerechtfertigt (Kap. 2.8.4). Als Potential für Ungenauigkeiten ist indessen die über Luftbildaufnahmen her- 
geleitete Fertilität der Winterlinden einzuschätzen (Kap. 3.9.2.4). Ein direkter Schluß aus dem blühenden Kronenraum der Linden auf deren Pollenproduktion ist plausibel, könnte aber mit Unsicherheiten behaftet sein. Um den Faktor Pollenproduktion nicht überzubewerten, wurde daher der logarithmierte Wert der Pollenproduktion für den Faktor Fertilität verwendet. Auch wenn auf diesem Weg eventuell kein exakter Wert für die Fertilität einer Linde geschätzt werden kann, ist der Einsatz dieses Faktors als wichtig zu betrachten, da der Pollenbeitrag einer Winterlinde mit einem blühenden Kronenraum von $1,3 \mathrm{~m}^{2}$ bedeutend geringer sein wird, als der Pollenbeitrag einer $300 \mathrm{~m}^{2}$ großen Winterlinde. Eine Nichtbeachtung dieser wichtigen Information würde größere Ungenauigkeiten bei der Bestimmung nach sich ziehen, als die Verwendung tendenziell korrekter aber ungenauer Fertilitäten.

Gerade weil die relativ einfache Berechnung der Wahrscheinlichkeit der Gametenproduktion über die genotypische Kombination aus Samenelter, Nachkomme und potentiellem Pollenelter ohne Simulationen auskommt, ist sie meiner Ansicht nach für die Bestimmung des Faktors G sehr geeignet (Kap. 3.9.2.4); denn Simulationen setzen Annahmen voraus, und ob die Natur diesen Annahmen folgt, ist nur schwer zu überprüfen bzw. kann angezweifelt werden. Im Falle der Annahme der Existenz einer einheitlichen Pollenwolke läßt sich dies sogar falsifizieren (s. Kap. 4.3). Aus diesem Grund bleiben bei der in dieser Arbeit entwickelten Methode zur Bestimmung des Faktors $G$ die Allelhäufigkeiten der Population unberücksichtigt; dies steht im Gegensatz zu MEAGHER's (1986) „most-likely“-Methode oder zu dem Programm CERVUS. Auf die Annahme einer bei allen Populationsmitgliedern einheitlichen Gametensegregation kann jedoch auch bei EFG nicht verzichtet werden.

Je nach Verfügbarkeit an Informationen können auch weniger oder zusätzliche Faktoren für die Schätzung des wahrscheinlichsten Pollenelters verwendet werden. Je nach Baumart und Bestäubungsökologie können z. B. topographische Gegebenheiten, Windrichtung, lokale Unterschiede der Insektenabundanz, Lichtverhältnisse, Mikroklima, Alter der Pflanzen usw. $a$ priori Informationen über die Wahrscheinlichkeit einer Pollenelternschaft liefern.

\section{Schlußfolgerungen}

Allein aufgrund der hohen Effizienz bei der Bestimmung von Polleneltern ist das Verfahren EFG $2 \Delta$ dem eindeutigen Ausschlußverfahren und dem Programm CERVUS vorzuziehen. Durch die Einbeziehung für Reproduktionssystem wichtigen Informationen, den Verzicht auf Simulationen und den Gebrauch nur weniger Annahmen darf man auch von einer relativ hohen Genauigkeit bei der Bestimmung von Polleneltern ausgehen. Ebenfalls durch wenige Simulationen und Annahmen belastet ist das eindeutige Ausschlußverfahren. Das Problem bei diesem Verfahren ist jedoch die sehr geringe 
Aufklärungsquote, die bei Verwendung weniger und/oder gering variierender Genorte gegen Null gehen kann. Simulationen sind bei CERVUS die Basis fast aller Berechnungen. Inwieweit diese Simulationen die Verhältnisse in der Natur repräsentieren bzw. erfassen, bleibt offen. Aber nicht nur unter diesem Aspekt ist die Anwendung von CERVUS nur bedingt zu empfehlen. Neben der relativ geringen Effizienz bei der Bestimmung von Polleneltern kommt die Problematik der Wahl der Eingabeparameter hinzu. Je nach Kombination der Eingabeparameter werden für ein und denselben Datensatz unterschiedlich viele und unterschiedliche Polleneltern bestimmt. Zudem wurden mit CERVUS in einigen Fällen Polleneltern nicht bestimmt, obwohl aufgrund ihres Genotyps kein anderer Pollenelter in Betracht gekommen wäre.

Falls für die Verwendung von EFG keine Informationen über die Entfernung zum nächsten Paarungspartner und die Fertilität verfügbar sind, ist aus den genannten Gründen das eindeutige Ausschlußverfahren dem Programm CERVUS vorziehen.

Ein Nachteil des Verfahrens EFG ist jedoch noch das Fehlen eines anwenderfreundlichen Programms.

\subsection{Selbstbefruchtung}

Über die Bestäubungs- und Keimungsversuche wurde bei der Winterlinde sowohl Selbstbefruchtung als auch grundsätzliche Selbstfertilität nachgewiesen (s. Kap. 4.4 und 4.5). Diese Ergebnisse stehen im Einklang mit denen von ANDERSON (1976), EISENHUT (1957) und PIGOTT und HuNTLEY (1981) in Kapitel 2.9.

\subsubsection{Bestimmung von Selbstbefruchtungsraten}

Aufgrund der relativ geringen Effizienz von CERVUS und dem Verfahren EFG mit Diskriminanzschwellen von $4 \Delta$ bzw. $8 \Delta$ wird auf die nach diesen Verfahren ermittelten Selbstbefruchtungsraten nicht näher eingegangen (Kap. 4.7.2). Somit stehen im Folgenden für die Herleitung von Selbstbefruchtungsraten drei Verfahren zur Diskussion: Das Ausschlußverfahren, EFG $2 \Delta$ nach Bereinigung und MLTR (s. Kap. 4.7.1).

Im Gegensatz zum eindeutigen Ausschlußverfahren, bei dem die Bestimmung eines Pollenelters im Vordergrund steht (Kap. 3.9.1), überprüft das (einfache) Ausschlußverfahren lediglich, ob der Nachkomme eine Allel aufweist, welches nicht vom Samenelter stammen kann. Durch den Nachweis eines Fremdtypallels wird Selbstbefruchtung ausgeschlossen (s. Kap. 3.10.1). Wird kein Fremdtypallel nachgewiesen, gilt der betreffende Nachkomme als selbstbefruchtet, auch wenn außer dem Samenelter theoretisch andere Populationsmitglieder als Pol- 
leneltern in Betracht gekommen wären. Die mit dem Ausschlußverfahren ermittelte Selbstbefruchtungsrate entspricht somit dem je nach Genotyp maximal möglichen Anteil an Selbstbefruchtung.

Die mit MLTR und dem Ausschlußverfahren ermittelten Werte sind sich sehr ähnlich und in ihrer Tendenz einheitlich. MLTR berechnet in den meisten Fällen geringere Selbstbefruchtungsraten als das Ausschlußverfahren (Tab. 4.18, S. 122). Diese Übereinstimmung beider Verfahren liegt vermutlich an der Anlehnung von MLTR an das Prinzip des Ausschlußverfahrens. Warum MLTR für zwei der 54 untersuchten Einzelbaumnachkommenschaften negative Selbstbefruchtungsraten berechnet (Winterlinden Nr. 97 und 113, Tab. 4.18), kann aus den Arbeiten von RITLAND (1994) bzw. RITLAND und JAIN (1982) nicht eruiert werden. Es ist daher nicht möglich zu sagen, ob diese negativen Selbstbefruchtungsraten, die logisch jeglicher Grundlage entbehren, auf Besonderheiten der Genotypstrukturen in den Eltern oder Nachkommen oder auf ein fehlerhaftes Programm zurückzuführen sind. Läge ein fehlerhaftes Programm vor, wären auch alle anderen Selbstbefruchtungsraten anzuzweifeln. Negative bzw. $100 \%$ übersteigende Fremdbefruchtungsanteile sind mit MLTR auch für Nachkommenschaften anderer Baumarten berechnet worden und auf Unzulänglichkeiten des Programms wird in der Arbeit von IVEY und WyATT (1999) hingewiesen.

Die Verfahren EFG 2 $\Delta$ und MLTR weisen bei Betrachtung der durchschnittlichen Selbstbefruchtungsraten der Gesamtpopulation eine bessere Kongruenz als MLTR und das Ausschlußverfahren auf (s. Tab. 4.17, S. 120). Auf der Ebene der Einzelbaumnachkommenschaften ist diese Übereinstimmung jedoch nicht gegeben; die über EFG $2 \Delta$ bzw. MLTR berechneten Selbstbefruchtungsraten in den Nachkommen der einzelnen Winterlinden unterscheiden sich zum Teil sogar erheblich (s. Tab. 4.19, S. 124). Es ist anzunehmen, daß die Einbeziehung der Faktoren Entfernung (zu den nächsten Paarungspartnern) und Fertilität diese teils beträchtlichen Unterschiede hervorrufen. Die Vermutung wird durch die Tatsache gestützt, daß MLTR für Linden im Bestand höhere und für die isoliert in der Feldmark stehenden Linden geringere Selbstbefruchtungsanteile berechnet als EFG $2 \Delta$.

Die Bestimmung von Polleneltern über das eindeutige Ausschlußverfahren hat gezeigt, daß die Kurve für die Pollentransportweiten leptokurtisch verläuft (Abb. 4.23, S. 140). Leptokurtische Verteilungen der Entfernungen des Pollentransports durch Insekten werden auch in der Literatur für andere entomophile Pflanzen beschrieben (Kap. 2.8.6). Die Wahrscheinlichkeit, daß Pollen in der näheren Umgebung des Pollenelters effektiv werden, ist also bedeutend gröBer als in weiter Entfernung. Eine Einbeziehung des Faktors Entfernung a priori führt daher wahrscheinlich zu plausibleren Ergebnissen bei der Bestimmung von Selbstbefruchtungsan- 
teilen. Man möchte meinen, daß durch den Faktor Entfernung der Anteil der Selbstbefruchtung bei EFG höher ausfällt als beim Verfahren MLTR, da hierfür eine exponentiell verlaufende Kurve eingesetzt wird und dadurch der Samenelter selbst a priori eine höhere Wahrscheinlichkeit für eine Pollenelterschaft erhält. Im Mittel der Gesamtpopulation wird für EFG $2 \Delta$ indes eine niedrigere Selbstbefruchtungsrate als bei MLTR ermittelt (s. Tab. 4.17, S. 120). Auch die Verwendung des Faktors „Fertilität“ hat sich im Nachhinein als richtig erwiesen; denn die Selbstbefruchtungsrate ist signifikant mit der Kronengröße des Samenelters korreliert und diese spielt eine zentrale Rolle für das Ausmaß der Selbstbefruchtung (Kap. 4.7.3). Bei EFG wird über den Faktor Fertilität die Kronengröße des Samenelters angemessen berücksichtigt. Nur bei den sehr kleinen Winterlinden mit einer Kronengröße $<18 \mathrm{~m}^{2}$ ist die Selbstbefruchtungsrate mit EFG vermutlich unterschätzt worden. Bei Individuen mit kleinen Kronen wird eventuell durch den relativ kleinen Faktor Fertilität a priori die Wahrscheinlichkeit, daß der Samenelter auch Pollenelter ist, unterschätzt. Für entomophile Baumarten mit einer der Linde ähnlichen Bestäubungsökologie sollte die geringe Attraktivität kleiner Kronen (= Nahrungsquellen) mit EFG zukünftig besser berücksichtigt werden. Bis auf letztere Einschränkung muß das Verfahren EFG für die Bestimmung von Selbstbefruchtungsraten als sehr plausibel gelten und rechtfertigt größeres Vertrauen in die so ermittelten Werte als in die mit dem Ausschlußverfahren oder MLTR berechneten Selbstbefruchtungsraten.

\section{Schlußfolgerungen}

Wenn bezüglich des Reproduktionssystems relevante Informationen verfügbar sind (z. B. Fertilität, Entfernung der nächsten Paarungspartner etc.), dann ist zumindest bei entomophilen Baumarten für die Bestimmung von Selbstbefruchtungsraten die Verwendung von EFG $2 \Delta$ zu empfehlen.

Sind diesbezüglich keine Informationen vorhanden, können die mit dem Ausschlußverfahren ermittelten Werte als grober Anhaltspunkt dienen; sie entsprechen der theoretisch maximal möglichen Selbstbefruchtungsrate. Sind sie auch in Einzelfällen fragwürdig, so dürften die mit MLTR berechneten Selbstbefruchtungsraten die tatsächlichen Verhältnisse von Fremd- und Selbstbefruchtung doch weit besser wiedergeben als das Ausschlußverfahren.

\subsubsection{Ausmaß der Selbstbefruchtung}

So unterschiedlich die Verfahren zur Bestimmung von Selbstbefruchtungsanteilen auch sind, so läßt die geringe Streubreite der Ergebnisse doch eine gute Schätzung des Anteils der 
Selbstbefruchtung in der Winterlindenpopulation in Schwiegershausen zu. Individuell sind die Selbstbefruchtungsraten von Baum zu Baum sehr unterschiedlich und nehmen Werte von $0 \%$ bis $90 \%$ beim Ausschlußverfahren bzw. bei MLTR und bei EFG $2 \Delta$ Werte von $0 \%$ bis $89 \%$ an.

Im Durchschnitt der Gesamtpopulation liegt die Selbstbefruchtungsrate zwischen 38,7 \% für das Ausschlußverfahren und 30,1 \% für EFG 2 $\Delta$. Der mit MLTR berechnete Anteil an Selbstbefruchtung liegt mit 32,6 \% zwischen diesen beiden Werten. Da das Ausschlußverfahren den aufgrund der Genotypen der Samenelter und Samen maximal möglichen Anteil an Selbstbefruchtung ermittelt, ist dieser Wert als Obergrenze anzusehen, aber nicht als exakter Wert zu betrachten. Aufgrund der im vorigen Kapitel aufgeführten Argumente erscheint die mit EFG $2 \Delta$ ermittelte Selbstbefruchtungsrate von 30,1\% sicherer. Aber auch ohne eine Festlegung auf eine wahrscheinlichste durchschnittliche Selbstbefruchtungsrate ist die Aussage, der Anteil Selbstbefruchtung liege in dem engen Bereich zwischen 30,1\% und 32,6\%, bereits ein sehr befriedigendes Ergebnis.

Das Gleiche gilt dementsprechend für eine weitere Unterteilung der Gesamtpopulation in Bestandes- und Feldlinden bzw. den für diese Teilpopulationen berechneten Selbstbefruchtungsraten. Die Selbstbefruchtungsraten nach MLTR und EFG $2 \Delta$ stimmen hier nicht so gut überein, wie bei Betrachtung der Gesamtpopulation. Für die im Bestand stehenden Linden wird für das Ausschlußverfahren ein Anteil an Selbstbefruchtung von 35,8 \%, für MLTR 29,0\% und für EFG $2 \Delta$ gar nur 25,1 \% ermittelt. Für die in der Feldmark stehenden Linden sind es

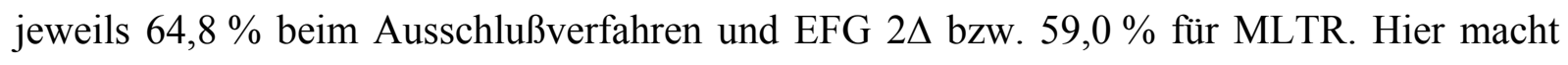
sich bemerkbar, daß EFG unter anderem die Entfernung berücksichtigt und im Vergleich zu MLTR für den Bestand niedrigere bzw. für die Feldlinden höhere Selbstbefruchtungsraten berechnet. Aber auch hier liegen die Werte überraschend nahe beieinander. Aber gerade die Ergebnisse dieser Unterteilung in Linden im Bestand und Feldlinden bestätigen die Entscheidung, den mit EFG 2 $\Delta$ berechneten Selbstbefruchtungsraten den Vorzug zu geben.

Geht man von dem mit EFG $2 \Delta$ ermittelten Wert aus, sind im Mittel der Gesamtpopulation ca. $30 \%$ aller vitalen Nachkommen auf Selbstbefruchtung zurückzuführen. Bei einem Vergleich mit zoophilen Baumarten der Tropen und Subtropen ist die Selbstbefruchtungsrate der Winterlinde als überdurchschnittlich hoch zu bewerten. Nur wenige Baumarten weisen vergleichbare oder gar höhere Selbstbefruchtungsraten auf (s. FINKELDEY 1997, loc. cit. S. 90, MORAN und Bell 1983, MurAwSKI und HAMrICK 1992). Man ist versucht, eine Selbstbefruchtungsrate von $30 \%$ in den Samen generell als hoch zu bewerten. Betrachtet man jedoch die Be- 
stäubungsökologie der Winterlinde als Ganzes, ist es erstaunlich, daß die Selbstbefruchtungsrate überhaupt so niedrig liegt. Die durchschnittliche blühende Kronenoberfläche betrug bei den näher untersuchten 54 Winterlinden gut $72 \mathrm{~m}^{2}$ (im Mittel aller 141 Linden der Population Schwiegershausen rund $59 \mathrm{~m}^{2}$ ). In Anbetracht dessen, daß schon bei krautigen Pflanzen mit nur wenigen Blüten ein hohes Ausmaß an Geitonogamie festgestellt wurde, das Ausmaß an Geitonogamie bei vielblütigen Pflanzen bis zu $90 \%$ betragen kann und Futterflüge von Bienen sich zu $99 \%$ innerhalb blühender Baumkronen abspielen (s. Kap. 2.8.5.1 und 2.8.5.3), muß das Ausmaß der Selbstbefruchtung in einer großen Lindenkrone in einem anderen Licht gesehen werden. Auch die mittlere Selbstbefruchtungsrate von $65 \%$ bei den in der Feldmark stehenden Winterlinden ist unter diesem Aspekt als erstaunlich niedrig zu bewerten, da ihre ca. $300 \mathrm{~m}^{2}$ großen Kronen ein entsprechendes Nahrungsangebot bieten und die Bäume räumlich abgegrenzt von anderen Paarungspartnern stehen. Die Feldlinde F4 z. B. hat einen Abstand zu den nächsten Paarungspartnern, den Feldlinden F2 und F3, von 360 m und zur Feldlinde F1 einen Abstand von $968 \mathrm{~m}$. Zu allen anderen im Bestand stehenden Linden beträgt die Entfernung mindestens $1268 \mathrm{~m}$. Man muß sich unter diesen Bedingungen nicht fragen, warum der Anteil Selbstbefruchtung mit $82 \%$ für die Winterlinde F4 so hoch ausfällt, sondern wie es zu $18 \%$ Fremdbefruchtung gekommen ist.

\subsubsection{Ursachen selbstbefruchteter Nachkommen}

Im Falle der in der Feldmark stehenden Winterlinde F4 sollte man annehmen, die $300 \mathrm{~m}^{2}$ große Krone stellt ein so üppiges Nahrungsangebot zur Verfügung, daß zur Deckung des Energiebedarfs eines Insekts keine zusätzliche Nahrungsressource angeflogen werden muß, zumal die anderen Nahrungsquellen mindestens $360 \mathrm{~m}$ weit entfernt stehen und deren Anflug für Insekten einen enormen Energieaufwand bedeutet. Die in Kapitel 2.8 geschilderten Untersuchungsergebnisse anderer Autoren und deren Bestätigung bzw. Ergänzung durch eigene Untersuchungen bieten gute Möglichkeiten der Erklärung dafür, daß es trotz der großen Krone der Linden zu einem beträchtlichen Umfang an Fremdbefruchtung kommt.

Prinzipiell könnte die Attraktivität einer Lindenpopulation größer nicht sein. Denn sie sichert den Reproduktionserfolg, indem sie bestäubungseffektive Insekten dazu animiert, die Linde anderen Blütenpflanzen vorzuziehen (interspezifische Konkurrenz um Pollinatoren). Eine große Attraktivität durch ein üppiges Nahrungsangebot macht auch längere Flüge ökonomisch und veranlaßt Pollinatoren, größere Entfernungen zu dieser Nahrungsquelle zurückzulegen. Der Kreis der Bestäuber wird durch flugaktive Insekten mit hohem Energieumsatz zusätzlich erweitert. Das Dilemma einer massenblühenden entomophilen Baumart wie der Linde ist je- 
doch die Gratwanderung zwischen einer zu geringen und einer zu großen Attraktivität des einzelnen Individuums (s. a. Kap. 2.8.5). Um die Fortpflanzung des Individuums zu sichern, sollte seine Attraktivität gegenüber anderen Populationsmitgliedern groß genug sein, um eine ausreichende Bestäubung durch Insekten zu sichern (intraspezifische Konkurrenz um Pollinatoren). Bietet indessen die Tracht einer einzelnen Linde ein zu üppiges Nahrungsangebot in Form von Nektar und Pollen an, wird sie zwar von vielen Insekten besucht, doch werden diese vorwiegend nur innerhalb dieser Krone Nahrung sammeln. Sie haben keinen Anreiz, Futterflüge zu den anderen Populationsmitgliedern zu unternehmen und die Folge ist eine Selbstbestäubung der Blüten, ein Ausbleiben des erwünschten Genflusses zwischen den Mitgliedern einer Population und damit Inzucht. Geitonogamie betrachtete schon EISENHUT (1957) als die häufigste Form der Paarung bei den Linden. Geitonogamie ist bei den vielblütigen Arten eine übliche Erscheinung und kommt gerade bei massenblühenden, zoophilen Baumarten häufig vor (BAWA 1974, GILL 1986). Problematisch wird es für den Reproduktionserfolg dann, wenn der Anteil der Geitonogamie im Verhältnis zur Fremdbestäubung sehr hoch wird, d. h. eine Fremdbestäubung sehr selten ist.

Geitonogamie dürfte auch bei den Linden die dominierende Bestäubungsart darstellen. Die Winterlinde bzw. die Natur verfügt über Mechanismen, die es ermöglichen, den Anteil an selbstbefruchteten Nachkommen in Grenzen zu halten bzw. einen ausreichenden Genfluß über Fremdbefruchtung zu sichern. Im Folgenden werden Mechanismen und Faktoren beschrieben, die bei der Winterlinde Selbstbestäubung verhindern oder doch erschweren (Pollentransport auf die Narbe) und die nach erfolgter Selbstbestäubung die Möglichkeit der Befruchtung durch Eigenpollen reduzieren (Inkompatibilität) und/oder die Vitalität der aus Selbstbefruchtung entstandenen Nachkommen einschränken (Inzuchtdepression).

Zu den Faktoren, die das Ausmaß der Selbstbestäubung beeinflussen, zählen generelle Faktoren, die für alle Populationsmitglieder gleich sind, und individuelle Faktoren, die in den spezifischen Eigenschaften des Individuums wie Kronengröße, Fertilität, Abstand zu Paarungspartnern usw. bestehen.

\subsubsection{Generelle Faktoren}

Für Proctor und Yeo (1973) gelten Diözie, Heterostylie und Inkompatibilität zu den effektivsten Mechanismen zur Vermeidung von Selbstbefruchtung. Die Linde verfügt weder über ein diözisches Sexualsystem noch über Heterostylie, an welcher man sporophytische Inkompatibilität unmittelbar erkennen könnte. Diözie wäre für eine typische Mischbaumart wie die Linde viel zu riskant. Dafür ist sie zu selten und zu verstreut in natürlichen Waldgesellschaf- 
ten verbreitet. Diözie würde die Anzahl der potentiellen Paarungspartner zusätzlich einschränken und damit die Entfernungen zwischen den potentiellen Paarungspartnern vergrößern. Für Hermaphroditen wie die Linde sind für LLOYD und WEBB (1986) Dichogamie und Synchronie der Blüte der Populationsmitglieder probate Mechanismen zur Vermeidung von Geitonogamie. Die Synchronie der Blüte aller Populationsmitglieder wird an den Luftbildaufnahmen der Winterlinden des Versuchsbestandes Schwiegershausen offensichtlich (s. Kap. 2.7). Zudem berichtet EISENHUT (1957) bei der Winterlinde von geringen individuellen Unterschieden der Blühtermine. Mit Protandrie verfügt die Linde über eine Form der Dichogamie (Kap. 2.6.1). Die Protandrie einer Lindenblüte ist jedoch nicht immer vollständig ausgeprägt; denn Pollen wurden noch aus den Antheren entlassen, während die Narbe schon rezeptiv war. Die räumliche Trennung von Griffel und Staubbeuteln (Herkogamie) dürfte nur bei der Vermeidung von Autogamie wirksam sein (Kap. 2.6.1). In einer blühenden Lindenkrone können alle Phasen der Anthesis beobachtet werden; eine Blühsynchronie ist für große Teile der Blüten also auch in ein und derselben Krone gegeben (Kap. 2.7). Selbstbestäubung durch Geitonogamie ist daher problemlos möglich. Ein bereits erwähntes Problem einer massenblühenden Baumart wie der Linde ist das große Nahrungsangebot, das für Insekten keinen Anreiz gibt, zu einem anderen Populationsmitglied zu wechseln. Für DE JONG et al. (1992) ist daher das Anbieten von wenig Blüten pro Individuum auf vielen Populationsmitgliedern zu einer Zeit ein Ausweg aus diesem Dilemma. Die Hauptphase der Lindenblüte kann allerdings nicht den Eindruck erwecken, es würden nur wenige Blüten zu einer Zeit blühen; die Lindenkrone gleicht einem weißen Blütenmeer. Die Winterlinde behilft sich anderer Mittel, das Nahrungsangebot nicht allzu üppig zu gestalten: In Kap. 2.6.1.3 werden die Periodizität und die räumliche Variation der Nektarproduktion und -konzentration der Linde ausführlich beschrieben. Diese Variation bedingt Folgendes: Eine hohe Attraktivität für eine Fernorientierung der Insekten ist durch eine optische Präsenz der zahlreichen Blüten gegeben, aber nur ein kleiner Teil der Blüten bietet die Nektarmenge bzw. -konzentration für die jeweilige Insektengruppe (vgl. Kap. 2.8.1). Die Insekten sammeln nur von einem relativ kleinen Anteil der Blüten Nahrung und suchen relativ schnell die nächste Nahrungsquelle auf. FRANKIE und HABER (1983) nennen auch für neotropische Baumarten eine im Tagesverlauf, innerhalb der Krone eines Baumes und zwischen Populationmitgliedern variierende Nektarproduktion und konzentration als Gründe für einen Flug der Insekten zwischen Individuen innerhalb einer Art (Kap. 2.8.5.1). Zumindest für Honigbienen, Hummeln und Fliegen wurden nicht nur eine Periodizität des Blütenbesuchs, sondern auch eine wechselnde Bevorzugung bestimmter Bereiche einer Lindenkrone beobachtet (Kap. 2.8.1). Aber auch andere Verhaltensmuster der 
Bestäuber können den Anteil der Selbstbestäubung beeinflussen: Bienen sind imstande, die Nektarmenge und -Konzentration zu riechen (HEß 1983, SEELEY 1997); sie fliegen leere Blüten nicht mehr an, indem sie besuchte Blüten mit Duft markieren (GIURFA 1992). Hummeln können pollenleere Blüten optisch erkennen und meiden diese (Kap. 2.8.5.3). Diese für die Insekten nützlichen Eigenschaften steigern durch gezieltes Anfliegen noch nicht besuchter Blüten bei der Linde die Fremdbefruchtung. Fremdbefruchtung wird auch durch die Direktionalität der Insekten bei ihren Futterflügen gefördert. Die große Anzahl der von der Linde angelockten Insekten führt zu einer intra- und interspezifische Konkurrenz der Insekten. Neben der bloßen Präsenz anderer Insekten kann auch das schneller aufgebrauchte Nahrungsangebot zu kürzeren Besuchszeiten auf einer Pflanze führen (ARROYO 1976, FrANKIE 1976, FREE 1970). Es ist somit nicht auszuschließen, daß überwiegend als Nektar- und Pollenräuber fungierende Insekten durch die interspezifische Konkurrenz bestäubungseffektive Insekten zu kurzen Besuchszeiten veranlassen und unter evolutionären Aspekten als ein Teil der Bestäubungsökologie der Linde zu sehen sind.

Zum Verhaltensmuster der Insekten muß auch die Konditionierung von Insektengruppen auf eine Pflanzenart gezählt werden (s. Kap. 2.8.5.3). Eine Konditionierung (Blütenkonstanz) der Insekten hat ANDERSON (1976) bei der Linde festgestellt und ist auch durch VON DER OHE (1993) über hohe Lindennektaranteile im Bienenhonig nachgewiesen worden (s. Kap. 2.8.1). STEPHENSON (1982) beschreibt die Wirkungsweise und Effektivität einer Konditionierung folgendermaßen: Die Anfangs- und Hauptphase der Blühperiode dient dazu, Insekten anzulocken und auf eine Nahrungssuche auf einer Baumart zu konditionieren. In der Hauptphase ist das Nahrungsangebot so groß, daß überhaupt nicht alle Blüten angeflogen werden und der Anreiz für Futterflüge zwischen Bäumen gering ist. In dieser Phase ist ein hoher Anteil an Selbstbestäubung obligatorisch. In der Endphase kommt es dann zu einem schnellen Rückgang der Blütenneubildung und zusätzlich fallen die schon bestäubten Blüten durch vorzeitige Seneszenz aus. Die Folge ist ein geringeres Nahrungsangebot eines Baumes für die mittlerweile konditionierten Insekten. Die relative kleine Zahl der verbliebenen rezeptiven Blüten wird von der noch großen Zahl der Insekten deutlich intensiver besucht und effektiver bestäubt. Das reduzierte Nahrungsangebot zwingt die Insekten vermehrt zu Futterflügen zwischen den Bäumen und fördert dadurch Fremdbefruchtung. Die von STEPHENSON (1982) erwähnte vorzeitige Seneszenz bzw. Verlust der Attraktivität der Blüten nach Bestäubung erklären BоTHA und WHITEHEAD (1992) mit einem durch die Bestäubung der Narbe induzierten Anstieg der Ethylenproduktion. HEINRICH (1975) beobachtete, daß Insekten schon bestäubte Blüten meiden. EISENHUT (1957) berichtet bei der Winterlinde von Einstellung der Nektar- 
produktion nach Degeneration des Griffels. Zudem wird die Rezeptivität der Narbe mit einer sehr breiten Spanne von 2 bis 7 Tagen angegeben (ANDERSON 1976, EISENHUT 1957). Die Vermutung liegt nahe, daß auch bei der Linde nach Bestäubung der Narbe vorzeitige Seneszenz eingeleitet wird. Diese vorzeitige Seneszenz bestäubter oder befruchteter Blüten wurde im Rahmen dieser Arbeit nicht explizit untersucht. Trotzdem ist vorzeitige Seneszenz zumindest in Form einer geringeren Attraktivität für Insekten über optische (z. B. Welke der Blütenblätter) oder olfaktorische Reize (Einstellung der Produktion des Duftstoffes Farnesol o. ä.) bzw. durch die Einstellung der Nektarproduktion nicht nur bei der Linde zu vermuten.

Als ein nicht zu unterschätzender Faktor für die Steigerung von Fremdbefruchtung muß zudem sicherlich das sog. Carry-over von Pollen durch Insekten gelten. Bei dem Besuch einer Blüte nimmt das Insekt unfreiwillig Pollen auf seinen Körper auf. Die Pollen werden beim Besuch der nächsten Blüten nicht vollständig auf diese deponiert, sondern ein Teil der Pollen wird erst bei späteren Blütenbesuchen erfolgreich auf Narben transportiert. Nachweislich konnten Pollentransporte bis zur 54. Blüte beobachtet werden (s. Kap. 2.8.5.4).

\subsubsection{Individuelle Faktoren}

Nach den Ergebnissen des Kapitels 4.7.3 spielt die Kronengröße des Samenelters eine entscheidende Rolle für die Höhe des Selbstbefruchtungsanteils in den Nachkommen. Die höchsten Selbstbefruchtungsraten wurden in den Nachkommenschaften von Linden mit besonders kleinen $\left(<32 \mathrm{~m}^{2}\right)$ und sehr großen Kronen $\left(>140 \mathrm{~m}^{2}\right)$ ermittelt; für die eingehend untersuchten 54 Winterlinden betrug die durchschnittliche Kronengröße $72 \mathrm{~m}^{2}$. Generell erhöht sich der Anteil der Selbstbefruchtung mit zunehmender Kronengröße bzw. mit zunehmendem Nahrungsangebot des Samenelters. Dieses deckt sich mit den Ergebnissen anderer Autoren (Kap. 2.8.5.1). Da alle für die Linde bestäubungsrelevanten Insekten eine ökonomisches Nahrungssucheverhalten zeigen, werden die Blüten einer Lindenkrone so lange angeflogen, wie das Nahrungsangebot lohnend ist. Erst nach Ausschöpfung des Angebotes wird die nächste Nahrungsquelle aufgesucht. Eine anhaltende Nahrungssuche innerhalb einer Krone bedingt zwangsläufig ein hohes Ausmaß an Geitonogamie und damit Selbstbefruchtung.

Ein weiterer möglicher Grund für gesteigerte Selbstbefruchtungsraten tiefbeasteter Solitärbäume wurde bereits in Kapitel 5.2.2 diskutiert. Frei stehende Bäume entwickeln Blüten bis in die untersten Kronenbereiche und die Tracht nimmt eine dreidimensionale kugelige Form an. Damit ist ein Transport von Pollen von höher auf tiefer gelegene Blüten allein aufgrund der Schwerkraft denkbar. Dies könnte auch ein Grund für die hohen Selbstbefruchtungsraten der 
in der Feldmark stehenden Linden sein, da diese eine bis zum Boden beastete Krone aufweisen.

Mit Ausnahme der kleinen Individuen (Kronengröße $<32 \mathrm{~m}^{2}$ ) zeigt sich für die im Bestand stehenden Linden, daß die Entfernung zu den nächsten Paarungspartnern keine signifikante Auswirkung auf die Selbstbefruchtungsrate hat (s. Kap. 4.7.3). Die Entfernungen zwischen den Populationsmitgliedern des Bestandes werden effektiv überbrückt und es kommt zu Fremdbefruchtung auch dann, wenn die betreffende Winterlinde $100 \mathrm{~m}$ und mehr vom nächsten Paarungspartner entfernt ist. Für die in der Feldmark stehenden Linden kann eine Isolation durch die Entfernung nicht nachgewiesen werden. Ein Vergleich der vier Feldlinden (Kronengröße ca. $300 \mathrm{~m}^{2}$ ) mit den vier größten im Bestand stehenden Linden (Kronengrößen 140 bis $280 \mathrm{~m}^{2}$ ) ergab keine Abhängigkeit der Selbstbefruchtungsrate in den Nachkommen vom Abstand des Samenelters zu den nächsten Paarungspartnern. Die Nachkommenschaften der vier im Bestand stehenden Linden weisen ebenfalls sehr hohe Selbstbefruchtungsraten auf. Entweder ist die Entfernung der Feldlinden von den anderen Paarungspartnern nicht weit genug, um eine Isolation herbeizuführen, oder die sehr großen Kronen der in der Feldmark stehenden Winterlinden überlagern den Effekt einer Isolation.

Neben den Linden mit großen Kronen zeigen auch die sehr kleinen Linden einen hohen Anteil an Selbstbefruchtung. Diese kleinen Linden scheinen für flugaktive Insekten mit hohem Energieumsatz nicht ausreichend attraktiv zu sein und werden nicht angeflogen. Bei Unterschreitung einer Kronengröße von $32 \mathrm{~m}^{2}$ ist die Attraktivität wahrscheinlich überwiegend davon abhängig, ob die Linde in einer für das Insekt energetisch adäquaten Entfernung steht. Ist eine relativ kleine Winterlinde zu weit entfernt von dem derzeitigen Aufenthaltsort des Insekts, werden attraktivere Nahrungsquellen bevorzugt. Betrachtet man nur die Winterlinden mit einer Kronengröße $<18 \mathrm{~m}^{2}$, kann keine signifikante Korrelation der Selbstbefruchtungsrate zur Kronengröße des Samenelters und Entfernung zu den nächsten Paarungspartnern festgestellt werden. Ab einer Kronengröße des Samenelters $<18 \mathrm{~m}^{2}$ ist, unabhängig vom Faktor Abstand zu den nächsten Paarungspartnern, eine hohe Selbstbefruchtungsrate zu verzeichnen. Linden mit kleinen Kronen sind für bestimmte Insektengruppen (mit hohem Energieumsatz) nicht attraktiv genug und werden nicht angeflogen. Hier kommen nur die sich schon auf dem Individuum befindlichen Insekten mit geringem Energieumsatz als Bestäuber in Betracht. Die Bestäubung sehr kleiner Winterlinden dürfte von ortsfesten Kleininsekten (Fliegen, Wanzen, Käfer) mit geringer Neigung zu Flügen zwischen Populationsmitgliedern übernommen werden. Auch eine Bestäubung über Schwerkraft bzw. Wind ist nicht auszuschließen. Beide Möglichkeiten der Bestäubung bringen einen hohen Anteil Selbstbefruchtung mit sich. 
Die Aussage, daß die Entfernung zu den nächsten Paarungspartnern keinen signifikanten Einfluß auf die Höhe der Selbstbefruchtungsraten hatte, gilt selbstverständlich nur für die gegebenen Verhältnisse der Winterlindenpopulation Schwiegershausen. Nur für die im Bestand stehenden Populationsmitglieder ist der Faktor Entfernung zum nächsten Paarungspartner (außer für die sehr kleinen Winterlinden) zu vernachlässigen. Ob die hohe Selbstbefruchtungsrate der in der Feldmark stehenden Winterlinden lediglich auf deren sehr große Kronen zurückzuführen ist und Entfernungen von knapp 370 m zum nächsten Paarungspartner nicht vielleicht doch Einfluß auf die Selbstbefruchtungsrate hatten, ist trotz schwacher nichtsignifikanter Korrelationen nur unter Vorbehalt zu sagen. Um die Faktoren Kronengröße und Entfernung zu trennen, müßte eine Vergleichbarkeit zwischen isolierten Winterlinden mit kleinen, mittleren und großen Kronen hergestellt werden. Diesen Vergleich kann der Versuchsbestand Schwiegershausen nicht bieten, da sich in der Population keine isolierten Winterlinden mit kleiner und mittlerer Kronengröße befinden. Es ist auch in Betracht zu ziehen, daß der Abstand von $370 \mathrm{~m}$ zum nächsten Paarungspartner für eine einschneidende Isolation nicht ausreichend ist und die Dichte der Winterlindenpopulation in Schwiegershausen vom kritischen Bereich eines eingeschränkten Paarungskontakts weit entfernt ist.

Auch wenn im Falle der Population Schwiegershausen keine Abhängigkeit der Selbstbefruchtungsrate von der Entfernung zu den nächsten Paarungspartnern festgestellt wurde, besteht generell bei isoliert stehenden Pflanzen die Gefahr, daß Fremdbefruchtung nur in sehr geringen Maße oder überhaupt nicht stattfindet. Eine mit abnehmender Populationsdichte zunehmende Selbstbefruchtungsrate wurde bei mehreren zoophilen Baumarten festgestellt (HARDNER et al. 1996, MURAWSKI und HAMRICK 1991, 1992). Isoliert stehende Pflanzen werden seltener besucht, das Nahrungsangebot ist kaum verbraucht und die Insekten unternehmen viele Futterflügen innerhalb dieser Pflanze (KLINKHAMMER und DE JONG 1990).

Wie bisher gezeigt wurde, besteht eine Abhängigkeit zwischen der Höhe der Selbstbefruchtungsrate und der Kronengröße des Samenelters, bei kleinen Winterlinden auch von der Entfernung zu den nächsten Paarungspartnern (Tab. 4.23, S. 130 und Tab. 4.24, S. 134). Betrachtet man nur die „neutralen“ Verfahren zur Bestimmung von Selbstbefruchtungsraten, die $a$ priori die Faktoren Entfernung und Fertilität (= Kronengröße) bei der Bestimmung wahrscheinlichster Polleneltern nicht einbeziehen, sind diese Abhängigkeiten bei den im Bestand stehenden Linden meist nur auf dem $5 \%$-Niveau signifikant. Die Selbstbefruchtungsraten vieler der diesbezüglich untersuchten 54 Winterlinden können nur teilweise über die Korrelation mit diesen Faktoren zu erklären sein, nicht aber alle. Es müssen noch weitere Faktoren existieren, die im Einzelfall das Ausmaß der Selbstbefruchtung beeinflussen. 


\subsubsection{Selbststerilität}

Trotz der Mechanismen und Faktoren, die zu einer Verringerung der Selbstbestäubung beitragen (s. o.), wird bei vielblütigen Hermaphroditen Selbstbestäubung die dominierende Art der Bestäubung sein. Kann eine Selbstbestäubung nicht verhindert werden, besteht für die Pflanze die Möglichkeit, über Inkompatibilitätsmechanismen die Befruchtung der Eizelle durch Eigenpollen zu verhindern oder doch sehr zu erschweren. Ist es trotz oder aufgrund fehlender Inkompatibilitätsmechanismen zur Befruchtung durch Eigenpollen gekommen, können in allen Phasen - von der Embryonalentwicklung bis zum reproduktionsfähigen Individuum Mechanismen der Inzuchtdepression die Vitalität der Nachkommen herabsetzen und eine Viabilitätsselektion gegen diese einleiten.

Die Wirkungsweise von Inkompatibilität und Inzuchtdepression sowie Beispiele von Selbsterilität in der Familie der Tiliaceaen und bei anderen Baumarten sind in Kapitel 2.9 nachzulesen.

\subsection{Inkompatibilität}

PigotT und Huntley (1981) haben die Pollenkeimung von Eigen- und Fremdpollen auf den Narben verglichen. Nach den Ergebnisse ihrer Untersuchungen erscheint die Existenz einer sporophytischen Inkompatibilität bei der Winterlinde als sehr wahrscheinlich. Die Ausprägung dieser sporophytischen Inkompatibilität war von Winterlinde zu Winterlinde sehr verschieden und variierte von einer vollständigen Selbstinkompatibilität bis zu einer völligen Selbstkompatibilität des Eigenpollens (Kap. 2.9.1.1).

Weitere Untersuchungen von PigOTT und HunTLEY (1981) über das Pollenschlauchwachstum zeigten die Keimung von Eigenpollen auf der Narbe und eine, im Vergleich zu Fremdpollen deutlich langsameres Pollenschlauchwachstum von Eigenpollen (Kap. 2.9.1.2). Diese Ergebnisse deuten auf die Existenz einer gametophytischen Inkompatibilität bei der Winterlinde hin. Die Untersuchungsergebnisse von PIGOTT und HuNTLEY (1981) sind allerdings statistisch nicht gesichert und bedürfen einer weiteren Überprüfung. Nach HESLOP-HARRISON und SHIVANNA (1977) sowie eigenen Beobachtungen ist die Narbe der Linde dem trockenen Narbentyp zuzuordnen. Nach HESLOP-HARRISON (1975) arbeiten alle sporophytischen Inkompatibilitätssysteme mit dem trockenen Narbentyp. Ist dieses auch bei der Linde der Fall, wäre eine sporophytische Inkompatibilität zu bestätigen, eine gametophytische Inkompatibilität zu verwerfen. Allerdings wurde bei verschiedenen Arten die Aktivität sowohl eines sporophytischen als auch eines gametophytischen Inkompatibilitätssystems beobachtet (STEINER 1992). 


\subsection{Inzuchtdepression}

Die bezüglich des Reproduktionssystems der Winterlinde bisher veröffentlichten Arbeiten hatten nicht zum Ziel, die Existenz von Inzuchtdepression bei der Winterlinde nachzuweisen. Trotzdem kann aus den Ergebnissen mehrerer Untersuchungen nur gefolgert werden, daß die Winterlinde über Mechanismen der Inzuchtdepression verfügen muß (Kap. 2.9.2 und 2.10). Nach EISENHUT (1957) sowie PigOtT und HuntLey (1981) besitzt die Linde zehn entwicklungsfähige Samenanlagen. Daß sich in der Regel nur ein und maximal drei Samen pro Fruchtknoten entwickeln, wird auf die starke physiologische Konkurrenz innerhalb des Fruchtknotens zurückgeführt (EISENHUT 1957), die bei der selbstfertilen Winterlinde in einem frühen Stadium effektive Selektion gegen inzuchtdepressive Samen einleitet.

Anhand der Ergebnisse der Bestäubungsversuche (Kap. 4.4) ist keine Unterscheidung zwischen Inkompatibilität und früher Inzuchtdepression möglich. Ob ein vorzeitiger Abwurf von Samenanlagen auf mangelnde Befruchtung durch Inkompatibilitätsmechanismen oder auf eine frühe Inzuchtdepression gegen Embryonen zurückzuführen ist, wurde nicht geklärt. Die Ergebnisse der Bestäubungsversuche zeigen jedenfalls einen vorzeitigen Abwurf selbstbestäubter Blüten. Von Anbeginn der Beobachtungen ist die Reduktion selbstbestäubter Blüten hoch signifikant stärker als bei unbestäubten und fremdbestäubten Blüten und läßt nur die Schlußfolgerung von Inkompatibilität und/oder früher Inzuchtdepression bei der Winterlinde $\mathrm{zu}$.

Auch über die Keimungsversuche (Kap. 4.5) war Inzuchtdepression nachzweisen. Nachkommenschaften mit hohen Selbstbefruchtungsraten wiesen hoch signifikant niedrigere Keimprozente auf, als Nachkommenschaften mit niedrigeren Selbstbefruchtungsraten. Daß nicht zufallsmäßig, sondern gegen selbstbefruchtete Nachkommen selektiert wurde, zeigen die im Vergleich zu den Samen signifikant geringeren Selbstbefruchtungsraten in den Jungpflanzen (Tab. 4.14. S. 113). Daß Inzuchtdepression mit Selektion gegen bestimmte Allele verbunden sei, wurde nicht festgestellt. Die hier untersuchten Genorte scheinen diesbezüglich keine adaptive Funktion zu besitzen mit entsprechenden Genorten gekoppelt zu sein.

Im Gegensatz zur Winterlinde stellte ANDERSON (1976) bei der Sommerlinde keine Selbstfertilität fest. Die Winterlinde reicht in ihrem Verbreitungsgebiet viel weiter in den Norden und in den Westen Europas. Die Sommer sind in diesen Randgebieten ihrer natürlichen Verbreitung kühler und stehen unter maritimem Einfluß. Die Bestäubung durch Insekten ist in nassen und kühlen Sommern nicht immer gewährleistet bzw. nur unvollkommen (s. Kap. 2.8.3.6). Bei ungünstiger Witterung kann es zu einem verringerten Transport von Pollen zwischen den 
Individuen, also zu geringeren Anteilen an Fremdbefruchtung, kommen. Inkompatibilitätsmechanismen gegen Eigenpollen bzw. Selektion gegen aus Selbstbefruchtung entstandene Samen greifen aufgrund der nicht vorhandenen Konkurrenz durch Fremdpollen bzw. durch fremdbefruchtete Samen nicht. Der Mangel an Konkurrenzdruck beginnt sich beim Pollenschlauchwachstum bemerkbar zu machen und setzt sich bei der Entwicklung der Samen im Fruchtknoten bis hin zur Reproduktionsphase fort. So können sich bei ungünstigen klimatischen Gegebenheiten auch die aus Selbstbefruchtung hervorgegangenen Samen etablieren und zum Erhalt einer Population beitragen. Es stellt die von vielen Autoren schon für andere Arten beschriebene Versicherung in gegen den durch ungenügende Fremdbefruchtung ausgelösten Notfall dar (Kap. 2.9).

Die Sommerlinde hingegen ist (vielleicht aufgrund ihrer Selbststerilität!) in kontinentaler geprägten und südlicheren Teilen Europas mit konstanteren und wärmeren Sommern verbreitet, die für ausreichende Fremdbestäubung durch Insekten sorgen. Inkompatibilitätsmechanismen gegen Selbstbefruchtung sind bei ihr stärker ausgeprägt als bei der Winterlinde, da eine witterungsbedingte Fremdpollenlimitation über einen längeren Zeitraum unwahrscheinlich ist. Die Sommerlinde kann sich sozusagen den Verzicht auf die oben erwähnte Versicherung leisten; denn ihr Reproduktionssystem ist nicht auf Nachkommen aus Selbstbefruchtung angewiesen. Dabei ist zu vermuten, daß die Sommerlinde über starke Inkompatibilitätsmechanismen verfügt, die Eigenpollen nicht zu einer Befruchtung kommen lassen. Wird Eigenpollen gar nicht erst erfolgreich, brauchen Mechanismen der Inzuchtdepression nicht so stark ausgeprägt zu sein; denn es hat bereits eine intensive Selektion stattgefunden. Ein Hinweis für die Richtigkeit dieser Theorie ist die Tatsache, daß die Sommerlinde deutlich häufiger mehrsamige Früchte bildet, die zudem bis zu fünf Samen enthalten können. Sie scheint im Gegensatz zur Winterlinde aufgrund ihres nicht (oder deshalb nicht!) so weit in die maritimen Klimate reichenden Verbreitungsgebietes nicht in dem Maße auf Selbstbefruchtung angewiesen zu sein, da Fremdbefruchtung durch Insekten gesichert ist. Ein weiterer Hinweis könnten die bei der Winterlinde aufrecht gerichteten Blütenstände sein, welche in Notfallsituationen der Bestäubung über Wind bzw. Schwerkraft entgegenkommen. Die Sommerlinden verfügen hingegen über hängende Blütenstände.

\section{Schlußfolgerungen}

Wie bei allen massenblühenden, hermaphroditen Baumarten findet auch bei der Winterlinde der überwiegende Teil der Futterflüge der Insekten innerhalb einer Krone statt und führt zu Selbstbestäubung der Blüten. Zwar wird Autogamie durch Protandrie und Herkogamie weitgehend vermieden, Geitonogamie kann jedoch über die Anthesis bzw. 
Blütenmorphologie nicht verhindert werden. Im Laufe der Evolution haben sich bei der Winterlinde Strategien entwickelt, die den Genfluß durch einen nennenswerten Anteil an Fremdbestäubung sichern sollen. Als wichtigste Faktoren, die zu einer Aufrechterhaltung des Genflusses durch Pollen beitragen, wären die weitgehende Synchronie der Blüte aller Populationsmitglieder, eine im Tagesverlauf variierende Nektarproduktion und -konzentration, die Konditionierung der Insekten auf die Tracht der Winterlinde und verschiedene Verhaltensmuster der Insekten zu nennen. Stark erhöhte Selbstbestäubung ist bei Winterlinden mit großen Kronen nachgewiesen und bei räumlicher Isolation anzunehmen.

Selbst unter günstigen Verhältnissen und voller Wirkungsweise oben genannter Faktoren ist ein relativ großer Anteil an Selbstbestäubung zu erwarten. Um die Befruchtung durch die auf die Narbe gelangten Eigenpollen zu erschweren, verfügt die Linde offensichtlich über wirksame Inkompatibilitätsmechanismen ${ }^{3}$. Die Existenz sporophytischer Inkompatibilität bei der Winterlinde ist wahrscheinlich, die Existenz gametophytischer Inkompatibilität ist ebenfalls möglich. Nur ein Teil der Eigenpollen wird durch diese Inkompatibilitätsmechanismen zugunsten von Fremdpollen selektiert. In dieser Phase, also nach erfolgreicher Befruchtung der Eizelle durch Eigenpollen, kann bei der Winterlinde Inzuchtdepression in Erscheinung treten. Im Beobachtungszeitraum von der Samenreife bis zur 4-jährigen Jungpflanze war in Bestäubungs- und Keimungsversuchen wirkungsvolle Selektion gegen selbstbefruchtete Nachkommen festzustellen. Demnach verfügt die Linde, zumindest in frühen ontogenetischen Stadien, auch über Mechanismen der Inzuchtdepression.

\subsection{Genfluß durch Pollen}

Geht man von der Annahme aus, daß Pollen durch einen beliebigen Vektor überhaupt erfolgreich transportiert werden, dann geht es um die triviale wie entscheidende Frage, über welche Entfernung der Pollentransport erfolgt. Dies ist für die Erhaltung einer Art insofern entscheidend, als geringe Pollentransportweiten die Anzahl der potentiellen Paarungspartner generell einschränken oder speziell bei einer monözischen Baumart zu Selbstbefruchtung (Autogamie

\footnotetext{
${ }^{3}$ Es ist zu beachten, daß der Begriff Eigenpollen als Synonym für Pollen gebraucht wird, welche im Falle von Inkompatibilität über Inkompatibilitätsallele bzw. im Falle von Inzuchtdepression über rezessive Letalallele verfügen, die Sterilitätsmechanismen induzieren. Diese Allele können auch in Fremdpollen vorhanden sein. Die Wahrscheinlichkeit einer wirkungsvollen Kombination dieser Allele ist jedoch nach Selbstbefruchtung am größten (s. Kap. 2.9.1 und 2.9.2).
} 
und Geitonogamie) führen. Bei der Linde ist Transport effektiver Pollen über größere Distanzen besonders wichtig. Zum einen können in großen Lindenkronen selbst Pollentransporte über mehrere Meter noch zu einer Befruchtung der eigenen Blüten führen, zum anderen erfordert die zerstreute Verteilung dieser Mischbaumart im Bestand große Pollentransportweiten, um den Paarungskontakt aufrecht zu erhalten.

\subsubsection{Bestimmung von Pollentransportweiten über Polleneltern}

Voraussetzung für die Herleitung von Pollentransportweiten ist die vorherige Bestimmung von Polleneltern (Kap. 3.11). Die in Kapitel 5.4 und 5.5.1 für oder gegen die verschiedenen Pollenelterbestimmungsverfahren geäußerten Argumente gelten ohne Ausnahme auch für dieses Kapitel. Auf den Einfluß unterschiedlicher Kombinationen von Eingabeparametern bei CERVUS wurde in Kapitel 5.4.2 gesondert eingegangen: Je nach Wahl der Eingabeparameter sind über die unterschiedlichen wahrscheinlichsten Polleneltern auch sehr unterschiedliche Pollentransportweiten ermittelt worden.

Die Effizienz der Bestimmung von Polleneltern ist wie im Zusammenhang mit Selbstbefruchtungsraten auch für die Herleitung von Pollentransportweiten ein entscheidendes Kriterium. Bei der Berechnung durchschnittlicher Pollentransportweiten für die Nachkommenschaften der einzelnen Winterlinden zeigte sich, daß nicht selten keine oder nur wenige Polleneltern und damit Pollentransportweiten bestimmt werden konnten (Tab. 4.30, S. 146). Können nur wenige Pollentransportweiten ermittelt werden, stellt sich die Frage nach der Repräsentativität für die gesamte Nachkommenschaft eines Baumes. Anhand der Winterlinde F4 sollen die von Verfahren zu Verfahren häufig sehr abweichenden druchschnittlichen Pollentransportweiten näher betrachtet werden (Tab. 4.30). Für die 103 untersuchten Nachkommen der Winterlinde F4 konnten mit dem eindeutigen Ausschlußverfahren zwei, mit EFG $2 \Delta 92$ und mit CERVUS 25 Polleneltern bestimmt werden. Die beiden über das eindeutige Ausschlußverfahren bestimmten Polleneltern standen im Durchschnitt 1548,9 m, die 92 mit EFG $2 \Delta$ bestimmten Polleneltern 74,2 $\mathrm{m}$ und die 25 von CERVUS ermittelten 249,4 m von der Winterlinde F4 entfernt. Für diese Linde wurde eine Selbstbefruchtungsrate von $82 \%$ berechnet (Tab. 4.20, S. 126). Mit dem eindeutigen Ausschlußverfahren konnte aufgrund von deren Genotyp aber nur für zwei fremdbefruchtete Nachkommen ein eindeutiger Pollenelter bestimmt werden; daraus resultiert die sehr hohe durchschnittliche Pollentransportweite von 1548,9 m. Dieser Wert dürfte kaum die Transportweite der Pollen repräsentieren, die zu einer Befruchtung der restlichen Nachkommen geführt haben. Eine hohe Effizienz bei der Bestimmung von Polleneltern trägt demnach zur Güte der hergeleiteten mittleren Pollentransportweiten bei. Eine hohe 
Effizienz zeigte nur das Verfahren EFG 2 $\Delta$. Im Falle der Winterlindenpopulation Schwiegershausen gelang es nur mit diesem Verfahren für den Großteil (56\%) der untersuchten Nachkommen Pollenelter zu bestimmen (Tab. 4.15, S. 114).

Bei der Bestimmung von Polleneltern ist neben der Quantität auch die Qualität entscheidend. Unter Qualität ist die Plausibilität der den Nachkommen zugewiesenen Polleneltern zu verstehen. Für das eindeutige Ausschlußverfahren stellt sich die Frage der Plausibilität nur bedingt: hiermit werden nur diejenigen Polleneltern bestimmt, die aufgrund ihrer Genotypen als einzige Polleneltern in Betracht kommen. Es wird nicht aus einer Auswahl von mehreren Pollenelter der wahrscheinlichste ermittelt, wie es bei EFG und CERVUS der Fall ist. Zudem ist das Ausschlußverfahren mit sehr wenigen Annahmen belastet und die Sicherheit bei der Bestimmung von Polleneltern kann daher als groß angesehen werden. Das Manko des eindeutigen Ausschlußverfahrens ist aber die geringe Effizienz bei der Identifizierung von Polleneltern mit der oben erwähnten schlechten Repräsentativität der wenigen identifizierten Polleneltern für die Gesamtheit der Nachkommen. Bezüglich der Qualität werden demnach nur die Verfahren EFG $2 \Delta$ und CERVUS überprüft und verglichen.

Bei einer näheren Betrachtung der den Samen mit CERVUS zugeordneten Polleneltern gibt es zahlreiche Fälle, die einer Überprüfung auf Plausibilität nicht standhalten. Ein Beispiel: Für einen bestimmten Nachkommen kamen aufgrund ihrer Genotypen mehrere Winterlinden als Polleneltern in Betracht. Über die in Kapitel 3.9.2.2 beschriebenen Simulationen bestimmte CERVUS unter den möglichen Winterlinden die Winterlinde Nr. 3 als wahrscheinlichsten Pollenelter. Bei genauerer Betrachtung zeigt sich, daß die unterständige Winterlinde Nr. 3 mit $4 \mathrm{~m}^{2}$ eine der kleinsten Kronen aller 138 Winterlinden besitzt und in einer Entfernung von $800 \mathrm{~m}$ zum Samenelter steht. Direkt um den Samenelter herum stehen mehrere üppig blühende Winterlinden, die aufgrund ihrer Genotypen auch zum Kreis der möglichen Polleneltern gehören. Nur aufgrund der Genotypstukturen wurde die Winterlinde Nr. 3 und damit eine Pollentransportweite von $800 \mathrm{~m}$ bestimmt. Daß dieses Beispiel keinen Einzelfall darstellt und über CERVUS die größten Pollentransportweiten aller Verfahren hergeleitet werden, zeigen die Verteilungen der Pollentransportweiten (Abb. 4.26, S. 147 und Abb. 4.27, S. 148) und die durchschnittlichen Pollentransportweiten auf der Ebene der Population und der Einzelbäume (Tab. 4.28 - Tab. 4.30). Zudem werden für die mit CERVUS bestimmten Pollentransportweiten auch die mit Abstand niedrigsten und nicht signifikanten Bestimmtheitsmaße $\left(\mathrm{r}^{2}\right)$ aller Pollenelterbestimmungsverfahren bei der Korrelation zwischen Pollentransportweite und Abstand zu den nächsten Paarungspartnern berechnet (Tab. 4.31, S. 149 (ohne Feldlinden)). Wie der Literatur und den Ergebnissen dieser Arbeit zu entnehmen ist, sind die Pollentransport- 
weiten nach Fremdbefruchtung u. a. von der Populationsdichte abhängig (s. Kap. 2.8.5.2 und 4.8.5). Das heißt, je größer die Abstände zwischen den Populationsmitgliedern sind, desto weiter müssen Fremdpollen transportiert werden, um im Sinne einer Befruchtung effektiv zu werden. Diese Abhängigkeit ist scheinbar trivial: Befindet sich ein Individuum vom nächsten Paarungspartner $100 \mathrm{~m}$ entfernt, kann es nicht von Fremdpollen befruchtet werden, wenn dieser nur 50 m weit transportiert wird. Für isoliert stehende Bäume können für Fremdbefruchtung keine geringeren Pollentransportweiten gemessen werden, als deren Entfernungen zu den nächsten Paarungspartnern sind. Unter diesem Aspekt ist zu erwarten, daß für Nachkommenschaften dicht stehender Populationsmitglieder geringere Pollentransportweiten ermittelt werden, als für verstreut oder isoliert stehende. Diese Abhängigkeit ist dann nicht gegeben, wenn nicht die nächsten, sondern überwiegend weiter entfernt stehende Paarungspartner als Polleneltern fungieren.

Im Falle der mit CERVUS ermittelten durchschnittlichen Pollentransportweiten konnte keine signifikante Korrelation mit der Dichte der im Bestand stehenden Winterlinden festgestellt werden. Für das eindeutige Ausschlußverfahren waren die Bestimmtheitsmaße um ein Vielfaches höher auch signifikant ${ }^{4}$ (Tab. 4.31 (ohne Feldlinden)). Nach dem Stand der Forschung und aufgrund der eigenen Ergebnisse nimmt die Wahrscheinlichkeit einer Pollenelterschaft mit zunehmender Entfernung vom Samenelter ab; daher sind die Ergebnisse der Pollenelterbestimmung mit CERVUS fragwürdig. Dies widerspricht nicht der in Kapitel 4.7.3 gemachten Aussage, daß die Entfernungen zwischen den Winterlinden im Bestand grundsätzlich ohne Probleme überbrückt werden (da keine Abhängigkeit zwischen der Selbstbefruchtungsrate und dem Abstand zu den nächsten Nachbarn festgestellt wurde). Damit ist der Transport zwischen benachbarten Paarungspartnern gemeint und es darf darunter nicht verstanden werden, daß, wie von CERVUS ermittelt, die Pollen in aller Regelmäßigkeit über viele andere potentielle Polleneltern hinweg zum Samenelter transportiert werden. Zudem beziehen sich alle Korrelationen auch auf den Abstand zu den nächsten 10 Paarungspartnern, daher ist schon eine größere Nachbarschaft um den Samenelter herum involviert. Somit kann das Programm CERVUS sowohl bezüglich der Effizienz (Kap. 5.4.2) als auch der Qualität (Plausibilität) der ermittelten Polleneltern nicht überzeugen. Die Bestimmung eines wahrscheinlichsten Pollenelters aus mehreren potentiellen Polleneltern nur über den Genotyp ist unsicher, zumal von einer einheitlichen Fertilität der Polleneltern und einer einheitlichen Pollenwolke ausgegangen

\footnotetext{
${ }^{4}$ Bei dem Verfahren EFG wird die Entfernung des Pollenelters zum Samenelter berücksichtigt. Die bei EFG berechneten hochsignifikanten Korrelationen zwischen der Dichte des Bestandes und der Entfernung zu den nächsten Nachbarn sind daher wegen der Abhängigkeit der Variablen nur bedingt vergleichbar.
} 
wird. Beides ist aber nur in den seltensten Fällen gegeben und gerade in der in vorliegenden Winterlindenpopulation ist das Gegenteil der Fall: Die individuellen Pollenwolken waren in der Blühperiode des Jahres 1995 sehr unterschiedlich und die Pollenwolke für den Gesamtbestand nicht einheitlich. Auch bleibt bei CERVUS die Entfernung zwischen Sameneltern und Polleneltern unberücksichtigt.

Die Einbeziehung der Faktoren Entfernung und Fertilität ist sinnvoll und bedeutet einen großen Vorteil von EFG 2 $\Delta$. Durch die Einbeziehung der Faktoren Entfernung und Fertilität wird a priori eine Wahrscheinlichkeit berechnet, die zusammen mit den Genotypstrukturen zu einer plausiblen Bestimmung des Pollenelters führt. Durch die hohe Effizienz des Verfahrens konnte mit EFG $2 \Delta$ für $56 \%$ der 3864 Samen ein Pollenelter bestimmt werden und es ist daher sowohl gegenüber dem eindeutigen Ausschlußverfahren und als auch gegenüber CERVUS eine weitaus bessere Repräsentation der Population bzw. der Nachkommen gegeben. Es steht außer Frage, daß EFG ein grobes Modell darstellt, welches sicherlich in vielen Punkten noch verbesserungsfähig ist. Dennoch sind die von EFG gelieferten Pollentransportweiten plausibel und vertrauenswürdig. Nicht geklärt ist, inwieweit durch die a priori getroffenen Annahmen die Pollentransportweiten mit EFG unterschätzt werden. Vorteilhaft ist jedenfalls, daß im Vergleich zum eindeutigen Ausschlußverfahren und zu CERVUS zumindest keine Überschätzung der Pollentransportweiten zu erwarten ist.

Schlußfolgerungen

Entscheidend für die repräsentative Bestimmung von Polleneltern und damit von Pollentransportweiten ist die ausreichende Effizienz der Verfahren bei der Bestimmung von Polleneltern. Ausreichende Effizienz wird nur mit dem Verfahren EFG $2 \Delta$ erreicht. Bezüglich der Plausibilität bei der Bestimmung der Polleneltern kann CERVUS nicht überzeugen. Im Vergleich zu dem eindeutigen Ausschlußverfahren und zu EFG $2 \Delta$ werden über CERVUS durchweg größere durchschnittliche Pollentransportweiten hergeleitet. Die von CERVUS bestimmten Polleneltern weisen häufig eine Kombination aus einer geringen Fertilität und einer großen Entfernung zum Samenelter auf.

Sind Informationen über die Fertilität des Pollenelters und/oder über die Entfernung zum Samenelter vorhanden, sollte das Verfahren EFG eingesetzt werden. Liegen nur Informationen über Genotypen vor, sollten die wenigen, aber dafür verläßlichen Informationen des eindeutigen Ausschlußverfahrens zu verwendet werden, da die Ergebnisse der Pollenelterbestimmung über CERVUS fraglich sind. 


\subsubsection{Ausmaß und Faktoren des Genflusses}

Da das Verfahren EFG 2 $\Delta$ am geeignetsten für die Herleitung von Pollentransportweiten erscheint, werden nur die über dieses Verfahren ermittelten Transportweiten diskutiert (Kap. 5.6.1).

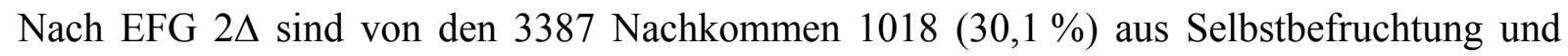
2369 (69,9\%) aus Fremdbefruchtung entstanden (Tab. 4.16 bzw. Tab. 4.17). Für 2163 der insgesamt 3387 bzw. für 1145 der 2369 fremdbefruchteten Nachkommen konnte über EFG $2 \Delta$ ein Pollenelter bestimmt und über diesen eine Pollentransportweite hergeleitet werden. Die maximale Pollentransportweite beläuft sich auf 1666,4 m, die durchschnittliche Transportweite auf 79,8 m (inkl. Selbstbefruchtung) bzw. 148,2 m nach Fremdbefruchtung (Tab. 4.28 und Tab. 4.29). Knapp 70\% der Samen sind demnach durch Pollen befruchtet worden, welche durchschnittlich über eine Entfernung von 148,2 m transportiert wurden. Durch diese hohen mittleren Pollentransportweiten ist erklärbar, warum in Kapitel 4.7.3 keine signifikante Abhängigkeit zwischen der Selbstbefruchtungsrate und dem Abstand des Samenelters zu den nächsten Paarungspartnern festgestellt wurde.

Welche Faktoren bzw. Mechanismen dazu führen, daß Pollen zwischen Populationsmitgliedern transportiert und erfolgreich werden, ist in Kapitel 5.5.3 geschildert worden. Daß ein effektiver Pollentransport nicht nur zwischen direkt benachbarten Winterlinden stattfindet, zeigen die gemessenen Pollentransportweiten. Auch findet ein effektiver Pollentransport über den nächststehenden Paarungspartner hinweg zu weiter entfernt stehenden Paarungspartnern relativ häufig statt. Dies zeigt sich u. a. darin, daß für das eindeutige Ausschlußverfahren eine signifikante Abhängigkeit der Transportweite der Pollen von der Dichte der Population für den Abstand des Samenelters zu den nächsten zehn Paarungspartnern am größten ist. Diese Abhängigkeit ist bei Betrachtung des nächsten Paarungspartners bzw. der nächsten fünf Paarungspartner nicht so stark ausgeprägt (Tab. 4.31, S. 149 (ohne Feldlinden)). Die Weite des Pollentransports wird möglicherweise neben der Populationsdichte auch von anderen Faktoren beeinflußt. Generell sind viele der in Kapitel 5.5.3 aufgezählten Faktoren und Mechanismen auch zur Klärung großer Pollentransportweiten geeignet. Warum die Pollentransportweiten teilweise größer sind als die Abstände der Polleneltern zu ihrem nächsten Nachbar, soll hier nur noch ergänzt bzw. vertieft werden: 
Bei der Konditionierung von Insekten auf eine Nahrungsquelle (Kap. 2.8.3.7) ist in der Endphase der Blühperiode eine drastische Reduktion des Nahrungsangebotes zu vermuten. Das Nahrungsangebot der einzelnen Winterlinden könnte aufgrund unterschiedlicher Kronengröße, Nektarproduktion, Besucherfrequenz etc. unterschiedlich schnell erschöpft sein. Winterlinden ohne attraktives Nahrungsangebot werden in dieser Phase von den Insekten nicht mehr angeflogen, obwohl sie sich in direkter Nachbarschaft des betreffenden Baumes befinden. Dazu fügt sich nahtlos die Beobachtung an, daß generell bei Futterflügen entfernt gelegene, große Nahrungsquellen direkt angeflogen, kleinere Nahrungsquellen hingegen überflogen werden (HEINRICH 1975).

Die Direktionalität der Insekten auf ihren Futterflügen kann auch dazu führen, daß nicht die nächststehenden Winterlinden angeflogen werden, sondern die Linden, die sich als erste in der Orientierungsrichtung der Insekten befinden. Bienen orientieren sich optisch an der Sonne oder an Landmarken, Hummeln und Motten fliegen gegen die Windrichtung (Kap. 2.8.5.3). Diese Direktionalität erhöht generell die Pollentransportweite, da diese Insekten die Pollen nur in eine Richtung und nicht hin und her transportieren.

Die große Attraktivität der Tracht einer Lindenpopulation lockt viele flugaktive Insekten auch aus großer Entfernung an. SEELEY (1997) konnte Sammelbienen in einer Entfernung von 14 km vom Stock nachweisen und er vermutet noch größere Flugweiten. Große Entfernungen werden nicht ohne zwischenzeitliche Energieaufnahme überbrückt. Vereinzelte Linden, die sich zwischen der eigentlichen Population und dem Stock befinden, dürften einen sog. Stepping-stone darstellen und regelmäßig auf Hin- und Rückflug angeflogen werden. Da zum Zeitpunkt der Lindenblüte keine anderen nennenswerten Nahrungsquellen existieren, dürfte dieser Effekt nicht zu unterschätzen sein. Dies könnte auch die Fremdbefruchtung bei den in der Feldmark stehenden Winterlinden erklären.

CHASE et al. (1996) stellten bei ihren Untersuchungen bei Motten ein nicht nach rein ökonomischen Gesichtspunkten geprägtes Nahrungssucheverhalten fest (Kap. 2.8.6). Sollten die die Linde besuchenden Mottenarten ein ähnliches Verhalten zeigen, wären durch sie größere Pollentransportweiten vorstellbar.

Eine Klumpung verwandter Individuen durch eine geringe Verbreitung der Samen oder sogar eine Klonbildung durch Wurzelbrut ist bei der Linde anzunehmen bzw. auch im Bestand Schwiegershausen festgestellt worden (Kap. 4.2). Ein kleinräumiger Pollentransport auf den nächsten Paarungspartner hieße eine Bestäubung verwandter Winterlinden. Durch die bei der Winterlinde effizienten Sterilitätsmechanismen (s. Kap. 5.5.3.3) wird gegen diese Pollen 
selektiert. In diesem Fall würden Pollen von weiter entfernten, nicht verwandten, Individuen erfolgreicher sein.

Als bedeutendster Faktor für große Pollentransportweiten ist das sog. Carry-over von Pollen anzusehen (Kap. 2.8.5.4). Gerade bei einer Pollenübertragung im Stock sozial lebender Insekten (Bienen, Hummeln) sind enorme Pollentransportweiten denkbar. Durch Wind wird Pollen nur in geringem Umfang und nur kleinräumig verfrachtet; Anemophilie als Ursache für große Pollentransportweiten ist nicht sehr wahrscheinlich.

\section{Schlußfolgerungen}

Der Genfluß der Winterlinde durch Pollen muß im Beobachtungsjahr 1995 als sehr effektiv beurteilt werden. Die Bestäubungsökologie der Winterlinde ist, zumindest bezüglich des Pollentransports, sehr gut an das verstreute Vorkommen als Mischbaumart angepaßt. Die Pollentransportweiten sind u. a. von der Populationsdichte abhängig. Je zerstreuter die Population, je größer sind die nachgewiesenen Pollentransportweiten. Die Abhängigkeit der Pollentransportweite von der Populationsdichte ist nur auf geringem Niveau signifikant. Die Weite des Pollentransports wird auch von anderen Faktoren beeinflußt werden. Von mehreren möglichen Faktoren kann sicherlich das Carry-over von Pollen herausgehoben werden.

\subsection{Reproduktion}

Über die Bestäubungsversuche kann asexuelle Reproduktion in Form von Apomixie bei der Winterlinde ausgeschlossen werden (Kap. 4.4). Asexuelle Reproduktion über Stockausschlag und Wurzelbrut ist bei der Linde hingegen ausgeprägt und Populationen können auch ohne sexuelle Fortpflanzung über Jahrhunderte fortbestehen (Kap. 2.3).

Bleiben die Samenanlagen unbefruchtet, werden kleine, hohle Samen gebildet (Parthenokarpie). Wird in frühen Phasen der Embryonalentwicklung Inzuchtdepression wirksam, werden Samen gebildet, die keinen oder nur einen verkümmerten Embryo enthalten. Äußerlich sind diese Samen nur schwer von normal entwickelten Samen zu unterscheiden

\subsubsection{Reproduktionserfolg}

Viele Untersuchungen sprechen von einem geringen Reproduktionserfolg der Winterlinde. Die Reproduktion der Winterlinde ist geprägt von einem vorzeitigen Abwurf des Samenansatzes, hohen Hohlkornanteilen und geringen Keimprozenten. Dabei schwankt der Reproduktionserfolg von Individuum zu Individuum und von Jahr zu Jahr erheblich (s. Kap. 2.10 und 
4.9). Die im Rahmen dieser Arbeit durchgeführten Bestäubungs- und Keimungsversuche sowie die Untersuchung zahlreicher Nachkommenschaften bestätigen im Großen und Ganzen die Beobachtungen anderer Autoren. Dabei waren die Hohlkornanteile in den Nachkommenschaften der einzelnen Winterlinden individuell sehr unterschiedlich. Der Anteil an Hohlkörnern variierte von $3 \%$ bis zum Neunfachen der Anzahl vitaler Samen (Tab. 4.26, S. 138).

Im Zuge der im Rahmen dieser Arbeit durchgeführten Bestäubungsversuche entwickelten sich unter natürlichen Bedingungen (freie Abblüte) ca. 3,4 \% der untersuchten Blüten zu vitalen Samen. Da mittels künstlicher Bestäubung bei der Winterlinde jedoch Werte von 4,9\% und 6,6 \% an einem Ast ermitteln wurden, kann bei der Winterlinde zumindest für einen Blütenstand bzw. für einen Ast ein Samenansatz von 3,4 \% nicht als physiologische Obergrenze der Fruchtbildung angesehen werden (Kap. 4.4). Dabei ist zu erwähnen, daß diese 3,4 \%ige Samenbildung optisch den Eindruck eines üppigen Samenansatzes machte. KLEIN (1992) berechnete, daß durch die hohe Produktion an Samen selbst bei 80 \%igem Hohlkornanteil sexuelle Reproduktion der Winterlinden gesichert sei. Offensichtlich produziert die Winterlinde weit mehr Blüten, als lebensfähige Samen aus ihnen entstehen.

Für massenblühende, entomophile Baumarten scheint der Umfang der Samenbildung in diesen Bereichen zu liegen. Einen fast identischen Wert ermittelten TANGMITCHAROEN und OWENS (1997) bei Teak, wo es bei 3,5 \% der Blüten zu einer Samenbildung kam.

\subsubsection{Ursachen des Reproduktionserfolgs}

Es stellt sich die Frage, warum der reichlichen Tracht der Linde ein geringer Reproduktionserfolg in Form vitaler Nachkommen gegenübersteht und warum der Reproduktionserfolg individuell und jährlich großer Variation unterliegt.

Für effektiven Genfluß ist die Winterlinde auf den Transport von Pollen durch Insekten angewiesen. Intensiver Insektenbesuch kann nur durch eine ausreichende Attraktivität der Lindentracht gewährleistet werden. Als typischer Generalist ist die Linde auf keine Insektengruppe spezialisiert und verfügt über ein breites Spektrum an effektiven Attraktionen. Eine weitgehende Synchronie der Blüte aller Populationsmitglieder und der späte Zeitpunkt der Blüte bedingen große interspezifische Konkurrenzkraft der Winterlinde. Nach CORBET et al. (1979) wird das üppige Nahrungsangebot der Linde in dieser Phase von keiner anderen Pflanze (auch nicht von Kulturpflanzen) erreicht und Insekten werden auch zu Futterflügen über mehrere Kilometer motiviert (s. Kap. 2.8). Die Produktion vieler Blüten sichert also eine konkurrenzlose Attraktivität für Insekten, welche für den Genfluß durch Pollen benötigt werden. 
Die große Attraktivität drückt sich in großer Blütenkonstanz der Insekten aus. Wie wichtig eine Blütenkonstanz für den Genfluß ist, wurde in Kapitel 5.5.3.1 geschildert.

$\mathrm{Da}$ der hohen Blütenproduktion nur eine relativ geringe Produktion lebensfähiger Nachkommen gegenübersteht, kann viele Ursachen haben, welche im Stand der Forschung und im Ergebnisteil zusammengetragen worden sind. In dem folgenden Schaudiagramm ist dargestellt, wie bestimmte Faktoren in verschiedenen ontogenetischen Stadien den Reproduktionserfolg der Winterlinden einschränken können.

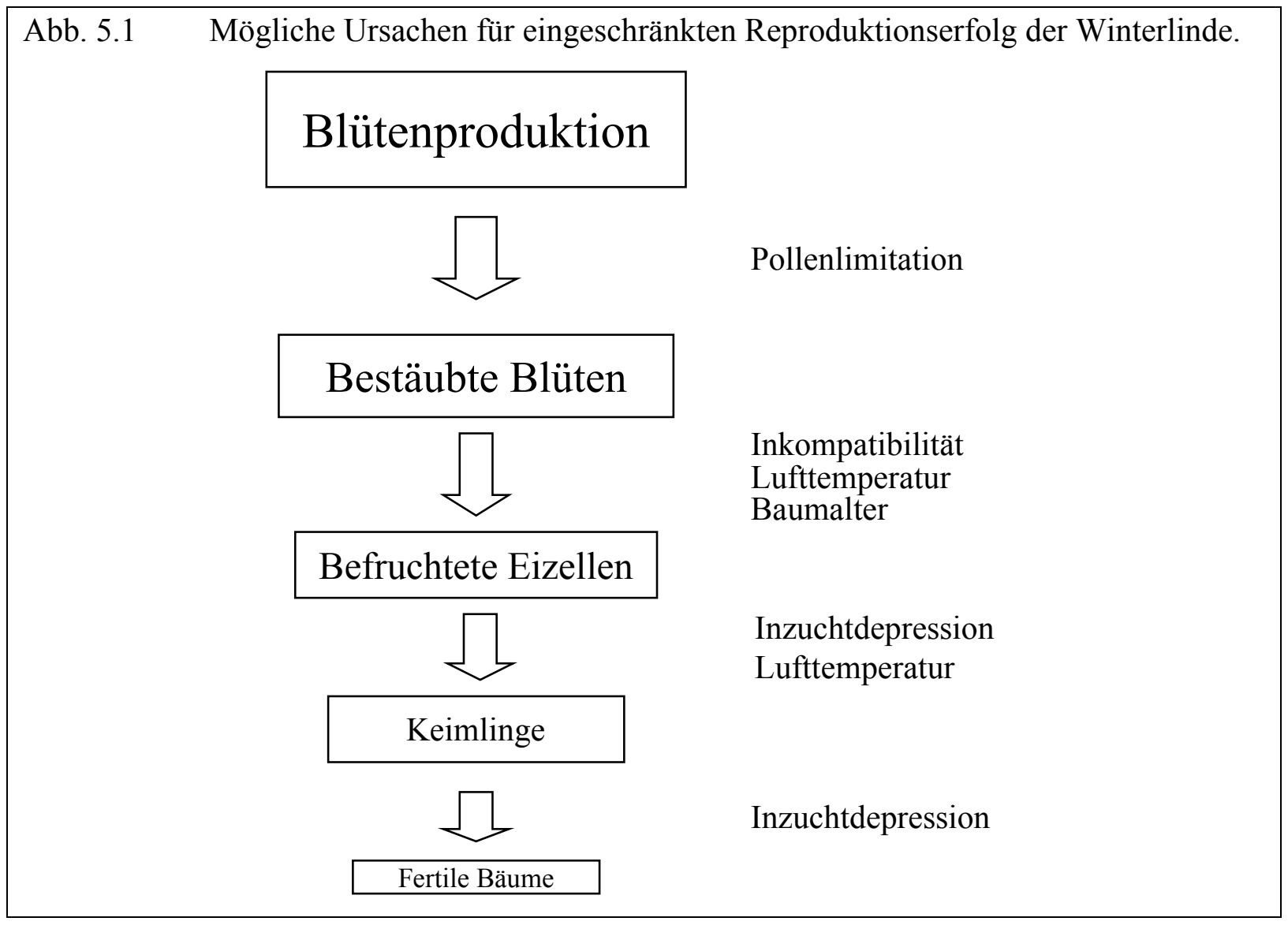

Daß die Winterlinde gerade bei ungünstigen Witterungsverhältnissen unter Pollenlimitation leidet, haben PigotT und HunTLEy (1981) nachgewiesen (s. Kap. 2.10). Die Anzahl bestäubter Narben war bei kühler und nasser Witterung weit geringer als bei sonnigem Wetter. Durch kühle und nasse Witterung wird die Flugaktivität der Insekten drastisch gesenkt. Auch ist denkbar, daß es aufgrund ungünstiger Witterungsbedingungen, durch Fragmentierung der Landschaft, Einsatz von Herbiziden usw. zu einer Verarmung des Insektenspektrums und zur Reduktion der Populationsgrößen von Insekten kommt (Kap. 2.8.3.6). Selbst wenn während der Blühphase optimale Witterungsbedingungen herrschen, kann durch die geringe Abundanz der Insekten nur eine eingeschränkte Bestäubung erfolgen. Geringe Insektenabundanz könnte eine Ursache dafür gewesen sein, daß bei dem warmen und trockenem Wetter während der 
Bestäubungsversuche anscheinend das Maximum an Bestäubung nicht erreicht worden ist: Der im Mittel mit Abstand höchste Samenansatz wurde nach künstlicher Bestäubung festgestellt (Kap. 4.4). Da nur drei Winterlinden mit ähnlichen Umweltbedingungen Gegenstand der Bestäubungsversuche waren, sind aber auch andere Ursachen denkbar. Daß der Pollentransport über Insekten oder Wind bei vielen Pflanzen einen minimierenden Faktor darstellt, kann zahlreichen Arbeiten entnommen werden (s. Kap. 2.9). Neben dem Einfluß auf Insekten kann regnerisches Wetter auch Auswaschung und vorzeitige Keimung der Pollens bewirken. Eine Auswaschung und Verdünnung des Nektars durch Niederschlag mit der Folge einer geringeren Attraktivität der Blüten ist ebenfalls möglich (Kap. 2.8.3.6).

Ein wichtiger Faktor für eine Pollenlimitation stellt sicherlich auch die Effizienz der Bestäuber dar. Für viele Blütenpflanzen konnte ein Pollentransport von maximal einem Prozent des produzierten Pollens beobachtet werden. Der weitaus größte Teil des produzierten Pollens geht beim Transport durch Insekten verloren (Kap. 2.8.3.7). Als Generalist ist die Linde auf keine Insektengruppe spezialisiert und der Verlust an Pollen dürfte bei ihr noch höher einzuschätzen sein. Eine angemessene Blüten- bzw. Pollenproduktion muß diese unvermeidbaren Verluste ausgleichen. Eine Spezialisierung auf eine Insektengruppe wäre für eine entomophile Baumart mit dem Verbreitungsgebiet der Winterlinde nicht denkbar: Der Ausfall der auf die Linde spezialisierten Insektengruppe durch unsichere klimatische Verhältnisse, die fragmentierte Kulturlandschaft usw. käme einem kompletten Ausfall des Genflusses gleich.

Die bei der Winterlinde wirksamen Mechanismen der Inkompatibilität und Inzuchtdepression wurden in Kapitel 5.5.3.3.1 und 5.5.3.3.2 diskutiert. Da Selbstbestäubung aufgrund der Blühökologie nicht vermieden werden kann, führt einsetzende Inkompatibilität bzw. Inzuchtdepression zwangsläufig zu einer Reduktion des Samenansatzes.

Die Lufttemperatur während des Pollenschlauchwachstums und der Samenreife hat nach den Untersuchungen von PIgOTT und HuntLey (1981) einen maßgeblichen Einfluß auf den Reproduktionserfolg der Winterlinde (Kap. 2.10). Die Keimung des Pollens auf der Narbe erfordert Temperaturen von mindestens $15^{\circ} \mathrm{C}$; nennenswertes Pollenschlauchwachstum ist bei der Winterlinde erst ab Temperaturen von $19{ }^{\circ} \mathrm{C} \mathrm{zu}$ verzeichnen und steigert sich bei höheren Temperaturen deutlich. Für die Reifung der Embryonen zu vitalen Samen bedarf es im August und September Lufttemperaturen von mehr als $20{ }^{\circ} \mathrm{C}$ über mehrere Stunden täglich. Die durchschnittliche Tageshöchsttemperatur ist während der Blühperiode der Winterlinde mit $18{ }^{\circ} \mathrm{C}$ in den Monaten Juli und August im Nordwesten Englands um $2{ }^{\circ} \mathrm{C}$ niedriger als im 
Süden Englands. Während die Winterlinden in Südengland in der Regel über einen nennenswerten Fruchtansatz verfügen, konnte dies im Norden Englands während eines Zeitraums von 25 Jahren nur in drei überdurchschnittlich warmen Jahren beobachtet werden. Aufgrund des langsamen Pollenschlauchwachstums sind die Pollen nicht bis zu den Samenanlagen durchgedrungen und konnten die Eizellen nicht befruchten. In Schweden und Finnland herrschen während der Winterlindenblüte ausreichend hohe Temperaturen für die erfolgreiche Befruchtung der Eizellen, ein klimatisch bedingter starker Temperaturabfall im August führt aber zu einen Abbruch der Samenentwicklung und es werden keine vollentwickelten Samen ausgebildet (PigOTt 1981, Kap. 2.10). Die im Norden Englands bestehende Winterlindenvorkommen sind nach PIGOTT (1991) Reliktvorkommen, die sich währen der Wärmzeit vor 5000 Jahren etabliert haben und heutzutage überwiegend asexuell über Stock- und Stammausschlag reproduzieren. Vor 5000 Jahren lag die Durchschnittstemperatur im Norden Englands mit $20^{\circ} \mathrm{C}$ um zwei Grad höher als heute. EISENHUT (1957) sieht den Rückzug der Winterlinde in südlichere Regionen ebenfalls in der Abkühlung des Klimas nach der Wärmezeit begründet. Dabei wird das Verbreitungsgebiet nicht durch kalte Wintertemperaturen eingeschränkt; denn die Winterlinde gilt als frosthart. Entscheidend ist nach EISENHUT (1957) mangelnde Sommerwärme. Ein Vergleich des Reproduktionserfolgs der Winterlindenpopulation Schwiegershausen mit den Temperaturen der Sommer 1995 bis 1998 bestätigen die Untersuchungen von PigotT und Huntley (1981) eindrucksvoll (Kap. 4.9.1). Der mit Abstand höchste Fruchtansatz wurde im außergewöhnlich warmen Sommer des Jahres 1995 beobachtet. Die mittlere Tagesdurchschnittstemperatur erreichte während der Blühperiode in diesem Jahr $20,7^{\circ} \mathrm{C}$ (Tab. 4.33, S. 152) und die mittlere Tageshöchsttemperatur im Zeitraum der Samenreife $20,9{ }^{\circ} \mathrm{C}$ (Tab. 4.34, S. 153). Kein oder nur spärlicher Fruchtansatz war hingegen in den Jahren 1996 und 1998 zu verzeichnen. In diesen Jahren wurden in den Blühperioden mittlere Tagesdurchschnittstemperaturen von $16,9^{\circ} \mathrm{C}$ bzw. $17,5^{\circ} \mathrm{C}$ und während der Samenreife mittlere Tageshöchsttemperaturen von $19,1{ }^{\circ} \mathrm{C}$ bzw. $19,6{ }^{\circ} \mathrm{C}$ gemessen. Bedingungen für mäßigen und im Vergleich zum Jahr 1995 deutlich geringeren Reproduktionserfolg herrschten im Jahr 1997. Während der Blüte der Winterlinden lag die mittlere Tagesdurchschnittstemperatur bei moderaten $17,9^{\circ} \mathrm{C}$, während die Samenreife unter einer ausgesprochen hohen mittleren Tageshöchsttemperatur von $23,4{ }^{\circ} \mathrm{C}$ erfolgte. In den Jahren 1995 bis 1998 hat mit Sicherheit die Temperatur während der Blühperiode entscheidenden Einfluß auf den Reproduktionserfolg der Winterlinden der Population Schwiegershausen gehabt. Ob im Jahr 1995 höhere Temperaturen im Zeitraum der Samenreife zu einem noch größeren Reproduktionserfolg geführt hätten, kann nicht ausgeschlossen werden. Da nach Pigott (1981) bzw. PigotT und HuntLey 
(1981) die Samen für eine volle Entwicklung Temperaturen von ca. $20^{\circ} \mathrm{C}$ über mehrere Stunden des Tages benötigen, ist die Reproduktion vermutlich nicht durch zu niedrige Temperaturen im August/September eingeschränkt worden. Demgegenüber erfolgt während der Blühperiode bei mittleren Tagesdurchschnittstemperaturen unter $18^{\circ} \mathrm{C}$ nur unvollständige Befruchtung der Eizellen. Ansonsten wäre im Jahre 1997 ein weit höherer Fruchtansatz zu erwarten gewesen. Die Temperatur während der Samenreife wird 1997 mehr als ausreichend gewesen sein und ist nicht als limitierender Faktor einzuschätzen. Der weitgehende Ausfall der sexuellen Reproduktion der Jahre 1996 und 1998 dürfte auf zu kühle Witterung während der Blühperiode und während der Samenreife zurückzuführen sein.

Eisenhut (1957) sowie PigotT und Huntley (1981) beobachteten bei der Winterlinde im hohen Alter des Baumes zunehmende Sterilität der Eizellen. Bei sehr alten Winterlinden (ca. 250 Jahre) ist weitgehende Sterilität der Eizellen ebenfalls als Ursache für einen geringen Fruchtansatz in Betracht zu ziehen. Auch wäre Ressourcenlimitation denkbar. KLEIN (1992) zieht als Ursache des von ihm beobachteten geringen Samenansatzes der Winterlinde die unzureichende Versorgung mit Wasser und Nährstoffen in Erwägung. Eine Ressourcenlimitation ist in Ausnahmefällen nicht auszuschließen, kann aber den Ausfall der Reproduktion in den feuchten und kühlen Sommern Englands (s. o.) bzw. die hohe Trockenresistenz und die Verbreitung der Winterlinde bis in die kontinentalen Klimate Zentralrusslands nicht erklären.

Die Ursachen für jährlich schwankenden Reproduktionserfolg der Winterlinde kann über genannte Faktoren plausibel erklärt werden. Daß zwischen den Populationsmitgliedern größere Unterschiede bezüglich der Hohlkornanteile existieren, ist auf die unterschiedliche Zusammensetzung der individuellen Pollenwolken (Kap. 4.3), das unterschiedliche Alter (Sterilität der Eizellen), die unterschiedliche Exposition und auf die soziale Stellung der Winterlinden zurückzuführen. Nicht alle Beobachtungen lassen sich aber durch diese Faktoren erklären:

Die in einer Gruppe direkt nebeneinander stehenden und ungefähr 70 Jahre alten Winterlinden Nr. 8, 10 und 11 haben Hohlkornanteile von dem Fünffachem vitaler Samen, $39 \%$ und 186 \%. Die Feldlinden F1, F2 und F3 haben alle ein Alter von ca. 200 Jahren. Der Hohlkornanteil beträgt bei den Winterlinden F1 und F2 jeweils $16 \%$, bei der Winterlinde F3 das 7,7fache vitaler Samen (Tab. 4.20, S. 126). Zwar sind Alter, Entfernungen zu den nächsten Paarungspartnern und Umweltbedingungen vergleichbar, doch zeigen sich sehr große Unterschiede bei den Hohlkornanteilen und Samengewichten (Kap. 4.7.4). Physiologische und bestäubungsökologische Ursachen kommen daher nicht allein als Gründe in Betracht und der Hohlkornanteil bzw. das Samengewicht standen auch nicht mit der Selbstbefruchtungsrate, 
der Kronengröße des Samenelters, dem Abstand des Samenelters zu den nächsten Paarungspartnern und den durchschnittlichen Kronengrößen der nächsten Paarungspartner in Zusammenhang (Tab. 4.26). Als Erklärung bleiben individuell unterschiedlich wirksame Inkompatibilitätsmechanismen oder frühe Inzuchtdepression. Nach HAUSER und LOESCHKE (1995), Krebs und HANCOCK (1990), van TEUREN et al. (1993) und WOLFE (1993) ist die Effektivität von Sterilitätsmechanismen abhängig vom Inzuchtniveau der Eltern. Wenn die Eltern schon einen hohen Fixierungskoeffizienten aufweisen und unter Inzuchtdepression leiden, sind Sterilitätsmechanismen in der Phase der Reproduktion stärker ausgeprägt. Dabei wird unter den Nachkommen inzuchtdepressiver Pflanzen überproportional stark gegen selbstbefruchtete Embryonen selektiert (s. Kap. 2.9.2). Die Winterlinde Nr. 8 hat mit dem Fünffachem dessen vitaler Samen einen sehr hohen Hohlkornanteil und eine nach dem Ausschlußverfahren ermittelte (und damit maximal mögliche) Selbstbefruchtungsrate von nur $5 \%$. Die Vermutung liegt nahe, daß Winterlinde Nr. 8 unter Inzuchtdepression leidet. Die Inzuchtdepressivität der Winterlinde Nr. 8 bewirkt generell hohe Sterilität (hoher Hohlkornanteil), welche besonders nach Selbstbestäubung zum Tragen kommt (nur $5 \%$ Selbstbefruchtung).

Damit hängt der Reproduktionserfolg und die Selbstbefruchtungsrate einer Winterlinde auf individueller Ebene von der Inzuchtdepressivität von Samen- und Pollenelter und von der effektiven Pollenwolke ab. Ist große Konkurrenz durch Fremdpollen gegeben, wird tendenziell stärker gegen Eigenpollen selektiert. Diese Selektion ist um so stärker, je höher die Inzuchtdepressivität der Eltern ausgeprägt ist. Individuelle Selbstfertilität wurde auch bei Cassia fasciculata (Caesalpiniaceae) (MARTIN und LEE 1993), bei Blandifordia grandiflora (Liliaceae) (RAMSEY et al. 1993), Eucalyptus regnans (ELDRIDGE und GRIFFIN 1983), bei Shorea (MURAWSKI et al. 1994) und bei Teak (Tectona grandis) (FINKELDEY 1999) beobachtet.

\subsubsection{Individueller Genfluß über Pollen}

Eine große Krone fördert Geitonogamie und damit Selbstbefruchtung. Ein individueller Erfolg einer Winterlinde in Form der Befruchtung andere Winterlinden, ist dagegen unabhängig von der Kronengröße (Kap. 4.9.2). Dieses spricht abermals für eine überwiegende (Fremd-) Bestäubung der Winterlinde durch Insekten, da nach Windbestäubung eine Korrelation zwischen Kronengröße (= Fertilität) und individuellem Reproduktionserfolg zu erwarten gewesen wäre. Warum die Kronengröße keinen Einfluß auf den individuellen Reproduktionserfolg bei Befruchtung anderer Populationsmitglieder hat, läßt sich nur vermuten. Entweder fliegen Insekten nach langem Aufenthalt in einer großen Krone mit Pollen voll beladen andere Linden weniger oft an. Denkbar wäre auch, daß das Insekt ab einer bestimmten Anzahl besuchter 
Blüten keine weiteren Pollen mehr aufnehmen kann, so daß ab diesem Zeitpunkt ein längerer Aufenthalt nicht mit einer höheren Pollenfracht verbunden ist. Möglich ist zudem, daß der Pollen beim Besuch von Blüten anderer Bäume relativ schnell verloren geht. Im Sinne einer Sicherung des Genflusses und der Erhaltung einer Population ist dieser Umstand sicherlich von Vorteil, da auch kleinere Populationsmitglieder an der Reproduktion beteiligt sind, sehr große Winterlinden aber proportional geringer, als es ihrer Fertilität entspräche. Die Anzahl der effektiven Paarungspartner wird dadurch erhöht. Sehr kleine Winterlinden werden Dagegen weniger stark von flugaktiven Insekten frequentiert und ihre Pollen werden nur in geringem Umfang zu Fremdbefruchtung führen. Dies erscheint unter evolutionären Aspekten sinnvoll, da Linden mit kleinen Kronen entweder junge oder konkurrenzschwache Populationsmitglieder repräsentieren dürften. Im letzteren Fall wäre eine Weitergabe minderwertigen Erbguts für die Population von Nachteil.

\section{Schlußfolgerungen}

Zur Reproduktionsstrategie gehört die Sicherstellung einer interspezifisch konkurrenzlosen Attraktivität für Insekten. Dies erreicht die Winterlinde durch eine synchrone Massenblüte aller Populationsmitglieder. Aus der relativ großen Anzahl der Blüten entwickelt sich jedoch auch unter günstigen Bedingungen nur ein Bruchteil $(3,4 \%)$ zu vitalen Samen. Auch bei massenblühenden Baumarten ist ein gewisser Umfang an Selbstbestäubung nicht zu vermeiden. Gegen die Eigenpollen wird bei der Winterlinde effektiv durch Inkompatibilität bzw. gegen Nachkommen aus Selbstbefruchtung durch Inzuchtdepression selektiert. Voraussetzung einer Selektion gegen Eigenpollen ist Konkurrenz durch Fremdpollen. Ist diese Konkurrenz nicht gegeben, können auch aus Selbstbefruchtung Nachkommen entstehen und ein reproduktives Alter erreichen. Aber selbst in der Reproduktionsphase können noch Sterilitätsmechanismen in Form geringer Reproduktionserfolge zum Tragen kommen.

Unter ungünstigen Witterungsbedingungen kann die Reproduktion komplett ausfallen. Kühle und nasse Witterung kann zum einem über mehrere Faktoren zu Pollenlimitation führen, zum anderen muß für das Pollenschlauchwachstum und für die Samenreife eine gewisse Temperaturgrenze überschritten werden. Während der Blüte der Winterlinde im Juni/Juli sollte die mittlere Tagesdurchschnittstemperatur nicht unter $20^{\circ} \mathrm{C}$ fallen. Für die Samenreife im August/September werden Temperaturen von über $20^{\circ} \mathrm{C}$ über mehrere Stunden am Tag benötigt. Da die Winterlindenpopulation Schwiegershausen in den Beobachtungsjahren nur im überdurchschnittlich warmen Sommer 1995 einen nennenswerten Samenansatz aufwies, ist zu vermuten, daß der Vorharz die Grenze des, 
über sexuelle Reproduktion gesicherten, natürlichen Verbreitungsgebiets der Winterlinde darstellt (vgl. Abb. 2.1, S. 5 ). Die Aussagen von DengLer (1992), die Winterlinde zeichne sich durch reichliche Fruktifikation aus, der aber nur geringer Verjüngungserfolg gegenüberstünde, und die Winterlinde reproduziere weitgehend asexuell über Ausschläge am Stammfuß oder über Stockausschlag, ist nur für die Grenzbereiche ihres Verbreitungsgebiets zutreffend. In ihrem Hauptverbreitungsgebiet dürfte einer sexuellen Reproduktion der Winterlinde nichts im Wege stehen.

\subsection{Hybridisierung}

Von einer spontanen Bildung von Hybriden aus Winter- und Sommerlinde wird relativ häufig berichtet (Kap. 2.11 und 4.10). Darüber, inwieweit die $F_{1}$-Hybrid-Generation zu sexueller Fortpflanzung und zur Bildung von $\mathrm{F}_{2}$-Hybriden fähig ist, gibt es widersprüchliche Aussagen (s. Kap. 2.11). Auf den Luftbildaufnahmen sind Winter- und Hybridlinden in voller Blüte zu sehen. Von deren für die Reproduktion ausreichenden Überschneidung der Blühperioden ist auszugehen. Die Ergebnisse in Tab. 4.36 (S. 156) bestätigen eine Überlappung der Blühperioden und zeigen, daß die beiden Hybriden Nr. 116 und 137 im Stande sind, zumindest bis zum Beobachtungszeitpunkt des reifen Samens vitale Nachkommen zu bilden. Allerdings ist der Samenansatz der Hybriden nur sehr gering und der Hohlkornanteil ist im Vergleich zu Nachkommenschaften der Winterlinde sehr hoch (Kap. 2.11 und Tab. 4.36).

Als Polleneltern sind Hybriden bei der Befruchtung von Winterlinden erfolgreicher. Über das Pollenelterbestimmungsverfahren EFG $2 \Delta$ wurde nachgewiesen, daß Hybridpollen Eizellen der Winterlinde befruchtet haben. In dreizehn Fällen sind Pollen der Hybride Nr. 116 bei Winterlinden effektiv geworden, in sieben Fällen Pollen der Hybride 137. Auch im Durchschnitt der 138 Winterlinden des Bestandes Schwiegershausen sind nur 7,5 Pollen erfolgreich auf die Narben der 54 eingehend untersuchten Winterlinden transportiert worden (s. Kap. 4.9.2). Mit einem Beitrag von sieben bzw. dreizehn Pollen haben die beiden Hybriden also durchschnittlich bzw. überdurchschnittlich erfolgreich genetische Information weitergegeben. Der geringe Samenansatz der beiden untersuchten Hybriden ist damit weniger auf mangelnde Bestäubung durch geringe Überschneidung der Blühperioden von Winter- und Hybridlinden zurückzuführen. Die Bildung einer $\mathrm{F}_{2}$-Hybridgeneration ist vermutlich aufgrund von Sterilität der Eizellen oder Inkompatibilität gegenüber Hybrid- und Winterlindenpollen nicht oder nur selten zu beobachten. Die hohen Hohlkornanteile der Hybriden deuten darauf hin.

Beim Einsatz genetischer Marker zeigt sich, daß die Winter- und die Sommerlinde an mehreren Genorten artspezifische Allele besitzen, die eine klare Diskriminierung beider Arten so- 
wie die Identifizierung von Arthybriden (zumindest der $\mathrm{F}_{1}$-Generation) ermöglichen (Kap. 4.1.2). Die Existenz einer großen Anzahl artspezifischer Allele deutet ebenfalls auf eine stark eingeschränkte Introgression (im Gegensatz etwa zu Eichen- und Pappelarten) und somit auf eine Präsenz von Inkompatibilitätsmechanismen oder einer Sterilität der Eizellen hin.

Schlußfolgerungen

Kommen Winter- und Sommerlinde sympatrisch vor und überschneiden sich deren Blühtermine, kann es zu spontaner Hybridisierung kommen. Bei einer weitgehenden Überschneidung der Blühphasen von Winterlinde und Hybride ist die Hybride als Pollenelter der Winterlinde erfolgreich, als Samenelter ausgesprochen erfolglos. Sterilität der Eizellen und/oder Inkompatibilitäten sind vermutlich die Ursachen für den geringen Samenansatz der Hybriden. Es wurden nur wenige vital erscheinende Samen gebildet. Die Etablierung einer $F_{2}$-Hybridgeneration über die Hybride als Samenelter ist nicht sehr wahrscheinlich, eine Produktion von $F_{2}$-Nachkommen scheint nur über die Kombination von Hybridpollen und der Winterlinde als Samenelter möglich. Die Introgression der Winter- und Sommerlinde ist also eingeschränkt. Ebenso sprechen die vielen artspezifischen Allele der Winter- und Sommerlinde für eine begrenzte Introgression der beiden Arten. 


\section{Waldbauliche Konsequenzen}

\section{Reproduktionserfolg}

Über geringen Fruchtansatz, hohe Hohlkornanteile und geringe Keimfähigkeit der Winterlinde wird oft berichtet (Kap. 2.9). Diese Erscheinungen sind auch in vorliegender Arbeit beobachtet worden (Kap. 2.10 und 4.9). Nach ROHMEDER (1972) erwiesen sich im Durchschnitt langjähriger Samenprüfungen nur knapp 48 \% der Samen der Winterlinde als keimfähig. Eine noch geringere Keimfähigkeit wurde bei zwei zugelassenen hessischen Erntebeständen festgestellt: Im langjährigen Mittel keimten nur $9 \%$ bzw. $22 \%$ der Winterlindensamen (KLEIN 1992). Als Normwert für Handelssaatgut der Winterlinde wird jedoch 80 \% Keimfähigkeit der Samen vorausgesetzt (ROHMEDER 1972). Saatguternte und Anzucht von Winterlindenpflanzgut sind also oft von nur bescheidenem Erfolg gekrönt.

Ein größerer Erfolg ließe sich durch Beachtung einiger Punkte erzielen: Generell wird ein für die Einleitung von Naturverjüngung oder für die Beerntung befriedigender Samenansatz bei der Winterlinde nur in warmen Sommern gegeben sein. Zum einen ist in warmen Sommern die Gefahr der Pollenlimitation geringer und zum anderen werden die für das Pollenschlauchwachstum und für die Samenreife benötigten Temperaturen erreicht (Kap. 5.7.2).

Es sollte vermieden werden, Winterlinden mit sehr großen und mit sehr kleinen Kronen zu beernten. Unter den Nachkommen dieser Linden sind besonders hohe Selbstbefruchtungsanteile nachgewiesen worden (Kap. 4.7.3). Diese führen zu verminderter Viabilität durch einsetzende Sterilitätsmechanismen (Kap. 5.5.3.3). Dabei ist das Ausmaß der Selbstbefruchtung in den Nachkommen großer Winterlinden von deren Entfernung zu anderen Winterlinden unabhängig. Die Nachkommen großer, im engen Paarungskontakt mit anderen Winterlinden stehender, Winterlinden zeigten ähnlich hohe Selbstbefruchtungsraten wie die Nachkommen der isoliert in der Feldmark wachsenden Winterlinden (Kap. 4.7.3). Selbst in den Nachkommenschaften der sehr großen Winterlinden war ein Fremdbefruchtungsanteil von mindestens $11 \%$ festzustellen. Von Naturverjüngung dieser Linden kann nicht abgeraten werden, da unter natürlichen Bedingungen der Selektionsdruck verstärkt gegen inzuchtdepressive Individuen wirksam wird. Dagegen wird die Samenernte bei solchen Sameneltern ausdrücklich nicht empfohlen, da nur geringe Ausbeute zu erwarten ist und man davon auszugehen hat, daß der schwache Selektionsdruck bei der Anzucht in der Baumschule nicht effektiv genug Auslese gegen inzuchtdepressive Nachkommen induziert. Dies hätte zur Folge, daß genetisch minderwertiges Pflanzgut in Verkehr gebracht würde. Bei Begründung von Winterlindenbestän- 
den mit solchem Pflanzgut ist, abhängig von den bestehenden Konkurrenzverhältnissen (je nach Umwelt, Pflanzverband und Bestandespflege), entweder mit starken Ausfällen zu rechnen und/oder mit einer Etablierung inzuchtdepressiver Individuen.

Eine Begründung von Winterlindenbeständen sollte aufgrund der effektiven Inzuchtdepressionsmechanismen generell mit großen Pflanzenzahlen erfolgen. Da in der Regel die lohnendsten, also größten Bäume für die Saatguternte ausgewählt werden, sind die festgestellten Hohlkornanteile und geringen Keimprozente des gehandelten Saatguts nicht verwunderlich. Es wäre unrealistisch, die Empfehlung zu geben, nur mittelgroße Bäume zu beernten; es sollte aber zumindest darauf geachtet werden, möglichst viele Winterlinden zu beernten. Auch sollten die zur Ernte zugelassenen Populationen ausreichend groß sein und viele Paarungspartner zur Verfügung stehen.

Eine räumliche Trennung der Populationsmitglieder von 200 und mehr Metern dürfte keine maßgebliche Einschränkung des Paarungskontakts darstellen; der Genfluß der Winterlinde war zumindest im Beobachtungsjahr 1995 sehr effektiv (Kap. 5.6.2). Auch wenn im Falle der Population Schwiegershausen Isolation durch die Entfernung der Winterlinden zum nächsten Paarungspartner nicht festgestellt werden konnte, werden ab einem gewissen Abstand auch flugaktive Insekten den Paarungskontakt nicht mehr aufrecht erhalten können. Einzelbäume bzw. kleine Bestände sind von der Beerntung auszunehmen. Bei kleinen Reliktvorkommen ist zudem von Verwandschaftsstrukturen und Inzuchtdepression der Eltern auszugehen, welche wiederum eine geringe Samenproduktion nach sich ziehen. Da ein hohes Alter zur Sterilität der Eizellen führt, sind auch von der Beerntung älterer Winterlinden (ca. älter 250 Jahre) überwiegend hohle Samen zu erwarten.

Eine Förderung der Insektenfauna durch erhöhte Biodiversität (z. B. Feldrand) und der gezielte Einsatz von Bienenvölkern während der Blühperiode der Winterlinde können der Pollenlimitation entgegenwirken bzw. durch eine hohen Anteil an Fremdpollen Selektion gegen Eigenpollen erhöhen.

\section{Hybridisierung}

Die vorzüglichen waldbaulichen Eigenschaften der Linden und deren hoher ökologischer Nutzen fanden in den vergangenen Jahren immer mehr Berücksichtigung und führten zu einem verstärkten Anbau dieser Gattung. Der gestiegene Bedarf an Saatgut konnte dafür aus den heimischen Saatgutbeständen nicht gedeckt werden und wurde im großen Umfang aus Osteuropa importiert (LENTFER 1979, NAMVAR und SPETHMANN 1986). Mit den in den letzten Jahren angelegten und sich in Planung befindlichen Samenplantagen soll in Zukunft ausrei- 
chend Vermehrungsgut zur Verfügung stehen. Natürlich stellt sich diesbezüglich die Frage, welches Material bislang bei der Begründung der Bestände und der Samenplantagen Verwendung fand und in Zukunft verwendet wird. Sommer- und Winterlinde unterscheiden sich erheblich u. a. aufgrund ihrer Standortansprüche, ihrer Frost- und Trockenresistenz, ihres Wachstumsverhaltens, ihrer Holzeigenschaften sowie Austriebs- und Blühtermine voneinander und decken deshalb im Waldbau verschiedene Einsatzbereiche ab (EISENHUT 1957, NAMVAR und SPethmann 1986, SDW 1991). Die Hybride liegt bezüglich ihrer morphologischen Merkmale zwischen denen der Sommer- und der Winterlinde. Bei Begründung eines Bestandes sollten diese unterschiedlichen Eigenschaften der drei Lindenarten berücksichtigt und einwandfrei identifiziertes Pflanzgut verwendet werden. Besonders bei der Anlage einer Samenplantage ist zum Erhalt des gewünschten Saatgutes auf Artreinheit zu achten ${ }^{5}$. Die etwas durchlässige Introgressionsbarriere hat wegen überlappender Blühtermine in gewissem Umfang Paarungskontakt zwischen Winter- und Sommerlinde zur Folge. Da Winter- und Sommerlinde die gleiche Bestäubungsökologie besitzen und Inkompatibilitätsmechanismen nicht sehr ausgeprägt sind, können sich vitale Hybriden bilden. Eine Reproduktion zwischen den Arten sollte in Samenplantagen jedoch unbedingt vermieden werden. Zudem zeigen die Hybriden trotz ausgiebiger Blüte einen Samenansatz mit stark erhöhtem Hohlkornanteil (Kap. 5.8). Die geringe Fertilität der Hybride senkt somit die Viabilität der Gesamtpopulation.

Eine spontane Bildung von Hybriden der $\mathrm{F}_{1}$-Generation ist relativ häufig zu beobachten und unterstreicht die notwendige räumliche Trennung der Arten. Da der Genfluß bei der Winterlinde sehr effektiv ist und Pollentransportweiten von mehr als $1000 \mathrm{~m}$ keine Seltenheit sind (Kap. 4.8.4), sollte der Abstand entsprechend gewählt werden, um Hybridisierung zu vermei-

\footnotetext{
${ }^{5}$ Im Rahmen dieser Arbeit wurde eine Elektrophoresemethodik entwickelt, die eine gesicherte Artunterscheidung über Isoenzymgenmarker ermöglicht (Kap. 4.1.2 und Kap. 5.8). Diese Methodik wurde bereits von mehreren Bundesländern für den Nachweis der Artreinheit der für Samenplantagen ausgewählten Plusbäume erfolgreich eingesetzt.
} 
den oder eine Samenplantage vor arteigener Pollenkontamination zu schützen. Ein Abstand von 2 km schließt zwar grundsätzlich Paarungskontakt nicht aus, ist vermutlich ausreichend. Der von ROHMEDER (1972) für Samenplantagen empfohlene Abstand von 300 m wird bei den effektiven Pollenvektoren der Winterlinde Pollenkontamination kaum verhindern können. 


\section{Zusammenfassung}

Die Winterlinde (Tilia cordata Mill.) tritt in Waldbaumpopulationen ganz überwiegend als Mischbaumart auf. Das Vorkommen in geringer Dichte läßt einen eingeschränkten Paarungskontakt innerhalb der Lindenpopulation erwarten. Zudem wird die Übertragung des Pollens durch andere Baumarten abgeschirmt, die während der Blühperiode der Linde im Laub stehen. Es stellt sich die Frage, wie effizient die entomogame Linde durch tierische Pollenvektoren über größere Entfernungen bestäubt wird, und ob mit abnehmender Populationsdichte der Anteil der Selbstbefruchtung steigt. Bei den meisten Pflanzen ist eine Abnahme der Viabilität selbstbefruchteter Nachkommen durch einsetzende Sterilitätsmechanismen zu beobachten und auch bei der Winterlinde zu vermuten. In den Randgebieten ihres Verbreitungsgebietes ist der sexuelle Reproduktionserfolg der Winterlinde von Jahr zu Jahr sehr unterschiedlich und in der Regel bescheiden. Ob eine Pollenlimitation, unzureichende Pollenverbreitung und damit verbundener unzureichender Genfluß, Sterilitätsmechanismen oder andere Ursachen für die hohen Hohlkornanteile und geringen Keimprozente verantwortlich gemacht werden können, sollte neben weiteren Aspekten des Reproduktionssystems anhand von Bestäubungsversuchen, Keimungsversuchen und einer genetischen Inventur des Altbestandes und zahlreicher Nachkommen verschiedener ontogenetischer Stadien geklärt werden.

Als Untersuchungsobjekt diente eine 138 Winterlinden und drei Hybriden umfassende, weiträumig isolierte Lindenpopulation bei Schwiegershausen, einem Dorf im westlichem Vorharz. Dabei waren die Linden sehr heterogen in einem ca. 40 ha großen, überwiegend aus Buchen bestehenden, Bestand verteilt: Teile der Lindenpopulation erreichten die Dichte eines Reinbestandes, andere, in der Feldmark stehende Linden waren über mehrere hundert Meter von anderen Populationsmitgliedern getrennt. Zwischen diesen beiden Extremen waren alle Abstufungen von Populationsdichten vorzufinden, so daß dieser Bestand optimale Voraussetzungen für die Behandlung oben genannter Fragestellungen bot.

Der Versuchsbestand in Schwiegershausen wurde während der Blühperiode der Linde mit einem zweisitzigen Ultraleichtflugzeug überflogen und aus einer Höhe von ca. $1800 \mathrm{~m}$ foto-

grafiert. Über ein digitalisiertes Luftbild wurde eine Entfernungsmatrix der 141 Linden des Versuchsbestandes generiert. Bei der Zwittrigkeit der Lindenblüten war es zudem über die digitale Karte möglich, die in der Blüte stehende Kronenoberfläche in $\mathrm{m}^{2}$ zu berechnen und die damit korrelierte Blühintensität bzw. männliche Fertilität der einzelnen Linden zu schät- 
zen. Dabei zeigten die Auswertungen der Luftbildaufnahmen und Beobachtungen vor Ort eine weitgehend einheitliche Blühperiode aller Linden. Daher konnten grundsätzlich alle 141 Linden des Versuchsbestandes als potentielle Paarungspartner gelten.

In umfangreichen Laborarbeiten gelang für die hexaploide Winterlinde die Identifikation von zwölf Isoenzym-Genloci. Die Vererbungsanalysen zeigten, dass die Winterlinde trotz Polyploidie den Vererbungsmodus diploider Organismen aufweist (Allopolyploidie). Der Einsatz einer ausreichenden Anzahl variabler Genmarker war Voraussetzung für fast alle weiteren Untersuchungen im Rahmen dieser Arbeit.

Die Identifizierung der drei Hybriden (Tilia $x$ vulgaris) gelang nach der genetischen Inventur des Altbestandes: Es zeigte sich, daß Sommer- und Winterlinde über artspezifische Allele verfügen, die eine Unterscheidung der beiden Arten und die Identifizierung der Hybride ermöglichen. Gerade die Identifizierung der Hybride, aber auch die Unterscheidung der beiden reinen Arten in unbelaubtem Zustand, ist nur anhand morphologischer Merkmale oft schwierig.

Neben der Identifizierung von Genorten war für die Bestimmung von Pollentransportweiten die Identifizierung von Polleneltern notwendig. Nur wenn zu dem Nachkommen eines bekannten Samenelters ein bestimmter Pollenelter zugeordnet werden kann, ist es möglich, die Entfernung des vorausgegangenen Pollentransportes zu determinieren. Neben des Einsatzes bekannter Verfahren des eindeutigen Ausschlusses und CERVUS wurde im Rahmen dieses Projektes das Pollenelterbestimmungsverfahren EFG $2 \Delta$ entwickelt, welches die Entfernung, Fertilität und Wahrscheinlichkeit für einen Gametenbeitrag der potentiellen Pollenelter berücksichtigt.

Über die Bestimmung von Polleneltern können zudem auch die Anteile von Selbstbefruchtung in den Nachkommen geschätzt werden. Die verschiedenen Verfahren wurden dabei eingehend bezüglich ihrer Effizienz und Plausibilität bei der Bestimmung von Polleneltern (bzw. Pollentransportweiten) und Selbstbefruchtungsanteilen verglichen.

Die Auswertung der Bestäubungsversuche sowie die individuell sehr unterschiedlichen effektiven Pollenwolken zeigten, daß Windbestäubung im Reproduktionssystem der Winterlinde nur eine untergeordnete Rolle spielt. Dadurch wurden Angaben in der Literatur bestätigt. Windbestäubung ist zwar generell möglich, quantitativ aber zu vernachlässigen und die Transportweiten müssen hierbei als gering eingeschätzt werden. Für die bestäubungseffektive 
Verbreitung von Pollen über größere Entfernungen sind bei der Linde Insekten zahlreicher Gattungen und Arten verantwortlich. Zu einer apomiktischen Reproduktion ist die Winterlinde nicht fähig.

Die genetischen Unterschiede zwischen den individuellen effektiven Pollenwolken der Winterlinden sind groß. Im Mittel haben die Pollenwolken der Sameneltern 44,9 \% ihrer Allele nicht gemeinsam (maximal aber 94,7\%). Die sehr unterschiedliche genetische Variation innerhalb der einzelnen Pollenwolken sowie ihre sehr unterschiedliche genetische Differenzierungen bestätigen dies. Die genetische Variation (gemessen durch $\delta_{\mathrm{T}}$ ) innerhalb einer Pollenwolke ist dann groß, wenn sie überwiegend mit Fremdbefruchtung im Zusammenhang steht. Hat überwiegend Selbstbefruchtung stattgefunden, kann die Variation innerhalb einer Pollenwolke dann besonders groß sein, wenn der Samenelter einen hohen Heterozygotiegrad aufweist. Eine enge Korrelation besteht zwischen der genetischen Differenzierung $\mathrm{D}_{\mathrm{j}}$ der Pollenwolke und der Selbstbefruchtungsrate des betreffenden Samenelters, die Differenzierung einer Pollenwolke steigt mit der Selbstbefruchtungsrate des Samenelters an.

Die Selbstbefruchtungsraten sind individuell von Baum zu Baum sehr unterschiedlich und nehmen Werte von $0 \%$ bis $89 \%$ an. Nach dem Pollenelterbestimmungsverfahren EFG $2 \Delta$ liegt die Selbstbefruchtungsrate im Durchschnitt der Gesamtpopulation bei 30,1 \%. Zumindest für den im diesem Projekt verwendeten Datensatz konnten im Vergleich mit dem Aus-

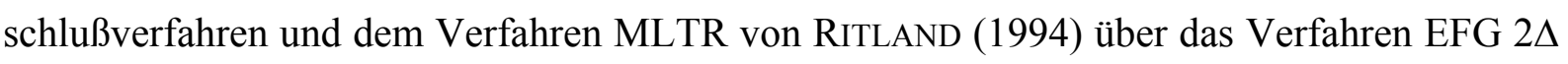
die plausibelsten Werte ermittelt werden. Interessant war eine weitere Unterteilung der Gesamtpopulation in Bäume innerhalb des Bestandes und in vier isoliert in der Feldmark stehende Bäume. Für die im Bestand stehenden Linden wurde nach Verfahren EFG $2 \Delta$ eine Selbstbefruchtungsrate von 25,1\% ermittelt, für die in der Feldmark stehenden Linden dagegen $64,8 \%$.

Zwischen einer erhöhten Selbstbefruchtungsrate und dem Abstand des Samenelters zu den nächsten Paarungspartnern wurde eine signifikante Korrelation nur bei den isoliert in der Feldmark stehenden Winterlinden gefunden. Weder die vier größten Winterlinden des Bestandes noch die vier in der Feldmark stehenden zeigten eine signifikante Korrelation ihrer Selbstbefruchtungsrate mit ihrem Abstand zu den nächsten Paarungspartnern, so daß von einem Einfluß einer räumlichen Isolation eigentlich nicht gesprochen werden kann. Innerhalb der eigentlichen Winterlindenpopulation zeigte sich definitiv keine Abhängigkeit von der Po- 
pulationsdichte, obwohl einige Winterlinden vereinzelt und durch andere Baumarten getrennt bis zu 106 m vom nächsten Paarungspartner entfernt standen. Für die Insekten stellt die Überbrückung solcher Entfernungen offenbar keinerlei Hindernis dar, welches eine Präferenz für Selbstpaarung verursacht hätte. Die Winterlinde ist aufgrund optischer und olfaktorischer Reize sowie aufgrund des großen Nahrungsangebotes einer Baumkrone für Insekten ausreichend attraktiv, so daß diese auch weitaus größere Entfernungen zurücklegen. Es war nachzuweisen, daß die Attraktivität mit zunehmender Größe der blühenden Krone steigt. Die Selbstbefruchtungsrate ist signifikant mit der Kronengröße des Samenelters korreliert; die Insekten fliegen bevorzugt große Kronen an und halten sich lange in diesen auf, was in einem erhöhten Anteil von Selbstbefruchtung resultiert. Ebenso war ein hoher Anteil an Selbstbefruchtung in den Nachkommen sehr kleiner Winterlinden festzustellen; die kleinen Kronen sind für flugaktive Insekten offenbar nicht ausreichend attraktiv, sobald sie sich nicht in direkter Nachbarschaft mit anderen Winterlinden befinden.

Dank der großen Anzahl variabler Genloci konnten mit dem Verfahren EFG für $56 \%$ der 3864 untersuchten Nachkommen der Pollenelter und damit eine Pollentransportweite ermittelt werden. Im Vergleich zu dem Programm CERVUS und dem eindeutigen Ausschlußverfahren lieferte das Verfahren EFG $2 \Delta$ die geeignetsten Resultate bei der Bestimmung von Pollentransportweiten.

Bei vorsichtiger Schätzung liegt die durchschnittliche Pollentransportweite in der Gesamtpopulation Schwiegershausen bei $79 \mathrm{~m}$. Betrachtet man nur die aus Fremdbefruchtung entstandenen Nachkommen, beläuft sich die durchschnittliche Transportweite auf knapp $150 \mathrm{~m}$. Maximal wurden effektive Pollen über mindestens 1666 m zwischen den Populationsmitgliedern transportiert. Trotzdem bei den ermittelten Pollentransportweiten ein sog. Carry-over von Pollen involviert ist und diese daher nicht mit den Flugweiten der Insekten gleichzusetzen sind, ist der Pollentransport durch Insekten, selbst über größere Entfernungen, sehr effektiv. Auch wenn ein hoher Prozentsatz an Selbstbefruchtung zu verzeichnen ist, wird der überwiegende Teil des effektiven Pollens der Winterlinde über beträchtliche Entfernungen transportiert. Die Bestäubungsbiologie der Winterlinde ist also gut an ein zerstreutes Vorkommen im Mischbestand angepaßt.

Diese Angepaßtheit besteht auch hinsichtlich anderer Aspekte der Reproduktionsbiologie. Über Bestäubungs- und Keimungsversuche wurden bei der Winterlinde, zumindest bis zur Phase einer 4-jährigen Jungpflanze, Selbststerilität in Form von Selbstinkompatibilität und Inzuchtdepression nachgewiesen werden. Die Winterlinde kann demnach einen aufgrund ihrer 
Blühbiologie hohen Anteil an Selbstbefruchtung durch Selbststerilitätsmechanismen abpuffern und so einem Anstieg der Homozygotie entgegenwirken. Während Inkompatibilitätsmechanismen Bestäubung der Eizellen mit Eigenpollen erschweren, setzt Inzuchtdepression durch die verminderte Viabilität aus Selbstbefruchtung entstandener Nachkommen Selektion gegen diese in Gang.

In dem Beobachtungsjahr 1995 entwickelten sich bei drei eingehender untersuchten Winterlinden 3,4 \% der Blüten zu vitalen Samen. Aufgrund der absolut hohen Anzahl von Blüten einer Lindenkrone ist aber davon auszugehen, daß damit sexuelle Reproduktion gesichert ist. Die große Anzahl der Blüten der gesamten, weitgehend synchron blühenden, Population bewirkt offenbar konkurrenzlose Attraktivität und die Konditionierung der Insekten auf die Tracht der Winterlinde. Der relativ geringe Samenansatz kann als Teil einer im Laufe der Evolution entwickelten Strategie für die Sicherung des Genflusses gesehen werden.

In den Jahren 1996 - 1998 wurde in der Population Schwiegershausen hingegen kein oder nur ein spärlicher Samenansatz beobachtet. Beim Vergleich der Klimadaten dieser Jahre zeigte sich, daß ungünstige Witterungsverhältnisse entscheidenden Einfluß auf den Reproduktionserfolg der Winterlinde haben. Kühles und nasses Wetter reduziert die Abundanz und die Flugaktivität der Insekten und kann zu Pollenlimitation führen.

Wichtig scheint auch eine ausreichend hohe Lufttemperatur während der Blühperiode der Winterlinde zu sein. Erst ab einer Tagesdurchschnittstemperatur von $20^{\circ} \mathrm{C}$ ist das Pollenschlauchwachstum ausreichend schnell, damit Pollen durch den Griffel zu den Samenanlagen gelangen und Eizellen befruchten können. Die Bildung vitaler Samen könnte auch wegen niedriger Temperaturen im August und September negativ beeinflußt worden sein; niedrige Temperaturen lassen nur unvollständige Samenreife zu.

Nicht nur zwischen den Jahren, sondern auch zwischen den einzelnen Populationsmitgliedern war der Reproduktionserfolg sehr unterschiedlich. Im Jahr 1995 variierte der Anteil an Hohlkörnern unter den Samen der Winterlinden von 0 \% bis zum $90 \%$ der keimfähigen Samen. Eine signifikante Korrelation des Hohlkornanteils mit der Bestandesdichte bzw. der Selbstbefruchtungsrate war nicht festzustellen. Auch konnten variierende Hohlkornanteile nicht immer durch unterschiedliche effektive Pollenwolken, die kleinstandörtlichen Verhältnisse oder die mit der im Alter der Winterlinde abnehmenden Fertilität der Eizellen erklärt werden. Als Ursache kommen auch individuell unterschiedliche Grade von Inzuchtdepression in der Elterngeneration in Betracht. 
Im Randgebiet ihres natürlichen Verbreitungsgebietes ist bei der Winterlinde nur in überdurchschnittlich warmen Sommern mit einer, für Beerntung bzw. Einleitung einer Naturverjüngung, ausreichenden Samenproduktion zu erwarten. Die Winterlinde ist selbstfertil, besitzt aber bei Konkurrenz durch Fremdpollen über wirksame Sterilitätsmechanismen. Diese Konkurrenz durch Fremdpollen ist bei sehr großen, sehr kleinen und isoliert stehenden Winterlinden nicht gegeben. Daher ist bei diesen Bäumen von einer Beerntung von Samen und anschließender Anzucht von Pflanzen in der Baumschule abzuraten, da dieses eine Etablierung inzuchtdepressiver Nachkommen zur Folge hätte. Bei der Anlage von Samenplantagen sollte auf die gesicherte Artidentität der Plusbäume sowie auf einen mindestens 2 Kilometer umfassenden Abstand zu anderen Linden geachtet werden, da spontane Hybridisierung der Arten nicht selten und effektiver Pollentransport durch Insekten über weite Entfernungen möglich ist. 


\section{Summary}

In forests, small-leaved linden (Tilia cordata Mill.) occurs primarily as a minor mixed species. The sporadic occurrence in low density leads one to expect restricted mating-contact within small-leaved linden populations. Furthermore the transfer of pollen is hindered by other tree species, which are in full foliage during the flowering period of the small-leaved linden. The question is how efficient the entomogamic linden is pollinated by insects over larger distances and if the proportion of selfing increases with decreasing population density. In most plants a loss of viability through sterility-mechanisms is observed in selfed progeny and is assumed in small-leaved linden as well. Along the edges of the natural distribution range the reproductive-success of the small-leaved linden differs from year to year and usually is quite modest. Additional aspects of the reproduction system such pollination experiments, germination experiments and the genetic inventory of the old stand and numerous single-tree progenies in order to clarify whether a pollen-limitation, insufficient pollen distribution and hence insufficient gene-flow, sterility-mechanisms or other reasons may be held responsible for the high proportions of empty seeds and the low germination rates.

A long-ranged isolated small-leaved linden population near Schwiegershausen (a village west of the Harz mountains), composed of 138 small-leaved lindens and three hybrids, served as a study object. The small-leaved linden were distributed irregularly over a 40 ha stand consisting predominantly of beech: parts of the linden population almost reached the density of a pure stand, while other linden standing in the fields outside the stand were separated by more than several hundreds of meters from the rest of the members of the small-leaved linden population. Between these extremes, all gradations of population densities occurred, so that this stand provided optimal requirements for investigating the above-mentioned problems.

During the flowering period aerial photographs were taken of the study stand in Schwiegershausen from an altitude of $1800 \mathrm{~m}$. On the basis of digitalized aerial photographs a distance matrix of the 141 lindens was generated. Since the monoecious linden has perfect flowers it was furthermore possible, on the basis of the aerial photographs, to calculate the surface of the flowering crowns in squaremeters and to estimate the correlated flowering intensity and the male fertility, respectively. The evaluation of the aerial photographs and on the ground observations in the study site showed a widely uniform flowering period of all lindens. Thus, theoretically all 141 lindens of the study stand could be considered as potential mating partners. 
In extensive laboratory work the identification of twelve isozyme-gene loci was attained for the hexaploid Tilia cordata. The inheritance analyses showed that in spite of its polyploidy Tilia cordata featured the inheritance modus of diploid organisms (allopolyploidy). The use of a sufficient number of variable gene markers was required for almost all further investigations within the scope of this work.

The identification of the three hybrids (Tilia $\mathrm{x}$ vulgaris) succeeded after the genetic inventory of the old stand. Broad-leaved and small-leaved lindens possess species-specific alleles, which permit a differentiation of both species and the identification of the hybrids. The identification of the hybrids but also the differentiation of both pure species is often difficult on morphological traits alone.

In addition to the identification of gene loci it was necessary to identify the pollen parents in order to determine the pollen transport-distances. Only if it is possible to assign a pollen parent to the progeny of a specific, known, seed parent is it possible to assess the distance of the previous pollen transport. Various methods were employed to determine the pollen-parent relationship such as the known procedures "unique exclusion" and "CERVUS". In addition a further method called "EFG $2 \Delta$ " was developed, which takes the distance, fertility and the likelihood for a contribution of gametes into account.

Furthermore it is possible, via the pollen parents-determination, to estimate the proportion of selfings in the progenies. The different applications were compared in terms of efficiency and plausibility in the determination of pollen parents (pollen-transport-distances respectively) and the proportion of selfings.

The analysis of the pollination tests and the highly variable effective pollen clouds showed that wind pollination plays only a minor role; thus confirming what other references have found. Wind pollination is possible but quantitatively negligible and pollen transport distances are estimated to be very short. Numerous species of insects are responsible for an effective distribution of pollen over large distances in the small-leafed linden. Small-leaved lindens are not able to reproduce by apomixes.

Genetic differences are large between individual pollen clouds of small-leaved linden. The pollen clouds of the seed parents have on the average $44.9 \%$ non-common alleles (with a maximum of $94.7 \%$ ). The high genetic variation within the individual pollen clouds as well 
as the varying degree of their genetic differentiations substantiate this. The genetic variation (measured by $\delta_{\mathrm{T}}$ ) within a pollen cloud is very high if it is predominantly associated with cross-fertilization. If self-fertilization took place variation within a pollen cloud can be particularly high if the seed parents have a high degree of heterozygosity. Narrow correlation exists between the genetic differentiation $D_{j}$ of the pollen cloud and the selfing rate of the concerned seed parents, the differentiation of a pollen cloud increases with the selfing rate.

Selfing-rates are very variable from tree to tree and reach values from $0 \%$ to $89 \%$. According to the pollen parent determination application ,EFG $2 \Delta$ “ the selfing-rate averages $30,1 \%$ of the total population. For the dataset applied in this study the most plausible values were acquired with „EFG 2 $2 \Delta$ “ in comparison to the application „MLTR“ by RITLAND (1994). Interesting was an additional separation of the total population from trees within the stand and the four trees standing isolated in the field. The selfing rate calculated with the application „EFG $2 \Delta$ “ for the trees within the stand was $25.1 \%$, in contrast to $64.8 \%$ for the lindens standing in the field.

A significant correlation between an increased selfing rate and the distance of the seed parents to their nearest mating parents could only be found for isolated small-leaved lindens in the field. Neither the four largest lindens in the stand nor the four solitary lindens in the field showed a significant correlation of their selfing rate to their distance from the next mating parents, so that one cannot speak of spatial isolation. Within the small-leaved linden population no dependence of selfing rate and population density was shown, although some smallleaved linden stood insular-like and separated by other tree species up to $106 \mathrm{~m}$ away from the nearest mating partner. Apparently there is no barrier for insects to bridge over such distances, which expectedly might have caused a preference for selfing. Due to optical and olfactoric attractants as well as due to the abundant food supply in the crown, the small-leaved linden is sufficiently attractive to insects. It was shown that insects preferentially fly to large crowns and stay on them for a long time, this results in an increased proportion of selfing. Likewise a high proportion of selfing in the progeny of linden trees with very small crowns was assessed; apparently small crowns are not sufficiently attractive for flight-active insects, when they are not located in direct neighbourhood with other small-leaved linden.

Due to the high number of variable gene loci and with the application „EFG $2 \Delta$ “ it was possible to assign a pollen parent for $56 \%$ of the 3864 investigated progeny and thus a pollen 
transport distance. In comparison to the program „CERVUS“ and the „unique exclusion“ application the application „EFG $2 \Delta$ “ provides the most suitable results for the determination of pollen transport distances.

A cautious estimate of the average pollen transport distance is around $79 \mathrm{~m}$. If one considers only cross-fertilization, the average transport distance increases to nearly $150 \mathrm{~m}$. The maximum effective pollen transport between members of the population was found to be at least over $1666 \mathrm{~m}$. Nevertheless, a so called „carry-over“ of pollen is involved and these distances cannot be equated to the flight distance of insects. The pollen transport through insects is very effective even over larger distances. Even if a high percentage of selfing is registered the predominant part of effective pollen is transported over considerable distances. The pollination biology of the small-leaved linden is well adapted to a scattered occurrence in a mixed stand.

This adaptedness exists in terms of other aspects of the reproduction biology as well. On the basis of pollination- and germination-tests self-sterility in form of self-incompatibility and inbreeding depression was shown for up to the age of four years. Thus the small-leaved linden is able to buffer a flowering biology induced high proportion of selfing and counteract an increase of homozygosity through self-sterility mechanisms. While incompatibility mechanisms make pollination with the plants own pollen difficult, inbreeding depression induces selection against selfed progeny through diminished viability.

In 1995, $3.4 \%$ of the blossom of three investigated small-leaved lindens developed into vital seeds. Due to the high number of blossoms in a linden crown one can assume that sexual reproduction is assured. The numerous blossoms of the flowering population apparently affect an unrivalled attractiveness and conditioning of the insects to the small-leaved linden. The relatively low seed set can be considered as a part of an evolutionary developed strategy for the maintenance of gene flow.

In contrast to 1995 in the years 1996 - 1998 no or only sparse seed set was observed. A comparison of the climatic data for these years showed that adverse weather conditions have a crucial influence on reproductive success of the small-leaved linden. Cool and wet weather reduce the abundance and the flying activity of the insects and can lead to pollen limitation.

A sufficient high temperature during the flowering period of the small-leaved linden seems to be important. Not until an average daily temperature of $20^{\circ} \mathrm{C}$ is reached does the pollen tube grow fast enough for the pollen to fertilize the ovules. The development of vital seeds is also 
influenced negatively by low temperatures in August and September; low temperatures can lead to incomplete seed maturation.

Not only between the years but also between the individual members of the population the reproductive success was very different. In 1995 the proportion of empty seeds varied between $0 \%$ and $90 \%$ of the vital seeds. A significant correlation between the proportion of empty seeds and the population density was not assessable. Also varying proportions of empty seeds could not be explained by different effective pollen clouds, different microsites or by reduced fertility of ovules with age of the small-leaved linden. As a possible cause different grades of inbreeding depression in the adult trees must also be considered.

Near the limits of her natural range, sufficient seed production for seed collection or the establishment of a natural regeneration can be expected only in above-average warm summers. Small-leaved linden is self-fertile but possesses efficient sterility mechanisms in competition with foreign-pollen. This competition with foreign-pollen is not given for isolated small small-leaved linden. Thus, for such isolated trees seed collection for forest nurseries is not advised, because this would result in the establishment of inbred-depressive progeny. For the establishment of seed orchards one must be sure of the species identity and assure that the trees are at least $2 \mathrm{~km}$ from other linden trees since spontane hybridisation with other linden species can occur and the effective pollen transport by insects is possible over long distances. 


\section{Literaturverzeichnis}

ADAMS, W.T. 1992. Gene dispersal within forest tree populations. New Forests 6: 217-240

AdAms, W.T., Griffin, A.R. and Moran, G.F. 1992. Using paternity analysis to measure effective pollen dispersal in plant populations. Am. Nat. 140: 762-780

ANDERSON, G.J. 1976. The pollination biology of Tilia. Amer. J. Bot. 63: 1203-1212

ANDERSSON, S. 1988. Size dependent pollination efficiency in Anchus officinale (Boraginaceae): causes and consequences. Oecologia 76: 125-130

ANDREW, R. 1971. Exine pattern in the pollen of British species of Tilia. New. Phytol. 70: $683-686$

ANONYMUS 1979. Zur forstlichen Bedeutung der Linden. Allgemeine Forstzeitschrift 34: 833835

ARROYO, M.T.K. 1976. Geitonogamy in animal-pollinated tropical angiosperms: A stimulus for the evolution of self-incompatibility. Taxon 25: 543-548

ASHTON, P.S. 1984. Biosystematics of tropical woody plants: a problem of rare species: In: Grant, W.F. (ed.). Plant Systematics. Academic Press, New York

BARRETT, S.C.H. and HELENURM, K. 1987.The reproductive biology of forest herbs. I. Breeding systems and pollination. Can. J. Bot. 65: 2036-2046

BARRETT, S.C.H. 1988. The evolution, maintenance, and loss of self-incompability systems. In: Doust, J.L. and Doust, L.L. Plant Reproductive Ecology, Patterns and Strategies. New York, Oxford: Oxford University Press

BARTEls, H 1983. Bedecktsamer - Material zur Vorlesung Dendrologie. Forstbotanisches Institut der Universität Göttingen.

BAWA, K.S. 1974. Breeding systems of tree species of a lowland tropical community. Evolution 28: 85-92

BAWA, K.S., PERRY, D.R. and BEACH, J.H. 1985. Reproductive biology of tropical lowland rain forest trees. I. Sexual systems and incompatibility mechanisms. Amer. J. Bot. 72: 331345 
BeLL, G. 1985. On the function fo flowers. Proceedings of the Royal Society of London Series B 224: 223-265

BeutLer, R. 1930. Biologisch-chemische Untersuchungen am Nektar der Immenblumen. $Z$. vergl. Physiol. 12: 72-176

Boinska, U. and ChMielewskA, A. 1977. Charakterystyka biometryczna Tilia cordata MiLl. i T. platyphyllos SCOP. oraz ich mieszancow w rezerwacier Ostrów k. Pszczolczyna w woj. bydgoskim. Fragm. Florist. Geob. 23: 45-56

Boshier, D.H., Chase, M.R. and BAWA, K.S. 1995. Population genetics of Cordia alliodora (Boraginaceae). A neotropical tree. 3. Gene flow, neighborhood, and population substructure. Amer. J. Bot. 82: 484-490

Botha, M.L. and Whitehead, C.S. 1992. The effect of polyamines in ethylene synthesis during normal an pollination-induced senescence of Petunia hybrida L. flowers. Planta 188: $478-483$

BritTAIN, W.H. 1935. Studies in bee activity during bloom. J. Econ. Entomol. 28: 553-559

Brotschol, J.V, Roberds, J.H. and NAmkoong, G. 1986. Allozyme variation among North Carolina populations of Liriodendron tulipifera L. Silvae Genetica 35: 131-138

Broyles, S.B. and WyATt, R. 1995. A reexamination of the pollen-donation hypothesis in an experimental population of Asclepias exaltata. Evolution 49: 89-99

BURD, M. 1994. A probalistic analysis of pollinator behavior ans seedproduction in Lobelia deckenii. Ecology 75: 1635-1646

CAlzoni, G.L. and Speranza, A. 1998. Insect controlled pollination in Japanese plum (Prunus salicina LINDL.). Scientia Horticulturae 72: 227-237

Casilda, A., Munoz, F. and Gomez, P. 1994. Pollination of japanese plum. Vida Apicola No. 65: $30-37$

Chakraborty, R., Meagher, T.R. and Smouse, P.E. 1988. Parentage analysis with genetic markers in natural populations. I. The expected proportion of offspring with unambiguous paternity. Genetics 118: 527-536

Charlesworth, D. and Charlesworth, B. 1987. Inbreeding depression and its evolutionary consequences. Ann. Rev. Ecol. Syst. 18: 237-268 
Charlesworth, B., Morgan, M.T. and Charlesworth, D. 1991. Multilocus models of inbreeding depression with synergetic selection and partial self-fertilization. Genet. Res., Camb. 57: 177-194

Charnov, E.L. 1979. Simultaneous hermaphroditism and sexual selection. Proc. Natl. Acad. Sci. USA 76: 2480-2484

Chase, M.R., Moller, C., Kesseli, R. and BawA, K.S. 1996. Distant gene flow in tropical trees. Nature Vol. 383: 398-399

CHOI, S.Y. 1987. Foraging activity of honeybees during the flowering of basswood (Tilia kiusiana). Korean Joural of Apiculture 2 (2): 21-29

ChUnG, Y.H. and KIM, K.J. 1984. Flowering process and pollination mechanism of genus Tilia. Korean Journal of Botany 27 (3): 107-127

Collevatti, R.G., Amaral, M.E.C. and Lopes, F.S. 1998. Role of pollinators in seed set and a test of pollen limitation hypothesis in the tropical weed Triumfetta semitriloba (Tiliaceae). Revista de Biologia Tropical 1997, publ. 1998 45: 1401-1407

Corbet, S.A., Unwin, D.M. and Prys-Jones, O. E. 1979. Humidity, nectar and insect visits to flowers, with special reference to Crataegus, Tilia and Echium. Ecological Entomology 4: $9-22$

Crawley, M.J. 1997. Sex. In: Crawley, M.J. (ed.) Plant Ecology. 2nd ed.: 156-213. Blackwell Scienctific Publications, Oxford

Cresswell, J.E. and Robertson, A.W. 1994. Discrimination by pollen-collecting bumblebees among differentially rewarding flowers of an alpine wild flower, Campanula rotundifolia (Campanulaceae). Oikos 59: 304-308

CRUDEN 1977. Pollen-ovule ratios: A conservative indicator of breeding systems in flowering plants. Evolution 31: 32-46

CzUBACKI, W. 1996. Niektore szczegoly biologii kwitnienia i nektarowania lip (Tilia platyphyllos ScOP. i Tilia cordata MiLl.). Pszczelnicze-Zeszyty-Naukowe 40: 15-26

DARWIN, C 1862. On the Various Contrivances by which British and Foreign Orchids are Fertilized by Insects. Murray, London 
Dawson, I.K., Waugh, R., Simons, A.J. and Powell, W. 1997. Simple sequence repeats provide a direct estimate of pollen-mediated gene dispersal in the tropical tree Gliricidia sepium. Molecular Ecology 6: 179-183

De Jong, T.J., Waser, N.M., Price, M.V., and Ring, R.M. 1992. Plant size, geitonogamy and seed set in Ipomopsis aggregata. Oecologia 89: 310-315

DengleR, A. 1992. Waldbau auf ökologischer Grundlage. Bd. 2: Der Wald als Vegetationsform und seine Bedeutung für den Menschen. 6. Auflage von RÖHRIG, E. und BARTSCH, N. Verlag Paul Parey. Hamburg und Berlin

Devlin, B., Roeder. K. and Ellstrand, N.C. 1988. Fractional paternity assignment: theoretical development and comparison to other methods. Theoretical and Applied Genetics 76: $369-380$

DuDAsh, M.R. 1990. Relative fitness of selfed and outcrossed progeny in a self-compatible, protandrous species, Sabatia angularis L. (Gentianaceae): A comparison in three environments. Evolution 44: 1129-1139

ECKERT, C.D. and BARRETT, S.C.H. 1994. Post-pollination mechanisms and the maintenance of outcrossing in self-compatible, tristylous, Decodon verticillatus (Lythraceae). Heredity 72: $396-411$

ECKert, C.D., Winston, M.L. and YDEnBERG, R.C. 1994. The relationship between population size, amount of brood, and individual foraging behaviour in the honey bee, Apis mellifera L. Oecologia 97: 248-255

EISENHUT, G. 1957: Blühen, Fruchten und Keimen in der Gattung Tilia. Dissertation, Universität München.

ELDRIDGE, K.G. and GRIFFIN, A.R. 1983. Selfing effects in Eucalyptus regnans. Silvae Genetica 32: 216-221

EllStRAnD, N.C. 1992. Gene flow by pollen-implications for plant conservation genetics. Oikos 63: 77-86

ENGLER, V. 1909: Monographie der Gattung Tilia. Dissertation, Universität Breslau.

ENGLund, R 1993. Movement patterns of Cetonia beetles (Scarabaeidae) among flowering Viburnum opulus (Caprifoliaceae). Oecologia 94: 295-302 
FERRAZZI, P. 1996. Apis mellifera L. foraging activity on Tilia spp. and pollen content of lime honeys. Apicoltore Moderno 87: 169-174

FInKeldey, R. 1997. Grundlagen der Forstgenetik in den Tropen und Suptropen. Univ. Göttingen. Institut für Forstgenetik und Forstpflanzenzüchtung.

FINKELDEY, R. 1999. Genetische Untersuchungen zur Reproduktion von Teak (Tectona grandis L.f.) in Thailand. Habilitationschrift, Univ. Göttingen.

FrANKIE, G.W., OPLER, P.A. and BAWA, K.S. 1976. Foraging behaviour of solitary bees: Implications for outcrossing of neotropical forest tree species. J. of Ecology 64: 1049-1057

FrANKIE, G.W. and HABER, W.A. 1983. Why bees move among mass-flowering neotropical trees. In: Jones, C.E. and LitTLE, R.J. (eds.): Handbook of Experimental Pollination Biology. Scientific and academic editions. New York etc.

FreE, J.B. and DuRRANT, A.J. 1966. The transport of pollen by honeybee from one foraging trip to the next. J. Hort. Sci. 41: 87-89

FreE, J.B. 1970. Insect Pollination of Crops. Academic Press. London and New York

FreE, J.B. and WiLliams, I.H. 1972. The transport of pollen on the body hairs of honeybees (Apis mellifera L.) and bumblebees (Bombus spp. L.). J. Appl. Ecol. 9: 609-615

Fromm, M. 1999. Artbestimmung von Winterlinde, Sommerlinde und der Arthybride. AFZ/Der Wald 5: 244-246

GILL, D.E. 1986. Individual plants as genetic mosaics: ecological organismsversus evolutionary individuals. In: CRAWLEY, M.J. (ed.). Plant Ecology:156-213. Blackwell Scienctific Publications, Oxford

GILL, D.E. 1989. Fruiting failure, pollinator inefficiency, and speciation in orchids. In: OTTE, D. and EndLER, J.A. (eds.). Speciation and its Consequences: 458-481, Sinauer, Sunderland, Massachusetts

GILLET. E. 1994. GSED - Genetic Structures from Electrophoresis Data. User's Manual. Göttingen. www.uni-forst.gwdg.de/forst/fg/software/htm

GILLET, E. 1997: Maximum likelihood estimators of the gametic contributions to single-plant progenies. Biometrics 53: 504-523.

Gillet, E. and HATTEMER, H. H. 1989. Genetic analysis of isoenzyme phenotypes using single tree progenies. Heredity 63: 135-141. 
GINSBERG, H. 1986. Honey bee orientation behaviour and the influence of flower distribution on foraging movements. Ecol. Entom. 11: 173-179

GIURFA, M. and NúNEZ, J.A. 1992. Honeybees mark with scent and reject recently visited flowers. Oecologia 89: 113-117

Godley, E.J. and SMITH, D. H. 1981. Breeding systems in New Zealand plants 5. Pseudowintera colorata (Winteraceae). N. Z. J. Bot. 19: 151-156

GodT, M.J. and HAMrick, J.L. 1993. Patterns and levels of pollen-mediated gene flow in Lathyrus latifolius. Evolution 47: 98-110

Gregorius, H. R. 1974. Genetischer Abstand zwischen Populationen. I. Zur Konzeption der genetischen Abstandsmessung. Silvae Genetica 23: 22-27

GREGORIUS, H. R. 1978. The concept of diversity and its formal relationship to heterozygosity and genetic distance. Mathem. Biosciences 41: 253-271

GREGORIUS, H. R. 1985. Measurement of genetic differentiation in plant populations. In: Population Genetics in Forestry. Lecture Notes in Biomathematics No. 60. Springer Verlag, Berlin, Heidelberg, S. 276-285

GREGORIUS, H. R. 1987. The relationship between the concepts of genetic diversity and differentiation. Theor. and Appl. Genetics 76: 947-951

GrifFin, A.R. and CotTERILl, P.P. 1988. Genetic variation in growth of outcrossed, selfed and open-pollinated progenies of Eucalyptus regnans and some implications for breeding strategy. Silvae Genetica 37: 124-130

Guitan, J. 1993. Why Prunus mahaleb (Rosaceae) produces more flowers than fruits. Amer. J. Bot. 80: 1305-1309

Guitan, J., Guitan, P. and Sanchez, J.M. 1993. Reproductive biology of two Prunus species (Rosaceae) in the Nothwest Iberian Peninsula. Pl. Syst. Evol. 185: 153-165

Haber, W.A. and Frankie, G.W 1982. Pollination of Luehea (Tiliaceae) in Costa Rican deciduous forest. Ecology 63: 1740-1750

Hagerup, O. 1951. Pollination in the Faroes - in spite of rain and poverty in insects. Kon. Danske Viden. Selskap Biol. Medd. 18: 1-18

HAMriCK, J.L. and MurawSKI, D.A. 1990. The breeding structure of tropical tree populations. Pl. Sp. Biol. 5: 157-165 
HARAGSIM, O. 1976. Nektarodarnost nejrozsirenejsich druhu lip v CSR. Vedecke Prace Vyzkumneho Ustavu Vcelarskeho v Dole u Libic. 7-9: 9-18

HARDNER, C.M. and PoTTS, B.M. 1995. Inbreeding depression and changes in variation after selfing in Eucalyptus globulus ssp. globulus. Silvae Genetica 44: 46-54

Hardner, C.M. Vaillancourt, R.E. and PotTs, B.M. 1996. Stand density influences outcrossing rate and growth of open-pollinated families of Eucalyptus globulus. Silvae Genetica 45: 226-228

HARTUNG, J. 1989. Statistik - Lehr- und Handbuch der angewandten Statistik. 7. Aufl. Oldenbourg Verlag

Hattemer, H.H., Bergmann, F. und Ziehe, M. 1993. Einführung in die Genetik für Studierende der Forstwissenschaft. J.D. Sauerländer`s Verlag, Frankfurt am Main

Hattemer, H.H., Ziehe, M., Finkeldey, R. and Fromm, M. 2001. Genetic diversity and differentiation of individual effective pollen clouds in trees. im Druck

HAUSER, T.P. and LOESCHKE, V. 1995. Inbreeding depression in Lychnis flos-cuculi (Caryophyllaceae): effects of different levels of inbreeding. J. Evol. Biol. 8: 589-600

Heard, T.A., Vithanage, V. and Chacko, E.K. 1990. Pollination biology of cashew in the Northern Territory of Australia. Austr. J. Agric. Res. 41: 1101-1114

Hedkte, C. 1996. Pollen sources of Apis mellifera and three Bombus species. PszczelniczeZeszyty-Naukowe 40 (2): 255-256

HeINRICH, B. 1975. Energetics of pollination. Ann. Rev. Ecol. Syst. 6: 139-170

HEINRICH, B. 1983. Insect foraging energetics. In: Jones, E.C. and LiTTLE, R.J. (eds.). Handbook of Experimental Pollination Biology. Scientific and Academic Editions, New York

HeSlOP-HARRISON, Y. 1975. Incompatibility and the pollen-stigma interaction. Ann. Rev. Plant Physiol. 26: 403-425

HeSlop-HARRison, Y. and ShivanNA, K.R. 1977. The receiptive surface of the angiospem stigma. Ann. Bot. 41: 1233-1258

Hesse, M. 1979. Entwicklungsgeschichte und Ultrastruktur von Pollenkitt und Exine bei nahe verwandten entomo- und anemophilen Angiospermen: Salicacae, Tiliaceae und Ericaceae. Flora 168: 540-557 
Hessing, M.B. 1988. Geitonogamous pollination and its consequences in Geranium caespitosum. Amer. J. Bot. 75: 1324-1333

HESMER 1933.Die natürliche Bestockung und die Waldentwicklung auf verschiedenartigen märkichen Standorten. Z. f. Forst- u. Jagdwesen. Sonderdruck

HEß, D. 1983. Die Blüte. Verlag Eugen Ulmer.

Hocker, R. 1979. Die Winterlinde im Kottenforst. Allgemeine Forstzeitschrift 31: 842-844

HodGES, S.A. 1995. The influence of nectar production on hawkmoth behavior, self pollination, and seed production in Mirabilis multiflora (Nyctaginaceae). Amer. J. Bot. 82: 197204

Holsinger, K.E. and THOMSON, J.D. 1994. Pollen discounting in Erythronium grandiflorum: Mass-action estimates from pollen transfer dynamics. Amer. Nat. Vol. 144: 799-812

HopPer, S.D. 1980. Pollination of the rain-forest tree Syzigium tierneyanum (Myrtaceae) at Kuranda, Northern Queensland. Austr. J. Bot. 28: 223-237

HousE, S.M. 1993. Pollination success in a population of dioecious rain forest trees. Oecologia 96: 555-561

Houston, D.B. and JoEhLin, K.A. 1989. Are pollination bags needed for controlled pollination programms with yellow poplar? Silvae Genetica 38: 137-140

HurYN, V.M.B. 1997. Ecological impacts of introduced honey bees. Quart. Rev. Biol. 72: 275-297

IshidA, K. and NAGASAKA, K. 1997. Pollination biology of entomophilous tree species in a deciduous broad-leaved forest in northern Japan. Annual Report of the Hokkaido Research Center, Forestry and Forest Product Research Institute No. 1996: 37-40

IVEY, C.T. and WYATT, R. 1999. Family outcrossing rates and neighborhood floral density in natural populations of swamp milkweed (Asclepias incarnata): potential statistical artefacts. Theor. Appl. Genet. 98: 1963-1971

IwASA, Y., DE JONG, T.J. and KLINKHAMMER, P.G.L. 1995. Why pollinators visit only a fraction of the open flowers on a plant. J. Evol. Biol. 8: 439-453

JANZEN, D. H. 1971. Euglossine bees as long distance pollinators for tropical palms. Science 171: $203-205$

JAY, S.C. 1986. Spatial management of honey bees on crops. Ann. Rev. Entomol. 31: 49-65 
JoHnStON, M.O. 1992. Effects of cross and self-fertilzation on progeny fitness in Lobelia cardinalis and L. silphilitica. Evolution 46: 688-702

Karron, J.D., Tucker, R., Thumser, N. N. and Reinartz, J.A. 1995. Comparisons of pollinator flight movements and gene dispersal patterns in Mimulus ringens. Heredity 75: 612617

KAto, E. and HiURA, T. 1999. Fruit set in Styrax obassia (Styracaceae): the effect of light availabilitiy, display size, and local floral density. Amer. J. Bot. 86: 495-501

KeIPER, J. 1916. Die Linde im Pfälzerwald und in den übrigen Waldgebieten der Pfalz. Forstw. Cbl. 38: 223-369

Kennington, W.J. and JAmES, S.H. 1997. The effect of small population size on the mating system of a rare clonal mallee, Eucalyptus argutifolia (Myrtaceae). Heredity 78: 252-260

Keys, R.N., BuchmanN, S.L. and Smith, S.E. 1995. Pollination effectiveness and pollination efficiency of insects foraging Prosopis velutina in South-eastern Arizona. Journal of Applied Ecology 32: 519-527

Kleber, E. 1935. Hat das Zeitgedächtnis der Bienen eine biologische Bedeutung? Z. vergl. Physiol. 22: 221-262

KLEIN, W. 1992. Untersuchungen des Reproduktionsverhaltens der Winterlinde (Tilia cordata MILL.). Diplomarbeit am Forstwissenschaftlichen Fachbereich der Universität Göttingen.

KleIN, W. und Roloff, A. 1993. Geringere Fruktifikation bei der Winterlinde. Allgemeine Forstzeitschrift 18: 943-946

Klinkhammer, P.G.L., De Jong, T.J. and DE BruYn, G.J. 1989. Plant size and pollinator visitation in Cynoglossum officinale. Oikos 54: 201-204

Klinkhammer, P.G.L. and DE JONG, T.J. 1990. Effects of plant size, plant density and sex differential nectar reward on pollinator visitation in the protandrous Echium vulgare (Boraginaceae). Oikos 57: 399-405

KlinkHAmmeR, P.G.L. and DE JONG, T.J. 1993. Attractiveness to pollinators: a plant's dilemma. Oikos 66: 180-184

KlinkHammer, P.G.L., DE Jong, T.J and MetZ, J.A.J. 1994. Why plants can be too attractive - a discussion of measures to estimate male fitness. Journal of Ecology 82: 191-194

KNOLL, F. 1932. Über die Fernverbreitung des Blütenstaubes. Forsch.- Fortschr. 8: 301-302 
KNUTH, P. 1898. Handbuch der Blütenbiologie (Band II). Leipzig.

KOHLERMANN, L. 1950. Untersuchungen über die Windverbreitung der Früchte und Samen mitteleuropäischer Waldbäume. Forstw. Cbl. 69: 606-624

KoltzenbuRG, C. 1973. Aufkommen und Verwendung von Buntlaubhölzern in der BRD. Teil I. Einschlag und Außenhandel. Forstarchiv 44: 193-199

Koss, H. 1982. Verbreitung, ökologische Ansprüche und waldbauliche Verwendung der Winterlinde (Tilia cordata MILL.). Der Forst- und Holzwirt 37: 381-385

KRAUSS, S.L. 1994. Restricted gene flow within the morphologically complex species Persoonia mollis (Proteaceae): contrasting evidence from the mating system and pollen dispersal. Heredity 73: 142-154

KREBS, S.L. and HANCOCK, J.F. 1990. Early-acting inbreeding depression and reproductive success in the highbuch blueberry, Vaccinium corymbosum L. Theor. Appl. Genet. 79: 825832

KRÜSSMANN, G. 1978. Handbuch der Laubgehölze III. Verlag Paul Parey. Berlin, Hamburg

Kugler, H. 1970. Blütenökologie. Gustav Fischer Verlag. Stuttgart, Jena, New York

Lalonde, R.G. and Roitberg, B.D. 1994. Mating system, life-history, and reproduction in canada thistle (Cirsium arvense: Asteraceae). Amer. J. Bot. 81: 21-28

LANDE, R. and SCHEMSKE, D.W. 1985. The evolution of self-fertilization and inbreeding depression in plants. I. Genetic models. Evolution 39: 24-40

LANGRIDGE, D.F. and GoOdman, R.D. 1985. Honeybee pollination of Japanese plums (Prunus salicina LiNDL. cv. Satsuma) in the Goulburn Valley, Victoria. Austr. J. Exper. Agricult. 25: 227-230

LENTFER, 1979: Die Lindenanzucht aus der Sicht der Forstsamen- und Baumschulbetriebe. Allgemeine Forstzeitschrift 34: 840.

LINHART, Y.B. 1973. Ecological and behavioral determinants of pollen dispersal in hummingbird-pollinated Heliconia. Amer. Nat. 107: 511-523

Linhart, Y.B., Busby, W.H., BEACH, J.H. and Feinsinger, P. 1987. Forager behavior, pollen dispersal, and inbreeding in two species of hummingbird-pollinated plants. Evolution 41: $679-682$ 
LlOYD, D.G. and WeBB, C.J. 1986. The avoidance of interference between the presentation of pollen and stigmas in angiosperms. I. Dichogamy. N. Z. J. Bot. 25

LLOYD, D.G. 1992. Self- and cross-fertilization in plants. II. The selection of self-fertilization. Int. J. Plant Sci. 153: 370-380

LOveless, M.D., Hamrick, J.D. and Foster, R.B. 1998. Population structure and mating system in Tachigali versicolor, a monocarpic neotropical tree. Heredity 81: 134-143

Marshall, D.L. and Ellstrand, N.C. 1988. Effective mate choice in wild radish: Evidence for selective seed abortion and its mechanism. Am. Nat. 131: 736-759

Marshall, T.C., Slate, J., Kruuk, L.E.B. and Pemberton, J.M. 1998. Statistical confidence for likelihood-based paternity inference in natural populations. Molecular Ecology 7: 639-655

MARTIN, M.E. and LEE, T.D. 1993. Self-pollination and resource availability affect ovule abortion in Cassia fasciculata (Caesalpiniaceae). Oecologia 94: 503-509

MAURER, W.D. und TABEL, U. 1995a. Erhaltung forstlicher Genressourcen in RheinlandPfalz. Allgemeine Forstzeitschrift 2: 102-105.

MAureR, W.D. und TABel, U. 1995b. Conservation of genetic resources of Tilia tree species in Rheinland-Pfalz Germany. In: Ph. BARAdat, W.T. AdAMS \& G. MÜller-Starck (Hsg.). Population Genetics of Forest Trees, SPB Academic Publishing: S.421-426

MAureR, W.D. und TABEL, U. 1995c. A methodical study to improve the isozyme analysis for identification of clones of Tilia. Silvae Genetica 44: 351-356.

MeAgheR, T.R. 1986. Analysis of paternity within natural population of Chamaelirium luteum. 1. Identification of most-likely parents. Am. Nat. 128: 199-215

MeDAn, D. 1994. Reproductive biology of Frangula alnus (Rhamnaceae) in southern Spain. Pl. Syst. Evol. 193: 173-186

Meusel, H. 1978. Vergleichende Chorologie der zentraleuropäischen Flora. Karten. Band II. Gustav Fischer Verlag Jena

Moran, G.F. and Bell, J.C. 1993. Eucalyptus. In TANKSLEY, S.D. and OrTON, T.J. (eds.): Isozymes in Plant Genetics and Breeding. Part B. Elsevier, Amsterdam: 423-441.

MORSE, D. H. 1994. The role of self-pollen in the female reproductive success of common milkweed (Asclepias syriaca: Asclepiadaceae). Am. J. Bot. 81: 322-330 
MÜLler [-STARCK], G. 1977. Cross-fertilization in a conifer stand inferred from enzyme gene markers in seeds. Silvae Genetica 26, 223-226

Müller[-Starck], G. und Starke, R. 1993. Inheritance of isoenzymes in European beech (Fagus sylvatica L.). J. Heredity 84: 291-196

MurAwSKI, D.A. and HAMrICK, J.L. 1991. The effect of the density of flowering individuals on the mating systems of nine tropical tree species. Heredity 67: 167-174

MurawsKi, D.A. and HAmRICK, J.L. 1992. The mating system of Cavanillesia platanifolia under extremes of flowering-tree density: a test of predictions. Biotropica 24: 99-101: 23

MurawsKi, D.A., DAYANANDAN, B. and BAWA, K.S. 1994. Outcrossing rates of two endemic Shorea species from Sri Lankan tropical rain frorests. Biotropica 26: 23-29

NAmVAR, K. und SpethmanN, W. 1986. Die heimischen Waldbaumarten der Gattung „Tilia“ (Linde). Allgemeine Forstzeitschrift 41: 42-45

NASON, J.D. and HAMRICK, J.L. 1997. Reproductive and genetic consequences of forest fragmentation: two case studies of neotropical canopy trees. Heredity 88: 264-276

Nilsson, L.A., Rabakonandrianina, E. and Pettersson, B. 1992. Exact tracking of pollen transfer and mating in plants. Nature Vol 360: 666-668

PaCinI, E. and Franchi, G.G. 1982. Germination of pollen inside anthers of some noncleistogamous species. Caryologia 35: 205-215

Petanidou, T., Denniss, J.C.M. and OostermeiJer, J.G.B. 1995. Pollination ecology and constraints on seed set of the rare perennial Gentiana cruciata L. in the Netherlands. Acta Botanica Neerlandica 44: 55-74

PerCy, D.M. and CronK, Q.C.B. 1997. Conservation in relation to mating system in Nesohedyotis arboea (Rubiaceae), a rare endemic tree from St. Helena. Biol. Conserv. 80: 135145

PigOTT, C.D. 1969. The status of Tilia cordata and T. platyphyllos on the Derbyshire limestone. J. Ecology 57: 491-504

PIGOTT, C.D. 1981. Nature of seed sterility and natural regeneration of Tilia cordata near ist northern limit in Finland. Ann. Bot. Fennici 18: 255-263

PIgOTT, C.D. 1991: Biological flora of the British Isles. Tilia cordata Miller. Journal of Ecology 79: 1147-1207. 
PigotT, C.D. and HunTLEY, J.P. 1978. Factors controlling the distribution of Tilia cordata at the northern limits of its geographical range. I. Distribution in north-west England. New Phytol. 81: 429-441

PigotT, C.D. and HunTLEY, J.P. 1980. Factors controlling the distribution of Tilia cordata at the northern limits of its geographical range. II. History in north-west England. New Phytol. 84: 145-164

PigotT, C.D. and HunTLEY, J.P. 1981. Factors controlling the distribution of Tilia cordata at the northern limits of its geographical range. III. Nature and causes of seed sterility. New Phytol. 87: 817-839

PleasAnTs, J.M. 1991. Evidence of short-distance dispersal of pollinia in Asclepias syriaca L. Funct. Ecol. 5: 75-82

Plowright, R.C. and GALEN, C. 1985. Landmarks or obstacles: the effects of spatial heterogeneity on bumble bee foraging behaviour. Oikos 44: 459-464

POHL, F. 1929a. Beziehungen zwischen Pollenbeschaffenheit, Bestäubungsart und Fruchtknotenbau. Untersuchungen zur Morphologie und Biologie des Pollens I. Beih. Bot. Cbl. 46 I: 247-285

POHL, F. 1929b. Kittstoffreste auf der Pollenoberfläche windblütiger Pflanzen. Untersuchungen zur Morphologie und Biologie des Pollens II. Beih. Bot. Cbl. 46 I: 286-305

PoHL, F. 1936. Die Pollenerzeugung der Windblütler. Beih. Bot. Cbl. 56/A: 365-470

Pockberger, J. 1963. Die Linden. Ein Beitrag zur Bereicherung des mitteleuropäischen Waldbildes. Cbl. ges. Forstwes. 80: 99-123

Proctor, H.C. and Yeo 1973. The Pollination of Flowers. Taplinger, New York

PuCHNER, H. 1922. Die verzögerte Keimung von Baumsämereien. Forstw. Cbl. 66: 445-455

PYKE, G.H. 1978. Optimal foraging: Movement patterns of bumblebees between inflorescences. Theor. Popul. Biol. 13: 72-98

PYKE, G.H. and WASER, N.M. 1981. The production of dilute nectars by hummingbird and honeyeaters flowers. Biotropica 13: 260-270

PYKE, G.H. 1982. Foraging in bumblebees: rule of departure from an inflorescence. Can. J. Zool. 60: 417-428 
RAMireZ, N. and SERES, A. 1994. Plant reproductive biology of herbaceous monocots in a Venezuelan tropical cloud forest. Pl. Syst. Evol. 190: 129-142

RAMSEY, M., PraKash, N. and CAIRnS, S. 1993. Breeding systems of disjunct populations of christmas bells (Blandfordia grandiflora R. BR., Liliaceae): Variation in self-fertility and an ovular mechanism regulating self-fertilisation. Aust. J. Bot. 41: 35-47

RathKe, B. and ReAL, L. 1993. Autogamy and inbreeding depression in mountain laurel, Kalmia latifolia (Ericaceae). Amer. J. Bot. 80: 143-146

REDDY, E.U.B. 1987. Under-pollination: a major constraint of cashewnut production. Proceedings of the Indian National Science Academy 53: 249-251

REMPE, H. 1937. Untersuchungen über die Verbreitung des Blütenstaubes durch Luftströmungen. Planta 27: 93-147

RiCK, C.M. 1966. Some plant-animal relations in the Galápagos Islands. In: BowMANN, R.I. (ed.). The Galápagos Islands. Univ.Calif. Press, Berkeley

RITLAND, K. and JAIN, S. 1981. A model for the estimation of outcrossing rate and gene frequencies using $n$ independent gene loci. Heredity 47: 35-52

Ritland, K. 1994. Multilocus Mating System Program (MLTR version 1.1). Department of Botany, University of Toronto

Robertson, A.W. and MCNAIR M.R. 1995. The effects of floral display size on pollinator service to individual flowers of Myosotis and Mimulus. Oikos 72: 106-114

RÖHRIG, E. 1967. Wachstum junger Laubholzpflanzen bei unterschiedlichen Lichtverhältnissen. AFJZ 138: 224-239

Rohmeder, E. 1972. Das Saatgut in der Forstwirtschaft. Verlag Paul Parey. Berlin, Hamburg

RoutLedge, R. D. 1979. Diversity indices: Which ones are admissible? J. Theor. Biol. 76: 503-515

RÜHL, A. 1968. Lindenmischwälder im südlichen Nordwestdeutschland. AFJZ 139: 118-130

SACCHI, C.F. and PriCE, P.W. 1988. Pollination of the Arroyo willow, Salix lasiolepis: Role of insects and wind. Amer. J. Bot. 75: 1387-1393

SACHSSE, H und SchwAER, W. 1991. Holzeigenschaften der Winterlinde (Tilia cordata MiLl.). Holz als Roh- und Werkstoff 49: 423-427. 
SCHELleR, H. 1972: Die Linden in Gärten und Parks des unteren Maingebietes. Mitteil. Deutsch. Dendrol. Ges. 65: 7-42

SCHEMSKE, D.W. 1983. Breeding system and habitat effects on fitness components in three neotropical Costus (Zingiberaceae). Evolution 37: 523-539

SchmitT, J. 1980. Pollinator foraging behaviour and gene dipersal in Senecio (Compositae). Evolution 34: 934-943

SCHWAPPACH 1929. Ertragstafeln der wichtigeren Holzarten. Neudamm: Neumann.

SDW - Schutzgemeinschaft Deutscher Wald 1991. Die Linden. Unser Wald 43: 19-22

Sedgley, M. and Griffin, A.R. (1989). Sexual Reproduction of Tree Crops. Academic press. London, etc.

SEeley, T.D. 1997. Honigbienen. Im Mikrokosmos des Bienenstockes. Birkhäuser Verlag. Basel, Boston, Berlin.

SIEPENKÖTTER, B. 1987. Markt und Verwendung des Lindenholzes. Diplomarbeit an der Fachhochschule Hildesheim/Holzminden, Fachbereich Forstwirtschaft in Göttingen.

SNOw, A 1994. Postpollination selection and male fitness in plants. Amer. Nat. Vol. 144, Suppl.: 69-83

Stacy, E.A., Hamrick, J.L., Nason, J.D., Hubbell. S.P., Foster, R.B. and Condit, R. 1996. Pollen dispersal in low-density populations of three neotropical tree species. Amer. Naturalist 148: 275-298

Stanton, M.L., Young, H.J., Ellstrand, N.C. and ClegG, J.M. 1991. Consequences of floral variation for male and female reproduction in experimental populations of wild radish, Raphanus sativus L. Evolution 45: 268-280

Stanton, M.L., Ashman, T.L., Galloway, F.G. and Young, H.J. 1992. Estimating male fitness of plants in natural populations. In: WYATT, R. (ed.). Ecology and Evolution of Plant Reproduction: New Approaches. Chapman and Hall, New York

STEINER, W. 1992. Inkompatibilitätssysteme bei Pflanzen und ihre populationsgenetischen Bedeutung. Göttingen Research Notes in Forest Genetics 12

STEPHENSON, A.G. 1982. When does outcrossing occur in mass-flowering plants? Evolution 36: 762-767 
StePHENSON, A.G. and WinSOR, J.A. 1986. Lotus corniculatus regulates offspring quality through selective fruit abortion. Evolution 40: 453-458

STOTT, K.G. 1972. Pollen germination and pollen-tube characteristics in a range of apple cultivars. J. Hortic. Sci. 47: 191-198

Strasburger, E., Noll, F., Schenck, H., Schimper, A.F.W. 1991. Lehrbuch der Botanik für Hochschulen. Gustav Fischer Verlag. Stuttgart, Jena, New York

Sun, M., WOnG, K.C. and LEE, J.S.Y. 1998. Reproductive biology and population genetic structure of Kandelia candel (Rhizophoraceae), a viviparous mangrove species. Amer. J. Bot. 85: 1631-1637

Surles, S.E., Hamrick, J.L. and Bongarten, B.C. 1990. Mating Systems in open-pollinated families of black locust (Robinia pseudoacacia). Silvae Genetica 39: 35-40

Talavera, S., GibBs. P.E. and Herrera, J. 1993. Reproductive biology of Cistus ladanifer (Cistaceae). Pl. Syst. Evol. 186: 123-134

Thomson, J.D. and Plowright, R.C. 1980. Pollen carryover, nectar rewards, and pollinator behavior with special reference to Diervilla lonicera. Oecologia 46: 68-74

Thomson, J.D., Price, M.V., Waser, N.M. and Stratton, D.A. 1986. Comparative studies of pollen and fluorescent dye transport by bumblebees visiting Erythronum grandiflorum. Oecologia 69: 561-566

TYBIRK, K. 1993. Pollination, breeding system and seed abortion in some African acacias. Bot. J. Linn. Soc. 112: 107-137

UshimarU, A. and KiKUZAWA, K. 1999. Variation of breeding system, floral rewards, and reproductive success in clonal Calystegia species (Convolvulaceae). Amer. J. Bot. 86: 436446.

Van Teuren, R., Bijsma, R., Ouborg, N.J. and VAn Delden, W. 1993. The significance of genetic erosion in the process of extinction. IV. Inbreeding depression and heterosis effects caused by selfing and outcrossing in Scabiosa columbaria. Evolution 47: 1669-1680

Vogel, S. and Westerkamp, C. 1991. Pollination: An integrating factor of biocenoses. In: Seitz, A. and LoeschKe, V. (eds.). Species Conservation: A Population-biological Approach. Birkhäuser Verlag, Basel 
VoGT, W.G. 1986. Influences of weather and time of day on trap catches of bush fly, Musca vetustissima WALKER (Diptera: Muscidae). Bull. Entomol. Res. 76: 359-366

VON BERLEPSCH, B. 1979. Die Linde im südlichen Vogelsberg. Allgemeine Forstzeitschrift 31: $845-846$

von der Ohe, W., Pechhacker, H., von der Ohe, K., KäFerböck, K. 1993. Chemismus und Pollenpräsentanz der Lindentracht. Apidologie 24: 478-479

WADDINGTON, K.D. 1981. Factors influencing poolen flow in bumblebee-pollinated Delphinium virescens. Oikos 37: 153-159

WASER, N.M. and PriCE, M.V. 1983. Optimal and actual outcrossing in plants, and the nature of plant-pollinator interaction. In: JONES, E.C. and LITTLE, R.J. (eds.). Handbook of Experimental Pollination Biology. Scientific and Academic Editions, New York

WeBB, C.K. and BAWA, K.S. 1983. Pollen dispersal by hummingbirds and butterflies: A comparative study of two lowland tropical plants. Evolution 37: 1258-1270

Weber el Ghobary, M.O. 1984. Observation of flowering, pollen, nectar and pollen loads due to Apis mellifera in some Mediterranean plants. In: Proceedings of the 5th International Symposium on Pollination. Versailles, France, September 1983: 245-250. INRA Colloques No. 21, Versailles

WeSterkamP, C. 1991. Honeybees are poor pollinators - why? Pl. Syst. Evol. 177: 71-75

WeStRICH, P. 1989. Die Wildbienen Baden-Württembergs. Ulmer, Stuttgart

WhiSLeR, S.L. and SNOW, A.A. 1992. Potential for the loss of self-incompatibility in pollenlimited populations of mayapple (Podophyllum peltatum). Amer. J. Bot. 79: 1273-1278

WIENS, D. 1984. Ovule survivorship, brood size, life history, breeding systems and reproductve success in plants. Oecologia 64: 47-53

Wiens, D., CAlvin, C.L., Wilson, C.A., Davern, D.F and SEavey, S.R. 1987. Reproductive success, spontaneous embryo abortion, and genetic load in flowering plants. Oecologia 71: 501-509

WOLFE, L.M. 1993. Inbreeding depression in Hydrophyllum appendiculatum: role of maternal effects, crowding, and parental mating history. Evolution 47: 374-386

Woltering, E.J., van Hout, M., SOMHORSt, D. and HARren, F. 1993. Roles of pollination and short-chain saturated fatty acids in flower senescence. Plant Growth Regul. 12: 1-10 
Wright, S. 1977. Evolution and the Genetics of Populations. Vol. 3 Experimental Results and Evolutionary Deductions. Univ. of Chicago Press, Chicago

WyAtT, R. 1988. Phylogenetic aspects of the evolution of self-pollination. In: GotTLIEB, L.D. and JAIN S.K. (eds.). Plant Evolutionary Biology: 109-131. Chapman and Hall, London

YOUNG, Y.L. and StANTON, M.L. 1990. Influences of floral variation on pollen removal and seed production in wild radish. Ecology 71: 536-547

ZANDER, E. 1935. Beiträge zur Herkunftsbestimmung bei Honig. Teil I, Berlin

ZIEGLER, H. 1953. Über die Zusammensetzung des Bestäubungstropfens und den Mechanismus seiner Sekretion. Planta 52: 587-599

ZiETSMAn, P.C. 1991. Reproductive biology of Grewia occidentalis L. (Tiliaceae). S. Afr. J. Bot. 57: 348-351 


\section{Anhang}

Tab. I Genotypen der 141 Linden des Versuchsbestandes Schwiegershausen

\begin{tabular}{|c|c|c|c|c|c|c|c|c|c|c|c|c|c|c|c|}
\hline autochton & $\begin{array}{c}\text { ge- } \\
\text { pflanzt }\end{array}$ & $\begin{array}{l}\text { A } \\
\text { A } \\
\text { P } \\
- \\
\text { B }\end{array}$ & $\begin{array}{l}\text { A } \\
\text { A } \\
\text { P } \\
- \\
D\end{array}$ & $\begin{array}{l}F \\
D \\
H\end{array}$ & $\begin{array}{l}\text { M } \\
\text { D } \\
\text { H } \\
- \\
\text { B }\end{array}$ & $\begin{array}{l}\text { M } \\
D \\
H \\
- \\
C\end{array}$ & $\begin{array}{l}M \\
D \\
H \\
- \\
D\end{array}$ & $\begin{array}{l}M \\
N \\
R\end{array}$ & $\begin{array}{l}\text { P } \\
\text { G } \\
\text { I } \\
- \\
\text { B }\end{array}$ & $\begin{array}{l}\mathbf{P} \\
\mathbf{G} \\
\mathbf{I} \\
- \\
\mathbf{C}\end{array}$ & $\begin{array}{l}\text { P } \\
\text { G } \\
\text { M } \\
- \\
\text { A }\end{array}$ & $\begin{array}{l}\text { P } \\
\text { G } \\
\text { M } \\
- \\
\text { B }\end{array}$ & $\begin{array}{l}\text { P } \\
\text { G } \\
\text { M } \\
- \\
\text { C }\end{array}$ & $\begin{array}{l}\text { P } \\
\text { G } \\
\text { M } \\
- \\
\text { D }\end{array}$ & $\begin{array}{l}\text { S } \\
\text { K } \\
\text { D } \\
\text { H } \\
- \\
\text { B }\end{array}$ \\
\hline 0 & & 33 & 22 & 35 & 22 & 11 & 12 & 33 & 23 & 11 & 22 & 22 & 22 & 22 & 33 \\
\hline 1 & & 33 & 22 & 35 & 22 & 11 & 22 & 33 & 33 & 12 & 12 & 22 & 22 & 22 & 14 \\
\hline 2 & & 33 & 22 & 35 & 12 & 11 & 22 & 33 & 33 & 11 & 22 & 22 & 22 & 23 & 14 \\
\hline 3 & & 23 & 22 & 33 & 12 & 11 & 22 & 33 & 33 & 11 & 22 & 22 & 22 & 22 & 34 \\
\hline $3 b$ & & 33 & 12 & 33 & 12 & 12 & 12 & 34 & 23 & 12 & 22 & 22 & 22 & 33 & 23 \\
\hline $3 c$ & & 12 & 22 & 33 & 22 & 11 & 22 & 33 & 33 & 11 & 22 & 22 & 11 & 23 & 33 \\
\hline 4 & & 33 & 22 & 33 & 12 & 12 & 22 & 33 & 33 & 11 & 22 & 22 & 12 & 33 & 24 \\
\hline 5 & & 23 & 22 & 33 & 22 & 12 & 22 & 33 & 33 & 12 & 22 & 23 & 22 & 22 & 34 \\
\hline 6 & & 23 & 22 & 33 & 12 & 11 & 12 & 33 & 33 & 11 & 12 & 22 & 22 & 22 & 34 \\
\hline 7 & & 23 & 12 & 33 & 12 & 12 & 22 & 33 & 33 & 12 & 22 & 22 & 12 & 22 & 33 \\
\hline 8 & & 33 & 12 & 35 & 22 & 11 & 22 & 34 & 23 & 11 & 22 & 23 & 12 & 23 & 24 \\
\hline 9 & & 23 & 22 & 33 & 22 & 11 & 22 & 33 & 33 & 11 & 22 & 22 & 12 & 23 & 34 \\
\hline 10 & & 23 & 12 & 33 & 22 & 12 & 22 & 33 & 33 & 11 & 22 & 22 & 12 & 33 & 33 \\
\hline 11 & & 23 & 22 & 33 & 12 & 11 & 22 & 33 & 33 & 11 & 22 & 22 & 12 & 23 & 34 \\
\hline 12 & & 33 & 22 & 33 & 22 & 11 & 22 & 34 & 23 & 11 & 22 & 22 & 12 & 23 & 34 \\
\hline 13 & & 33 & 22 & 33 & 22 & 12 & 22 & 33 & 33 & 11 & 22 & 22 & 22 & 23 & 34 \\
\hline 14 & & 23 & 22 & 33 & 12 & 11 & 22 & 33 & 33 & 11 & 22 & 22 & 22 & 22 & 34 \\
\hline 15 & & 23 & 22 & 33 & 11 & 12 & 22 & 33 & 33 & 11 & 22 & 22 & 22 & 23 & 34 \\
\hline 16 & & 23 & 22 & 33 & 22 & 11 & 22 & 33 & 33 & 11 & 22 & 22 & 22 & 23 & 34 \\
\hline 17 & & 33 & 22 & 33 & 22 & 11 & 12 & 34 & 33 & 11 & 22 & 23 & 22 & 23 & 33 \\
\hline 18 & & 23 & 22 & 35 & 12 & 12 & 22 & 33 & 33 & 11 & 22 & 22 & 12 & 22 & 34 \\
\hline 19 & & 33 & 22 & 33 & 22 & 11 & 22 & 33 & 33 & 12 & 12 & 22 & 22 & 23 & 23 \\
\hline 20 & & 23 & 22 & 35 & 12 & 11 & 12 & 33 & 33 & 11 & 22 & 22 & 12 & 23 & 34 \\
\hline 21 & & 23 & 22 & 33 & 22 & 12 & 12 & 33 & 33 & 11 & 22 & 22 & 22 & 23 & 23 \\
\hline 22 & & 23 & 22 & 33 & 12 & 11 & 22 & 33 & 33 & 11 & 22 & 22 & 12 & 22 & 33 \\
\hline 23 & & 23 & 22 & 35 & 22 & 11 & 12 & 33 & 33 & 11 & 22 & 22 & 11 & 22 & 13 \\
\hline 24 & & 23 & 22 & 33 & 22 & 11 & 22 & 33 & 33 & 11 & 22 & 12 & 22 & 22 & 33 \\
\hline 25 & & 33 & 22 & 33 & 12 & 11 & 12 & 33 & 33 & 11 & 22 & 22 & 12 & 22 & 33 \\
\hline 26 & & 23 & 12 & 35 & 22 & 11 & 22 & 33 & 23 & 11 & 22 & 23 & 22 & 23 & 44 \\
\hline 27 & & 33 & 22 & 33 & 22 & 11 & 22 & 34 & 23 & 11 & 22 & 22 & 22 & 23 & 24 \\
\hline 28 & & 33 & 22 & 33 & 22 & 11 & 22 & 34 & 23 & 11 & 22 & 22 & 22 & 23 & 34 \\
\hline 29 & & 24 & 12 & 33 & 12 & 11 & 22 & 33 & 33 & 11 & 22 & 22 & 12 & 33 & 44 \\
\hline 30 & & 12 & 22 & 33 & 22 & 11 & 12 & 34 & 33 & 11 & 22 & 22 & 12 & 23 & 23 \\
\hline 31 & & 23 & 22 & 33 & 22 & 11 & 11 & 33 & 12 & 11 & 22 & 12 & 12 & 23 & 33 \\
\hline 32 & & 33 & 12 & 35 & 12 & 11 & 22 & 33 & 22 & 11 & 22 & 22 & 12 & 33 & 44 \\
\hline
\end{tabular}




\begin{tabular}{|c|c|c|c|c|c|c|c|c|c|c|c|c|c|c|c|}
\hline autochton & $\begin{array}{c}\text { ge- } \\
\text { pflanzt }\end{array}$ & $\begin{array}{l}\text { A } \\
\text { A } \\
\text { P } \\
- \\
\text { B }\end{array}$ & $\begin{array}{l}\text { A } \\
\text { A } \\
\text { P } \\
- \\
D\end{array}$ & $\begin{array}{l}\mathrm{F} \\
\mathrm{D} \\
\mathrm{H}\end{array}$ & $\begin{array}{l}\text { M } \\
\text { D } \\
\text { H } \\
- \\
\text { B }\end{array}$ & $\begin{array}{l}M \\
D \\
H \\
- \\
C\end{array}$ & $\begin{array}{l}\text { M } \\
D \\
H \\
- \\
D\end{array}$ & $\begin{array}{l}M \\
N \\
R\end{array}$ & $\begin{array}{l}\text { P } \\
\text { G } \\
\text { I } \\
- \\
\text { B }\end{array}$ & $\begin{array}{l}\mathbf{P} \\
\mathbf{G} \\
\mathbf{I} \\
- \\
\mathbf{C}\end{array}$ & $\begin{array}{l}\mathbf{P} \\
\mathbf{G} \\
\mathbf{M} \\
- \\
\mathbf{A}\end{array}$ & $\begin{array}{l}\text { P } \\
\text { G } \\
\text { M } \\
- \\
\text { B }\end{array}$ & $\begin{array}{l}\mathbf{P} \\
\mathbf{G} \\
\mathbf{M} \\
- \\
\mathbf{C}\end{array}$ & $\begin{array}{l}\text { P } \\
\text { G } \\
\text { M } \\
- \\
\text { D }\end{array}$ & $\begin{array}{l}\text { S } \\
\text { K } \\
\text { D } \\
\text { H } \\
- \\
\text { B }\end{array}$ \\
\hline 33 & & 22 & 22 & 35 & 12 & 22 & 22 & 33 & 33 & 11 & 22 & 22 & 12 & 22 & 14 \\
\hline 34 & & 23 & 22 & 35 & 22 & 11 & 22 & 34 & 33 & 12 & 22 & 22 & 12 & 23 & 24 \\
\hline 36 & & 12 & 22 & 33 & 22 & 11 & 22 & 33 & 12 & 11 & 22 & 22 & 12 & 33 & 44 \\
\hline 37 & & 13 & 22 & 33 & 12 & 11 & 22 & 34 & 13 & 11 & 23 & 22 & 22 & 33 & 44 \\
\hline \multirow[t]{27}{*}{38} & & 13 & 22 & 33 & 12 & 11 & 22 & 34 & 13 & 11 & 22 & 22 & 22 & 33 & 44 \\
\hline & 39 & 33 & 22 & 35 & 12 & 12 & 12 & 33 & 33 & 11 & 22 & 22 & 22 & 23 & 44 \\
\hline & 40 & 23 & 22 & 33 & 22 & 11 & 22 & 33 & 12 & 12 & 12 & 22 & 22 & 33 & 24 \\
\hline & 41 & 24 & 22 & 33 & 11 & 11 & 22 & 33 & 33 & 11 & 22 & 22 & 12 & 33 & 34 \\
\hline & 42 & 33 & 22 & 33 & 12 & 11 & 12 & 33 & 33 & 11 & 22 & 22 & 22 & 33 & 24 \\
\hline & 43 & 33 & 12 & 35 & 12 & 11 & 22 & 33 & 23 & 11 & 22 & 22 & 11 & 23 & 44 \\
\hline & 44 & 23 & 22 & 35 & 12 & 11 & 12 & 33 & 23 & 11 & 22 & 23 & 12 & 23 & 44 \\
\hline & 45 & 23 & 22 & 33 & 12 & 11 & 22 & 33 & 33 & 11 & 22 & 23 & 22 & 23 & 13 \\
\hline & 46 & 23 & 22 & 35 & 12 & 11 & 22 & 33 & 12 & 11 & 22 & 23 & 22 & 33 & 23 \\
\hline & 47 & 22 & 12 & 35 & 12 & 11 & 22 & 33 & 23 & 11 & 22 & 23 & 11 & 23 & 34 \\
\hline & 48 & 22 & 22 & 33 & 12 & 11 & 22 & 33 & 33 & 11 & 22 & 23 & 22 & 33 & 34 \\
\hline & 49 & 22 & 22 & 35 & 12 & 11 & 12 & 33 & 22 & 11 & 22 & 22 & 22 & 22 & 24 \\
\hline & 50 & 13 & 12 & 35 & 11 & 11 & 22 & 33 & 22 & 11 & 22 & 22 & 12 & 33 & 34 \\
\hline & 51 & 23 & 12 & 33 & 22 & 11 & 22 & 34 & 33 & 11 & 22 & 22 & 12 & 23 & 44 \\
\hline & 52 & 24 & 22 & 55 & 12 & 11 & 22 & 34 & 33 & 11 & 22 & 22 & 22 & 23 & 24 \\
\hline & 54 & 33 & 22 & 35 & 12 & 11 & 22 & 34 & 23 & 11 & 22 & 22 & 22 & 33 & 24 \\
\hline & 56 & 33 & 22 & 35 & 22 & 11 & 22 & 33 & 33 & 11 & 22 & 22 & 11 & 23 & 34 \\
\hline & 57 & 33 & 22 & 35 & 22 & 11 & 12 & 34 & 33 & 11 & 22 & 23 & 11 & 33 & 33 \\
\hline & 58 & 33 & 22 & 33 & 22 & 12 & 22 & 33 & 33 & 11 & 22 & 23 & 22 & 33 & 44 \\
\hline & 59 & 23 & 22 & 33 & 12 & 12 & 22 & 33 & 23 & 11 & 22 & 22 & 22 & 33 & 24 \\
\hline & 60 & 33 & 22 & 33 & 12 & 12 & 22 & 33 & 23 & 11 & 22 & 22 & 22 & 33 & 24 \\
\hline & 61 & 12 & 22 & 33 & 22 & 11 & 22 & 33 & 23 & 11 & 22 & 22 & 12 & 33 & 23 \\
\hline & 62 & 33 & 22 & 35 & 12 & 11 & 22 & 33 & 33 & 11 & 22 & 22 & 12 & 33 & 23 \\
\hline & 64 & 23 & 22 & 35 & 22 & 11 & 22 & 33 & 23 & 11 & 22 & 22 & 22 & 23 & 34 \\
\hline & 65 & 23 & 22 & 35 & 22 & 11 & 22 & 33 & 23 & 11 & 22 & 22 & 22 & 23 & 34 \\
\hline & 66 & 23 & 22 & 35 & 12 & 11 & 12 & 33 & 33 & 11 & 22 & 22 & 22 & 33 & 24 \\
\hline & 67 & 23 & 22 & 35 & 22 & 11 & 22 & 33 & 23 & 11 & 22 & 22 & 22 & 23 & 24 \\
\hline 68 & & 23 & 22 & 33 & 22 & 11 & 12 & 33 & 33 & 11 & 22 & 22 & 22 & 22 & 44 \\
\hline 69 & & 22 & 22 & 33 & 22 & 11 & 22 & 33 & 23 & 11 & 22 & 22 & 22 & 23 & 24 \\
\hline $69 a$ & & 22 & 22 & 33 & 22 & 11 & 12 & 33 & 33 & 11 & 22 & 22 & 11 & 23 & 33 \\
\hline 70 & & 23 & 22 & 35 & 22 & 11 & 22 & 33 & 33 & 11 & 22 & 23 & 22 & 33 & 24 \\
\hline 71 & & 23 & 22 & 33 & 22 & 11 & 22 & 33 & 33 & 11 & 22 & 23 & 11 & 33 & 22 \\
\hline 72 & & 24 & 22 & 33 & 22 & 11 & 22 & 33 & 33 & 11 & 22 & 22 & 12 & 33 & 34 \\
\hline 74 & & 22 & 22 & 33 & 22 & 11 & 22 & 33 & 23 & 11 & 22 & 22 & 22 & 23 & 14 \\
\hline & 75 & 22 & 22 & 35 & 22 & 11 & 22 & 33 & 33 & 12 & 22 & 22 & 12 & 22 & 44 \\
\hline & 76 & 22 & 22 & 35 & 12 & 11 & 22 & 34 & 33 & 11 & 22 & 23 & 22 & 23 & 34 \\
\hline
\end{tabular}




\begin{tabular}{|c|c|c|c|c|c|c|c|c|c|c|c|c|c|c|c|}
\hline autochton & $\begin{array}{c}\text { ge- } \\
\text { pflanzt }\end{array}$ & $\begin{array}{l}\text { A } \\
\text { A } \\
\text { P } \\
- \\
\text { B }\end{array}$ & $\begin{array}{l}\text { A } \\
\text { A } \\
\text { P } \\
- \\
D\end{array}$ & $\begin{array}{l}\mathrm{F} \\
\mathrm{D} \\
\mathrm{H}\end{array}$ & $\begin{array}{l}\text { M } \\
\text { D } \\
\text { H } \\
- \\
\text { B }\end{array}$ & $\begin{array}{l}M \\
D \\
H \\
- \\
C\end{array}$ & $\begin{array}{l}\text { M } \\
D \\
H \\
- \\
D\end{array}$ & $\begin{array}{l}M \\
N \\
R\end{array}$ & $\begin{array}{l}\text { P } \\
\text { G } \\
\text { I } \\
- \\
\text { B }\end{array}$ & $\begin{array}{l}\text { P } \\
\text { G } \\
\mathbf{I} \\
- \\
\mathbf{C}\end{array}$ & $\begin{array}{l}\mathbf{P} \\
\mathbf{G} \\
\mathbf{M} \\
- \\
\mathbf{A}\end{array}$ & $\begin{array}{l}\text { P } \\
\text { G } \\
\text { M } \\
- \\
\text { B }\end{array}$ & $\begin{array}{l}\mathbf{P} \\
\mathbf{G} \\
\mathbf{M} \\
- \\
\mathbf{C}\end{array}$ & $\begin{array}{l}\text { P } \\
\text { G } \\
\text { M } \\
- \\
\text { D }\end{array}$ & $\begin{array}{l}\text { S } \\
\text { K } \\
\text { D } \\
\text { H } \\
- \\
\text { B }\end{array}$ \\
\hline & 77 & 22 & 22 & 55 & 22 & 11 & 22 & 34 & 33 & 11 & 22 & 22 & 22 & 23 & 14 \\
\hline & 78 & 33 & 12 & 33 & 22 & 11 & 12 & 33 & 23 & 11 & 22 & 22 & 12 & 23 & 34 \\
\hline & 79 & 23 & 22 & 35 & 12 & 11 & 22 & 34 & 23 & 11 & 22 & 22 & 12 & 23 & 34 \\
\hline & 81 & 22 & 22 & 35 & 11 & 11 & 22 & 33 & 23 & 11 & 22 & 23 & 22 & 33 & 34 \\
\hline & 82 & 33 & 22 & 35 & 11 & 11 & 22 & 33 & 12 & 11 & 22 & 22 & 12 & 23 & 34 \\
\hline & 83 & 12 & 22 & 33 & 22 & 11 & 22 & 33 & 33 & 11 & 22 & 23 & 12 & 23 & 33 \\
\hline & 84 & 22 & 22 & 33 & 11 & 11 & 22 & 34 & 33 & 11 & 22 & 23 & 12 & 22 & 23 \\
\hline & 85 & 13 & 12 & 33 & 22 & 11 & 22 & 33 & 33 & 11 & 22 & 22 & 22 & 33 & 34 \\
\hline & 86 & 13 & 22 & 35 & 22 & 11 & 22 & 33 & 23 & 11 & 22 & 23 & 11 & 23 & 34 \\
\hline & 87 & 22 & 22 & 33 & 22 & 11 & 22 & 33 & 33 & 11 & 22 & 23 & 12 & 22 & 33 \\
\hline & 88 & 34 & 22 & 35 & 22 & 11 & 22 & 33 & 23 & 11 & 22 & 22 & 12 & 33 & 44 \\
\hline & 89 & 23 & 22 & 33 & 11 & 11 & 22 & 33 & 23 & 11 & 22 & 23 & 12 & 22 & 33 \\
\hline & 91 & 22 & 22 & 33 & 12 & 11 & 22 & 33 & 33 & 12 & 22 & 23 & 12 & 23 & 23 \\
\hline 92 & & 13 & 22 & 33 & 12 & 12 & 22 & 33 & 33 & 12 & 22 & 22 & 12 & 23 & 13 \\
\hline 93 & & 13 & 22 & 35 & 11 & 12 & 22 & 34 & 33 & 11 & 22 & 22 & 12 & 23 & 24 \\
\hline 94 & & 23 & 22 & 35 & 12 & 11 & 22 & 33 & 23 & 11 & 22 & 22 & 12 & 23 & 44 \\
\hline $94 a$ & & 33 & 22 & 35 & 12 & 11 & 22 & 33 & 23 & 11 & 22 & 22 & 12 & 33 & 24 \\
\hline 95 & & 33 & 22 & 35 & 22 & 11 & 22 & 33 & 33 & 11 & 22 & 22 & 22 & 33 & 33 \\
\hline 96 & & 33 & 22 & 33 & 22 & 11 & 22 & 33 & 23 & 11 & 12 & 22 & 22 & 33 & 24 \\
\hline 97 & & 23 & 22 & 35 & 12 & 11 & 22 & 33 & 33 & 11 & 22 & 22 & 22 & 33 & 24 \\
\hline 98 & & 14 & 12 & 33 & 22 & 11 & 11 & 33 & 23 & 11 & 22 & 22 & 12 & 33 & 14 \\
\hline $98 a$ & & 34 & 22 & 35 & 22 & 12 & 12 & 34 & 33 & 11 & 22 & 22 & 11 & 33 & 33 \\
\hline 99 & & 24 & 12 & 33 & 12 & 11 & 12 & 33 & 23 & 11 & 22 & 22 & 12 & 23 & 44 \\
\hline 100 & & 13 & 22 & 33 & 22 & 11 & 12 & 33 & 33 & 11 & 22 & 22 & 22 & 23 & 14 \\
\hline 101 & & 23 & 22 & 35 & 22 & 11 & 22 & 34 & 23 & 11 & 22 & 22 & 22 & 33 & 34 \\
\hline 102 & Hybride & 23 & 23 & 33 & 11 & 12 & 12 & 23 & & & 23 & 22 & 11 & 13 & 36 \\
\hline 103 & & 22 & 22 & 33 & 11 & 11 & 22 & 33 & 23 & 11 & 22 & 22 & 11 & 33 & 34 \\
\hline 104 & & 23 & 22 & 33 & 12 & 11 & 22 & 34 & 33 & 11 & 22 & 22 & 22 & 23 & 24 \\
\hline 105 & & 13 & 22 & 35 & 12 & 11 & 22 & 33 & 33 & 11 & 22 & 22 & 11 & 23 & 44 \\
\hline 106 & & 33 & 22 & 33 & 22 & 11 & 22 & 34 & 23 & 11 & 22 & 22 & 12 & 22 & 44 \\
\hline 107 & & 23 & 12 & 33 & 22 & 12 & 22 & 33 & 23 & 11 & 22 & 23 & 22 & 23 & 44 \\
\hline 108 & & 23 & 12 & 33 & 12 & 11 & 22 & 33 & 23 & 11 & 22 & 22 & 12 & 33 & 44 \\
\hline 109 & & 22 & 22 & 33 & 22 & 11 & 22 & 33 & 33 & 11 & 22 & 22 & 22 & 23 & 14 \\
\hline 110 & & 33 & 22 & 33 & 12 & 11 & 22 & 33 & 33 & 11 & 22 & 22 & 12 & 22 & 23 \\
\hline 111 & & 23 & 22 & 33 & 12 & 11 & 22 & 33 & 23 & 11 & 22 & 22 & 11 & 33 & 23 \\
\hline 112 & & 23 & 22 & 35 & 22 & 11 & 22 & 33 & 33 & 11 & 22 & 22 & 12 & 23 & 44 \\
\hline 113 & & 23 & 22 & 35 & 12 & 12 & 22 & 33 & 23 & 11 & 22 & 22 & 11 & 22 & 24 \\
\hline 114 & & 33 & 22 & 35 & 12 & 22 & 12 & 33 & 33 & 11 & 22 & 22 & 12 & 33 & 13 \\
\hline 115 & & 33 & 22 & 55 & 22 & 12 & 12 & 33 & 33 & 11 & 22 & 23 & 12 & 33 & 11 \\
\hline 116 & Hybride & 13 & 24 & 45 & 12 & 12 & 22 & 23 & & & 23 & 22 & 12 & 13 & 45 \\
\hline
\end{tabular}




\begin{tabular}{|c|c|c|c|c|c|c|c|c|c|c|c|c|c|c|c|}
\hline autochton & $\begin{array}{c}\text { ge- } \\
\text { pflanzt }\end{array}$ & $\begin{array}{l}A \\
A \\
P \\
- \\
B\end{array}$ & $\begin{array}{l}\text { A } \\
\text { A } \\
\text { P } \\
- \\
\text { D }\end{array}$ & $\begin{array}{l}F \\
D \\
H\end{array}$ & $\begin{array}{l}\text { M } \\
\text { D } \\
\text { H } \\
- \\
\text { B }\end{array}$ & $\begin{array}{l}\text { M } \\
\text { D } \\
\text { H } \\
- \\
\text { C }\end{array}$ & $\begin{array}{l}\text { M } \\
\text { D } \\
\text { H } \\
- \\
\text { D }\end{array}$ & $\begin{array}{l}\mathbf{M} \\
\mathbf{N} \\
\mathbf{R}\end{array}$ & $\begin{array}{l}\mathbf{P} \\
\mathbf{G} \\
\mathbf{I} \\
- \\
\mathbf{B}\end{array}$ & $\begin{array}{l}\mathbf{P} \\
\mathbf{G} \\
\mathbf{I} \\
- \\
\mathbf{C}\end{array}$ & $\begin{array}{l}\mathbf{P} \\
\mathbf{G} \\
\mathbf{M} \\
- \\
\mathbf{A}\end{array}$ & $\begin{array}{c}\mathbf{P} \\
\mathbf{G} \\
\mathbf{M} \\
- \\
\mathbf{B}\end{array}$ & $\begin{array}{l}\mathbf{P} \\
\mathbf{G} \\
\mathbf{M} \\
- \\
\mathbf{C}\end{array}$ & $\begin{array}{l}\mathbf{P} \\
\mathbf{G} \\
\mathbf{M} \\
- \\
\mathbf{D}\end{array}$ & $\begin{array}{l}\text { S } \\
K \\
\text { D } \\
\text { H } \\
- \\
\text { B }\end{array}$ \\
\hline 117 & & 23 & 22 & 33 & 22 & 11 & 12 & 34 & 33 & 11 & 22 & 12 & 11 & 33 & 44 \\
\hline 118 & & 22 & 22 & 33 & 12 & 11 & 22 & 33 & 33 & 11 & 22 & 22 & 12 & 33 & 12 \\
\hline 119 & & 33 & 22 & 33 & 12 & 12 & 22 & 33 & 33 & 11 & 22 & 22 & 12 & 33 & 34 \\
\hline 120 & & 33 & 22 & 33 & 12 & 12 & 12 & 33 & 33 & 11 & 22 & 22 & 11 & 33 & 13 \\
\hline 121 & & 23 & 12 & 35 & 22 & 11 & 22 & 33 & 23 & 11 & 22 & 22 & 12 & 23 & 14 \\
\hline 122 & & 22 & 22 & 33 & 22 & 11 & 12 & 34 & 33 & 11 & 22 & 22 & 12 & 23 & 11 \\
\hline 123 & & 11 & 22 & 35 & 22 & 11 & 22 & 34 & 23 & 11 & 22 & 22 & 22 & 23 & 24 \\
\hline $123 b$ & & 22 & 22 & 35 & 12 & 11 & 12 & 34 & 33 & 11 & 22 & 23 & 12 & 23 & 23 \\
\hline 124 & & 23 & 22 & 33 & 12 & 11 & 12 & 34 & 33 & 11 & 22 & 22 & 22 & 23 & 34 \\
\hline 125 & & 23 & 22 & 33 & 12 & 11 & 22 & 34 & 33 & 11 & 22 & 22 & 22 & 23 & 34 \\
\hline 126 & & 23 & 22 & 35 & 12 & 12 & 12 & 33 & 33 & 12 & 22 & 22 & 22 & 23 & 34 \\
\hline 127 & & 23 & 22 & 33 & 12 & 12 & 22 & 33 & 23 & 11 & 22 & 22 & 12 & 33 & 14 \\
\hline 128 & & 23 & 22 & 33 & 22 & 11 & 22 & 33 & 33 & 11 & 22 & 22 & 12 & 23 & 44 \\
\hline 129 & & 12 & 22 & 35 & 12 & 11 & 22 & 44 & 33 & 12 & 22 & 23 & 12 & 23 & 11 \\
\hline 130 & & 13 & 22 & 35 & 22 & 11 & 22 & 34 & 33 & 11 & 22 & 22 & 12 & 23 & 34 \\
\hline 131 & & 33 & 22 & 33 & 22 & 11 & 22 & 33 & 33 & 11 & 22 & 23 & 22 & 23 & 33 \\
\hline 132 & & 33 & 22 & 33 & 12 & 11 & 12 & 33 & 33 & 11 & 22 & 23 & 11 & 23 & 34 \\
\hline 133 & & 23 & 22 & 33 & 11 & 11 & 22 & 33 & 33 & 11 & 22 & 22 & 12 & 22 & 13 \\
\hline 134 & & 24 & 22 & 35 & 12 & 11 & 22 & 34 & 33 & 12 & 22 & 22 & 22 & 23 & 44 \\
\hline 135 & & 23 & 22 & 55 & 22 & 11 & 22 & 33 & 22 & 11 & 22 & 22 & 12 & 33 & 22 \\
\hline 136 & & 23 & 22 & 35 & 11 & 12 & 22 & 33 & 22 & 11 & 22 & 22 & 12 & 23 & 23 \\
\hline 137 & Hybride & 12 & 24 & 35 & 12 & 12 & 22 & 23 & & & 22 & 22 & 11 & 34 & 16 \\
\hline F1 & & 33 & 12 & 35 & 12 & 11 & 12 & 34 & 33 & 11 & 22 & 12 & 11 & 22 & 33 \\
\hline F2 & & 33 & 22 & 33 & 12 & 11 & 22 & 34 & 33 & 11 & 22 & 22 & 22 & 23 & 44 \\
\hline F3 & & 23 & 22 & 33 & 22 & 11 & 12 & 33 & 33 & 12 & 22 & 22 & 12 & 23 & 23 \\
\hline F4 & & 33 & 22 & 35 & 12 & 11 & 22 & 33 & 33 & 12 & 22 & 22 & 22 & 33 & 33 \\
\hline
\end{tabular}

\begin{tabular}{|c|c|c|c|c|c|c|c|c|c|c|c|c|c|c|}
\hline \multirow{2}{*}{$\begin{array}{c}\text { Tab. II } \\
\text { Allel }\end{array}$} & \multicolumn{14}{|c|}{$\begin{array}{l}\text { Relative Allelhäufigkeiten und Diversität (v) für die Winterlindenpopulation } \\
\text { Schwiegershausen (ohne Hybriden). }\end{array}$} \\
\hline & AAP-B & AAP-D & FDH & MDH-B & MDH-C & MDH-D & MNR & PGI-B & PGI-C & PGM-A & PGM-B & PGM-C & PGM-D & SKDH-B \\
\hline 1 & 0,073 & 0,069 & & 0,294 & 0,897 & 0,130 & & 0,027 & 0,954 & 0,019 & 0,011 & 0,347 & & 0,088 \\
\hline 2 & 0,382 & 0,931 & & 0,706 & 0,103 & 0,870 & & 0,195 & 0,046 & 0,977 & 0,885 & 0,653 & 0,416 & 0,141 \\
\hline 3 & 0,515 & & 0,782 & & & & 0,878 & 0,779 & & 0,004 & 0,103 & & 0,584 & 0,336 \\
\hline 4 & 0,031 & & & & & & 0,122 & & & & & & & 0,435 \\
\hline 5 & & & 0,218 & & & & & & & & & & & \\
\hline $\mathbf{v}$ & 2,396 & 1,147 & 1,516 & 1,710 & 1,227 & 1,292 & 1,273 & 1,551 & 1,096 & 1,047 & 1,258 & 1,829 & 1,945 & 3,032 \\
\hline
\end{tabular}




\begin{tabular}{|c|c|c|c|c|c|c|c|c|c|c|c|c|c|c|}
\hline \multirow{2}{*}{$\begin{array}{l}\text { Tab. III } \\
\text { Genotypen }\end{array}$} & & \multicolumn{13}{|c|}{$\begin{array}{l}\text { Relative Genotyphäufigkeiten und Diversität (v) für die Winterlindenpopulation } \\
\text { Schwiegershausen (ohne Hybriden). }\end{array}$} \\
\hline & AAP-B & AAP-D & FDH & MDH-B & MDH-C & MDH-D & MNR & PGI-B & PGI-C & PGM-A & PGM-B & PGM-C & PGM-D & SKDH-B \\
\hline 11 & 0,008 & & & \begin{tabular}{l|l}
0,076 \\
\end{tabular} & 0,809 & 0,015 & & & 0,908 & & & 0,130 & & 0,023 \\
\hline 12 & 0,046 & 0,137 & & 0,435 & 0,176 & 0,229 & & 0,038 & 0,092 & 0,038 & 0,023 & 0,435 & & 0,008 \\
\hline 13 & 0,076 & & & & & & & 0,015 & & & & & & 0,046 \\
\hline 14 & 0,008 & & & & & & & & & & & & & 0,076 \\
\hline 15 & & & & & & & & & & & & & & \\
\hline 22 & 0,145 & 0,863 & & 0,489 & 0,015 & 0,756 & & 0,023 & & 0,954 & 0,771 & 0,435 & 0,176 & 0,008 \\
\hline 23 & 0,389 & & & & & & & 0,305 & & 0,008 & 0,206 & & 0,481 & 0,092 \\
\hline 24 & 0,038 & & & & & & & & & & & & & 0,168 \\
\hline 25 & & & & & & & & & & & & & & \\
\hline 33 & 0,275 & & 0,588 & & & & 0,763 & 0,618 & & & & & 0,344 & 0,130 \\
\hline 34 & 0,015 & & & & & & 0,229 & & & & & & & 0,275 \\
\hline 35 & & & 0,389 & & & & & & & & & & & \\
\hline 44 & & & & & & & 0,008 & & & & & & & 0,176 \\
\hline $\begin{array}{l}45 \\
55\end{array}$ & & & & & & & & & & & & & & \\
\hline 55 & & & 0,023 & & & & & & & & & & & \\
\hline $\mathbf{v}$ & 3,87819 & 1,3107 & 2,00972 & 2,30504 & 1,45815 & 1,60308 & 1,57426 & 2,09306 & 1,19965 & 1,09648 & 1,56879 & 2,52851 & 2,63084 & 5,94012 \\
\hline
\end{tabular}

\begin{tabular}{|c|c|c|c|c|c|c|c|c|c|c|c|c|c|c|}
\hline Tab. IV & & $\begin{array}{l}\text { Relatis } \\
\text { ZW. g }\end{array}$ & $\begin{array}{l}\text { e All } \\
\text { epfla }\end{array}$ & $\begin{array}{l}\text { elhäuf } \\
\text { azten }\end{array}$ & $\begin{array}{l}\text { gkeite } \\
\text { Vinter }\end{array}$ & $\begin{array}{l}\text { n und } \\
\text { linden }\end{array}$ & $\begin{array}{l}\text { Dive } \\
\text { der P } \\
\text { autoc }\end{array}$ & $\begin{array}{l}\text { sität } \\
\text { opula }\end{array}$ & $\begin{array}{l}\text { (v) fü } \\
\text { tion } \\
\text { interlin }\end{array}$ & $\begin{array}{l}\text { r die v } \\
\text { Schwie } \\
\text { den }\end{array}$ & $\begin{array}{l}\text { ermutl } \\
\text { gersha }\end{array}$ & $\begin{array}{l}\text { ich aut } \\
\text { usen. }\end{array}$ & tochtor & hen \\
\hline Allel & AAP-B & AAP-D & FDH & MDH-B & MDH-C & MDH-D & MNR & PGI-B & PGI-C & PGM-A & PGM-B & PGM-C & PGM-D & SKDH-B \\
\hline 1 & \begin{tabular}{|l|l|}
0,078 \\
\end{tabular} & 0,067 & & \begin{tabular}{l|l}
0,261 \\
\end{tabular} & \begin{tabular}{l|}
0,872 \\
\end{tabular} & 0,150 & & 0,022 & 0,950 & \begin{tabular}{l|}
0,022 \\
\end{tabular} & \begin{tabular}{l|l}
0,017 \\
\end{tabular} & \begin{tabular}{l|}
0,361 \\
\end{tabular} & & 0,117 \\
\hline 2 & 0,356 & 0,933 & & 0,739 & 0,128 & 0,850 & & 0,156 & 0,050 & 0,972 & 0,917 & 0,639 & 0,444 & 0,128 \\
\hline 3 & 0,539 & & 0,828 & & & & 0,867 & 0,822 & & 0,006 & 0,067 & & 0,556 & 0,333 \\
\hline 4 & 0,028 & & & & & & 0,133 & & & & & & & 0,422 \\
\hline 5 & & & 0,172 & & & & & & & & & & & \\
\hline $\mathbf{v}$ & 2,360 & 1,142 & 1,399 & 1,628 & 1,287 & 1,342 & 1,301 & 1,427 & 1,105 & 1,057 & 1,183 & 1,857 & 1,976 & 3,132 \\
\hline & & & & & & vermutlic & h gepfl & anzte W & interlin & den & & & & \\
\hline Allel & AAP-B & AAP-D & FDH & MDH-B & MDH-C & MDH-D & MNR & PGI-B & PGI-C & PGM-A & PGM-B & PGM-C & PGM-D & SKDH-B \\
\hline 1 & 0,061 & 0,073 & & 0,366 & 0,951 & 0,085 & & 0,037 & 0,963 & 0,012 & & 0,317 & & 0,024 \\
\hline 2 & 0,439 & 0,927 & & 0,634 & 0,049 & 0,915 & & 0,280 & 0,037 & 0,988 & 0,817 & 0,683 & 0,354 & 0,171 \\
\hline 3 & 0,463 & & 0,683 & & & & 0,902 & 0,683 & & & 0,183 & & 0,646 & 0,341 \\
\hline 4 & 0,037 & & & & & & 0,098 & & & & & & & 0,463 \\
\hline 5 & & & 0,317 & & & & & & & & & & & \\
\hline $\mathbf{v}$ & 2,424 & 1,157 & 1,764 & 1,866 & 1,102 & 1,185 & 1,214 & 1,830 & 1,076 & 1,025 & 1,426 & 1,764 & 1,842 & 2,769 \\
\hline
\end{tabular}


Tab. V Relative Genotyphäufigkeiten und Diversität (v) für die vermutlich autochtonen bzw. gepflanzten Winterlinden der Population Schwiegershausen.

vermutlich autochtone Winterlinden

\begin{tabular}{|c|c|c|c|c|c|c|c|c|c|c|c|c|c|c|}
\hline Genotyp & AAP-B & AAP-D & FDH & MDH-B & MDH-C & MDH-D & MNR & PGI-B & PGI-C & PGM-A & PGM-B & PGM-C & PGM-D & SKDH-B \\
\hline 11 & 0,011 & & & 0,044 & 0,767 & 0,022 & & & 0,900 & & & 0,133 & & 0,033 \\
\hline 12 & 0,044 & 0,133 & & 0,433 & 0,211 & 0,256 & & 0,022 & 0,100 & 0,044 & 0,033 & 0,456 & & 0,011 \\
\hline 13 & 0,078 & & & & & & & 0,022 & & & & & & 0,056 \\
\hline 14 & 0,011 & & & & & & & & & & & & & 0,100 \\
\hline 15 & & & & & & & & & & & & & & \\
\hline 22 & 0,100 & 0,867 & & 0,522 & 0,022 & 0,722 & & 0,011 & & 0,944 & 0,833 & 0,411 & 0,200 & 0,011 \\
\hline 23 & 0,433 & & & & & & & 0,267 & & 0,011 & 0,133 & & 0,489 & 0,078 \\
\hline 24 & 0,033 & & & & & & & & & & & & & 0,144 \\
\hline 25 & & & & & & & & & & & & & & \\
\hline 33 & 0,278 & & 0,667 & & & & 0,744 & 0,678 & & & & & 0,311 & 0,144 \\
\hline 34 & 0,011 & & & & & & 0,244 & & & & & & & 0,244 \\
\hline 35 & & & 0,322 & & & & & & & & & & & \\
\hline 44 & & & & & & & 0,011 & & & & & & & 0,178 \\
\hline 45 & & & & & & & & & & & & & & \\
\hline 55 & & & 0,011 & & & & & & & & & & & \\
\hline $\mathbf{v}$ & 3,516 & 1,301 & 1,824 & 2,162 & 1,580 & 1,702 & 1,628 & 1,881 & 1,220 & 1,118 & 1,402 & 2,536 & 2,661 & 6,511 \\
\hline
\end{tabular}

vermutlich gepflanzte Winterlinden

Genotyp AAP-B AAP-D FDH MDH-B MDH-C MDH-D MNR PGI-B PGI-C PGM-A PGM-B PGM-C PGM-D SKDH-B

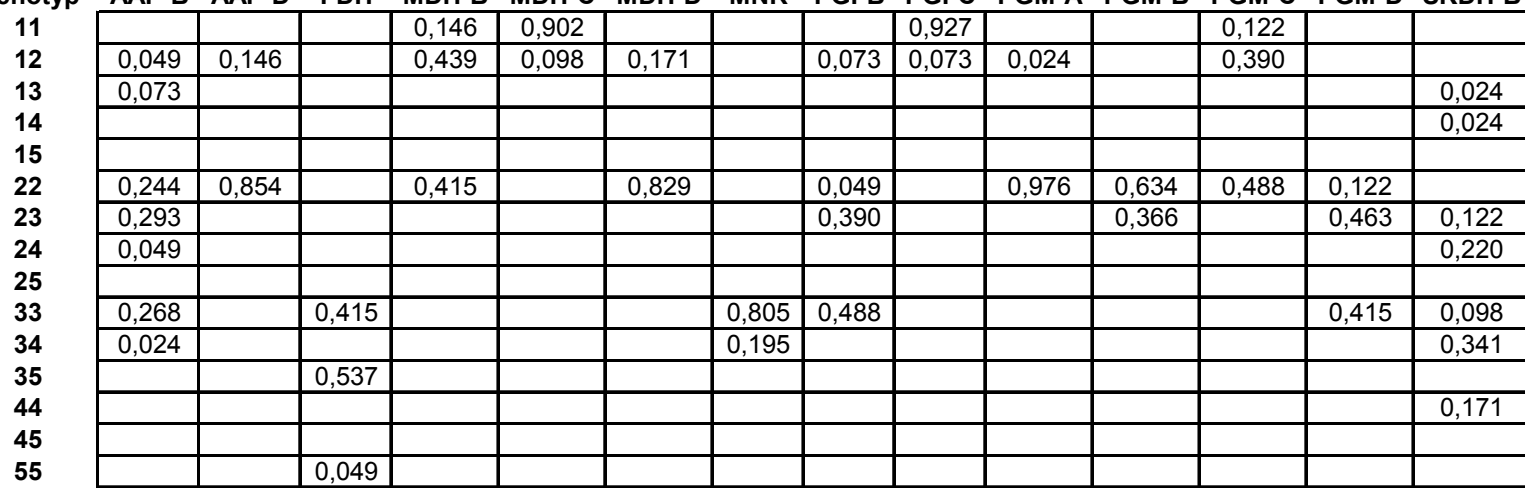

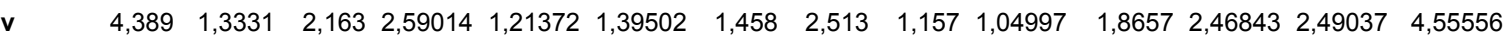




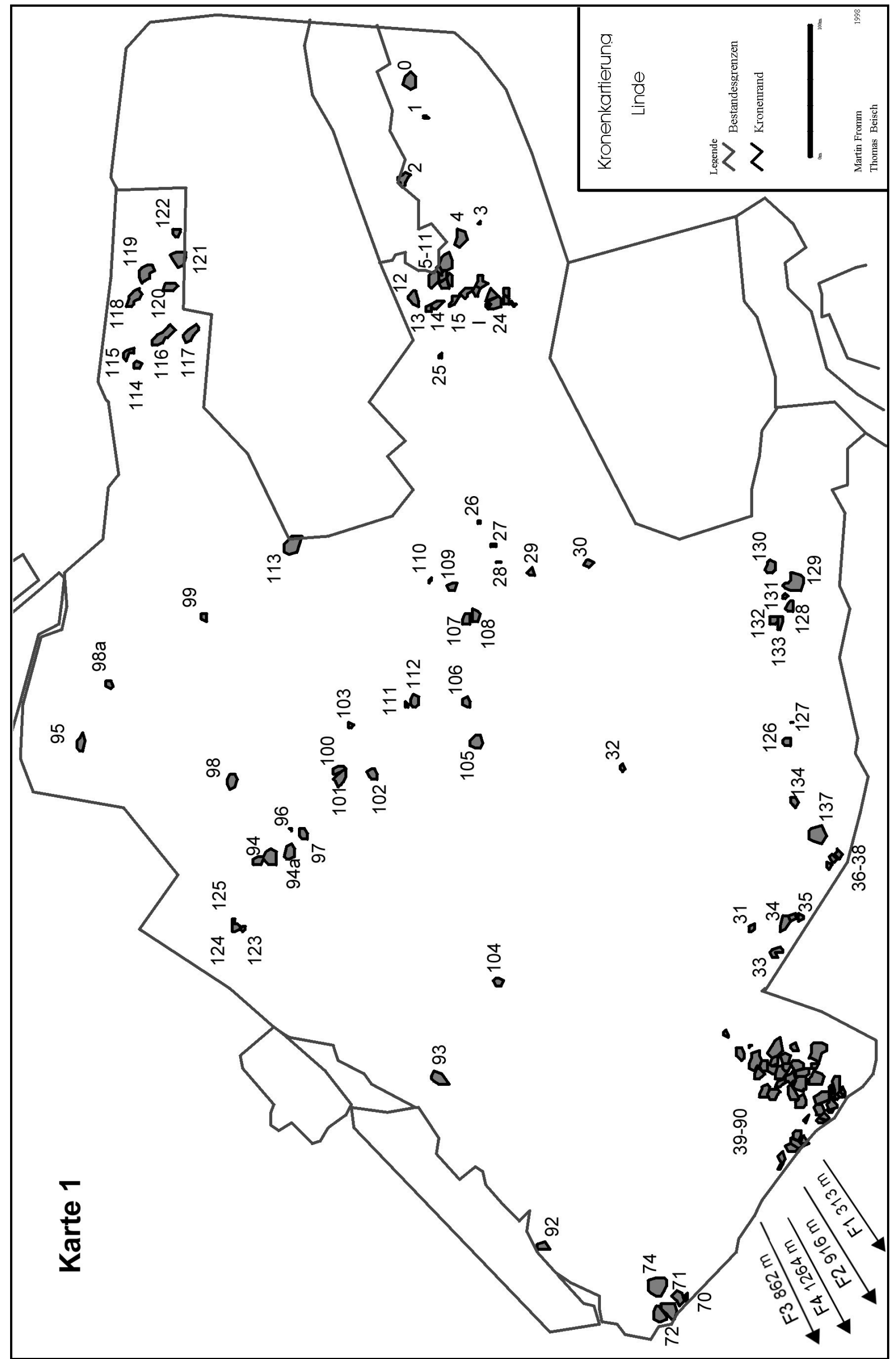




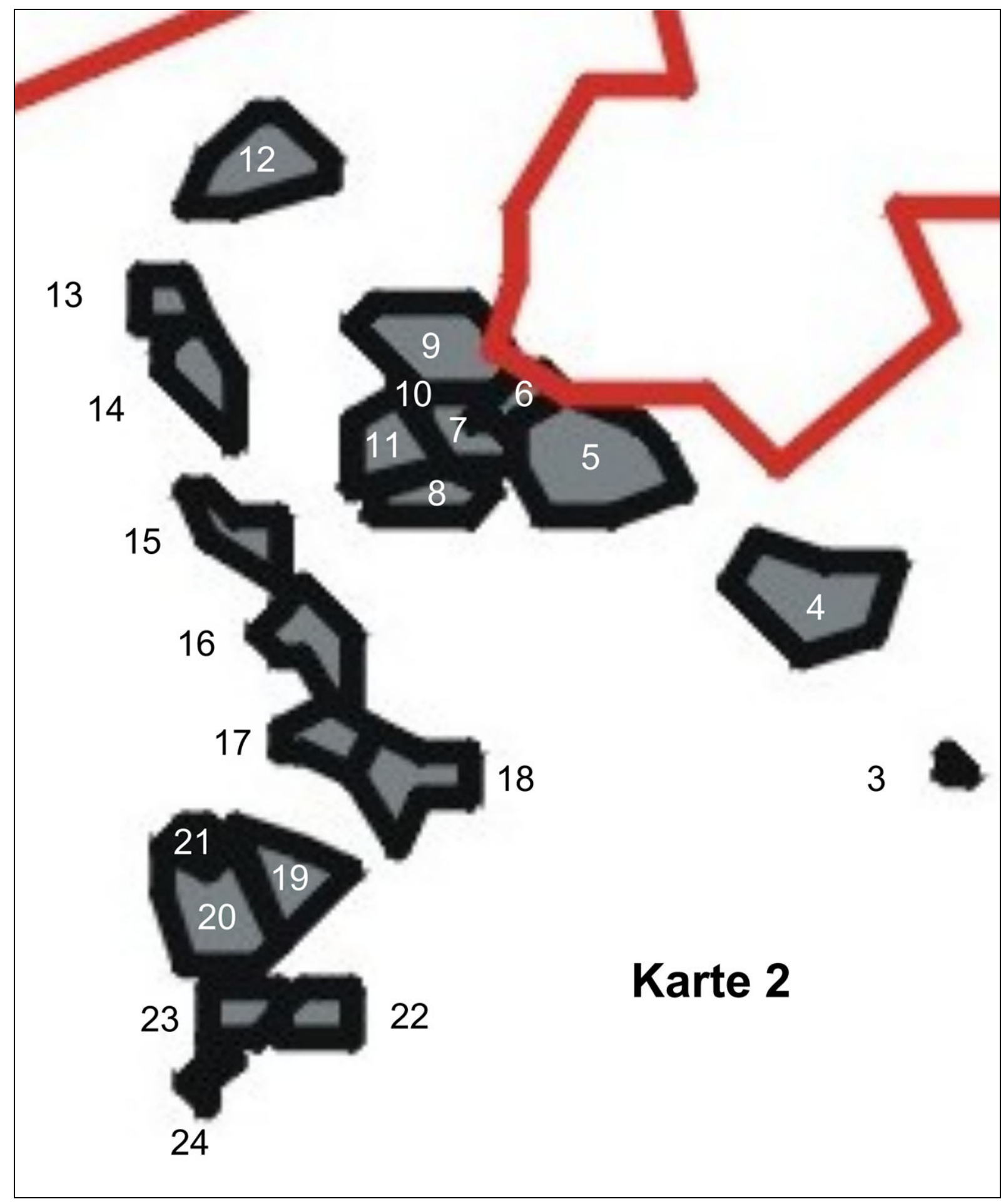




\section{Karte 3}

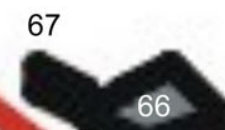

60
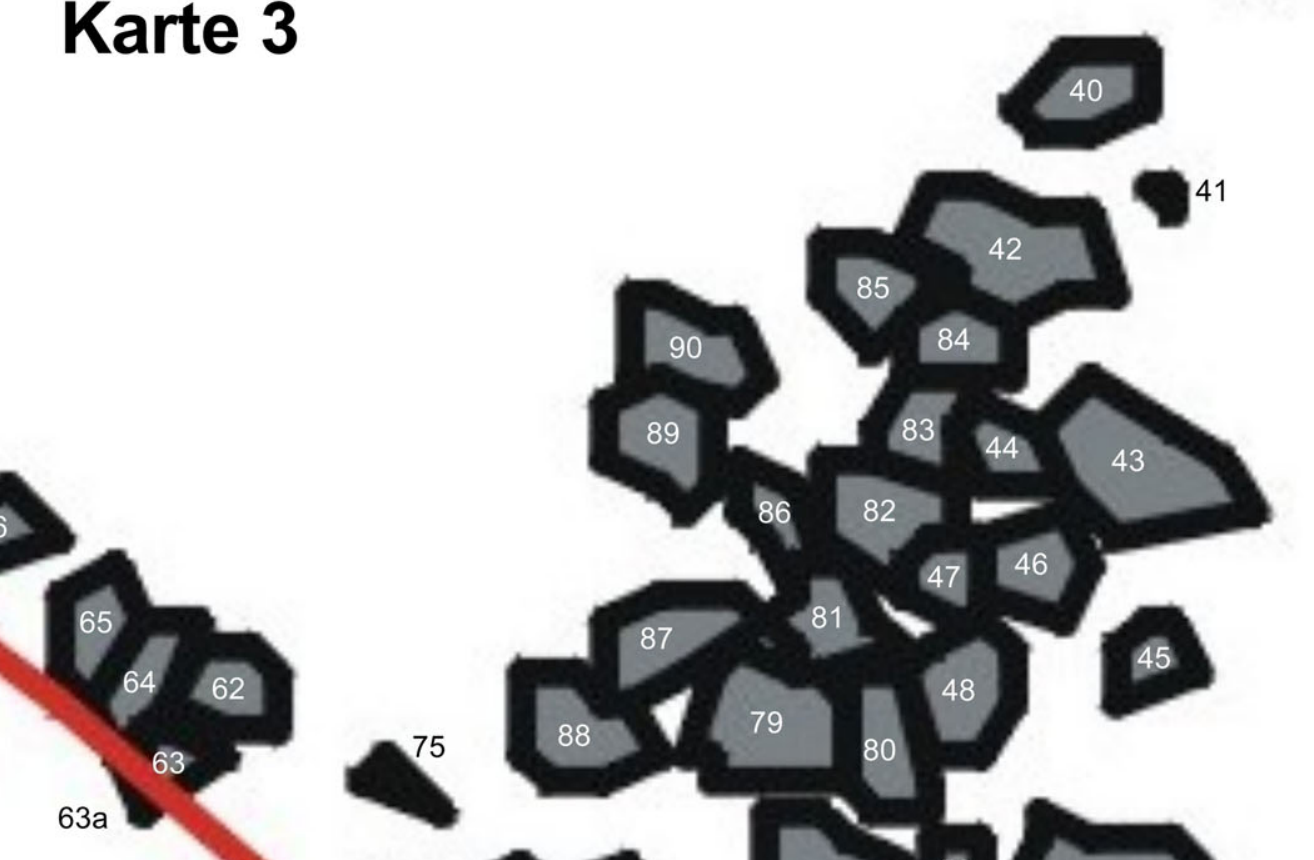

6
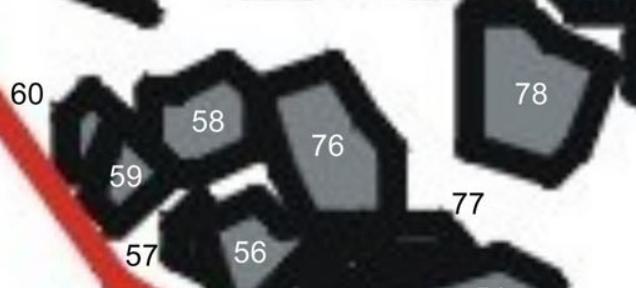

51

45. 